QL
666
0 636X
Rept.

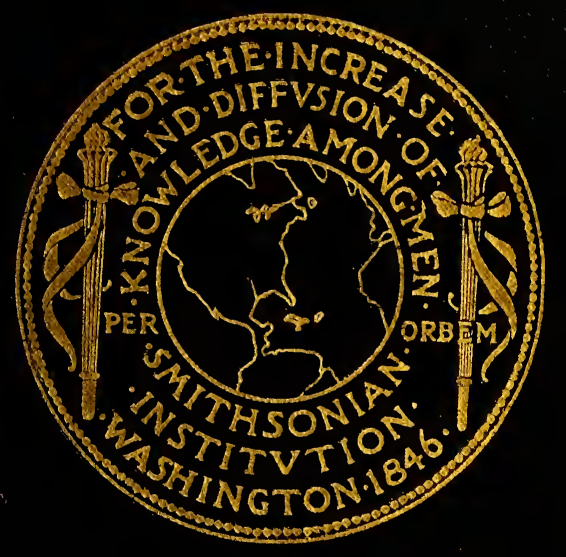






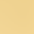


$\cdots$ 


\section{$Q L$ \\ $06 B 6 X$ REPT.}

\author{
SMITHSONIAN INSTITUTION \\ UNITED STATES NATIONAL MUSEUM \\ Bulletin 114 \\ UNITED STATES NATIONAL MUSEUM
}

Divisim of Peptiles

Bulletin 114

\title{
A REVISION OF THE KING SNAKES: GENUS LAMPROPELTIS
}

\author{
BY \\ FRANK N. BLANCHARD \\ Instructor in Zoology, University of Michigan, Ann Arbor
}

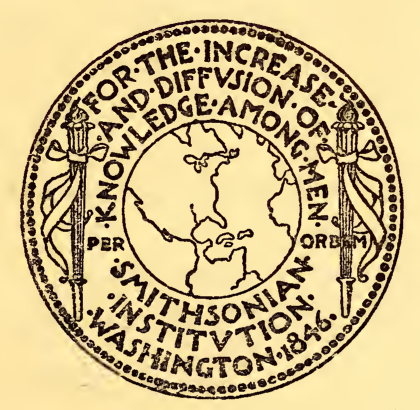





\section{ADVERTISEMENT.}

The scientific publications of the United States National Museum consist of two series, the Proceedings and the Bulletins.

The Proceedings, the first volume of which was issued in 1878, are intended primarily as a medium for the publication of original, and usually brief, papers based on the collections of the National Museum, presenting newly acquired facts in zoology, geology, and anthropology, including descriptions of new forms of animals, and revisions of limited groups. One or two volumes are issued annually and distributed to libraries and scientific organizations. A limited number of copies of each paper, in pamphlet form, is distributed to specialists and others interested in the different subjects as soon as printed. The dates of publication are recorded in the tables of contents of the volumes.

The Bulletins, the first of which was issued in 1875 , consist of a series of separate publications comprising chiefly monographs of large zoological groups and other general systematic treatises (occasionally in several volumes), faunal works, reports of expeditions, and catalogues of type-specimens, special collections, etc. The majority of the volumes are octavos, but a quarto size has been adopted in a few instances in which large plates were regarded as indispensable.

Since 1902 a series of octavo volumes containing papers relating to the botanical collections of the Museum, and known as the Contributions from the National Herbarium, has been published as bulletins.

The present work forms No. 114 of the Bulletin series.

William deC. Ravenel, Administrative Assistant to the Secretary In charge of the United States National Museum.

Washington, D. C., July 19, 1921. 


\section{TABLE OF CONTENTS.}

Page.

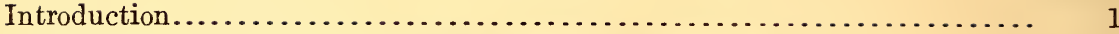

Genus Lampropeltis........................................... 4

Description............................................ 4

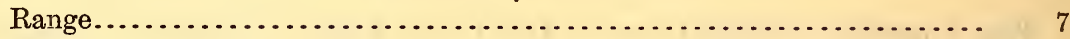

Habitat and habits.......................................... 7

Variation.................................................... 8

Subdivisions of the genus Lampropeltis .......................... 16

Key to the forms of Lampropeltis................................. 18

Summary of structural characteristics of the forms of Lampropeltis.......... 24

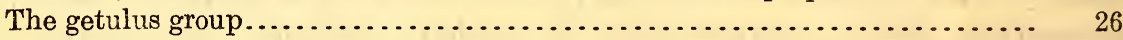

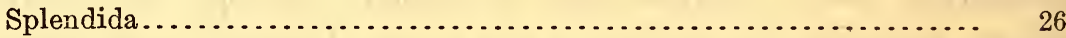

Holbrooki............................................ 33

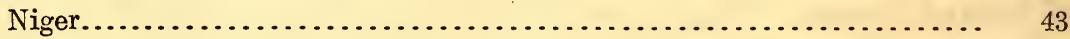

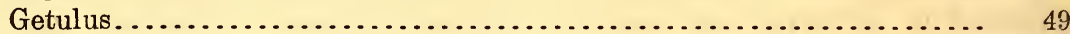

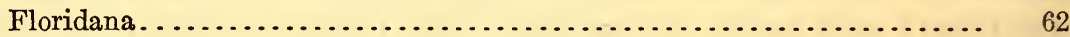

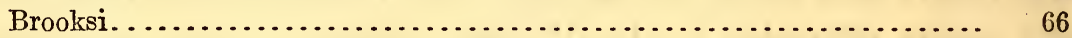

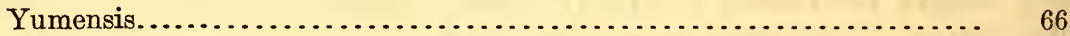

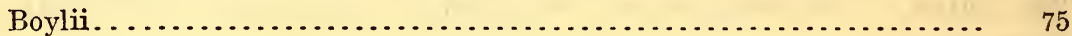

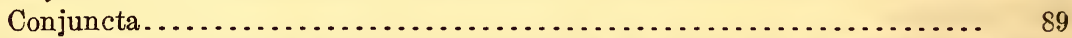

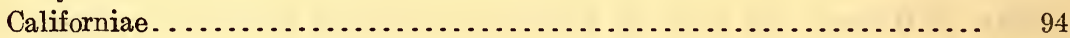

Nitida. . . . . . . . . . 103

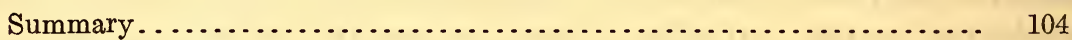

The calligaster group............................................ 115

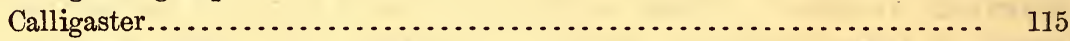

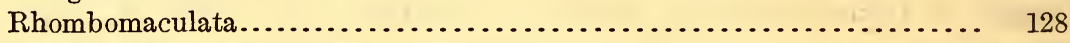

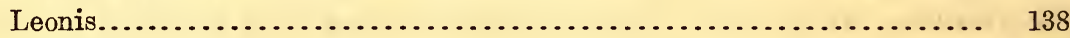

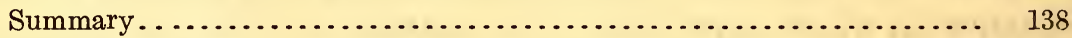

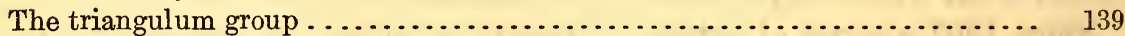

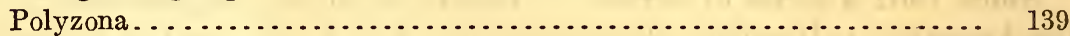

Micropholis.......................................... 149

Nelsoni. . ............................................... 155

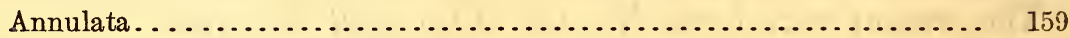

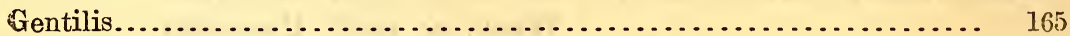

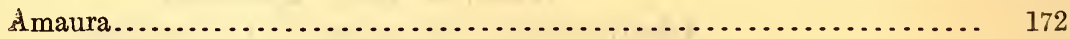

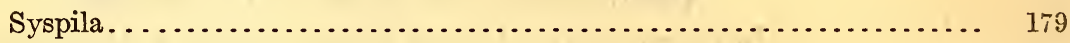

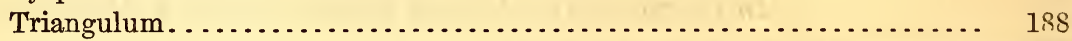

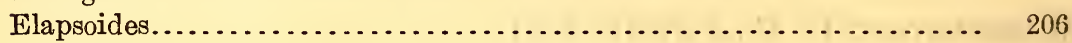

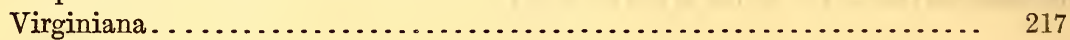

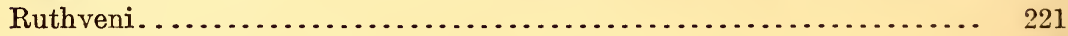

Multicincta......................................... 222

Pyrrhomelaena........................................... 231

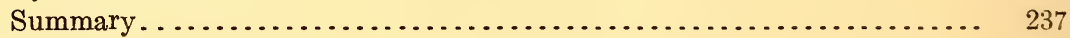

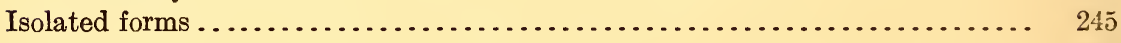

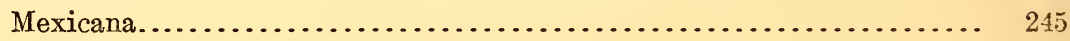

Alterna................................................. 247

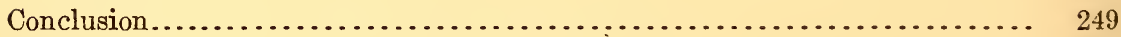

Bibliography ................................................ 255

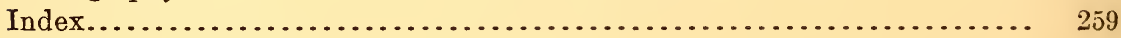




\section{LIST OF ILLUSTRATIONS.}

Fra. 1. Lampropeltis getulus splendida, showing normal arrangement of head

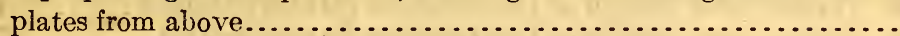

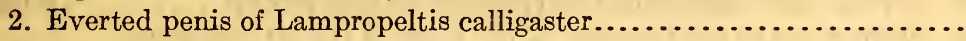

3. Lampropeltis getulus splendida, showing normal arrangement of head

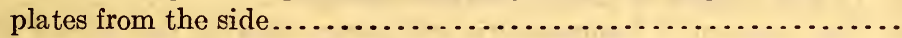

Page.

4. Lampropeltis getulus getulus, showing extra supralabial scute interpolated between normal second and third......................

5. Lampropeltis pyrrhomelaena, showing an extra labial in each series..

6. Lampropeltis calligaster, showing position of the added labial in each

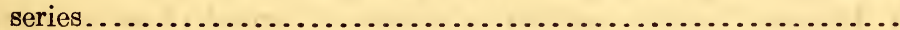

7. Lampropeltis elapsoides elapsoides, showing reduction of lower labials

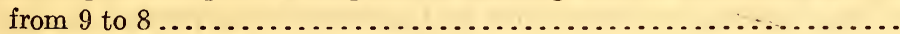

8. Map showing locality records for Lampropeltis getulus splendida....

9. Map showing locality records for Lampropeltis getulus holbrooki....

10. Map showing locality records for Lampropeltis getulus niger........

11. Diagram showing geographic variation in number of ventral plates in

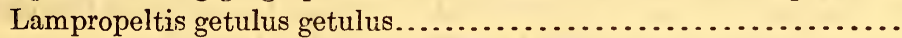

12. Map showing locality records for Lampropeltis getulus getulus......

13. Map showing locality records for Lampropeltis getulus floridana.....

14. Diagram for comparison of numbers of ventral plates in Lampropeitis getulus boylii, L. g. yumensis, and L. g. splendida.............

15. Diagram for comparison of numbers of cross bands or rings in Lampropeltis getulus boylii, L. g. yumensis, and L. g. splendida.........

16. Map showing locality records for Lampropeltis getulus yumensis....

17. Diagram showing geographic variation in numbers of ventral plates in Lampropeltis getulus yumensis and L. g. boylii..............

18. Diagram showing geographic variation in numbers of annuli in Lampropeltis getulus yumensis, and L. g. boylii..................

19. Diagram showing geographic variation in numbers of lalial plates in Lampropeltis getulus boylii, L. g. yumensis, and L. g. conjuncta...

20. Map showing locality records for Lampropeltis getulus boylii.......

21. Color pattern of Lampropeltis getulus conjuncta.................

22. Color pattern of Lampropeltis californiae californiae from San Diego

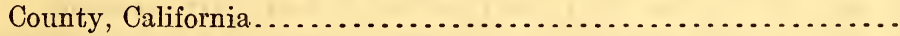

23. Map showing locality records for Lampropeltis californiae californiae..

24. Map showing the distribution of the various forms of the getulus

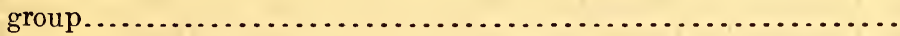

25. Diagram showing geographic variation in numbers of ventral plates

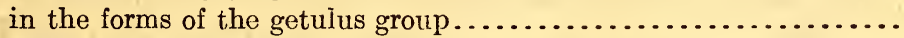

26. Diagram showing geographic variation in numbers of rings or cross bands in the various forms of the getulus group.............. 111

27. Typical color pattern of Lampropeltis getulus boylii......... To face 112

28. Typical color pattern of Lampropeltis getulus yumensis........ To face 112

29. Color pattern of Lampropeltis getulus splendida, showing approach to the pattern of L. g. yumensis in the widened dark areas.. To face 112

30. Color pattern of Lampropeltis getulus splendida, showing the theoretically most primitive type of pattern in the getulus group. To face 112

31. Color pattern of Lampropeltis getulus splendida, showing the common pattern of this form ........................... To face 112

32. Typical color pattern of Lampropeltis getulus holbrooki ...... To face 112

33. Typical color pattern of Lampropeltis getulus niger........... To face 112 
Fig. 34. Color pattern of Lampropeltis getulus getulus, showing approach to

Page.

pattern of L. g. niger........................... To face 112

35. Typical color pattern of Lampropeltis getulus getulus ......... To face 112

36. Typical color pattern of Lampropeltis getulus floridana ....... . To face 112

37. Typical color pattern of Lampropeltis getulus brooksi......... To face 112

38. Diagram of the relationships of the forms of the getulus group...... 115

39. Typical pattern of Lampropeltis calligaster.................. 118

40. Color pattern of Lampropeltis calligaster, showing the striped effect commonly exhibited by dark individuals.................. 119

41. Map showing locality records for Lampropeltis calligaster.......... 122

42. Color pattern of Lampropeltis rhombomaculata................. 129

43. Map showing locality records for Lampropeltis rhombomaculata.... 131

44. Diagram showing variation in number of ventral plates in Lampro-

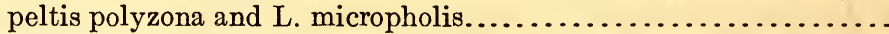

45. Map showing locality records for Lampropeltis polyzona..........

46. Map showing locality records for Lampropeltis micropholis.........

47. Map showing locality records for Lampropeltis triangulum nelsoni....

48. Map showing locality records for Lampropeltis triangulum annulata..

49. Map showing locality records for Lampropeltis triangulum gentilis...

50. Diagram showing interrelationships between Lampropeltis triangulum annulata, L. t. gentilis, L. t. amaura, and L. t. syspila ............

51. Map showing locality records for Lampropeltis triangulum amaura ...

52. Lampropeltis triangulum syspila, showing typical color pattern of

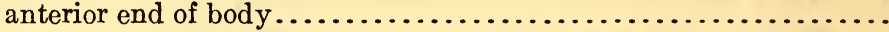

53. Map showing locality records for Lampropeltis triangulum syspila....

54. Lampropeltis triangulum triangulum, showing typical pattern of

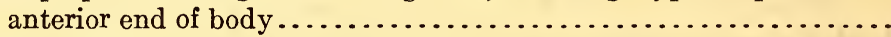

55. Map showing locality records for Lampropeltis triangulum triangulum.

56. Diagram showing geographic variation in number of ventral plates in

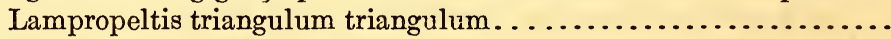

57. Diagram showing geographic variation in number of dorsal blotches

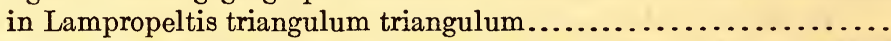

58. Lampropeltis elapsoides elapsoides, showing typical pattern of anterior

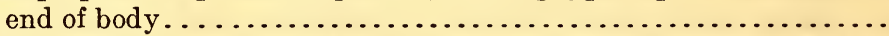

59. Map showing locality records for Lampropeltis elapsoides elapsoides. .

60. Map showing locality records for Lampropeltis elapsoides virginiana..

61. Map showing locality records for Lampropeltis multicincta.........

62. Map showing locality records for Lampropeltis pyrrhomelaena.......

63. Map showing distribution of the various forms of the triangulum group. 238

64. Lampropeltis polyzona, typical color pattern ............. To face 242

65. Lampropeltis triangulum nelsoni, typical color pattern ........ To face 242

66. Lampropeltis triangulum annulata, typical color pattern ...... To face 242

67. Lampropeltis triangulum amaura, a common color pattern of this

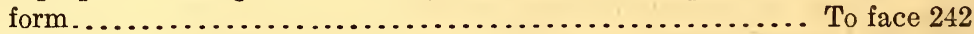

68. Lampropeltis triangulum syspila, typical pattern of this form.. To face 242

69. Lampropeltis triangulum triangulum, typical color pattern..... To face 242

70. Lampropeltis micropholis, typical color pattern in Ecuador-in

Colombia the heavily spotted intervals are narrower........ To face 242

71. Lampropeltis pyrrhomelaena, typical color pattern ......... To face 242

72. Lampropeltis triangulum gentilis, typical color pattern....... To face 242

73. Lampropeltis elapsoides elapsoides, typical color pattern...... To face 242

74. Lampropeltis ruthveni, color pattern of type specimen........ To face 242

75. Lampropeltis multicincta, typical pattern................ To face 242

76. A diagrammatic presentation of the relationships of the forms of the triangulum group.................................. 245

77. Lampropeltis mexicana, showing color pattern............... 246

78. Lampropeltis alterna, showing style of color pattern........... 248 


\title{
A REVISION OF THE KING SNAKES: GENUS LAMPROPELTIS
}

\author{
By Frank N. Blanchard, \\ Instructor in Zoology, University of Michigan, Ann Arbor.
}

\section{INTRODUCTION.}

The snakes of the genus Lampropeltis have long been in a state of great confusion from the systematic standpoint. Only about onethird of the forms now recognized have been at all clearly defined; of the rest some have been known from only a few specimens each, some have been unnaturally divided among several forms, and others have been included under a single name. The confusion has been greatest among the forms here included in the "triangulum group." In this group wide differences occur in color pattern among forms exhibiting great similarity in structural features and striking resemblance in pattern between others that are quite distinct in scutellation.

The reasons for this systematic confusion are mainly two: (1) Many of the forms have been known from only a very few specimens, and even these have not been assembled by any one reviewer. This has made it difficult or impossible to correctly evaluate the differences exhibited, with the result that forms only distantly related have been regarded as identical or only subspecifically distinct, and others that are obviously identical have been considered distinct. (2) Taxonomists have often disregarded the geographic probabilities. Thus many absurd definitions and groupings have made identification difficult and uncertain. Locality meant little; sometimes the head of a specimen would belong to one name and the body to another. With the systematic status of forms in such confusion, but little can be done toward acquiring a knowledge of habits, life histories, and ecologic and economic relations.

It was to bring order into this puzzling group of important and economically valuable North American snakes and to put their classification on a genetic basis that the present study was undertaken, and the work is regarded as completed if the numerous forms have been defined, our knowledge about them brought up to date, and their genetic relationships traced out as well as the material at present available will allow. 
Every means has been taken to make the present review as accurate and as complete as possible. Specimens have been borrowed from many collections, both public and private, throughout the United States. The assembling thus of a great many specimens not previously reported upon has helped greatly to a better understanding of the distribution and relationships of the various forms. Every specimen has been subjected to a careful examination of structural and color pattern features. The former have of course been regarded as of more significance than the latter in establishing relationships, but, as a matter of fact, when the patterns of two specimens were similar and the structural features different it was evident in nearly every case that the resemblance in patterns was only superficial or general, and that features easily overlooked were usually present to confirm the fundamental differences.

It is fully realized that the present effort is but a preliminary attempt at an understanding of the genus, and for this reason care has been taken not to obscure features that may later prove to be of importance. Nothing is to be gained by "lumping" of doubtful forms; apparent constancy throughout a definite geographic range has been deemed sufficient to warrant recognition by name, and intergradation has been the criterion of subspecific distinction. If an error has been made, the name will call attention to it, and will result in ultimately determining the proper status of the form. However, it is believed that more abundant material will increase rather than diminish the number of forms now recognized, and, where the material has suggested such a possibility, attention has been drawn to the fact.

About 1,600 specimens have been assembled for examination. This is but few, to be sure, when compared with the numbers often available in other groups of animals, but very good for king snakes, for it should be noted that the great bulk of this number is the result of chance collecting of forms that are, in general, not plentiful anywhere, and that it is more than four times as many as could erer have been examined by any previous reviewer. Nearly all the type specimens of the genus are in the United States National Museum, in Washington, and the Academy of Natural Sciences of Philadelphia, and these have been examined. One hindrance to the work has been the occasional lack or ambiguity of information as to locality. Specimens without locality labels or with vague or indefinite localities are valueless, and those with incorrect labels are worse than useless, because they are apt to be misleading. Collectors can not be too careful about attaching to their specimens exact information as to locality as soon as possible after collecting, and if they will also attach brief notes on habitat, they will add much to the value of the specimens.

It is hoped that the present work will emphasize the serious jnadequacy of our knowledge of the king snakes. The maps of distri- 
bution will show from what localities specimens are needed. But above all there is great need of reliable information on the natural history and ecological relations of all forms in the genus. Many students of wild life already know far more about the habits of some of these forms than they will find in these pages, and this fact should encourage them to report any careful observations on all phases of the natural history and ecological relations that they may have opportunity to make.

Grateful acknowledgment is hereby extended to the numerous museum. 3 and individuals who have assisted by loaning specimens or supplying needed information on particular points. First of all the writer desires to express his gratitude to Prof. Alexander G. Ruthven, director of the Museum of Zoology of the University of Michigan, under whose general direction the work has been carried on, for suggestions and encouragement throughout its progress. Much assistance has been rendered by Dr. Leonard Stejneger for providing the opportunity to study the large collection at the United States National Museum, and for placing every available facility at the writer's disposal. Thanks for the use of large and important collections are due especially to Dr. John Van Denburgh of the California Academy of Sciences, to Dr. Thomas Barbour of the Museum of Comparative Zoology, to Mr. Henry W. Fowler of the Academy of Natural Sciences of Philadelphia, to Dr. J. O. Snyder of Leland Stanford University, to Miss Mary C. Dickerson of the American Museum of Natural History, to Dr. Joseph Grinnell of the University of California, to Dr. Lawrence E. Griffin of the Carnegie Museum of Pittsburgh, to Dr. Albert H. Wright of Cornell University, and to Mr. Carl L. Hubbs of the Field Museum of Natural History. Smaller, but for the most part very important collections, have been received from the Kansas State Agricultural College, the University of Kansas, the Brooklyn Museum, Iowa State College, the San Diego Natural History Society, Ohio State University, Wesleyan University of Connecticut, the Colorado State Teachers' College, the University of Colorado, the Colorado State Agricultural College, the Alabama Natural History Museum, the University of Arizona, Smith College, the Public Museum of Milwaukee, Charles Mohr Natural History Museum of Mobile, the Victoria Memorial Museum, the University of Wisconsin, Dr. W. S. Blatchley, Dr. T. L. Hankinson, Mr. H. P. Löding, Dr. E. R. Dunn, Dr. Thomas Van Aller, Mr. J. W. Mackelden, and Mr. W. R. Jones. Everything received has been of material help. Often the receipt of only a few specimens has resulted in the solution of an important problem.

In the lists of specimens examined, which accompany the descriptions of the various forms of the genus, the collections in which the specimens may be found are referred to as follows: Acad. Phila., 
Academy of Natural Sciences of Philadelphia; Ala. Mus., Alabama Museum of Natural History; American, American Museum of Natural History; W.S. Blatchley, private collection of Doctor Blatchley of Indianapolis; Brooklyn Mus., Brooklyn Museum; Calif. Acad. Sci., California Academy of Sciences; Carnegie, Carnegie Museum of Pittsburgh; Colo. S. Agr. Col., Colorado State Agricultural College; Colo. S. T. C., Colorado State Teachers' College; Cornell Univ., Cornell University; Field, Field Museum of Natural History; W. $R$. Jones, private collection of W. R. Jones of Satsuma, Alabama; Kans. S. Agr. Col., Kansas State Agricultural College; Kans. Univ., Kansas University; H. P. Löding, collection of H. P. Löding of Mobile, Alabama; M. C. Z., Museum of Comparative Zoology; San Diego Mus., San Diego Natural History Society; Ohio Univ., Ohio State University; Stan. Univ., Stanford University; U.S.N.M., United States National Museum; Univ. Ariz., University of Arizona; M. V.Z., Museum of Vertebrate of Zoology of the University of California; Univ. Colo., University of Colorado; Univ. Mich., Museum of Zoology of the University of Michigan; T. van Aller, collection of Dr. T. van Aller of Mobile; Wesleyan Univ., Wesleyan University of Conneciticut.

References in the text are to author, year, and page, and are to be found in full in the Bibliography. References in the synonomies, which are inclosed in brackets have not been examined by the writer.

All of the outline and color pattern drawings are the work of Miss Doris M. Cochran of Washington, District of Columbia, and all are originals except figure 37 of Lampropeltis getulus brooksi which was prepared from a drawing kindly loaned by Dr. Thomas Barbour of the Museum of Comparative Zoology.

In further explanation it should be mentioned that solid circles on the maps of distribution indicate localities from which specimens have been examined, and hollow circles indicate reports that are believed to be trustworthy. Only localities that are at least as specific as counties are plotted, and a single circle may represent several records near together.

\section{Genus LAMPROPELTIS Fitzinger.}

1843. Sphenophis Frtzinger, Sys. Rept., p. 25 (type, Coronella coccinea Schlegel). 1843. Lampropeltis Fitzinger, Sys. Rept., p. 25 (type, Herpetodryas getulus Schlegel).

1853. Osceola Baird and Girard, Cat. N. Amer. Rept., pt. 1, p. 133 (type, Calamaria elapsoidea Holbrook).

1853. Ophibolus BaIRD and Girard, Cat. N. Amer. Rept., pt. 1, p. 82 (type, Herpetodryas getulus Schlegel).

1876. Bellophis Lockington, Proc. California Acad. Sci., vol. 7, p. 52 (type, zonatus Lockington).

Description.-The genus Lampropeltis of Fitzinger, established upon the Herpetodryas getulus of Schlegel $(1837,198)$ and later defined as 
Ophibolus by Baird and Girard (1853, 82), belongs to the family Colubridae. It was separated in 1860 by Cope (254) from the Coronella of the Old World on the presence of the entire instead of divided anal plate, and in 1862 (302) the same author noted the further difference of two scale pits instead of one.

The genus may be diagnosed as follows: Maxillary teeth, 12 to 20, solid, slightly increasing or slightly decreasing in size posteriorly, subequal, or the last two a little enlarged; mandibular teeth decreasing in size posteriorly; head not or but slightly distinct from neck; eye moderate, with round pupil; scales smooth, with two apical pits, in 17 to 27 rows; anal plate entire; tail moderate, caudals in two rows.

The cephalic plates are normal (fig. 1), consisting of paired parietals, prefrontals, internasals, and single frontal; the nostril lies between two nasals; the loreal is normally present (commonly absent only in elapsoides and virginiana); there is normally one preocular, and two postoculars; the temporals are normally two in the first row, three in the second, and four in the third (except elapsoides, virginiana, and microphotis in which there is usually one less in each row, and alterna in which there is one more in each row); the upper labials are normally seven, varying frequently to eight only in floridana, pyrrhomelaena, and calligaster; the lower labials are normally nine, the fifth largest, being commonly eight only in elapsoides, virginiana, and rhombomaculata, and commonly ten

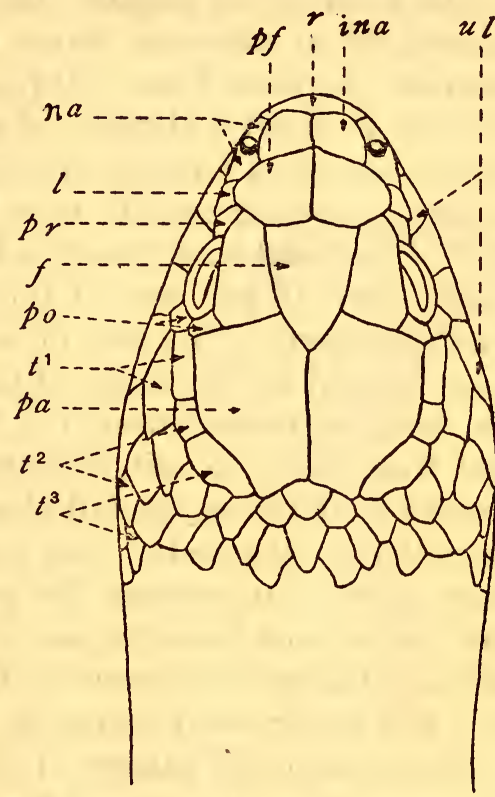

Fig. 1.-Lampropeltis getulus Splendida (U.S.N.M. NO. 1849). $1 \frac{1}{3} \times$ NAT. SIZE. SHOWING NORMAL ARRANGEMENT OF HEAD PLATES FROM ABOVE. $f$, FRONTAL; $i$ Na, INTERNASAL; $l$, LOREAL; $n a$, NASAL; $p a$, PARIETAL; $p f$, PREFRONTAL; $p o$, POSTOCULAR; $p r$, PREOCULAR; $r$, ROSTRAL; $t^{2}, t^{2}, t^{3}$, TEMPORALS OF THE FIRST, SECOND, AND THIRD ROWS, RESPECTIVELY; $u l$, UPPER LABIALS.

only in conjuncta, pyrrhomelaena, and calligaster. The first lower labials meet on the median line behind the triangular mental plate at the symphysis of the lower jaw, and are succeeded by two pairs of parallel chin shields, the posterior of which are not often longer than the anterior and may be only half as long and separated by one or two small scales.

On the body there are from 17 to 27 longitudinal rows of dorsal scales wider on the lower row or two and narrower above, all perfectly smooth, and each provided with two pits near the posterior extremity. On the abdomen is a single series of large transverse plates, the ven- 
trals, which vary in number, in the genus, from 152 to 254 . These are terminated posteriorly by a single anal plate (found divided in only three specimens examined, one triangulum, one elapsoides, and one californiae, and it is reported as divided in the type of Coronella formosa anomala Bocourt). The plates under the tail, or caudals, are normally in two rows, but occasional individuals have one or several of these entire (particularly in micropholis, pyrrhomelaena, and some forms of getulus); they vary in number in the genus from 27 to 79 .

The head is but slightly distinct from the neck, except in a few specialized or aberrant forms in which it is plainly wider at the temples (pyrrhomelaena, alterna, mexicana, and micropholis). The body is in general slender, of nearly uniform diameter, cylindrical above, the sides meeting the belly in a noticeable angle. The tail is short, tapering rapidly to a horny tip, and varying from 0.09 to 0.18 of the total length; only a few aberrant forms have it commonly longer than 15 per cent of the total length (mexicana, alterna, and pyrrhomelaena). The sex of an individual may in a majority of cases be told by the shape of the posterior end of the body. When the body is viewed from the side, an abrupt slope on the dorsal line from body to tail indicates a female, a gentle slope a male. Viewed from below, the tail of a female is much narrower at the base than that of the male. The tail of the male must be larger at the base in order to contain the copulatory organs, while the body of the female must be larger near the end to hold the eggs; therefore the sudden change in diameter in the female where the body meets the tail, and the gradual change in the male.

No fundamental pattern of coloration holds throughout the genus, but, except for two isolated forms of dubious affinities (mexicana and alterna), all the styles of coloration may be put into three groups. In one (the getulus group) the pattern is fundamentally an oval white center in a black scale, and from this may be derived every other arrangement in the group, including two other kinds of spotted patterns, two of cross bands, one of rings, and one of longitudinal stripes. In another (the calligaster group) the pattern is of numerous black-edged brown blotches set on a ground color of lighter brown. In the third (the triangulum group) the pattern is of encircling rings of white or yellow, bordered with black, and separated by red. By a joining on the ventral plates of the black borders of adjacent pairs of black rings the red becomes restricted to dorsal saddles, and by a migration upward, onto the dorsal scales, of these black borders the red finally becomes restricted to dorsal blotches, and in this case, smaller blotches are developed on the sides in alternation with those above. In this group red is a fundamental and almost universal color, but when it becomes restricted to dorsal blotches it changes to 
a brown or gray in the adult. In alterna (fig. 78) the pattern is of two kinds of transverse bands in alternation on a uniform brown ground color, one plain black, the other split or mixed with red. In mexicana (fig. 77) the pattern is of dorsal blotches of red, but the shape, scutellation, and pattern of the head forbid its association with any of the other groups.

The penial characters are as follows (fig. 2), (terms as used by Cope, 1894, 831): Organ rounded, bilobed, or forked at end; sulcus spermaticus single; calyces, continuous across the end of the organ or leaving there a small bare space, apical, few, with short processes (fringes) which may be few-5 or 6 to 10 , or numerous-15 to 20; the latter passing into spines which increase in size gradually toward the base; no spines distinctively enlarged or separated from their fellows; basal portion of organ, below the large spines, smooth or with numerous minute spines.

The dentition may be summarized as follows: Maxillary teeth, 12 to 20, subequal, the last two sometimes a little stouter and longer than the preceding, not separated from the latter by an interspace; mandibular teeth, 12 to 18 , decreasing in size posteriorly; palatines, 8 to 14 , subequal; pterygoids, 12 to 23 , a little smaller than the palatines, and decreasing gradually in size posteriorly.

Range.-The genus Lampropeltis is represented throughout North America, south of the forty-sixth parallel east of the Rocky Mountains and the forty-third

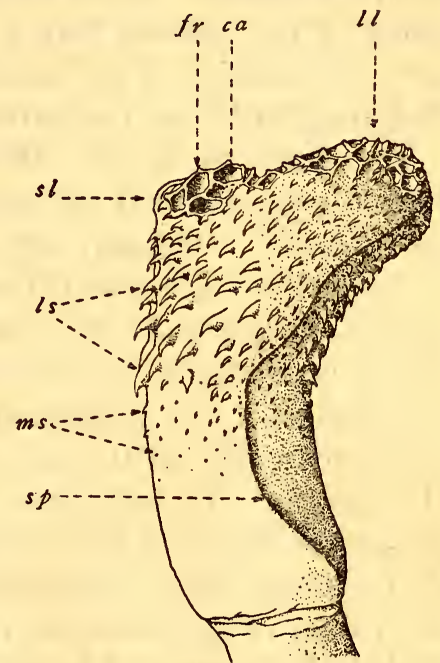

Fig. 2.-Everted penis of LamproPELTIS CALLIGASTER. (U.S.N.M. No. 61726). АвOUT $22 \times$ NAT. SIZE. $c a$, CALYX; $f r$, LOBE OF FRINGE; $l l$, LARGER LOBE; $l s$, LAPGE SPINES; $m s$, MINUTE SPINES; $s l$, SMALLER LOBE; $s p$, SULCUS SPERMATICUS. west, including Florida, Yucatan, and Lower California, and extends into South America west of the Andes Mountains as far as southern Ecuador.

Habitat and habits.-As will appear from the descriptions of the various forms, surprisingly little is known of the life histories of these snakes. It is hoped that the scarcity of information on this subject will prompt those who have the opportunity, to make accurate observations and report them.

There is great diversity in choice of habitat among the various forms. Some belong in the deserts (yumensis, splendida), some in the mountains and canyons of the west (multicincta, pyrrhomelaena, and perhaps gentilis), some on the prairies (calligaster, holbrooki), one (triangulum) has become adapted to the deciduous forest region 
of the northeastern States, and three have adopted burrowing habits (elapsoides, virginiana, and rhombomaculata). They may all be classed as truly land snakes; so far as known none seek their food in the water. They have not the stout body of the snakes that depend for safety upon inconspicuousness or poison, nor the attenuated body and tail of the tree snakes and racers, but rather a wellproportioned body and short tail, adapted to life on the ground and more or less in the open. They seem in general to be fearless and self-reliant. Their immunity to snake venom and their powerful constricting ability render them truly kings among the reptiles of North America. Much remains to be learned about the food preferences of the various forms, but in general it may be said that they are the enemies of all small rodents and of all snakes and lizards; fledgling birds are undoubtedly eaten on opportunity.

But little is known about hibernation and reproduction. The fullest accounts will be found under the descriptions of triangulum and getulus. Probably all are oviparous.

Variation.-Since so little careful study has been made of variation in scutellation and color pattern in snakes, it is unsafe to generalize on the systematic value of any of these points without a thorough knowledge of the particular situation. Ruthven has shown, in his excellent review of the garter snakes (1908), the extent and meaning of variations in the genus Thamnophis, but a comparison with the present review will show that not the same value can be placed in all instances upon variation in any particular characteristic. Thus the forms of Thamnophis exhibit great similarity in color pattern, while in both series of labials there is much variation of specific value. Lampropeltis, by comparison, exhibits the widest variation in pattern, while there is remarkably little variation in the labials. This is but one of numerous possible illustrations that color pattern may be less variable than scutellation. It seems usually to be more so, but, as said above, it is not safe to generalize upon the value of characters, for what is true in one case may be quite otherwise in another. The relative value of characters must be determined separately for each group of genetically related forms. By a careful study of the extent and meaning of variations in different characters in different genera we may learn something more definite of the genetic relations between genera, as we are now able to learn these relations between species and subspecies. It is a lack of knowledge of the meaning of differences between genera that results in errors and uncertainties as to their relations. For instance, it is not now known what meaning to place upon differences in method of change in number of scale rows. The present review can not, of course, determine this, but it serves to confirm the results obtained by Ruthven in the garter snakes to the extent of showing the method of change in number of scale rows to 
be constant for the genus and to be distinctively, although not greatly, different from that in Thamnophis.

As in any study of this kind, it becomes essential to distinguish between several kinds of variation, particularly individual, sexual, and geographic. Since in the present study a deficiency of material has been a great handicap, usually not more than supportive reliance can be placed upon statistical results. It is hoped, however, that conclusions have been sufficiently conservative to allow for the greater quantity of material that will be available to later workers.

Variation in dorsal scale rows. - The dorsal scales are arranged in alternate series throughout the length of body, an even number of rows on each side of a middorsal series. The number of rows varies in the genus from a maximum of 27 to a minimum of 15 ; but in no single individual is the variation less than 2 nor more than 6 (with the exception of a few examples of elapsoides to be presently mentioned). If we take an average example, say, a boylii, and c unt the number of rows of scales behind the neck, we will find there are 23 ; if now we trace the sixth row backward (counting upward from the ventral plates) we will find that at some point past the middle of the body this row is lost or fused with the next row below, and since this occurs almost simultaneously on both sides of the body, the number of rows changes here to 21 ; if now we follow the fifth row backward, we will find that this row, toward the posterior end of the body, is either dropped or fused with the row below it, leaving 19; we call the dorsal scale formula in this case, therefore, 23-21-19. If we take any other form in the genus that makes the change from 23 to 21 rows, we will find that this change always takes place by a loss of the sixth row, due either to diminution and disappearance or to fusion with the row below. Likewise any form or individual in the genus that makes the change from 21 to 19 rows always does so by loss of the fifth row or by its fusion with the fourth. We may express these facts in figures as follows:

$$
\text { 23-21-19 }
$$

65

in which the upper line denotes the number of scale rows around the body, and the figures of the lower line denote which row, counting from the ventral plates upward, is involved in the change indicated by the figures above it. From a study of all the forms in the genus it is found that the change from any particular number of rows to the next lower number always involves the same row, counting upward from the ventrals. Expressing these results in the same manner as above, we get the following:

$$
27-25-23-21-19-17-15
$$


A most interesting uniformity is revealed. It is only in a few individuals of a single form (calligaster) that 27 rows are ever found, and only in a few individuals of two degenerate forms (elapsoides and virginiana) that 15 rows occur. Just as before the presence of 15 and of 27 rows was discovered, it was expected, from the table as then worked out, that the change from 17 to 15 rows would involve the loss of the fourth, and the change from 27 to 25 would involve the loss of the seventh, so now we may expect if 29 rows should ever be found, it would be by addition of a seventh row, and that a drop to 13 would involve the fourth. The latter might not hold, however, for we know that some snakes have the same number of rows throughout the length of their body, and that such generally possess a small number of rows, as 19,17 , or 15 . It is not impossible that these forms are the end results of degenerative evolution, involving diminution in number of scale rows. This is suggested by the case of elapsoides, the most diminutive and degenerate form in the genus. This form has clearly been evolved from the typical forms by degenerative evolution. In southern Florida it reaches its greatest reduction and it is here only, out of the whole genus, that individuals have been found which possess the same number of scale rows throughout the length of the body. Several individuals from here have been noted with 17 rows of scales throughout the body. It is as if extreme reduction leads to a minimum number of rows, uniform throughout the length of the body. That an increase from 27 to 29 rows would involve the addition of a seventh row is indicated by the genus Elaphe. Examination of a few individuals of E. laeta, E. guttata, and $E$. obsoleta gives the following formula for change in number of scale rows in this genus:

$$
\begin{array}{ccccc}
29-27-25 & -23-2 & -19 \\
7 & 7 & 6 & 6 & 5
\end{array}
$$

This, it will be noticed, is the same rule as derived from Lampropeltis. The rule as derived by Ruthven for the genus Thamnophis is as follows:

$$
\text { 23-21-19-17-15 }
$$

$$
\begin{array}{llll}
5 & 5 & 4 & 4
\end{array}
$$

This formula is the same in kind as for Lampropeltis and Elaphe, but the lower line of figures has been moved one place to the left. The rule for Thamnophis appears, quite according to expectation, to hold likewise for Natrix, but as to whether the similarity in formulae between Elaphe and Lampropeltis indicates community of descent, we can not say. Further investigation may show what value to place upon similarity in method of change in number of scale rows, in establishing relationships between genera.

The value of a knowledge of variations in scale rows in a study of relationships within the genus lies not in which row is dropped, since 
that is a constant for the genus, but in the kinds of formulae possessed by any single form or group of forms. No individual ever drops more than three rows on a side, and only certain formulae of this kind occur. Thus while any individual that possesses a maximum of 25 rows may drop three rows on each side, making the formula 25-23-21-19, in only two forms (multicincta and pyrrhomelaena) is it common for an individual with a maximum of 23 rows to have 17 rows at the posterior end, and in only three others has such a situation been observed to occur even rarely (as in polyzona, micropholis, and one specimen of triangulum). All others having a maximum of 23 rows possess the formulae $23-21-19,23-21$, or $21-23-21-19$, or 21-23-21; those having a maximum of 21 rows never have a minimum lower than $17 ; 15$ rows is reached only by those that never have more than 19.

It is very noticeable that some forms in the genus (elapsoides in particular) are undergoing, or have undergone, a reduction in number of scale rows concomitant with reduction in bodily size and in scutellation. This shows that evolution in Lampropeltis may involve reduction in scutellation, and that this reduction may be one evidence that evolution away from the primitive type has taken place. On the other hand, there is evidence from at least one instance (floridana) that evolution has taken place by increase in scutellation, including increase in number of scale rows. From these definite instances of evolution, involving change in number of scale rows, it is shown that the formulae may be represented in descending order as follows:

$$
\begin{array}{r}
21-19 \\
21-19-17 \\
19-21-19-17 \\
19-17 \\
17-19-17 \\
17-19-17-15 \\
17-15 \\
15-17-15
\end{array}
$$

In some forms, between the formulae 21-19 and 21-19-17, there occurs the formula 19-21-19, and then 21-19-17 may occur but rarely or not at all (the getulus group in particular). Reduction takes place by a shortening of the rows to be lost, proceeding first from behind forward and later, in addition, by a drop in the region behind the neck, approximately opposite to the twentieth to thirtieth ventral scute; from this point the loss proceeds in both directions. Exactly a reverse in this process is the means by which a higher formula is attained, and is best illustrated by floridana. The added row enters at some point anterior to the middle of the body, and extends its length from here in both directions. 
In nearly all forms the influence of sex upon the scale formula is evident. While the extremes for the form are generally attained by both sexes, more females possess the higher formulae and more males the lower, and in some forms the sex can be told in many cases by the formula alone. Thus in multicincta and pyrrhomelaena the formula 23-21-19-17 appears to be possessed by males only, and in some of the forms of triangulum the formula 21-19 is possessed in the great majority of cases by females and 21-19-17 or 19-21-

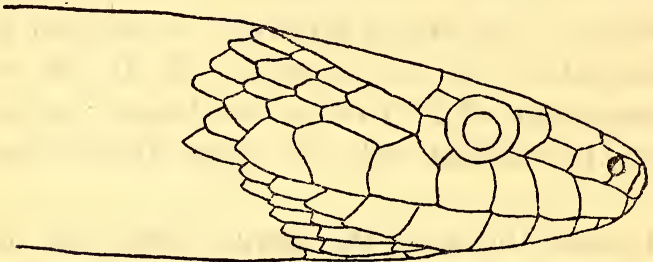

Fig. 3.-Lampropeltis getulus splendida (U.S.N.M. No. 22374). $2 \times$ NAT. SIZE. SHOWING NORMAL ARRANGEMENT OF HEAD PLATES FROM THE SIDE.

$19-17$ by males. The exact situation for each form is included with its description. As a general rule it is common for the male to have one less row of scales near the posterior end of the body than the female. This is undoubtedly correlated with the fact that the body of the female has a greater diameter in this region, due to the necessity at the breeding season for containing the eggs. This is another illustration of the fact insisted upon by Ruthven that the number of rows of scales is correlated with the size of the body.

The rule derived by Ruthven for the garter snakes that decrease in number of scale rows is $d$ to a dwarfing of the body is, in a general way, borne out by the present study. Rhombomaculata and elapsoides are excellent examples. However, it does not appear that decrease in size of body is neces-

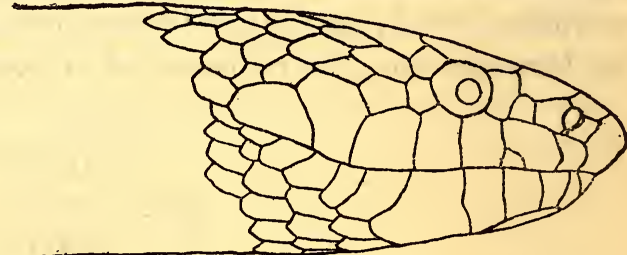

Fig. 4.-Lampropeltis getulus getulus (U.S.N.M. No. 14140). $1 \frac{1}{3} \times$ NAT. SIZE. SHOWING EXTRA SUPRALABIAL SCUTE INTERPOLATED BETWEEN NORMAL SECOND AND THIRD.

sarily accompanied by decrease in number of scale rows, or that the latter is evidence of a decrease in size of body. Thus holbrooki, niger, and getulus are undoubtedly derived from splendida and their scale formulae are decidedly lower, but it is certainly yet to be proved that they are smaller snakes; furthermore, conjuncta is in all probability a derivative of boylii, but while its scale formula is the same as that for boylii, it gives strong evidence of being a smaller snake. It seems quite evident that these facts are to be explained by a geographic change in shape of the dorsal scales. In the western forms of the getulus group the scales are more elongate, in the eastern forms relatively shorter and broader. 
A study of the whole genus indicates most strongly that the primitive scale formula is $23-21-19$. This and its simple derivative, 21-23-21-19, is characteristic of those forms of the two most widespread and diversified groups (triangulum and getulus) which show, in other structural features, the most primitive condition. Higher and lower formulae in the genus Lampropeltis are believed to indicate specialization, or depar-

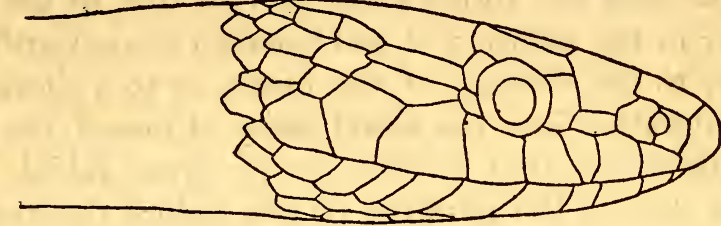

Fig. 5.-Lampropeltis Pyrrhomelaena. About $2 \times$ nat. Size. SHOWING AN EXTRA LABIAL IN EACH SERIES. ture from the original stock of the genus.

Variation in labials.-Both upper and lower labial series are remarkably constant throughout the genus. The supralabials are normally seven (fig. 3 ), but in very rare instances this number is reduced to six by a fusion of the sixth with the fifth. Variation to eight occurs occasionally in $\mathrm{many}$ forms and in a few (calligaster, pyrrhomelae$n a)$ it is rather common. In all cases the presence of eight supralabials is due to the interpolation
Fig. 6.-LAMPropeltis CAlligaster (UNIV. Mich. NO. 44973). $1 \frac{1}{3} \times$ NAT. SIZE. SHOWING POSITION OF THE ADDED LABIAL IN EACH SERIES.

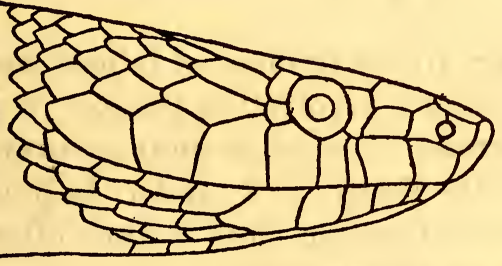

of a scute between second and third (figs. 4, 5, and 6), or to the division of the second.

The infralabials are more variable. Normally there are nine (fig. 3), but in a few forms ten is common or usual (conjuncta, pyrrhomelaena, calligaster, floridana, mexicana, alterna), and in a few others eight is common or usual (micropholis, rhombomaculata, elapsoides, virginiana); those that commonly have eight may rarely have seven, and those that commonly have ten may occasionally have eleven. Reduction from nine to eight takes place in the great majority of cases by reduction of the seventh and its fusion with the eighth (fig. 7); in some instances it seems to occur by loss of the ninth. The method of increase to ten is less constant. Since this is commonly accompanied by increase to eight in the upper series, and since the latter is due to the addition of a scute in front of the eye, it is most natural to expect that the tenth lower labial would also be inserted in front 
of the eye, and beneath the newly added labial in the upper row. That this is normally the case seems evident from a study of pyrrhomelaena and calligaster (fig. 6), but that the extra scute is often acquired behind the eye must also be admitted. When the latter is the case the added scute may be due to the division of the seventh or to the addition of one between the seventh and the eighth (fig. 5), or to the division of the ninth, or to a shortening of the last and a migration into the labial series of one of the gular scales. The few specimens that possess eleven lower labials usually show that this is due to the addition of one before the eye and one behind. It is not improbable that when the change from nine to ten is due to the division of the seventh that this is an accident in place of the third, and that the next division would then be due to occur before the eye instead of behind. We may therefore express the normal change in the lower labials as follows:

$$
\begin{gathered}
8-9-10-11 \\
74 \quad 8
\end{gathered}
$$

in which the upper line refers to the number of labials and the lower to the number of the scute that is involved in the loss or gain, as the case may be. In case of increase it might be more accurate to replace the second row above with the figures 6,3 , and 7 , to indicate which scute is divided to increase the number, since it more often looks like a case of division than like an interpolation.

If we express the changes in the upper labials, as we have done for the lower, we get the following:

$$
6-7-8
$$

63

This fits the scheme for the lower labials, and the two may be combined thus:

$$
\begin{gathered}
6-7-8-9-10-11 \\
6 \begin{array}{llll}
6 & 7 & 4 & 8
\end{array}
\end{gathered}
$$

We may express this in the following general rule, which seems to hold throughout the genus, subject to the exceptions explained above: In reduction - when the number of labials is odd, a scute is lost behind the eye, and when the number is even, one is lost in front of the eye; in addition-when the number of labials is odd, a scute is added in front of the eye, and when the number is even, a scute is added behind the eye. The two labials of each series that lie directly beneath the eye are never concerned in any change.

The actual method of change in the number of labials is of scant importance in determining the relationships of the forms within the 
genus. It is included here only on the possibility that it may be of value in establishing relationships with other genera. The real value of the labial count in the present study is the sure indication it gives of the degree of specialization of the form. Any marked change in the normal 7-9 formula is, in the present genus, an earmark of specialization. We may call attention here to the following forms that show conspicuous departure from the 7-9 arrangement: Conjuncta, micropholis, pyrrhomelaena, floridana, elapsoides, virginiana, rhombomaculata, and calligaster. The descriptions and discussions following will make it clear that these are the most specialized forms in the genus, and in several instances occupy, geographically, the most isolated portions of the entire range.

Variation in other features of scutellation.-The caudals and ventrals vary geographically, sexually, and individually. A brood of eight young of triangulum from Indiana shows a range in ventrals of from 200 to 208; of these, 5 are females and 3 males, and their averages are respectively 205 and 203 . This expresses fairly well the average difference between the sexes in the number of ventral plates for any form in the genus. Sometimes a large series will show an average difference of only half a plate in favor of the females. The influence of sex on these averages is therefore negligible when they are to be used to show geographic differences. And as the latter undoubtedly occur the number of ventrals proves to be an important character in the determination of relationships.

The caudals show a more distinct relation to sex than the ventrals. The males always average to have a higher number, sometimes only one or two, but usually four or five, more than the females. Geographic differences in their number can be satisfactorily demonstrated only by comparing averages of like sexes. As this always reduces the dependability of the averages by reducing the number of specimens upon which they are based, the caudals are much less valuable in the present study than the ventrals. In subspecific determination the number of caudals may be of more value than the proportionate tail length, since the latter may remain the same throughout a series of closely allied forms, while the ventrals and caudals are increasing or decreasing together.

The temporals are normally two in the first row, three in the second, and four in the third, expressed: $2+3+4$ (fig. 3 ). Variation in some forms is normally by increase of a scute in any row, more often in the last row (getulus, pyrrhomelaema, calligaster), in others it is normally by decrease (syspila, triangulum), but in only a few forms has this formula been altered racially. In elapsoides, virginiana, and micropholis the temporals are usually $1+2+3$. Reduction in the temporals takes place by a decrease in size of the upper scute in each 
row and its final disappearance or its fusion with the next lower scute. Usually the latter increases in size as the upper decreases, but reduction in number is very evidently due to a flattening of the head, and while the single anterior temporal is frequently larger than either when both are present, it is generally narrower than the combined width of the two, and in elapsoides the space between the upper labials and the parietals has become decidedly narrowed (fig. 7).

The loreal plate in the great majority of the forms of the genus is distinctly longer than high and nearly quadrilateral in outline (fig. 3 ). It may be absent by anomaly in any form and is commonly absent in elapsoides, its place being taken by a downward extension of the prefrontal (fig. 7). In some its shape has been noticeably altered; in getulus and holbrooki it is commonly nearly square or higher than long (fig. 4); in pyrrhomelaena its length is increased and its lower posterior angle is strongly acute; in microphotis its shape is distinctly atypical. The assumption is inevitable that the ancestral type has this scute longer than high and with nearly right angles.

Variation in dentition.-Dental characters are of uncertain value in a work of this kind. No relationships have been discovered by their means that were not already evident from external characters. The variability of the teeth is greater than that of the head scutes, necessitating the examination of many skulls to determine the extremes and averages of the characteristics. The chief value in the present study has been the confirmation derived from dental characters of the validity of the major groupings within the genus.

Variation in color pattern.-There is no evidence of a fundamental pattern from which all forms of the genus have been derived. On the other hand, there are at least three styles of patterns, and, if we include mexicana and alterna, probably two more. On the color patterns alone the major groups in the genus can be recognized. Two of the groups in particular (triangulum and getulus) show most remarkable evolution in pattern. When we see the changes that may take place in the color pattern within a single group of closely related forms, we conclude that scant dependence can be placed upon differences and resemblances in pattern until these are supported by structural evidence. Furthermore, where structural differences are slight or unreliable the color pattern may furnish conclusive evidence as to relationships.

\section{SUBDIVISIONS OF THE GENUS LAMPROPELTIS.}

The many forms of king snakes fall naturally into three groups (exclusive of the aberrant and little-known forms, alterna and mexicana), recognizable on structural characters as follows: 
$a^{1}$. Last two maxillary teeth usually not longer and stouter than those preceding; spines of penis stout, extending one-third to one-half the distance to base of organ.

$b^{1}$. Penis bilobed or bifurcate; pattern in black, and white or yellow, in rings, bands, or stripes, but fundamentally of a light spot on a dark scale.

getulus group.

$b^{2}$. Penis scarcely bilobed; pattern of dorsal blotches of brown with black borders.............................................

$a^{2}$. Last two maxillary teeth usually larger and stouter than those preceding; spines of penis slender, extending half way or more than half way to base of organ; pattern fundamentally of rings of black, red, and yellow.....triangulum group.

The greatest separation in the genus (still excluding alterna and mexicana) is undoubtedly between the sections $a^{1}$ and $a^{2}$ above. The getulus group includes 10 very closely allied forms spread over the southern two-thirds of the United States, Lower California, and northern Mexico. This group is distinctly marked off by style of color pattern from all other forms in the genus, but is closely allied with the calligaster group in characters of skull, dentition, copulatory organ, proportions, and scutellation.

The calligaster group includes but three forms, one of which is known from only a single specimen. The other two are found only east of the Rocky Mountains, one in the Mississippi Valley and the other east and south of the Alleghenies. Both are more specialized than any of the forms of getulus, and this together with the fact that the group to which they belong is far less diversified than the latter indicates that it is the result of an older radiation than the getulus group.

In the triangulum group the anterior maxillary and particularly the anterior dentary teeth are longer than the corresponding teeth in the other two groups. The relative size of the last two maxillaries is a fairly, although not fully, distinctive feature. The penial characters are likewise for the most part distinctive; the calyces are commonly more numerous and have more and longer fringes, and the spines are more slender, more numerous, and do not stop as abruptly.

The name mexicana has been applied to two specimens from San Luis Potosi. The description will show that these can not be assigned on structure or pattern to any of the above three groups, but, as the genus is now defined, they must be assigned to Lampropeltis. Practically the same situation holds with respect to the specimen said to have come from the Davis Mountains, Texas, and named by Brown, alterna. Penial characters can not be determined, since all three of these specimens are females.

A fuller discussion of the three major groups is reserved for the summaries following the descriptions of their component forms.

The following key is expected to work for the great majority of specimens, but difficulty may be expected from occasional individuals. 
Fuller knowledge of some forms that are now known from but few specimens may be expected to reveal limits of variation that will render invalid some of the distinctions now used, but this contingency has been guarded against as much as possible.

\section{KEY TO THE FORMS OF LAMPROPELTIS.}

$a^{1}$. Pattern of narrow cross bands of black, the alternate bands mixed or split with red; ground color above, slate gray; head very distinct from neck. alterna, p. 247.

(Davis Mountains, Texas.)

$a^{2}$. Pattern not of narrow dorsal cross bands of black with the alternate bands mixed or split with red; head usually only slightly distinct from neck.

$b^{1}$. Color pattern without red ${ }^{1}$ and without dorsal blotches of brown or gray with black borders................................... getulus group.

$c^{1}$. Scales chiefly black with sharply defined white or yellow spots (not light at base shading gradually into a dark distal border); these yellow spots often so grouped as to form 50 or more narrow cross bands on body and tail.

$d^{1}$. Scale rows on middle of body 23 or 25 ; no light centers, dorsally, on the scales between the cross bands; head mostly black.......splendida, p. 26 .

(Southeastern Arizona to the ninety-seventh meridian; southern Texas, and northern Mexico.)

$d^{2}$. Scale rows on middle of body usually 21 .

$e^{1}$. A yellow spot on practically all of the dorsal scales.......holbrooki, p. 33 .

(Eastern Texas to southeastern Wyoming, east to eastern Illinois, and south to the Gulf of Mexico.)

$e^{2}$. Scales between the dorsal cross bands without light centers or with only

a very few small ones...........................niger, p. 43 .

(Eastern Illinois to Ohio, south to central Alabama.)

$c^{2}$. Pattern in rings, cross bands, or stripes, or chiefly of scales white at base shading gradually into a black distal border, but not chiefly of sharply defined white or yellow spots on black scales.

$f^{1}$. Posterior chin shields nearly as long and nearly as wide as anterior, in contact or separated by not more than one small scale; pattern neither of rings nor of longitudinal stripes.

$g^{1}$. Many dorsal cross bands of white or yellow.

$h^{1}$. Cross bands less than $50 ; 21$ (sometimes 23) rows of scales.

(From New Jersey to Mobile Bay and Central Florida.) getulus, p. 49.

$h^{2}$. Cross bands more than 50 , or nearly indistinguishable; 23 (sometimes 21) rows of scales; scales between the cross bands usually white at base...........................floridana, p. 62 .

(Central to southern Florida.)

$g^{2}$. No dorsal cross bands distinguishable; dorsal scales light at base, shading gradually into a dark distal border..........brooksi, p. 66 .

(Extreme southern Florida.)

$f^{2}$. Posterior chin shields generally much shorter and narrower than anterior and separated by one or two small scales; pattern of rings, or of longitudinal stripes of white or yellowish.

$i^{1}$. A dorsal longitudinal stripe, complete or interrupted.

$j^{1}$. Dorsal stripe white or yellow, sharply defined on a dark brown or black ground color...................californiae, p. 94.

(Fresno County, California to northern Lower California.)

1 The red fades to whitish in alcohol, but it is sufficient, for the purpose of the key, to determine that the pattern is in two colors instead of in three. 
$j^{2}$. Dorsal stripe poorly defined, of light brown or cinnamon on a dark brown ground color; belly uniform brown..nitida, p. 103.

(Southern Lower California.)

$i^{2}$. Pattern of rings.

$k^{1}$. White ${ }^{2}$ scales white to their bases, forming rings of uniform white............................ boylii, p. 75 .

(California, Nevada, southwestern Utah, northern and western Arizona, and northern Lower California.)

$k^{2}$. White ${ }^{2}$ scales mostly brown at their bases.

$l^{1}$. White bars on prefrontals occupying less than half the area of these scutes; frontal plate uniform black, or with the white restricted to a narrow transverse bar at its anterior end; no white on parietals; infralabials

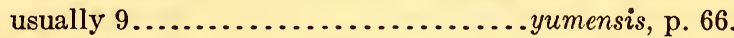

(Southern Arizona, extreme southeastern California, northeastern Lower California, and northwestern Sonora.)

$l^{2}$. White bars on prefrontals occupying more than half the area of these plates; frontal plate with prominent white markings, or at least with a central spot of white; each parietal with one or more white spots; infralabials usually $10 \ldots \ldots \ldots \ldots . . . . . . . .$. . conjuncta, p. 89 .

(Southern Lower California.)

$b^{2}$. Pattern with red, or with dorsal blotches of brown, gray, or red, with black borders.

$m^{1}$. Pattern of black-edged dorsal blotches of brownish or dark red, only narrowly in contact with the fifth row of scales or extending no lower than the sixth or seventh rows....................... calligaster group.

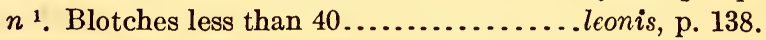
(Nuevo Leon, Mexico.)

$n^{2}$. Blotches 45 to 80 .

$o^{1}$. Scale rows 25 to 27 on middle of body; dorsal blotches with concave anterior and posterior margins; infralabials 9 or 10 , rarely 8 .

calligaster, p. 115.

(Western Texas to Mississippi, north to Indiana) and northwest to Minnesota, thence south to Texas.)

$o^{2}$. Scale rows 23 or 21 on middle of body; dorsa $]$ blotches with straight or convex anterior and posterior margins; infralabials 8 , less often 9 ................... rhombomaculata, p. 128.

(Mobile, Alabama, to Knoxville, Tennessee, north to Maryland, south to Central Florida.)

$m^{2}$. Pattern in rings; or, if in blotches or saddles of brown, gray, or red, these broadly in contact with the fifth or a lower row of scales.

$p^{1}$. Whitish cross bands on body and tail less than 40 ; or, if more than 40 , the snout not uniformly whitish.

2 Specimens may be found which can be accurately identified only by loca!ity; in paiticular it should be noted that young examples of yumensis and conjuncta may resemble boylii. See table, p. 77. comparing these three forms. 
$q^{1}$. Whitish cross bands little if any widened on the lower rows of dorsal scales, and the scale rows more than 17 on the anterior portion of the body.

$r^{1}$. Red scales usually tipped with black.

$s^{1}$. Snout black, with usually a light transverse bar on or near the prefrontals; two temporals in the first row; caudals usually not less than $49 . . . .$. . polyzona, p. 139.

(Southern Mexico to Costa Rica.)

$s^{2}$. Snout yellowish with transverse black spóts; a single, anterior temporal, or, if two, the upper much the smaller; caudals not more than $49 . . . \ldots \ldots \ldots$...... micropholis, p. 149.

(Panama to Colombia and Ecuador.)

$r^{2}$. Red scales not tipped with black.

$t^{1}$. Whitish annuli usually more than 30 ; snout black.

$\iota^{1}$. Ventrals more than 200; black rings often meeting across the red dorsally.............multicincta, p. 222 .

(California.)

$u^{2}$. Ventrals less than 200 ; black rings not meeting across the red dorsally. ruthveni, p. 221.

(Southern Mexico.)

$t^{2}$. Whitish annuli less than 30 .

$v^{1}$. Dorsal red areas usually continuous across the belly; snout whitish, specked with black.

$w^{1}$. Ventrals usually more than 210 (199 to 231).......nelsoni, p. 155.

(Western Mexico.)

$w^{2}$. Ventrals usually less than 200 , (180 to 212)......amaura, p. 172.

(Lower Mississippi Valley.)

$v^{2}$. Spaces on belly between the yellow rings filled with black; snout totally black, or only very slightly lightened on the top or sides.

$x^{1}$. Yellowish rings 19 to 25 ; black spaces on belly usually longer than the intervening yellow ones......... annulata, p. 159.

(Plateau region of southern Mexico north to extreme southern Texas.)

$x^{2}$. Yellow rings 25 to 40 ; black spaces on belly usually shorter than the intervening yellow ones..........gentilis, p. 165 .

(Texas to South Dakota, west to Utah and Arizona.) 
$u^{2}$. Dorsal whitish bands usually distinctly widened on the first row of scales, or the scale rows anteriorly not more than 17 .

$y^{1}$. Black practically uniform over the head, except for the snout region, which is more or less lightened, at least on the sides; scale rows anteriorly more than 17 .

$z^{1}$. Whitish annuli or cross bands 25 to 40 ; black often strongly encroaching upon the red on the middorsal line.

gentilis, p. 165.

$z^{2}$. Whitish annuli or cross bands 18 to 25 ; black showing not more than a slight tendency to encroach upon the red areas on the middorsal line.

amaura, p. 172.

(Lower Mississippi Valley.)

$y^{2}$. Black of head practically restricted to posterior portion, or to various black-edged light markings.

$a a^{1}$. Usually a single anterior temporal; scale formula usually 17-19-17, rarely higher than 1917.

$b b^{1}$. Red areas continuous across the belly.

clapsoides, p. 206.

(North Carolina and Kentucky,south to New Orleans, and throughout Florida.)

$b b^{2}$. Red not continuous across the belly, but restricted to blackbordered dorsal saddles that extend upon the ventrals.

virginiana, p. 217.

(Northern North Carolina to Deleware.) 
ui $i^{2}$. Usually two anterior temporals; scale formula very rarely lower than 19-21-19-17.

$c c^{1}$. Whitish annuli or cross bands 18 to 23; pattern of body practically in rings. umaura, p. 172. (Lower Mississippi Valley.)

$c c^{2}$. Whitish across bands. 23 to 60 ; pattern of dorsal saddles or blotches of red or brown.

$d d^{1}$. Infralabials 8 or 9 , rarely 10; tail less than 16 per cent of total length; often a dark band from eye to angle of mouth.

$\epsilon e^{1}$. Dorsal saddles 35 to 60 , reaching down to the fifth or third row of scales; often two rows of lateral alternating blotches; a dark band on posterior portion of prefrontals; a black-bor dered light band from the eye to the angle of the mouth; usually a $\quad \mathrm{Y}$-shaped light spot on the back of the head.

trian $g u l u m$, p. 188.

(Eas t e $\mathrm{r} \mathrm{n}$ United States and southern Canada.) 
$c e^{2}$. Dorsal saddles 23 to 35 , extending down to the third row of scales, or lower; only one series of alter $\mathrm{n}$ a $\mathrm{t}$ in $\mathrm{g}$ spots; head markings of triangulum only partially or not at all developed.

syspila,p.179.

(Southern

Indian a to

Minn e s o t a , south to central Arkansas and west to central Kansas.)

$d d^{2}$. Infralabials 10 ; tail more than .16 of total length; a dark blotch behind the eye. mexicana,p.245. (San Luis Potosi, Mexico.)

$p^{2}$. Whitish cross bands on body and tail more than 40 ; top of head black, snout uniformly white.

pyrrhomelaena, p. 231.

(Utah, Arizona, Western New Mexico, and northern Mexico. 
SUMMARY OF STRUCTURAL CHARACTERISTICS OF THE FORMS OF LAMPROPELTIS.

\begin{tabular}{|c|c|c|c|c|c|c|c|c|}
\hline Narne. & Ventrals. & Caudals. & $\begin{array}{c}\text { Su- } \\
\text { pra- } \\
\text { labi- } \\
\text { als. }\end{array}$ & Infralabials. & $\begin{array}{c}\text { Tem- } \\
\text { po- } \\
\text { rals. }\end{array}$ & $\begin{array}{c}\text { Tail } \\
\text { divided } \\
\text { by total } \\
\text { length. }\end{array}$ & Pattern. & $\begin{array}{l}\text { Num- } \\
\text { ber } \\
\text { of } \\
\text { bands } \\
\text { or } \\
\text { spots. }\end{array}$ \\
\hline alterna... & 213 & 60 & 7 & $10-11$ & $3+4$ & 0.170 & Alternating ban & \\
\hline amaura. & 180-212 & $39-51$ & & $9(8-10)$ & $2+3$ & $.118-0.156$ & Rings......... & $18-26$ \\
\hline lata & $197-212$ & $40-57$ & $7(8)$ & $9(10)$ & $2+3$ & $.123-.167$ & .....do. & $19-26$ \\
\hline boylii..... & $206-254$ & 41-62 & $7(8)$ & $9-10$ & $2+3$ & $.107-.145$ & .....do. & $28-49$ \\
\hline $\begin{array}{l}\text { brooksi .... } \\
\text { californiae. }\end{array}$ & $\begin{array}{l}\text { Similar to } \\
229-241\end{array}$ & $\begin{array}{r}0 \text { floridana } \\
47-60\end{array}$ & $\dddot{7-8}$ & (8) $9-10$ & $2+3$ & $.113-.140$ & Stripes. & …... \\
\hline calligaster. & $196-215$ & $38-57$ & $7(8)$ & (C) $\begin{array}{r}y-10 \\
9-10\end{array}$ & $\begin{array}{l}2+3 \\
2+3\end{array}$ & $.110-.150$ & Blotches & $\ddot{4} \ddot{6}-\ddot{78}$ \\
\hline ncto & $228-240$ & $48-54$ & & $10(9-11)$ & $2+3$ & $.115-.132$ & Rings... & $30-40$ \\
\hline elapsoide & $152-193$ & $32-48$ & & $8(7-9)$ & $1+2$ & $.118-.169$ & ....do..... & $15-25$ \\
\hline floridana & $210-225$ & $42-55$ & $7(8)$ & $9-10$ & $2+3$ & $.107-.146$ & Cross band & $46-85$ \\
\hline gentilis. & 176-212 & $41(31)-53$ & $7(8)$ & $9(8)-10$ & $2+3$ & $.115-.156$ & Rings.... & $25-40$ \\
\hline getulus ....... & $\begin{array}{l}203-224 \\
200-220\end{array}$ & $\begin{array}{r}38-58 \\
38-55\end{array}$ & $\begin{array}{l}7(6-8) \\
7(6-8)\end{array}$ & $9(8-10)$ & $2+3$ & $.100-.155$ & Cross banc & $23-52$ \\
\hline leonis........ & $\begin{array}{r}200-220 \\
200\end{array}$ & $\begin{array}{r}50-50 \\
50\end{array}$ & $\begin{array}{r}(0-8) \\
7\end{array}$ & & $2+3$ & $.090-.150$ & Blotches & 27 \\
\hline mexicana & $193-199$ & 55 & & 10 & $\begin{array}{r}2+3 \\
1+2\end{array}$ & $.16-.17$ & .....do... & 39 \\
\hline micropholis . & $211-228$ & $40-49$ & $7(8)$ & $9-8(10)$ & & $.112-.136$ & Rings..... & $13-21$ \\
\hline multicincta. & 202-222 & $45-61$ & $7(8)$ & $9(8-10)$ & $\begin{array}{r}(2+3 \\
2+3\end{array}$ & $.131-.161$ & do. & $23-57$ \\
\hline nelsoni... & $199-231$ & $42-59$ & $7(8)$ & $9(10)$ & $2+3$ & $.120-.150$ & .....do... & $13-24$ \\
\hline niger...... & $\begin{array}{r}199-216 \\
227\end{array}$ & $41-53$ & & $9(8-10)$ & $2+3$ & $.110-.146$ & Narrow bands.. & $50-90$ \\
\hline polyzona.... & 208-239 & $42-61$ & $7(8)$ & $9(8-10)$ & 203 & $124-.164$ & $\begin{array}{l}\text { Stripes. } \\
\text { Rings. }\end{array}$ & $i \ddot{1}-3 \ddot{7}$ \\
\hline pyrrhomelaena... & $216-235$ & $61-79$ & $7-8$ & $9-10(11-12)$ & $2+3$ & $.153-.182$ & .....do...... & $35-71$ \\
\hline rhombomaculata. & $191-213$ & $31-55$ & & $8-9$ & $2+3$ & $.100-.150$ & Blotches. & $48-64$ \\
\hline ruthveni.. & 190 & 50 & $7-8$ & & $2+3$ & 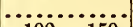 & Rings............ & \\
\hline splendida & $207-225$ & $43-56$ & $7(8)$ & $9(10-11)$ & $2+3$ & $.100-.150$ & Light cross bands. & $41-85$ \\
\hline syspila... & $180-215$ & $40-54$ & & $9(8-10)$ & $2+3$ & $.114-.157$ & Blotches... & $23-36$ \\
\hline triangulun & $180-213$ & $29-54$ & $7(8)$ & $9(8-10)$ & $2+3$ & $.100-.155$ & .....do... & $28-62$ \\
\hline yumensis & $212-240$ & $44-57$ & $7(8)$ & $9-10$ & $2+3$ & $.090-.140$ & Rings... & $29-45$ \\
\hline virginiana... & $173-188$ & $36-44$ & & & $1+2$ & $.129-.145$ & Blotches..... & $18-27$ \\
\hline
\end{tabular}


Summary of siructural characteristics of the forms of Lampropeltis-Continued.

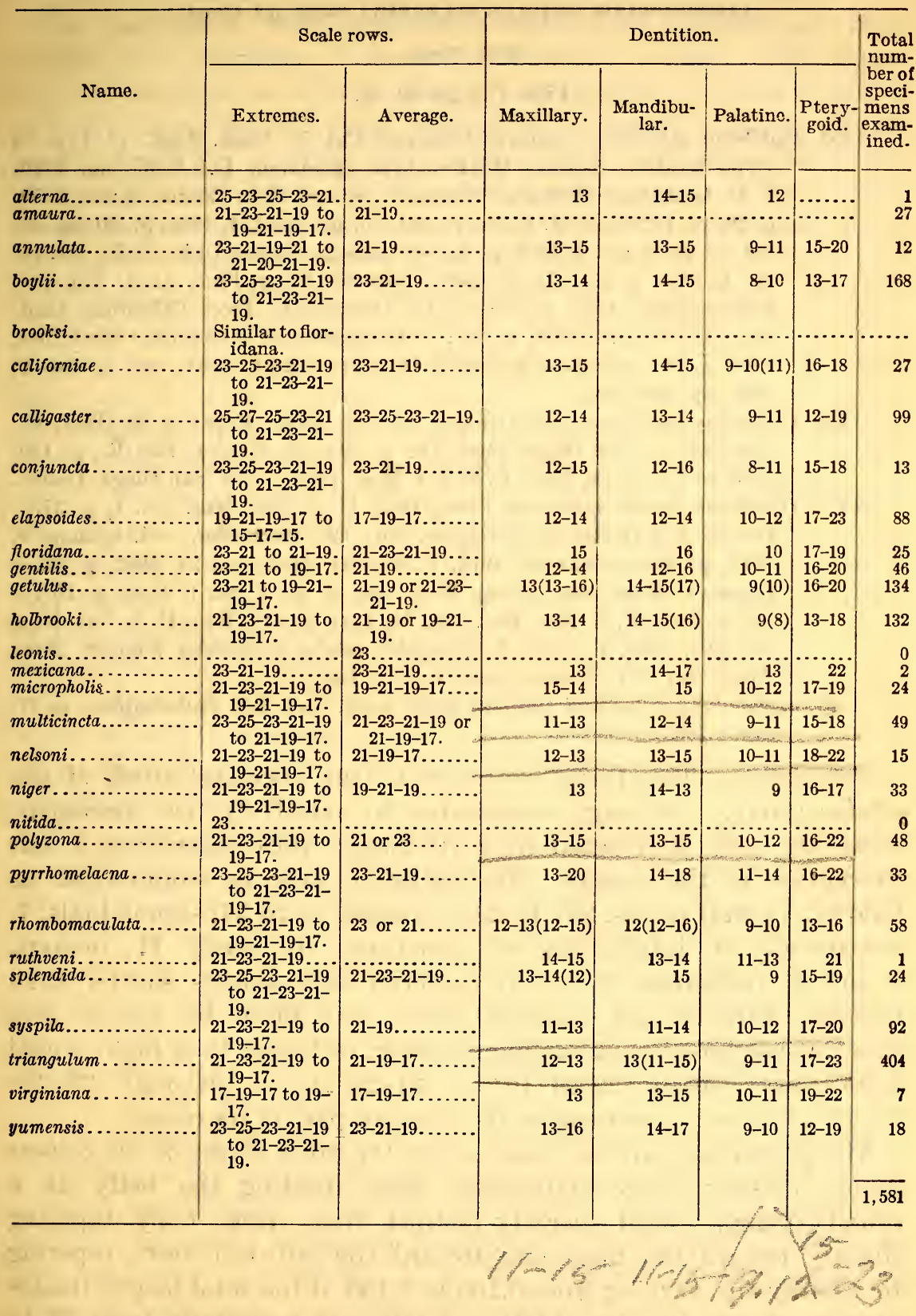




\section{THE GETULUS GROUP.}

\section{LAMPROPELTIS GETULUS SPLENDIDA (Baird and Girard).}

KING SNAKE.

Figs. 1, 3, 29, 30, 31 .

1853. Ophibolus splendidus BaIrd and Girard, Cat. N. Amer. Rept., pt. 1, p. 83 (type locality, Sonora, Mexico; type specimen, U.S.N.M., no. 1726; J. D. Graham, collector).-BAIRD, U. S. and Mex. Bound. Surv., 1859, p. 20, pl. 14; Pacif. R. R. Surv., vol. 10, pt. 3, art. 1, 1859, pl. 30, fig. 58; vol. 10, pt. 6 , art. 4, 1859, p. 43.-Strecker, Baylor Univ. Bull., vol. 18, no. 4, 1915, p. 39.-Lampropeltis splendida Cope, Proc. Acad. Nat. Sci. Philadelphia, 1860, p. 255.-Van Denburgh, Proc. California Acad. Sci., ser. 2, vol. 6, 1896, p. 347.-Stejneger and Barbour, Check List, 1917, p. 89.-Coronella splendida JAN, Arch. Zool. Anat., vol. 2, fasc. 2, 1863, pp. 238, 245.

1853. Ophibolus sayi BaIrd and Girard, Cat. N. Amer. Rept., p. 85 (Red. R., Arkansas), p. 159 (Eagle Pass, Tex.).-Marcy, Explor. Red R., p. 199, 1854, pl. 7.-Cope, Proc. U. S. Nat. Mus., 1888, p. 398 (San Diego, Texas).

1875. Ophibolus getulus splendidus Cope, Bull. U. S. Nat. Mus., no. 1, p. 37.Coues, Rep. Geog. Geol. Explor. Surv. W. 100th Mer., vol. 5, chap. 5, 1875, p. 619.-Yarrow, Bull. U. S. Nat. Mus., no. 24, 1882, p. 93.Garman, Mem. Mus. Comp. Zool., vol. 8, no. 3, pt. 1, 1883, p. 157.Cope, Proc. U. S. Nat. Mus., vol. 14, 1891, p. 613; Rep. U. S. Nat. Mus. for 1898, 1900, p. 918.-Lampropeltis getulus splendidus Wright, Proc. Acad. Nat. Sci., Philadelphia, 1915, p. 148.

1901. Ophibolus getulus sayi Brown, Proc. Acad. Nat. Sci. Philadelphia, p. 77; same, 1903, p. 550 .

Description.-This form is nearest to the ancestral stock of the getulus group. Although represented by relatively few specimens, these are well distributed over its range, thus presenting a fair conception of the species. The scalation may be summarized as follows: Ventral plates, 207 to 225 ; caudals, 43 to 56 ; supralabials, 7 , occasionally 8 ; infralabials, 9 , sometimes 10 , rarely 11 ; oculars, 1 and 2 ; temporals, $2+3+4$; posterior chin shields shorter than anterior, parallel, and separated from each other by one or two small scales; loreal about as high as long, or longer than high; dorsal scale rows usually 23-21-19, or 21-23-21-19, although 23-2523-21-19 is not uncommon in the western part of its range.

The proportions are the same as for the other forms of the getulus group, namely: body cylindrical; sides meeting the belly at a rounded angle; head scarcely distinct from neck; body tapering slightly toward the head and toward the tail; tail short, tapering to a horny tip, varying from 0.100 to 0.150 of the total length (males average, 0.130 ; females, 0.120 ). Adults are commonly from 75 to $115 \mathrm{~cm}$. in length. The largest examined was from Bexar County, Texas, and measured 1,432 millimeters.

The color pattern is, briefly: Black, spotted on the sides with white or yellow, one spot on each scale; across the back about 70 
(41 to 85 ) narrow dotted cross bands of white or yellow separated by unspotted areas; head, neck, and under parts mostly black.

The pattern is most typically developed in southwestern New Mexico and northern Chihauhua. Specimens from this region may be described as follows: Head, from between the eyes to about a dozen dorsal scales behind the parietals, black; neck and throat black, except for a white spot, more or less developed, lengthwise of each of the labial and chin shields and anterior gulars, and a median light band on the anterior ventrals. On the frontal plate two narrow transverse white spots anteriorly. On each prefrontal and internasal, anteriorly, a similar white transverse band. Rostral black at center and along posterior border. Nasals, loreals, preoculars, and sometimes oculars with a central development of white. Belly and caudals mostly black, with a development of white on the ends of each alternate ventral plate and sometimes a median white spot on ventrals that alternate with those bearing lateral spots. Dorsal scales each with an oval white center, oriented lengthwise of the scale. These white centers occupy the most of the scale on the first row and decrease in size dorsally, leaving three or four rows of middorsal scales entirely black, except where the white centers are continued across the back to form transverse white bands, from two to four scales apart, throughout the length of the body. In distinction from holbrooki the orientation of most of the white centers of the cross bands is lengthwise of the scales and the spaces between the bands are entirely unspotted, except rarely those close behind the neck.

The penial characters as indicated by specimens from New Mexico are as follows: distinctly bilobed; sulcus single, extending over the side of the larger lobe, and ending in a small bare space, surrounded by a few calyces; the latter extending far enough beyond the end of the organ to be very evident in a lateral view; calyces with five to ten fringes, which may be conspicuous or very short; latter passing into spines which increase gradually in size to about one-third the distance from the apex, here being replaced rather suddenly by a few minute spines; remainder of organ smooth.

The dentition, as derived from examination of a few specimens, is as follows: Maxillary teeth, 12 to 14, subequal, the last two scarcely stouter; mandibulars, 15, third to sixth largest, decreasing posteriorly, the last very small; palatines, 9 , subequal, but slightly smaller than the maxillaries; pterygoids, 15 to 19 , subequal, smaller than the palatines, decreasing a little in size posteriorly.

To distinguish splendida from holbrooki and from yumensis, see under these respective forms.

186550-21-Bull. 114-3 
Habitat and habits. - The only reference that we have been able to find concerning the natural history of this form is by Van Denburgh (1897, 347): "Two specimens of this handsome snake were taken, one of which was 'shot in a tree in a river bottom near Fort Lowell (Tucson, Ariz.) May 28, 1893.",

Range.-The range of splendida extends east to about the 97 th meridian; northward to southern Oklahoma, and west as far as Tucson. It is probable that it will be found of general distribution in northern Mexico, although the only definite record for south of the international boundary is for San Diego, Chihuahua. In New

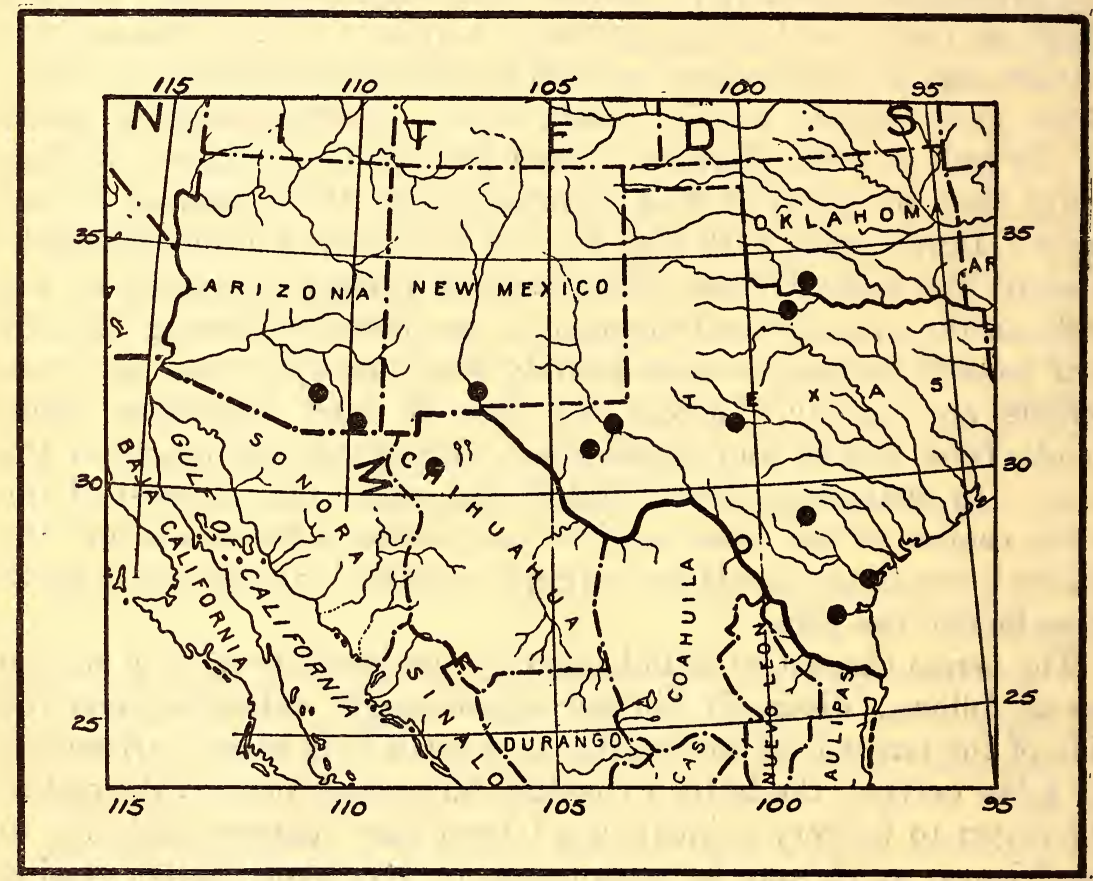

FIG. 8.-MAP SHOWING LOCALITY RECORDS FOR LAMPROPELTIS GETULUS SPLENDIDA.

Mexico it doubtless extends considerably north of Fort Fillmore, which is now the most northern record for that state.

The only published record for a locality not included in the list of specimens examined is one for Eagle Pass, Maverick County, Texas (Baird and Girard, 1853, 159). This specimen is listed as a variety of Ophibolus sayi, but as it occurs well within the range of splendida, it is undoubtedly this species.

Variation.-Throughout the central portion of its range splendida is a distinct and well-defined form, but at its east and west limits it intergrades with holbrooki and yumensis, respectively. Only.23 specimens have been examined from the entire range, but these are 
well distributed and indicate certain points which a fuller series may confidently be expected to confirm. Thus the number of scale rows is higher in the central and western portion of the range than in the east. No specimen showed a lower maximum than 23 rows, but in some of the specimens from central Texas this number was retained for only a very brief space near the middle of the body, while in the west it was present for a much greater distance, and some had 25 rows. The table of scale rows brings this out to some extent. Approach to holbrooki is shown also in the penial characters. That form is oharacterized by having many minute spines below the large ones, and this character is nearly as well developed in specimens of splendida from San Diego, and Bexar County, Texas, as in typical examples of holbrooki; a specimen from Reeves County, in western Texas, shows the minute spines present over nearly as great an area as that occupied by the large ones, but they are only scarcely discernible, while specimens from Tucson, Arizona, show minute spines present for only two or three millimeters below the large ones, thus being close to yumensis in this respect. The ventrals and labials seem to be much the same in one part of the range as in another.

Table of scale rows in splendida.

\begin{tabular}{|c|c|c|c|c|c|c|c|c|}
\hline \multirow{2}{*}{ Formula. } & \multicolumn{2}{|c|}{ Arizona. } & \multicolumn{2}{|c|}{$\begin{array}{l}\text { New Mexicoand } \\
\text { Western Texas. }\end{array}$} & \multicolumn{2}{|c|}{ Central Texas. } & \multicolumn{2}{|c|}{ Totals. } \\
\hline & Male. & Female. & Male. & Female. & Male. & Female. & Male. & Female. \\
\hline $\begin{array}{l}23-25-23-21-19 \ldots \ldots \ldots \ldots \\
23-21-19 . \ldots \ldots \ldots \ldots \ldots \\
21-23-21-19 \ldots \ldots \ldots \ldots\end{array}$ & $\begin{array}{l}2 \\
1 \\
1\end{array}$ & $\begin{array}{c}\cdots \\
1 \\
1\end{array}$ & $\begin{array}{l}\ddot{2} \\
2\end{array}$ & $\begin{array}{c}1 \\
3 \\
\cdots \\
\cdots\end{array}$ & $\begin{array}{l}3 \\
1\end{array}$ & $\begin{array}{l}\ddot{1} \\
4\end{array}$ & $\begin{array}{l}2 \\
4 \\
4\end{array}$ & $\begin{array}{l}1 \\
5 \\
5\end{array}$ \\
\hline Total.... & 4 & 2 & 4 & 4 & 2 & 5 & 10 & 11 \\
\hline
\end{tabular}

The most noticeable geographic variation occurs in the color pattern, the full significance of which will be brought out in the discussion of the evolution of the color pattern in the getulus group. Briefly it is as follows: Westward from the central portion of the range the number of dorsal cross bands is decreased perceptibly; they become broader, the dorsal black areas become wider, and, on the sides, opposite each dorsal white band, there is a fading out of the white spots, tending to produce a series of lateral dark areas in alternation with the dorsal series. Eastward from this central region, the white centers of the cross bands tend to lose their symmetrical orientation parallel to the long axes of the scales; the number of bands decreases somewhat; the dorsal dark areas widen very slightly; there is a distinct tendency for the development of a lateral alternating series of dark areas, as in the western forms, sometimes also a second and 
lower series alternating with the last, and extreme individuals begin the development of white centers in the dorsal dark areas; the proportion of white on the belly is increased, and near its eastern limits, the head may become as speckled with white as a true holbrooki.

Affinities. - There can be no doubt, even from this brief summary, that splendida bridges the gap between holbrooki and yumensis, in structural and color pattern features as well as in geographic position. We will leave a fuller discussion of its relationships with these forms to the section on the evolution of the group, and here offer only the following diagram of affinities:

yumensis—splendida-holbrooki. 


\begin{tabular}{|c|c|}
\hline 离 & 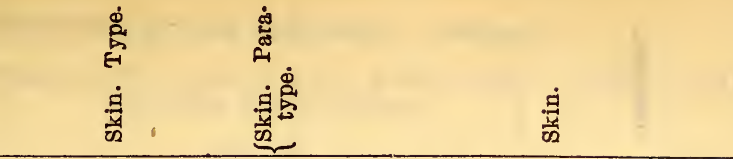 \\
\hline 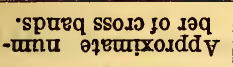 & ஃテ ロ \\
\hline 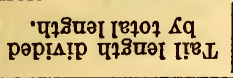 & 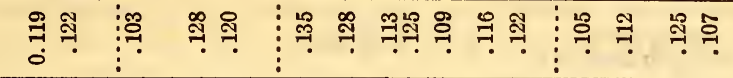 \\
\hline 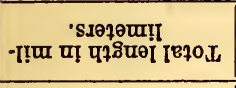 & 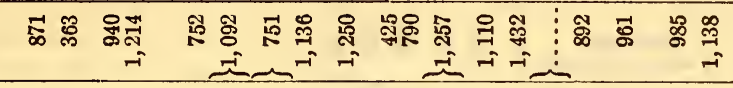 \\
\hline 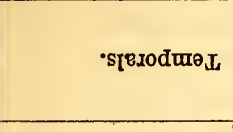 & 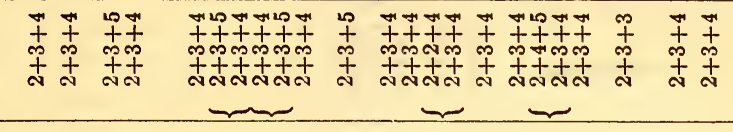 \\
\hline •sirinoo & 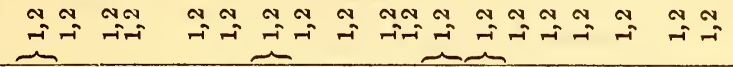 \\
\hline 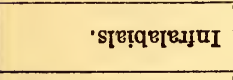 & 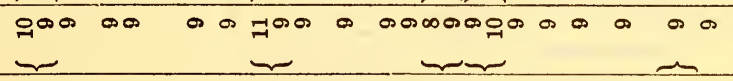 \\
\hline 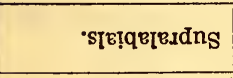 & 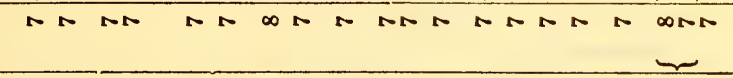 \\
\hline •sזвpnвр & 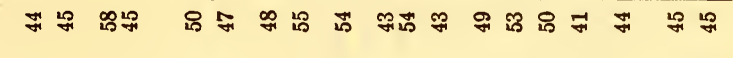 \\
\hline 'sโBIquө $\Lambda$ & 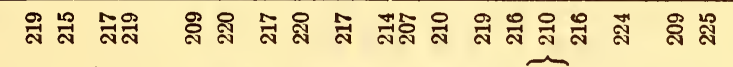 \\
\hline 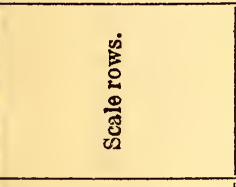 & 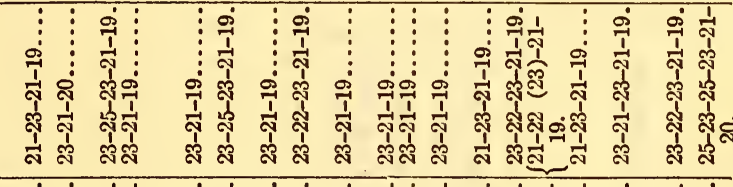 \\
\hline 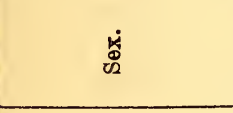 & 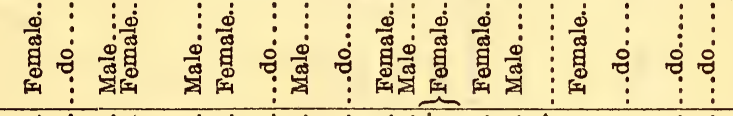 \\
\hline 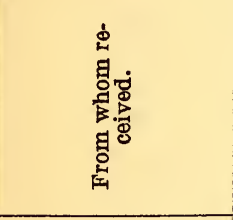 & 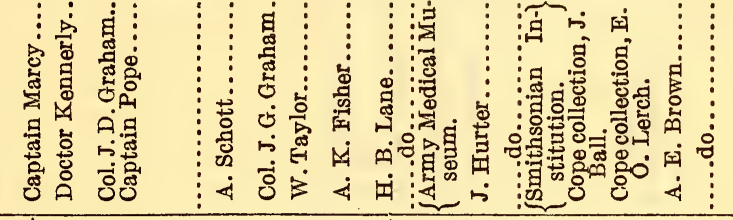 \\
\hline 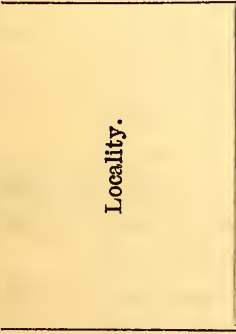 & 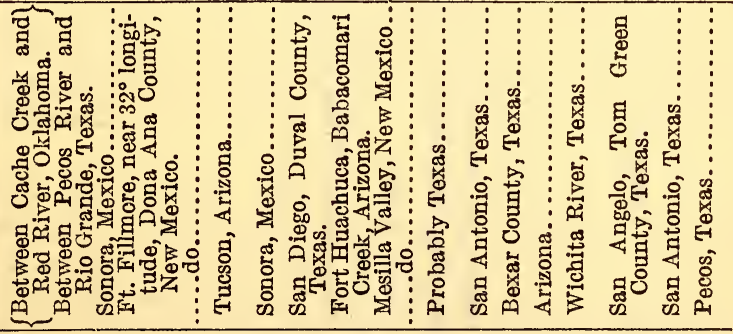 \\
\hline$\dot{0}$ & 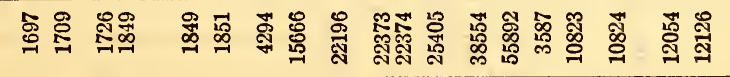 \\
\hline 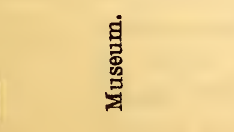 & 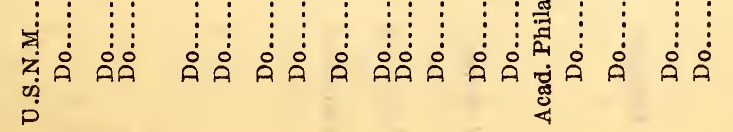 \\
\hline
\end{tabular}




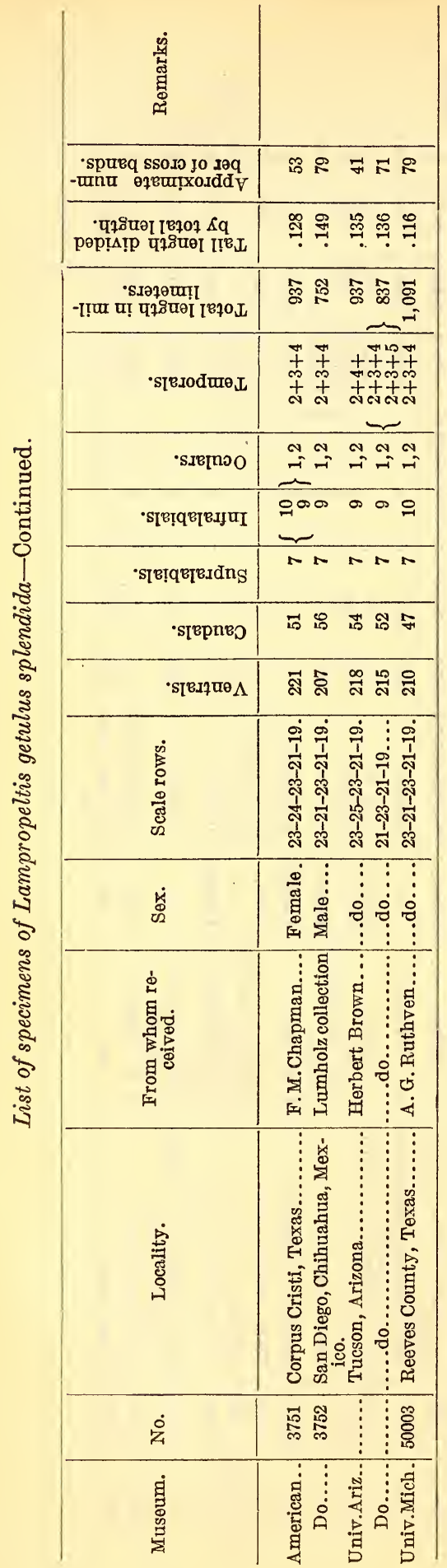




\section{LAMPROPELTIS GETULUS HOLBROOKI (Stejneger).}

SPECKLED KING SNAKE, SAY'S KING SNAKE, KING SNAKE, GUINEA SNAKE, SPOTTED KING SNAKE.

Fig. 32.

1842. Coronella sayi Ноцвкоок, N. Amer. Herp., ed. 2, vol. 3, p. 99, pl. 22.Dumeril and Bibron, Erp. Gen., vol. 7, pt. 1, 1854, p. 619.-Lichtenstern, Nomenclator, Mus. Zool. Berolinensis, 1856, p. 25, ("Mexico"!).GÜNTHER, Cat. Colubr. Snakes Brit. Mus., 1858, p. 41.-JAN, Icon. Gen. Ophid., livr. 14, 1861, fig. 2, pl. 5; Arch. Zool. Anat., vol. 2, fasc. 2, 1863, pp. 238, 245.-Coluber sayi De Kay, Nat. Hist. New York, pt. 3, 1842, p. 41.-Ophibolus sayi BaIRD and GIRARD, Cat. N. Amer. Rept., pt. 1, 1853, p. 84.-BAIRD, U. S. and Mex. Bound. Surv., 1859, p. 20 (Indianola, Texas); Pacif. R. R. Surv., vol. 10, pt. 3, no. 1, 1859, pl. 30, fig. 59.-Humphreys, Amer. Nat., vol. 15, 1881, p. 561.-Lampropeltis sayi Cope, Proc. Acad. Nat. Sci. Philadelphia, 1860, p. 254.Garman, S., Bull. Essex Inst., vol. 24, 1892, p. 10.-Beyer, Proc. Louisiana Soc. Nat., (1897-1899), 1900, p. 14.

1875. Ophibolus getulus sayi Cope, Bull. U. S. Nat. Mus., no. 1, p. 37.-Coves and YARRow, Bull. U. S. Geol. Geog. Surv. Terr., vol. 4, art. 11, 1878, p. 269.-Cope, Bull. U. S: Nat. Mus., no. 17, 1880, pp. 23, 44.-YARRow, Bull. U. S. Nat. Mus., no. 24, 1882, p. 93.-Garman, S., Mem. Mus. Comp. Zool., vol. 8, no. 3, pt. 1, 1883, pp. 68, 156, pl. 5, fig. 4.-Davis and Rice, Bull. Chicago Acad. Sci., vol. 1, no. 3, 1883, p. 29 (Wisconsin).- $\mathrm{H}_{\mathrm{AY}}, 36$ th Annual Rep. Indiana State Board Agri. for 1886, vol. 28, 1887, p. 210; 17th Annual Rep. Dept. Geol. Nat. Res. Indiana, 1892, p. 518.-Garman, H., Bull. Illinois State Lab. Nat. Hist., vol. 3, art. 13, 1892, p. 297.-Cope, Proc. Acad. Nat. Sci. Philadelphia, 1893, pp. 385, 387.-Hurter, Trans. Acad. Sci. St. Louis, vol. 6, no. 2, 1893, p. 255.Rhoades, Proc. Acad. Nat. Sci. Philadelphia, 1895, p. 392.-Cope, Rep. U. S. Nat. Mus. for 1898, 1900, p. 911, fig. 226.-Strecker, Trans. Texas Acad. Sci. for 1901, vol. 4, pt. 2, no. 5, 1902, p. 4.-Brown, Proc. Acad. Nat. Sci. Philadelphia, 1901, p. 76; 1903, p. 550.-Branson, Kansas Univ. Sci. Bull., vol. 2, no. 13, 1904, p. 397.-Ditmars, Reptile Book, 1907, pp. 341, 358, pl. 107 (lower fig.); Reptiles of the World, 1910, p. 271.-Viosca, 6th Bien. Rep. Bd. Curators Louisiana State Mus., 1918, p. 72.-Lampropeltis getulus sayi Stone, Proc. Acad. Nat. Sci. Philadelphia, 1903, p. 542 (Sugar Loaf Mt., Oklahoma).-Rutrven, Proc. Iowa Acad. Sci., vol. 19, 1912, p. 207.-Wright, Proc. Acad. Nat. Sci. Philadelphia, 1915, p. 148.-Coronella getula, var. sayi Boetraer, Kat. Rept.-Samml. Mus. Frankfurt, pt. 3, 1898, p. 71.-Lampropeltis getula sayi Strecker, Proc. Biol. Soc. Washington, vol. 21, 1908, pp, $75,89$.

1880. Ophibolus getulus getulus Cope, Bull. U. S. Nat. Mus., no. 17, p. 23.

1894. Coronella getula (part)Boulenger, Cat. Snakes Brit. Mus., vol. 2, p. 198.JoHnson and JoHnson, Reptile Life, 1907, fig. p. 64.

1903. Lampropeltis holbrooki Stejneger, Proc. U. S. Nat. Mus., vol. 25, p. 152 (=Coronella sayi Holbrook; type locality, valley of the Mississippi).STEJNEGer and BARBour, Check List, 1917, p. 188.

1905. Lampropeltis getula holbrooki BaILey, N. Amer. Fauna, no. 25, p. 47.Lampropeltis getulus holbrooki Hurter and Strecker, Trans. Acad. Sci. St. Louis, vol. 18, no. 2, 1909, p. 26.-Hurter, Trans. Acad. Sci. St, Louis, vol. 20, no. 5, 1911, p. 185.-STrecker, Baylor Univ. Bull. vol. 18 , no. 4,1915, p. 38 . 
1909. Lampropeltis getula holbrookii Strecker, Baylor Univ. Bull., vol. 12, no. 1, 1909, p. 7 (Burnet, Texas).

1912. Ophibolus getulus, var. sayi Somes, Proc. Iowa Acad. Sci., 1912, p. 150.

As Stejneger has already pointed out $(1902,152)$, the name Coronella sayi was originally used for this form by Holbrook under the misapprehension that it was the species previously described by Schlegel as Coluber sayi. As the latter is a very different snake, Pituophis sayi, the name sayi can not be applied to this form.

Description.-Holbrooki is nearly as well known as its representative on the Atlantic Coast. The scutellation as derived from about 132 specimens, is as follows: Ventral plates, 200 to 220 ; caudals, 38 to 55 (one specimen, 30 ); supralabials, 7 , rarely 6 or 8 ; infralabials, 9 , rarely 8 or 10 ; oculars, 1 and 2 ; temporals, $2+3+4$, occasionally varying by one in any row; posterior chin shields usually a little shorter and a little narrower than the anterior, parallel, and generally separated by one or two small scales; loreal usually as high as long or higher than long, although sometimes longer than high; dorsal scale rows commonly $21-19$ or $19-21-19$, occasionally as high as 21-23-21-19, and often as low as 19-21-19-17, very rarely 19-17.

The general proportions are the same as with splendida and getulus, that is, head but slightly distinct from neck, belly meeting the sides in a rounded angle; body cylindrical and of nearly the same diameter except for tapering a little toward the neck and toward the tail, latter short, tapering quickly to a horny tip, varying from 0.096 to 0.150 of the total length, the average for males 0.130 , for females 0.120 . The great majority of adult specimens measure between 75 and $95 \mathrm{~cm}$; the largest examined was from Galveston, Texas, and measured $1,634 \mathrm{~mm}$.

The general color above is blue-black with an oval white or yellow or greenish-yellow spot near the center of each scale. At regular intervals the white centers lose their normal orientation with the long axes of the scales and become so grouped and oriented as to form from 50 to 100 distinct, short, transverse bands on the back, which are commonly less than half a scale in width and usually form a dotted rather than continuous white band. Ventrally the white centers increase in size so that the scales of the first row may be described as white with black borders. The belly is checked with black and white, the white usually predominating. The head like the body is spotted with white. Transverse bars of white cross the internasals, prefrontals, and supraoculars. There is a light spot on each of the loreals, nasals, oculars, and temporals. The common borders of the labials are black.

The copulatory organ may be described as follows: Bilobed or slightly forked; sulcus single, extending over the side of the larger lobe; calyces fairly numerous, apical, surrounding a small bare place 
at the tip; fringes of calyces few, fairly prominent, passing into spines; latter extending a little less than half way to the base; not particularly numerous or thick set (although apparently so if the organ is not fully everted); basal portion with many conspicuous but minute spines, extending downward for a distance about equal to that covered by the major spines. This latter character appears to be restricted to this form and niger. It is conspicuously well developed in specimens examined from Missouri, Arkansas, and Louisiana, and specimens from the following localities have these minute spines developed over as much area but often more or less imbedded in the tissue, and therefore less conspicuous: Galveston, Texas; Mobile, Alabama; Kansas; Grinnell, Iowa; Reelfoot Lake, Tennessee; Kemper County, Mississippi. It is thus a characteristic of this form throughout its range.

The dentition is as follows: Maxillary teeth usually 13, sometimes 14, the first very small, the rest large and subequal; mandibular teeth, 14 or 15 , rarely 16 , the first very small, the next seven or eight the largest, the remainder decreasing gradually to about the size of the first; palatines usually 9 , sometimes 8 , subequal and about the size of the anterior maxillaries; pterygoids, 13 to 18 , usually 16 , smaller than the palatines and subsequal.

Intergradation between this form and splendida undoubtedly takes place in Texas in the region of the ninety-seventh or ninety-eighth meridians. It is impossible in some instances to refer a specimen definitely to one form or the other. Distinctions which usually hold are as follows: The head of holbrooki has many small yellow spots, that of splendida is mostly black, with but few spots; in holbrooki the dorsal spaces between the cross bands have a yellow spot on each scale in adults (in young, few or none), in splendida there are no spots here, or but few; holbrooki usually has no more than 21 rows of scales, while splendida has 23 . To distinguish from niger and from getulus see under these forms.

Habitat and habits.- Very little has been recorded on the natural history of this form. Hurter (1911, 185, 255) states for Missouri that it inhabits hilly places with sunny glades, occurring under rocks and fallen trees. On the other hand, Mr. Percy Viosca informs the writer that in Louisiana it is found in moist places throughout the entire alluvial section of the State. Mr. H. P. Löding says that near Mobile, Alabama, they are turned up by the plow in the spring.

Like getulus it is reported to be the enemy of the rattlesnake and the moccasin. Coues $(1878,269)$ mentions this, and Humphreys (1881, 561-2) gives a rather elaborate account of how one swallowed a water moccasin (Ancistrodon piscivorous). Branson (1904, 397-8) states it to be the enemy of all other snakes. 
Mr. Mackelden of St. Louis writes that a large specimen of this snake from St. Louis County, Missouri, which he kept in captivity for five months, ate 21 Bascanion constrictors, some of which were from a foot to 18 inches longer than the king snake and required sometimes three days to swallow. It was often tempted with garter and water snakes, but seemed to have an aversion to them as food.

Hurter $(1911,185)$ says that its food consists of mice, small birds, lizards, and snakes. It seems to be much less amenable to life in captivity than getulus. Most specimens kept by the writer refused to eat, and long continued to vibrate the tail in nervousness or fear whenever handled. Some individuals would always assume the striking position whenever anyone approached the cage. Such as could be induced to feed were observed to eat Thamnophis butleri $T$. sirtalis, and dead mice. They constricted their prey exactly as does getulus.

There are no records of breeding observations.

Range.-This form ranges from Mobile, Alabama, west to about the ninety-seventh meridian in Texas. It extends north in the Mississippi Valley probably to southern Wisconsin, west to southeastern Wyoming, southwest to the panhandle of Texas, and east to eastern Illinois. It appears to be a common snake in eastern Kansas, Missouri, southern Illinois, eastern Oklahoma, Arkansas, eastern Texas, and Louisiana. Records are very few for Nebraska, Iowa, and Mississippi.

Specimens have been examined from the following localities, in addition to those represented by specimens in the United States National Museum: Near Columbus Junction, Iowa; Duntanville (Tuscaloosa County), University, Alabama Point (Mobile County), and Mobile, Alabama; Cat Island and University, Mississippi; Manhattan, Twin Mounds, Mount Oread, Coal Creek in Coffey County, Long Creek in Osage County, and Jefferson, Trego, Labette, and Anderson Counties, Kansas; Dallas, Clifton, and Tule Canyon, Staked Plain, Texas; Wister, Sugar Loaf Mountain, and Fort Supply, Oklahoma; Arkadelphia, Greenway, Donaldson, Fayetteville, and Garland and Jefferson Counties, Arkansas; Horseshoe Lake, Olive Branch, Illinois; Reelfoot Lake, Samburg, Tennessee; Chastine, Louisiana; Galena, Missouri.

Published records for other localities are as follows: Deming's Bridge, Matagorda County, Texas (Garman, S., 1892, 10); Burnet, Texas (Strecker, 1909, 7); Peoria, Illinois (Garman, H., 1892, 298); Wisconsin (same); Montgomery County, Missouri (Hurter, 1911, 185); and the following counties in Kansas (Branson, 1904, 398): Mitchell, Republic, Montgomery, Miami, Greenwood, Potawatomie, Franklin, Lyon, Sumner, Scott, Logan, and Gove. 
Variation.-Minor variations of pattern appear to characterize certain regions of the range. Thus specimens from southern Mississippi, Louisiana, and southeastern Texas usually show the dorsal cross bands plainly, but the spaces between and the sides are prominently spotted with rounded or oval white spots (in specimens from New Orleans the spots are a pale greenish white and the ground color is velvety black).

In the area from extreme northeastern Texas to southern Kansas, St. Louis, and the Mississippi River the cross bands are almost indis-

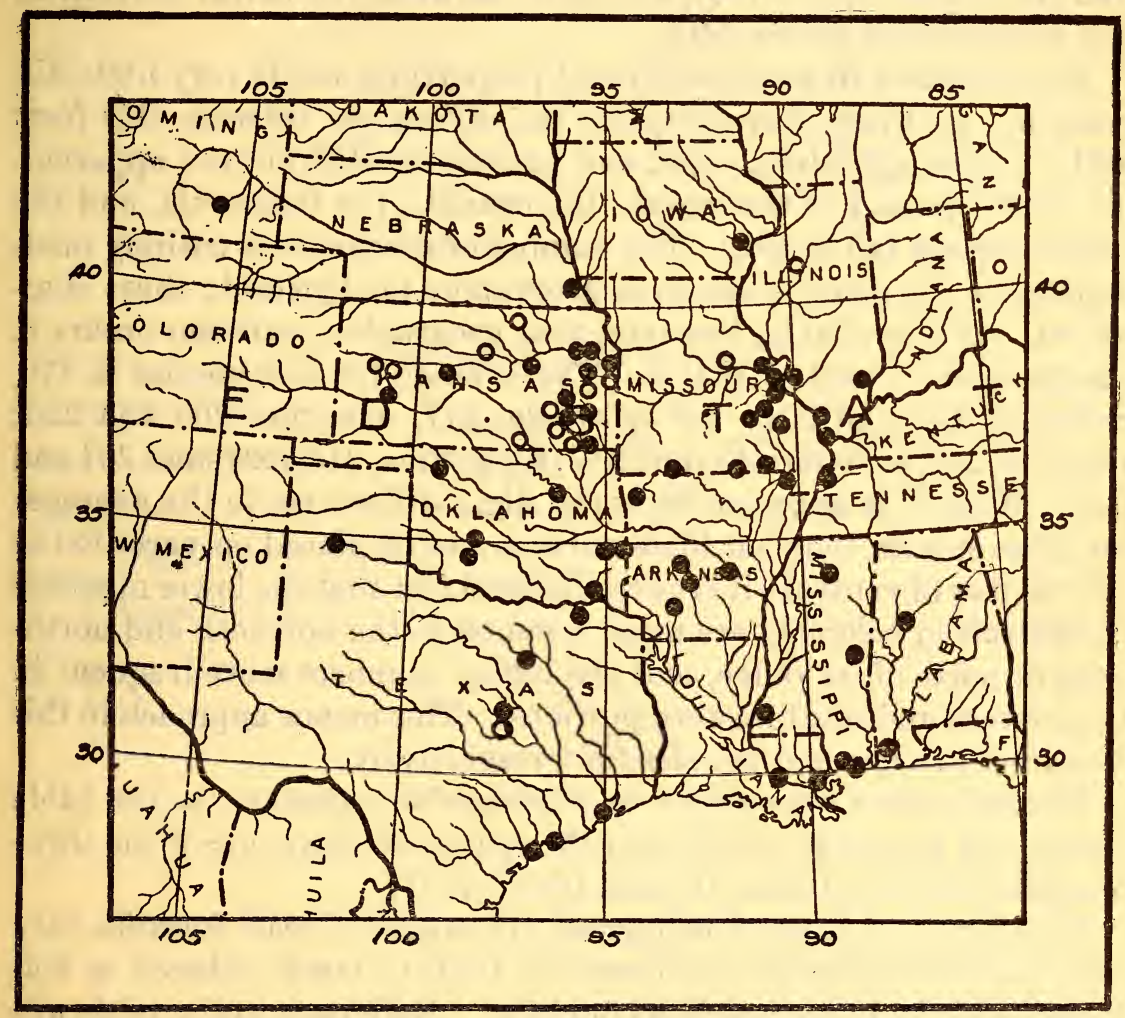

FIG. 9.-MAP SHOWING LOCALITY RECORDS FOR LAMPROPELTIS GETULUS HOLBROOKI.

tinguishable; every scale has a large white or yellow spot on a ground color of dark brown to bluish black (Hurter, 1911, 185), which, proceeding ventrally, occupies more and more of the area of the scale. Often the only indication of cross bands is the asymmetrical orientation or atypical shape of certain of the dorsal spots, but the regularity of their distribution indicates that they represent the original bands. These spots may be unusually long and narrow and oriented either lengthwise or crosswise of the scales, and, judging from recently preserved specimens, they are white or pale greenish on a nearly black ground color. 
Specimens from Kansas are more like those from New Orleans in respect to the distinctness of the dorsa bands and the prominence of the spots between, but the spots are yellow (in alcohol)-Branson says $(1904,398)$ pearly white or yellow.

The pattern of young individuals is deserving of attention. In all the specimens examined the white crossbars are prominently developed and the scales between are unspotted, or the spots are small, or present only midway between the bands. From the material at hand it seems probable that, as suggested by Branson (1904, 398) and by Hurter $(1911,185)$, the spots between the bands develop as the young snake grows older.

The variation in scutellation and proportions needs very little discussion. In these characteristics the differences between this form and its allies, splendida, niger, and getulus, are slight or not apparent. This may be said of the labials, the caudals, the temporals, and the proportionate tail length. The number of specimens is entirely inadequate for the demonstration of geographic tendencies in these characters. It is probable, however, that geographic variation occurs in the number of ventral plates. The average for this species is 210, extremes 201 and 221; for splendida, 217, extremes 208 and 226; for niger, 209, extremes 200 and 217; for getulus, 215, extremes 204 and 223. While it is apparent from the slight differences in the averages for these species that but little reliance can be placed on variation in the number of ventrals, it is nevertheless a fact that the lower numbers of ventrals in holbrooki are more common in the northern and northeastern parts of its range, and the higher numbers more frequent in the western and southwestern portions. This means approach in this character to niger and to splendida, respectively.

The scale rows are subject to considerable variation, as the table shows, but the great majority of the specimens have one of the three formulae-21-19, 19-21-19, and 19-21-19-17.

This form can thus be compared in lowness of scale formula only with niger and getulus; the former is fully as much reduced as holbrooki, and the latter nearly as much so. Reference to the table will show that the higher formulae characterize the western and southwestern parts of the range, and the lower formulae the northeastern and the extreme southern. If holbrooki had a southwestern origin, these regions would be the last reached, the former because it is the farthest removed from the southwest, and the latter because it is but recently elevated above the sea.

Affinities.-Holbrooki is without doubt very closely allied to splendida and to niger, and with both of these forms intergradation takes place along the common boundaries of their respective ranges. We will, however, leave a fuller discussion of affinities to the section on 
the evolution of the group, and leave the subject here with the following diagram of relationships:

$$
\text { splendida - holbrooki- niger. }
$$

Scale formulae of holbrooki.

DISTRIBUTION BY SEX.

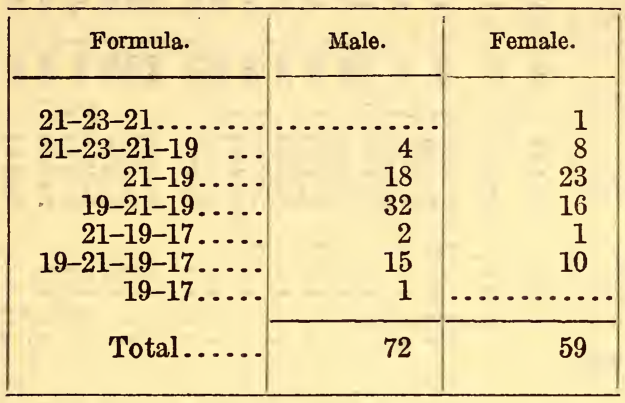

DISTRIBUTION BY LOCALITY.

\begin{tabular}{|r|r|r|r|r|r|}
\hline Formula. & $\begin{array}{r}\text { Oklahoma } \\
\text { and north- } \\
\text { ern Texas. }\end{array}$ & Kansas. & Arkansas. & Missouri. & Louisiana. \\
\hline Higher than 21.-19..... & 5 & 2 & 3 & 1 & 2 \\
$21-19 \ldots .$. & 6 & 17 & 9 & 1 & 7 \\
Lower than 21-19..... & 6 & 7 & 7 & 13 & 25 \\
\hline Total............. & 17 & 26 & 19 & 15 & 34 \\
\hline
\end{tabular}




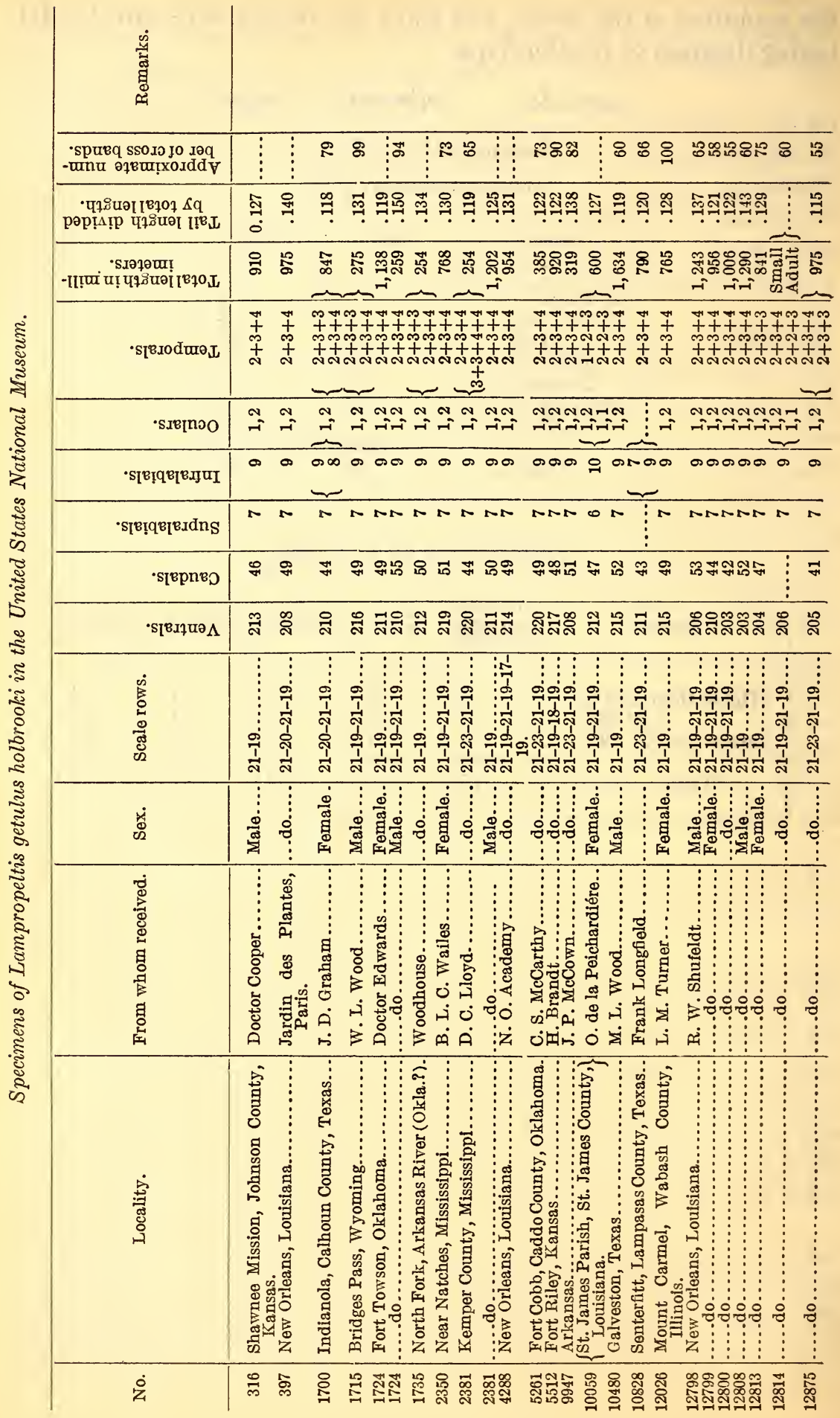




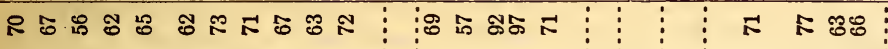

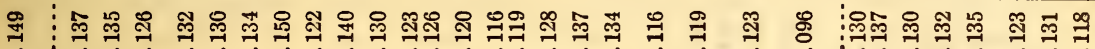

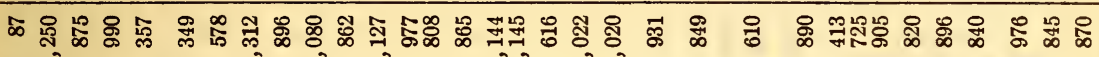

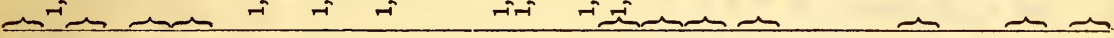

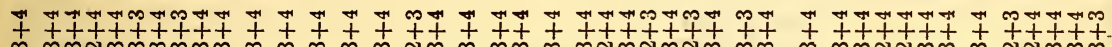

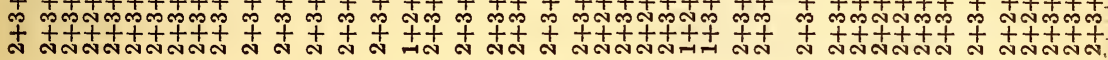

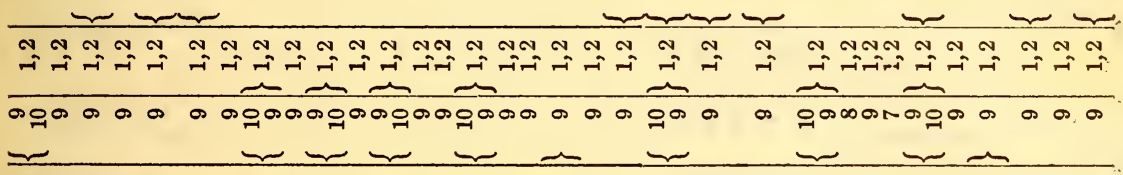

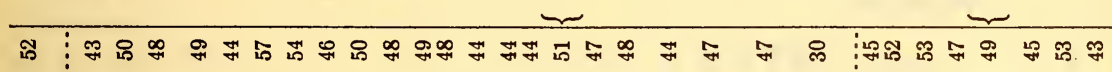

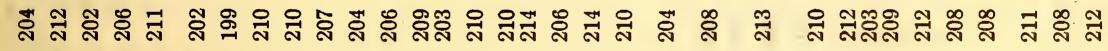

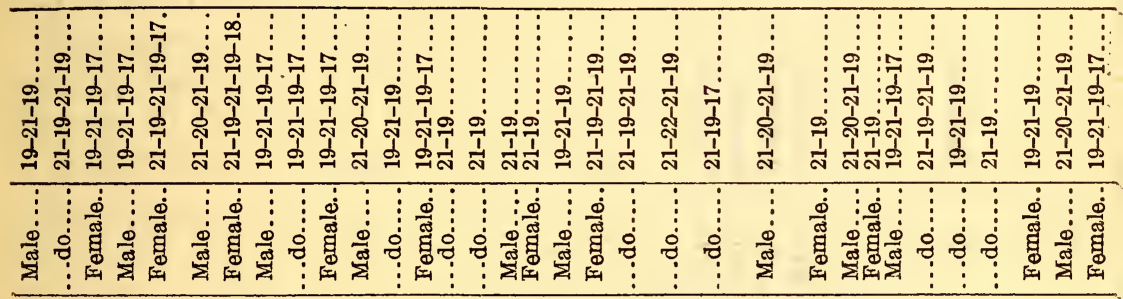

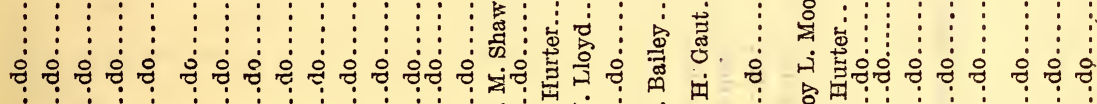
究

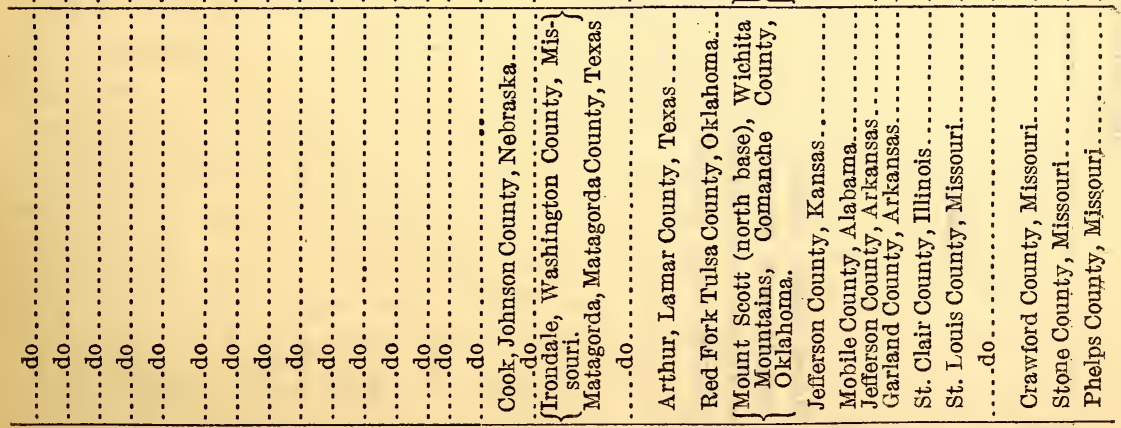

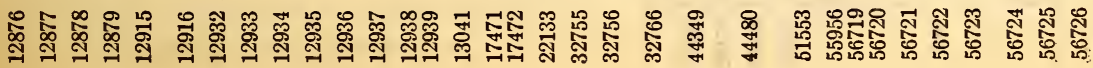




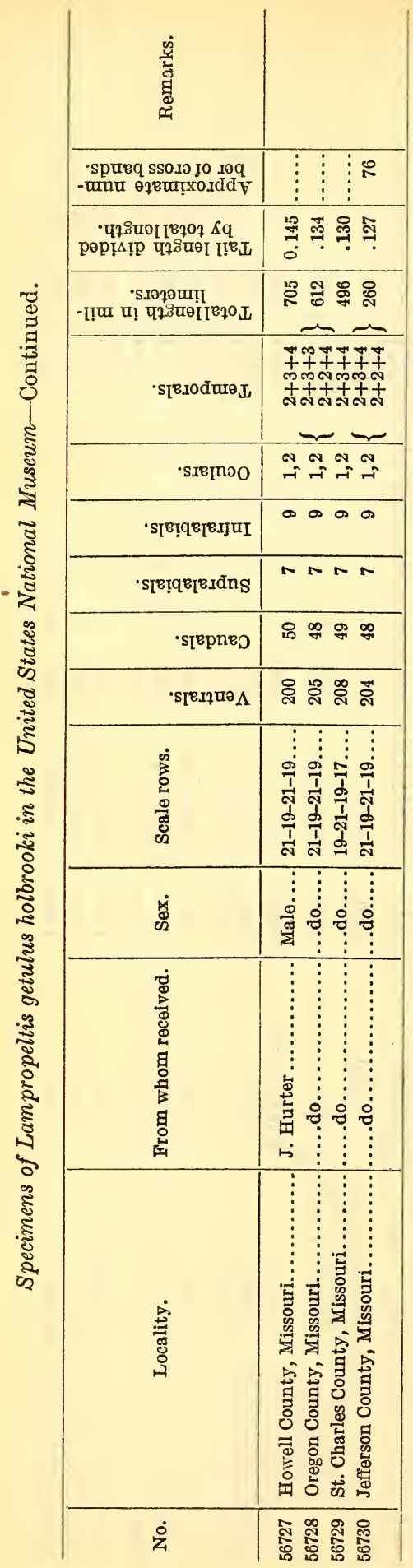




\section{LAMPROPELTIS GETULUS NIGER (Yarrow).}

Fig. 33.

1837. Herpetodryas getulus ScHLeged, Phys. Serp., p. 198.

1882. Ophibolus getulus niger YaRRow, Proc. U. S. Nat. Mus., vol. 5, p. 438 (type locality, Wheatland, Indiana; cotypes, U. S. Nat. Mus., no. 12149-two specimens; Robert Ridgway, collector); Bull. U. S. Nat. Mus., no. 24, 1882, p. 93.-HAY, Journ. Cincinnati Soc. Nat. Hist., vol. 10, no. 2, 1887, p. 64.-Garman, Bull. Illinois State Lab. Nat. Hist., vol. 3, art. 13, 1892 p. 299.-HAY, Batr. Rept. of Indiana, 1893, p. 111.-Cope, Rep. U. S. Nat. Mus. for 1898, 19C0, p. 917, fig. 228.-Brown, Proc. Acad. Nat. Sci. Philadelphia. 1901, p. 77.

1887. Ophibolus niger Hay, 36th Annual Rep. State Board Agri. Indiana for 1886, vol. 28, p. 210.

1891. Ophibolus getulus sayi Bratchley, Journ. Cincinnati Soc. Nat. Hist., 1891, p. 32; 24th Ann. Rep. Dept. Geol. Nat. Res. Indiana, 1899, p. 545.

1893. Ophibolus doliatus, var sayi HAY, Batr. Rept. State Indiana, p. 110.

1894. Ophibolus getulus Garman, H., Bull. Essex Inst., vol. 26, nos. 1, 2, 3, p. 35.

The status of this form has never been settled, and the specimens available for study are still too few. The writer, however, believes it to be entitled to the rank of subspecies, but should fuller material prove it to be but a local or inconstant variation of holbrooki, its name will have to supersede the latter, a change by no means to be desired.

Description. - The scutellation of the 32 specimens examined is as follows: ventral plates, 199 to 216 ; caudals, 41 to 53 (males, 46 to 53, average 50 ; females, 41 to 47 , average 43 ); supralabials, 7 ; infralabials, 9 , rarely 8 or $10 ; 1$ preocular, 2 pustoculars; temporals usually $2+3+4$; posterior chin shields generally shorter than the anterior and separated from each other by one or two small scales; loreal higher than long, or about as high as long; scale formula usually 19-21-19.

The bodily proportions are the same as for holbrooki and getulus. The tail varies from 0.110 to 0.146 of the total length (males, 0.120 to 0.146 , average 0.133 ; females, 0.110 to 0.128 , average 0.120 ). The largest specimen examined was the type-1,431 millimeters in length.

The color pattern (fig. 33) is a reduction from that of holbrooki by obliteration of the yellow centers on the scales of the dark areas on the back, and contraction in size of all the other light spots. This leaves the dorsal surface black, crossed by 50 to 90 very narrow crossbands of yellow, which tend to fork on the sides and there join an alternating series of short, narrow transverse bars. Occasionally the crossbands on the back may have nearly or quite disappeared, or sometimes the white spots between the bands may be somewhat developed. The lower rows of dorsal scales are more or less spotted with yellow. The belly is checked with black and white or yellow, the black sometimes predominating. The spotting on the head is 186550-21-Bull. 114-4 
exactly like that of holbrooki except that the spots are fewer and much smaller.

The penial characters seem to agree with those of holbrooki, even to the extent and prominence of the minute spines.

The dentition of a specimen from Wheatland, Indiana, is as follows: Maxillary teeth, 13-13; mandibular, 14-13, palatine, 9-9; pterygoid, 16-17.

This form may be known from holbrooki from the fact that the adults have no white spots, or but very few, on the scales between the dorsal crossbands; young examples may resemble holbrooki, but the crossbands are very narrow, less than half a scale in width, and all the white spots are smaller than in the latter form. It may be known from splendida by the fact that the dorsal scales are in 21 instead of 23 rows; and from getulus it may be distinguished by the narrower and dotted crossbands instead of wider and continuous ones, and by their greater number, more than 50 .

Habitat and habits.-Almost nothing is recorded upon this subject. Blatchley $(1899,545)$ says for Vigo County, Indiana, that it "frequents rocky hillsides and the vicinity of streams," and mentions finding one in the act of swallowing a Eutaenia sirtalis. The writer found an adult at Henry, Tennessee, a little after sunset, stretched. out at full length by the side of a road through farming country. It had doubtless been concealed during the day in the thick bushes between the side of the road and the open field adjacent. It offered no resistance whatever to being picked up.

Range.-This form occurs from extreme eastern Illinois to southern Ohio and south to northern Alabama.

The only published records for specimens not examined by the writer are those of $\mathrm{H}$. Garman $(1894,35)$, for Midland, Kentucky, which was probably this form, and Blatchley $(1899,545)$ for Putnam County, Indiana.

Three specimens in the collection of the Museum of Comparative Zoology (no. 33), labeled "Ohio," are almost typical of holbrooki and one in the National Museum collection (no. 12026) labeled "Mt. Carmel, Illinois" is quite so. More specimens are much needed to definitely settle the status of this form.

Variation and affinities.-The specimens named niger by Yarrow were supposed to have been derived from typical getulus by increase in black pigment at the expense of the yellow. It was evidently overlooked that the crossbands were the same in character and in number as in holbrooki. The scale formulae and the penial characters also ally it much closer with holbrooki than with getulus. That it is, however, closely connected with the latter there can be no doubt. A specimen from the Cherokee Nation in the mountains of North Carolina with 37 crossbands presents a strong contrast with one 
from so short a distance west as Knoxville, Tennessee, with 73, and even though the former specimen shows the bands narrower than usual for getulus, these forms might be supposed from these specimens to be distinct even where their ranges meet, but specimens from Georgia and Alabama practically prove intergradation. The speci-

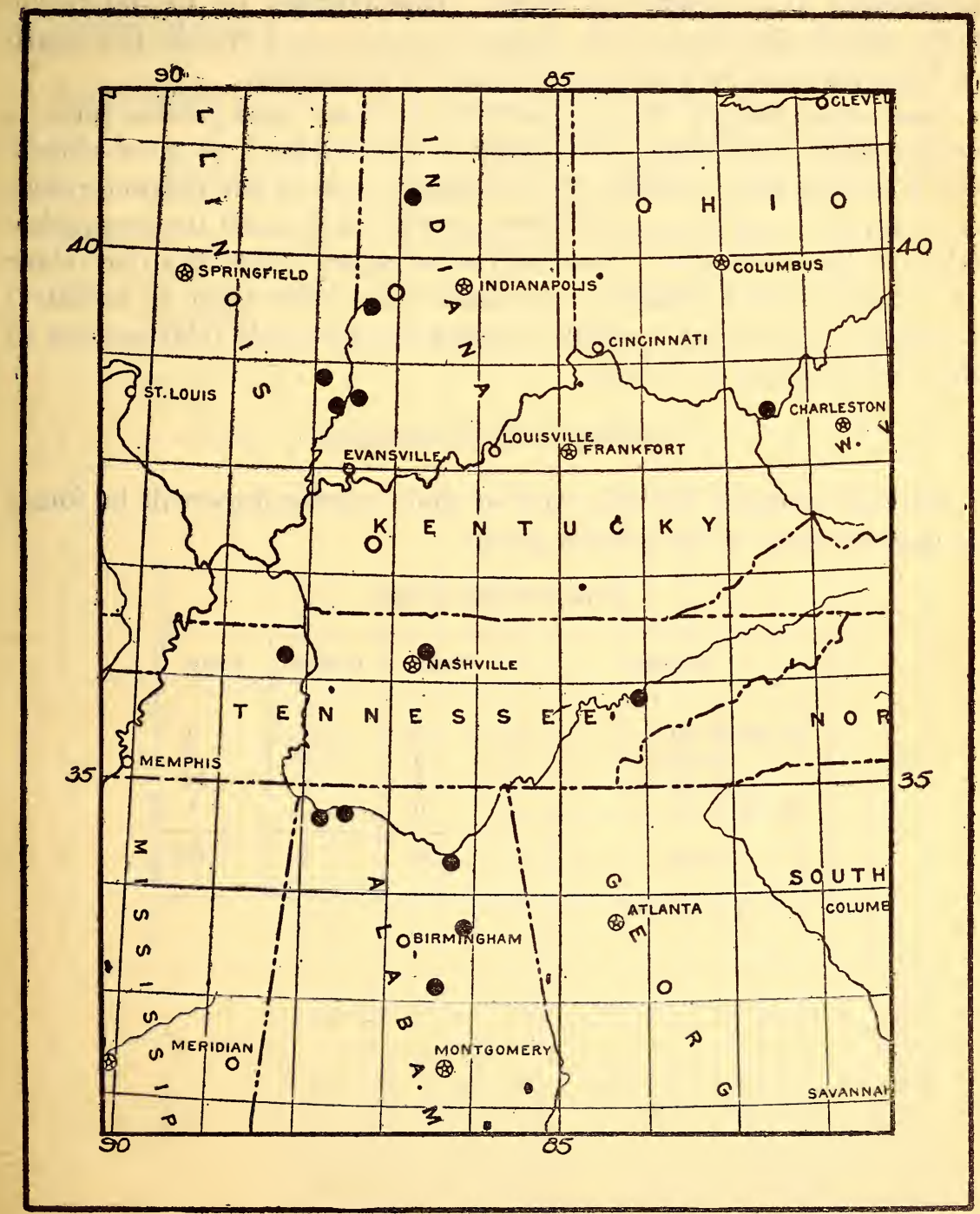

Fig. 10.-MAP SHOWING LOCALITY RECORDS FOR LAMPROPELTIS GETULUS NIGER.

mens from Marietta (fig. 34) and from Augusta, Georgia, cited by Yarrow $(1882,91)$, have the cross bands very narrow, unlike any typical getulus, but their number is 38 and 31, respectively, and one would doubtless not hesitate to assign them to getulus. Specimens from Ida and Gallant, Alabama, are decidedly niger, but one from 
Anniston, Alabama, collected in 1919 by E. R. Dunn, is practically transitional. This specimen shows the crossbands to be almost obsolete, but where they can be made out they seem to be reduced in number. The alternating light and dark areas on the sides of the belly are about 33 in number-a getulus character, but in general appearance it is nearer to niger. This enables us to determine fairly closely the limits of the ranges of these two forms in the South and the region where intergrades may be looked for.

That niger bridges the gap between holbrooki and getulus there is hardly room for doubt. Also that on the whole it is more closely allied to holbrooki is evident from consideration of the characteristics of all three. And from consideration of the latter and the geographic relationships, it becomes most logical to regard niger as a derivative of holbrooki. This makes it necessary to consider niger as ancestral to getulus. We may therefore express the probable relationships of these three forms as follows:

\section{holbrooki $\rightarrow$ niger $\rightarrow$ getulus.}

Further evidence for this view of their relationships will be found in the summary of the getulus group.

Scale formulae of niger.

\begin{tabular}{|c|c|c|c|}
\hline Formula. & Male. & Female. & Totals. \\
\hline 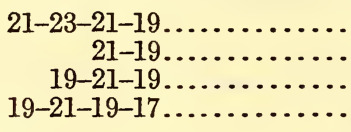 & $\begin{array}{l}1 \\
5 \\
8 \\
6\end{array}$ & $\begin{array}{c}3 \\
6 \\
6 \\
\cdots \cdots\end{array}$ & $\begin{array}{r}1 \\
8 \\
14 \\
6\end{array}$ \\
\hline Total.......... & 20 & 9 & 29 \\
\hline
\end{tabular}




\begin{tabular}{|c|c|c|}
\hline 高 & 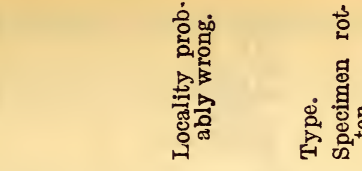 & \\
\hline 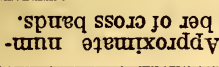 & 우 $\vdots \vdots \begin{array}{c}\text { i⿱ } \\
\vdots\end{array}$ & ำ \\
\hline 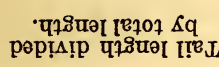 & 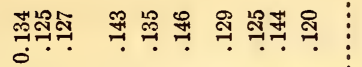 & సี 국유: \\
\hline 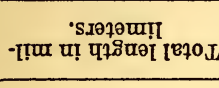 & 유슈 & 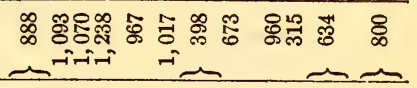 \\
\hline •słejodweI & 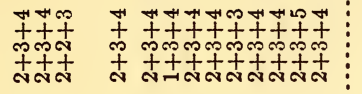 & 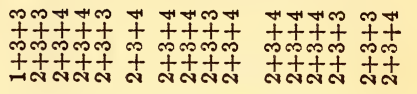 \\
\hline 'sxernoo & ๙NN & 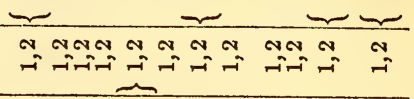 \\
\hline 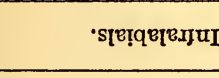 & $0000 \underbrace{00000000000}$ & $\infty \underbrace{\infty 0000000000000}$ \\
\hline 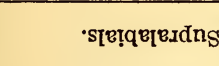 & MNR NNA NMN & $\operatorname{chn} 2 \operatorname{chn} h+h$ \\
\hline •sıpnep & 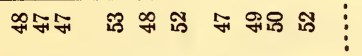 & 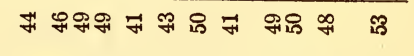 \\
\hline$\cdot \operatorname{s[EI} 4 \theta \Lambda$ & 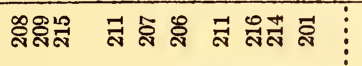 & 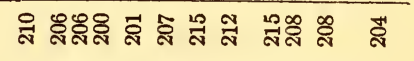 \\
\hline 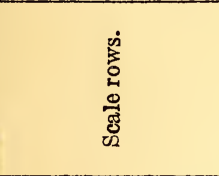 & 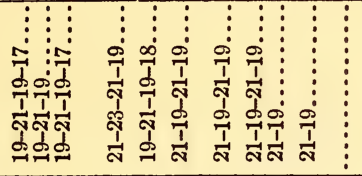 & 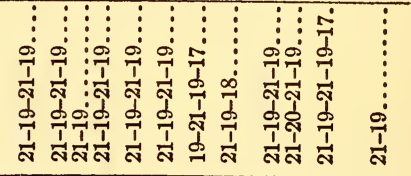 \\
\hline 峁 & 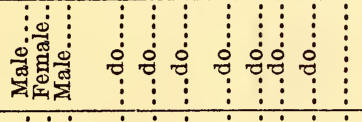 & 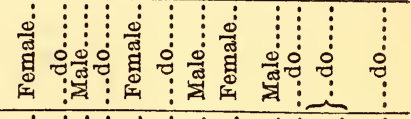 \\
\hline 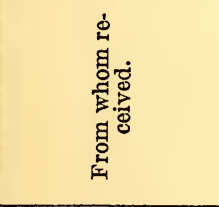 & 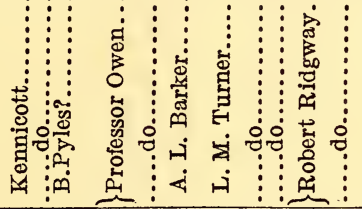 & 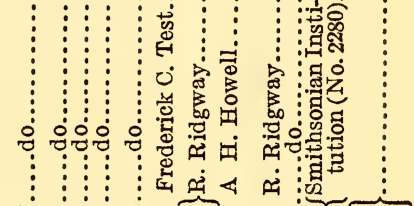 \\
\hline 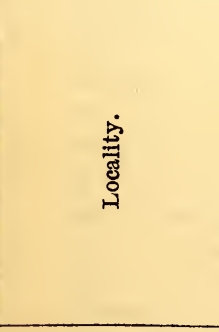 & 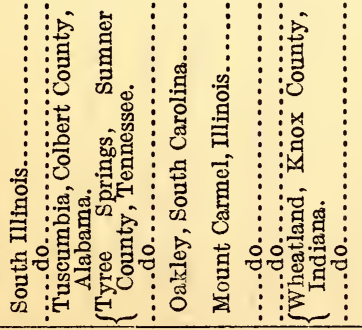 & 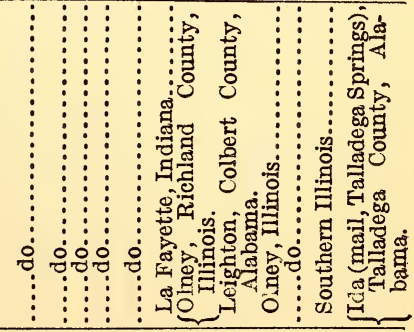 \\
\hline 字 & 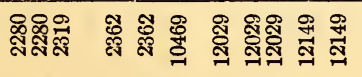 & 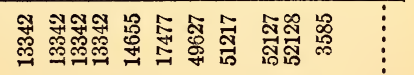 \\
\hline $\begin{array}{l}\text { 离 } \\
\text { 苋 }\end{array}$ & 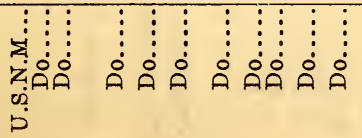 & 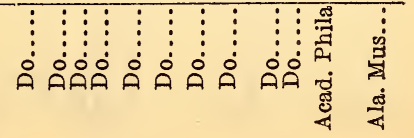 \\
\hline
\end{tabular}




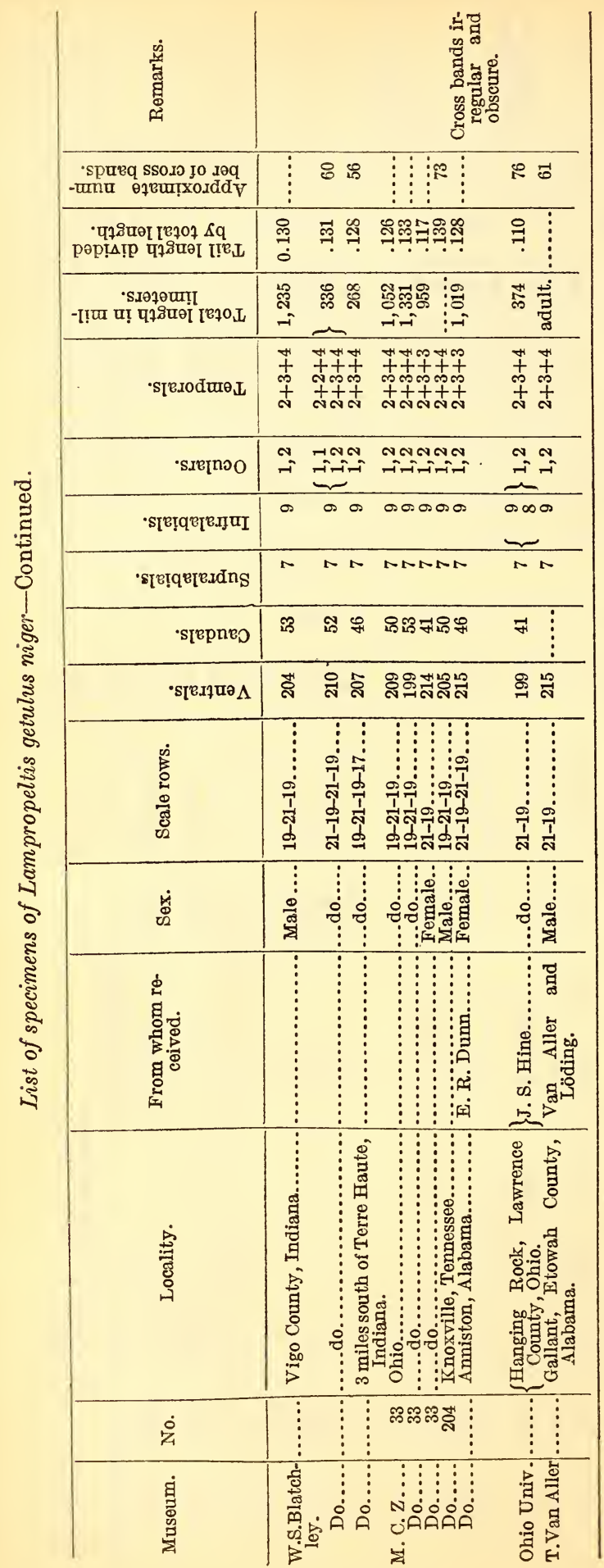




\section{LAMPROPLLTIS GETULUS GETULUS (Linnaeus).}

IING SNAKE; CHAIN SNAKE; COWSUCKER; BLACK MOCCASIN; HORSE RACER; MASTER SNAKE; BASTARD HORN SNAKE; THUNDER SNAKE; THUNDER AND LIGHTNING SNAKE; WAMPER; WAMPUM SNAKE; RATTLESNAKE PILOT.

Figs. 4, 34, 35 .

1766. Coluber getulus Linnaeus, Syst. Nat., ed. 12, vol. 1, p. 382 (type locality Carolina).-GMeLIN, Syst. Nat., vol. 1, pt. 3, 1788, p. 1106.-LACÉPìdE, Hist. Nat. Serp., vol. 2, 1789, pp. 84, 300.-BonnaterRe, Tabl. Encycl. Meth., 1790, p. 45, pl. 18, fig. 33.-Sonnini and Latreille, Hist. Nat. Rept., vol. 4, pt. 2, 1799, p. 174.-DaUdiN, Hist. Nat., vol. 6, 1800, p. 314, pl. 77, fig. 1.-SHAw, Gen. Zool., vol. 3, pt. 2, 1802, p. 467.-SAY, Amer. Journ. Sci., vol. 1, 1818, p. 260.-BoIE, Isis, 1827, p. 537.Harlan, Journ. Acad. Nat. Sci. Philadelphia, vol. 5, pt. 2, 1827, p. 358.-Peale, Contr. Macl. Lyc., vol. 1, 1829, pl. 5.-Harlan, Med. Phys. Researches, 1835, p. 122.-LACÉPÈDE, Hist. Nat. Quad. Ovip., vol. 1, 1836, p. 300.-De KAY, New York Fauna, 1842, plates, rept. amph., pl. 10, fig. 21, pt. 3, p. 37.-Linsley, Amer. Journ. Sci., vol. 46, 1843, p. 43.-Hough, 5th Annual Rept. State Cab. Nat. Hist. New York, 1852, p. 23.-GüNTHer, Cat. Colubr. Snakes Brit. Mus., 1858, p. 249.Pseudoelaps getulus Fitzinger, Neue Class. Rept., 1826, p. 56.-Coronella getula Hоцвкоок, N. Amer. Herp., ed. 2, vol. 3, 1842, p. 95, pl. 21.Lichtenstein, Nomenclator, Mus. Zool. Berolinensis, 1856, p. 25.Boulenger, Cat. Snakes Brit. Mus., vol. 2, 1894, p. 198 (part).-Ophibolus getulus BAIRd and Girard, Cat. N. Amer. Rept., pt. 1, 1853, p. 85.-BAIRd, Serp. of N. Y., 1854, p. 20; Pacif. R. R. Surv., vol. 10, pt. 3 , no. 1, 1859, pl. 31, fig. 65.-Coues, Proc. Acad. Nat. Sci. Philadelphia, 1871, p. 48.-YARRow, Amer. Nat., vol. 12, 1878, p. 470.-GarmaN, S., Mem. Mus. Comp. Zool., vol. 8, no. 3, pt. 1, 1883, pp. 68, 156, pl. 5, fig. 3 ; Nat. Hist. Notes, Boston, 1887, p. 2.-HAY, 36th Annual Rep. Indiana State Board Agri. for 1886, vol. 28, 1887, p. 210.-NeLson, Rep. State Geol. New Jersey, vol. 2, 1890, p. 647.-Cope, Proc. Amer. Philos. Soc., vol. 33, 1894, p. 221; Rep. U. S. Nat. Mus. for 1898, 1900, pl. 18, fig. 7.Brimley, Journ. Elisha Mitchell Sci. Soc., vol. 21, no. 4, 1905, p. 152.Ditmars, Reptile Book, 1907, pp. 341, 351, pl. 103, figs. 11, 12, pl. 108 (upper fig.).-Brimlex, Proc. Biol. Soc. Washington, vol. 22, 1909, p. 134.-Ditmars, Reptiles of the World, 1910, p. 267, pl. 59 (upper fig.); Sci. Contr. New York Zool. Soc., vols. 1, 2, 1912, p. 222.-BrimLeY, Journ. Elisha Mitchell Sci. Soc., vol. 30, no. 4, 1915, p. 202.-EnGLeHARDT, et al., Copeia, no. 17, 1915, p. 1.-Coronella getulus DuMÉrIL and BIBron, Erp. Gen., vol. 7, pt. 1, 1854, p. 616.-JAN, Icon. Gen., livr. 14, 1861, pl. 5, fig. 1; Arch. Zool. Anat., vol. 2, fasc. 2, 1863, pp. 238, 244.Lampropeltis getula CoPe, Proc. Acad. Nat. Sci. Philadelphia, 1860, p. 255.-Аввотт, Geol. of New Jersey, Appendix E, 1868, p. 802.-Lampropeltis getulus Аввотт, Nat. Rambles, 1894, p. 476.-LoenNBerG, Proc. U. S. Nat. Mus., vol. 17, no. 1003, 1894, p. 317.-Cory, Hunting and Fishing in Florida, 1896, p. 131.-Ditmars, Proc. Linn. Soc. New York, 1896, p. 12; 1902, p. 2.-BrIMLeY, Amer. Nat., vol. 37, p. 263.Stone, Amer. Nat., vol. 40, no. 471, 1906, p. 167; BrIMLEY, Journ. Elisha Mitchell Sci. Soc., 1907, p. 145.-Fowler, Annual Rep. New Jersey State Mus. for 1906, 1907, p. 178, text figs., pl. 45.-BRIMLEY, Proc. Biol. Soc. Washington, vol. 22, 1909, p. 134.-Hurter, Trans. Acad. Sci. St. Louis, vol. 20, 1911, p. 186.-BrImLeY, Journ. Elisha Mitchell Sci. Soc., vol. 30, no. 4, 1915, p. 202.-DunN, Copeia, no. 18, 1915, p. 6; Bull. Amer. Mus. Nat. Hist., vol. 37, art. 23, 1917, p. 593,Stejneger and Barbour, Check List, 1917, p. 88.-Brimley, Copeia, no. 64,1918 , p. 97 ; no. 88,1920 , p. 100. 
1875. Ophibolus getulus getulus Cope, Bull. U. S. Nat. Mus., no. 1, p. 37.Yarrow, Bull. U. S. Nat. Mus., no. 24, 1882, p. 91.-DAvis and Rrce, Bull. Illinois State Lab. Nat. Hist., no. 5, 1883, p. 33.-Cope, Rep. U. S. Nat. Mus. for 1898, 1900, p. 914, fig. 227.-EckeL, Amer. Nat., vol. 35, 1901, p. 153.-Brown, Proc. Acad. Nat. Sci. Philadelphia, 1901, p. 77.Eckel and Paulmier, Bull. New York State Mus., no. 51, 1902, p. 375.Henshaw, Occ. Pap. Boston Soc. Nat. Hist., vol. 7, 1904, p. 9.-Drowne, Mon. Roger Williams Park Mus., no. 15, 1905, p. 12.-Lampropeltis getulus getulus HAY, Proc. Biol. Soc. Washington, vol. 15, 1902, p. 139.Wright, Proc. Acad. Nat. Sci. Philadelphia, 1915, pp. 139 et seq., 168, fig. 10 .

Description.-The eastern representative of this group is well known and easily recognized. The scutellation as determined from 134 specimens is as follows: Ventral plates, 203 to 224 ; caudals, 38 to 58 ; supralabials, 7 (rarely, 6 or 8 ); infralabials, 9 (rarely, 8 or 10); oculars, 1 and 2 ; temporals, $2+3+4$; posterior chin shields about equal in length to the anterior, and parallel; loreal as high as, or higher than, long; dorsal scale rows commonly $21-23-21-19$ or 21-19, the higher formula being characteristic of the southern portion of the range and the lower of the northern; rarely as high as 23-21 and sometimes as low as 19-21-19-17.

This snake is somewhat stouter than the western representatives of the group, and the head is distinctly narrower and higher. This is reflected in the broader dorsal scales, the higher labials and loreal, and narrower rostral. The tail raries from 0.100 to 0.155 of the total length (males, 0.104 to 0.155 , average, 0.127; females, 0.103 to 0134 , average, 0.119). The largest specimen examined was from Gainesville, Florida, and measured 1,752 mm.; the largest specimen from the northern part of the range measured $1,434 \mathrm{~mm}$., and was taken in Caroline County, Virginia.

The pattern (fig. 35) is formed of a series of narrow white or yellow bands, 23 to 52 in number that cross the back transversely or obliquely, bifurcate on the sides, and there join a series of quadrate light spots. The latter overlap a little on the ventral plates, and alternate with the dorsal bands. The belly is checked with a light brown, and white or yellow, with a tendency for the dark to be mostly opposite to the light areas on the sides.

The ground color of the head is dark. The rostral is white with a black posterior border. The internasals, prefontals, and frontal are dark, with each a transverse light bar anteriorly. There is a medial light spot on each supraocular near the frontal suture. Each parietal has a round light spot medially, near the common suture, and an elongate light spot on the anterior-lateral border. There is a light spot near the center of the nasals, loreals, oculars, and temporals. The labials are white, with dark posterior borders: the chin and gular shields are white. Close behind the head is a light spot about three 
scales long and two wide, or this may be elongated as the first transverse band.

Normally the white is restricted as above, but in the southern portion of the range there is commonly a development of white in the centers of the scales of the dark areas of the back and sides. This is usually most pronounced midway between the light bands.

The belly is checked with black or brown and white, or yellow and may be nearly all dark or nearly all light.

The copulatory organ may be described as follows: Distinctly forked; sulcus single, extending over the side of the longer fork; a bare space at the apical end, surrounded by low calyces which extend but slightly below the tips of the forks; fringes few, soon developing into spines, which increase in size to about one-third the distance to the base, and then stop suddenly, being succeded by a few minute spines, or none at all; remainder of organ smooth. This description holds for specimens from Baldwin County, Alabama, Indian River, and Charlotte Harbor, Florida, Virginia Beach and Dunn Loring, Virginia, and Montgomery County, Maryland. This organ differs. from that of holbrooki in the great restriction or entire absence of the minute spines, the more distinctly forked character of the apical end, the fewer calyces and their shorter fringes. It does not seem to differ particularly from that of floridana, except in having shorter forks.

The skull is essentially like that of holbrooki. Maxillary teeth 13 to 16 , usually 13 , subequal, the last one or two slightly stouter than the preceding or actually a little smaller; mandibular teeth 14 to 17 , usually 14 or 15 , the anterior a little the larger, the first and the last five or six the smallest; palatines 9 , sometimes 10 , subequal; pterygoids 16 to 20 , subequal, a little smaller than the palatines and decreasing in size posteriorly.

While getulus is a distinct and well-defined form, throughout its. range, at its southwestern limits it intergrades with niger, and in central Florida with floridana. The only character by which it may be distinguished in doubtful cases from niger is the number of cross bands, which are more than 50 in the latter and usually less than 40 in getulus. Where the range of getulus meets that of floridana, again the most valid separation may be made on the number of cross bands; getulus generally has less than 50, and floridana more. The totality of characters is the best guide, and yet there may still be doubt about exceptional individuals from near the common boundary of the ranges.

Habitat and habits.-This species has received frequent mention in the literature. Probably the first reference to it was that of Catesby $(1731,52)$. He says: "It was the first one of the kind I ever saw, nor was it known to any of the inhabitants I showed it to, therefore as 
it wanted a name, the best I could think of was that of Chain-Snake, from some resemblance to a chain that seems in many cases to environ the body." Shaw (1802, 467-468) says: "This snake is found in Carolina, Virginia, etc., frequenting moist woods and shady places, and preying on lizards, etc." DeKay says of it (1842, 37): "Not uncommon in the pine woods of New Jersey, and is also found but rarely in what are called the Brush Plains of Long Island." Ditmars says with reference to habitat $(1907,359)$ : "Specimens captured by the writer were in rather dry patches of timber; some were taken while basking in the sun of small glades in the forest; others were found hiding under fallen tree trunks." Dunn has taken numerous examples in Nelson County, Virginia, in hay fields, near creeks, and about farm buildings. Some of these would resent handling at first by chewing at hand or arm, but usually they were perfectly tame from the first. Wright says, for the Okefinokee Swamp (1915, 168-169): "Thirteen specimens of this fine snake were taken and many more seen. It is common throughout the drier parts of the swamp and frequents the outskirts of the swamp as well. It keeps to the islands and none were taken in other situations than the saw palmetto or heath societies of the piney woods where it courses through the low cover after its living prey or eggs. This species is one of the most strikingly marked snakes of the swamp. The shining black or brown with the contrasting white or yellow cross-bands makes its appearance very attractive. In nature, it is mild, proves an interesting and safe pet, and in no instance during our stay in the swamp did it display any belligerency or sullenness toward any member of the party."

This is a large, powerful, and fearless snake. It does not appear to be secretive or to avoid an encounter. In fact (Ditmars, 1907, 360-361), "besides the promptings of its appetite this snake exhibits a pugnacious interest in other serpents that may be considerably larger than itself, engaging these creatures in a duel to the death, during which, however, they are able to make but little resistance, when encircled by the wonderfully strong constricting coils of the enemy." Although sometimes (Ditmars, 1907, 363) "when first caught, they strike vigorously, emitting a short hiss which sounds more like a sneeze," they are frequently perfectly gentle and unafraid from the beginning. In fact, Loennberg (1894, 324-325) writes that "when caught they never tried to bite, only one opened its mouth, but they wind themselves round one's arm, showing great muscular strength." For observation in captivity they are probably the most desirable of all the North American snakes.

They feed upon other snakes, lizards, birds, and small rodents. In this latter respect and because they are always victorious in an encounter with a venomous snake, they are very useful to the agri- 
culturist and should receive full protection. When their prey is large enough to struggle effectively, the King snake coils about it in true constrictor style, but if it small or dead it may swallow it directly. Definite food records are few. Dunn has captured several that contained mice. In captivity they have been observed to eat Thamnophis butleri, T. sirtalis, Carphophis amocnus, house mice, dead or alive, and even their relatives, L. geitulus holbrooki and $L$. calligaster. Two of the latter kept by the writer were eaten, one by accident (both starting to swallow the same mouse), and the other apparently by intent, although they had both lived in the same cage for more than a year. Hurter $(1911,186)$ records the Black snake, Bascanion constrictor, as having been eaten in captivity, and Dunn mentions Heterodon contortrix, Natrix sipedon, $N$. septemvittata, and the Chipping Sparrow.

By far the best account is given by Wright. Discussing the King snake, as he found it in the Okefinokee Swamp, he writes $(1915,169)$ :

The natives recognize its good nature and consider it harmless, though the king of the snakes. They are aware of its usefulness as an enemy of moccasins and rattlesnakes and report several combats which always resulted successfully for the King snake, but these unlettered people, unlike many sentimental writers, do not hold that the King snake deliberately searches for the poisonous snakes in particular. We, as they, believe it the enemy of every species of snake in the swamp, preying of course more on the terrestrial species of its own haunts. All the smaller snakes suffer, and of the larger species, the blacksnake and spreading adder are the commonest prey. It is surely a good "pilot" to the naturalist whenever one finds it digging, for it almost invariably means other snakes, eggs, or some good capture. It will seldom fail to react per schedule if you loosely hold it in one hand and a live blacksnake in the other. Almost before you can predict the outcome, the former may be far within its captor-a demonstration we have tried more than once in the field. It is especially fond of young snakes. One of our specimens had taken a newly hatched Heterodon and the natives recounted several occasions when they had found it working beneath a $\log$ for what proved a brood of young snakes. We do not doubt but that it feeds on mice, rats, and other small mammals, but of such evidence we found little in the swamp. Possibly, in early spring or in the fall these are more its reliance. The principal food of this species is turtles' eggs, with snakes or their eggs a second choice. Four of our specimens had eaten Florida cooters' (Chrysemys floridana) eggs, which they dug out of the sand, and two had mud turtle (Cinosternum pennsylvanicum) eggs in their stomachs. Mr. Francis Harper tells us that he and David Lee almost stepped on a King snake. After their recovery, what should they find but a Kinosternon digging in sand, probably preparatory to laying, and the King snake was close at hand. In fact, so addicted are they to this egg diet, that the natives consider that it is a common happening to find the snake awaiting the egg deposition. Unless it be the Florida bear, there is no form in the swamp which eats turtles' eggs in such quantity as the King snake. It will take a whole nest of eggs at one time, as many as 14 being found in the stomach of one snake.

This species, like the other King snakes, is oviparous, and (Ditmars, 1907, 363) "deposits from 10 to 24 eggs, which require from five to six weeks to complete the incubation." Wright $(1915,170)$ says: "Mr. Harper reports a pair of them mating on May 19, 1912, 
[Okefinokee Swamp], and says another King snake was watching the pair. One of our specimens (no. 6145), taken on June 15, 1912, had 7 fair-sized eggs."

C. S. Brimley $(1903,263)$ says: "The eggs of the King snalie (Ophibolus getulus) are long, oblong in shape, with a smooth, tough skin and are more or less adherent to one another in clusters."

Range.-This form is known to extend from central New Jersey to central Florida, and west from the coast to the Alleghenies and to Mobile Bay, Alabama. On the west side of Mobile Bay it appears to be entirely replaced by holbrooki, and in northern Alabama by niger. The few specimens from the southwestern portion of the range indicate that intergradation takes place in the region of a line drawn from the point where the North Carolina-Tennessee State boundary line meets that of Georgia southwest to Mobile Bay. (The locality of specimen no. 2294, United States National Museum, labeled "Miss.," must be an error.) While there appear to be no verifiable records north of New Jersey, numerous references in the literature can not be overlooked. DeKay refers to it as occurring in the "Brush Plains of Long Island" (1842, 38). Ditmars $(1896,13)$ says he has not heard of one being found in Long Island or the vicinity of New York in the last five years. Baird $(1854,21)$ says "it is quite maritime in its northern distribution, being rarely found in the northern states except near the coast." A specimen in the United States National Museum (no. 459), received from the Jardin des Plantes, Paris, in 1858, bears the label "New York." This may easily be an error. Hough $(1852,23)$ reports this snake for Rossie, St. Lawrence County, New York, "of common occurrence in this section of the state," and Eckel (1902, 376) refers to this record as one that "can not be neglected or suppressed." Linsley $(1843,43)$ reports it at Milford, Connecticut, on the word of a man whom he considers trustworthy.

Besides the localities represented by specimens in the United States National Museum, specimens have also been examined from the following localities: Bridgeton, Point Pleasant, Port Republic, Stafford's Forge, Vineland, Lakewood, Lakehurst, and Beesley's Point, New Jersey; Williams, Maryland; Seaford, Delaware; Midway Mills, Nelson County, Virginia; Bluffton, Hampton County, and Hilton Head, South Carolina; Raleigh, and Fort Macon (Carteret County), North Carolina; Fargo, Savannah, and Billy's Island, Okefinokee Swamp, Georgia; Orange Lake, Eustis, and Marion County, Florida; Daphne, Baldwin County, Alabama.

Published records for localities from which no specimens have been examined are as follows: Port Tobacco, Maryland (Yarrow, 1878, 470); Rossie, St. Lawrence County, New York (Hough, 1852, 
23) ; Milford, Connecticut (Linsley; 1843, 43); Nashville and Alapaha, Berrien County, Georgia (Wright, 1915, 140).

Variation.-The averages for the ventral plates show distinct differences with latitude. Thus the diagram (fig. 11) shows that there is a progressive decrease in number of ventrals northward from Georgia and an increase southward into Florida. The former is much more gradual than the latter and is accompanied with other gradual changes, which make a slight but not very distinctive difference in the appearance of the specimens from widely separated parts of the range. The change into southern Florida is much less gradual and is accompanied by other marked changes, particularly of pattern,

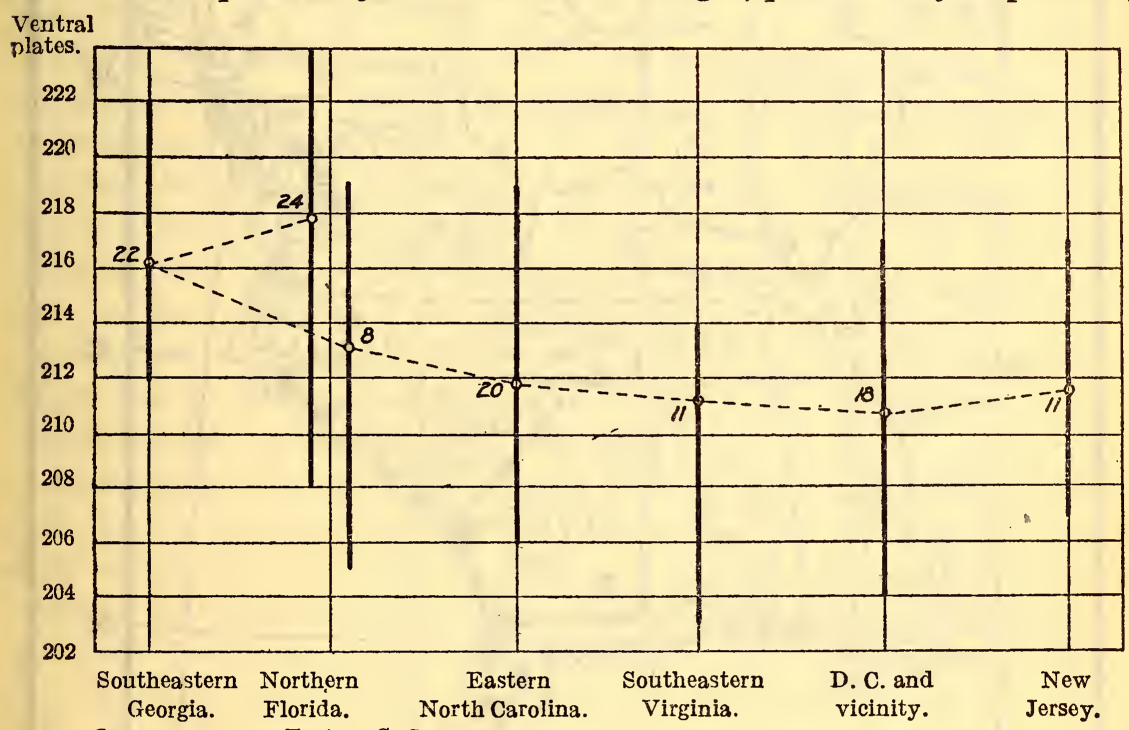

Localities. Eastern S. C.

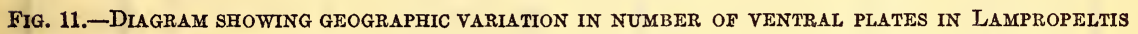
GETULUS GETULUS.

sufficient altogether to make necessary the recognition of a distinct subspecies there (as floridana).

The averages of the numbers of caudal plates are based upon too few specimens to be of much value, but, such as they are, they support the figures for the ventrals, that is, there is a slight decrease in number northward, and increase southward. The same is true of the infralabials. The higher numbers are more frequent in the south, the lower in the north. Specimens from northern Florida show about 15 per cent of increase to 10 infralabials; in floridana this is increased to about 30 per cent; north from Florida 10 is of less common occurrence, and the number is not infrequently reduced to 8 .

The dorsal scale rows vary between the rather widely separated formulae of $23-21$ and 19-21-19-17. The extremes are uncommon, 
however. North of Georgia the usual formula is 21-19, sometimes 23 rows is attained and more often the formula is lowered to 19-21-19, 21-19-17, or 19-21-19-17. South of Georgia a maximum of 23 rows is more common than a maximum of 21 , and of all the specimens examined from Florida, no individual had a lower formula than 21-19. It seems almost certain that extensive series of specimens

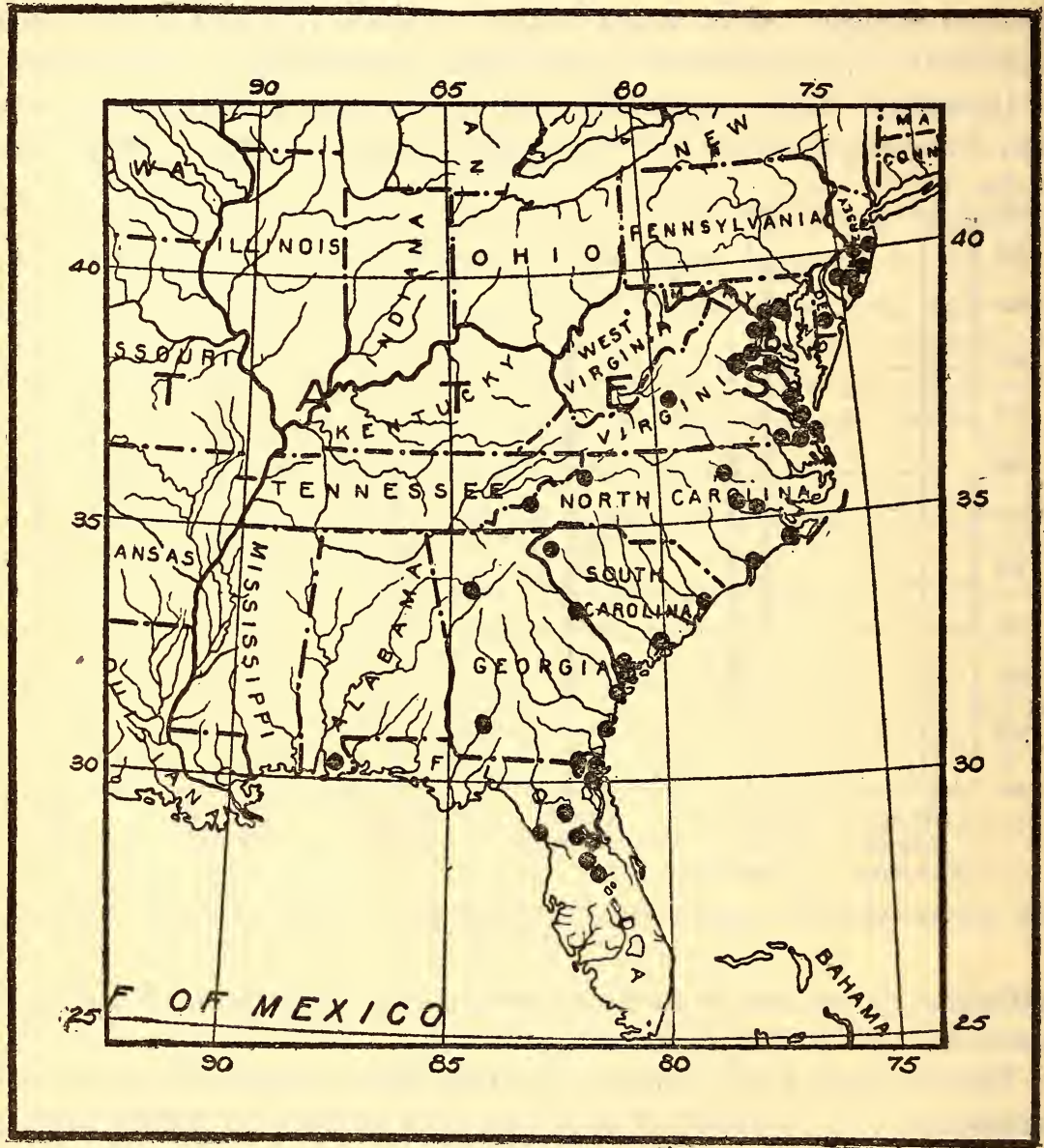

FIG. 12.-MAP SHOWING LOCALITY RECORDS FOR LAMPROPELTIS GETULUS GETULUS.

will demonstrate a progressive decrease in number of scale rows with increase in latitude.

The pattern, as already described, is fundamentally a series of transverse dorsal bands which bifurcate on the sides to join there an alternating series of light areas. This arrangement is subject to much variation. The bands vary from $\frac{1}{2}$ to $1 \frac{1}{2}$ scales in width; the forks are always narrower, and vary from interrupted spots, or nothing whatever, to unbroken lines a scale wide; and the lateral 
white areas vary from squarish, about 2 scales by 2 to oblong and about 4 or 5 scales long and 3 or 4 wide. In position the dorsal bands may be transverse or oblique, and extend across from 9 to 15 or more rows of scales. The lateral alternating spots are always located on the first few rows of scales; they are usually longer than wide and nearly always overlap onto the ends of the ventrals. Depending upon the upward extension of these spots and the downward extension of the cross bands, the forks may be horizontal or set at as much as a 45 degree angle. It is rather more common for the white scales to be all white, but frequently these scales, particularly in the cross bands, are tipped, up to as much as half their area, with deep black.

These variations seem to be all common and widespread, and appear not to be of geographic significance. Of other variations the opposite can be said.

From Georgia to southern Virginia the number of white cross bands averages close to 30 , northward this is increased to more than 40 near the District of Columbia and in New Jersey, and southward into northern Florida it likewise is increased to 40. Correlated with the change in number of bands northward is an intensification of the white and a blackening of the ground color, and southward a lessening of the distinction between the light and dark.

In southern Georgia and northern Florida it is by no means uncommon for the scales of the dark areas to develop white centers. These may extend to all the dark scales, but usually are best developed midway between the white cross bands, fading gradually to disappearance on either side. It seems likely that the potentiality for the development of white centers is an inheritance from the form holbrooki. Evolution into floridana seems to have proceeded by an enlargement basally, then distally, of these white centers, a softening of their sharp outlines and a lightening of the dark parts, accompanied by an increase in number of cross bands and a decrease in their distinctness, resulting in a light brown spotted appearance in which the remains of the original pattern are to be distinguished with difficulty. This reaches its logical outcome in extreme southern Florida. In this phase, which has recently been described by Barbour as brooksi, the cross bands have completely disappeared, and all the dorsal scales are yellow at the bases, shading to dark brown at the tips.

Along with the general reduction in scutellation to the north is a slight decrease in size of body, perhaps best realized by comparison with the distinctly larger individuals from central and southern Florida.

Mention must here be made of a most interesting individual from Occoquan Creek, Virginia (Cat. No. 59354, U.S.N.M.). This is a 
variant in respect to pattern in every way similar to the specimens of californiae from Fresno County, California. The belly is almost an immaculate white on the anterior half of the body, but on the posterior half it is mostly black, mixed with some white. The dorsal pattern of cross bands is broken up into spots of varying shapes, chiefly elongate, with a conspicuous tendency to form a dorsal white stripe. It is to be hoped that more collecting in this vicinity will reveal other examples. It indicates the inherent potentiality in getulus for the production of an Atlantic coast analogue of californiae.

Affinities.-It will doubtless already have been noticed that ventrals, caudals, labials, scale rows, and color pattern all indicate the same thing, that is, that the region represented by Georgia is the meeting ground of two diverging lines of evolution in getulus. That one line has been southward there can hardly be a doubt. Floridana is clearly an end form in all its characters, and it is certainly so in geographic position. Similarly getulus, as it occurs in the northern portion of its range, demonstrates itself to be a reduced form of the southern type. Consequently evolution has proceeded from the Georgia-Alabama region northward along the coastal plain, and southward into Florida. In central Alabama and northern Georgia getulus and niger intergrade in the region indicated above under Range. The material at hand indicates that this is the only region where intergradation occurs between these forms. The relationships may therefore be expressed as follows:

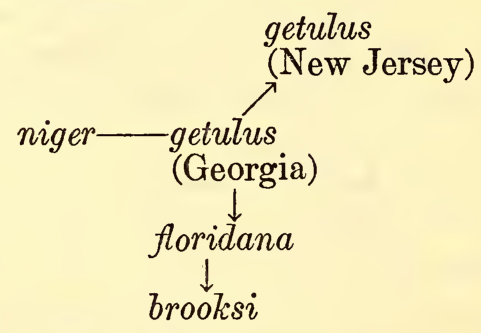




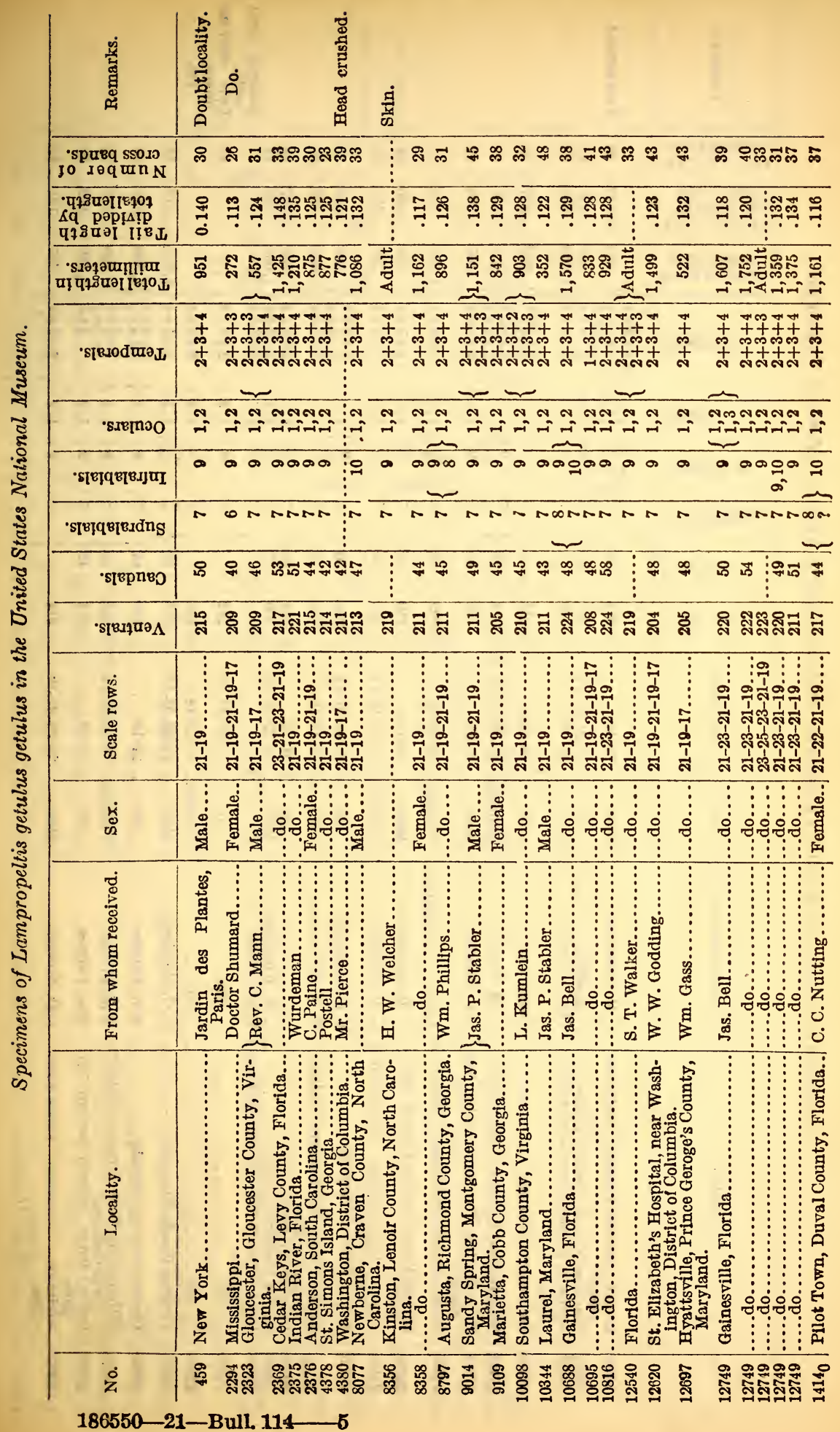




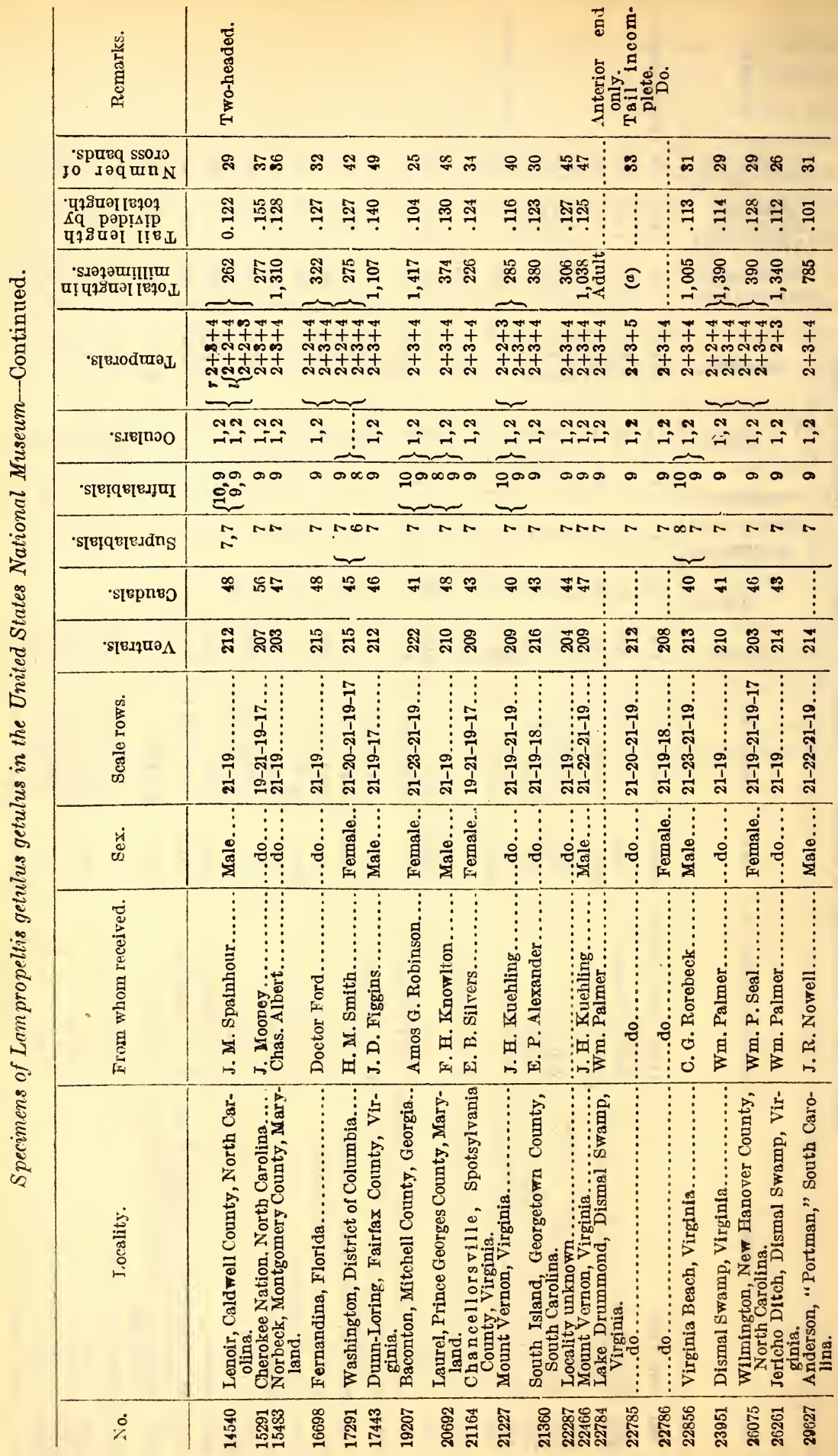




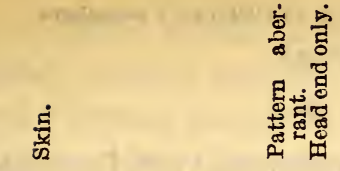

ஜ유 \%ం

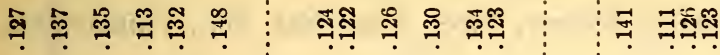

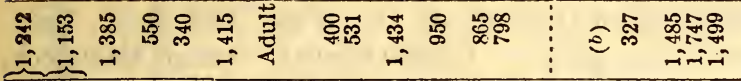

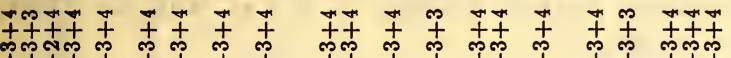

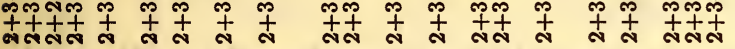

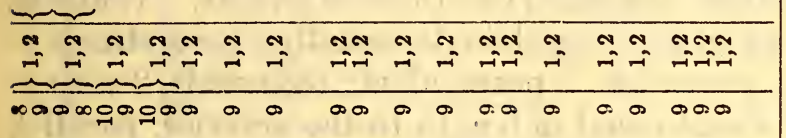

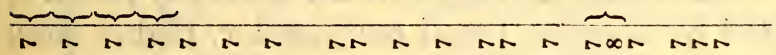

웅ำ

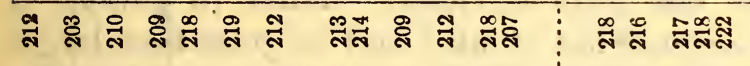

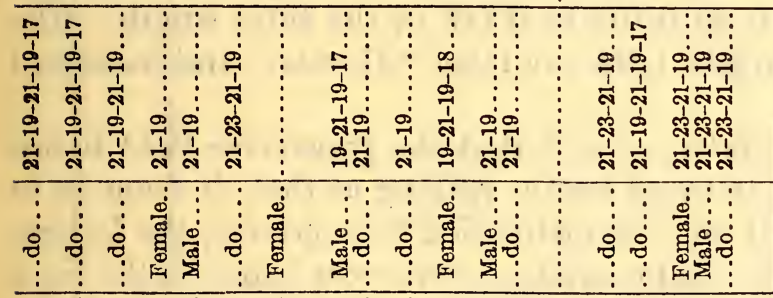

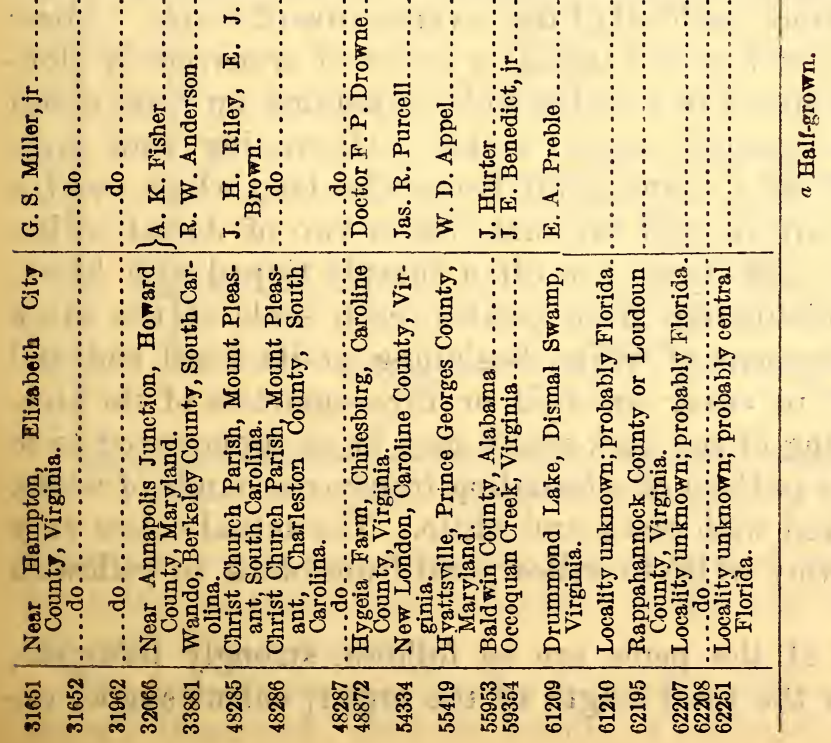


LAMPROPELTIS GETULUS FLORIDANA Blanchard.

KING SNAKE.

Fig. 36 .

1894. Lampropeltis getulus (part) LoennBerg, Proc. U. S. Nat. Mus., vol. 17, no. 1003, p. 324.-Ophibolus getulus (part) Drtmars, Reptile Book, 1907, p. 359.

1904. Ophibolus getulus getulus Brown, Proc. Acad. Nat. Sci., Philadelphia, p. 472.

1919. Lampropeltis getulus floridana Blanchard, Occ. Pap., Mus. Zool., Univ. Mich., no. 70, May 5, p. 1, pl. 1, fig. 1 (type locality: Orange Hammock, DeSoto County (northeast portion), Florida; U. S. Nat. Mus., no. 22368; William Palmer, collector).

Description.-Characters in general like those of getulus. Ventrals, 210 to 225 ; caudals, 42 to 55 ; supralabials, usually 7 , sometimes 8 ; infralabials, 9 or $10 ; 1$ preocular; 2 postoculars; temporals, $2+3+4$; posterior chin shields about equal in length to the anterior, parallel, and sometimes separated by a scale; loreal rectangular, higher than long or about as high as long (in one specimen fused with postnasal); scale rows 23 or 21 , formulae, 23-21, 21-23-21-19, 21-19.

In bodily proportions this form is closely similar to getulus; it appears, however, to be somewhat stouter and to grow to a larger size. The tail varies from 0.107 to 0.146 of the total length. The largest specimen examined bore the label "Florida," and measured $1,753 \mathrm{~mm}$.

Pattern similar to getulus, except that the transverse light bands on the back are about twice as many, varying as they do from 46 to 85 , with an average of 66 . In distinction from getulus, the forking on the sides has usually disappeared, and the cross bands on the back end abruptly at about the level of the seventh row of scales. Alternating with the dorsal cross bands is a series of transversely elongated light spots, about two scales wide, extending up from about the second to the seventh row of scales. Alternating with these latter is a series of light spots about two scales long which overlap the ends of the ventrals and the first row or two of dorsal scales. The scales of the dark bands are often sharply tipped with black. Furthermore, in distinction from getulus, each scale of the black areas has a development of white, beginning at its basal end and spreading distally to cover one-half or three-quarters of its area. This basal lightening of the dark scales may be so pronounced as to greatly obscure the pattern of alternating transverse bands of white. The belly is checked with black and white. The actual colors vary from white to creamy white to yellow, and from black to yellowish brown.

The characters of the penis are as follows: strongly bifurcate, the forks one-fifth the total length of the organ; sulcus single, ex- 
tending over the side of the larger fork, and down the inner side of the V; distal surface smooth, succeeded proximally by a few slightly fringed calyces; the short fringes rapidly becoming modified into small spines which increase in size basally, and, one-half way

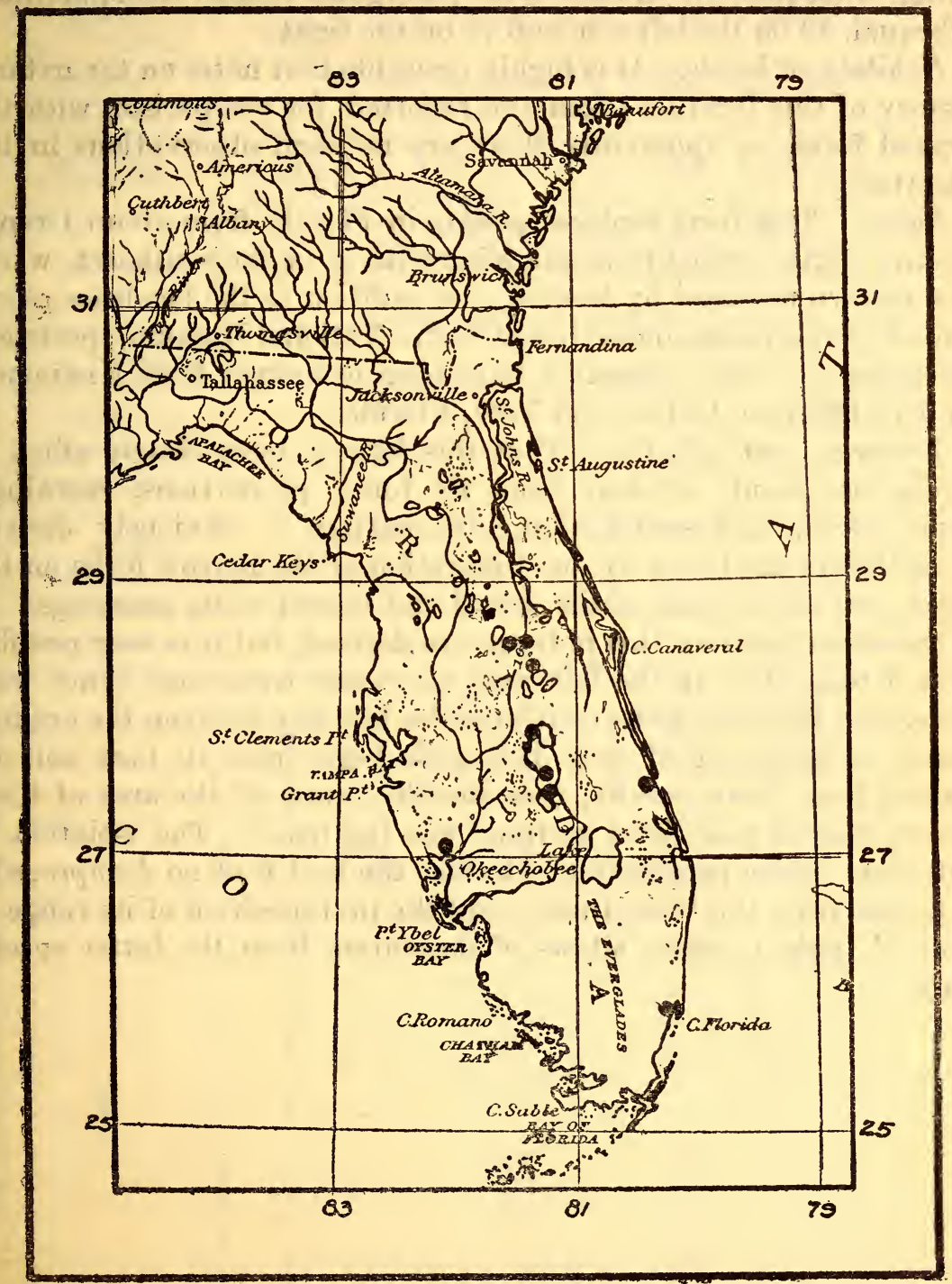

FIG. 13.-MAP SHOWING LOCALITY RECORDS FOR LAMPROPELTIS GETULUS FLORIDANA.

down the organ, stop abruptly; basal half of organ smooth except for a few scattered minute spines, chiefly near the large ones; no spines distinctly enlarged.

The skull is essentially like that of getulus. A specimen from Orange Hammock, De Soto County, Florida (U. S. Nat. Mus., no. 
22367) has the following dentition: maxillary teeth, 15 on each side, increasing very gradually in size posteriorly, the last three slightly larger than those preceding; mandibular teeth 16 on each side, somewhat larger anteriorly, decreasing in size posteriorly; palatines strong, subequal, 10 on each side; pterygoids smaller than palatines, subequal, 19 on the left side and 17 on the right.

Habitat and habits. - It is highly desirable that notes on the natural history of this form be taken and reported, for comparison with the typical form, as apparently there are no such observations in the literature.

Range.-This form replaces getulus in Florida from about Orange County south, probably to the Miami River in the southeast, where it is in turn replaced by brooksi. In addition to the localities represented by specimens in the United States National Museum, specimens belonging to other museums have been examined from Kissimmee Prairie, Orlando, Gotha, and Vero, Florida.

Variation and affinities.-That this form is most closely allied to getulus is plainly evident from its form, proportions, markings, penis, skull, and scutellation. Its pattern is obviously derived from that of the latter by an obliteration of the narrow forks on the sides, and an increase in the dorsal and lateral white markings. It is uncertain just how this pattern was derived, but it is very possible that it took place in the following way: new transverse bands were developed from the white central scales midway between the original bands; a lightening of each dark scale began near its base and extended from there basally, then distally, until all the area of these scales, except the distal margin, was lightened. The isolation of this form in the peninsula of Florida, the fact that no Lampropeltis is known from the West Indies, and the juxtaposition of its range to that of typical getulus allows of derivation from the latter species only. 


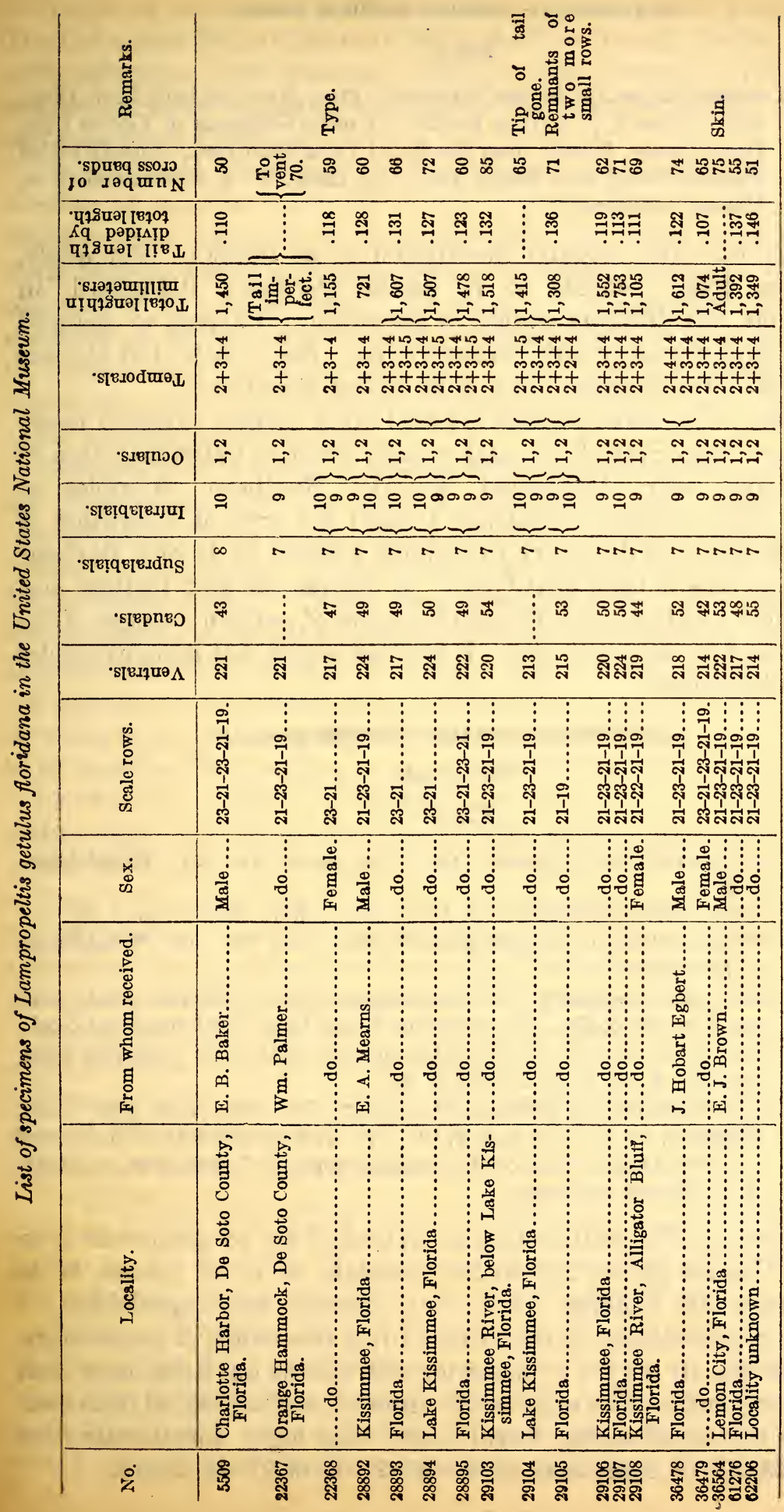




\section{LAMPROPELTIS GETULUS BROOKSI Barbour.}

Fig. 37.

1919. Lampropeltis getulus brooksi Barbour, Proc. New England Zool. Club, vol. 7, June 5, p. 1 (type locality, 14 miles southwest of Florida City, Dade County, Florida (near the Royal Palm State Park, formerly called Paradise Key); Mus. Comp. Zool., no. 12456; W. S. Brooks and C. A. Mosier, collectors).

Description.-The original description is as follows: "An adult, 1,350 mm. long. Similar to L. getulus floridana Blanchard, in squamation, but differing widely in coloration. Pattern so reduced as to be almost everywhere undiscernible. Each scale dull chrome yellow with a conspicuous, very dark brown apical spot."

Remarks. - The name brooksi, is based upon a single example taken near Royal Palm State Park, and a badly crushed individual seen in the highway near Homestead, Florida. Southern examples of floridana show a distinct tendency toward the type of coloration of brooksi, so that the discovery in tropical Florida by Doctor Barbour of this new race is most gratifying. It carries one step farther, and to its logical conclusion the interesting series of pattern changes of the getulus group in the southeast. It is to be hoped that more examples will soon be found.

\section{LAMPROPELTIS GETULUS YUMENSIS Blanchard.}

KING SNAKE.

Fig. 28.

1861. Lampropeltis boylii conjuncta Cope, Proc. Acad. Nat. Sci., Philadelphia, p. 301.

1865. Cornella getulus splendida JAN, Icon. Gen. Ophid., livr. 12, pl. 6, fig. 1.

1901. Ophibolus getulus boylii (part) Brown, Proc. Acad. Nat. Sci., Philadelphia, p. 78 (Yuma).

1912. Lampropeltis conjuncta Van Denburgh, Proc. California Acad. Sci., ser. 4, vol. 3, p. 154.-Grinnell and CAmp, Univ. California Publ. Zool., vol. 17, no. 10, 1917, p. 187- - Hall and Grinnell, Proc. California Acad. Sci., ser. 4, vol. 9, no. 2, 1919, p. 48.

1919. Lampropeltis getulus yumensis Blanchard, Occ. Pap., Mus. Zool. Univ. Michigan, no. 70, May 5, p. 6, pl. 1, fig. 2, (type locality, 27 miles west of Indian Oasis, Pima County, Arizona; type, U. S. Nat. Mus. no. 61318; A. H. Howell, collector).

Description.-The scutellation as indicated by 18 specimens is as follows: Ventral plates, 212 to 240 ; caudals, 44 to 57 (males, 50 to 57 , average 54 ; females, 44 to 51 , average 48 ); supralabials, 7 (rarely 8 ); infralabials, 9 , sometimes $10 ; 1$ preocular; 2 postoculars, temporals usually $2+3+4$; posterior chin shields but little more than half as long and half as wide as the anterior, and separated from each other by two small scales; loreal longer than high; dorsal scale rows usually $23-21-19$, sometimes $23-25-23-21-19$ or $21-23-21-19$. 
This form seems not to differ in size or proportions from boylii. The tail varies from 0.090 to 0.140 of the total length (males, .121 to .132 , average, .127; females, .093 to .128, average .117). The largest specimen examined was from the Graham Mountains, Arizona, and measured, 1,204 $\mathrm{mm}$.

The pattern is composed of white annuli separated by black, and varying in number from 29 to 45 (average 37 ). It differs from boylii in that the most of the white scales are marked basally with dark brown, which not infrequently extends irregularly over the scales so as to greatly obscure the rings. The latter are narrow on the back, 1 to $2 \frac{1}{2}$ scales in width, widening on the side to about 2 to 5 scales, and traversing the belly. They may be divided on the midventral line and alternated instead of joined, and this may occur less frequently above.

Characteristic of the group are the white bars across the prefrontals and internasals, and the white centers on rostral, nasals, loreal, oculars, and labials. Beneath the eye there is usually a rather conspicuous enlargement of the common dark border of the third and fourth upper labials. Other markings on the head are infrequent. There may be small white dots on supraoculars, anterior temporals, anterior portion of frontal, and rarely on the edges of the parietals. On the first scales behind the parietals there may be a small cluster of white spots, the homologue of the first white band or ring, which, in all members of the group, may at times be fairly well developed.

The belly is usually crossed by the continuations of the black and white rings, and, like the dorsal white scales, the white ventral plates are usually conspicuously edged basally with dark brown.

The skull is like that of boytii. The dentition, as indicated by a few specimens, is as follows: Maxillary teeth, 13 to 16, the last two somewhat stouter than those preceding; mandibular teeth, 14 to 17 , the anterior the larger; palatines, 9 or 10; pterygoids, 12 to 19.

The penial characters are very much like those of splendida. The organ is bilobed, and has a small smooth area at the distal end. The calyces are few, and their fringes may be fairly conspicuous or very short. Minute spines are barely distinguishable over nearly as much area as covered by the large spines.

To distinguish this form from conjuncta and from boylii, see the table under the description of the latter. From splendida it may be known by the fact that the white annuli are not joined on the sides, but are completely separated by the black interspaces.

Habitat and habits.-Except for C. L. Camp's note for the vicinity of Yuma, that this form "lives among cottonwoods and thick growth along the river bottom," there are, apparently, no observations available on the natural history of yumensis. Such observations would be very desirable for comparison with those of splendida and 
of boylii. It would be interesting to know how severe desert conditions it can withstand, and whether it differs in this respect from boylii. It may be a long time before the natural history of the various forms of the getulus group is well known, but, when it is, we shall expect to be able to trace courses of evolution in habits corresponding with and bearing out the observations on the structural evolution of the group.

Range.-This form inhabits the desert region of the southern third of Arizona (except the extreme southeastern corner), the Colorado Desert, and the area about the head of the Gulf of California.

Specimens are in the collection of the National Museum from Ash Creek in the Graham Mountains, Arizona, at 3,200 feet elevation (evidently the base of the mountains) and from Fort Grant and Calva in Graham County. It will be interesting to learn whether this form extends up the Gila River and its branches into New Mexico, and to see if the divide between the Colorado drainage system and the Rio Grande proves to be also the divide between this form and splendida. If this proves to be the case, it will be a matter of no small interest to see if these two forms are sharply distinct here. This is to be expected, since none of the members of this group are known to inhabit actually mountainous regions. Enough specimens are available from the vicinity of Tucson to show that this is a region of intergradation between splendida and yumensis. From the topography of the country it may be expected that yumensis ranges south on the east coast of the Gulf of California to the region of the twentyeighth parallel, perhaps farther. West of the Colorado River, except for the vicinity of Yuma, the only record is for Volcano Lake, Lower California, near the delta of the Colorado River, at the east base of the Cocopah Mountains. West of the Yuma region it is assumed that the range of yumensis extends throughout the Colorado Desert, since specimens from western San Diego County strongly suggest derivation from yumensis. South into Lower California its range is probably limited by the region where the mountains reach the east coast, at about the thirty-first parallel. Specimens in the United States National Museum from the northwest coast of Lower California and from San Pedro Martir Mountain, Lower California, are distinctly boylii.

Specimens have been examined from the following localities, in addition to those represented by specimens in the United States National Museum: Tucson, Fort Grant, and 10 miles below Cibola in Yuma County, Arizona; "Sonora" (southern Arizona); Pilot Knob (Imperial County), California.

There seem to be no published records for other localities than these. 
Variation and affinities.-The number of specimens at present available is too small to establish dependable averages. They are well distributed, however, and a consideration of their structural variations will be significant in relation to the intermediate or connecting position that this form occupies between boylii and splendida.

$\mathrm{By}$ reference to the accompanying table comparison may be made of the extremes and averages of the numbers of ventral plates in these forms for typical and for boundary regions. Southern New Mexico and western Texas may be considered the region where splendida is typical; the vicinity of Tucson, where this form intergrades with yumensis; Yuma, where yumensis is typical; and San Diego County, California, where boylii is typical.

From the graphic presentation of these figures (fig. 14) it will be apparent that yumensis, in the eastern portion of its range, commonly has numbers of ventral plates characteristic of splendida, and, in the western portion, numbers characteristic of boylii. The nine specimens from the Yuma region exhibit the ordinary variation and usual average of boylii; those from the Tucson region exhibit a range of variation and an average that is strongly suggestive of splendida, and that in fact bridges the gap between the latter and boylii.

It is at Tucson as well that great variability occurs in the pattern, and that all the transitional conditions are found between the patterns of yumensis and splendida.

Table for comparison of splendida, yumensis, and boylii.

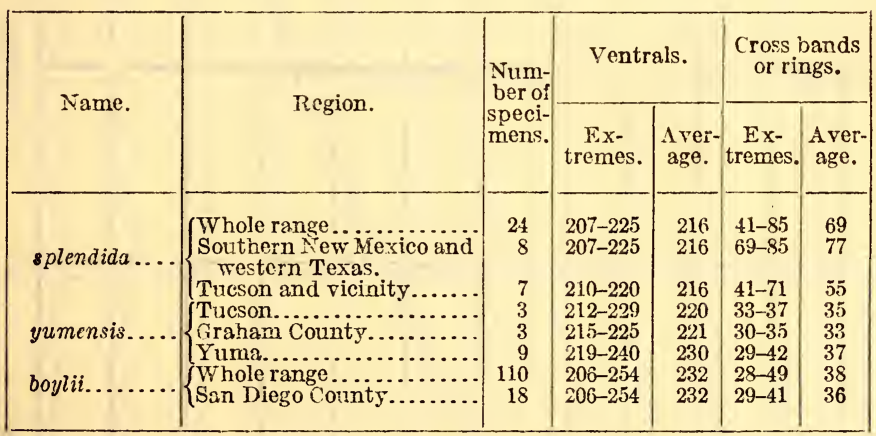

A comparison of the numbers of rings or dorsal bands of these related forms will be even more striking than the numbers of ventrals. From the table and diagram (fig. 15) it will be seen that the normal lower limit of variation in cross bands of splendida (in southern New Mexico) is above the upper limit of variation in rings of boylii. But in the vicinity of Tucson the lower limit of splendida overlaps the upper limit of boylii, and that, in specimens from this region in which the pattern is so altered as to be no longer recognized as splendida, but as yumensis, the number of bands-now changed to rings-has 


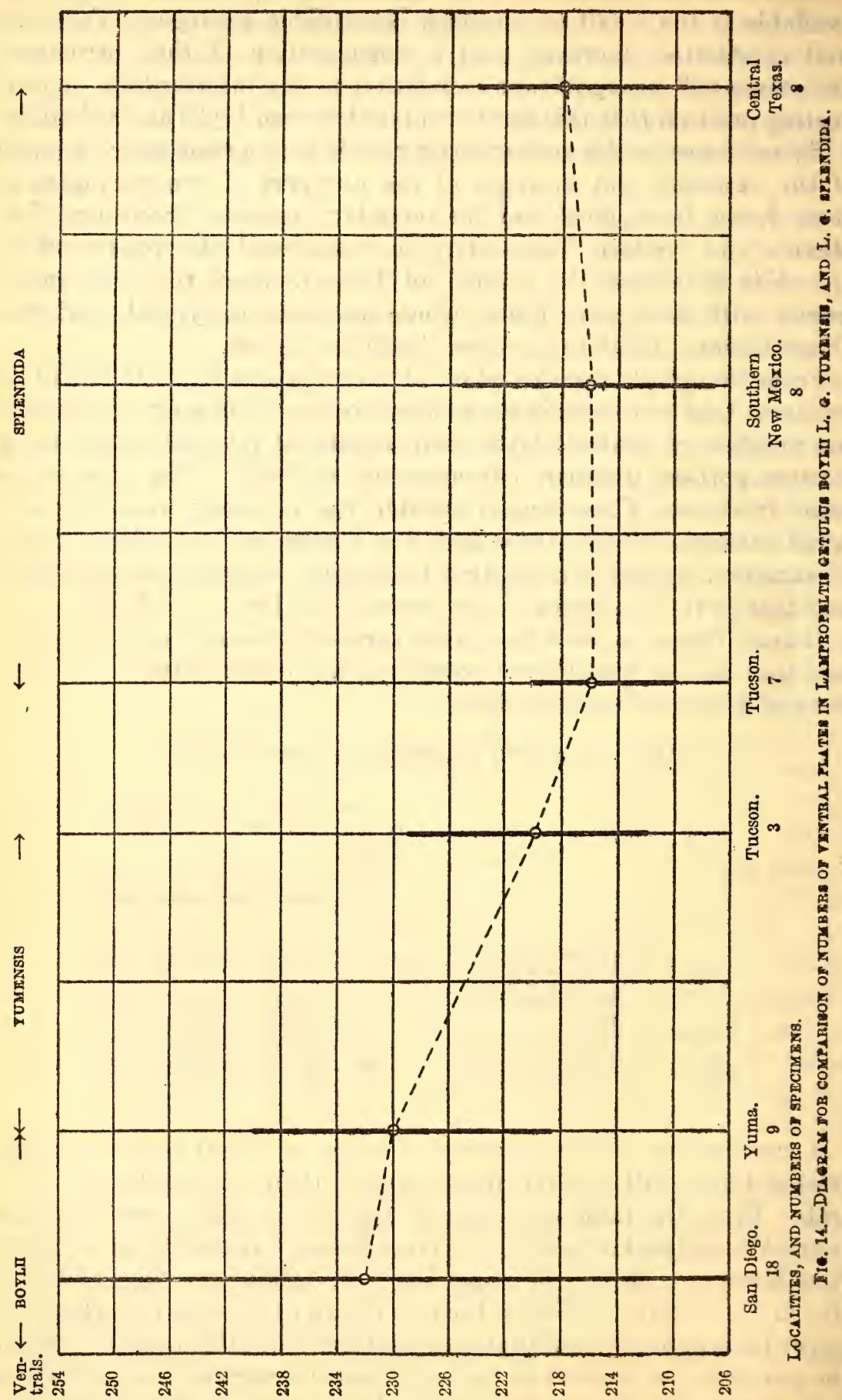




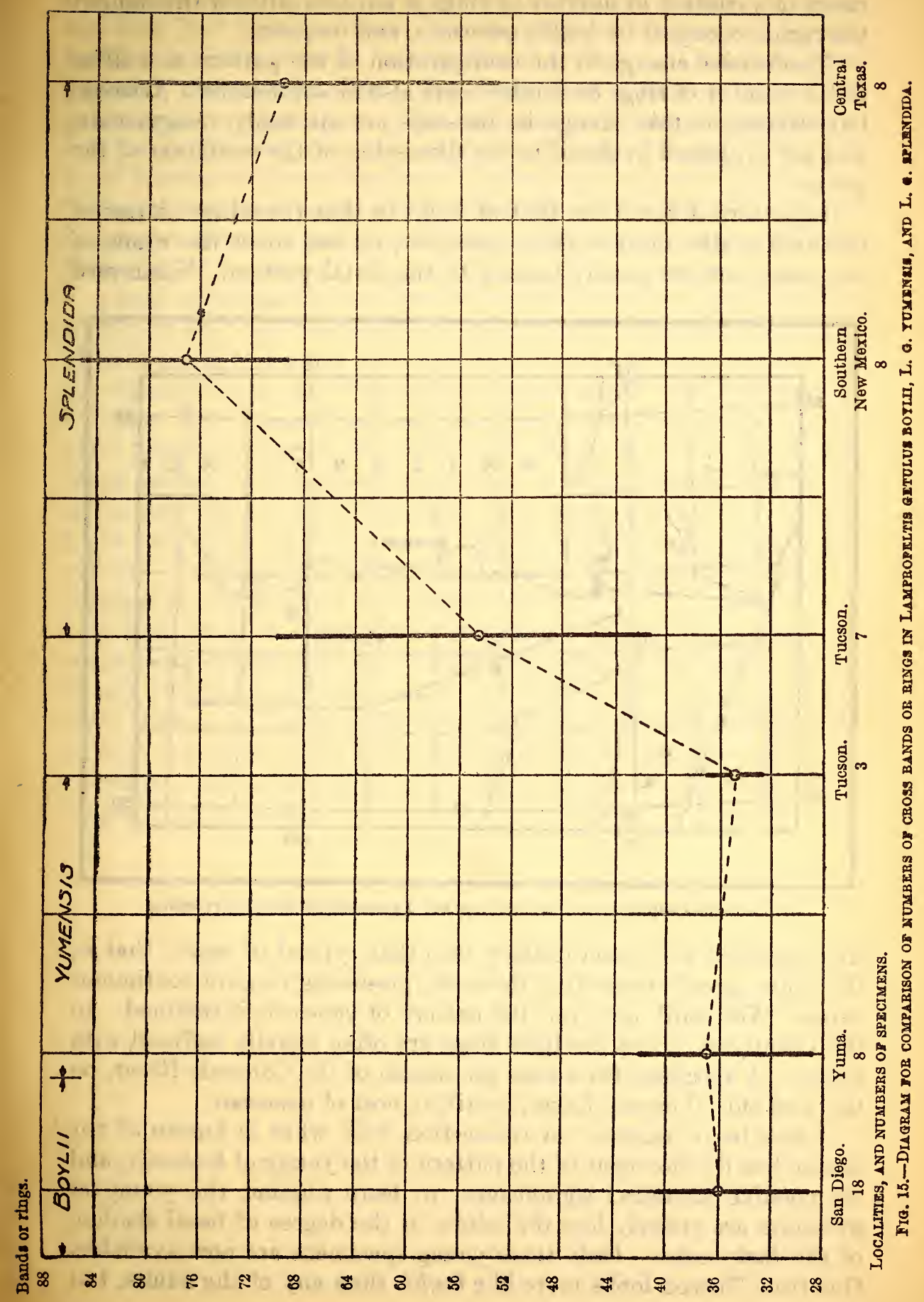


closely approximated the extremes and average of boylii. This range of variation in number of rings is not now altered throughout the region occupied by boylii, yumensis, and conjuncta.

The decisive change in the configuration of the pattern as well as in the number of rings or bands occurs also in southeastern Arizona, but striking as this change is, its steps are all easily recognizable, and are explained in detail in the discussion of the evolution of the group.

Its pattern differs from that of boyiii in that the white centers of the dark scales, derived from splendida, do not cover the whole of the scale, but are mainly limited to the distal portion. Northward

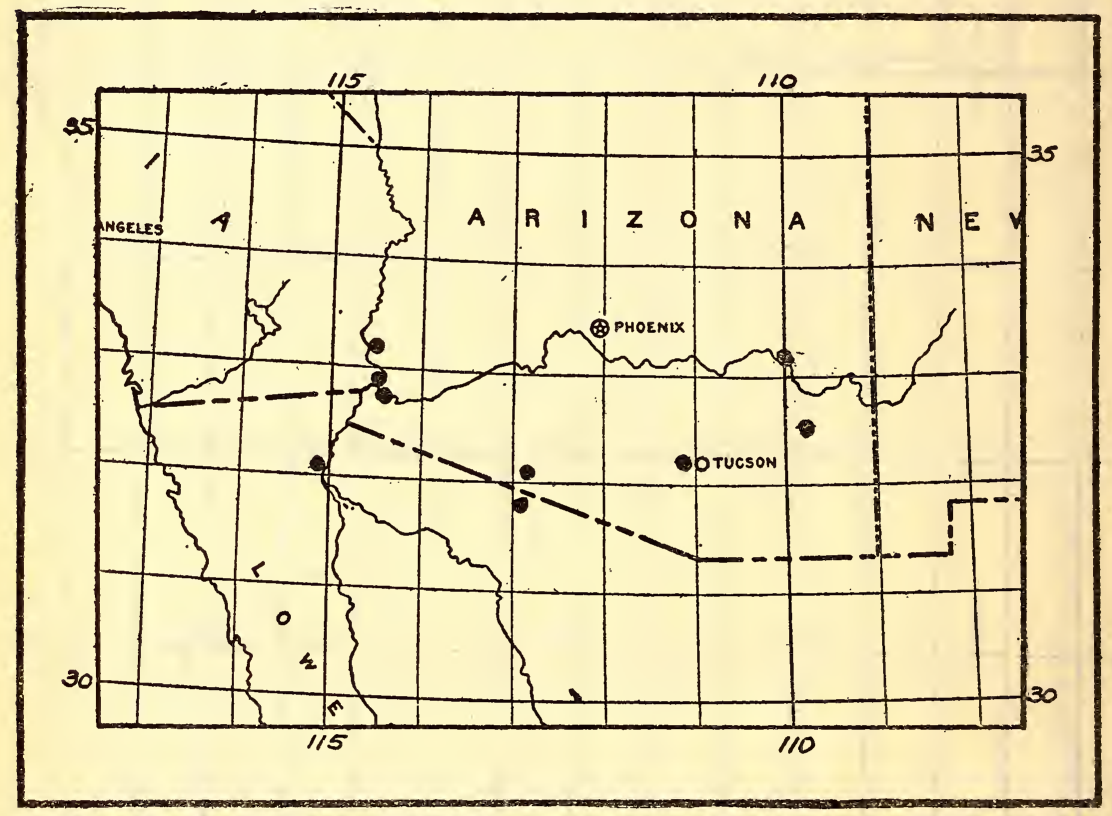

Fig. 16.-MAP SHOWING LOCALITY RECORDS FOR LAMPROPELTIS GETULUS YUMENSIS.

this condition very soon changes into that typical of boytii; that is, the white spreads over all of the scale, producing rings of continuous white. Westward, however, the pattern of yumensis is retained. In the vicinity of Yuma the light rings are often heavily suffused with brown. A specimen from near the mouth of the Colorado River, on the west side (Volcano Lake), is still typical of yumensis.

It will be of interest, in connection with what is known of the incomplete development of the pattern of the young of holbrooki, and its possible ancestral significance, to learn whether the young of yumensis are entirely like the adults in the degree of basal shading of the dark scales. Only three young specimens are now available. One from Tucson looks more like boylii, than any of the adults, but 
the white scales are nevertheless basally shaded with brown, and this condition is evident on many of the ventral plates. A young one from Fort Grant, Arizona, not far south of the range of typical boylii, is indistinguishable from the latter species, and is identified as yumensis only on locality. One from Fort Yuma is typical of yumensis in every respect. The evidence is of course inconclusive, but favors the view that the young are like the parents. This will be of interest in connection with the frequently noted fact that the young of conjuncta are not like the adults, but like boylii. This is in support of the distinctness of yumensis from conjuncta, and of the derivation of the latter from boylii instead of from yumensis.

A dark subocular spot originates in this form on the upper labials. In typical splendida the head is nearly all black, but across the center of each labial there is a narrow vertical band of white. Westward this band widens until the labials appear white with dark mutual borders. But beneath the eye there is a strong tendency for the black pigment adjacent to the suture between the third and fourth upper labials to be retained, or, if lost, to be recovered. The result is the conspicuous dark subocular spot characteristic of yumensis, boylii, californiae, and conjuncta. Some specimens, however, from the vicinity of Yuma have been subject to such a general increase in pigment that this spot is not recognizable.

In brief, then, it appears that yumensis is not an intergradational condition between splendida and boylii, nor yet, as will be more clearly brought out further on, is it identical with conjuncta of the Cape Region of Lower California, but a recognizably distinct form having a definite range that lies between the ranges of boylii and splendida, and intergrading with both of these forms where their ranges meet its own. 


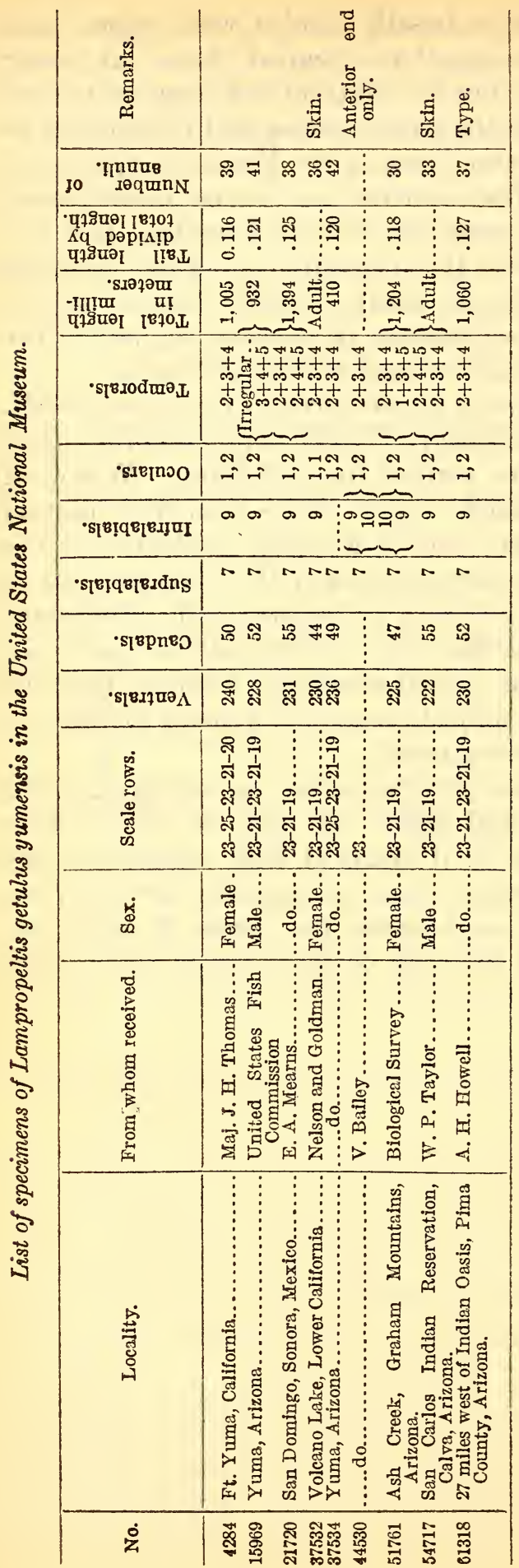


LAMPROPELTIS GETULUS BOYLII (Bsird and Girard).

MILI SNAKIF; BOTLE'S KING SNAKE; BLACK AND WHITE KING SNAKE.

Fig. 27.

1853. Ophibolus boylii BAIRD and Grrard, Cat. N. Amer. Rept., pt. 1, Jan., p. 82 (type locality, El Dorado County, California; typo, U. S. Nat. Mus., no. 1698; Dr. C. C. Boyle, collector).-BArRD, U. S. and Mex. Bound. Surv., 1859, p. 20; Pacif. R. R. Surv., vol. 10, pt. 3, no. 1, 1859, pl. 30, fig. 57; same, vol. 10 (Williamson's Route), pt. 4, no. 4, 1859, p. 11.Cope, Proc. Acad. Nat. Sci. Philadelphia, 1866, p. 305.-Lampropeltis boylii, same, 1860, p. 255.-Cooper, Proc. California Acad. Sci., vol. 4, 1873, p. 79.-Stejneger, N. Amer. Fauna, no. 7, pt. 2, 1893, p. 204.Van Denbungh, Proc. California Acad. Sci., ser. 2, vol. 5, 1895, p. 1006; Proc. California Acad. Sci., ser. 2, vol. 5, pt. 3, 1896, p. 1006; Occ. Papers California Acad. Sci., vol. 5, 1897, p. 169.-McLurs, Coll. Rept. W. Coast U.S., 1899, p. 11.-MEEK, Field Columb. Mus. Publ., no. 104, vol. 7, no. 1, 1906, p. 15.-Grinnell and Grinnell, Throop Inst. Bull., no. 35, 1907, p. 41.-Grinneld, Univ. California Publ. Zool., vol. 5, no. 1, 1908, p. 165.-Van Denburgh, Proc. California Acad. Sci., ser. 4, vol. 3, 1912, p. 150.-Van Denburgh and Stevin, Proc. California Acad. Sci., ser. 4, vol. 3, 1913, p. 415.-Camp, Univ. California Publ. Zool., vol. 12, no. 17, 1916, p. 531.-РемвеRтоN, Condor, 1916, p. 233.Grinnelu and Camp, Univ. California Publ. Zool., vol. 17, no. 10, 1917, p. 186.-Bentley, Copeia, no. 75, 1919, p. 90.-Coronella boylii JAN, Arch. Zool. Anat., vol. 2, fasc. 2, 1863, pp. 238, 246.

1853. Coronella balteata Halloweld, Proc. Acad. Nat. Sci. Philadelphia, vol. 6, p. 236 (type locality: California); Pacif. R. R. Surv., vol. 10, pt. 4, no. 1, 1859 , pp. 14, 24, pl. 5 .

1863. Coronella pseudogetulus JAN, Arch. Zool. Anat., vol. 2, fasc. 2, pp. 238, 247. 1865. Coronella getulus pseudogetulus JAN, Icon. Gen. Ophid., livr. 12, pl. 6, fig. $2(a-g)$.

1875. Ophibolus getulus boylii Cope, Bull. U. S. Nat. Mus., no. 1, p. 37.-YARRow, Rep. Geog. and Geol. Explor. Surv. W. 100th Mer., vol. 5, chap. 4, 1875, p. 538.-Coues, same, chap. 5, 1875, p. 618.-Coues and Yarrow, Bull. U. S. Geol. and Geog. Surv. Terr., vol. 4, art. 11, 1878, p. 283.YARrow, Bull. U. S. Nat. Mus., no. 24, 1882, p. 92.-Cope, Proc. Acad. Nat. Sci. Philadelphia, 1883, p. 29.-Garman, Mem. Mus. Comp. Zool., vol. 7 , no. 3 , pt. 1,1883 , pp. 69 , 157.-Townsend, Proc. U. S. Nat. Mus., vol. 10, 1887, p. 239.-Cope, Proc. U. S. Nat. Mus., vol. 14, 1891, p. 613; Rep. U. S. Nat. Mus. for 1898, 1900, p. 919, fig. 230.-Brown, Proc. Acad. Nat. Sci. Philadelphia, 1901, p. 78.-Ditmars, Reptile Book, 1907, pp. 341, 363, pl. 103, fig. 9, pl. 108 (lower fig.); Rept. of World, 1910, p. 271.

1894. Coronella getula (part) Boulenaer, Cat. Snakes Brit. Mus., vol. 2, p. 198. 1913. Lampropeltis boylei Atsatr, Univ. California Publ. Zool., vol. 12, no. 3, p. 41. 1917. Lampropeltis boylii boylii Stejneger and BArBour, Check List, p. 87.

Description.-The scutellation of the Pacific Coast representative of the getulus group may be defined as follows: Ventral'plates, 206 to 254; caudals, 41 to 62 ; supralabials, 7 , infrequently 8 ; infralabials 9 , often 10; oculars, 1 and 2; temporals, $2+3+4$; posterior chin shields only about two-thirds as long as the anterior, parallel, and separated

186550-21-Bull. 114-6 
by two small scales; loreal usually longer than high, less often about as high as long; scale rows on middle of body, 23 or 25 , formula usually $23-21-19$, or 21-23-21-19, often 23-25-23-21-19.

This is a somewhat smaller and slenderer form than the eastern representatives of the group. In proportions it is close to splendida. The tail varies from 0.107 to 0.145 of the total length (average for males, .130, for females, .120). The largest specimen examined was from Tehama County, California, and measured $1,280 \mathrm{~mm}$; the next largest was $1,234 \mathrm{~mm}$., from "California."

The pattern is of white rings, 28 to 49 , often disposed more or less obliquely, and separated by a ground color of black or dark brown; the rings widen rather suddenly on the sides, from one to two scales on the middorsal line to three to six on the first row of scales, and cross the abdomen as broad bands. In distinction from yumensis and conjuncta, the scales of the white rings are white to their bases. However, the basal shading, characteristic of these forms, may appear at almost any point in its range, and for identification in such cases study should be made of the pattern and scalation of the head (see Table of Comparisons, p. 77). The markings on the head are typically like those of yumensis, but further white spotting may be developed, particularly along the coast, and examples are not infrequent in which there is more white on the head than in conjuncta.

The copulatory organ may be described as follows: Bilobed; sulcus single, extending over one of the lobes, and ending in a small bare space; calyces strictly apical, fringes few, distinct or very short, passing into spines; latter close set, somewhat larger toward the base, covering from a third to less than half of the distal end of the organ, suddenly replaced by a few minute spines which soon disappear altogether, or which may not be present at all. A specimen from Washington County, Utah, shows a few pits as traces of the minute spines, but these are not evident at all in one from Overton, Nevada. Another from southern Nevada has the large spines passing rapidly, but not abruptly, into minute spines, and the latter then soon disappearing. Specimens from Palo Alto show minute spines only very close to the large ones.

The dentition of boytii is as follows: Maxillaries 13 or 14 , subequal except the last two or three which are slightly stouter; mandibulars, 14 or 15 , longer in front, diminishing in size posteriorly; palatines, 8 to 10 , usually 9 , subequal, a little larger than the pterygoids; latter 13 to 17 , diminishing posteriorly.

Although there is usually no difficulty in correctly identifying specimens of boylii, yumensis, and conjuncta, nevertheless puzzling individuals will be found. Adult examples of yumensis and conjuncta need never be confused, but specimens of boylii can be found to bridge all the distinctions. If the locality of a specimen is unknown, 
then reliance should be placed on the totality of characters. Adult specimens which show no basal shading of the scales of the white rings can be only boylii. If basal shading is present, boylii may be distinguished from conjuncta by the fact that the infralabials are usually 9 instead of 10 , the frontal plate has usually a right or obtuse posterior angle instead of an acute one, and its outline is distinctly pentagonal instead of nearly trigonal. However, too much reliance should not be placed upon these last two characters. If the number of ventral plates is well above the average for yumensis and conjuncta, the specimen is apt to be a boylii. Adult examples of boylii may resemble yumensis, but if the head is much spotted posteriorly and particularly if the white bars across the prefrontals are strongly convex behind and occupy more than half their area, it is a boylii.

The accompanying table should prove useful in placing doubtful examples, but since the distribution of these forms is fairly well known, specimens may, with safety, be referred to their proper form by locality only.

Table of comparisons.

\begin{tabular}{|c|c|c|c|}
\hline Character. & Yumensis. & Boylii. & Conjuncta. \\
\hline Infralabials.. & Usually $9 . .$. & Usually $9 . .$. & Usually 10 \\
\hline Frontal......... & Pentagonal...... & Pentagonal........ & More nearly trigonal. \\
\hline Posterior a & Right or obtuse. & Right or obtuse... & Us u a ll y distinctively \\
\hline Postero-lateral angle.. & Obtuse..... & Obtuse....... & Nearly or quite $180 \mathrm{de}$. \\
\hline $\begin{array}{l}\text { White rings: } \\
\text { Adults................. }\end{array}$ & $\begin{array}{l}\text { White scales always } \\
\text { dark brown at base. }\end{array}$ & $\begin{array}{l}\text { White scales only oc- } \\
\text { casionally dark brown }\end{array}$ & $\begin{array}{l}\text { grees. } \\
\text { White scales always dark } \\
\text { brown at base. }\end{array}$ \\
\hline Young........ & Usually liko adults....... & $\begin{array}{l}\text { No basal shading of } \\
\text { white scales. }\end{array}$ & $\begin{array}{l}\text { No basal shading of white } \\
\text { scales. }\end{array}$ \\
\hline $\begin{array}{l}\text { Head: Parietals, frontals, } \\
\text { supraoculars, s e c o nd } \\
\text { and third rows of temp- } \\
\text { orals: Adults and young. }\end{array}$ & $\begin{array}{l}\text { White spots very rc- } \\
\text { stricted or absent. }\end{array}$ & $\begin{array}{l}\text { Usually like yumensis, } \\
\text { except in southern } \\
\text { California and north- } \\
\text { ern lower California, } \\
\text { where it is usually like } \\
\text { conjuncta. }\end{array}$ & $\begin{array}{l}\text { Numerous white spots or } \\
\text { marks on these plates. }\end{array}$ \\
\hline $\begin{array}{l}\text { White bars on prefrontals: } \\
\text { Adults and young. }\end{array}$ & $\begin{array}{l}\text { Usually simple bars oc- } \\
\text { cupying less than half } \\
\text { tho area of the scute. }\end{array}$ & $\begin{array}{l}\text { Usually rounded or an- } \\
\text { gular posteriorly, and } \\
\text { occupying more than } \\
\text { half the area of the } \\
\text { scute. }\end{array}$ & Like boylii. \\
\hline
\end{tabular}

Habitat and habits.-Although this form has been known since 1853 there is very little recorded about its habits and habitat preferences. Townsend $(1887,239)$ refers to it as "not uncommon on the Lower McCloud, in damp places near the river." Hallowell $(1859,14)$ says of it, "found in valleys and open prairies, very abundant, often killed by travelers, and found lying on the roadside." A specimen from Marin County, California, bears the note "by roadside in shade." Merriam reports it (Stejneger, 1893, 204) as follows: "Found in the valley of the Lower Muddy near an abandoned mill at Overton, Nevada; where several were secured in dense thickets of Atriplex torreyi. About dark they began to emerge from these retreats, 
making a great noise in crawling over the dry leaves, and were soon found in the open." Van Denburgh (1897, 171-2) says "The black and white king snake is most abundant where the country is covered with chaparral and where small streams are numerous." Grinnell and Grinnell (1907, 41), reporting for Los Angeles County, California, say "it is one of our least common snakes," and that they have "met with it only in the upland regions bordering the foot hills." That it occurs in the foot hills, along streams and small canyons throughout its range, and not in the high mountains and on the open deserts, seems evident from the material at hand and the few references in the literature.

Its disposition Hallowell reports $(1859,14)$ as "timid, always endeavoring to escape its pursurers." Van Denburgh $(1897,172)$ says "it is usually very gentle, but sometimes fights its captor most fiercely, rarely however, being able to draw blood with its small teeth."

Concerning its food the last-named author (1897, 172) writes "I have twice found it swallowing the contents of quails' nests, and once observed one crawling along the ground and looking up into the bushes for nests of small birds. Several times while I watched, its quick eyes detected nests 3 or 4 feet above it, but although the snake immediately climbed up to these, it did not obtain a meal, for the nests which it examined had been abandoned by their builders or robbed by some earlier comer.

"While I was watching a man spade up a small plot of ground, he killed two gophers (Thomomys) and threw them a few feet away. A few minutes later a snake of this species appeared, went directly to the spot where the gophers lay side by side, and swallowed first the adult and then the half-grown one. It took no notice of our presence, and after completing its hearty meal disappeared in the direction whence it had come."

A specimen in the collection of the University of California is preserved in the act of swallowing a rattlesnake about 2 feet long.

So far as known, therefore, boylii, in disposition, food, and habitat preferences, is very much like getulus, the only other member of the group that is at all well known.

Range.-This form is known from Cape San Quintin and San Pedro Martir Mountain in Lower California, north in California to the forty-first parallel, and thence southeastward across western and southern Nevada and southwestern Utah to the latitude of Phoenix in Arizona. It appears to be generally distributed throughout the range, except for the driest deserts and the mountains above 5,000 feet. Altitudes at which specimens have been taken are frequently recorded on the accompanying labels and in the literature. The highest records are for 4,500 feet; one specimen was taken by Mr. Frank Stephens in the Providence Mountains, California, and another, 
in the Brooklyn Museum, was taken at Bellevue, Washington County, Utah. Other altitude records are as follows: Hemet Lake, San Jacinto Mountains, 4,400 feet; Wild Rose Spring, Panamint Mountains, 4,060 feet; Hackberry, Arizona, 3,500 feet; Grand Canyon of the Colorado, 3,000 feet; south of Mount Sanhedrin, Mendocino County, California, 2,340 feet; base of the San Jacinto Mountains, 2,200 feet and 1,700 feet; Santa Ana Canyon, west side of San Bernardino Mountains, 2,000 feet; Eldorado County, 2,000 feet; Jarupa Mountains, 1,200 feet; Turtle Mountains, 1,000 feet; Sonoma County, California, 1,000 feet. No other specific records are for more than a thousand feet. Grinnell and Camp $(1917,186)$ record it as distributed "throughout the southern and central parts of the State [California], except on the high mountains (above 6,000 feet altitude)." But, as noted above, the highest actual record is 4,500 feet. Since snakes are found in California at much greater altitudes than this, notably the coral king snake, multicincia, the absence of boylii from the mountains must be considered as the expression of a habitat preference or perhaps restriction, and this is quite in accord with what is known of the other members of the group.

Concerning its ability to live in the deserts, less is known. From the desert region between Yuma and Tucson only yumensis has been taken. There is no record of either form from the Mohave Desert or Death Valley. The Death Valley expedition of the United States Biological Survey collected in these and other desert regions of the vicinity but obtained boylii only in the vicinity of streams and at the bases of mountains.

Besides the localities represented by specimens in the United States National Museum, specimens belonging to other museums have been examined as follows: In California-Alameda County, Asuza and Bairdstown (Los Angeles County), Banning (Riverside County), Beveridge Canyon on east slope of Inyo Mountains, Cabazon (Riverside County), Campo (San Diego County), Cazadero and El Varano (Sonoma County), Forrest Lake (San Joaquin County), Gadwall, (Merced County), near Guerneville (Sonoma County), Hemet Lake (San Jacinto Mountains), Irishes (Mendocino County), Jarupa Mountains, La Puerta Valley (San Diego County), Los Angeles, near Mount Hamilton (Santa Clara County), Mount Sanhedrin (Mendocino County), Needles and Ontario (San Bernardino County), Owens Valley (Inyo County), Pasadena (Los Angeles County), Piru (Ventura County), Pleasant Valley (Mariposa County), Redondo Beach (Los Angeles County), Riverside, Rumsey (Yolo County), Sal Anselmo (Marin County), San Jacinto, Springs (San Luis Obispo County), Tehachapai Mountains (Kern County), Tehama (Tehama County), Turtle Mountains, Vacaville (Solano County), Vallecito and Vallecito Creek (San Diego County), Vincent Creek, Wheatville 
(Fresno County), Wild Rose Spring (Panamint Mountains); in Arizona-Cave Creek (Maricopa County), Fort Verde (Yavapai County), Cottonia (Mohave County); in Utah-Bellevue (Washington County); in Nevada-Current school district in Nye County; in Lower California-Cape Colnett, Cape San Quintin, San Salado, and the foothills of San Pedro Martir Mountain.

Published records for other localities are as follows: ArizonaDate Creek, 50 miles south of Fort Whipple (Coues, 1875, 618), Gila Desert (Baird, 1859, 20); California-Tujunga Wash, east of San Fernando (Grinnell and Grinnell, 1907, 41), Lower Santa Ana Canyon (Grinnell, 1908, 165), and the following records by Van Denburgh $(1897,171)$, Oakland, Mount Tamalpais, Camp Taylor, Santa Margarita, Healdsburg, Applegate; Nevada-St. Thomas (Clark County) (Van Denburgh, 1897, 171), Pahranagat Valley (Stejneger, 1893, 204), "El Paso Creek" and "Bernicia" (Hallowell, 1859, 14). In addition, the following localities in California are given on the authority of Mr. Carl L. Hubbs: Bed of the Nacimiento River near Jolon, Monterey County; road between San Luis Obispo and Avila, San Luis Obispo County; and near Fall Brook, San Diego County.

Variation.-In spite of similarity in general appearance throughout its range, boylii is very variable in all of its specific characters The range includes very diverse conditions of topography and climate. The long, high ridge of the Sierra Nevada extends from near its northern limits southeastward for nearly 500 miles, splitting the range into two sections - an east and a west. That this is a natural barrier to its east and west migration in this region seems fairly certain, and the Mohave Desert, just south of the Sierras, may perhaps continue the barrier where the mountains leave off-at least there is no record of a boylii from this desert, although it was found by the Death Valley Expedition in numerous other places.

Whether or not the Mohave Desert is or ever was a barrier to the westward migration of boylii, it is certain that this form must have obtained entrance to the Great Valley of California, either from around the south end of the Sierras or from the north. There is certainly no reason for excluding its entrance from the south, as Imperial and Riverside Counties offer no obstruction to yumensis from the lower Colorado region, and, as has already been brought out in the discussion of the latter form, yumensis undoubtedly intergrades with boylii in southern California.

In the north the situation is different. The Sierras continue to be a barrier to very near the northern limit of the form. That it is not adapted by nature to range much north of here is indicated by comparison with the northward distribution of its allies, holbrooki and getulus. The latter is not known north of the forty-first parallel, and that the former extends somewhat farther north is due to a more 
favoring topography. The present distinctness of the east and west sections of boylii, the availability of the southward route to the Great Valley, and the improbability of a northward one argue for the greater probability of the former route to northern and western California. This suggests the hypothesis that boylii was differentiated from yumensis in southern Arizona and spread from there north to Utah, Nevada, and eastern California, and that it was likewise differentiated from yumensis in southern California and from here migrated north throughout California west of the Sierras, and south to Cape Ventral

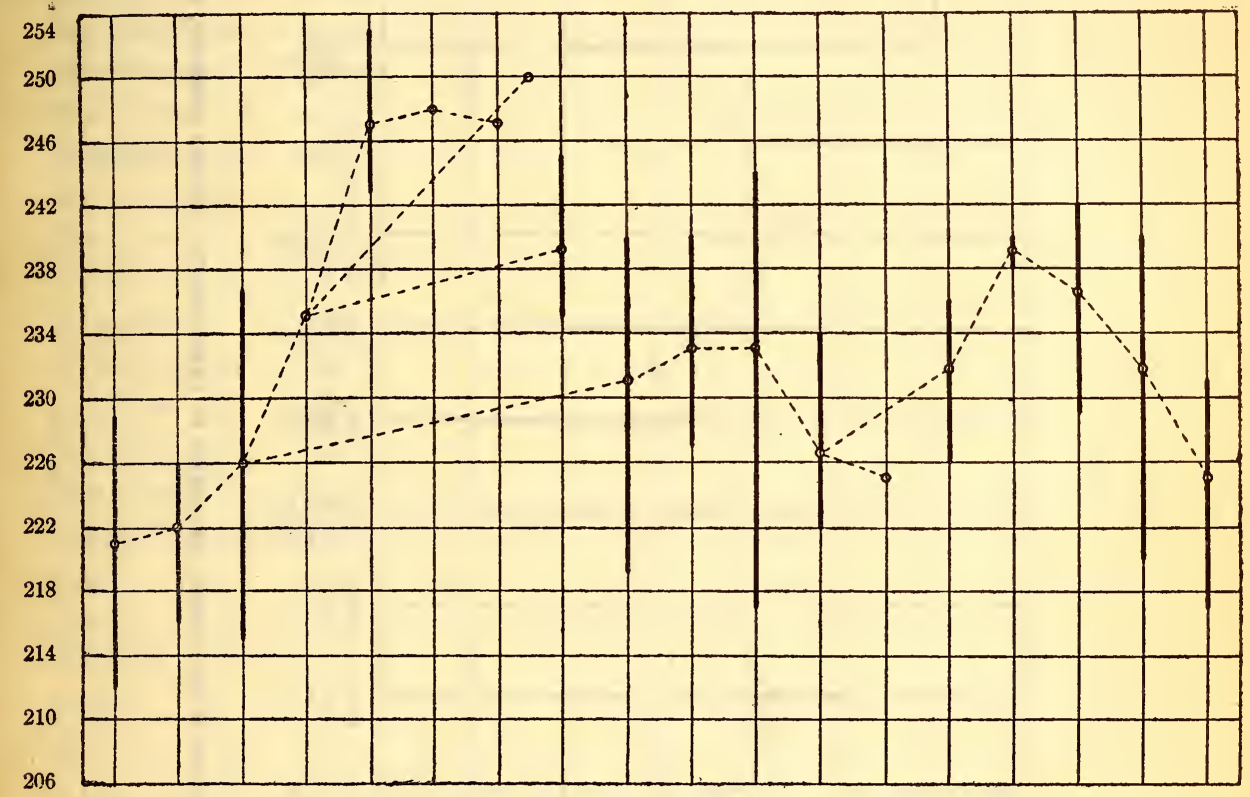

Tuc- Gra- Cen- Hack- Nee- Wild Inyo Over- Yu- San San Los Ava- Ft. Tu- Fres- San Shasson, ham tral berry, dles, Rose Mts., ton, ma, Diego, Ja- An- lon, Tejon, lare no, Fran- ta Ariz. Mts., Ariz. Ariz. etc., Spring, Calif. Nev. Calif. Calif. cinto, geles, Calif. Kern Co., Calif. cisco, Co.,

3 Ariz. $11 \quad 1$ Calif. Calif. 14 and 18 Calif. Calif. 2 Co., Calif. 15 Calif. Calif.

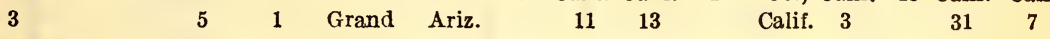

LOCALITIES, AND NUMBERS OF SPECIMENS.

Canyon, 9 Ariz.

3

1

Fig. 17.-Diagram showing geographic variation in Numbers of ventral plates in Lampropeltis Getulug YUMENSIS, AND L. G. BOYLII.

San Lucas. If there is any truth in this theory, there should be some confirmation from a study and comparison of variations in scutellation and pattern.

Examination of figures 17 and 18, on which have been plotted the extremes and averages of the ventral plates and the white annuli for numerous localities, brings out the following interesting relations: (1) All examples of boylii from western and northern Arizona, Utah, Nevada, and eastern California average much higher in number of ventrals and almost distinctly higher in number of rings than exam- 


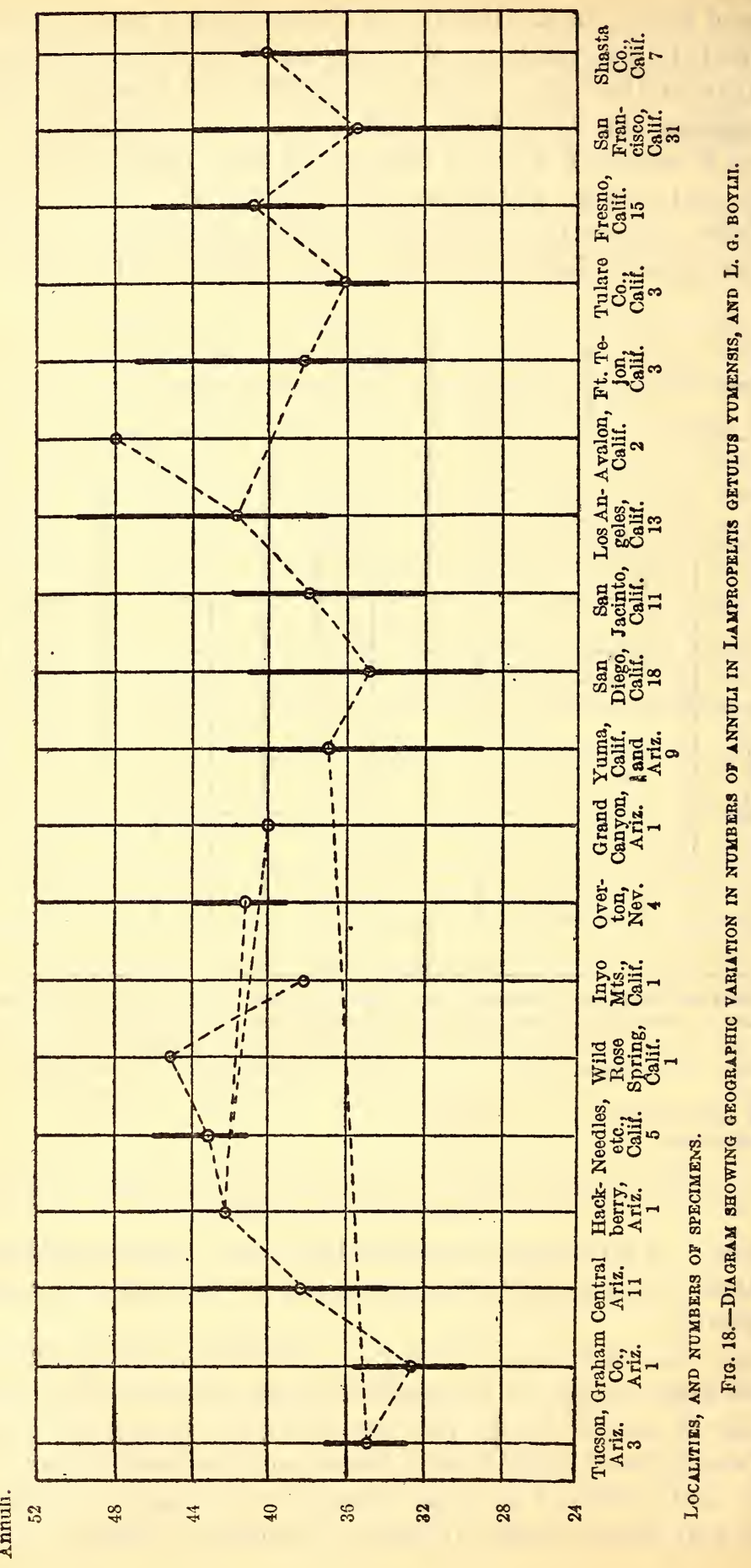


ples from western and southern California, and that these higher averages are bridged by a gradual change, through central Arizona, from yumensis in the south. (2) Proceeding west from Tucson there is an increase in number of ventrals to the average and approximate extremes characteristic of boylii west of the Sierras, while the number of rings, already the same as the average for boylii as soon as yumensis was differentiated from splendida, remains the same. The break from Yuma to San Diego County is slight. (3) North from here there is a progressive decrease in number of ventrals and increase in annuli to the vicinity of Los Angeles. Specimens from this region are sometimes distinguishable on sight by the evidently more numerous and narrower white bands-about one scale wide dorsally, and three on the first row of scales. It seems probable that these specimens are also more often brown than black, but all those we have examined were preserved. It should also be mentioned here that two examples from Santa Catalina Island are strikingly characteristic of those from the adjacent mainland-with a high number of rings and a low number of ventrals. (4) The vicinity of Los Angeles is doubtless west of the direct route of migration, as the normal number of ventrals and rings is exhibited by specimens from Kern County. (5) Thirty examples from the immediate vicinity of San Francisco show that the form is characteristically developed there, but leaves unexplained the high averages of the Fresno specimens. (6) A small number of specimens from the vicinity of Shasta County indicate that the tendency here is toward a decrease in number of ventrals and an increase in rings (like Los Angeles specimens). In fact, no specimen from here has even as many ventrals as the average for San Francisco, while the lowest number found here is not reached elsewhere in California, except by a single aberrant individual from San Diego County.

The situation with respect to the labials is shown by figure 19 . This indicates that on the west coast there is a uniform decrease in number of infralabials from south to north. In this there may be some significance. The change from Yuma to San Diego County is too slight to be very significant, but from this region northward a distinct retrograde tendency is evident attaining in northern California the 7-9 formula characteristic of the genus; southward there is an increase in the lower series that seems to have become distinctive in individuals from the Cape Region. Specimens from Arizona are too fow to indicate the tendency northward from the range of yumensis.

Further confirmation of the distinctness of the east section of boylii from the west is to be had by an examination of the pattern and markings. Specimens from the east section retain the head markings essentially as developed in yumensis. The white markings are 
increased in size but not in number. The head thus has a clean-cut, trim appearance with its well-defined black and white rings, and the latter are nearly always at least a scale and a half wide on the middorsal line. The eastern section, on the other hand, is much more variable, perhaps correlated with the much greater diversity in environmental conditions. Basal shading of the white scales occurs sporadically in all parts of its range, from Tehama County to San Diego. Frequently numerous additional white markings are developed on the head. As already noted, the number and width of the white rings is altered locally.

In brief, boylii is characterized east of the Sierras by a high average number of ventrals, by a somewhat greater number of rings, and by constancy in head and body pattern; while west of the Range it is characterized by a lower number of ventrals and a much greater

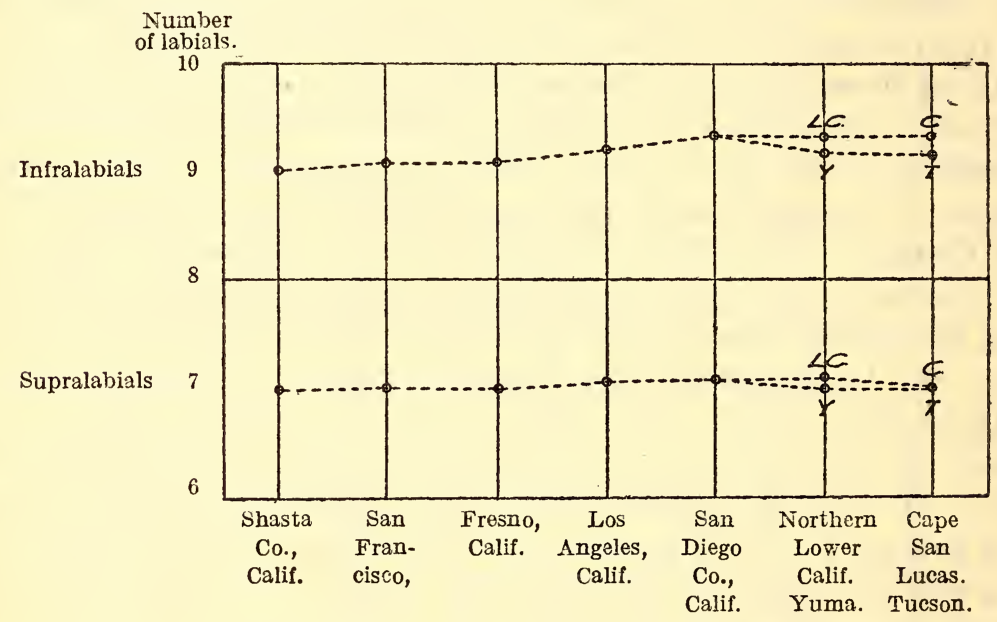

Fig. 19.-Diagram SHOWING GEOGRAPHIC VARIATION IN NUMBERS OF LABIAL PLATES IN LAMPROPELTIS GETULUS BOYLII, L. G. YUMENSI3, AND L. G. CONJUNCTA.

individual and local variation in other respects. It is not considered that these differences are of subspecific value because both sections of boylii were produced gradually by evolution from the same form and in the same way, and there has been developed no recognizably constant distinction in pattern, but it does seem to support strongly the view that the Sierra Nevada Mountains form a natural barrier that has forced boylii to develop in two distinct sections and that the Great Valley of California has been entered only from the south.

Affinities.-The preceding discussion of the variations and their significance leaves necessary here only a summary of such points as indicate its affinities.

The eastern section of boylii is related directly to yumensis, because (1) the distinction in number of ventrals and number of rings is 
bridged in central Arizona; (2) the head pattern shows no development not initiated in yumensis; (3) the change in coloration of the white rings is effected in the vicinity of the Florence River, the approximate boundary between the ranges of the two forms.

The western section of boylii approaches yumensis in southern California, and from here are developed new, although sometimes

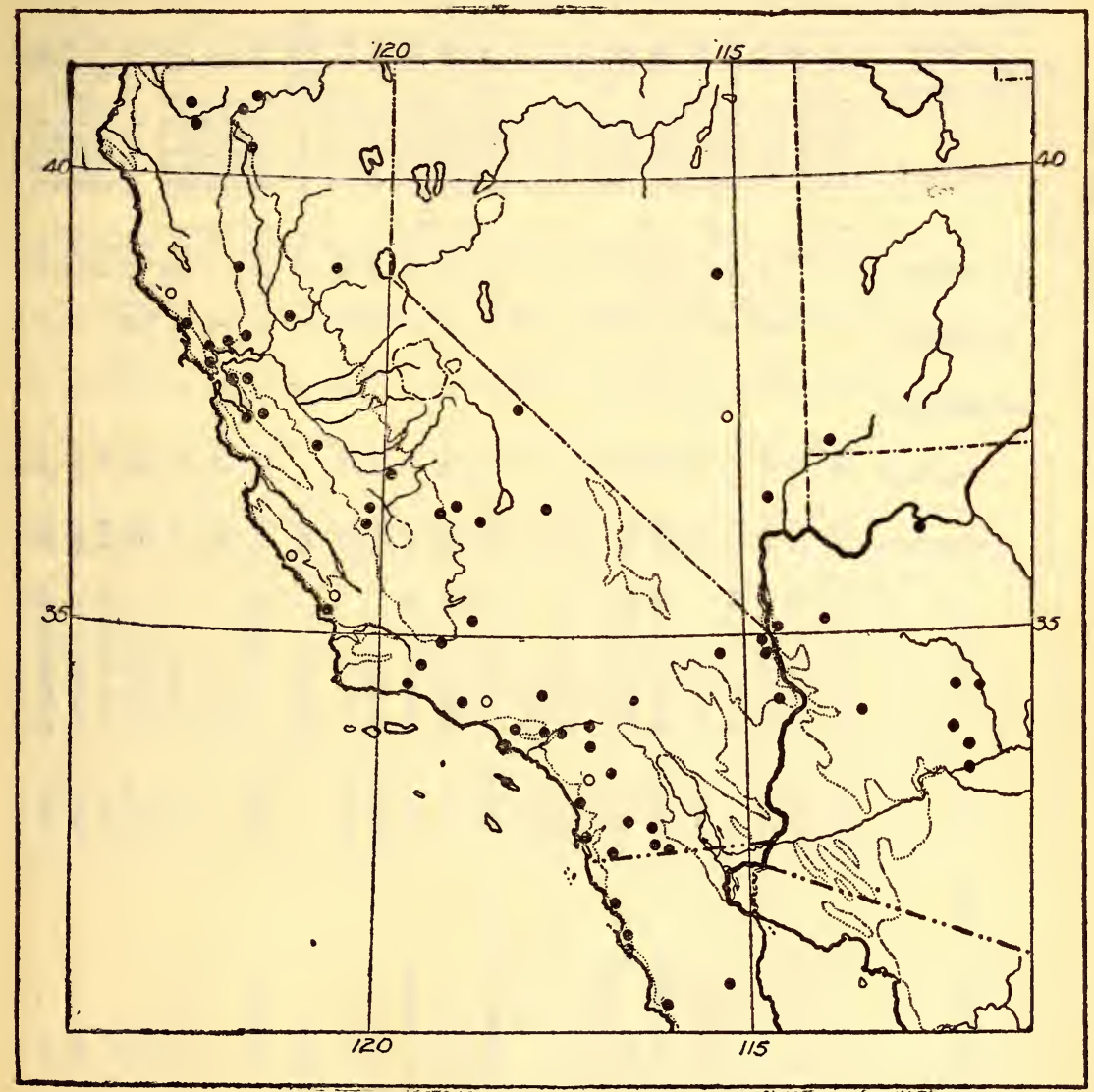

Fig. 20.-MAaP ShOWING LOCALITY RECORDS FOR LAMPROPELTIS GETULUS BOYLII.

minor and local changes, northward and southward. Comparison of variations and consideration of topography make it fairly evident that the Great Valley of California has been populated from the south and not from the east or from the north.

The relations of boylii to conjuncta and to californiae are discussed under those forms. 


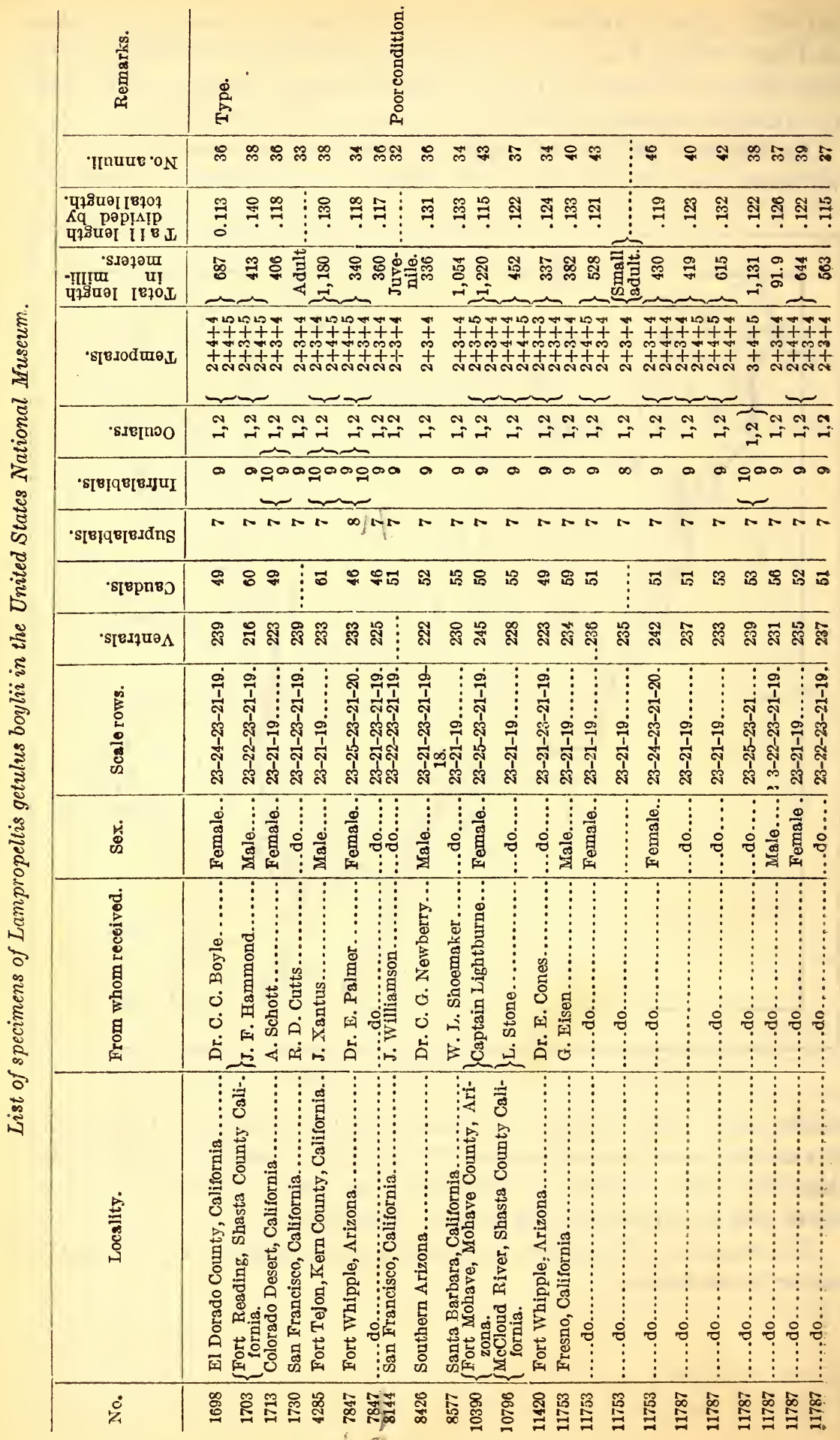




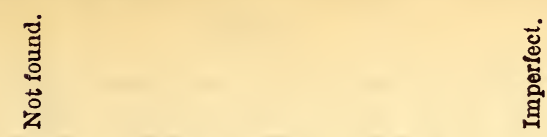

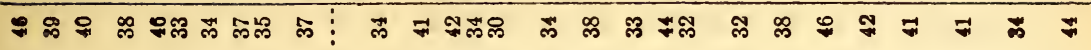

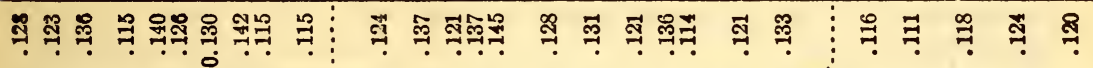

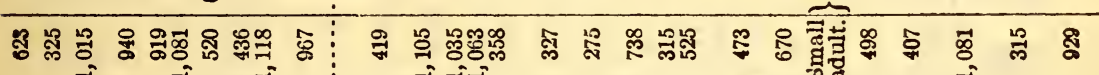

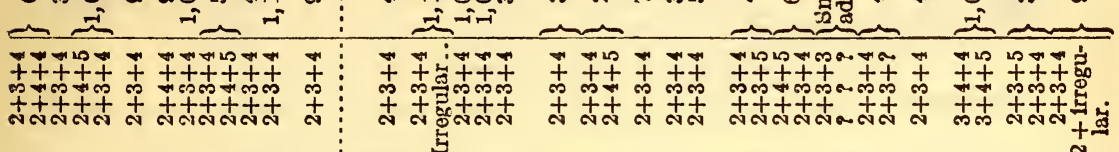

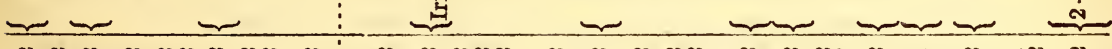
ก -i

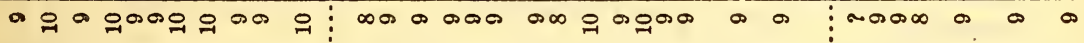

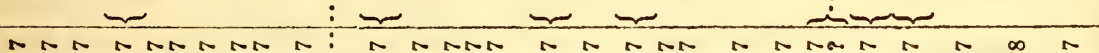

踇

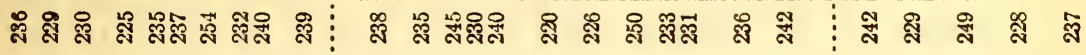

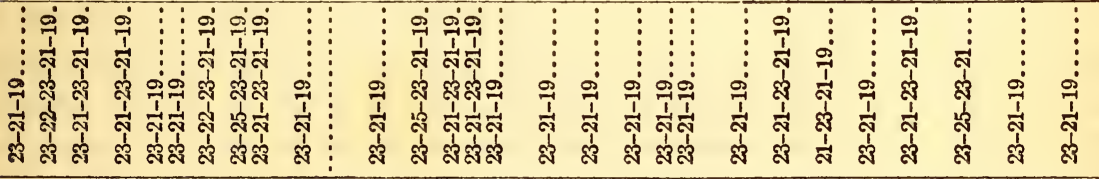

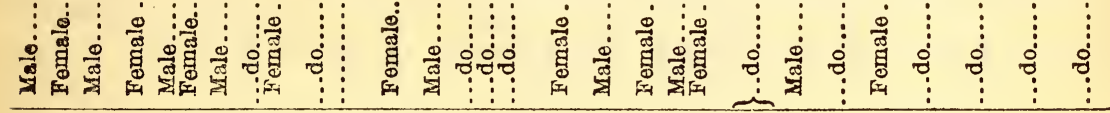

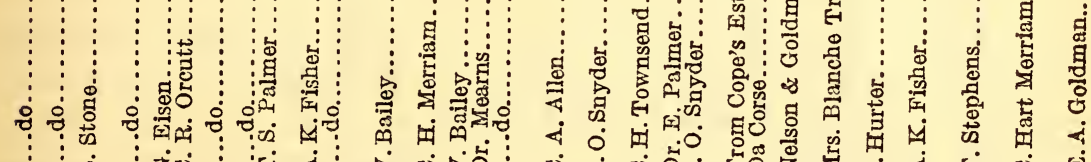
$\vdots \vdots \vdots 00$ :

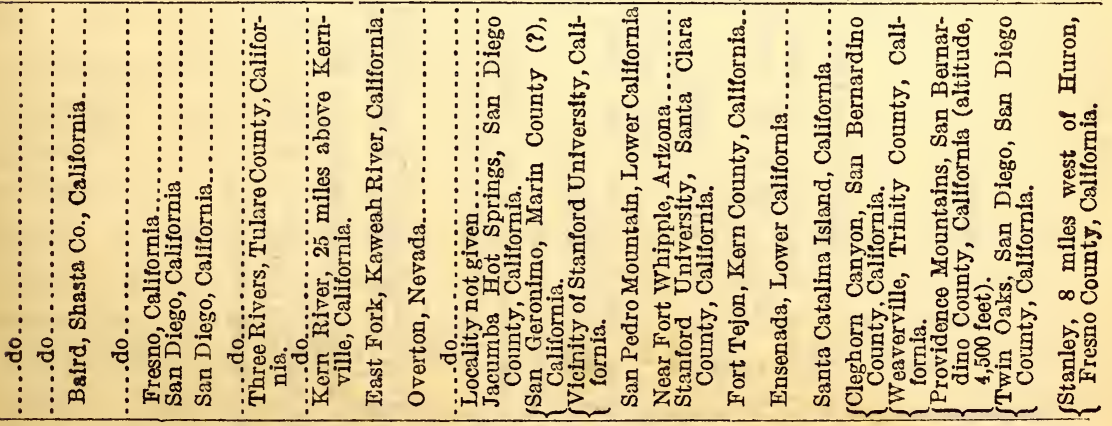

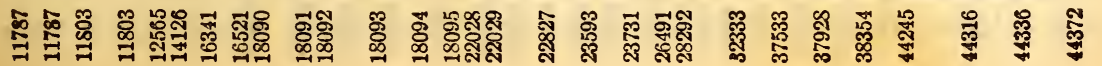


రే

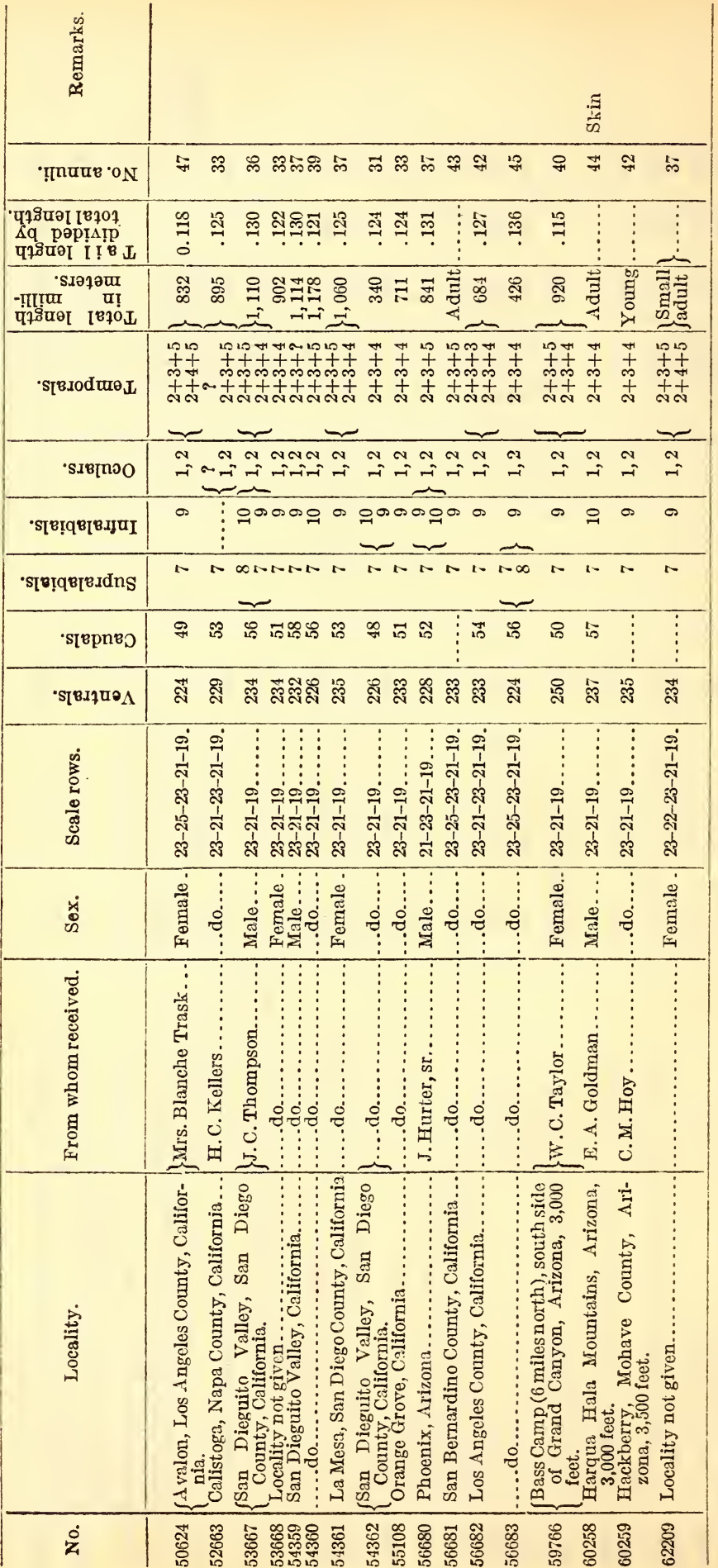


LAMPROPELTIS GETULUS CONJUNCTA (Cope).

Fig. 21.

1860. Lampropeltis boylii Cope, Proc. Acad. Nat. Sci. Philadelphia, p. 255.

1861. Lampropeltis boylii conjuncta Cope, Proc. Acad. Nat. Sci. Philadelphia, pp. 301, 305 (type locality, Cape St. Lucas, Lower California; cotypes (3), U. S. Nat. Mus.. no. 5288; J. Xantus, collector).-McLarn, Contr. Neotr. Herp., 1899, p. 5.-Stejneger and Barbour, Check List, 1917, p. 87.

1875. Ophibolus getulus conjunctus Cope, Bull. U. S. Nat. Mus., no. 1, pp. 37, 92 ; no. 32,1887, p. 78.

1882. Ophibolus getulus boylii (part) Yarrow, Bull. U. S. Nat Mus., no. 24, p. 92 (Cape St. Lucas, La Paz).-Belding, West Amer. Sci., vol. 3, no. 24, 1887, p. 98.-Cope, Rep. U. S. Nat. Mus. for 1898, 1900, p. 920.

1895. Lampropeltis conjuncta Van Denburgh, Proc. California Acad. Sci., ser. 2, vol. 5, pt. 1, p. 142.

Description.-Ventrals, 228 to 240 ; caudals, 48 to 54 (males, 53 to 54 ; females, 48 to 51 ); supralabials, 7 ; infralabials usually 10 , sometimes 9 or 11 ; oculars, 1 and 2 ; temporals normally $2+3+4$; posterior chin shields about half as long and half as wide as anterior, separated from each other by two small scales; loreal longer than high; frontal and parietals somewhat more elongate than in boylii and yumensis; scale rows on middle of body 23 or 25 .

In size and proportions this form is nearest like boylii; it seems, however, to be somewhat smaller and more slender, and to have a more elongate head. The tail varies from 0.115 to 0.132 of the total length (males, 0.122 to 0.132 , average 0.126 ; females, 0.115 to 0.122 , average, 0.119); more specimens may show that these limits are exceeded, and that the averages are practically the same as for the rest of the getulus group. The largest specimen examined measured $965 \mathrm{~mm}$.

The pattern is in general like that of boylii and yumensis, that is, white annuli on a dark brown or black ground color (fig. 21). Like yumensis, the white scales are edged basally with dark brown, except that the basal darkening is not always evident on some of the scales of the first one or two rows. None of the specimens examined shows any tendency for the brown to overspread all of the white, like some examples of yumensis from the Yuma region. Young specimens show no basal shading of the white scales. The rings are generally complete on the belly, but may be more or less imperfectly alternated; sometimes dark spots are developed on the belly in the white areas. Unlike yumensis and the great majority of specimens of boylii, the head, behind the prefrontals, is much lightened with white spots. The frontal usually has a roughly triangular white mark, or some fragments of this mark, located somewhat anteriorly. The supraocular has anterior and posterior white dots, which may be joined. The parietals have a lateral white dash, and on ten of the eleven specimens examined there is a white dot on each parietal near 
the common suture. There is a large white dot on each temporal of the first two rows and often on some of the temporals of the third rows. The light spots on the dorsal scales close behind the parietals are more extensively doveloped than is usual with boylii or yumensis. The anterior headplates have large light marks, as in boylii, and the mutual borders of the labials are dark; like this form, too, the subocular dark spot is well developed. Since the young specimens, as well as the adults, show these head markings, they may thus bo

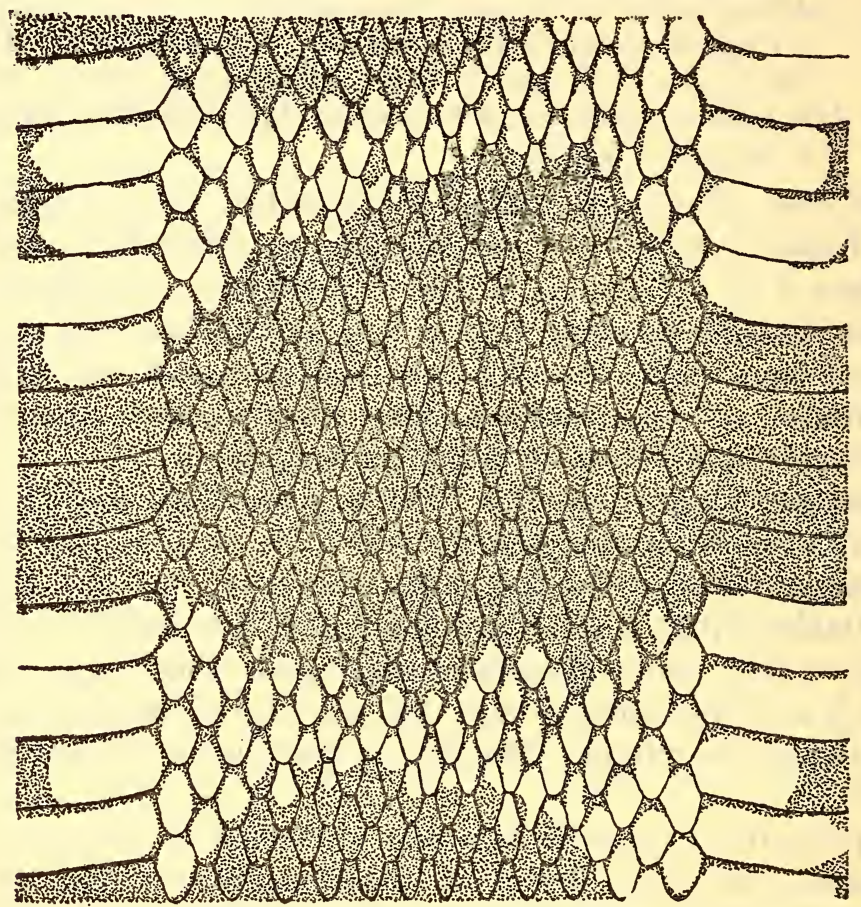

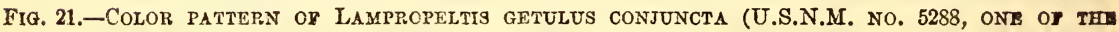
COTYPES). ABOUT $1 \frac{1}{3} \times$ NAT. SIZE.

usually distinguished from the young of boylii and yumensis, and the presence of 10 infralabials would be confirmatory.

The dentition is as follows: Maxillaries, 12 to 15, usually 13 or 14, subequal, the last two barely stouter than the preceding; mandibular, 14 to 16 , usually 14, longer in front, decreasing in size posteriorly; palatines, 8 to 11 , usually 9 , larger than the pterygoids; latter 15 to 18 , diminishing in size posteriorly.

The copulatory organ seems to be essentially like that of boylii. Minute spines are present only as traces just below the large ones; the fringes are very short, and perhaps slightly more numerous than in boylii. 
Habitat and habits.-Nothing is recorded on the natural history of this form.

Range.-Conjuncta is at present known only from the "Cape Region" of Lower California, from La Paz to Cape San Lucas. .

No published records for other localities than those given with the list of specimens have been noted.

Variation.-Little variation is to be expected in this form as at present known, and, as brought out in the description, the specimens examined are homogeneous in every respect. It will be noted that in general the scutellation is close to the mean for boylii, but differences are to be seen in the much greater frequency of ten infralabial plates than nine, in the more acute posterior angle of the frontal plate, in the more elongate parietals, in the narrower head, in the numerous light spots on the posterior portion of the head, and in the basal shading of the white scales, and it is on these points that this form is regarded as distinct.

Affinities.-Conjuncta has hitherto been considered as identical with what we have called yumensis. Cope first noticed the basal shading of the white scales $(1860,255)$ and later $(1862,301)$ called attention to the similarity between specimens from Cape San Lucas and Fort Yuma. He then based the name conjuncta on the specimens collected by Xantus at Cape San Lucas, and since that time they have been regarded as practically identical with those from the Yuma region. It is perhaps already plain why the separation has been made, but it may be well to summarize the situation. It is here held as certain that yumensis is derived directly from splendida, and that boylii is likewise derived from yumensis. It is believed, for the following reasons, that conjuncta is more closely allied to boylii than to yumensis.

1. The head markings of conjuncta are rather frequently developed in part, and sometimes in entirety, in specimens of boylii in various parts of its range, but especially in the San Diego region and in other localities along the coast, but not in any specimen of yumensis yet examined.

2. The ranges of conjuncta and yumensis apparently do not meet, but are separated in northern Lower California by a southward, and perhaps somewhat eastward extension of the range of boylii.

3. The similarity in the basal shading of the light scales of conjuncta and yumensis is not necessarily an indication of close affinity. Individuals of boylii from most diverse localities occasionally show this shading in as marked a form as it appears in conjuncta or typical yumensis. In boylii it must be regarded as an instance of reversion, a situation that is duplicated frequently in other members of the getulus group.

186550-21-Bull. 114-7 
4. The young of yumensis, with possible exceptions near the northern and western limits of its range, are like the adult, and if there had never been a boylii-stage between this form and conjuncta, the young of this latter would also be like the adult. But young examples of conjuncta are like boylii in the character of the white rings, their scales only with age attaining the basal shading, while in head pattern and in shape of frontal they are like a variation of boylii that is not uncommon in some coastal portions of its range, but not like any variations of yumensis.

The basal shading of the white scales of conjuncta, and the same condition as an individual or possibly local variation in boylii, is therefore to be regarded as a case of reversion to an ancestral type-analogous to the development of white centers or bases on the dark scales of floridana.

5. If, as noted elsewhere, nitida attained the Cape Region from southwestern California, there is then no reason why conjuncta may not have done so, too.

From the above considerations the following hypothesis is therefore presented to explain the derivation of conjuncta. Yumensis retained its identity in the desert region of southern Arizona and the head of the Gulf of California, but northward, westward, and perhaps southwestward, it developed into boylii. The latter migrated south into the desert of Lower California west of the mountains, and became altered, somewhere in the peninsula, into conjuncta, partially by the development of new characteristics, or the accentuation of certain variations, partially by reversion to the pattern of its desert ancestor, yumensis. 


\begin{tabular}{|c|c|}
\hline 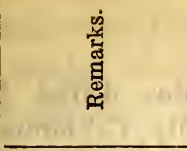 & 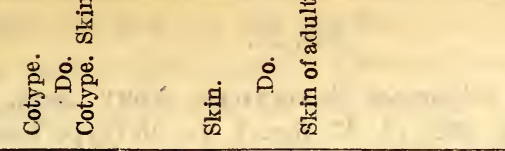 \\
\hline 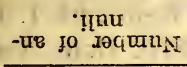 & 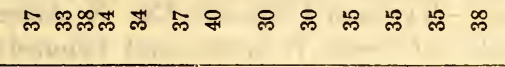 \\
\hline 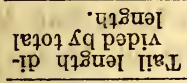 & 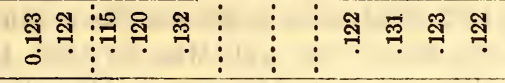 \\
\hline 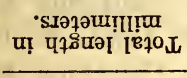 & 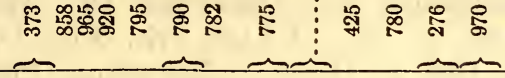 \\
\hline 's[ejodurelL & 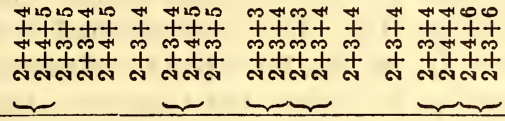 \\
\hline -siennoo & 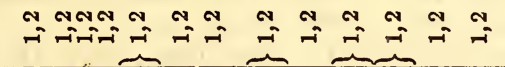 \\
\hline 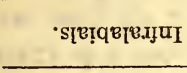 & 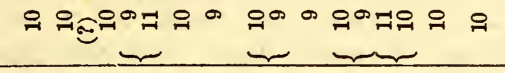 \\
\hline 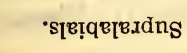 & 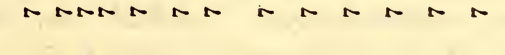 \\
\hline •sјерпео & 句 员 \\
\hline 's & 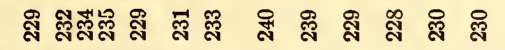 \\
\hline 总 & 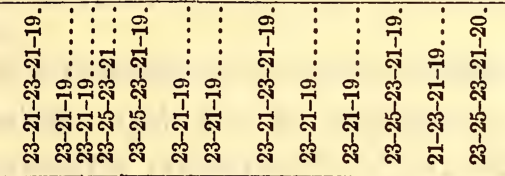 \\
\hline 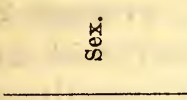 & 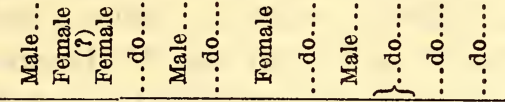 \\
\hline 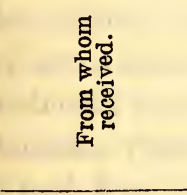 & 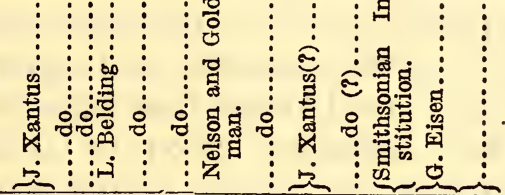 \\
\hline 灾 & 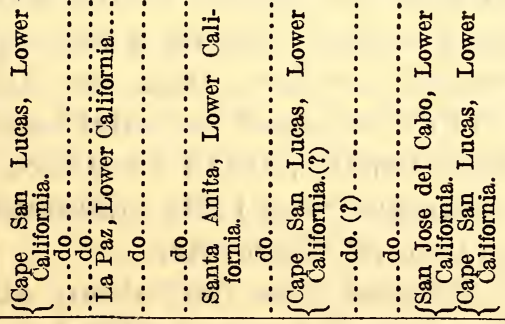 \\
\hline 字 & 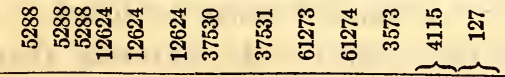 \\
\hline 兽 & 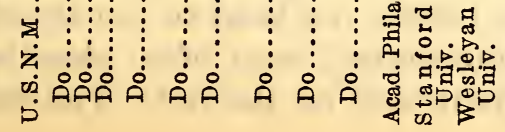 \\
\hline
\end{tabular}




\section{LAMPROPELTIS CALIFORNIAE CALIFORNIAE (Blainville).}

Fig. 22 .

1835. Coluber (Ophis) californiae Blainville, Nouv. Ann. Mus. d'Hist. Nat., Paris, vol. 4, p. 292, pl. 27, figs. 1, $1 a, 1 b$ (type locality, California; M. Botta, collector).-Baird and Girard, Cat. N. Amer. Rept., pt. 1, 1853, p. 153.-Coronella californiae Dumeril and Bibron, Erp. Gen., vol. 7, pt. 1, 1854, p. 623.-Ophibolus californiae Cope, Bull. U. S. Nat. Mus., no. 1, 1875, p. 37; Rep. U. S. Nat. Mus. for 1898, 1900, pl. 19, fig. 8.Lampropeltis californiae Van Denburgh, Occ. Pap. California Acad. Sci., vol. 5, 1897, p. 172.-McLain, Crit. Notes Coll. Rept. W. Coast United States, 1899, p. 11.-Van Denburgh, Proc. California Acad. Sci., vol. 3, 1912, pp. 149, 151.-Grinnell and CAMP, Univ. California Publ. Zool., vol. 17, no. 10, 1917, p. 187.-Stejneger and BARBodr, Check List, 1917, p. 87.-Hall and Grinnell, Proc. California Acad. Sci., ser. 4, vol. 9, no. 2, 1919, p. 54 .

1861. Coronella getulus californica JAN, Icon. Gen., Livr. 14, pl. 5, fig. 3.

1863. Coronella californica JAN, Arch. Zool. Anat., vol. 2, fasc. 2, pp. 238, 246.

1882. Ophibolus getulus eiseni YARRow, Proc. U. S. Nat. Mus., vol. 5, p. 439 (type locality, Fresno, California; type, U.S.N.M., no. 11788; G. Eisen, collector); Bull. U. S. Nat. Mus., no. 24, 1882, p. 94.

1883. Ophibolus getulus californiae Garman, Mem. Mus. Comp. Zool., vol. 8, pt. 1, p. 157.-Cope, Proc. U. S. Nat. Mus., vol. 14, 1891, p. 614; Rep.' U. S. Nat. Mus. for 1898, 1900, p. 922, fig. 231.-Brown, Proc. Acad. Nat. Sci. Philadelphia, 1901, p. 78.-Ditmars, Reptile Book, 1907, pp. $341,363$.

1894. Coronella getula (part) Boulenger, Cat. Snakes Brit. Mus., vol. 2, p. 198.

Description.-The scutellation of this form differs from that of boylii only in that the range of variation appears to be less. It may be described as follows: ventrals, 229 to 241, average 233; caudals, 47 to 60 (males 55 to 60 , average 57; females 47 to 53, average 50 ); supralabials, 7 , rarely 8 ; infralabials, 9 or 10 , sometimes 8 ; oculars 1 and 2 ; temporals, $2+3+4$; posterior chin shields much shorter and narrower than the anterior, and separated from each other by two small scales; loreal longer than high (rarely fused with the prefrontal); scale rows commonly 23-21-19 (although sometimes 25 rows are developed near the middle of the body, and less frequently a row is dropped on each side for a brief space anteriorly).

In size and proportions this form does not differ from boylii. The tail varies from 0.113 to 0.140 of the total length (males, 0.128 to 0.140 , average 0.133 ; females, 0.113 to 0.123 , average 0.120 ). The largest specimen examined was 1,233 millimeters long and was from Julian, San Diego County, California.

The pattern is very different from that of any other king snake. The ground color above is dark brown or black. A bright yellow or white stripe, about two scales wide, extends along the middorsal line from a few scales behind the head to the tip of the tail. This stripe is sometimes interrupted, most often close behind the head, in the region of the vent, and on the tail. The scales adjacent to 
the middorsal stripe are wholly dark brown or black, and this condition may obtain as low as the second or first row of scales, but the scales of the lower rows nearly always have white centers which are smaller dorsally and larger ventrally. These white centers may extend as high as the seventh row of scales, or no higher than the first. Usually the scales of the first row or two are all white. The belly is usually white or yellow with a development of black, laterally, on the posterior edges of the ventral plates. This black is increasingly pronounced posteriorly. The underside of the tail is almost constantly a uniform black or dark brown; when white occurs there, it is usually as a tapering midventral stripe extending back from the vent for a short distance.

The head markings are like boylii, except that numerous white spots are developed on the parietal, supraocular, and frontal plates, and on the anterior temporals, a condition which is not, however, uncommon in specimens of boylii from southern California, and which is developed likewise in conjuncta of the "Cape Region" of Lower California. The upper and lower labials are white or yellow with their common borders dark, except that, below the eye, on the third upper labial, or bridging the suture between it and the fourth, is the dark blotch characteristic of the western representatives of the getulus group.

Specimens from San Diego County usually have this typical and striking pattern (fig. 22): The conspicuous and often perfect dorsal stripe, the regular white spotting of the lower rows of scales, the nearly immaculate belly, and the uniformly black caudals. North of here the most constant feature of the pattern is the uniform dark color underneath the tail; the rest is extremely variable. This variation and its significance is discussed farther on.

The penial characters are practically identical with those of boylii. The following characters are derived from examination of alcoholic material: Apparently slightly bifurcate, the sulcus single, and extending over one of the lobes; calyces, with low fringes, restricted to the extreme distal end; the fringes soon becoming modified into spines which increase gradually in size toward the base; no spines unusually enlarged; about halfway toward the base of the organ the spines suddenly replaced by a few very small ones, which soon disappear entirely, leaving the basal portion smooth (or, in preserved specimens, wrinkled).

The dentition is as follows: Maxillary teeth, 13 to 15 , subequal, the posterior not enlarged; mandibular teeth, 14 to 15 , subequal; palatines, 9 to 10 (abnormally 11); pterygoids, 16 to 18 .

Habitat and habits.-Practically nothing is recorded on the natural history of this form. One specimen from Santa Ysabel, San Diego County, California, is recorded as having been taken "along a small 
stream." C. L. Camp refers to it as usually found in "brushy localities." It is highly desirable in connection with its alleged "mixing" with boylii, that all possible information bearing on its life history, habits, and habitat preferences be obtained and reported. In particular it would be desirable to obtain records and notes on complete broods of young. Breeding experiments, if they could be carried out, should yield valuable information.

Range.-This form is now known only from Fresno County, and from Los Angeles County south through San Diego County and

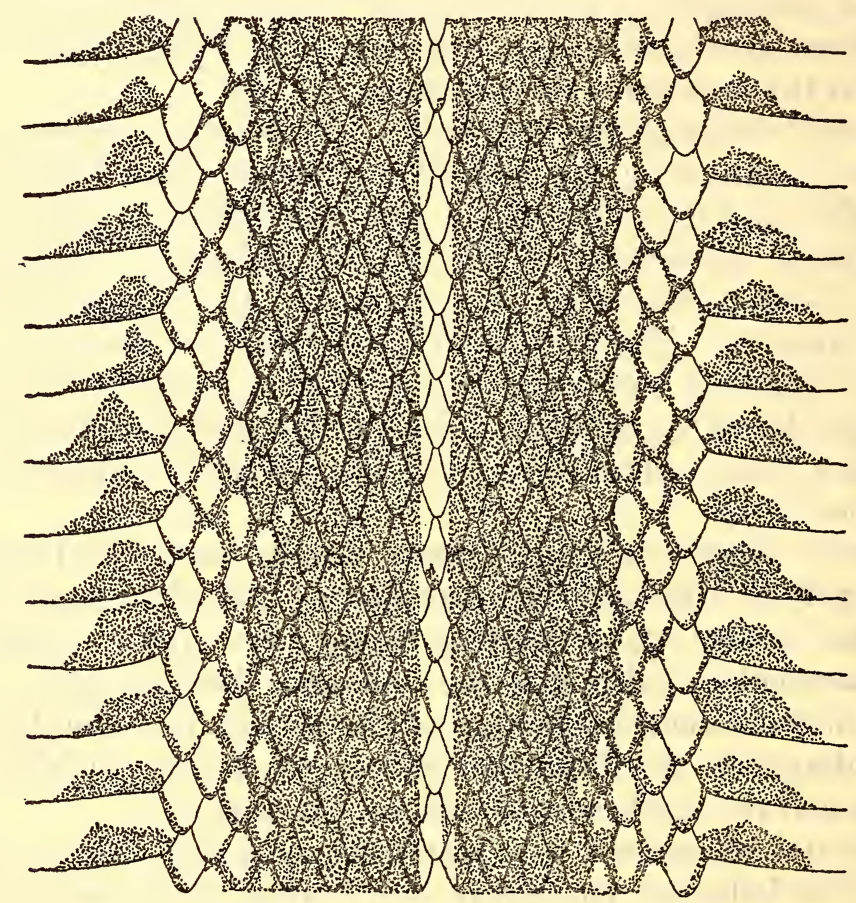

Fig. 22.-Color PATtern of LAMPROPELTIS CALIFORNIAE CALIFORNIAE (U.S.N.M. NO. 54363) FROM SAN Diego County, California. About $1 \frac{1}{3} \times$ nat. size.

just south of the international boundary. Further collecting will doubtless show its range to extend well south into Lower California, where an area of intergradation with nitida may be expected.

Published records for localities not included in the list of specimens examined are as follows: Waterman's Canyon, and Cuyamaca, California (Van Denburgh, 1912, 149, 151).

Variation.-Specimens are too few and variation too slight for the recognition of geographic differences in any characteristics except pattern. The latter, as already remarked, is very constant and distinctive in all specimens examined from San Diego County, but farther north it is extremely variable. The pattern of these 
more northern specimens is a variable mixture of the patterns of boylii and typical californiae. Frequently complete rings occur for a short distance behind the head and on the tail; more often these rings are continuous on the scales only; more commonly still they are reduced to short dorsal transverse bars. All stages occur between the latter and irregular or elongate middorsal blotches, short rounded spots, short and interrupted stripes, long and somewhat

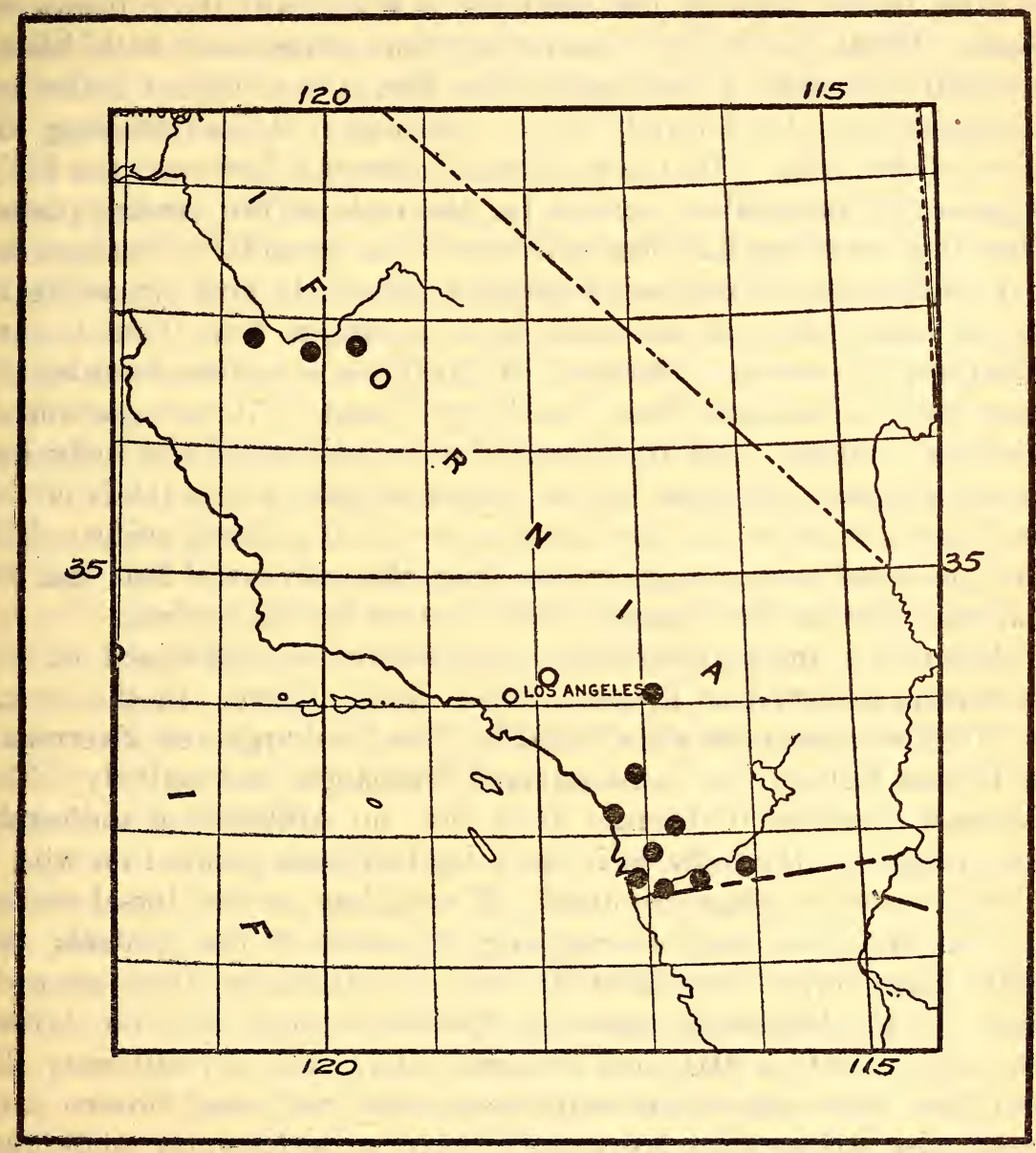

FIG. 23. - MAP SHOWING LOCALITY RECORDS FOR LAMPROPELTIS CALIFORNIAE CALIFORNIAE.

irregular stripes, and the continuous smooth stripe symmetrically placed on the middorsal line. Even in the last and most perfect case there is generally an enlargement at the anterior end of the stripe, not infrequently detached from the rest, which is obviously the homologue of the first complete ring of boylii. Most of the northern specimens have the underparts a uniform brown, although here too the ventral pattern of boylii may often be observed. Along 
with the progressive development of the dorsal stripe, the lateral pattern of californiae is gradually formed by a breaking up into spots of the lateral portion of the white rings, and the development of white centers in the dark scales between these areas.

The development of the coloration beneath, in californiae, appears to take place first by the formation of dark spots in the white portions of the belly. These enlarge until the whole ventral surface except for the lateral tips of the ventrals is a uniform dark brown or black. While the belly is becoming thus overspread with black, the white portions of the rings on the first row or two of scales are becoming extended laterally into a continuous stripe bordering the black of the belly. In the southern specimens, however, the belly is generally immaculate, except for the ends of the ventral plates. That this condition has been produced by a secondary development of a midventral white line, beginning anteriorly and increasing in length and width, is indicated by a specimen from San Jacinto (Stanford University collection, No. 1216), and is borne out by the majority of specimens from San Diego County. A few specimens, however, indicate that the immaculate condition of the belly has sometimes been produced by an extension onto the ventrals of the continuous white of the first row or two of the dorsal scales. The black in these cases disappears last from the midventral line, and the ventrals show no darkening of their postero-lateral borders.

Recently a most interesting confirmation was obtained of the specimens collected at Fresno in 1879 by G. Eisen. In the spring of 1918 two specimens were found by Van Denburgh and Evermann in Fresno County, at Jameson and Firebaugh, respectively. The Jameson specimen (California Acad. Sci., no. 41668) is as uniformly deep brown on the belly as if the color had been painted on with a brush; the white rings are nearly all complete on the dorsal scales; on the first row, and overlapping the ends of the ventrals, the white rings have fused laterally into a continuous stripe on each side. In the Firebaugh specimen (California Acad. Sci., no. 41700) the belly is only a little less uniformly dark; but dorsally only the first five white rings are continuous, the rest being broken into lengthwise stripes that are mostly short, except for the middorsal stripe which is prominent and practically continuous over nearly two-thirds of the posterior portion of body and tail. From Los Angeles County only a single specimen is known, and this is fully as aberrantly marked as any of the examples from Fresno County. Of the three from San Jacinto, one is rather aberrant, and the other two are as perfect as those from San Diego.

We may therefore summarize the situation by saying that (1) typical boylii is found throughout the region inhabited by cali- 
forniae, or its aberrant representatives, (2) typical californiae is found only south of Los Angeles County, (3) in San Diego County all the individuals are typical, (4) in Riverside County some are typical and some partly aberrant, and (5) north of Riverside County all are aberrant.

The specific identity of this form has been often questioned on account of (a) its identity in structural features with boylii, (b) the remarkable variation in its pattern and its evident approach in these variations to the pattern of boylii, $(c)$ its alleged rarity and apparently sporadic distribution, $(d)$ its occurrence wholly within the range of its nearest relative.

In support of its specific identity it may be remarked that (a) color pattern differences alone are often used in the differentiation of species. (b) There can be no doubt of its approach in pattern to boytii in the northern portion of its range, but typical boylii occurs here while typical californiae does not, indicating that this is not an instance of intergradation; and in the southern part of the range, both forms are common in the same localities and no aberrantly marked individuals are found. If interbreeding produces aberrant individuals, why is californiae not found in typical form in Fresno County, if boylii is; and if interbreeding takes place in San Diego County and Mendelian segregation is to explain the occurrence here of only the typical patterns of both forms, why should aberrant patterns be found in some other portion of the range? (c) Its rarity in the region of its typical development is not apparent; where it does seem to be rare it is variable. (d) The fact of its range lying wholly within that of its nearest relative is an unusual instance and in need of explanation.

Affinities.-As brought out in the discussion of variation, the affinities of this form are all with boylii. The only other member of the getulus group which ranges anywhere near californiae is yumensis. To assume yumensis to be the ancestor of californiae raises a question more difficult to answer than the one raised by assuming boylii to be the ancestor. It would then have to be explained how one species gave rise to two other species, which occupied the same region together, in competition, and both survived. Yumensis is however, excluded from direct relationship by the fact that the only region where its range is near that of boylii is the region where californiae is constant in its specific characters, and by the fact that the abberrations of californiae are toward boylii and are in a region that could never have been occupied by yumensis.

We have then the peculiar condition of a species being difierentiated within the range of its parent. If we say it is a mutation, we must explain why it is constant in pattern in the southern portion 
of its range and variable toward boylii in the northern. If we suggest that it was evolved from boylii by adaptation to a different habitat, we consider a possibility that may have no proved counterpart elsewhere, and that in this case has, as yet, no support from observation in the field.

The mutation theory, even though it rests upon no direct evidence in this case seems at present to offer the best exp anation of the origin of this form. On the basis of this theory the origin may then be hypothecated as follows: Californiae originated from boylii by mutation, somewhere in the Great Valley of California. It spread southward west of the Sierra Nevada Mountains and the deserts of southwestern California becoming more different from boylii toward southwestern California. From here it extended its range into Lower California to Cape San Lucas At some point in this peninsula, probably pretty well south, it became modified into the color variety nitida.

It will be recognized that more information is essential to an adequate explanation of californiae. 


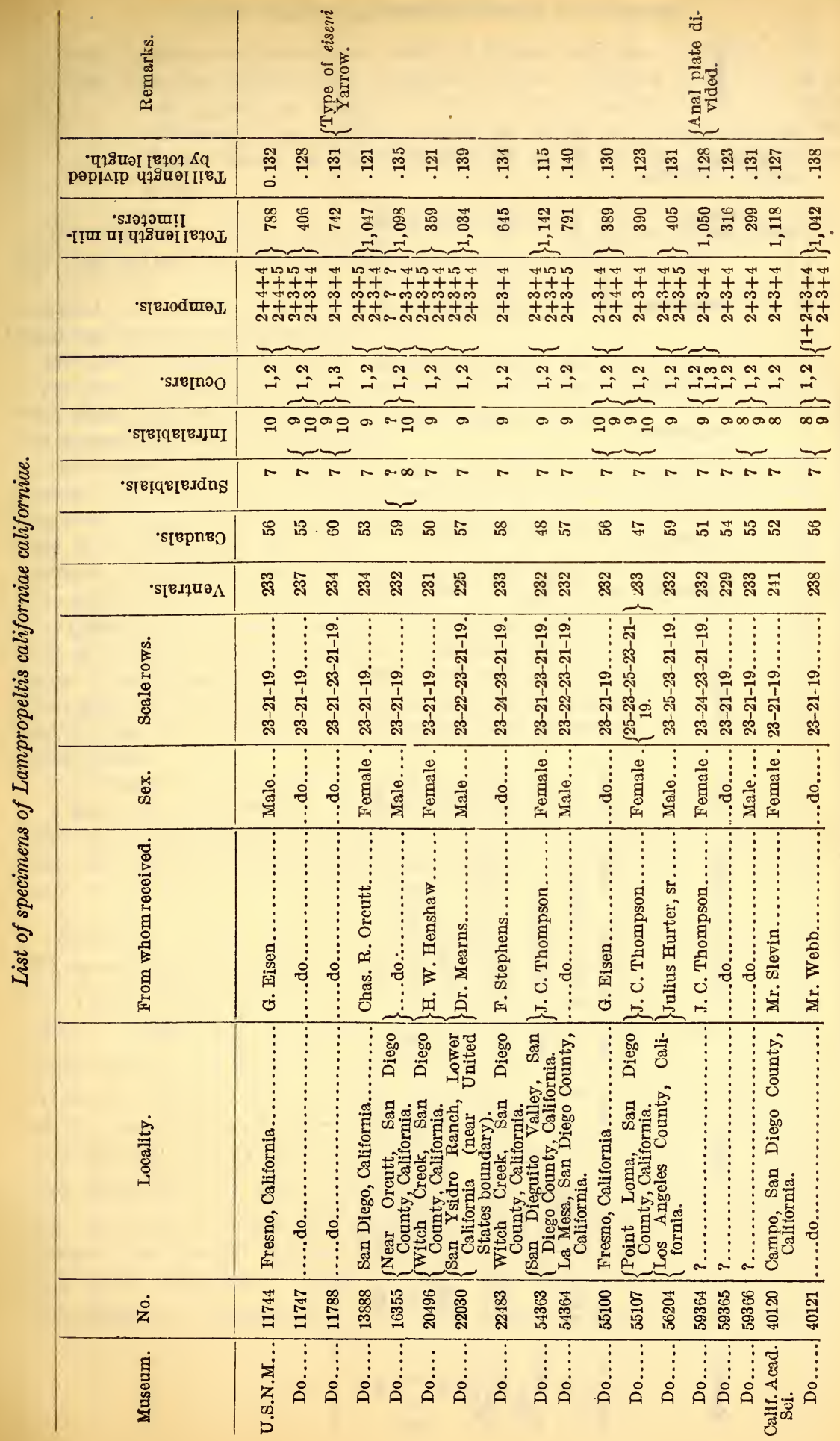




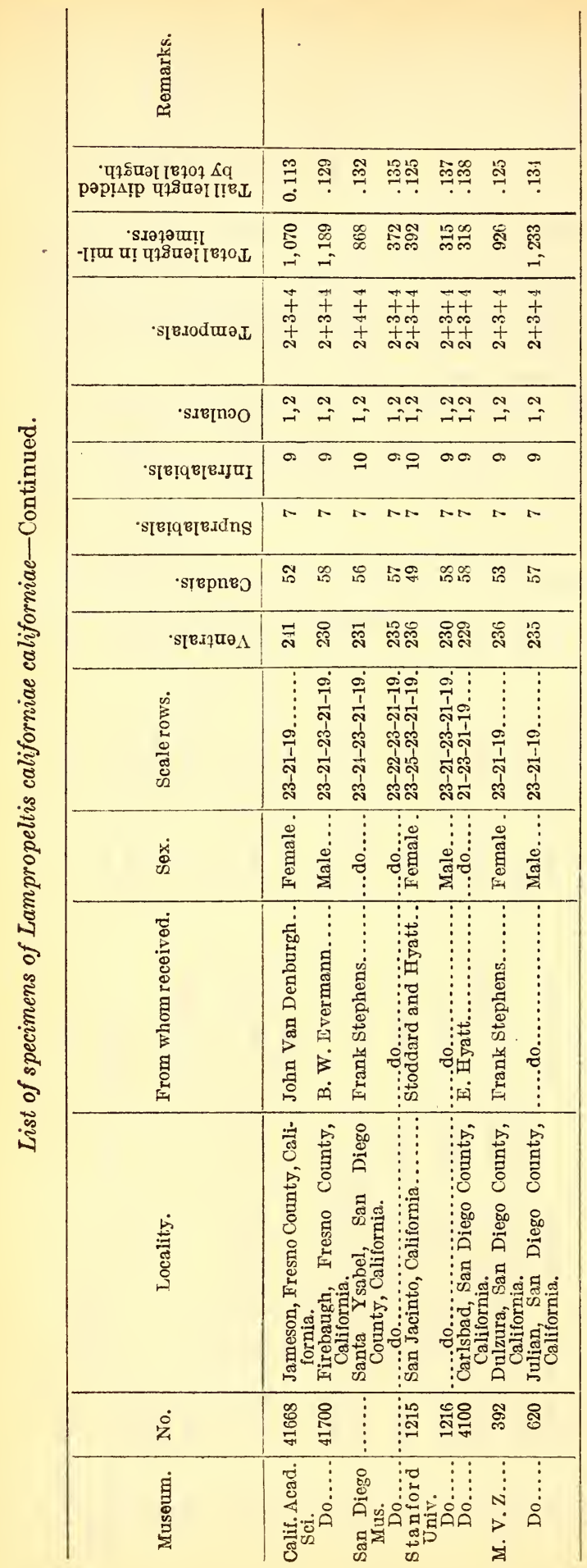




\section{LAMPROPELTIS CALIFORNIAE NITIDA (Van Denburgh).}

1887. Ophibolus californiae Cope, Bull. U. S. Nat. Mus., no. 32, p. 79.

1895. Lampropeltis nitida Van Denburgh, Proc. California Acad. Sci., ser. 2, vol. 5, pt. 1, p. 143, pl. 14 (type locality, San Jose del Cabo, Lower California; type, California Academy of Science collection, No. 800; Gustav Eisen, collector).-STEJNEger and BARBour, Check List, 1917, p. 88.

Description.- Since no specimen of this form has been examined by the writer, the original description is quoted in full:

Allied to $L$. californiae, but with the gastrosteges, urosteges, and upper surfaces of head and snout, entirely brownish black.

The head is slightly distinct, considerably depressed, its plates normal; 1 loreal; 1 pre- and 2 postoculars; scales in 23 rows, smooth, with 2 apical pits; postgeneials very small; anal entire; seven superior labials, the third and fourth entering the orbit; 227 gastrosteges; 56 pairs of urosteges.

The back and sides are blackish brown; the former, with a rather indistinct longitudinal line composed of cinnamon colored spots upon the centers of the scales of the median series, and upon the inner edges of those forming the first row on each side of this series; the latter, with a few scales of the first and second rows dotted, centrally, with cinnamon or yellowish white. A band of cinnamon crosses the nape. The gulars, geneials, and inferior labials, are blackish brown with paler centers. The plates on the top and sides of the head are brownish black, with faintly indicated dots of raw umber upon the loreal, pre-, and postocular plates, and near the posterior edges of the supraoculars and parietals. There are 6 cinnamon colored blotches on the upper surface of the tail. The gastrosteges and urosteges are entirely brownish black, with the exception of the first 10 gastrosteges, which show faint cinnamon colored dots.

Total length $965 \mathrm{~mm}$. Tail $125 \mathrm{~mm}$.

A small specimen (290 mm.) has, on the sides, rather numerous cinnamon colored blotches or enlargements of a similarly colored longitudinal line. This line is of about the width of one row of scales, and occupies the tips of the gastrosteges and the lower half of each scale of the first series.

Remarks.-Only the two specimens described above are known. They are of great interest, however, for they prove the occurrence in the Cape Region of an ally of californiae paralleling in every way the case of boylii and conjuncta. Since there is good reason to believe, from its present distribution, that californiae never reached southern Arizona, its derivative, nitida, must have attained the Cape by way of the pensinsula of Lower California, and not by way of Sonora and the islands of the Gulf of California. This is an argument in favor of the feasibility of the former route for conjuncta, thereby favoring its derivation from boylii instead of from yumensis; and it also favors the specific distinctness of californiae from boytii, as it shows the same situation to hold at Cape San Lucas with respect to these two forms as obtains in the vicinity of San Diego County, California. 
SUMMARY.

From the preceding descriptions it appears that this group is represented by a series of forms arranged in linear order across the United States and northern Mexico (fig. 24), and that each member

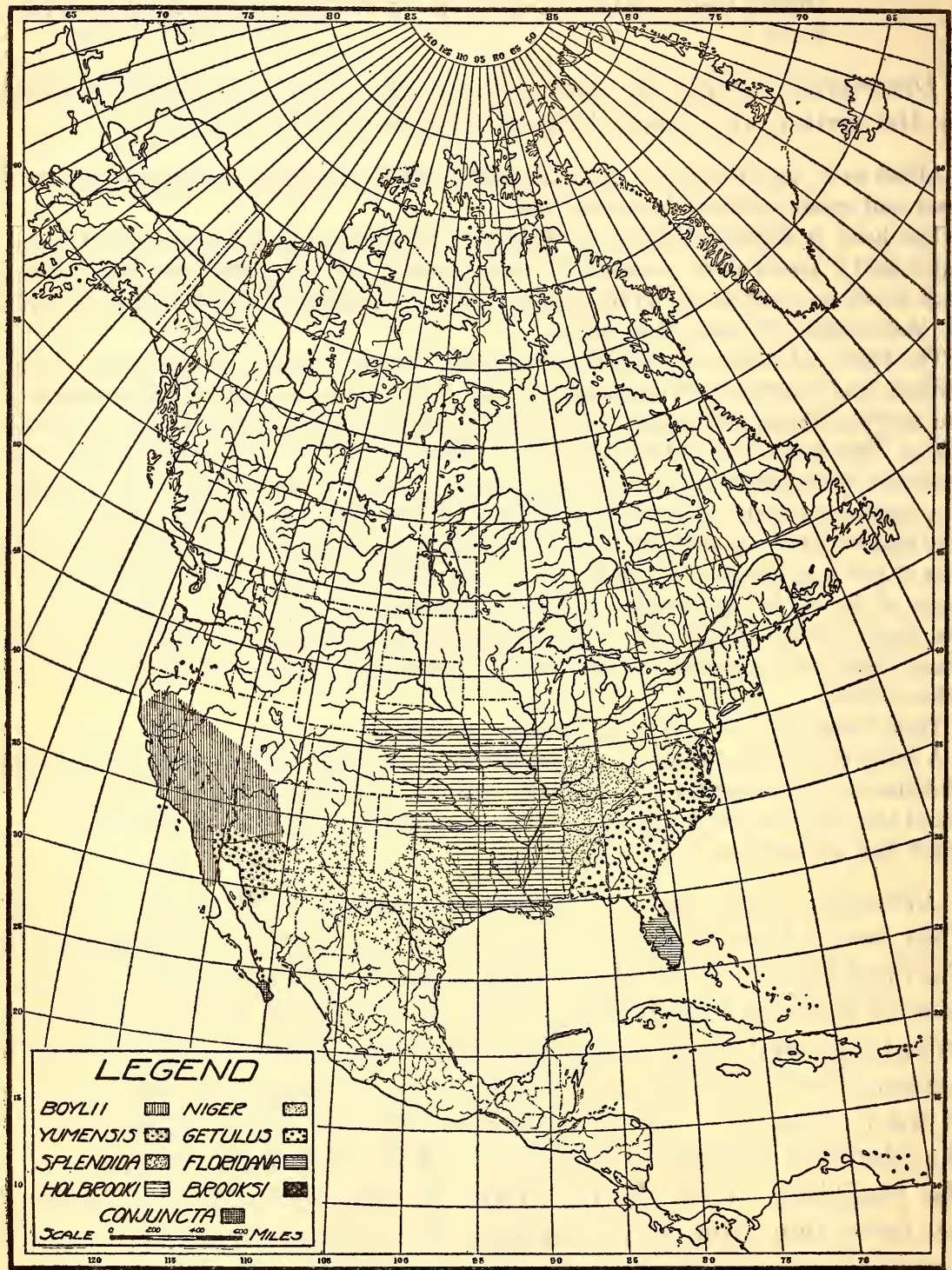

Fig. 24.-MAP SHOWING THE DISTRIBUTION OF THE VARIOUS FORMS OF THE GETULUS GROUP.

of the group is most closely related to the form inhabiting the contiguous region. Californiae offers the only exception, and this is discussed separately in the section devoted to it. 
Since the forms are thus linearly arranged and related, evolution may have proceeded from either extreme toward the opposite one, or from some intermediate point in two diverging directions. Floridana, brooksi, and conjuncta must be excluded from further consideration as ancestral forms, for reasons already discussed, chief of which are that they belong to regions that have received their faunas from the mainland to which the peninsulas are attached and which have thus not been centers of dispersal, and that they are very clearly derivatives of the adjacent forms, getulus and boylii, respectively. Also, californiae and nitida are too obviously derived from boylii to receive consideration in this connection. There are left therefore six forms to which to look for an approach to the ancestral condition of the group.

A comparison of the characteristics of these various forms may give some clue as to whether evolution has proceeded from one coast to the other or from some intermediate point in two directions. Certain structural features will be considered first.

Scale formulae of the forms of the getulus group.

\begin{tabular}{|c|r|r|r|}
\hline \multicolumn{1}{c|}{ Form. } & \multicolumn{1}{c|}{ Mraximum. } & \multicolumn{1}{c|}{ Minimum. } & \multicolumn{1}{c|}{ Average. } \\
\cline { 2 - 3 } conjuncta.... & $23-25-23-21-19$ & $21-23-21-19$ & $23-21-19$ \\
boylii....... & $23-25-23-21-19$ & $21-23-21-19$ & $23-21-19$ or $21-23-21-19$ \\
yumensis..... & $23-25-23-21-19$ & $21-23-21-19$ & $23-21-19$ \\
splendida.... & $23-25-23-21-19$ & $21-23-21-19$ & $23-21-19$ or $21-23-21-19$ \\
holbrooki.... & $21-23-21-19$ & $19-17$ & $21-19$ or $19-21-19$ \\
niger......... & $21-23-21-19$ & $19-21-19-17$ & $19-21-19$ \\
getulus...... & $23-21$ & $19-21-19-17$ & $21-19$ or $21-23-21-19$ \\
floridana..... & $23-21$ & $21-19$ & $21-23-21-19$ \\
\hline
\end{tabular}

The table giving maximum, minimum, and average scale formulae shows that the forms from splendida westward are identical in the matter of scale rows, and that those east of splendida have a decidedly lower range and average, with the exception of floridana. As explained in the discussion of getulus, the drop to 17 rows posteriorly is rather common from Virginia to New Jersey, and since this form must have reached this portion of its range from the south where 17 rows at the end is almost unknown, this must be considered a secondary and not a primitive character. Seventeen rows occur most frequently in holbrooki in the vicinity of New Orleans, and in niger in the northern portion of its range, both places that would be more recently populated whether the origin be placed in the southeast or in the southwest. This indicates that in these places a reduction in number of scale rows is taking place, and strongly suggests that the formula 19-21-19 is also a result of reduction from a higher formula. That evolution has taken place in this group in floridana, 
from a lower number of rows to a higher can not be denied, and it may therefore be admitted as possible to regard getulus or holbrooki as ancestral. But if we consider that a maximum of 23 rows and a minimum of 19 is characteristic of 5 of the 8 forms and common at widely senarated localities in the 3 (which, as will appear later, are

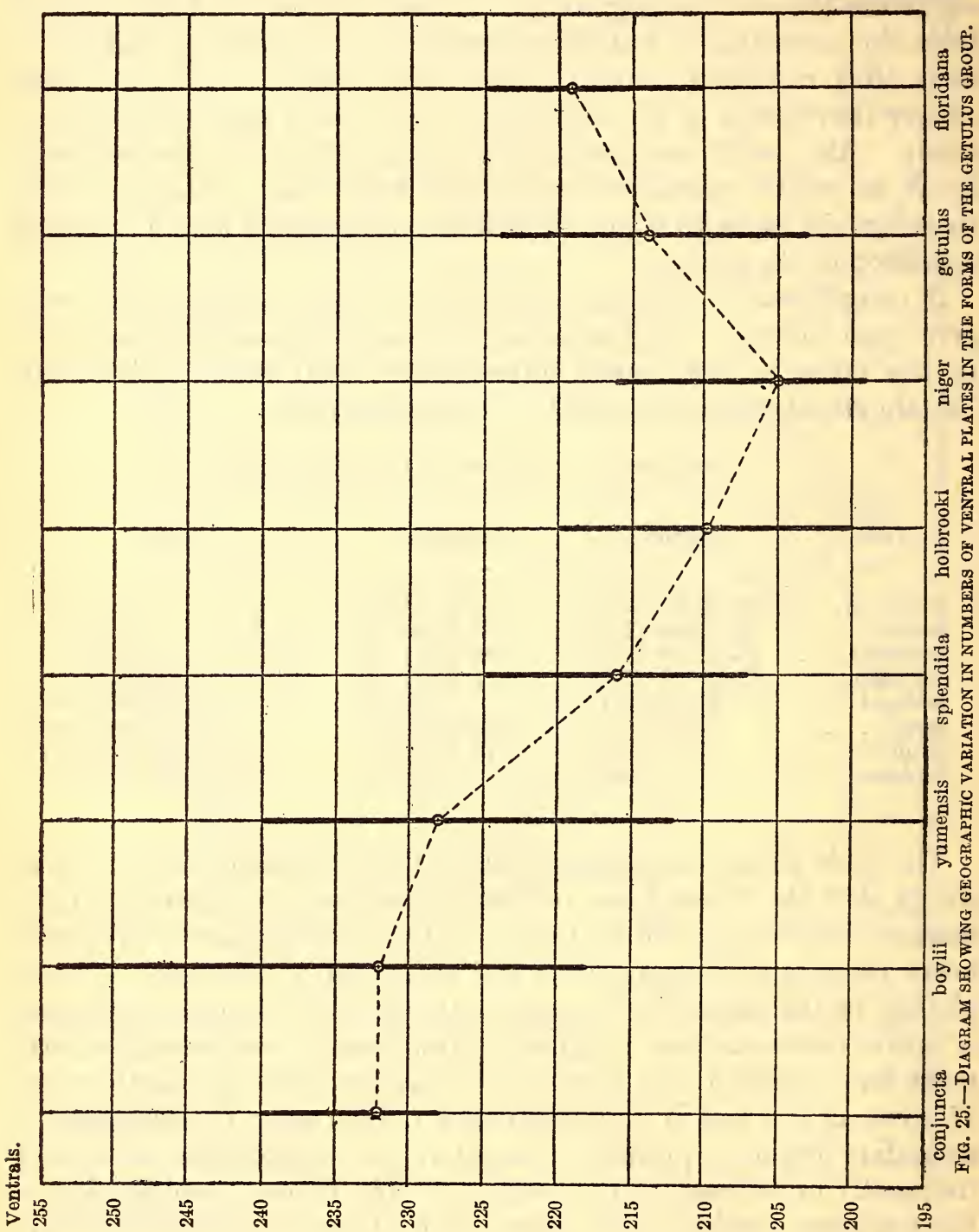

evidently specialized in other structural features), it looks as if this were a fundamental character of the getulus group, and as if forms possessing a lower maximum and a lower minimum were distinctly removed from the ancestral condition.

A glance at the diagram (fig. 25) of extremes and averages of ventral plates shows that the eastern forms differ decidedly in this respect. 
Again, it will be noticed that floridana has changed from getulus by an increase in number of ventrals. Since evolution by increase must therefore be considered as a possibility, we can base no argument for direction of evolution upon ventral plates alone. We may simply note, for later reference, that the forms exhibiting the lowest scale formulae also have the smallest number of ventral plates.

Variation in number of caudals and labials is of little use in itself in this discussion, but it is noticeable that the lowest numbers occur in the forms having the fewest ventral plates and the lowest scale formulae. Changes in the skull and dentition have been too slight to be of much use in tracing relationships within the group. This very constancy will, however, be of value later in connecting this group closely with the calligaster group.

The loreal shield is markedly different in the extremes of the group. On the east coast it is square or decidedly higher than long, while on the west coast it is usually longer than high, the dimensions here rarely approaching equality. The intermediate forms are intermediate in respect to the shape of the loreal, but holbrooki is more like getulus (fig. 4) and splendida (fig. 3) is more like boylii. If the getulus group is correctly associated with the other forms of Lampropeltis, the shape of the loreal in the eastern forms is a decidedly specialized instead of primitive condition. This is a very good reason for looking west for the origin of the group.

Like the loreal, the relative length of the posterior chin shields is decidedly different in the extremes of the group. In the eastern forms they are approximately as large as the anterior shields and usually in contact with each other, while in boylii and its allies they are hardly more than half as large as the anterior ones and are separated usually by two smaller scales. Splendida here occupies the intermediate position. Its western individuals are like boylii and its eastern show a decided approach to the getulus condition. The nearest allies to this group are calligaster and rhombomaculata, and here the posterior chin shields are usually a little shorter than the anterior and tend to be separated by about one scale, an arrangement that is true as well of the triangutum group. Both coast forms therefore represent extreme modification in the shape of the posterior chin shields, and it is splendida that presents the closest approach in this character to the other grouns of the genus.

186550-21-Bull. 114-8 
Comparison of the coast forms with respect to the shape of the head and its scutes shows considerable divergence. Such comparison may be tabulated as follows:

\begin{tabular}{|c|c|c|}
\hline Character. & boylii. & getulus. \\
\hline Snout. . & 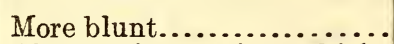 & More pointed. \\
\hline Rostral. & $\begin{array}{l}\text { About twice as wide as high } \\
\text { (proportion of height to } \\
\text { width averages distinctly } \\
\text { less than in getulus) }\end{array}$ & $\begin{array}{l}\text { Less than twice as wide as } \\
\text { high. }\end{array}$ \\
\hline Loreal......... & Usually longer than high.... & Usually higher than long, or \\
\hline Internasal suture. & Increased..$\ldots \ldots \ldots \ldots \ldots$ & Reduced. \\
\hline Eye............. & $\begin{array}{l}\text { Larger-its diameter gener- } \\
\text { ally greater than the great- } \\
\text { est height of the } 4 \text { th upper } \\
\text { labial. }\end{array}$ & $\begin{array}{l}\text { Smaller-its diameter gener- } \\
\text { ally less than the greatest } \\
\text { height of the } 4 \text { th upper } \\
\text { labial. }\end{array}$ \\
\hline $\begin{array}{l}\text { Upper temporal of third } \\
\text { row. }\end{array}$ & $\begin{array}{l}\text { Usually fails to reach the } \\
\text { posterior limit of the pari- } \\
\text { etal. }\end{array}$ & $\begin{array}{l}\text { Usually extends to the pos- } \\
\text { terior limit of the parietal. }\end{array}$ \\
\hline Supralabials........... & Average lower.............. & Average deeper. \\
\hline Posterior chin shields... & $\begin{array}{l}\text { About half as wide and half } \\
\text { as high as anterior, and } \\
\text { separated by two smaller } \\
\text { scales. }\end{array}$ & $\begin{array}{l}\text { About as long and nearly as } \\
\text { wide as anterior, and in } \\
\text { contact or separated by not } \\
\text { more than one small scale. }\end{array}$ \\
\hline
\end{tabular}

Briefly interpreted, getulus has a higher and more pointed head to which the deeper loreal and supralabials contribute, and boylii has a lower, flatter, and blunter head. The shape of head in holbrooki is decidedly like getulus; yumensis and conjuncta are decidedly like boylii; it is in splendida that we find a mean between these extremes, and the closest similarity with the other groups of the genus, and in the forms east and west that we find specialization.

The penis is essentially the same throughout the group. In holbrooki and niger, however, the basal half of the organ is beset with minute spines. It would be easy to say that this condition is primitive, and that the others have been derived by reduction of these small spines. But primitive conditions generally show more persistency than this. Most of the other structural characters show a marked degree of permanence; reduction or increase is the exception, not the rule. In the calligaster group, the one nearest related to this, the copulatory organ has the minute spines, when present at all, usually restricted to the immediate vicinity of the large ones. This is the situation that holds in the triangulum group and elsewhere in the getulus group, except that there may be a slight tendency tow ard extension of these spines in yumensis and boylii. Thus these small spines of the penis, instead of favoring holbrooki or niger, as ancestral, are distinctly against it, for the reason that they represent a specialized condition not found elsewhere in the genus.

In getulus, too, this organ is decidedly specialized. The bilobed condition, noted in the descriptions for holbrooki and probably for the 
other more western forms, is intensified in getulus into distinct forks, a character that is even more strongly developed in floridana. Since this feature is unique for the genus, we must consider it a strong reason for excluding these forms from the list of ancestral possibilities.

In connection with the positive evidence of specialization in the forms east of splendida derived from the characteristics of the loreal, chin shields, and copulatory organ, we must now consider that the reduced scutellation of these forms is also a result of specialization. We are forced to conclude, therefore, on structural grounds, that floridana, getulus, niger, holbrooki, and probably the forms west of the Rockies, must be excluded from consideration as possible ancestors of the group.

Turning now to the pattern, we find that its variations are truly remarkable, ranging as they do from cross bands, to small spots, to rings, and stripes, and to various combinations of these. In fact, the pattern is the most variable of all the characters upon which specific value is placed. It may therefore be expected that pattern, if anything, will give a clue to relationships.

Since the head pattern is the least variable, we may consider that first. One of its strikingly constant characters is the pair of white bars on the prefrontal and internasal plates. In the Pacific coast forms these are broad, occupying most of the area of the scutes, and usually so broadened as to largely lose their transverse character; in getulus and floridana they are narrow and usually close to the anterior and antero-lateral borders of the scutes; often they are curved, or broken in the middle, or reduced to spots; in holbrooki they are pretty constantly narrow transverse bars, the chief variation being to reduction, breaking into spots, and curving; in yumensis they are strong, symmetrical transverse bands on the anterior portions of the scutes; in splendida they vary from the yumensis form at the extreme west to the holbrooki condition in the east; in the central portion of its range these bars are narrow, rather irregular, sometimes broken, or somewhat bent or curved. These bars, therefore, reach their extremes of diversity in the east and west coast forms, and are developed most perfectly and symmetrically in Arizona and in the Mississippi Valley. If we feel it necessary to assume as the starting point the perfect and symmetrical condition, we must explain why, starting with either holbrooki or yumensis, evolution has proceeded in one direction to an extreme condition (the nearer coast forms), and in the other through a reduced condition (splendida), to a perfect condition again, and then to another variable extreme. To the writer the only logical explanation is to consider the condition presented by splendida in southern New Mexico as the starting point. Here we have the beginnings of the white bars, imperfectly formed as symmetrically placed lightened areas on a black head; evo- 
lution, resulting from radiate migration, has perfected the marks in central Texas and in Arizona; farther migration has resulted in further change in these bars by which they lose their simple form and become modified in two difierent ways independently-in the west becoming broadened, in the east more or less broken into spots, and bent, or curved. We see then, in these prefrontal and internasal bars, their inception, perfection, and diverse modification.

These white bars are not the only parts of the head pattern requiring mention. White markings, spots, and bars of various shapes, are considerably developed in all forms of the group except yumensis, the Great Basin section of boylii, and splendida. The first two are alike with white markings symmetrical, clean-cut, and limited to the snout and sides. In splendida, in the central portions of its range, the only white markings present occupy the same positions as in yumensis, but are much more restricted; the rest of the head is black. In the western portion of its range these markings attain the same development that they show in yumensis; in the eastern portion it develops the markings of holbrooki. It is not necessary to explain the variations of these markings in further detail; the case is the same as with the prefrontal white bars; in splendida we have the inception of two diverging lines of head markings, the east and the west.

One other portion of the head pattern may be mentioned. In all the forms west of splendida the labials are white with narrow dark mutual borders, except for the suture between the third and fourth upper labials, the dark mutual border of which is so much widened as to form a conspicuous circular spot or blotch on the upper lip beneath the eye. In all the forms east of splendida the labials are light with dark mutual borders, but there is no widening of the mutual dark border of the third and fourth supralabials. Only as an occasional individual variation is there any increase in pigment on the upper labials beneath the eye-a variation as uncommon as the occasional great reduction of the subocular spot in the west coast forms. Connecting these two divergent sections of the group we have splendida, in the New Mexican portion of its range, with an almost totally black head, its labials lightened only by a median narrow white bar on each scute which often is not even continuous across its middle. The condition in the other forms of the group has undoubtedly been produced by a widening of these narrow median white bars; while eastward they all widened, westward the dark pigment was retained on the upper series beneath the eye. This seems to be the only logical explanation of the peculiar distribution of this subocular dark patch.

Perhaps of even greater value is the evidencefrom the body pattern. Here the diversity is apparently much greater. If we except californiae (its relationship to boylii has been sufficiently discussed, along 


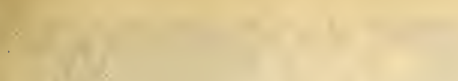

(4.

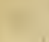

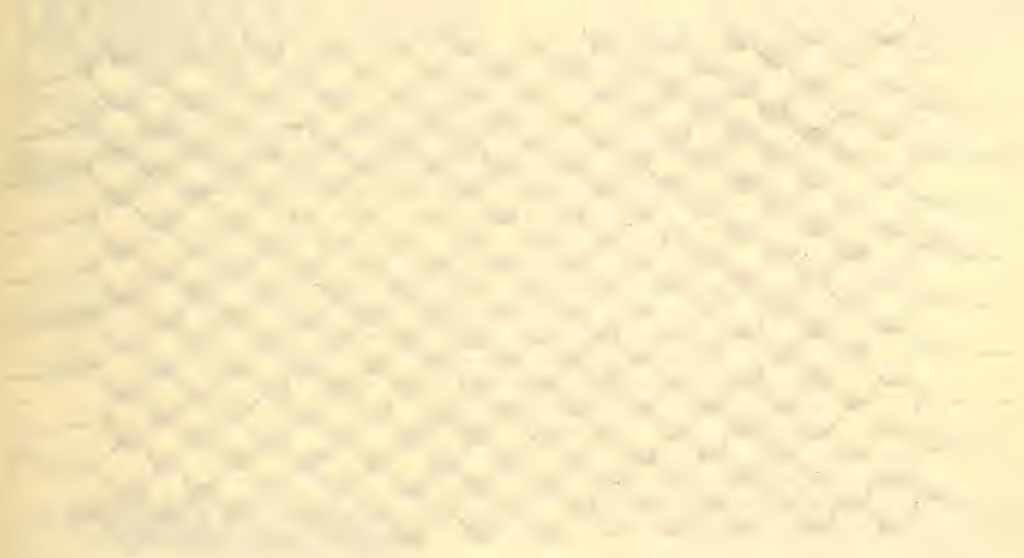

(19)

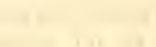



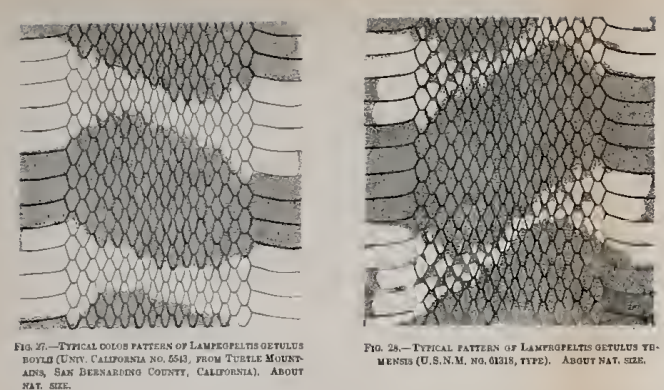

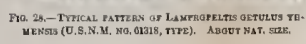

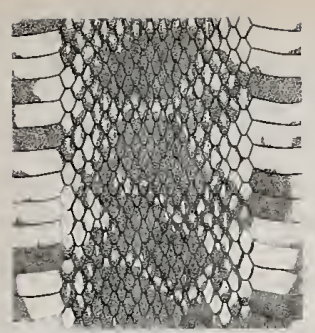

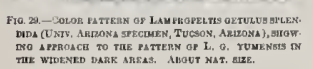

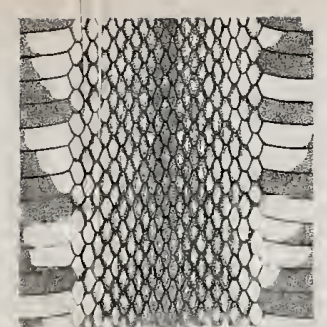

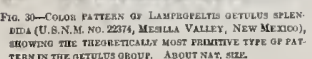

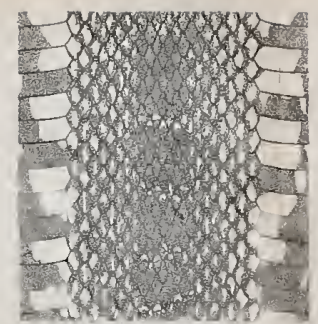

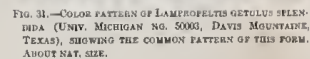

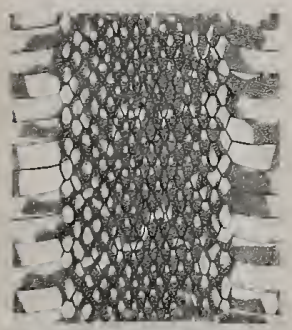

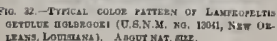
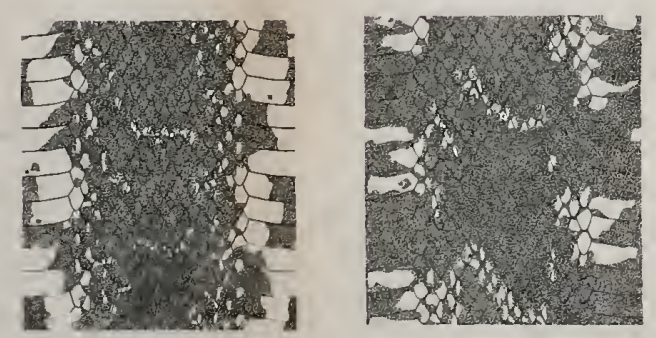

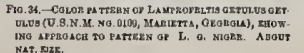

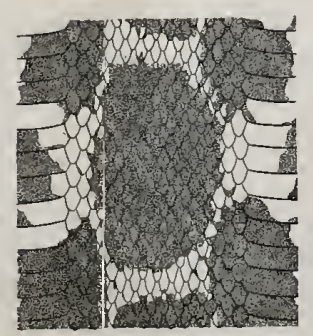

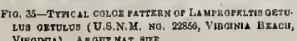

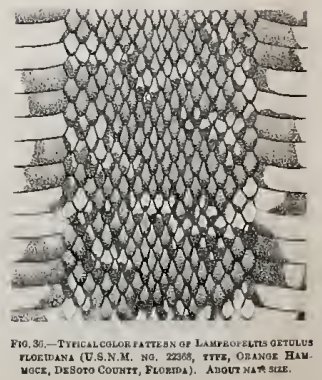

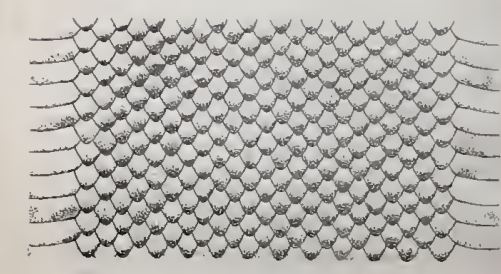

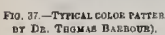




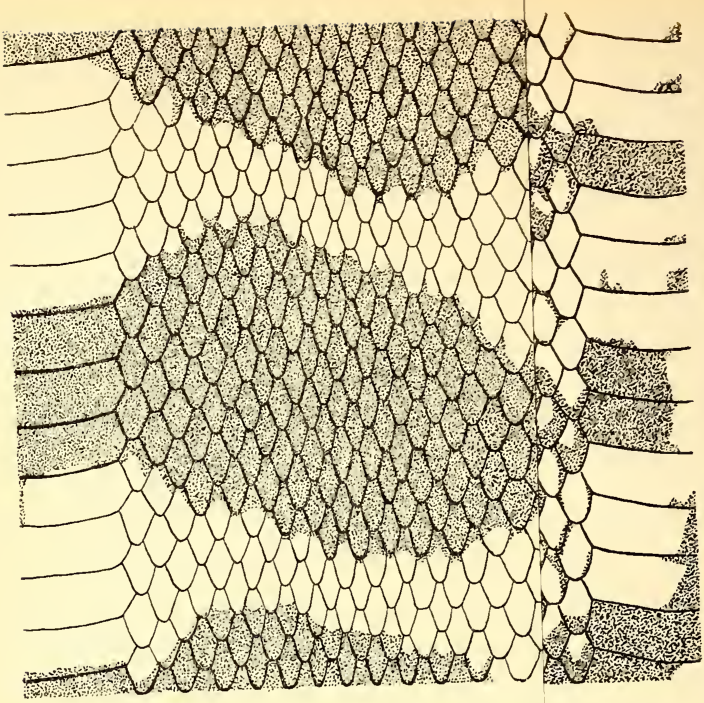

FIG 27-TYPICAL COLOR PATTERN OF LAMPROPELTIETULUS SPLENBOYLII (UNIV. CALIFORNIA NO. 5543, FROM TURTRIZONA), SHOWains, San Bernardino County, California yumensis in NAT. SIZE. SIZE.

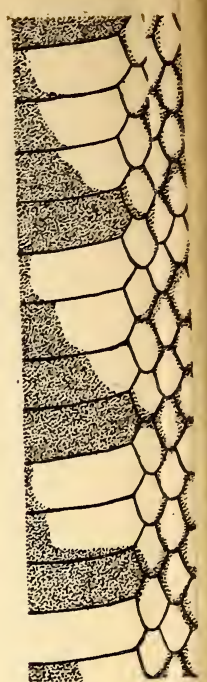

FIG. 30-COLOR DIDA (U.S.N.M SHOWING THE TERN IN THE GI

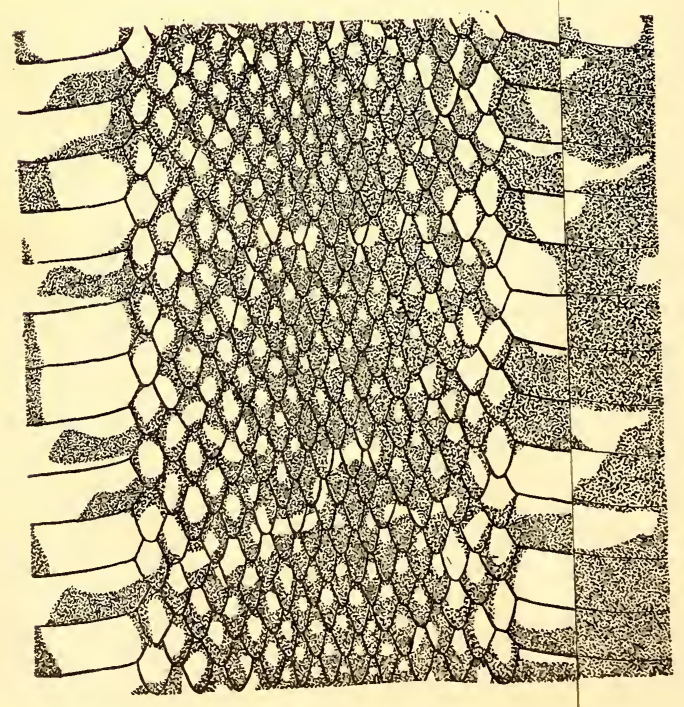

Fig. 32-TyPical color PATtern of LAMPROZULUS GetGETULUS HOLBROOKI (U.S.N.M. NO. 13041, NEদ), sHowleans, Louislana). About nat. size. A Bout

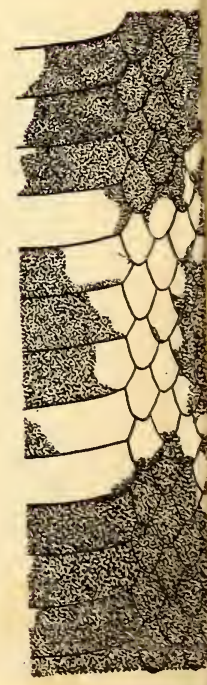

Fig. 35-TrPICAL LUS GETULUS ( VIRGINIA). AB 


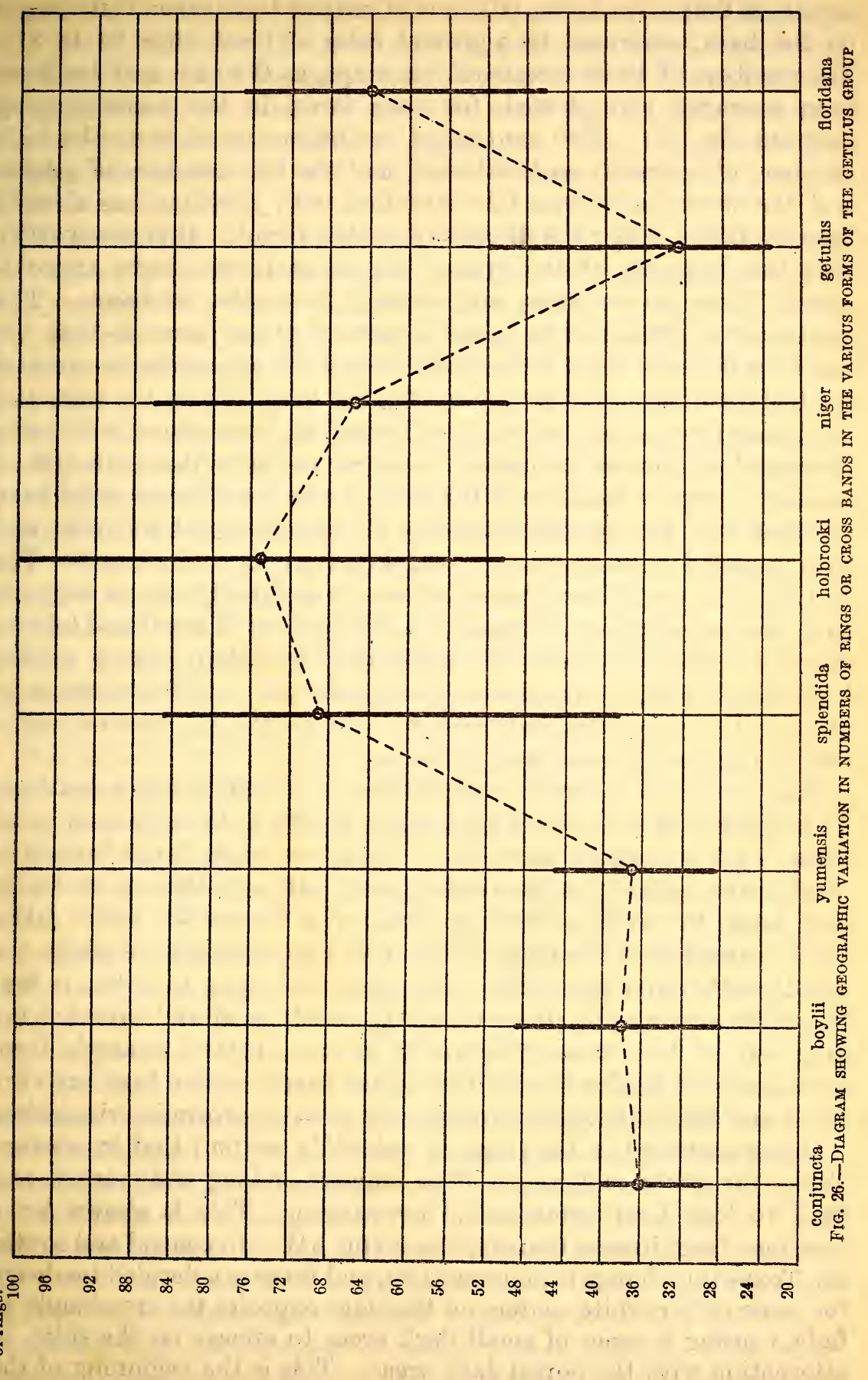


with its description), the various forms of the getulus group all have a pattern that is fundamentally one of narrow transverse white bands on the back, separated by a ground color of black (figs. 27 to 37). The numbers of these crossbands or rings, as the case may be, have been averaged and plotted, for each form, in the accompanying diagram (fig. 26). Two contrasted conditions are shown-the high numbers of splendida and holbrooki, and the low numbers of getulus and the west coast forms (the situation with floridana has already been explained under the discussion of that form). It is noteworthy that the extremes of the group-the coast forms-have approximately the same variation and average in number of bands. The fundamental difference in pattern between these forms is that the bands in the west coast forms (figs. 27 and 28) are continued around the body as rings, while in getulus (fig. 35) they fork on the sides and the connections across the belly are imperfect; from above both body patterns look almost identical. It seems to the writer quite out of reason to suppose that any of the west or east coast forms could have changed into the spotted condition of splendida and holbrooki and then emerged with the pattern exhibited on the other coast. The fact that the coast forms have patterns so strikingly similar suggests that, like the diverse modifications in the pattern of snout and labials, they have been produced by independent evolution from a similar beginning. Then, of necessity, either holbrooki or splendida must be examined for ancestral possibilities. The former is, however, sufficiently rejected on structural grounds.

The pattern of splendida as exhibited by examples from southern New Mexico and northern Chihuahua briefly is this: Ground color black; back crossed by about 50 or 60 narrow white bands formed of black scales with oval white centers; sides with a white oval center on each scale, the white occupying more area toward the belly; latter black, except that the ends of about two gastrosteges, opposite the dorsal white bars, are white. The important thing to notice is that the white centers are all very approximately oval and oriented the long way of the scales. Figure 30 shows a typical example from southern New Mexico in which the black spaces on the back are very small and the white centers are all very nearly uniform in orientation.

Going eastward in the range of splendida we find that in western Texas the white centers are often angular or long and narrow and tend to lose their symmetrical orientation. This is shown by a specimen from Reeves County, Texas (fig. 31). In central and southern Texas this change is more marked, and there is a decided tendency for some of the white centers on the sides opposite the crossbands to fade, causing a series of small dark areas to appear on the sides, in alternation with the dorsal dark areas. This is the beginning of the chain pattern of niger and getulus. It is obscured, however, in holbrooki by the appearance of an oval white center in each scale of 
the dark areas. This is well shown by a specimen from New Orleans (fig. 32). In this the symmetrical oval spots occupy only the areas that were without white spots in the specimens from central and southern Texas, and the spots which were present in these specimens are present here too, and with much the same unsymmetrical orientation as was shown initiated in figure 31. That is, holbrooki has retained the pattern of splendida, as developed in Texas, but has added something to it.

The form niger is developed from holbrooki by a fading of the newly derived white spots between the bands and a contraction of the white in the crossbands and sides (fig. 33). The exact derivation of getulus (fig. 35) from niger (fig. 33) is uncertain, due to scarcity of specimens from the critical region. A specimen from Anniston, Alabama, suggests that the transition to getulus was accomplished by a disappearance of alternate cross bands on the back and possibly by fusions of the light areas on the ends of the ventrals. In this specimen the crossbands are scarcely distinguishable but seem to be reduced in number. A specimen from Marietta, Georgia (fig. 34), has the pattern of getulus, but the crossbands are very narrow. The change from this to the typical pattern was accomplished by a widening of the white parts, thus making the crossbands conspicuous and bringing out the chain pattern that was initiated in the splendida of central and southern Texas and remained inconspicuous in holbrooki. The pattern of such a typical getulus is shown in figure 35.

Floridana was developed from geiulus by a basal lightening of each dark scale, and an increase in the number of crossbands (fig. 36). Here, as in holbrooki, we have a spotted pattern that is at the end of an evolutionary series, but it is a decidedly different sort of spotted pattern from that of splendida (fig. 30) in that it bears the vestiges of an earlier pattern while that of the latter apparently does not. In extreme southern Florida this series of patterns is carried one step farther and to its logical conclusion in brooksi (fig. 37), in which even traces of the crossbands appear to be lost. Numerous structural features, however, mark it as a specialized type.

Yumensis is formed from splendida even more simply. It occurs as follows: Westward from southern New Mexico splendia $a$ becomes somewhat altered. The essentials of the process are fundamentally the same as the changes eastward. The white centers lose their symmetrical form and arrangement and assume various shapes. Small dark areas develop on the sides opposite the crossbands (fig. 29). The dorsal dark areas increase in length and breadth. At this point we have the fundamentals of another getulus pattern, but, apparently by chance, rings are produced instead of a chain pattern. The intermediate forms upon which this outline is based show that the white spots separating the lateral dark areas from the dorsal ones are 
weaker on one side of the crossband than on the other, so that the dorsal dark areas become fused with the lateral on one side of the crossband, and on the other the white is strengthened. Similarly the lateral dark areas fuse with a ventro-lateral series, and thus become complete on the belly. It now only remains for these newly formed rings to be perfected. This occurs by a whitening of the white rings and a fading of the white that may still form ragged edges projecting into the dark areas. All these transitional stages may be observed in specimens from the vicinity of Tucson. With the perfection of the pattern of yumensis (fig. 28), the only change necessary to produce the pattern of boylii (fig. 27) is an extension of the white in the white rings to the whole of the scales in these rings.

Thus the patterns of the coast forms of the getulus group result from the tendency of the pattern of typical splenaida to become broken into an alternating series of black and white areas.

That splendida may well be the parent form of the getulus group is indicated by its present distribution. It appears to be confined to the region between central Texas and eastern Arizona. Its northern limit is unknown, but is doubtless the mountains of central or northern New Mexico. That it extends south into Mexico is as certain as anything can be, but how far we can only surmise. For southern Mexico, where considerable collecting has been done, there is no record of splendida, nor of any form allied to it. We may therefore say that the arid plateau region of the southwest is its home. This has of ten been commented upon as being a favorable center for preservation and for dispersal of reptilian life. The present diversity of forms may be considered the result of an east and west dispersal, with consequent modification in each major environment.

The foregoing discussion may be summarized as follows:

1. Since each member of the getuluis group is nearest and evidently directly related to the form inhabiting the adjacent region, and since the forms are in linear arrangement geographically, one of them must therefore present a condition from which all the others may be derived (californiae and nitida are ruled out of consideration here for reasons discussed under the former).

2. Of the eight forms entering the discussion, two-conjuncta and floridana-are eliminated because their geographic position and the evidence for their derivation from the adjacent continental forms is too strong to allow them to be considered as ancestral possibilities.

3. Comparative study of loreal and chin shields indicate that the east and west forms present specializations in these scutes.

4. The proportions of the head and its scutes indicate that splendida is the most closely allied to the other forms of the genus, and that both the east and the west forms of the getulus group are specialized.

5. Getulus, floridana, niger, and holbrooki are excluded from consideration as possible ancestral forms on account of the unique 
specializations in the structure of the copulatory organ. Since they are specialized in this respect we must regard the low averages in numbers of scale rows, ventrals, and labials as also due to specialization.

6. Splendida is the only member of the group not eliminated on structural grounds.

7. There are no structural peculiarities that can not be more easily explained by assuming splendida as the ancestor.

8. That splendida, as represented in southern New Mexico and northern Chihuahua, possesses the only pattern from which all the others may be simply and naturally derived is definitely indicated by the variations and geographical distribution of $(a)$ the white bars

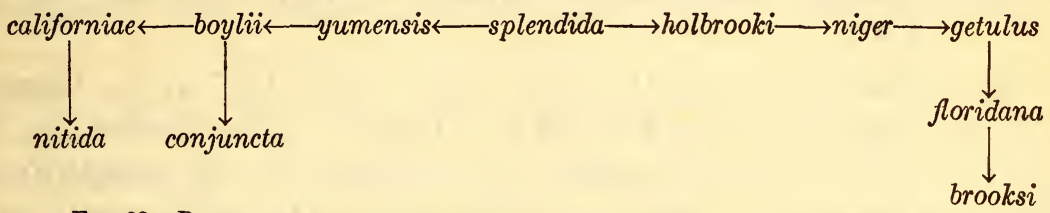

Fig. 38.-Diagram of the Relationships of the forms of the getulus group.

on the prefrontal and internasal scutes, $(b)$ the subocular black spot, $(c)$ the other head markings, and $(d)$ the body pattern.

9. The region inhabited by splendida is the one theoretically most favorable for being the center of preservation and dispersal of a plains form of land snake.

\section{THE CALLIGASTER GROUP.}

LAMPROPELTIS CALLIGASTER (Harlan).

YELLOW-BELLIED KING SNAKE; EVANS KING SNAKE.

Figs. 6, 39, 40.

1827. Coluber calligaster Harlan, Journ. Acad. Nat. Sci. Philadelphia, vol. 5, pt. 2, p. 359 (type locality, Missouri); Med. Phys. Researches, 1835, p. 122.-Lampropeltis calligaster Cope, Proc. Acad. Nat. Sci. Philadelphia, 1860, p. 255.-STrecker, Proc. Biol. Soc. Washington, vol. 21, 1908, p. 75.-Hurter and Strecker, Trans. Acad. Sci. St. Louis, vol. 18, no. 2, 1909, p. 26.-Hurter, same, vol. 20 , no. 5, 1911, p. 187.SteJNEGER and BARBour, Check List, 1917, p. 87.-O phibolus calligaster Cope, Bull. U. S. Nat. Mus., no. 1, 1875, p. 37.-SмrтH, Geol. Surv. Ohio, vol. 4, 1882, p. 689.-YARRow, Bull. U. S. Nat. Mus., no. 24, 1882, p. 94.-Cope, Proc. U. S. Nat. Mus., voi. 14, 1891, p. 610.-Garman, H., Bull. Illinois State Lab. Nat. Hist., vol. 3, art. 13, 1892, p. 293.HAy, Annual Rep. Indiana State Board Agric., vol. 28, 1887, p. 210; Batr. Rept. State Indiana, 17th Annual Rep. Indiana Dept. Geol. Nat. Resources, 1892, pp. 515, 590; Batr. Rept. Indiana, 1893, p. 182.Hurter, Trans. Acad. Sci. St. Louis, vol. 6, no. 2, 1893, p. 255.Blatchlex, 24th Ann. Rep. Dept. Geol. Nat. Res. Indiana, 1899, p. 545.-Cope, Rep. U. S. Nat. Mus. for 1898, 1900, p. 905, fig. 223, pl. 18, fig. 6.-Brown, Proc. Acad. Nat. Sci. Philadelphia, 1901, p. 80.Strecker, Trans. Texas Acad. Sci. for 1901, vol. 4, pt. 2, no. 5, 1902, p. 4.-Ditmars, Reptile Book, 1907, pp. 341, 355.-Somes, Proc. Iowa Acad. Sci., 1912, p. 150.-STrecker, Baylor Bull., vol. 18, no. 4, 1915, p. 38.-Coronella calligaster Boulenger, Cat. Snakes Brit. Mus., vol. 2, 1894, p. 198. 
1842. Coluber eximus (part) HоцвRоок, N. Amer. Herp., ed. 2, vol. 3, p. 72.

1856. Ablabes triangulum, var. calligaster Hallowell, Proc. Acad. Nat. Sci. Philadelphia, p. 244.

1859. Ophibolus evansii BAIRD, Pacif. R. R. Surv., vol. 10, no. 4, p. 43 (quotation from Kennicott's forthcoming manuscript).

1859. Ophibolus evansii Kennicotr, Proc. Acad. Nat. Sci. Philadelphia, p. 99 (type locality, central Illinois; cotypes, U.S.N.M., no. 1593; 3 specimens; R. Kennicott, collector).-Coronella evansii JAN, Arch. Zool. Anat., vol. 2, fasc. 2, 1863, pp. 237, 243; Icon. Gen. Ophid., livr. 17, 1866, pl. 2 , fig. 3 .

1863. Coronella tigrina JAN, Arch. Zool. Anat., vol. 2, fasc. 2, pp. 238, 244.

1883. Ophibolus triangulus calligaster Garman, S., Mem. Mus. Comp. Zool., vol. 8 , no. 3 , pt. 1 , pp. $66,155$.

1892. Lampropeltis rhombomaculatus Garman, S., Bull. Essex Inst., vol. 24, p. 9.

The first description of this form appeared in 1827 in the Genera of North American Reptiles and a Synopsis of the Species, by R. Harlan (p. 359). The description is applicable to the present form, but is very indefinite. Harlan attributed the name calligaster to Say, probably because the latter found the specimens, recognized them as new, and proposed the name. But it was Harlan who drew up and published the description. Thus Holbrook, in 1842 (vol. 3, p. 72), said: "Say seemed to consider the serpent he observed in Missouri as new; but I am not aware that he described it as such. Harlan, however, gave a description of it from specimens in the Philadelphia Museum, and under the name calligaster, from the beautiful arrangement of colors on the belly." That Harlan had the present form before him when he drew up the description, while not beyond doubt, yet appears fairly certain, for Cope in 1861 (1860, 255), says, in reference to the specimens from which Harlan prepared his description, "One of these, a stuffed skin, presented to the Academy by Doctor Holbrook, and labelled by Doctor Hallowell 'original specimen,' is now before us. We can assert its identity with Ophibolus evansii of Kennicott both from his description and from comparison with specimens collected by Doctor Hammond in Kansas, and described by Hallowell (1856, 244). They all have 25 rows of smooth scales." One of the specimens, however, described by Hallowell $(1856,244)$ is probably an Elaphe since it has 65 caudal plates and a divided anal. We have examined three of Doctor Hammond's Kansas specimens and there is no doubt about their identity, and two of these were evidently used by $\mathrm{Hal}$ lowell in his description and discussion of calligaster, just referred to above. Kennicott, in $1860(1859,99)$ thought that Harlan had before him a specimen closely related to what we now know as Elaphe laeta, and so attributed Harlan's Coluber calligaster to the genus Scotophis (Elaphe). Kennicott undoubtedly had before him specimens of Elaphe laeta which is considered as somewhat different 
from true E. laeta and to be the equivalent of Harlan's $C$. calligaster. Kennicott therefore gave a new name to the specimens in the collection of Northwestern University, which were unquestionably the Lampropeltis calligaster that we now know, calling them Ophibolus evansii.

Granting that Harlan had our form before him, the name calligaster has priority over evansii of Kennicott.

Description.-The scutellation is as follows: Ventral plates 196 to 215, average 205; caudals, 38 to 57 (males 44 to 57, average 51; females 38 to 52 , average 46 ); supralabials, 7 , sometimes 8 ; infralabials, usually 9 , often 10 , occasionally 11 ; oculars, 1 and 2 ; temporals normally $2+3+4$; posterior chin shields usually a little shorter than anterior, close together or separated by 1 or 2 small scales; loreal usually. longer than high, but sometimes as high as long; suture between the internasals only about half, or less than half, as long as that between the prefrontals; scale rows on middle of body usually 25 , sometimes 27, very rarely no more than 23. (For the scale formulae, see under Variation.)

The body is rather slender, and uniform in diameter; the head is scarcely distinct from the neck, the snout is generally somewhat longer and more pointed than in rhombomaculata, the tail is rather short and tapers rapidly, varying from 0.110 to 0.150 of the total length (males, 0.123 to 0.150 , average, 0.137 ; females, 0.110 to 0.145 , average, 0.123). The largest specimen examined measured about 1,355 mm., and was taken at Lawrence, Kansas.

The pattern (fig. 39) is composed of about 60 (46 to 78) transversely elongate quadrate brownish or greenish blotches (reddish in the young), 2 to 3 scales long and 8 to 12 across, narrowly margined with black, set on a ground color of lighter brown, and extending down on the sides to the seventh or sixth row of scales. These blotches are more or less concave before and behind and are occasionally divided on the median line; on the tail they may become narrowed to transverse black bands, indistinct and irregular near the end. On the sides, alternating with the dorsal row, there is a similar series of smaller dark-edged blotches, roundish for the most part, but often elongated anteriorly. On the first row or two of scales, and overlapping the ventrals, is a third series of spots, in alternation with the last, and tending, posteriorly, to fuse with them. Each scale, usually including the ends of the ventral plates, is minutely mottled with brown.

The head is somewhat variously spotted, but certain markings are usually evident. Transversely across the posterior portion of the prefrontals and not overlapping the frontal plate is a brown bar, edged with darker; extending forward from behind the parietals there is a dark-edged brown band which forks on the parietals, and 
extends thus forward to between the eyes, where the forks may unite again. From behind each eye a long black-bordered brown band about two scales wide extends backward on top of the neck. From the eye to the angle of the mouth there is a narrow dark band. Thus there is a strip of the ground color from the upper postocular to the last supralabial. The other head and throat plates are mostly light-colored. The belly may be faintly or heavily checked with

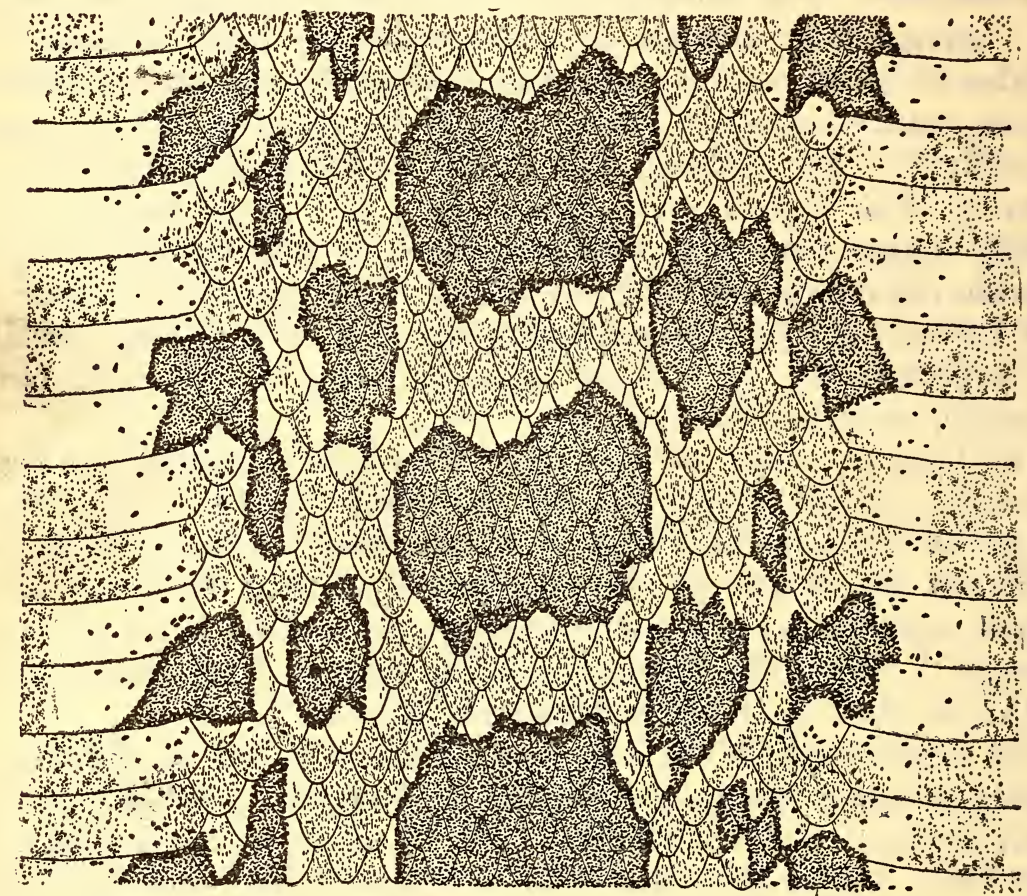

Fig. 39.-Typical Pattern on Lampropeltis Calligaster (U.S.N.M. No. 1593, COtYPe of Ophibolus EVANSI KENNICOTT FROM Central Illinois). ABOUt $1 \frac{3}{6} \times$ Nat. SIZE

small quadrate brownish or yellowish blotches, or nearly immaculate except for the ends of the ventrals.

This pattern is well defined in young individuals, but in many adults the markings, particularly of the head, lose their distinctness and become greatly obscured by a darkening of the ground color. Such darkening appears to be accompanied by an alternate lengthwise tightening and intensification of pigment, producing a rather prominently striped effect (fig. 40). Throughout the middorsal line there is a light stripe; bordering this on either side is a dark band which passes through the lower portions of the dorsal blotches. Below this, and between the dorsal and lateral series, is a light band; then below this last and passing through the upper lateral series of blotches is another dark band. The two or three lowest rows of 
scales are lighter and the belly is apt to be very light, due to a fading of the small quadrate dark spots. This darkening and striping seems to progress with age. Its beginnings may be detected in specimens that still show the normal pattern sharply defined. These darkened individuals seem to come chiefly from the region from eastern Missouri to Indiana.

The copulatory organ (fig. 2) is bilobed; the sulcus single, extending over the longer lobe and ending in a smooth area on the distal end of the shorter lobe; calyces best developed on the longer lobe, strictly apical, barely showing in a side view of the fully distended

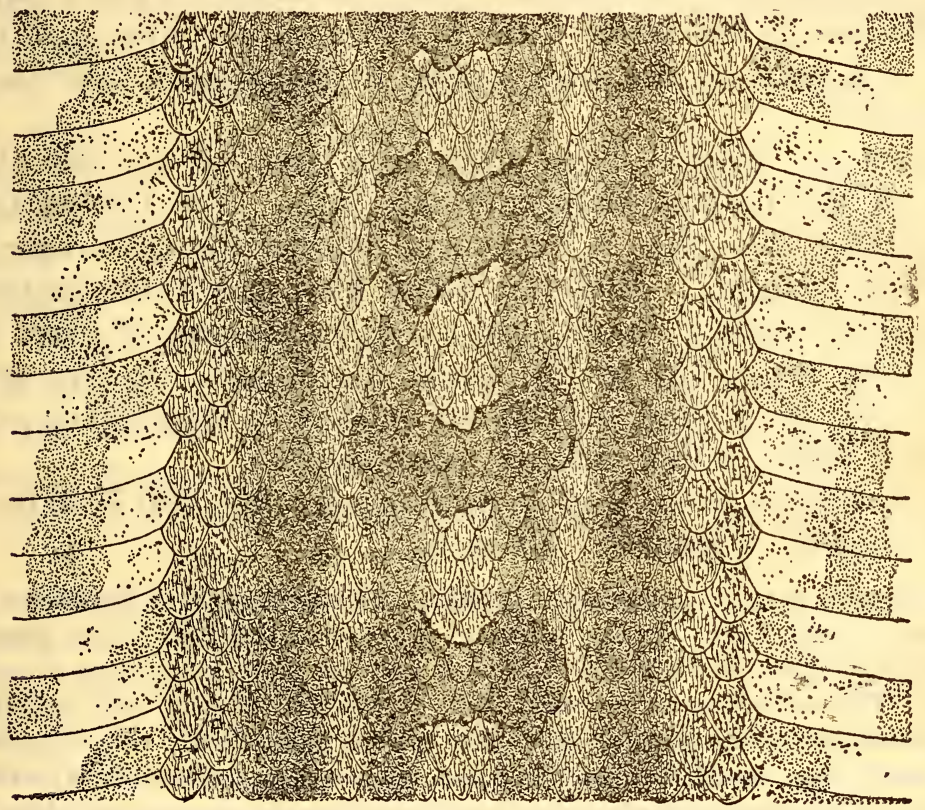

Fig. 40.-Color pattern of Lampropeltis Calligaster (U.S.N.M. No. 61726, Jerseyville, JerSey COUNTY, ILLINOIS), SHOWING THE STRIPED EFFECT COMMONLY EXHIBITED BY DARK INDIVIDUALS. ABOUT $1 \frac{1}{2}$ XiNAT. SIZE.

organ; fringes few and short; spines short and stout, increasing gradually in size to a little more than a third of the way to the base, stopping suddenly; minute spines may succeed the large ones for a fewimillimeters; basal portion of organ smooth.

The skull is very similar to that in the getulus group, and to that of rhombomaculata. Maxillary teeth, 12 to 14, usually 13 or 14, subequal, the anterior and posterior ones slightly smaller than those in the middle; mandibular teeth 13 or 14, the posterior smallest, the fourth to seventh largest; palatines subequal, larger than the pterygoids, 9,10 , or 11 in number; pterygoids 12 to 19 , most commonly 16 . 
While there is usually no trouble whatever in distinguishing this form from rhombomaculata, every individual test may be expected to fail in exceptional cases. The possession of 25 or 27 rows of scales will distinguish calligaster in nearly every instance; yet a specimen from southwestern Missouri has the formula 23-21-19-17-19, and a specimen from University, Mississippi, has the formula 23-21-19. So far no calligaster has been found with only eight infralabials and no rhombomaculata with ten, but both may have nine. The shape of the head is not reliable, nor are the markings on the head. In calligaster the dorsal blotches tend to have concave anterior and posterior margins, while in rhombomaculata these are usually slightly convex or straight, and in the latter these blotches are narrower and tend to come to a point on the sides instead of being more truncate, as in calligaster.

Habitat and habits.- There have been recorded but few observations on the natural history of this form. For Illinois Garman writes $(1892,294)$ that it "occurs on prairies throughout the State. Not very common." Blatchley $(1899,545)$ records the capture of a specimen in Indiana "in an open woods 2 miles east of Terre Haute, at a point where the prairie meets the upland. It was crawling slowly over the ground and did not quicken its speed when pursued, though it struck rather viciously when caught."

An excellent account is given by Branson (1904, 396-7) in his paper on The Snakes of Kansas. He says:

This species is quite numerous throughout the eastern part of Kansas and occurs in all parts of the State. In the collection of snakes at the Beloit High School there are eight specimens of Ophibolus calligaster and not more than seven of any other species. This collection is representative of Mitchell County and indicates that $O$. calligaster is as numerous as any other species found there. O. calligaster lives upon mice, frogs, small fish, etc. I kept three specimens in this laboratory last summer. Birds, toads, lizards, mice, insects, and smaller snakes were placed in the cage with them. They paid no attention to the birds, toads, lizards, and insects, but attacked the mice as soon as they saw them. They would attempt to swallow dead mice that were placed in the cage, but always seized them by the middle of the body. They could not swallow them without beginning at the head and eventually gave it up. I captured a specimen in Gove County in August, 1893, that had just swallowed a mouse. From these observations I conclude that mice are its principal food. This snake is not often found far from water. The ones that I kept in captivity last summer stayed in the water most of the time. One of these snakes molted three, one four, and one two times during their five months' captivity. The one that molted four times always became cross just before molting and would strike me when I attempted to handle him. He did not strike hard enough to do any injury.

The conclusion reached by Branson with regard to mice is fully confirmed by Mr. Mackelden, of St. Louis, who writes that-

On Easter Sunday, 1917, I collected 38 Lampropeltis calligaster along two ravines in Jersey County, Illinois, and every one of them when caught disgorged from 1 to 8 
mice, mostly young mice. We saw a great many more, but did not attempt to catch them. I consider the Evans King snake a valued asset to the farmer, for it comes out of hibernation earlier than most other species and lives largely upon mice, rats, and moles. I have never been bitten by the Evans King snake nor had one attempt to bite me, although I have caught hundreds of them. My experience has been that this snake does most of its hunting for food between sun-up and 10 o'clock. It is seldom that I have caught one out in the open in the afternoon.

Seven specimens of calligaster were taken in an open field along a small ravine in Jersey County, Illinois, early in April, 1919, by Mr. Mackelden and Mr. Froman A. Beach. One specimen disgorged three nestlings of the field mouse, Microtus acrogaster, about five hours after being caught. The mice showed no evidence that digestion had begun.

Eleven eggs of calligaster were plowed up early in August, 1918, by Mr. Beach. These all hatched about a month later.

Range.-This form is known from western Indiana south to Mississippi and Louisiana, westward to western Texas, and northeast to Minnesota. It appears to be well known only from Illinois, Missouri, and Kansas. The limits of its range can at present be only surmised. It should be expected in western Kentucky and Tennessee. The first record for Mississippi rests upon a specimen only recently sent to the Museum of Zoology of the University of Michigan from University, Mississippi, and the two records for Louisiana (Cornell Univ. no. 7154, Jennings, Jefferson Davis County, Louisiana, October, 1906, A. G. Hammer, collector; no. 7153, Chastine Natchitoches County, Louisiana, Apr. 2, 1915, K. P. Schmidt, collector) have not heretofore been recorded. It has several times been said to occur in Wisconsin, but no definite record has been cited. A specimen in the Museum of the Academy of Natural Sciences of Philadelphia bears the label "Minnesota." There is no record for Iowa or Nebraska and for Arkansas only the extreme northeastern corner of the State, Greenway. Writing for Texas, Strecker $(1915,38)$ says, "this beautiful King snake has been reported from only a few scattered localities. It is found in the neighborhood of Waco, but is extremely rare. In addition to the localities represented by specimens in the United States National Museum, specimens from other museums have been examined from the following localities: "Minnesota;" Winemac, and Vigo County, Indiana; Calhoun, Charleston and Cooks Mills, Illinois; Manhattan, Wathena, Salt Creek, Lawrence, Rock Creek, and Osage and Labette Counties, Kansas; Alva, Oklahoma; Jennings and Chastine, Louisiana; University, Mississippi.

Published records for other localities are as follows: Pekin, Illinois (Garman, H., 1892, 293); Deming's Bridge, Matagorda County, Texas (Garman, S., 1892, 9); Greenway, Arkansas (Hurter and Strecker, 1909, 26); and the following counties in Kansas (Branson, 
1904, 376), Mitchell, Lyon, Franklin, Republic, Shawnee, Scott, Gove, Logan, Geary, Sumner, Miami, Pottawatomie, and Neosho.

This form has been reported from Sapulpa, Oklahoma, by Mr. Karl P. Schmidt (1919, 71), but examination by the writer of the specimen upon which this record is based shows it to be a very different snake,

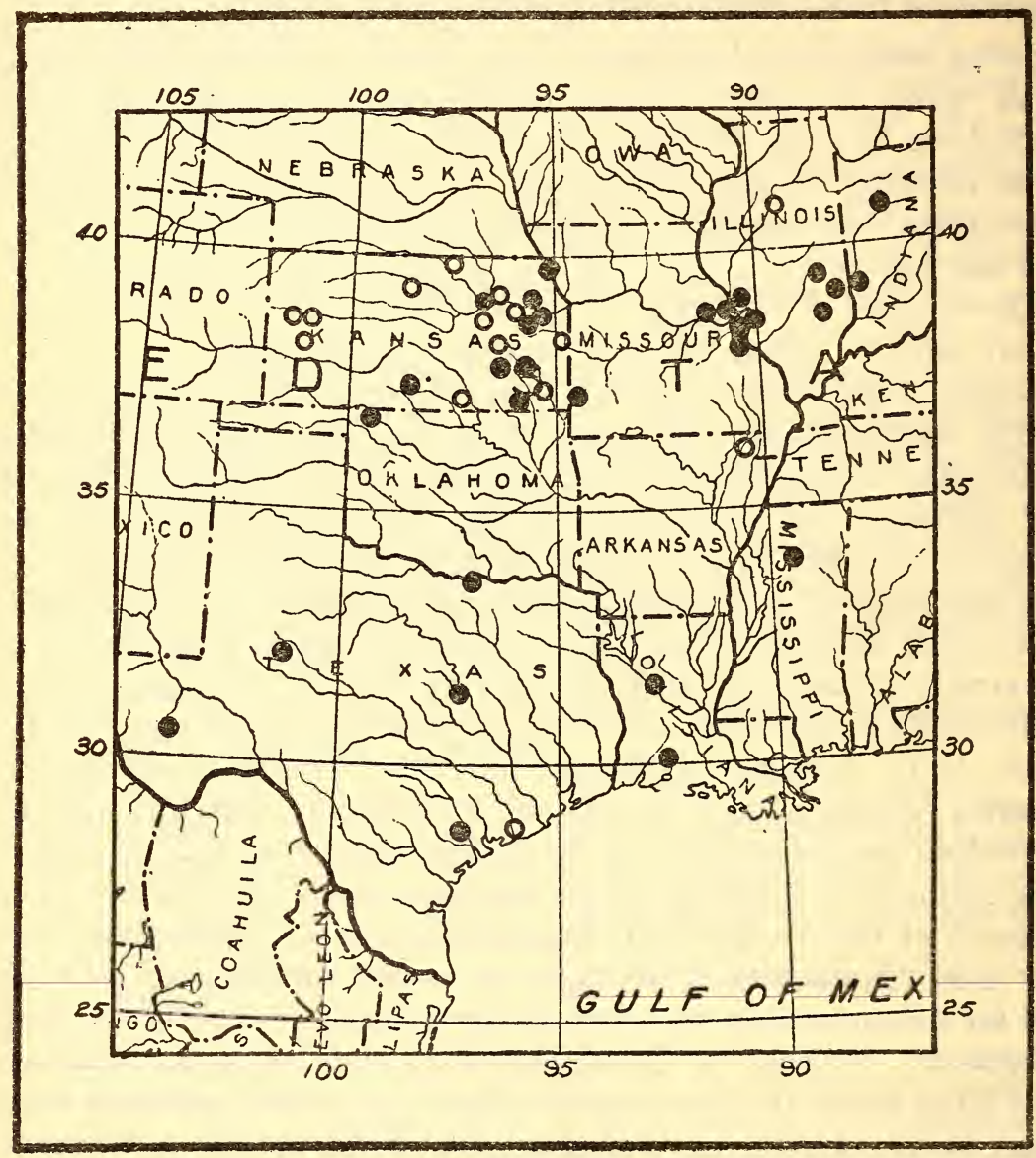

FIG. 41.-MAP SHOWING LOCALITY RECORDS FOR LAMPROPELTIS CALLIGASTER.

but one which is frequently confused with calligaster, that is, Elaphe laeta.

It is reported for Lancaster, Fairfield County, Ohio, by W. H. Smith $(1882$, 689), but, from the description, the identification is obviously incorrect. This is doubtless the basis of Morse's report of later date $(1904,130)$.

There is a specimen in the collection of the American Museum of Natural History, labeled "west coast of Mexico," Frank Trubaudt, collector, but it seems to be impossible to verify this record, or to learn anything more definite as to the locality. It is not at all im- 
possible that its range may actually extend to the west coast of Mexico, but the record here cited is too indefinite to bear any reliance. It may be remarked as bearing upon the unreliability of this record that there is also at the American Museum a specimen of holbrooki (no. R4298) labeled "West Coast of Mexico, Frank Trubaudt, collector."

Summary of certain structural characteristics of calligaster.

\begin{tabular}{|c|c|c|c|c|c|c|c|c|c|c|c|c|}
\hline \multirow[b]{2}{*}{ Locality. } & \multicolumn{2}{|c|}{$\begin{array}{l}\text { Ventral } \\
\text { plates. }\end{array}$} & \multicolumn{2}{|c|}{$\begin{array}{c}\text { Dorsal } \\
\text { blotches. }\end{array}$} & \multirow[b]{2}{*}{ 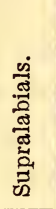 } & \multirow[b]{2}{*}{ 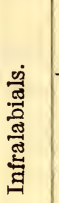 } & \multicolumn{2}{|c|}{$\begin{array}{l}\text { Tail divided by } \\
\text { total length. }\end{array}$} & \multicolumn{2}{|c|}{ Caudals. } & \multirow[b]{2}{*}{ 岗 } & \multirow{2}{*}{ 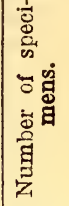 } \\
\hline & 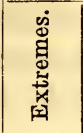 & 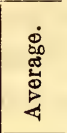 & 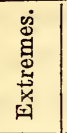 & 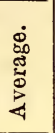 & & & 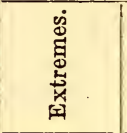 & 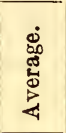 & 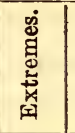 & 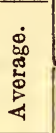 & & \\
\hline Texas. & $196-209$ & 205.2 & $61-69$ & 65 & 7.08 & 9.33 & 0.143 & & $49-56$ & & & 3 \\
\hline Kansas. & $196-213$ & 204.0 & 57- 78 & 68 & 7.05 & 9.40 & $\begin{array}{r}0.121-.138 \\
.124-.150 \\
1115-.135\end{array}$ & $\begin{array}{r}0.128 \\
.138\end{array}$ & $\begin{array}{l}38-52 \\
49-57 \\
41-48\end{array}$ & $\begin{array}{l}45 \\
52 \\
45\end{array}$ & Fen & $\begin{array}{r}3 \\
12\end{array}$ \\
\hline $\begin{array}{l}\text { St. Louis and vi- } \\
\text { cinity. }\end{array}$ & $195-214$ & 205.2 & $46-68$ & 57 & 7.08 & 9.23 & $\begin{array}{l}.124-.149 \\
.110 . .125\end{array}$ & $\begin{array}{l}.140 \\
.142\end{array}$ & $\begin{array}{l}41-48 \\
46-56 \\
40-47\end{array}$ & $\begin{array}{l}45 \\
52 \\
44\end{array}$ & $\begin{array}{l}\text { Female. } \\
\text { Male... }\end{array}$ & $\begin{array}{r}9 \\
15 \\
9\end{array}$ \\
\hline Illinois and west- & 201-212 & 206.0 & $53-69$ & 60 & 7.11 & 9.22 & $\begin{array}{r}.123 \\
.143\end{array}$ & .136 & $44-53$ & 50 & Male... & 17 \\
\hline Whole range.. & $\mid 195-214$ & 205 & 46-78 & 62 & 7.08 & 9.28 & $\begin{array}{l}.1122-.145 \\
.123-.150 \\
1115\end{array}$ & .137 & $\begin{array}{l}42-46 \\
44-57 \\
38-5\end{array}$ & $\begin{array}{l}45 \\
51 \\
45\end{array}$ & $\begin{array}{l}\text { Female. } \\
\text { Male... }\end{array}$ & $\begin{array}{l}10 \\
47\end{array}$ \\
\hline & & & & & & & $.110=.140$ & .123 & & 40 & Female. & \\
\hline
\end{tabular}

Scale formulae of calligaster.

\begin{tabular}{|c|c|c|c|c|c|c|c|c|c|c|c|c|}
\hline \multirow{2}{*}{ Locality. } & \multicolumn{2}{|c|}{$\begin{array}{c}25-27-25- \\
23-21\end{array}$} & \multicolumn{2}{|c|}{$25-23-21$} & \multicolumn{2}{|c|}{$\begin{array}{c}23-25-23- \\
21\end{array}$} & \multicolumn{2}{|c|}{$\begin{array}{c}23-25-21- \\
19\end{array}$} & \multicolumn{2}{|c|}{$\begin{array}{c}23-25-23- \\
21-19\end{array}$} & \multicolumn{2}{|c|}{ Total. } \\
\hline & Male. & $\begin{array}{c}\text { Fe- } \\
\text { male. }\end{array}$ & Male. & $\begin{array}{c}\mathrm{Fe}- \\
\text { male. }\end{array}$ & Male. & $\begin{array}{c}\mathrm{Fe}- \\
\text { male. }\end{array}$ & Male. & $\begin{array}{c}\text { Fe- } \\
\text { male. }\end{array}$ & Male. & $\begin{array}{c}\mathrm{Fe}- \\
\text { male. }\end{array}$ & Male. & $\begin{array}{c}\text { Fe- } \\
\text { male. }\end{array}$ \\
\hline 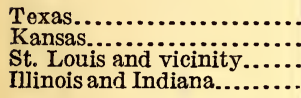 & $\begin{array}{c}\dddot{i} \\
\cdots \\
\cdots\end{array}$ & $\begin{array}{l}2 \\
2 \\
2 \\
1\end{array}$ & $\begin{array}{l}1 \\
1 \\
3 \\
1\end{array}$ & $\begin{array}{l}1 \\
1 \\
1 \\
5\end{array}$ & $\begin{array}{l}1 \\
2 \\
3 \\
1\end{array}$ & $\begin{array}{l}1 \\
2 \\
1 \\
1\end{array}$ & $\begin{array}{l}1 \\
1 \\
2 \\
1\end{array}$ & $\begin{array}{r}\cdots 3 \\
3\end{array}$ & $\begin{array}{r}1 \\
7 \\
7 \\
14\end{array}$ & $\begin{array}{l}\dddot{1} \\
4 \\
3\end{array}$ & $\begin{array}{r}4 \\
12 \\
15 \\
13\end{array}$ & $\begin{array}{r}4 \\
9 \\
11 \\
9\end{array}$ \\
\hline Total....... & 1 & 7 & 6 & 8 & 7 & 5 & 5 & 6 & 29 & 8 & 44 & 33 \\
\hline
\end{tabular}

One male, Jasper County, Missouri, has the formula, 23-21-19-17-19.

One male, University, Mississippi, has the formula, 23-21-19.

Variation and affinities.-The number of specimens and their distribution throughout the area inhabited by this form are entirely inadequate for the demonstration or even detection of geographic variations. The form appears to be very homogeneous throughout its range. It is not unlikely, however, that large series of specimens would reveal geographic tendencies or local differences that may not now be even suspected.

The accompanying tables of structural characters summarize the situation as well as can be done with the material at hand.

The table of scale formulae is built upon so little data that it can do no more than suggest the likelihood that specimens from the region 186550-21-Bull. 114-9 
from St. Louis to Indiana may have a lower average formula than those from farther west and southwest.

Sex influence on the number of scale rows seems evident. The large majority of individuals that attain the maximum number of rows, 27, are females; of those possessing the lowest formula, threefourths are males; of the individuals having the formula next to the highest, the majority are females; and of those possessing the intermediate formulae, $23-25-23-21-19$ and 25-23-21-19, about half are males and half females.

This form is not at present known to intergrade with rhombomaculata, but this may be due to our lack of knowledge of the situation in eastern Mississippi and western Alabama and Tennessee. The close relationship between calligaster and rhombomaculata is more fully brought out under the discussion of the latter form. 


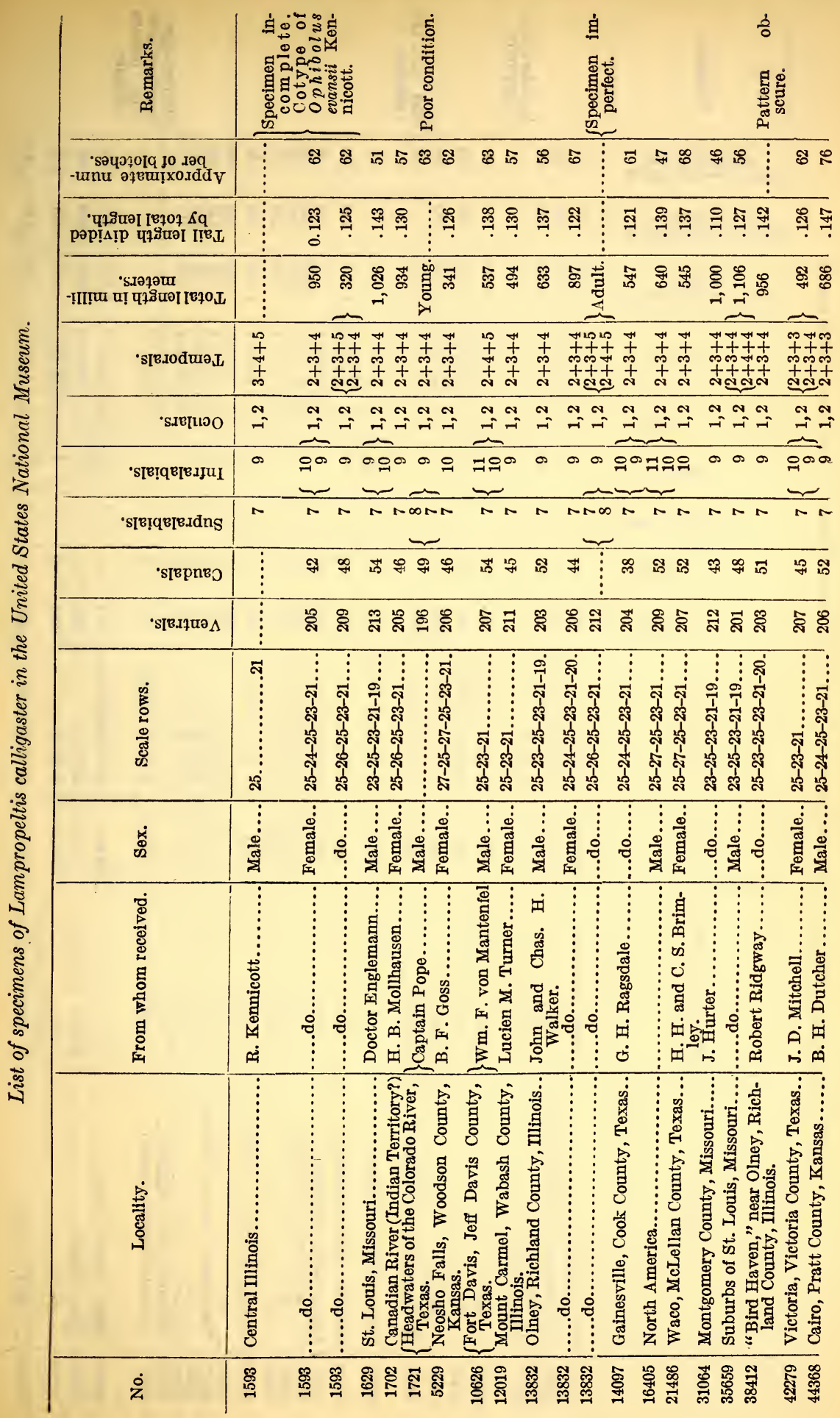




\begin{tabular}{|c|c|c|c|c|c|}
\hline 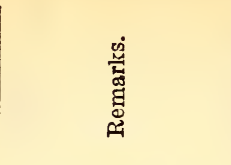 & & & & : & \\
\hline 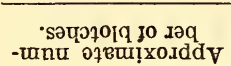 & เీ & 范苛藏的 & th 8 8 88 in & & 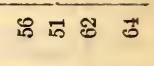 \\
\hline 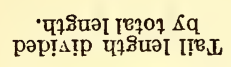 & $\underset{\exists}{~}$ & సิ ๆ & 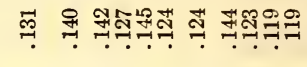 & & 学 \\
\hline 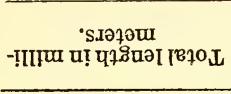 & 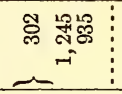 & 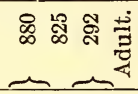 & 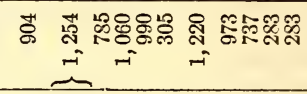 & & 点 \\
\hline 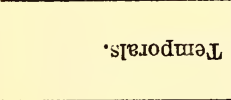 & 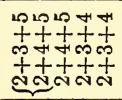 & 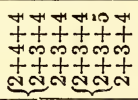 & 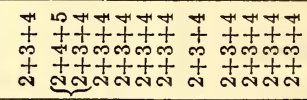 & 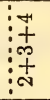 & 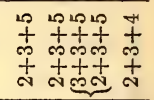 \\
\hline -srefnoo & กั กัก & $\overbrace{-i}^{N} \underset{-1}{N}$ & $\underset{\sim}{N} \approx$ N & & $\overbrace{-\sim}^{N} \approx-\tilde{N}$ \\
\hline 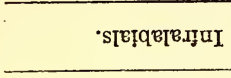 & 00000 & $\underbrace{000000}$ & $\Rightarrow 0000000,700000$ & & $\underbrace{\circ 00000}$ \\
\hline •stetqqiedđns & 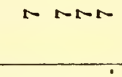 & $N N N$ & $\sim=\underbrace{\infty N+N M N N \infty N N A N R}$ & & NNA \\
\hline 'siepne, & 낙 당여 & 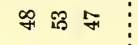 & 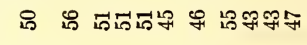 & & ํํำ 옹 중 \\
\hline •sโชдนนə $\Lambda$ & 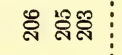 & 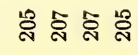 & 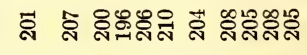 & : & 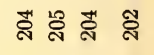 \\
\hline 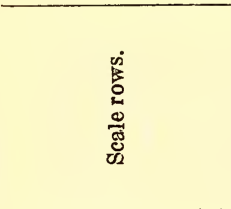 & 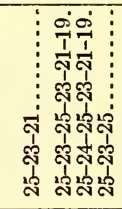 & 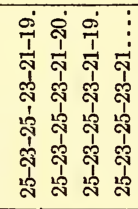 & 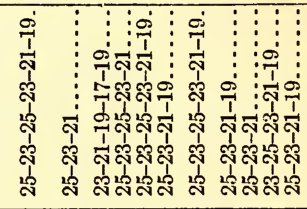 & 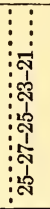 & 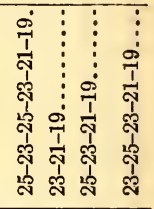 \\
\hline 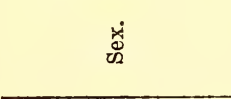 & 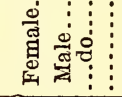 & 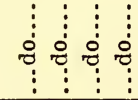 & 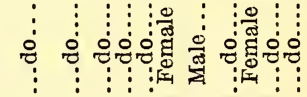 & ఏ) & 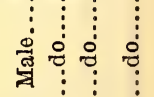 \\
\hline 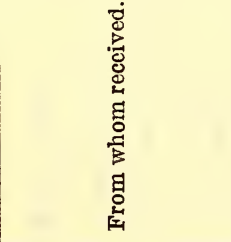 & 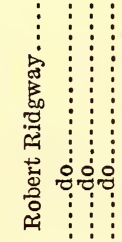 & 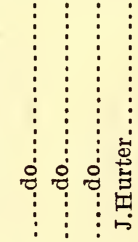 & 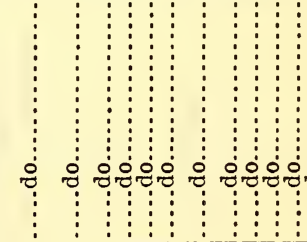 & $\begin{array}{c}\vdots \\
\vdots \\
\vdots \\
\vdots \\
\vdots \\
\vdots \\
\vdots \\
\vdots \\
\vdots \\
\vdots \\
\vdots \\
\vdots\end{array}$ & 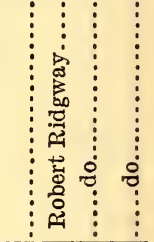 \\
\hline 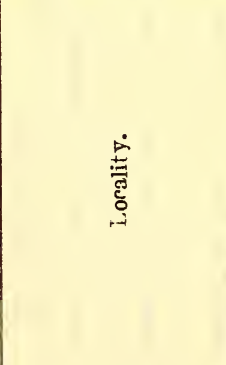 & 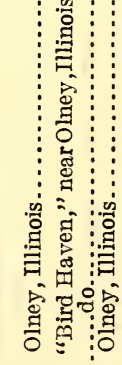 & 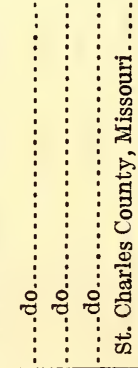 & 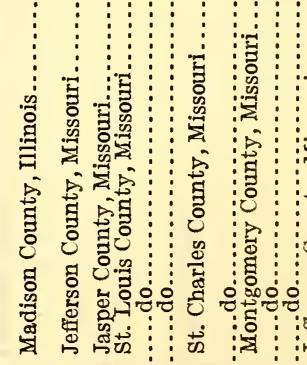 & 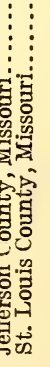 & 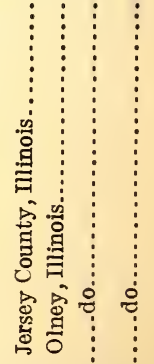 \\
\hline غ̇ & 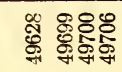 & 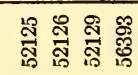 & 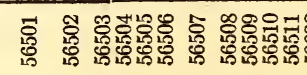 & & 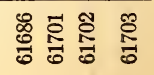 \\
\hline
\end{tabular}


ํํ หำ

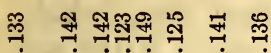

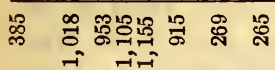

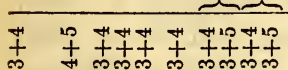

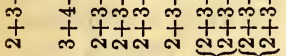

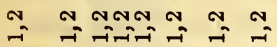

$\overbrace{0,0000000} 0$

n connnnon a i-

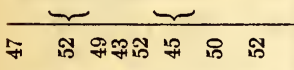

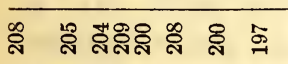

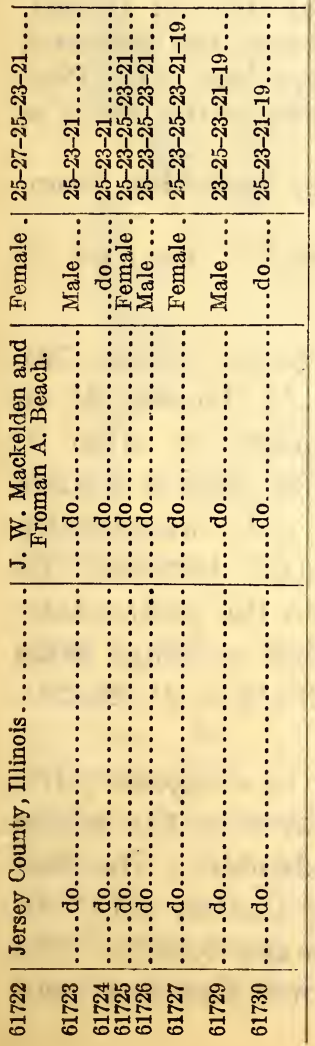


LAMPROPELTIS RHOMBOMACULATA (Holbrook).

MOLECATCHER; BROWN RING SNAKE.

Fig. 42 .

1840. Coluber rhombomaculatus Hоцввоок, N. Amer. Herp., ed. 1, vol. 4, p. 103, pl. 20 (type locality, Georgia and Alabama).-Coronella rhombo-maculata Holbrook, N. Amer. Herp., ed. 2, vol. 3, 1842, p. 103, pl. 23.-JAN, Arch. Zool. Anat., vol. 2, fasc. 2, 1863, pp. 237, 243; Icon. Gen. Ophid., livr. 17, 1866, pl. 2, figs. 1, 2.-Ophibolus rhombomaculatus BAIRD and Girard, Cat. N. Amer. Rept., pt. 1, 1853, p. 86.-Barrd, Pacif. R. R. Surv., vol. 10, pt. 3, no. 1, 1859, pl. 30, fig. 60.-Cope, Bull. U. S. Nat. Mus., no. 1, 1875, p. 37.-Yarrow, Bull. U. S. Nat. Mus., no. 24, 1882, p. 94.-Davis and Rice, Illinois State Lab. Nat. Hist. Bull. no. 5, 1883, p. 34; Bull. Chicago Acad. Sci., vol. 1, no. 3, p. 29 (Southern Illinoisprobably an error).-Cope, Proc. U. S. Nat. Mus., vol. 11, 1888, p. 381; same, vol. 14, 1891, p. 610.-Garman, H., Bull. Illinois State Lab. Nat. Hist., vol. 3, art. 13, 1892, p. 296.-Cope, Rep. U. S. Nat. Mus. for 1898. 1900, p. 903, fig. 222, pl. 18, fig. 5.-Brown, Proc. Acad. Nat. Sci. Philadelphia, 1901, p. 79.-Mrller, Proc. Biol. Soc. Washington, vol. 15, 1902, p. 36.-HAY, same, p. 90.-BRImLey, Journ. Elisha Mitchell Sci. Soc., vol. 21, no. 4, 1905, p. 152; same, 1907, p. 146.Drtmans, Reptile Book, 1907, pp. 341, 354, pl. 103, figs. 5, 8, pl. 104.Brrmley, Journ. Elisha Mitchell Sci. Soc., vol. 30, no. 4, 1915, p. 202.-Lampropeltis rhombomaculata Cope, Proc. Acad. Nat. Sci., Philadelphia, 1860, p. 255.-Stejneger, Proc. U. S. Nat. Mus., vol. 14, 1891, p. 503.-Dunn, Copeia, no. 18, 1915, p. 6.-STejNeger and BArBour, Check List, 1917, p. 89.-Lampropeltis rhombomaculatus HaY, Proc. Biol. Soc. Washington, vol. 15, 1902, p. 138.-SchureldT, Guide to Nature, vol. 5, no. 9, p. 269, fig. 2.

1883. Ophibolus triangulus rhombomaculatus Garman, S., Mem. Mus. Comp. Zool., vol. 8, no. 3, pt. 1, p. 156.

1894. Coronella calligaster (part) Boulenger, Cat. Snakes Brit. Mus., vol. 2, p. 199.

Description.-The scutellation is as follows: Ventral plates, 191 to 213 ; caudals, 31 to 55 (males 37 to 55 , average 45 ; females 31 to 44 , average 41); supralabials, 7 ; infralabials usually 8 , often 9 ; oculars, 1 and 2; temporals $2+3+4$; posterior chin shields a little shorter than the anterior or about equal, parallel, only occasionally separated from each other by a small scale; suture between the internasals only about half as long as that between the prefrontals; loreal usually longer than high, sometimes as high as long; scale rows on middle of body 21 or 23 , formula usually $21-19$ or 21-23-2119.

In bodily proportions this form is very similar to calligaster; the snout is generally shorter and blunter, and apparently the whole animal averages somewhat shorter and more slender. The tail varies from 0.100 to 0.150 of the total length (males, 0.111 to 0.150 , average 0.124 ; females 0.100 to 0.131 , average 0.119 ). The largest specimen examined was from Raleigh, North Carolina, and 
measured $1,137 \mathrm{~mm}$., although Hay records a specimen $1,150 \mathrm{~mm}$. in length $(1902,90)$.

The pattern is very similar to that of calligaster, but in adults it is, as a rule, so greatly obscured that an ordinary individual presents a nearly uniform brown appearance. In the young, however, and in some adults, the markings are well defined.

The body pattern consists of about 55 (48 to 64) transversely elongate dorsal blotches, about $1 \frac{1}{2}$ to 2 scales long, and 8 to 11 scales wide, that become narrower on the sides, and extend down to the

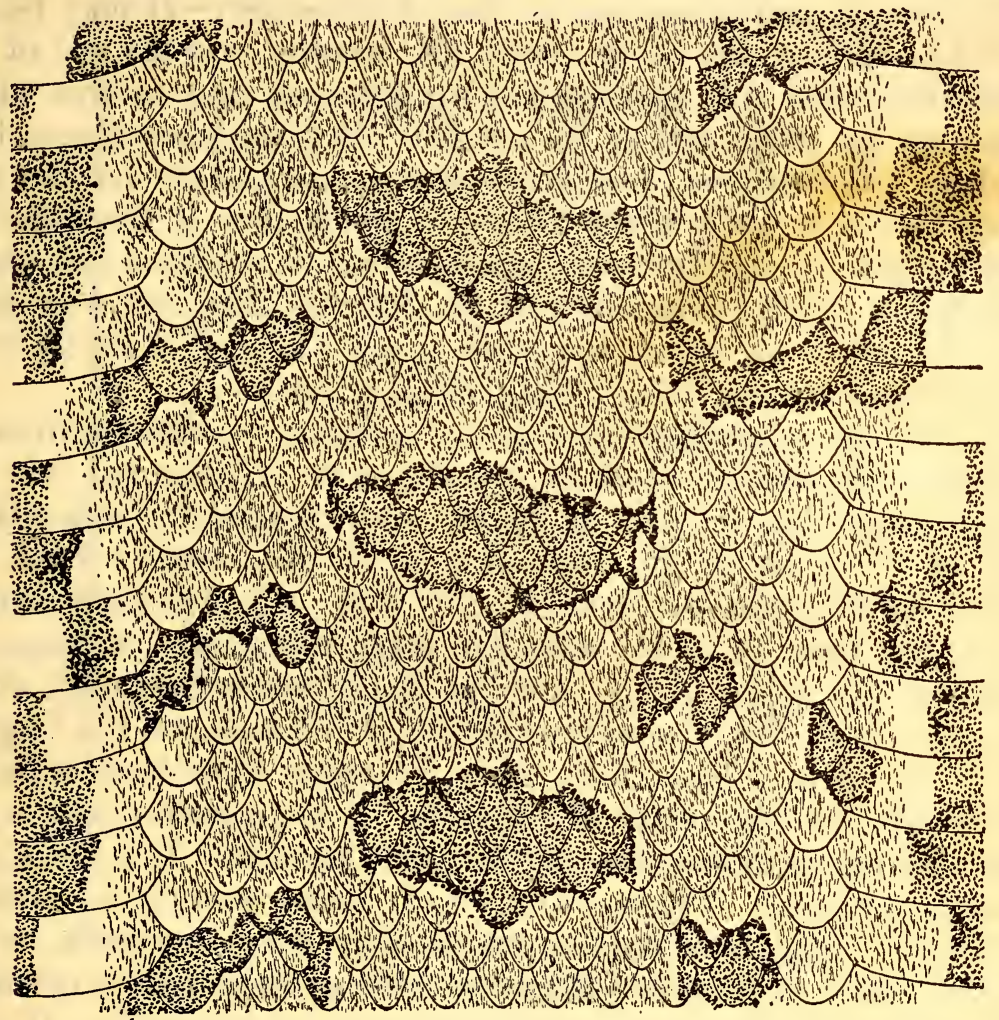

Fig. 42.-COLOR PatTERn of LAMPRopeltis Rhombomaculata (U.S.N.M. No. 16832, BrookLAND, DisIrict of Columbia). ABout $1 \frac{3}{5} \times$ Nat. Size.

sixth or fifth row of scales (fig. 42). On the tail they become much narrower. The two series of lateral alternating blotches are narrow, irregular, and commonly fused into a single series in alternation with the blotches of the dorsal row. Small dark spots are often present, posteriorly, between the spots of the lateral series. The belly is white or yellowish, and checked, scantily or heavily, with dark brown. Large dark individuals often exhibit a lengthwise striping precisely like that described for calligaster (fig. 40), and first observed by Miller in a specimen from Alexandria, Virginia $(1902,36)$. 
The head markings are like those of calligaster, but much less distinct. The prefrontal bar may be just visible; the forked mark on the parietals is evident; the elongate bands on the neck, and the dark diagonal from the lower postocular to the last supralabial are nearly as well developed as in calligaster.

The ground color is a light or dark brown or greenish, lighter on the sides. The dorsal blotches are a darker brown or reddish, narrowly margined with black. In young individuals the blotches are a dark red, and the belly is yellowish.

The penis is closely similar to that of calligasier. It may be described as bilobed; the sulcus single, and passing over the end of the larger lobe where it is continuous with a narrow smooth area which widens on the distal end of the smaller lobe; this smooth area bordered by a few calyces, most numerous on the larger lobe, but still so few that they are scarcely visible in a side view of the fully distended organ; fringes extremely short, becoming modified into short, stout spines which increase in size basally; less than half way down from the end of the organ the large spines replaced abruptly by a few scattered minute ones; basal portion smooth.

The skull is essentially like that of calligaster. The dentition is as follows: Maxillaries 12 to 15, usually 12 or 13, subequal, but distinctly decreasing in size anteriorly and posteriorly; mandibular teeth 12 to 16 , usually 12 , decreasing in size before and behind, the third to sixth largest; palatines, 9 or 10, subequal; pterygoids usually 14 , varying from 13 to 16 , subequal, smaller than the palatines.

Habitat and habits.-This form was rare in collections until about 1888 when it was found near the District of Columbia, on the Virginia side of the river. Since then many examples have been taken in this vicinity on both sides of the river. Its apparent rarity is undoubtedly due to its secretive and burrowing habits. It is sometimes found in the open. Ditmars $(1907,355)$ reports finding one in Fairfax County, Virginia, "that lay stretched upon a grassy bank, enjoying the warm rays of a spring sun. When captured it defended itself vigorously for the moment, but soon became quiet. Having no receptacle in which to place the snake, the writer carried it several miles coiled quietly about his hand. Its only symptom of anger was an occasional shaking of the tail." One taken near Mobile, Alabama, last spring by Mr. W. R. Jones was found "crossing a dry road in the latter part of the afternoon." Mr. Jones describes the situation as "cut-over pine land with more or less scrub oak. Not much brush, as it is frequently burned over. Light soil, sandy loam; about 600 yards from nearest water." Frequent notes on labeled specimens indicate that it is most commonly found in the ground, and turned out by the plow or in excavations. Mr. E. R. Dunn thinks they can be readily found by following a plow in any upland 
field near the District of Columbia, and reports seven plowed up in one 12-acre field in middle Virginia.

In regard to its food in captivity, Ditmars (1907, 355) says it "feeds upon the young of other snakes and upon lizards as well, but seems to prefer small rodents and birds," and to be especially fond of "very young birds. Some specimens refused these tempting morsels, and ultimately starved to death. Generally speaking, these snakes are sluggish and uninteresting in captivity." One example

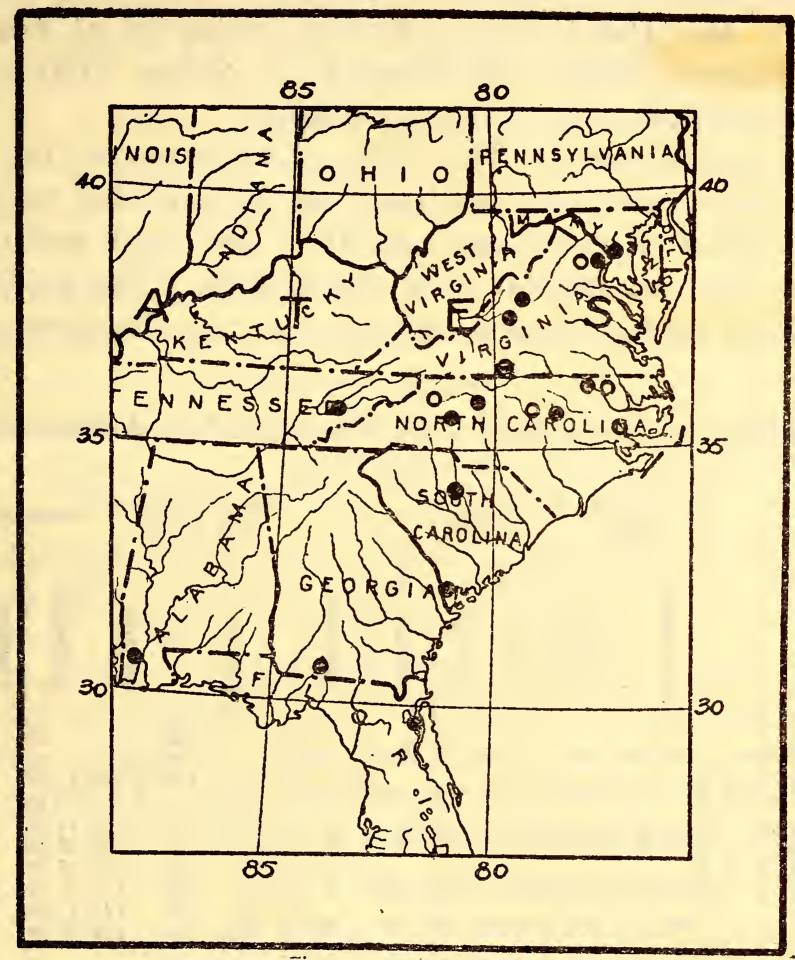

Fig. 43.-MAP SHOWING LOCALITY RECORDS FOR LAMPROPELTIS RHOMBOMACULATA.

found by Mr. Dunn in Nelson County, Virginia, disgorged a mouse. In captivity they will feed upon dead mice.

Accurate observations on the natural history of this form are very much to be desired.

Range.-This species is at present known from Montgomery County, Maryland, south through the Atlantic States to northern Florida, west to Mobile County, Alabama, and northeast to Knoxville, Tennessee. Until about 30 years ago it was considered a rare snake, and was known only from the Carolinas to Alabama. Since that time numerous examples have been taken from Raleigh, North Carolina, from Nelson County, Virginia, and from the vicinity of Washington, District of Columbia. Now that we know better how 
to look for it, we should be able to extend our knowledge of its range.

It is highly desirable to learn how far west it occurs in order to see if there is any approach in structural characters to calligaster.

It will undoubtedly be found farther north in Maryland, perhaps even in New Jersey.

Published records for localities not included in the list of specimens examined are as follows: Illinois (Davis and Rice, 1883, 34), undoubtedly an error; Groveton, Virginia (Ditmars, 1907, 345). Furthermore Mr. Dunn reports finding examples at Warminster, Norwood, Midway Mills, and Wingina, in Nelson County, and at Bent Creek in Appomattox County, Virginia.

Variation and affinities. - The study of variation in this form can not be undertaken at present with any satisfaction, due to the totally inadequate series of specimens available, and their unequal distribution over the area inhabited by the species. The accompanying table has been prepared as a summary of the situation as it now stands.

Summary of certain structural characteristics of rhombomaculata.

\begin{tabular}{|c|c|c|c|c|c|c|c|c|c|c|c|c|}
\hline \multirow[b]{2}{*}{ Region. } & \multicolumn{2}{|c|}{$\begin{array}{l}\text { Ventral } \\
\text { plates. }\end{array}$} & \multicolumn{2}{|c|}{$\begin{array}{c}\text { Dorsal } \\
\text { blotches. }\end{array}$} & \multirow[b]{2}{*}{ 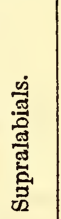 } & \multirow[b]{2}{*}{ 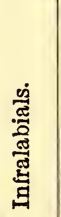 } & \multicolumn{2}{|c|}{$\begin{array}{l}\text { Tail divided by } \\
\text { total length. }\end{array}$} & \multicolumn{2}{|c|}{ Caudals. } & \multirow[b]{2}{*}{ 这 } & \multirow{2}{*}{ 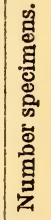 } \\
\hline & 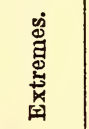 & 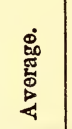 & 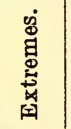 & 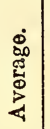 & & & 岕 & 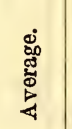 & 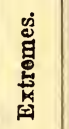 & 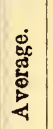 & & \\
\hline Knoxville, Tennessee. . & 202-205 & 203.5 & $51-55$ & 53 & 7.00 & 8.50 & 0.150 & & $\begin{array}{l}55 \\
44\end{array}$ & n & Male.. & 1 \\
\hline $\begin{array}{l}\text { Alabama, Georgia, and } \\
\text { Florida. }\end{array}$ & $197-208$ & 202.4 & $50-58$ & 53 & 7.00 & 8.50 & $\{0.127-.139$ & $\dddot{0.133}$ & $\begin{array}{r}47-52 \\
43\end{array}$ & 49 & Male.: & $\begin{array}{l}1 \\
3 \\
2\end{array}$ \\
\hline $\begin{array}{l}\text { Southern Virginia to } \\
\text { South Carolina. }\end{array}$ & $196-213$ & 203.7 & $48-60$ & 54 & 7.03 & 8.38 & $.121-.148$ & $\begin{array}{l}.132 \\
.118\end{array}$ & $\begin{array}{l}43-50 \\
42-43\end{array}$ & $\begin{array}{l}47 \\
43\end{array}$ & $\begin{array}{l}\text { Male..: } \\
\text { Female }\end{array}$ & $\begin{array}{r}14 \\
2\end{array}$ \\
\hline $\begin{array}{l}\text { District of Columbia } \\
\text { and vicinity. }\end{array}$ & $191-211$ & 200.3 & $48-64$ & 56 & 7.00 & 8.13 & $\begin{array}{l}.111-.135 \\
.101-.130\end{array}$ & $\begin{array}{l}.124 \\
.117\end{array}$ & $\begin{array}{l}37-48 \\
31-43\end{array}$ & $\begin{array}{l}42 \\
40\end{array}$ & $\begin{array}{l}\text { Male. } \\
\text { Fomale }\end{array}$ & $\begin{array}{l}19 \\
13\end{array}$ \\
\hline Whole range........... & $191-213$ & 201.5 & $48-64$ & 56 & 7.01 & 8.29 & $.111-.150$ & $\begin{array}{l}.124 \\
.119\end{array}$ & $\begin{array}{l}37-55 \\
31-44\end{array}$ & $\begin{array}{l}45 \\
41\end{array}$ & $\begin{array}{l}\text { Male.. } \\
\text { Female }\end{array}$ & $\begin{array}{l}37 \\
18\end{array}$ \\
\hline
\end{tabular}

Upon comparison with the similar table for calligaster, it will be noticed (1) that the averages are strikingly similar for everything except the labials, (2) that they are, in nearly every instance, slightly lower than the corresponding figures for the other form, (3) that the ventrals, infralabials, and caudals reach their lowest averages at the most northerly locality, and that here this form is farthest removed both structurally and geographically from calligaster.

Not only in its externally visible features of scalation, pattern, and bodily proportions, but also in its penial and dental characters does it demonstrate its close relationship with calligaster, and with or through calligaster its near relationship to the members of the getulus group. Its closest relatives, therefore, are all forms that get 
their living chiefly above ground. But it appears that this is largely a burrowing form. Certain degenerative tendencies may therefore be expected. The infralabials furnish one instance, the averages for which, although admittedly based on a very inadequate number of specimens, can hardly be without significance. This decrease in number of infralabials is probably to be correlated with a shortening of the snout, and the latter is very likely associated with burrowing habits. One of the charaicteristic differences between this form and calligaster is the shorter and blunter snout, a difference that may usually be observed but that is not easy to measure.

The number of specimens is too small to reveal geographic tendencies in the number of scale rows, but, for comparison with the condition in calligaster, it should be noted that along with the distinctive difference in numbers of labials and the somewhat smaller average size of body, there is a decided decrease in scale formula, an average difference of two rows on each side of the body.

A sexual difference in scale formula is fairly evident. The figures in the table may be summarized as follows: (1) About half of the individuals of each sex have the formula 21-19; (2) nearly all the rest of the females have a higher formula, 21-23-21-19 (one of those having the formula 19-21-19, U.S.N.M. no. 17444, is a highly aberrant individual in other matters of scalation), and most of the males have a lower; (3) no female has 17 rows at the end, while this is the case with about one-fourth of the males.

In pattern as well as in scutellation and proportions, this form shows itself to be a reduced calligaster. Moreover, the differences are but slight. The markings on the head are in every way similar, but are less well defined. The smaller average number of dorsal blotches may be accounted for by the shortening of the tail, but these blotches are different in shape. Their anterior and posterior borders are generally slightly convex, instead of concave, as in calligaster, and they taper nearly to a point on the sides, instead of being truncate or blunt, as in the latter form. The fact that they extend down on the sides commonly to the fifth row of scales instead of to the seventh or sixth is due to the loss of one or two rows on each side of the body. This lower extension of the dorsal blotches may account for the fact that the two lateral series of alternating spots, characteristic of calligaster, tend to fuse into a single series. Degeneracy is indicated by the contracted and transversely zigzag shapes that this lateral series assumes. Then, too, the tendency for the pattern to be indistinct seems to be an accentuation of the condition illustrated by the calligaster of the region from eastern Missouri to Indiana.

All the differences between rhombomaculata and calligaster are traceable to reduction or degeneration and not to any further development of the characteristics of the latter form. 
We may therefore summarize the situation with regard to rhombomaculata by considering it a derivative of calligaster by (1) a shortening and strengthening of the head, developed in response to burrowing habits, and particularly noticeable in the shape of the snout; (2) a reduction of one in the number of infralabials, correlated with the shortening of the head; (3) an average reduction of one tooth in the maxillary, palatine, and mandibular series, and of two in the pterygoid series; (4) a reduction in number of scale rows, amounting to about two on each side of the body; (5) a slight reduction in numbers of ventrals and caudals, and, correlated with the last, a decrease in the proportionate tail length; (6) reduction and fading of the pattern; and (7) a slight decrease in body length and girth.

Scale formulae of rhombomaculata.

\begin{tabular}{|c|c|c|c|c|c|c|c|c|}
\hline \multirow{2}{*}{ Locality. } & \multicolumn{2}{|c|}{$21-23-21-19$} & \multicolumn{2}{|c|}{$21-19$} & \multicolumn{2}{|c|}{$19-21-19$} & \multicolumn{2}{|c|}{$\begin{array}{l}19-21-19-17- \\
21-19-17\end{array}$} \\
\hline & Male. & $\begin{array}{l}\mathrm{Fe}- \\
\text { male. }\end{array}$ & Male. & $\begin{array}{l}\text { Fe- } \\
\text { male. }\end{array}$ & Male. & $\begin{array}{l}\text { Fe- } \\
\text { male. }\end{array}$ & Male. & $\begin{array}{c}\mathrm{Fe}- \\
\text { male. }\end{array}$ \\
\hline $\begin{array}{l}\text { District of Columbia and vi- } \\
\text { cinity } \ldots\end{array}$ & \multirow[t]{4}{*}{2} & \multirow{4}{*}{3} & \multirow{4}{*}{$\begin{array}{l}10 \\
11\end{array}$} & \multirow{4}{*}{7} & \multirow{4}{*}{3} & \multirow{4}{*}{2} & \multirow{2}{*}{4} & \\
\hline $\begin{array}{l}\text { Southern Virginia to South } \\
\text { Carolina }\end{array}$ & & & & & & & & \\
\hline $\begin{array}{l}\text { Georgia, Florida, and Ala- } \\
\text { bama.......................... }\end{array}$ & & & & & & & 1 & \\
\hline 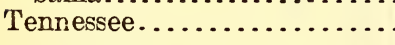 & & & & & & & 1 & \\
\hline Total...... & 3 & 7 & 24 & 9 & 3 & 2 & 9 & $\ldots \ldots$ \\
\hline
\end{tabular}

Total number of males, 39 .

Total number of females, 18. 


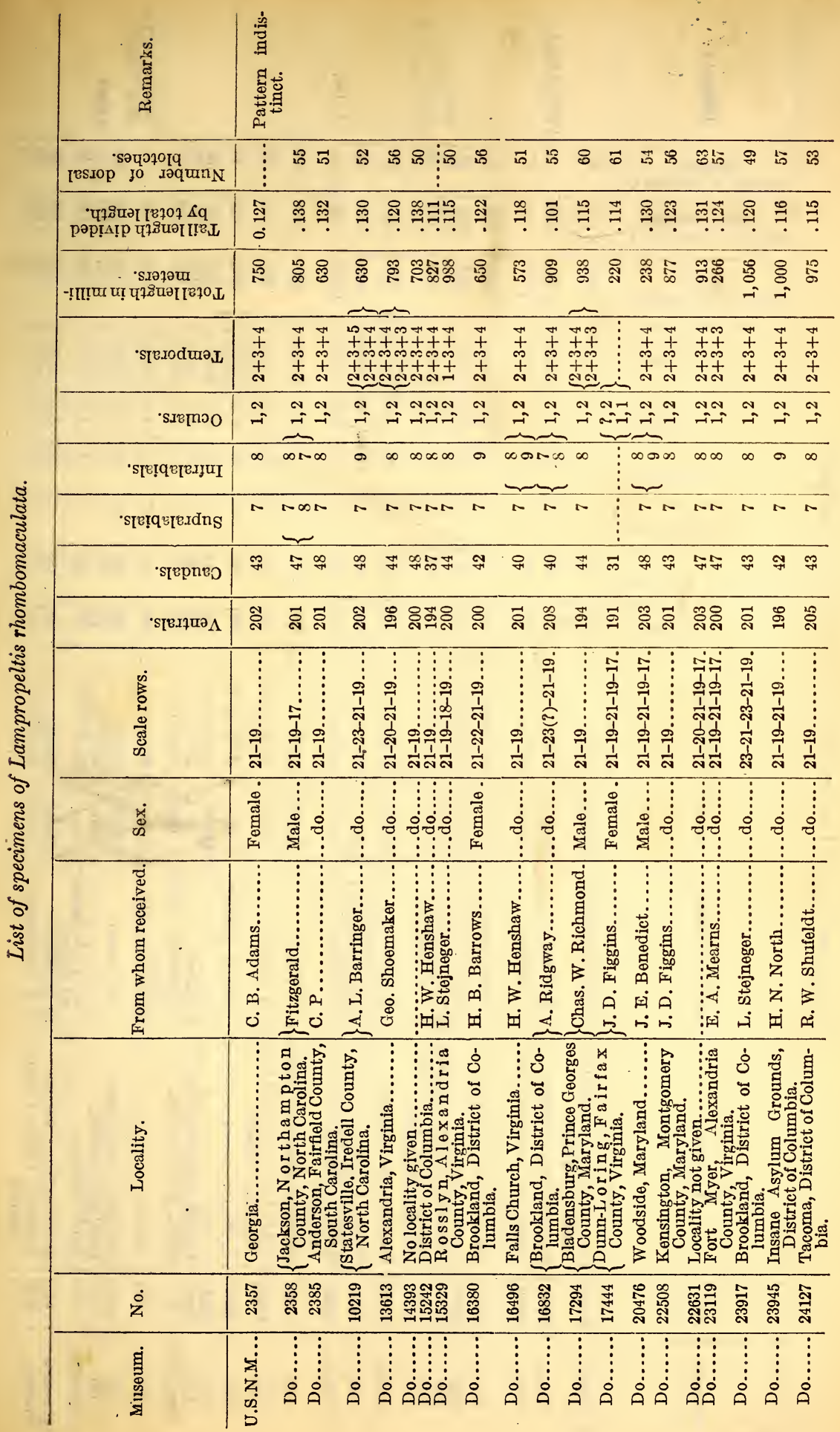




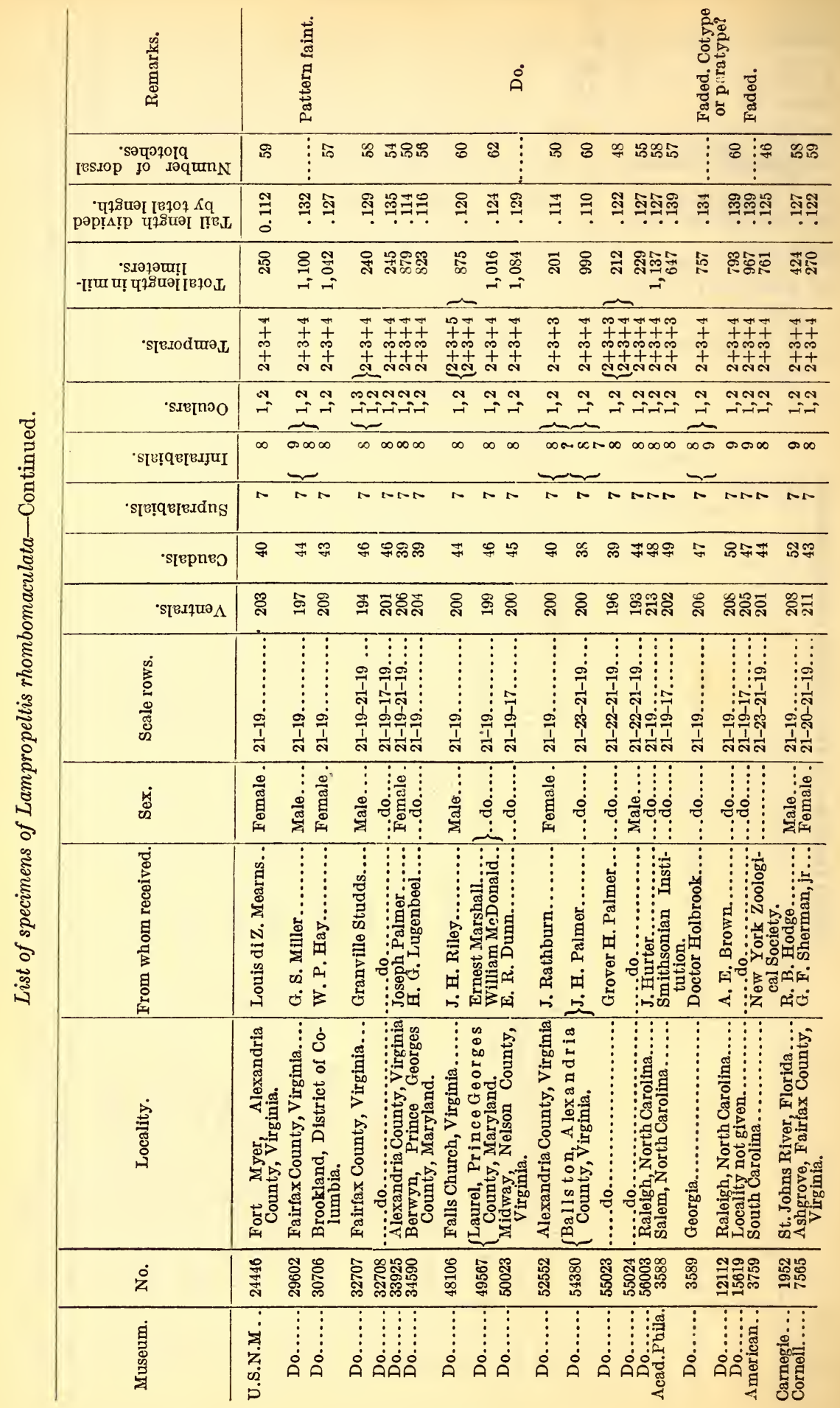




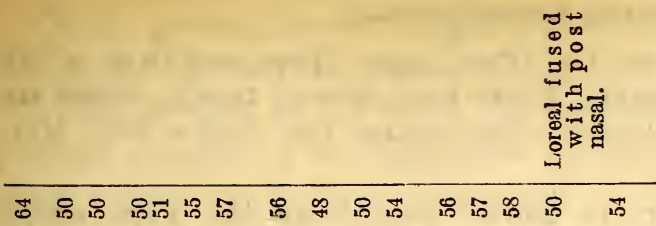

乐 굼

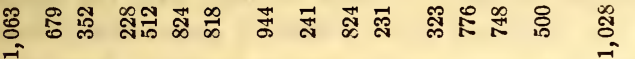

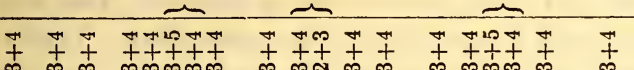

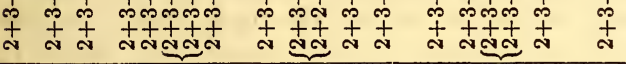

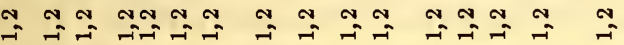

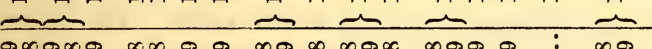

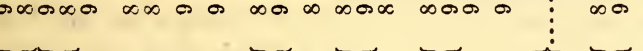

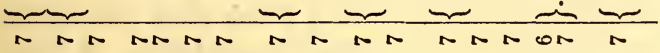

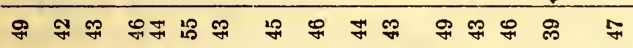

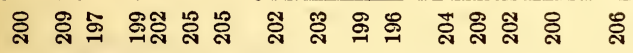

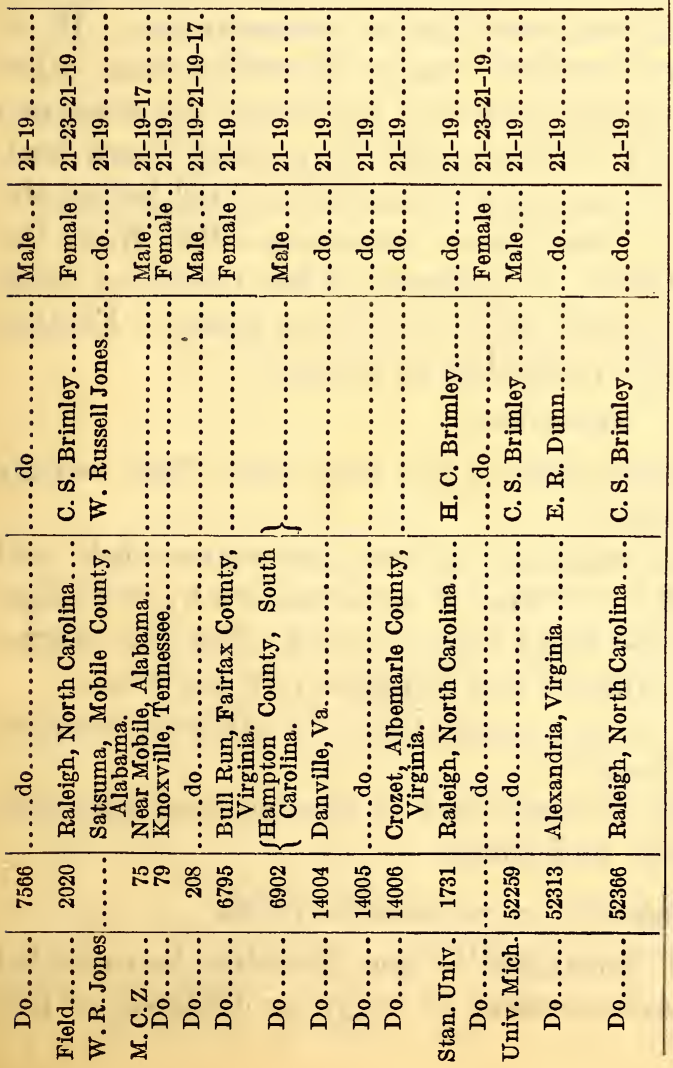




\section{LAMPROPELTIS LEONIS (Günther).}

1893. Coronella leonis GüNther, Biol. Cent. Amer., Rept. and Batr., p. 110, pl. 39, fig. A (type locality, Nuevo Leon, Mexico; type in British Museum; W. Taylor, collector).-Bodlenger, Cat. Snakes Brit. Mus., vol. 2, 1894, p. 199.

Description.-As this form is known only from the type specimen, the original description is here quoted in full:

Scales in 23 rows, without pit, smooth; head similar to that of Coronella laevis; anterior frontals not quite half the size of posterior; vertical 5-sided, with the lateral margins convergent; 1 praeocular not reaching the vertical; 2 postoculars; loreal longer than deep; 7 upper labials, the third and fourth entering the orbit; temporals $2+3$, of the 2 anterior only the upper one is in contact with the postoculars. Ventrals 200; anal entire; subcaudals 50. Body pale olive-color on the back, with 27 salmoncolored incompletely black-edged spots, some being of a transversely oval shape, but the majority presenting the appearance of being formed of 2 rounded portions. On the tail the spots lose their light center and appear merely as brown spots. The lateral spots which are so conspicuous in most variations of Coronella triangulum are here nearly entirely absent. Vertical and each occipital with a black spot, red in the center; abdomen with only a few blackish blotches irregularly scattered. A black band along the middle of the lower part of the tail. The single specimen measured $23 \frac{1}{2}$ inches, the tail $3 \frac{3}{4}$ inches. This snake may be considered to be one of the aberrant forms of Coronella triangulum.

Remarks.-The description is incomplete in some respects, and the type specimen has not been available for examination. If, as stated above, scale pits are actually absent, in which case other distinctive differences will almost certainly be found, the specimen can hardly be a Lampropeltis, but an error may easily have been made on this point. Further examples must be obtained before the status of this form can be stated with assurance. But from the description and excellent figure, it appears to be a distinct form closely allied to the other members of the calligaster group. Further discussion, however, is hardly profitable at present.

\section{SUMMARY.}

The handicap of insufficient material has been more than usually acute in the study of this group.

The intimate relationship existing between rhombomaculata and calligaster and the fact that the former is a derivative by reduction of the latter need not here be more than recalled, after the discussions already given under Variation and Affinities of these forms.

That leonis is a member of the group must be allowed, pending further knowledge of the form.

We may therefore express the relations of the forms of the calligaster group, diagramatically, as follows:

$$
\text { leonis_calligaster } \longrightarrow \text { rhombomaculata }
$$

The Atlantic States-the "Southeast"-may therefore be excluded from consideration as a possible center of origin or dispersal of this group. 
Of the present known range of calligaster, the northeast has points distinctly against its consideration as the required center, namely, (1) this portion is north of the southern limit of glaciers, (2) the pattern appears to be degenerate (indistinct) here, (3) the number of scale rows is somewhat diminished in the northeast, (4) the infralabials are here less often 10 . We must therefore look south of the Missouri River and west of the Mississippi for the center of the group. Of this region we know very little of the situation outside of Kansas, and this is too far north to be a center of reptilian preservation and radiation.

We are forced therefore to look to the "Southwest"-perhaps Texas or northern Mexico-for the center of dispersal of this group, and to await fuller information before being more specific.

\section{THE TRIANGUIUM GROUP. LAMPROPELTIS POLYZONA Cope. \\ CORALILLO.}

Fig. 64.

1858. Coronella doliata, var. A GüNTher, Cat. Colubr. Snakes Brit. Mus., p. 42.Salvin, Proc. Zool. Soc. London, 1861, p. 227 (Vera Paz, Guatemala).Ophibolus doliatus Dugés, La Naturaleza, 1876, vol. 3, pp. 222-226, fig. 1860. Lampropeltis polyzona Cope, Proc. Acad. Nat. Sci. Philadelphia, p. 258 (type locality, Quatupe, near Jalapa, Mexico; type specimen, Acad. Nat. Sci. Philadelphia, no. 9770; Mr. Pease, collector); same, 1861, p. 302 (Mirador, Vera Cruz).-Ophibolus polyzonus Cope, Proc. Amer. Philos. Soc., vol. 11, 1869, p. 162.-Sumichrast, Bull. Soc. Zool. France, 1880, p. 181.-Ferrari-Perez, Proc. U. S. Nat. Mus., 1886, p. 187.

1861. Lampropeltis micropholis Cope, Proc. Acad. Nat. Sci. Philadelphia, p. 302 (Minatitlan, Mexico).-McLain, Contr. Neotr. Herp., 1899, p. 5.-Coronella micropholis Boulenger, Cat. Snakes Brit. Mus., vol. 2, 1894, p. 203, vars. B, C, E, F.-Werner, Rept. Batr. Centralamerika, Chili, 1896, p. 10.Boettger, Kat. Rept.-Samml. Frankfurt, pt. 2, 1898, p. 72.-Werner, Abhand-Akad. Wiss. München, vol. 22, pt. 2, 1903, p. 347.-GADow, H., Proc. Zool. Soc. London, 1905, vol. 2, p. 196 (var. B, Chilpancingo, San Luis Allende).-Barbour and Cole, Bull. Mus. Comp. Zool.,vol. 50, no. 5, 1906, p. 152 (Chichen Itza, Yucatan).-GaDow, H., Zool. Jahrb., Abt. Syst. Geog. Biol., vol. 31, 1911, pp. 6, 24, pl. 1, figs. 6, 7 (Carrizal, S. Michoacan; Chilpancingo, Guerrero).-STernfeld, Sitz. Gesell. Nat. Freunde, 1913, pp. 105, 106, 115, pl. 10, fig. 4.

1861. Coronella doliata, var. formosa J AN (part), Icon. Gen. Ophid., livr. 14, Dec., pl. 4, fig. B (no locality given); Arch. Zool. Anat., vol. 2, fasc. 2, 1863, pp. 237, 241 (Mexico).

1883. Ophibolus triangulus zonatus Garman, S., Mem. Mus. Comp. Zool., vol. 8, no. 3, pt. 1, p. 67 (Acapulco, Mexico).

1886. Coronella formosa Bocourt, Miss. Sci. Mex., p. 612, pl. 39, figs. 3, $3 a$ to $3 e$. 1886. Coronella formosa polyzona Bocourt, Miss. Sci. Mex., p. 615, pl. 39, figs. 7, $7 a-7 d$ (Oaxaca).

1886. Coronella formosa anomala Bocourr, Miss. Sci. Mex., p. 614, figs. 4, 4a-4c

(type specimen in Paris Museum; type locality Haute Vera Paz, Guatemala).

$186550-21-$ Bull. $114-10$ 
1886. Coronella formosa oligozona Bocourt, Miss. Sci. Mex., p. 614, pl. 39, figs. 8, $8 a-8 d$ (Tehuantepec, west slope of Guatemala) (two cotypes in Paris Museum; type locality, Tehuantepec).

1887. Ophibolus doliatus coccineus (part) Cope, Bull. U. S. Nat. Mus., no. 32, p. 78 (Guatemala, Zacualtipan).

1887. Ophibolus doliatus polyzonus (part) Cope, Bull. U. S. Nat. Mus., no. 32, p. 78; Proc. U. S. Nat. Mus., vol. 11, 1888, p. 382; vol. 14, 1891, p. 608; Amer. Nat., vol. 27, 1893, p. 1067.-Osceola doliata polyzona Cope, Rep. U. S. Nat. Mus. for 1898,1900, p. 898.

1903. Coronella micropholis arcifera Werner, Zool. Anz., vol. 26, p. 250 (type specimen in Naturhistorischen Museum in Brüssel; type locality, Mexico).

In the same paper in which the original description of polyzona appeared Cope described a specimen from Panama under the name of micropholis. He later decided that it was identical with polyzona, and thereafter called both by the latter name. Other authors have likewise considered the two names synonymous, but have generally used the name micropholis in preference to polyzona, because it appeared a page earlier than the latter. The present review, however, has disclosed the fact that Cope really did have two very distinct forms before him. The great variability and relative abundance of specimens of the northern one and the scarcity of specimens of the southern form have hitherto obscured the distinctness of the latter.

The paper containing the original descriptions of polyzona and $m i$ cropolis was read before the Academy of Natural Sciences of Philadelphia in June, 1860, and was probably published before the end of that year in one of the quarterly issues of the Proceedings. The volume for 1860 bears the date 1861 . It seems to be impossible to determine the exact date for the whole volume or for the quarterly portion containing Cope's paper, but it in all probability antedates Jan's figure of Coronella doliata, var. formosa of December, 1861. Jan's formosa, however, was a composite, as a study of his figures B and B* shows, and the writer therefore, in accordance with his privilege as first reviser, designates as the type of formosa figure B* (Jan. 1861, livr. 14, pl. 4), thus making the type locality definite and fixing the name formosa Jan as a synonym of micropholis Cope.

Description.-In Mexico and Central America this is the best known form of the genus. The following summary of scutellation is based upon the examination of 48 specimens and published records of about a dozen more: Ventral plates, 208 to 239 ; caudal, 42 to 61 ; 1 preocular; 2, very rarely 1 or 3 , postoculars; supralabials, 7 , rarely 8 ; infralabials, 9 , sometimes 8 , less of ten 10 ; temporals usually $2+3+4$; loreal usually present, and longer than high, sometimes about as high as long, occasionally absent, its place being then occupied chiefly by a backward extension of the posterior nasal; posterior chin 
shields usually a little shorter than anterior, in contact with each other, or occasionally separated by 1 or 2 small scales. The maximum number of scale rows is nearly always 23 or 21, becoming posteriorly 19 or 17 , but examples from Costa Rica and Yucatan may not have more than 19 rows.

The proportions are nearly the average for the genus. The head is widest at the temples and tapers toward the snout, which is blunt; it is but slightly distinct from the body; the latter is cylindrical, fairly stout, and of approximately uniform diameter; the tail is short and stout, but averages a little longer than for most forms of the group; its length in proportion to the total length varies from 0.124 to 0.164 (males, 0.130 to 0.164 , average 0.144 ; females 0.124 to 0.140 , average 0.131 ). The largest specimen examined was $1,580 \mathrm{~mm}$. in length, and was from Nicaragua; however, a dried skin of one from the same country measured $1,610 \mathrm{~mm}$.

The body pattern is made up of from 17 to 37 paired rings of black bordering narrow annuli of white or yellow and separated by broader ones of red. The dorsal scales of the red areas are usually strongly tipped with black, but these black tips are sometimes very small or absent altogether. The white rings are $\frac{1}{2}$ to $1 \frac{1}{2}$ scales in width, widening but little if any on the first row of scales; the black rings are from $1 \frac{1}{2}$ to 3 scales wide on the middorsal line, and, rarely, excluding the red altogether from some of the annuli. The red rings, although not infrequently narrower, are usually wider than the groups of black and yellow rings that separate them. The scales of the yellow rings may be uniform in color, but more often they are strongly tipped and mottled with black, and infrequently the latter color may almost obliterate the yellow.

All of the annuli are usually continuous across the belly, but some specimens from the State of Vera Cruz and from Yucatan Peninsula show the red bands to have widened on the sides so far as to exclude the black and yellow annuli altogether from the belly. The yellow then appears in dorsal semicircles, bordered with black. (Further change in this direction probably accounts for Boulenger's variety $\mathrm{E}, 1894,205$.) In a few specimens the belly is much overspread with black, but usually the black is conspicuous only as a blotch in the yellow rings, and it may be absent even there.

The head is black except for a more or less perfect cross band of white or yellow on the snout, chiefly on the prefrontal plates. It is sometimes much reduced, and rarely absent. On top of the head the black extends back to the posterior portion of the parietal plates, on the supralabials it extends as far back as the fifth. The first black band is close behind the parietals, or involves the tips of these plates, and in the great majority of cases is continuous across the throat. 
Polyzona may be distinguished from annulata and from nelsoni by the presence of black tips on the red scales; by the snout, which usually has a transverse light band in polyzona, is entirely black in annulata, and is mottled with dark and light in nelsoni. From micropholis it may be known by the white cross band on the snout instead of the white snout with black transverse marks, and by the fact that the yellow annuli are narrow, and their scales plain or more or less mottled with black as well as black-tipped, instead of being wide with the scales heavily tipped with black and not mottled, and by the presence of two anterior temporals instead of usually only a single large one.

The dental characters are as follows: Maxillary teeth, 13 to 15, usually 14, subequal except that the last 2 or 3 are distinctly, although not strongly, enlarged; mandibulars, 13 to 15 , commonly 14, the third, fourth, and fifth or the fourth, fifth, and sixth, decidedly the largest, those posterior much smaller and decreasing slightly in size; palatines, 10 to 12 , commonly 10, subequal; pterygoids smaller, decreasing, varying from 16 to 22 .

The penial characters, as indicated by preserved specimens, are as follows: Sulcus single; a small space at the distal end without calyces or with only ridges across it; immediately adjacent to this a few calyces with only a very few fringes; succeeding calyces with numerous fringes, gradually changing to spines; latter closely set together, numerous and slender, increasing in size to about the middle of the organ, then rapidly decreasing to very small spines, and disappearing altogether; basal third of organ smooth (or ridged or ribbed in preserved specimens); no spines distinctly enlarged or set apart from the others.

Habitat and habits.- Sumichrast $(1880,181)$ says "Cette espèce vit dans les terres chaudes et tempérées des deux côtes du Mexique. Sa coloration, analogue à celles des Elaps, la fait injustement accuser de venin par les habitants qui l'appellent corallilo."

Cope $(1900,900)$ quotes, as from the manuscript notes of Sumichrast, as follows:

Among the numerous Mexican snakes which are called "coralillas," this one attains the largest dimensions. It is distributed throughout the warm and temperate regions, but disappears in the alpine region, where, at least, I have never observed it. This snake prefers shaded localities, as plains covered with tall herbs, and along rivers. Although of a very harmless disposition, it is not easily caught, since on being alarmed it glides swiftly through the vegetation and is not long in disappearing in the gallery excavated by some other animal. It also lives in the enormous nests of the ant, Orcodoma mexicana, on which it warms itself in the sun. Although entirely inoffensive, it does not escape the charge of being poisonous, as all the coralillas are supposed to be by the natives. 
Range.-This form is apparently the only representative of the genus in Central America. It is known from Costa Rica to southern Mexico; in the latter country it occurs at least as far north on the east side as Tuxpan in the Province of Vera Cruz, and, on the Pacific side, it is known from Oaxaca, Guerrero, and southern Michoacan. According to Cope $(1900,900)$ Sumichrast says of it in his manuscript notes: "It is distributed throughout the warm and temperate regions, but disappears in the alpine region, where, at least, I have never observed it." Apparently the only record at variance with this distribution is one for the "City of Mexico" (Boulenger, 1894, $204)$, and this may easily be an error.

Published records for other localities than those listed are as follows: Haute Vera Paz (Salvin, 1861, 227; Bocourt, 1886, 614), Retalhuleu (McLain, 1899, 5), and Coban, Guatemala (Werner, 1903, 347); Teziutlan (State of Puebla), and Misantla (State of Vera Cruz) (Ferrari-Perez, 1886, 187); Acapulco, Mexico (Garman, S., 1883, 67); Oaxaca (Bocourt, 1886, 616); Carrizal, South Michoacan, west of the lower Balsas River (Gadow, 1911, 6 and 24); Zamora, Michoacan (Dugés, 1876, 222); Chilpan-cingo, San Luis Allende (Gadow, 1905, $196)$; in Boulenger's Catalogue of Snakes $(1894,204)$ are the following records: Tierra Colorado and Amula, Guerrero; Teapa, Tabasco; Huatuzco; Belize; Duenas, Guatemala; Irazu, Costa Rica; Chiriqui; City of Mexico.

Variation.-The necessity of a knowledge of the variations in a form is well illustrated by the present case. Without regard for normal variation and geographic probabilities, numerous names have been applied to specimens from Mexico and Central America with the result that quite distinct forms have been lumped together and individual variations of the same form, even from the same locality, have been granted distinction. Confusion is the only end attained, and that was the situation in the beginning. It is by no means impossible that fuller series of specimens may demonstrate the necessity for further subdivision, but it is hoped that a natural group has been distinguished in polyzona as here defined, so that no radical rearrangements will be necessary.

The diagram of extremes and averages of ventral plates for certain regions (fig. 44) shows that throughout all the central portion of the range, from Nicaragua to southern Mexico, the numbers are high and fairly constant. North through Tehuantepec and Vera Cruz the decrease is distinct but not great. The material from Yucatan and Guerrero is too scanty to be more than suggestive, but differentiation by isolation is indicated in the former locality and either that or approach to nelsoni in Michoacan is the inference in the latter. Costa Rica and Panama show a definite passage to the low average of micropholis. 
The present material is too poorly distributed to show anything about variation in caudals or tail length, since the numbers for averages are too much reduced by the necessity of treating the sexes separately.

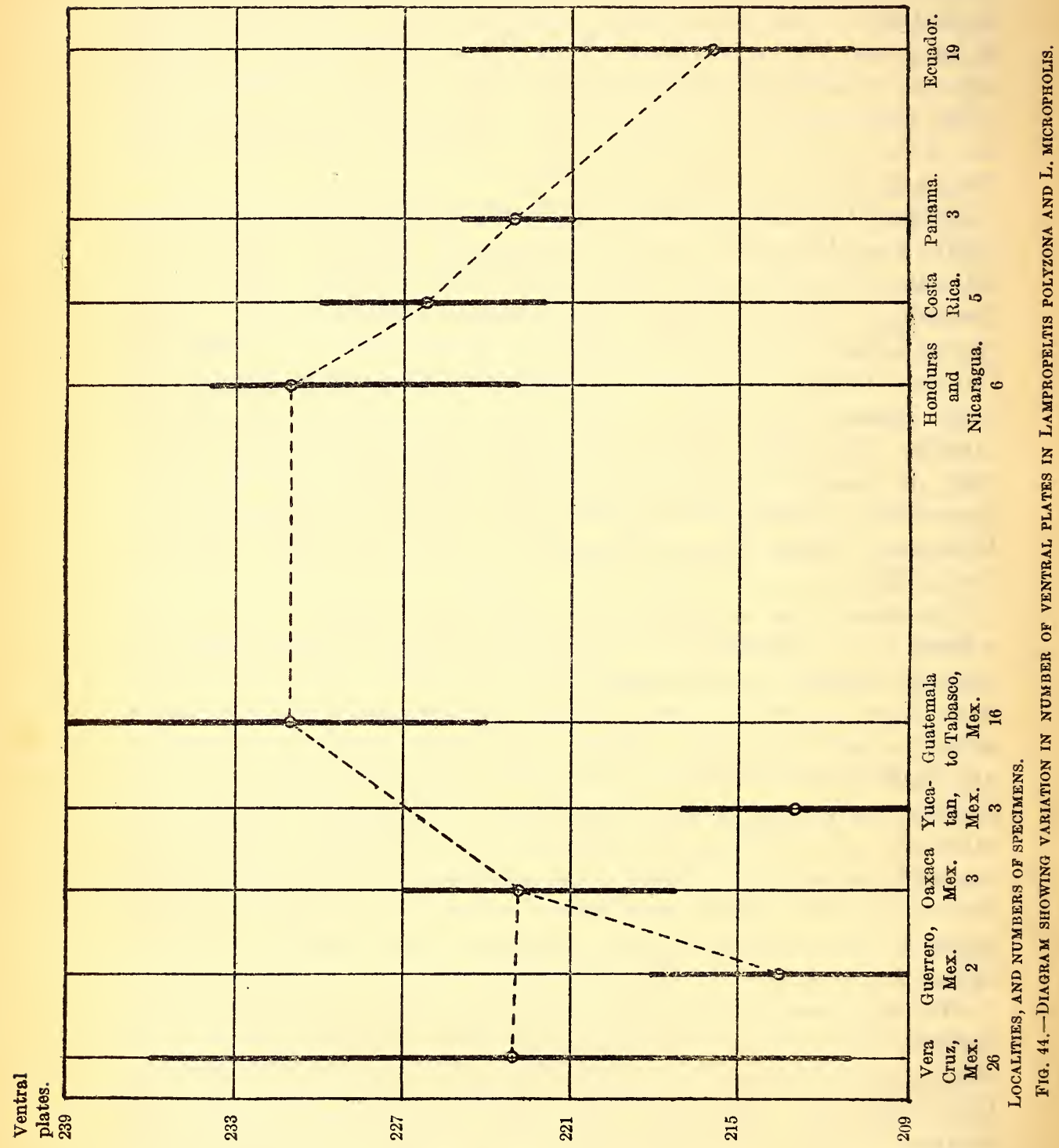

The number of yellow annuli of the color pattern is so variable that little can be said beyond calling attention to the fact that the averages for a few localities vary in the same sense as the averages for the ventrals-Vera Cruz, 25; Guatemala, 31; Nicaragua, 24; Costa Rica, 26; Panama to Ecuador, 18. 
Scale formulae of polyzona.

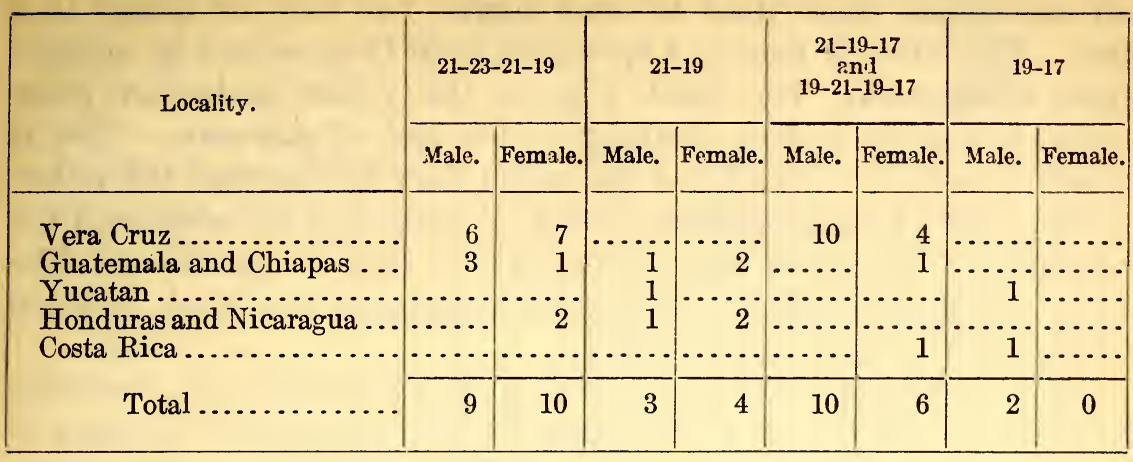

The table of scale formulae proves nothing, but points of interest indicated by it are (1) that the two higher formulae are evenly divided between the sexes, and, of the individuals having the two lower formulae, the majority are males; (2) that the great majority of the individuals from Nicaragua to southern Mexico have the higher formulae; (3) that the lower formulae are much commoner at the extremities of the range; that is, Yucatan, Costa Rica, and Vera Cruz. Boulenger records $(1894,204)$ the highest number of scale rows, 25, from Tabasco, and the lowest number, 19, from Costa Rica. His two specimens from Guerrero with 21 rows are in keeping with the suspected approach to nelsoni here.

We may safely say then that in the structural characteristics, ventral plates, and dorsal scale rows, polyzona shows approach to micropholis in the southern portion of its range and to nelsoni on the west coast of Mexico. Discussion of other structural characters can not be profitably undertaken here because the specimens at hand are too few to prove anything by figures. It can only be remarked that there appears to be nothing to refute the testimony of the ventrals and scale rows.

The striking characters of the pattern of polyzona are (1) the black head with white crossband on the snout; (2) the black tips on the yellow and the red scales; (3) the narrow yellow annuli not widening on the sides.

The white snout band may be V-shaped, pointing backward, and divided on the middle line, represented only by a few dots in the loreal region, of irregular outline, or prominent, well defined, and continuous across the snout. It appears to be most of ten poorly developed in Vera Cruz; in two from Yucatan it is absent; from Chiapas to Nicaragua it is usually well developed; two specimens from Costa Rica show it broad and transverse. This seems to be a change in the extreme south toward micropholis, and in the north appears like a primitive or an extreme condition, certainly not a typical one. 
The black tips on the red scales are exceedingly variable. Nearly all individuals show them to some degree, but they are absent in a few. The latter is true of a specimen from Chiapas and of another from Guatemala. The black tips on the yellow scales are often accompanied by a dark mottling of the rest of the scale. This is rarely excessive. Occasional specimens show no black on the yellow scales. Vera Cruz specimens show no approach to annulata, and the relationship to nelsoni can not be told for lack of specimens. The two examples from Costa Rica show no approach in black spotting of the yellow rings to micropholis.

The narrowness and uniform width of the yellow wings characterizes annulata and nelsoni as well as polyzona, and is probably evidence of relationship. The two Costa Rican specimens both have these rings

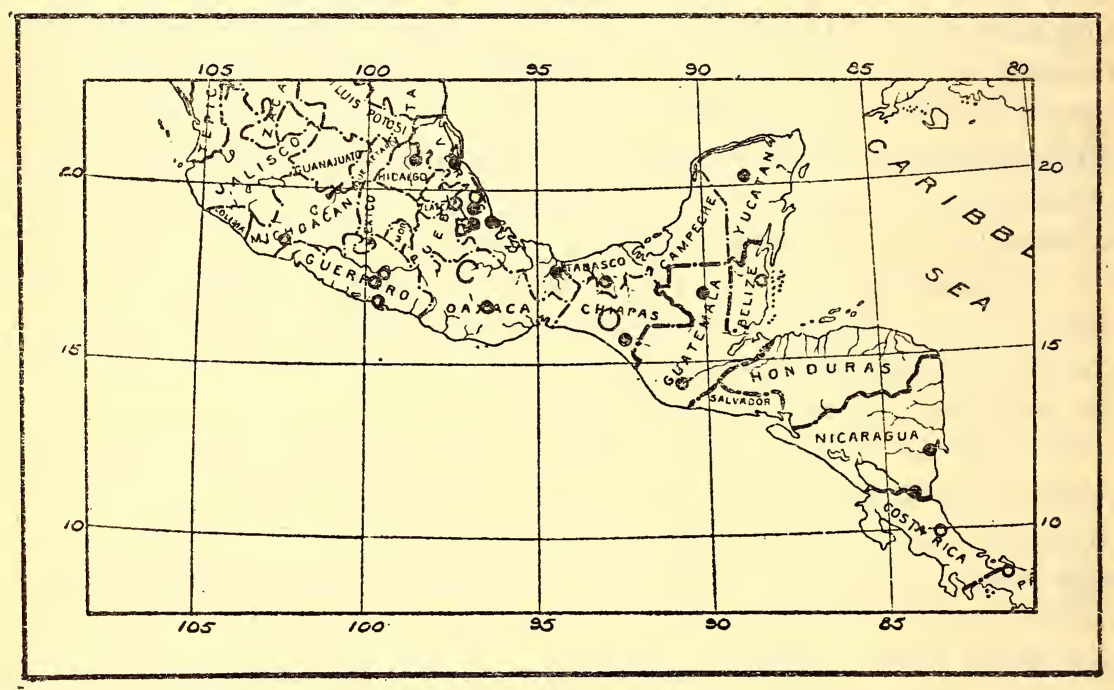

FIG. 45.-MAP SHOWING LOCALITY RECORDS FOR LAMPROPELTIS POLYZONA.

very narrow. The transition to micropholis is shown by a specimen from Panama and one from Darien, both of which have the yellow rings wider than in polyzona but decidedly narrower than Ecuadorean examples of microphotis. These have the scales of the yellow rings strongly black-tipped but less so than is typical of the latter form.

Affinities. - That all the Mexican and Central American representatives of the triangulum group are closely related hardly needs argument. It has not been doubted. The difficulty has lain in correctly defining the several forms and determining just what the relation of each to each is. The evidence from variation and geographic probabilities is that polyzona is directly related to microphotis and that it is distinct from annulata on the Gulf side of Mexico. The nature of its relationship to nelsoni, on the Pacific side of Mexico, must be learned at a future date. 


\begin{tabular}{|c|c|c|c|}
\hline घू. & 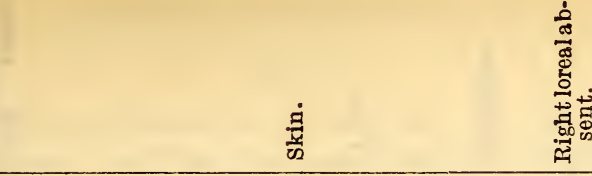 & \multicolumn{2}{|c|}{ 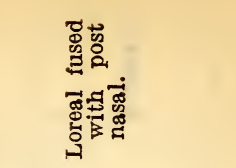 } \\
\hline 'য়nute jo ${ }^{\circ} \mathrm{N}$ & 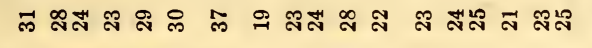 & สี ఇุ & ซ్สָస สి \\
\hline 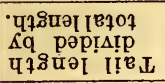 & 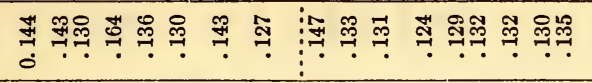 & $\stackrel{\infty}{\because} \underset{?}{\rightarrow}$ 유 & 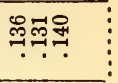 \\
\hline 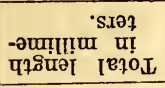 & 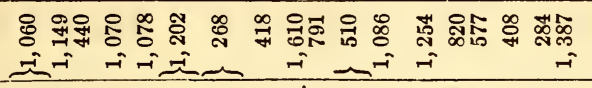 & $\overbrace{}^{\circ}$ & 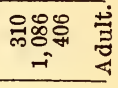 \\
\hline 's[ejodwot & 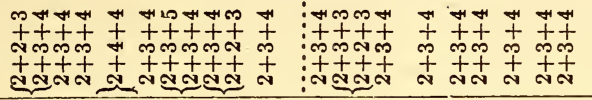 & 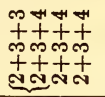 & 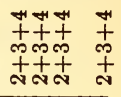 \\
\hline$\cdot \operatorname{sir}\left[n_{0}\right.$ & 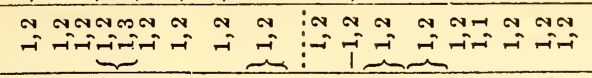 & $\cong$ NN & กำ \\
\hline 'sleịquiejuI & $000000000 \underbrace{00}$ & & 00000 \\
\hline 'stвiqgiexdns & 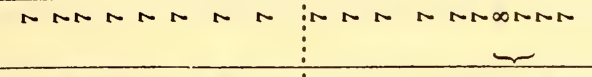 & & $=n+$ \\
\hline 's[epne, & 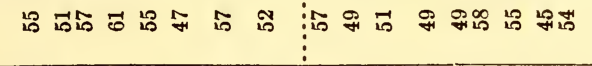 & ำำ 유소 & ஜึลี \\
\hline 's[e.xu次 $\Lambda$ & 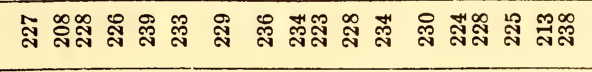 & สี สุన్ఞ & สีสิ๊ สิ สิ \\
\hline 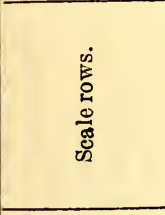 & 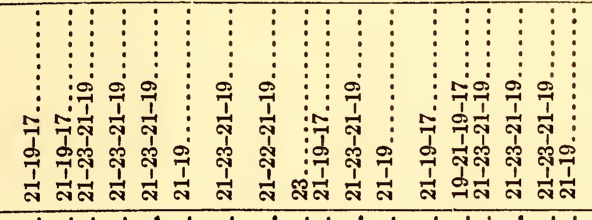 & 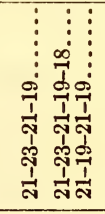 & 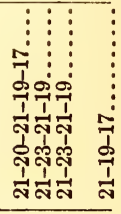 \\
\hline कू & 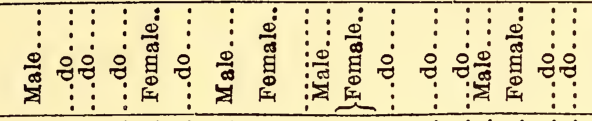 & 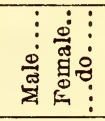 & 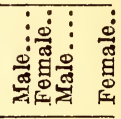 \\
\hline 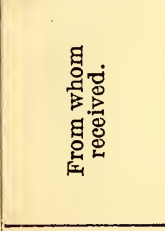 & 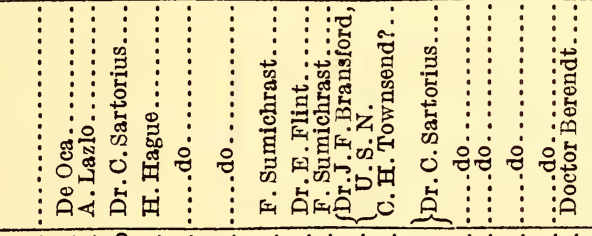 & 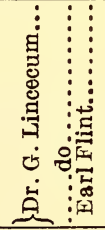 & 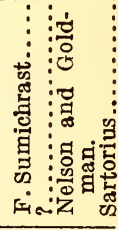 \\
\hline 密 & 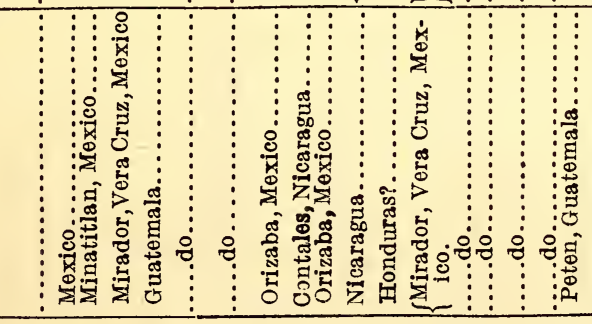 & 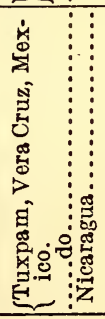 & 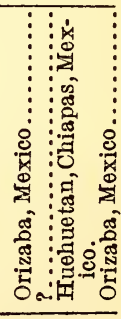 \\
\hline$\dot{\dot{z}}$ & 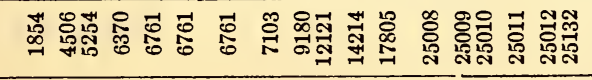 & 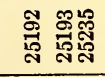 & 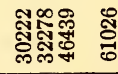 \\
\hline 竞 & 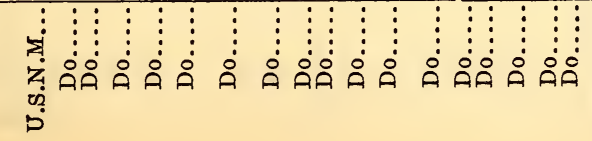 & $\begin{array}{cc}\vdots \\
\vdots \\
\vdots \\
\AA \\
\AA\end{array}$ & $\begin{array}{c}\vdots \vdots \vdots \\
\vdots \\
\vdots \\
\text { ค̊̊̊ } \\
\vdots\end{array}$ \\
\hline
\end{tabular}




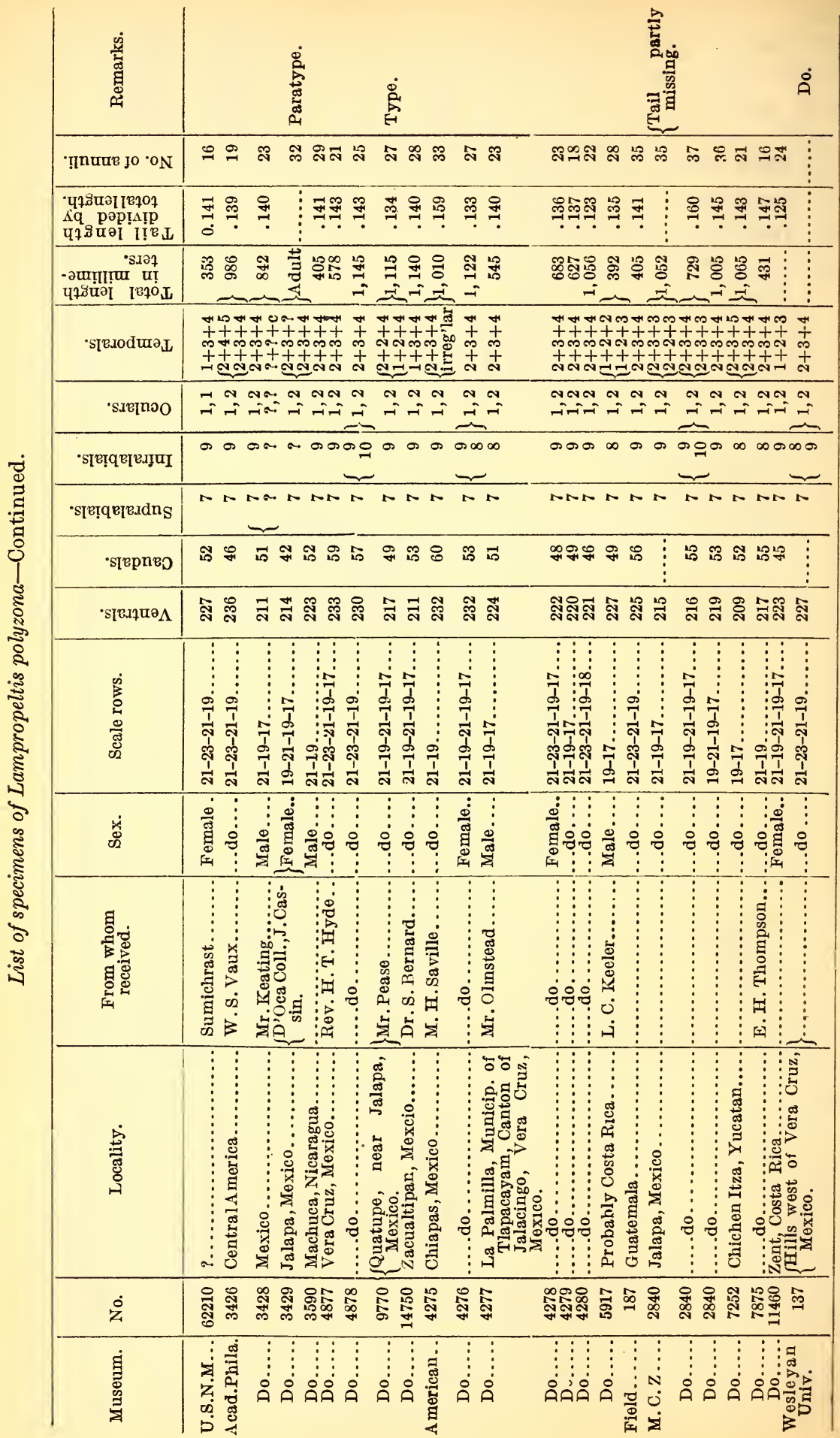


LAMPROPELTIS MICROPHOLIS Cope.

Fig. 70.

1860. Lampropeltis micropholis Cope, Proc. Acad. Nat. Sci. Philadelphia, p. 257 (type specimen originally at Acad. Nat. Sci. Philadelphia, now apparently lost; type locality, Panama; Dr. John L. LeConte, collector).Fowler, Proc. Acad. Nat. Sci. Philadelphia, vol.65, 1913, p. 168.-Coronella micropholis Peracca, Bull. Mus. Torino, vol.11, 1896, p. 9 (Panama); same, vol. 12, 1897, p. 17 (Cuenca, Ecuador); same, vol. 19, 1904, p. 13 (Vinces, Ecuador); Voy. Exp. Sci. Colombie, 1914, pp. 96-111.-DesPax, Bull. Mus. Nat. d'Hist. Nat. Paris, no. 7, 1910, p. 370; Rept. Batr. de l'Equateur, 1911, p. 28.-Griffin, Mem. Carnegie Mus., vol. 7, no. 3, 1916, p. 176 (Cacagualito, Colombia).

1861. Coronella doliata formosa JAN. Icon. Gen. Ophid., livr. 14, Dec., pl. 4, fig. " $B^{*}$ " (this specimen from Colombia, now probably at Vienna, may be taken as the type).-Boulenger, Bull. Zool. Soc. France, 1880, p. 44 (Quito, Ecuador).-Coronella doliata, var. formosa Bouleng ER, Ann. Mag. Nat. Hist., vol. 9, 1882, p. 458 (Guayaquil).

1887. Ophibolus doliatus polyzonus Cope, Bull. U. S. Nat.Mus., no. 32, p. 78 (Panama, Darien).

Description.-This is the most southern representative of the genus known. Its scalation is as follows: Ventral plates, 211 to 228, average about 218; caudals, 40 to 49 (males, 43 to 49 , average about 46 ; females, 40 to 44 , average 42 ), frequently several entire; supralabials, 7 , rarely 8 ; infralabials, 9 , sometimes 8 , rarely 10 ; one preocular, two postoculars (fused in one specimen); temporals usually $1+2+3$, varying to $2+3+4$; posterior chin shields in contact, shorter than anterior, or about as long; loreal longer than high or about as high as long, its upper posterior angle obtuse and its lower posterior angle acute; scale rows on middle of body 21 or 23 , the formulae commonly $21-23-21-19$, or $21-19-17$, or 19-21-19-17.

In proportions this form differs somewhat from its nearest relative, polyzona. The body is fairly stout and of nearly uniform diameter throughout; the head is more distinctly set off from the neck; the tail is distinctly shorter and blunter than is usual in polyzona, varying from 0.112 to 0.136 of the total length (males, 0.114 to 0.136 , average about 0.123 ; females 0.112 to 0.129 , average about 0.118). The largest of the few adults examined measured $1,232 \mathrm{~mm}$., and probably came from Ecuador.

The pattern (fig. 70) is conspicuously different from that of poly$z o n a$, although built upon the same plan. The homologues of the white or yellow rings, 13 to 21 in number, are much widened and the dorsal scales of these rings, instead of being tipped or mottled with black or entirely without black, have each a conspicuous oval black spot on the distal end, which often occupies more than half the area of the scale and may sometimes cover the whole scale. Furthermore, the black on the head has so receded as to be continuous only from the anterior end of the frontal plate to the posterior portion of 
the parietals, and laterally as far as the eyes. The temporals, labials, and anterior head plates have each a black blotch on the posterior portion. On the upper labials, beneath the eye, there is a large black spot.

The rings vary greatly in width, but the red ones are commonly about as wide as the black and white together. All the annuli are generally completed on the belly, but the red bands here are often

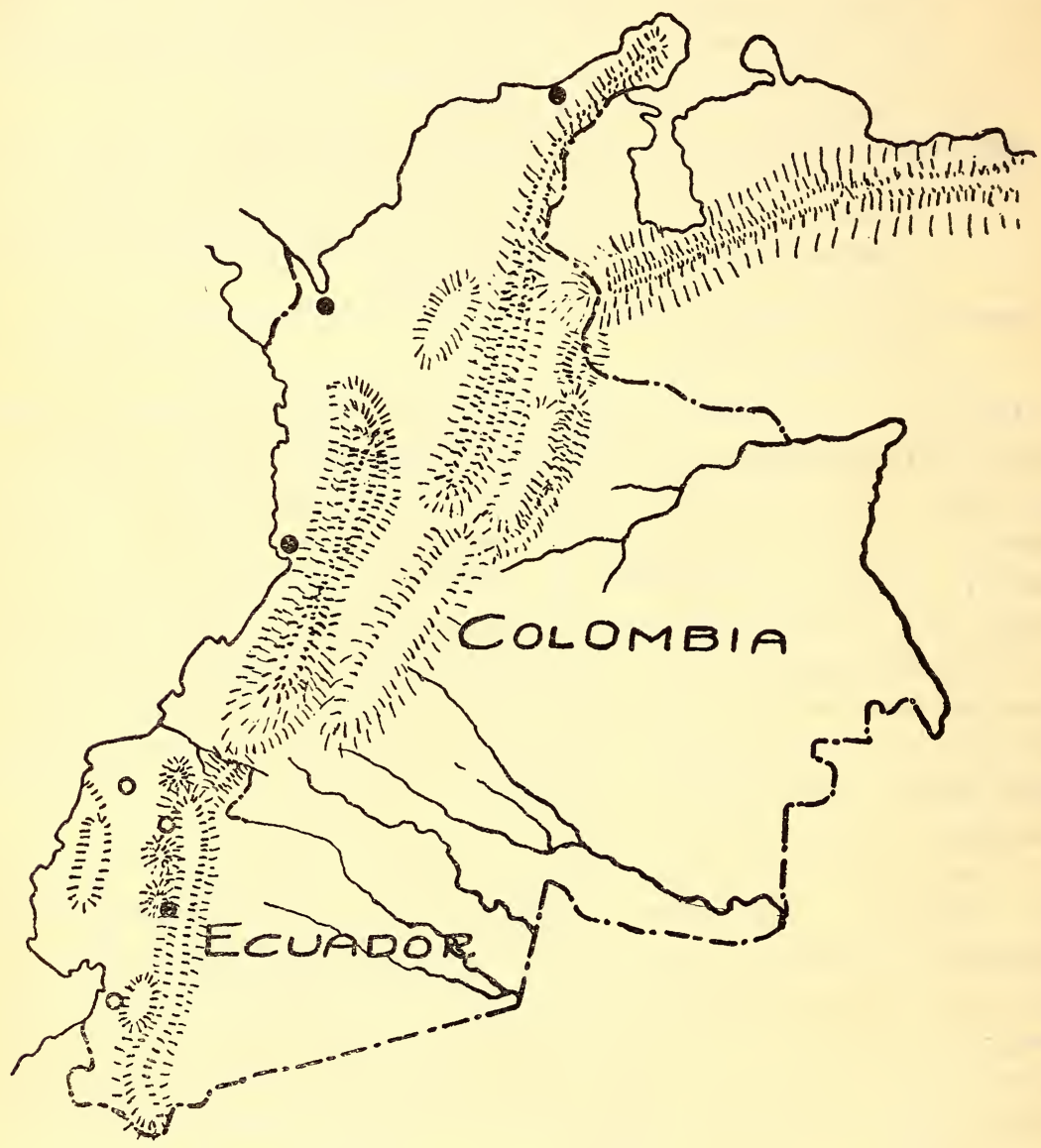

FIG. 46.-MAP SHOWING LOCALITY RECORDS FOR LAMPROPELTIS MICROPHOLIS.

checked or even completely filled with black, and, opposite the whitish bands, there is often a large black blotch. The dorsal scales of the red areas are usually black-tipped, but the black may be greatly reduced or entirely absent.

The colors can not be satisfactorily determined from alcoholic material, but some of that at hand is in excellent condition. It is quite evident that the homologues of the red areas of polyzona are red here also, and that this red may extend across the belly; further- 
more, that the homologues of the white or yellow rings may be strongly suffused with red (confirming Cope's original description of a specimen from Panama), and that this red may extend across the belly. The specimens at hand indicate that these rings may, on the other hand, of ten be white or yellowish instead of red.

The dental characters from a few specimens are as follows: Maxillary teeth, 15 or 14, subequal, the last two or three only slightly larger; mandibular teeth, 15, the anterior distinctly larger, decreasing in size posteriorly; palatines, 10 to 12 , more commonly 10 , subequal; pterygoids smaller than the latter, decreasing posteriorly, 17 to 19 in number.

Habitat and habits.-Apparently nothing is recorded upon this subject.

Range.-This form is at present known only from Panama, and from Colombia and Ecuador west of the Andes. In the latter country it has been taken at 4,200 feet elevation (Fowler, 1913, 168). Its range meets that of polyzona in western Panama or southeastern Costa Rica. If intergradation occurs it takes place in this region, but two specimens from Panama and two from Costa Rica are nearly typical of their respective forms.

Published records for other localities than those listed are as follows: Quito, Ecuador (Boulenger, 1880, 44); Cuenca, Ecuador (Peracca, 1897, 17); Vinces, Ecuador (Peracca, 1904, 13); Nanegal, Ecuador (Despax, 1910, 370); Angelopolis, Colombia (Peracca, 1914, 96-111).

Variation.-Since the specimens examined are nearly all from Ecuador, nothing definite can be said about geographic variation. Enough of individual variation is included in the description.

Affinities.-On geographic grounds polyzona is the only form from which micropholis can be derived, but from the description it will appear that it is very distinct from the latter in numerous structural as well as color pattern characters. The differences between the two are, however, only such as can be best explained on the assumption of the above relationship.

The most conspicuous changes, and how they may be accounted for, are as follows: (1) The reduced number of temporals has resulted from a reduction in size of the upper scute in each row and an accompanying increase in the size of the lower plates; (2) the ventrals have undergone a slight decrease in number, a change often paralleled by other forms in the genus; (3) the caudals have decreased distinctly, a change that is greater than but not different in kind from that illustrated by other forms; (4) the paired caudals frequently fuse, particularly near the tip of the tail; such fusion occurs sporadically throughout the genus, but is more noticeable here than in any other form; (5) the homologues of the yellow rings of polyzona, here more or less red, have decreased in number, accompanying a decided increase 
in width; (6) the black tips on most of the yellow scales of polyzona have here become much accentuated; (7) the black tips on the red scales have become reduced in area or have disappeared entirely; (8) the black of the head has receded, leaving a black spot on the upper labials below the eye, and leaving the snout and temples free from black except for a spot on the posterior portion of each scute, and occasional minute mottlings; (9) the number of dorsal scale rows averages decidedly lower.

The pattern changes represent only a further development of the pattern of polyzona. The structural changes represent normal variation in polyzona and all other forms of the genus, but they are changes that in other forms, notably elapsoides, are associated with specialization. In fact, in every way micropholis gives the impression that it is an end form-quite beyond consideration as an ancestral type. It must then be looked upon as derived from polyzona and not as ancestral to it. 


\begin{tabular}{|c|c|c|c|}
\hline 窟 & & 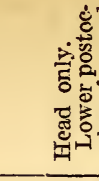 & 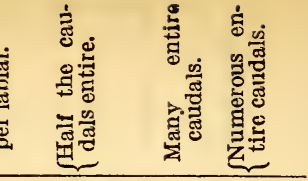 \\
\hline •!̣nute jo ${ }^{\circ} \mathrm{N}$ & 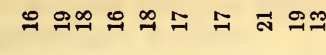 & $\stackrel{\vdots}{\cdots}$ & $\stackrel{\infty}{\sim} 9 \propto ⿻ 上 丨$ \\
\hline 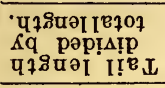 & 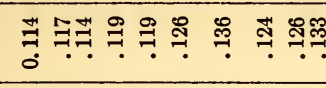 & $\exists \vdots$ & 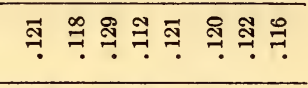 \\
\hline 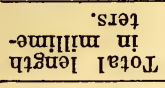 & 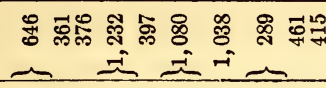 & 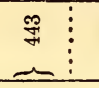 & 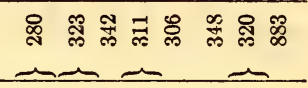 \\
\hline 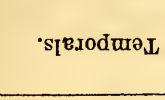 & 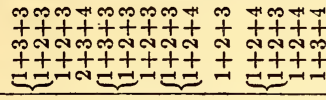 & 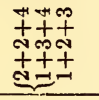 & 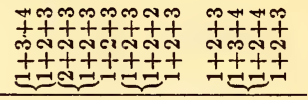 \\
\hline 'sıe[noO & 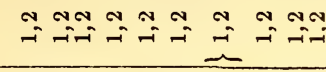 & $\cong$ & 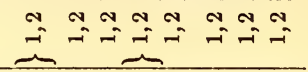 \\
\hline 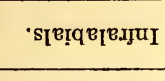 & 000000000000 & 00 & 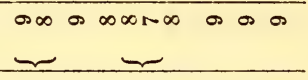 \\
\hline 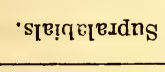 & $\operatorname{NanNDN} \underbrace{-N M}$ & $r$ & DNANRNA \\
\hline 's[epne] & 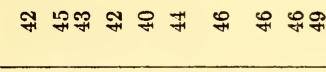 & 子 $\vdots$ & 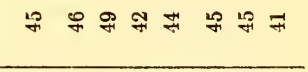 \\
\hline$\cdot$ sI expuə $\Lambda$ & 옻 สำ & สี $\vdots$ & 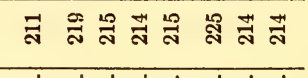 \\
\hline 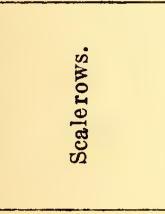 & 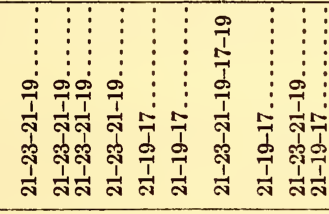 & $\begin{array}{cc}\vdots & \vdots \\
\vdots & \vdots \\
\vdots 1 & \vdots \\
\frac{1}{2} & \vdots \\
\frac{1}{2} & \vdots \\
\end{array}$ & 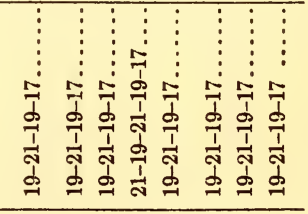 \\
\hline 㸃 & 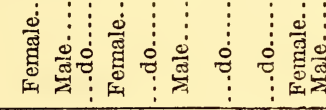 & 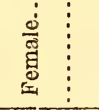 & 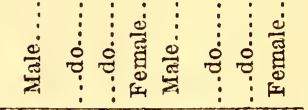 \\
\hline 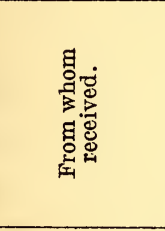 & 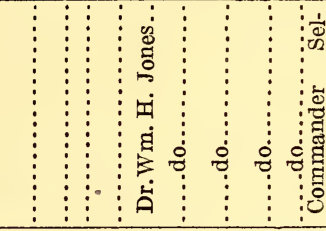 & 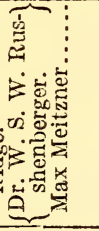 & 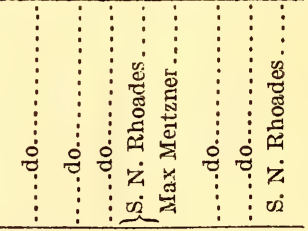 \\
\hline 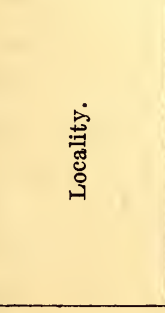 & 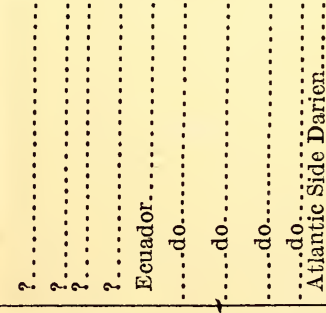 & 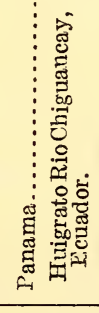 & 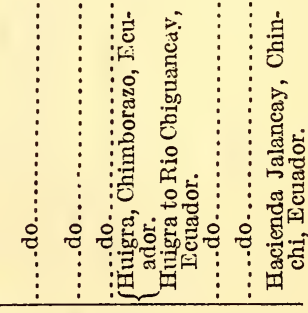 \\
\hline$\dot{0}$ & 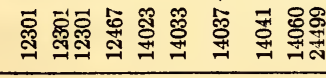 & స్ํ유. & 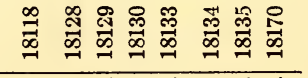 \\
\hline 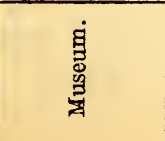 & 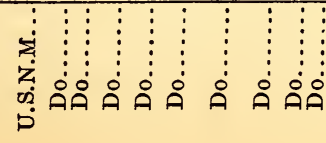 & 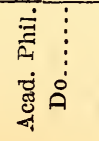 & 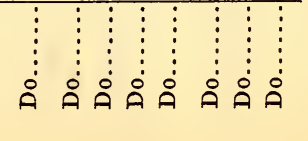 \\
\hline
\end{tabular}


154 BULLETIN 114, UNITED STATES NATIONAL MUSEUM.

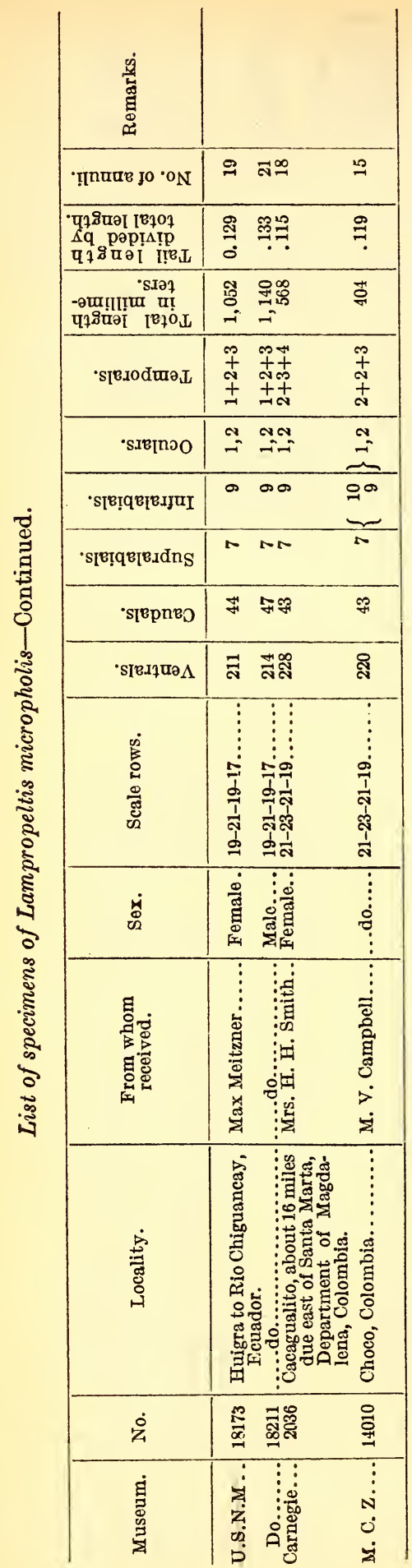




\section{LAMPROPELTIS TRIANGULUM NELSONI Blanchard.}

Fig. 65 .

1887. Ophibolus multistratus Cope, Bull. U. S. Nat. Mus. no. 32, p. 78 (Guanajuata).

1887. Ophibolus doliatus coccineus (part) Cope, Bull. U. S. Nat. Mus., no. 32, p. 78 (Guadelaxara; Colima).

1894. Coronella micropholis, var. A. Boulenger, Cat. Snakes Brit. Mus., vol. 2, p. 204.

1899. Lampropeltis micropholis oligozona Stejneger, N. Amer. Fauna, no. 14, p. 70 (Maria Madre Id).-Van Denburgh and Slevin, Proc. California Acad. Sci., ser. 4, vol. 4, 1914, p. 149.

1920. Lampropeltis triangulum nelsoni Blanchard, Occ. Pap., Mus. Zool., Univ. Mich., no. 81, p. 6, fig. 1 (type locality, Acambaro, Guanajuato, Mexico; type specimen, no. 46552, United States National : Museum; E. W. Nelson, collector.)

Description.-This is the west coast representative of the Mexican Lampropeltes allied to triangulum. Its scutellation may be summarized as follows: ventral plates, 199 to 231; caudals, 42 to 59; supralabials 7 , infrequently 8 ; infralabials 9 , sometimes 10 ; preoculars, 1 , postoculars, 2 ; temporals usually $2+3+4$; posterior chin shields usually in contact, and generally shorter than the anterior; loreal longer than high, sometimes as high as long; scales rows on middle of body 21 or 23 , the commonest formulae being 21-23-21-19 and 21-19-17.

The bodily proportions are practically the same as for the rest of the group. The head is only slightly distinct from the neck, the body cylindrical and of about the same diameter throughout, and the tail tapers uniformly. The latter varies from 0.120 to 0.150 of the total length (males, 0.128 to 0.150 , average, 0.140 ; females, 0.120 to 0.137 , average 0.129 ). The largest specimen examined was from Maria Madre Island, and measured $1070 \mathrm{~mm}$.

The pattern of this form (fig. 65) like that of the other Mexican members of the group, is made up of pairs of black annuli, 13 to 24 in number, bordering narrow rings of white or yellow and separated by bands of red. It differs from polyzona chiefly in the fact that the scales of the red areas are never tipped with black, and the pairs of black rings average fewer in number.

The black and yellow rings are complete on the belly, and this is generally true of the red ones, also. Opposite the latter on the belly, however, there is frequently a blackish mottling, and toward the interior of Mexico, this space may be as completely filled with black as in annulata. The yellow rings are of nearly uniform diameter or may widen a little on the sides. They are sometimes mottled with darker laterally, and a black spot may or may not be present within their area on the belly.

186550-21-Bull. 114_-11 
The black rings tend to extend their width dorsally at the expense of the red, and to become narrowed on the sides. They may completely obliterate the red toward the end of the tail, but on the body are usually widely separated.

The head is black, except for the region anterior to the frontal plate, which is much lightened or mottled with dark and light. In some individuals from the interior this condition is restricted to the extreme anterior end. It is in contrast with the black snout with light cross band of polyzona, and the entirely black snout of annulata.

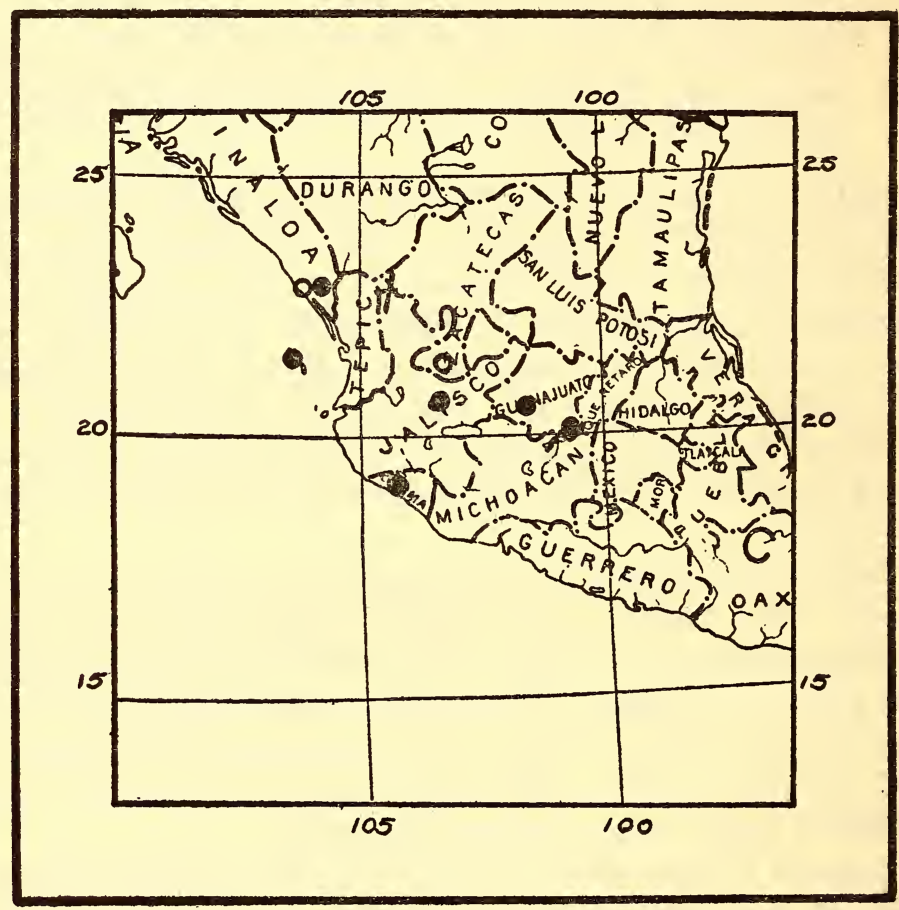

FIG. 47.-MAP SHOWING LOCALITY RECORDS FOR LAMPROPELTIS TRIANGULUM NELSONI.

The dental characters, as indicated by the examination of a few specimens, are as follows: maxillary teeth, 12 or 13 , subequal, except that the last two are somewhat enlarged; mandibulars, 13 to 15 , decidedly larger anteriorly, decreasing posteriorly; palatines, 10 or 11 , subequal; pterygoids, 18 to 22 , smaller than palatines and decreasing posteriorly.

Habitat and habits.-Nothing is recorded on this subject for this form.

Range.-At present nelsoni is known only from western Mexico, from Acambaro in the state of Guanajuato to southern Sinaloa and south to Colima, including the Tres Marias Islands. Its southern limit may be looked for in Michoacan or Guerrero, where its range 
meets that of polyzona. It is probable that it intergrades with annulata somewhere on the Mexican plateau, perhaps in the region of the divide between the Gulf and Pacific drainage. Its range northward can only be surmised, but it should be expected in Sonora west of the Sierra Madre.

Published records for localities not included in the list of specimens examined are as follows (Boulenger, 1894, 204): Mazatlan; Presidio, near Mazatlan; Mezquital del Oro.

Variation and affinities. - The material at hand indicates that this is a fairly homogeneous form, characterized by a low number of pairs of black annuli separated by broad red interspaces, absence of black tips on the red scales, and by a light colored snout mottled with darker. These characters apply equally well to the Tres Marias Islands and to the adjacent mainland, but the numbers of ventrals and scale rows is distinctly higher on the islands. Using Boulenger's figures $(1894,204)$ for Forrer's specimens from the Tres Marias, the average for 4 specimens is 231 , the extremes 229 to 232; this contrasts rather strongly with the average of 214 for 19 specimens from the mainland. The extremes for these, 200 to 221, do not even reach the numbers for the islands. All of the Tres Marias specimens attain 23 rows of scales, while from the mainland this number is possessed by only three, most of the others having the formula 21-19-17. Since the pattern and other structural features seem to be the same in the island as in the mainland forms, it is not desirable to make a specific distinction, on the basis of the specimens now on hand.

While the color pattern seems to be constant on the west coast, it is very noticeable that toward the interior of Mexico some specimens have the spaces on the belly opposite the dorsal red areas partially or completely filled with black, presenting in this a striking approach to annulata. The snout, too, may be blacker and the red interspaces between the pairs of black rings may be much narrower and strongly encroached upon by the latter.

Since, in other respects, this form is like annulata, it is believed that these similarities in pattern toward the interior of Mexico are evidence of close affinity between those forms, and, in fact, are sufficient evidence of intergradation.

If the writer's conclusions as to the stem-character of annulata, stated further on, with respect to the forms north of it be accepted then the most natural inference with respect to nelson $i$ is that it, too, is a derivative of annulata. 


\begin{tabular}{|c|c|}
\hline 它 & 菖 \\
\hline țnute jo $\circ^{\circ}$ & 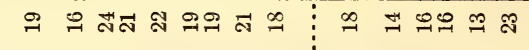 \\
\hline 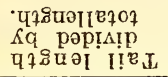 & 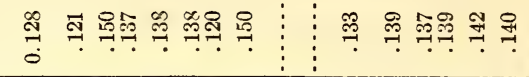 \\
\hline 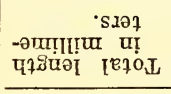 & 周 \\
\hline -sjexodur $L$ & 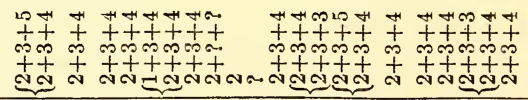 \\
\hline$\cdot \sin [\mathrm{n} \infty O$ & $\underset{\sim}{\sim} \cong \approx N$ \\
\hline 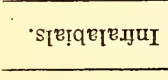 & 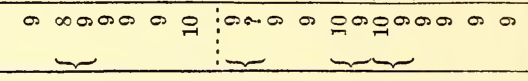 \\
\hline 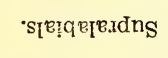 & $N N-N-M N N \infty N$ \\
\hline -sjepneo & 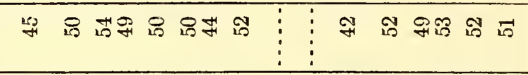 \\
\hline 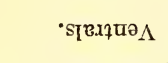 & 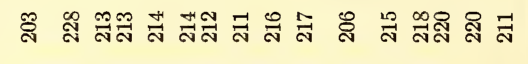 \\
\hline 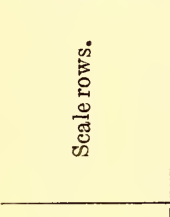 & 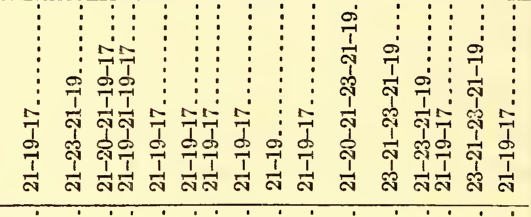 \\
\hline 宿 & 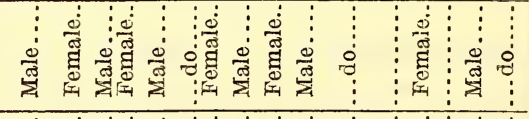 \\
\hline 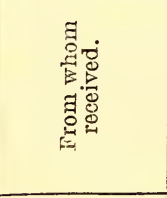 & 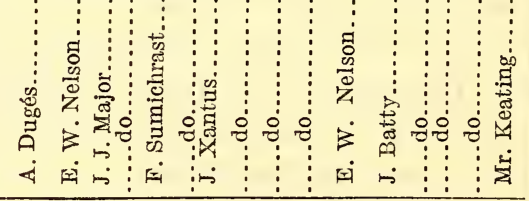 \\
\hline 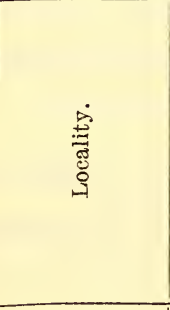 & 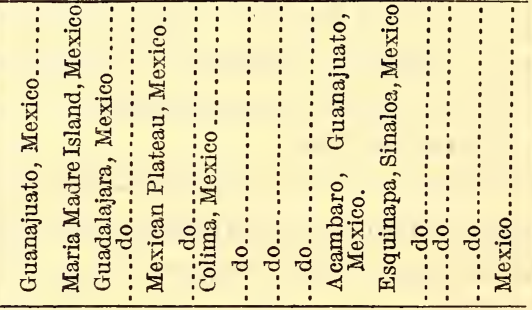 \\
\hline$\dot{8}$ & 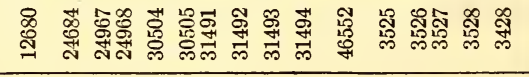 \\
\hline 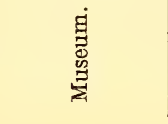 & 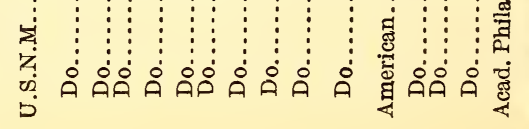 \\
\hline
\end{tabular}




\section{LAMPROPELTIS TRIANGULUM ANNULATA (Kennicott).}

Fig. 66 .

1860. Lampropeltis annulata Cope, Proc. Acad. Nat. Sci. Philadelphia, p. 257 (nomen nudum; advance reference to Kennicott's forthcoming article).

1860. Lampropeltis annulata Kennicotr, Proc. Acad. Nat. Sci. Philadelphia, p. 329 (type locality, Matamoros, Mexico; type, Acad. Nat. Sci. Philadelphia, $3613 ;^{3}$ Lieut. Couch, collector).-STEJneger, Proc. U. S. Nat. Mus., vol. 14, 1891, p. 503; Proc. Biol. Soc. Washington, vol. 31, 1918, p. 99.Coronella annulata (part) GÜNTHER, Biol. Cent.-Amer., 1893, p. 109, pl. 38, figs. A, B, C.

1861. Coronella doliata, var. conjuncta JAN, Icon. Gen. Ophid., livr. 14, Dec., pl. 4, fig. $c$ (type locality, Brazil-probably through error; type, Milan, Mus.; from the collection of Prince Max de Neuweid); Arch. Zool. Anat., vol. 2, fasc. 2, 1863, pp. 237, 242; Elenco sist. degli Ofidi, 1853, p. 46.Bocourt, Miss. Sci. Mex., pt. 3, vol. 2, 1886, p. 611, pl. 39, figs. 6, $6 a$ to 6d.-Ophibolus doliatus conjunctus Cope, Proc. U. S. Nat. Mus., vol. 14, 1891, p. 608; Amer. Nat., 1893, Dec., p. 1067.

1875. Ophibolus doliatus annulatus Cope, Bull. U. S. Nat. Mus., no. 1, 1875, p. 36.-Yarrow, Geog. Geol. Explor. Surv. W. 100th mer., vol. 5, chap. 4, 1875, p. 537.-(part) YARRow, Bull. U. S. Nat. Mus., no. 24, 1882, p. 90 (Matamoros).-Cope, Proc. U. S. Nat. Mus., vol. 11, 1888, p. 382; vol. 14, 1891, pp. 608, 609; Amer. Nat., vol. 27, no. 324, 1893, p. 1067, fig. 9; Rep. U. S. Nat. Mus. for 1898, 1900, pl. 36, fig. 10.-Brown, Proc. Acad. Nat. Sci., Philadelphia, 1901, Jan., p. 75.-Osceola doliata annulata Cope, Rep. U. S. Nat. Mus. for 1898, 1900, p. 895, fig. 219.

1882. Ophibolus doliatus gentilis (part) Yarnow, Bull. U. S. Nat. Mus., no 24, p. 90 (Brownsville, Texas; Caderita, Nuevo Leon, Mexico; Mexico).Strecker, Baylor Bull., vol. 18, no. 4, 1915, p. 38.-Coronella doliata, var. gentilis (part) Bocourt, Miss. Sci. Mex., pt. 3, vol. 2, 1886, p. 611.

1883. Ophibolus triangulatus annulatus Garman, Mem. Mus. Comp. Zool., vol. 8, no. 3, pt. 1, 1883, p. 156.

1888. Ophibolus doliatus occipitalis Cope, Proc. U. S. Nat. Mus., vol. 11, p. 382 (neither type nor locality designated); same, vol. 14, 1891, p. 609; Rep. U. S. Nat. Mus. for 1898,1900 , p. 883.

1894. Coronella micropholis Boulenger, Cat. Snakes Brit. Mus., vol. 2, p. 203, var. D.

Kennicott's description of annulata, which was read before the Academy of Natural Sciences of Philadelphia in August, 1860, undoubtedly was published before the appearance of Jan's conjuncta in December, 1861. The type locality is thus fixed satisfactorily, as it would not have been had the name conjuncta appeared first. The latter is recorded from Brazil and Caracas. It seems impossible that these localities can be correct, as the figure is exactly like

The location of the type specimen has only recently been learned. Kennicott gave it as number 4293 of the United States National Museum collection. This number at present belongs to a specimen from the same locality and collector as the type, but which was transferred at some unknown time to this number from the number 1857. Comparison with the original description proves that this is not the type. The latter has, however, been found in the collection of the Academy of Natural Sciences of Philadelphia, number 3613. It answers to Kennicott's description and bears the original parchment label of the Smithsonian Institution with the number 4293 and the measurements and scalation in the same handwriting as the original entry in the record book of this Museum. When it went to Philadelphia is not known. 
the form from northeastern Mexico (that the black on the belly is not solid between the yellow rings is because it is the anterior end of the body that is shown; this is the usual condition with typical specimens). If we are correct in judging Jan's conjuncta to be the equivalent of Kennicott's annulata, then the occipitalis of Cope is also a synonym of annulata, for he expressly states $(1891,609)$ that his name is a synonym of conjuncta Jan, having, in 1888, when he proposed the name occipitalis, apparently overlooked the name conjuncta.

Description.-The scutellation based upon twelve specimens is as follows: Ventral plates, 197 to 212; caudals, 40 to 57; supralabials, 7 , rarely 8 ; infralabials, 9 , sometimes 10 ; a single preocular, 2 postoculars; temporals generally $2+3+4$; posterior chin shields usually in contact with each other, sometimes separated by a small scale, shorter than, or about as long as, the anterior; loreal longer than high; scale rows usually $21-19$ or $21-23-21-19$.

The bodily proportions are much the same as for the rest of the group. The head, however, is less distinct from the neck, and the tail, in the vicinity of the type locality, is rather long. For this region the proportion of the tail to the total length ranges from 0.138 to 0.167 for eight females, averaging 0.151 ; two males have the proportions 0.150 and 0.156 ; and for a female from Puebla, Mexico, it is 0.123 . The largest specimens examined were from Montemoreles and Peubla, Mexico; each measured $836 \mathrm{~mm}$.

The pattern (fig. 66) is composed of from 19 to 26 white or yellow rings, from head to tip of tail, bordered by black and separated by broader areas of red. The white rings are about $1 \frac{1}{2}$ to 2 scales wide, uniform in diameter or a little widened on the first row of scales, completed upon the belly or partially interrupted there with black, and usually mottled on the sides with darker. The black rings are generally widest on the middorsal line, sometimes even confluent here across the red, and narrowest on the first row of scales. They are continuous across the belly. The red areas, except the first ones, are not completed across the belly, except partially so in individuals from the northern limits of the range, but are here replaced by black. The belly thus normally presents a series of large quadrate black areas separated by much narrower bands of white or yellow.

The head is normally black from the tip of the snout back to the posterior portion of the parietals and the fifth to seventh upper labials. In the northern portion of the range, lightening of the snout begins in the loreal and nasal region and the lower side of the rostral plate. The chin is more or less mottled with black and white. The first black ring is usually complete on the neck.

Dental characteristics, as exhibited by five specimens, are as follows: Maxillary teeth, 13 to 15 , subequal except the last two which 
are enlarged; mandibulars, 14, 13, or 15, the anterior enlarged, diminishing posteriorly, a little greater space between the fourth and the fifth; palatines, 11, 10, or 9, subequal; pterygoids 15 to 20 , smaller than the palatines, and diminishing posteriorly.

The penial characters could not be satisfactorily determined, since all the typical specimens were females.

That this form has suffered so at the hands of herpetologists is doubtless due to the fact that it inhabits a region where but little collecting has been done, and that it is consequently rare in museums. Its name has usually been included in the synonymy of its northern

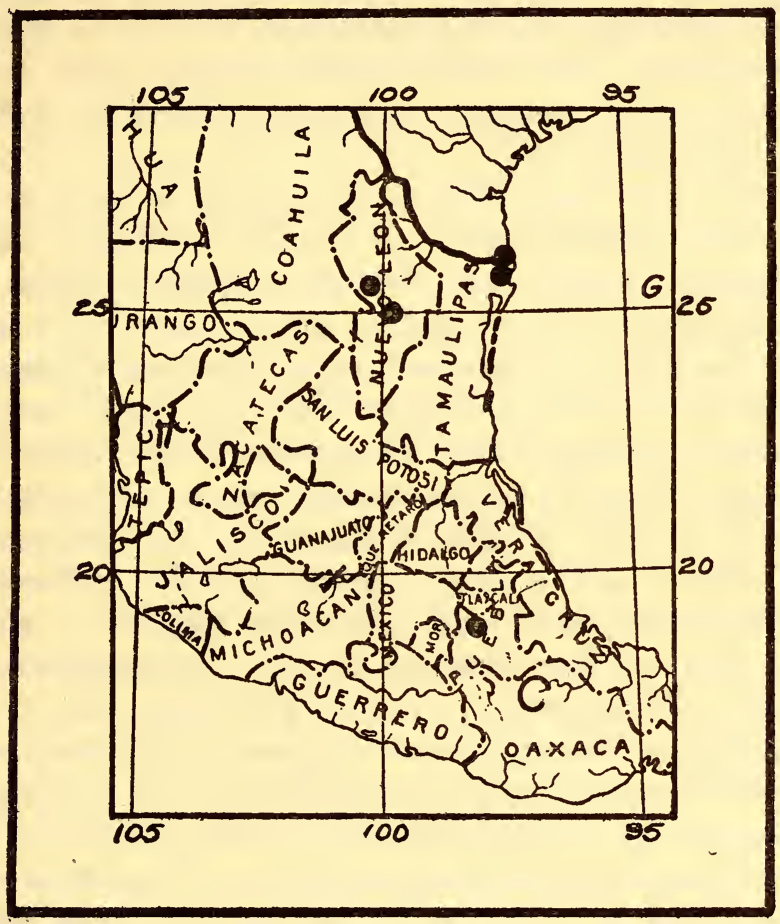

FIG. 48. -MAP SHOWING LOCALITY RECORDS FOR LAMPROPELTIS TRIANGULUM ANNULATA.

or southern relatives. It appears, however, to be a well marked form. From gentilis, its nearest relative on the north, it differs (1) in having the snout nearly or entirely black instead of lightened on the end; (2) in having the white rings of about the same width on sides and belly as on the middorsal line, instead of widened there; (3) in having the belly marked with broad areas of black, separated by narrower bands of white, instead of nearly equal areas of black and white; and (4) in having a distinctly higher average number of ventral plates. From polyzona it may be distinguished, (1) by the entire absence of black tips on the red scales, (2) by the absence of the white band across the snout, and (3) by the smaller number of ventrals. 
From nelsoni it is chiefly distinguished by the entirely black snout, and the completely black areas on the belly, between the white rings, and the narrower red areas.

Habitat and habits.-Of these nothing is recorded.

Range.-This form is best known from extreme southern Texas and northeastern Mexico. One from Peubla, Mexico, is referable to annulata, and one in the British Museum, labeled "Tehuantepec," belongs probably to this form (Boulenger, 1894, 205). It should be looked for in the plateau region of southern and eastern Mexico; westward it apparently intergrades with nelsoni. Since the gentitis of Arizona and New Mexico is most closely related to this form, the latter may be expected to range pretty well north in Mexico, east of the Sierra Madre. The only reliable record, aside from those included in the list of specimens examined, is that for Tehuantepec (Boulenger, 1894, 205).

Variation and affnities.-This form has never been collected in numbers, and the great majority of specimens obtained have come from northeastern Mexico and extreme southern Texas. Future collecting will undoubtedly extend its known range and increase the limits of its variation. Specimens from Cameron County, Texas, and the adjacent country in Mexico are typical and homogeneous; they need not be confused with the gentilis from farther north nor with the Mexican forms of the triangulum group. The ventrals here range from 197 to 210 - a number that is low for polyzona, a little lower than nelsoni, and a little high for gentilis and amaura. A specimen from San Antonio, which has been referred to gentilis, has 193 ventrals, and one from Puebla has 213. Boulenger's specimen $(1894,205)$ from Tehuantepec, which is probably close to anrulata, has 218 ventrals. This indicates that on the plateau region of southern Mexico annulata may be characterized by a higher arerage number of ventrals than it possesses in the northern part of its range. The same may be true of the dorsal scale rows. The Puebla specimen has the formula 23-21-19, while of those from the type region, only 3 out of 10 have the formula 23-21-19, the rest having it 21-19. This is significant of the reduced scutellation that will be noticed to characterize the forms of the triangulum group northeast and east from here.

The labials are, as usual, 7 and 9, but 10 in the lower row is attained by occasional specimens from the type region. The temporals are usually $2+3+4$, with infrequent drops of one in the second and third rows. The posterior chin shields are a little shorter or about equal to the anterior, and the loreal is oblong. The tail is about the same length as that of polyzona, a little longer than that of the major- 
ity of forms in the genus. The important thing to note in all these matters of structure is that annulata is typical of the conservative forms throughout the genus. It is not specialized by having a very short tail (micropholis) or very long one (pyrrhomelaena), in having the temporals reduced in number (elapsoides, micropholis) or irregular (triangulum), in having a high number of labials (pyrrhomelaena, conjuncta) or a low number (elapsoides, rhombomaculata), in having unusually short postgenials (boylii, californiae), in having a low scale formula (elapsoides, micropholis, holbrooki), or in having a low number of ventrals (elapsoides, gentilis in Utah). It is near to the normal or average for the genus.

The pattern, too, is one from which the patterns of all the northern members of the group may be derived. This will be made more plain later on, but it will be well here to describe the pattern of the Puebla specimen (fig. 66), since this is theoretically the most primitive in the group (no. 9555, Mus. Comp. Zool., Puebla, Mexico). It has 19 white (in alcohol) rings on the body and 4 on the tail. These are $1 \frac{1}{2}$ to 2 scales in width, are a little mottled with darker, chiefiy on the sides, and encircle the body. The space between the white rings may be described as black, more or less split with red. The red never extends onto the belly beyond the tips of the ventrals, and dorsally it narrows toward the median line and is frequently excluded therefrom by a widening of the black borders. The tail is ringed with black and white. The head is black as far back as the middles of the parietals, anterior temporals, sixth supralabials and fifth infralabials, except for small irregular spots of lighter on the prefrontals and anterior part of frontal, and in the loreal region. This last is suggestive of the light cross band on the snout of polyzona, but it is too much to say now what its significance may be. It is expected to be shown that all the forms of the group north and west of annulata may be easily derived from such a pattern as this.

About all that can be definitely said of the relationship of this form to those inhabiting adjacent ranges is that it is a direct relative of nelsoni, and of gentilis. It is a fairly safe conclusion that intergradation takes place with both of these forms. Its relationship to polyzona, judging from the material now at hand, is not at all clear, but it must be close. 


\begin{tabular}{|c|c|c|}
\hline 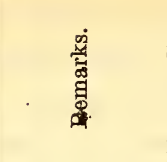 & 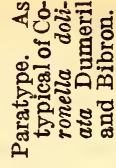 & 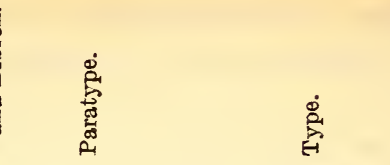 \\
\hline minute jo $0 \mathrm{~N}$ & $\stackrel{9}{-}$ & ֻึส \\
\hline 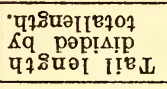 & $\vdots$ & 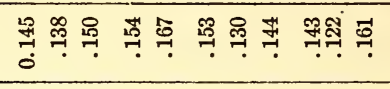 \\
\hline 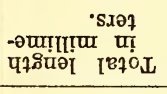 & 吾 & 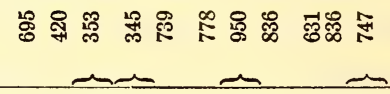 \\
\hline "sโBIoduə & 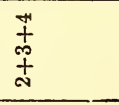 & 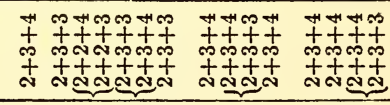 \\
\hline$\cdot$ s.Iernoo & $\cong$ & 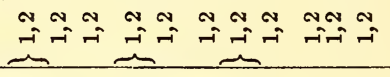 \\
\hline 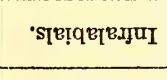 & $\theta$ & 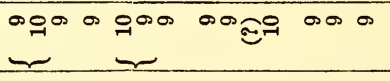 \\
\hline 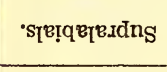 & $\sim$ & NNN N $\underbrace{\infty N \infty N}$ NN \\
\hline 'sðвpnвన & เด & 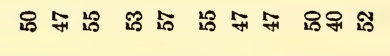 \\
\hline 'sүe्qua $\Lambda$ & $\stackrel{\infty}{\rightrightarrows}$ & 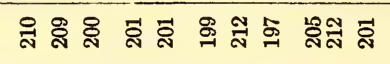 \\
\hline 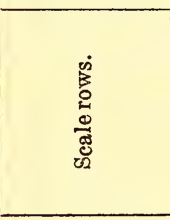 & $\begin{array}{c}\vdots \\
\vdots \\
\vdots \\
\vdots \\
\frac{I}{1} \\
\end{array}$ & 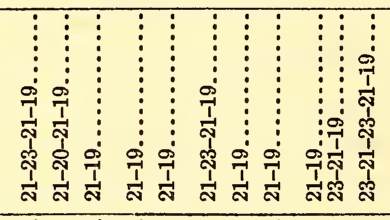 \\
\hline 峁 & 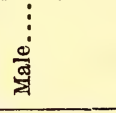 & 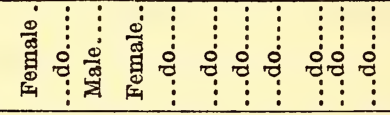 \\
\hline 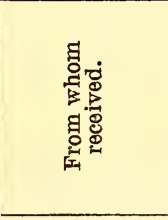 & 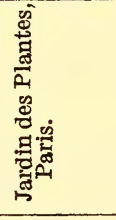 & 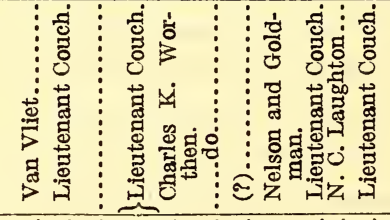 \\
\hline 危 & \begin{tabular}{c}
$\vdots$ \\
$\vdots$ \\
$\vdots$ \\
$\vdots$ \\
$\vdots$ \\
$\vdots$ \\
\hdashline \\
\hdashline
\end{tabular} & 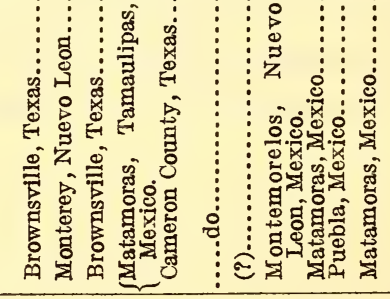 \\
\hline$\dot{\circ}$ & มึ & 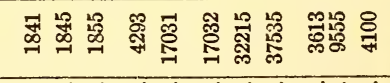 \\
\hline 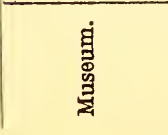 & 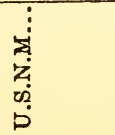 & 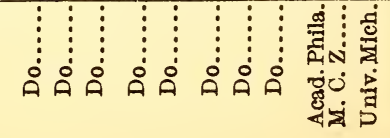 \\
\hline
\end{tabular}


LAMPROPELTIS TRIANGULUM GENTILIS (Baird and Girard).

Fig. 72.

1853. Ophibolus ${ }_{\text {s. }}^{*}$ gentilis BaIRD and Girard, Cat. N. Amer. Rept., pt. 1; p. 90 (type locality: North Fork, Red River, near Sweetwater Creek, Wheeler County, Texas; type, U. S. Nat. Mus. no. 1853; Capt. Marcy, collector).Marcy, Ex. Doc. Ho. of Rep., 33d Congress, 1st sess., 1854, p. 200, pl. 8.-Barrd, Pacif. R. R. Surv., vol. 10, pt. 3, no. 1, 1859, pl. 30, fig. 64.Coronella gentilis (part ?) Boulenger, Cat. Snakes Brit. Mus., vol. 2, 1894, p. 201.

1860. Lampropeltis doliata (part) Cope, Proc. Acad. Nat. Sci. Philadelphia, p. 256 (Kansas).

1860. Lampropeltis multistriata Kennicotr, Proc. Acad. Nat. Sci. Philadelphia, p. 328 (type locality, Fort Lookout, South Dakota; type specimen, U. S. Nat. Mus., no. 1842; Lieut. Warren and Dr. Hayden, collectors).

1875. Ophibolus multistratus Cope, Bull. U. S. Nat. Mus., no. 1, p. 36; Proc. U. S. Nat. Mus., vol. 14, 1891, p. 611.-Ophibolus multistrata Coues and YARRow, Bull. U. S. Geol. Geog. Surv. Terr., vol. 4, art. 11, 1878, p. 284.Cope, Rep. U. S. Nat. Mus. for 1898, 1900, p. 909, fig. 225.-Lampropeltis multistrata Stejneger, Proc. U. S. Nat. Mus., vol. 14, 1891, p. 502.

1882. Ophibolus doliatus gentilis (part) Yarrow, Bull. U. S. Nat. Mus., no. 24, p. 90.-Brown, Proc. Acad. Nat. Sci. Philadelphia, 1901, p. 75.-Branson, Kansas Univ. Sci. Bull., vol. 2, no. 13, 1904, p. 402, figs. 25, 25a.Ditmars, Reptile Book, 1907, pp. 340, 348, pl. 106 (upper fig.).-CockERELL, Univ. Colorado Studies, vol. 7, 1910, p. 131 (footnote).-Ellis and Henderson, Univ. Colorado Studies, vol. 10, no. 2, 1913, p. 91, pl. 4, fig. 23.-Osceola doliata gentilis Cope, Rep. U. S. Nat. Mus. for 1898, 1900, p. 894.

1882. Ophibolus doliatus annulatus (part) YARRow, Bull. U. S. Nus. Mus., no. 24, p. 90 (Apache, Arizona).

1883. Ophibolus triangulus gentilis Garman, Mem. Mus. Comp. Zool., vol. 8, no. 3 , pt. 1 , pp. 66,155 .

1893. Ophibolus doliatus sysputus Cope, Proc. Acad. Nat. Sci. Philadelphia, p. 387 (Hennessy, Oklahoma).

1903. Lampropeltis pyrrhomelaena celaenops Stejneger, Proc. U. S. Nat. Mus., vol. 25, p. 153 (type locality, Mesilla Valley, New Mexico; type specimen, U. S. Nat. Mus., no. 22375; H. B. Lane, collector).-SteJneger and Barbour, Check List, 1917, p. 89.

1917. Lampropeltis triangulum gentilis STEJneger and Barbour, Check List p. 90.-Stejneger, Proc. Biol. Soc. Washington, vol. 31, 1918, p. 99.

Description.-Forty-six specimens of this form have been available for study, and from these the following summary of the scutellation has been derived: Ventral plates, 176 to 212 ; caudals, 31 to 53 (males, 41 to 53, average 48; females, 31 to 49, average 45); supralabials, 7 , rarely 8 ; infralabials, 9 , rarely 8 or 10 ; one preocular; two postoculars, rarely one; temporals usually $2+3+4$, occasionally one less in any row; posterior chin shields shorter than the anterior or nearly as long, in contact with each other or separated by one or two small scales; loreal distinctly longer than high; scale rows usually 21-19, often 21-19-17, on middle of body sometimes 23 . 
Head somewhat distinct from the neck; body moderately stout, cylindrical; tail tapering, 0.115 to 0.156 of the total length (males, 0.124 to 0.156 , average about 0.141 ; females, 0.115 to 0.148 , average about 0.134$)$. The largest specimen from a typical portion of the range (Wheeler County, Texas) is $713 \mathrm{~mm}$. in length. Some examples from central Kansas are larger than this.

The pattern (fig. 72) on body and tail is composed of 25 to 40 whitish annuli from one to three scales wide dorsally and from two to five in width on the first row of scales. Between these rings are pairs of black annuli separated by red. The black and white rings are continuous across the belly, but the space there between the black rings and opposite the dorsal red areas is usually filled with black. The latter color tends to encroach upon the red, and, on the middorsal lines the black rings of adjacent pairs are often confluent. The whitish rings are usually mottled on the sides with darker; the belly is generally crossed by approximately equal bands of black and white, but the white areas may be blotched with darker, the black may be partly broken up, and rarely there is little or no black below.

The head is generally a uniform black on the posterior half, and this black may extend forward over the snout. The latter is, however, usually lightened, at least on the sides. The labials show varying proportions of dark and light, corresponding with the extent of black on the head.

The actual colors of the whitish annuli, according to Ellis $(1913,91)$, are light gray to bright yellow, while the red varies from slate brown, through brick red, to scarlet. A specimen from Blue River, Nebraska, bears the note: "Original color: Deep orange, lemon yellow, and black." The red and yellow fade to white in alcohol.

The dentition, as revealed by the examination of a few specimens, is as follows: Maxillary teeth, 12 to 14 , most often 13, the last 2 slightly larger; mandibulars, 12 to 15 , the third and fourth largest, a little greater space between the fourth and fifth; palatines, 10 or 11 , of tener 10 ; pterygoids, 16 to 20 .

This form may nearly always be immediately recognized by its black head with snout mottled with red and black, its conspicuous black rings which encroach on the red dorsally and are separated by not more than 40 nor less than 25 whitish annuli on body and tail. Specimens examined from west of the Rockies, where the color pattern is confusingly similar to that of pyrrhomelaena and multicincta, have less than 200 ventrals, while the latter forms have several to many more. Its distinction from amaura and from syspila is given under these respective forms.

Habitat and habits.-Apparently nothing has been recorded on the natural history of this form. 
Range.-As here defined, gentilis occurs from western Utah and southeastern Arizona east to the ninety-seventh meridian, north to southern South Dakota, and south probably to northern Mexico.

Besides the localities included in the accompanying list of specimens Ellis $(1913,92)$ has recorded a few other stations for Colorado; Yuma; Orchard; Clear Creek, near Golden; Beulah; and Baca County.

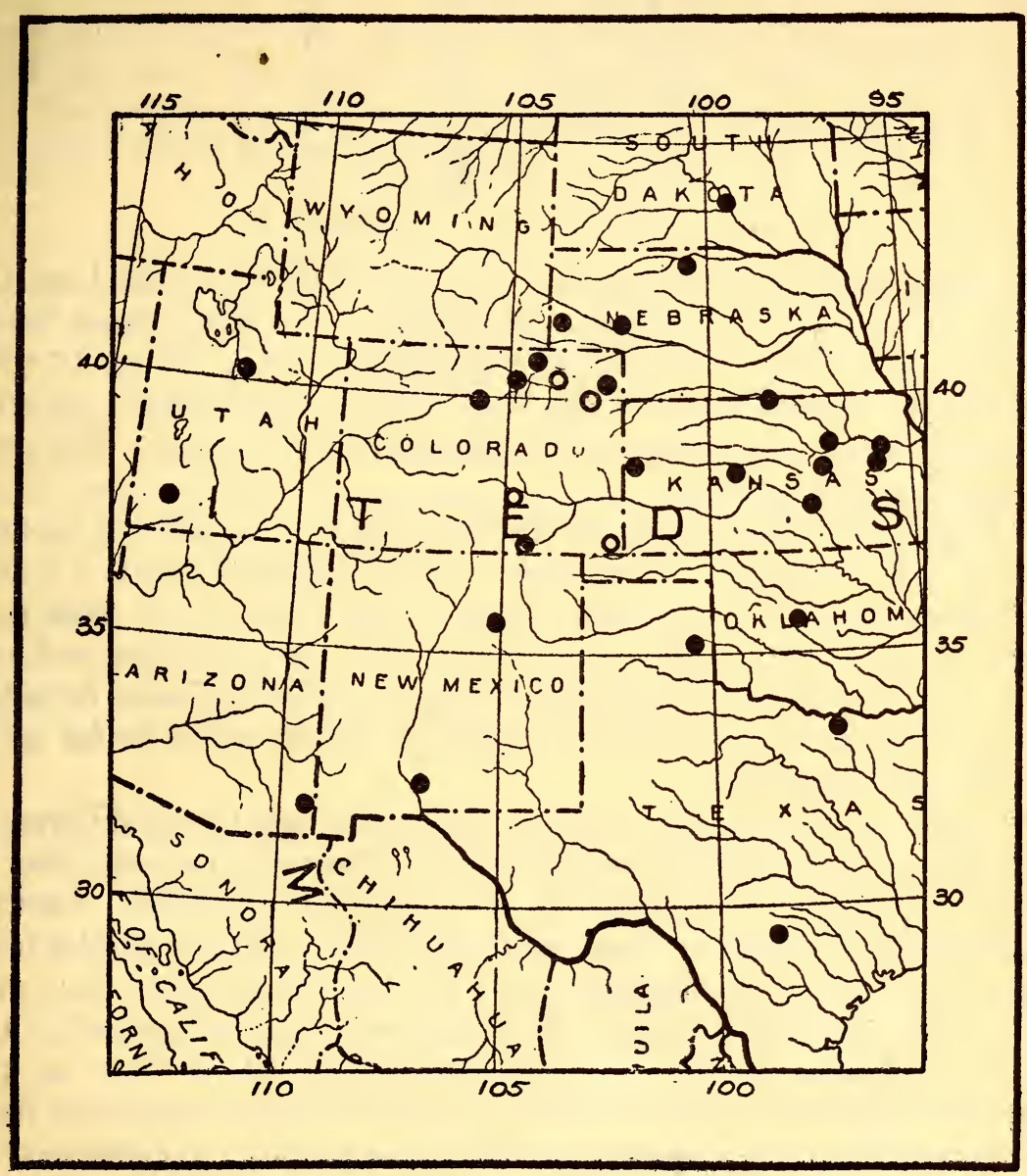

FIG. 49.-MAP SHOWING LOCALTY RECORDS FOR LAMPROPELTIS TRIANGULUM GENTILIS.

Variation.-Considerable variation with locality is indicated by the ventral plates. The extremes and average for Kansas are about the same as for syspita in that region; the number is lower in Colorado, and the few from west of the Rockies indicate a still greater reduction. It will be interesting to see whether future specimens bear out the unusual lack of variation in the four Utah specimens now on hand. Subsequent proof of the existence of a distinct race west of the Rockies would not be surprising, but the present material certainly would not justify any separation. 
Table of scale formulae of gentilis.

\begin{tabular}{|c|c|c|}
\hline Formula. & Male. & Female. \\
\cline { 1 - 2 } $23-21$ & & \\
$21-23-21$ & 1 &. \\
$23-21-19$ & 1 & \\
$21-23-21-19$ & 1 & 3 \\
$21-19$ & 9 & 9 \\
$19-21-19$ & 1 & 1 \\
$21-19-17$ & 5 & $\dddot{1}$ \\
$19-21-19-17$ & 1 & $\ldots$ \\
$19-17$ & 1 & $\frac{1}{15}$ \\
Total........ & $\frac{1}{20}$ & \\
\hline
\end{tabular}

Geographic differences on scale rows can not be detected from the scanty material now arailable. A notable point is the great variability in formulae. Like the southern forms of the group, 17 rows toward the posterior end of the body is much less common than 19, and this number is possessed almost exclusively by males. The commonest formula is 21-19.

Variation in other points of scalation may be considered as only normal for the group. Reduction in the temporals below $2+3+4$ occurs frequently in the third row and less often in the first two. There is no evidence that the lower labials are becoming reduced to 8. In fact, it may be said that reduction in scutellation from the mean of the group has not proceeded in gentitis quite as far as in syspila and triangulum.

In spite of the scarcity of specimens certain significant differences that depend upon locality may be noted in the color pattern, chief of which is perhaps the increase in dark pigment westward. Eastern specimens as a rule have more red on the snout, while examples from west of the Rocky Mountains may have the whole head black with only a very little lightening in the loreal region and at the end of the snout. Likewise on the body, the black pigment increases at the expense of the red, and frequently excludes the latter altogether from the dorsal line, thus presenting a striking resemblance to multicincta of the Pacific region. These differences in pigment are, however, only average; occasional specimens from east of the Rockies are as heavily pigmented as those west. The latter are definitely ringed, while those on the east side of the mountains show a variation toward syspila. Here the black on the belly opposite the dorsal red areas is sometimes split lengthwise in the middle or is continuous across the belly but much narrower. Thus specimens from Nebraska and Kansas may have the red restricted to wide dorsal saddles, but there are usually no lateral alternating spots. 
Affinities.-Very few specimens are available from the southern portion of the range, but the indication is that no constant differences will be found to separate gentilis from annulata. Their close affinity is indicated in every characteristic. Annulata becomes gentilis when the yellowish annuli widen on the sides and restrict the black on the belly to an area no greater than that of the yellow, and when the black snout becomes lightened with reddish. Intergradation certainly takes place with amaura and with syspila where their respective ranges meet its own. The relationship held to exist between these forms and discussed at greater length in the summary of this group may be expressed in the following diagram:

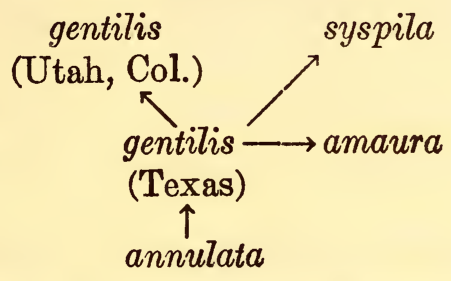

FIG. 50.-DIAGRAM SHOWING INTERRELATIONSLIPS BETWEeN LAMPROPELTIS TRLANGULUM ANNULATA L. T. GENTIIIS, L. T. AM IURA, AND L. T. SYSPILA. 


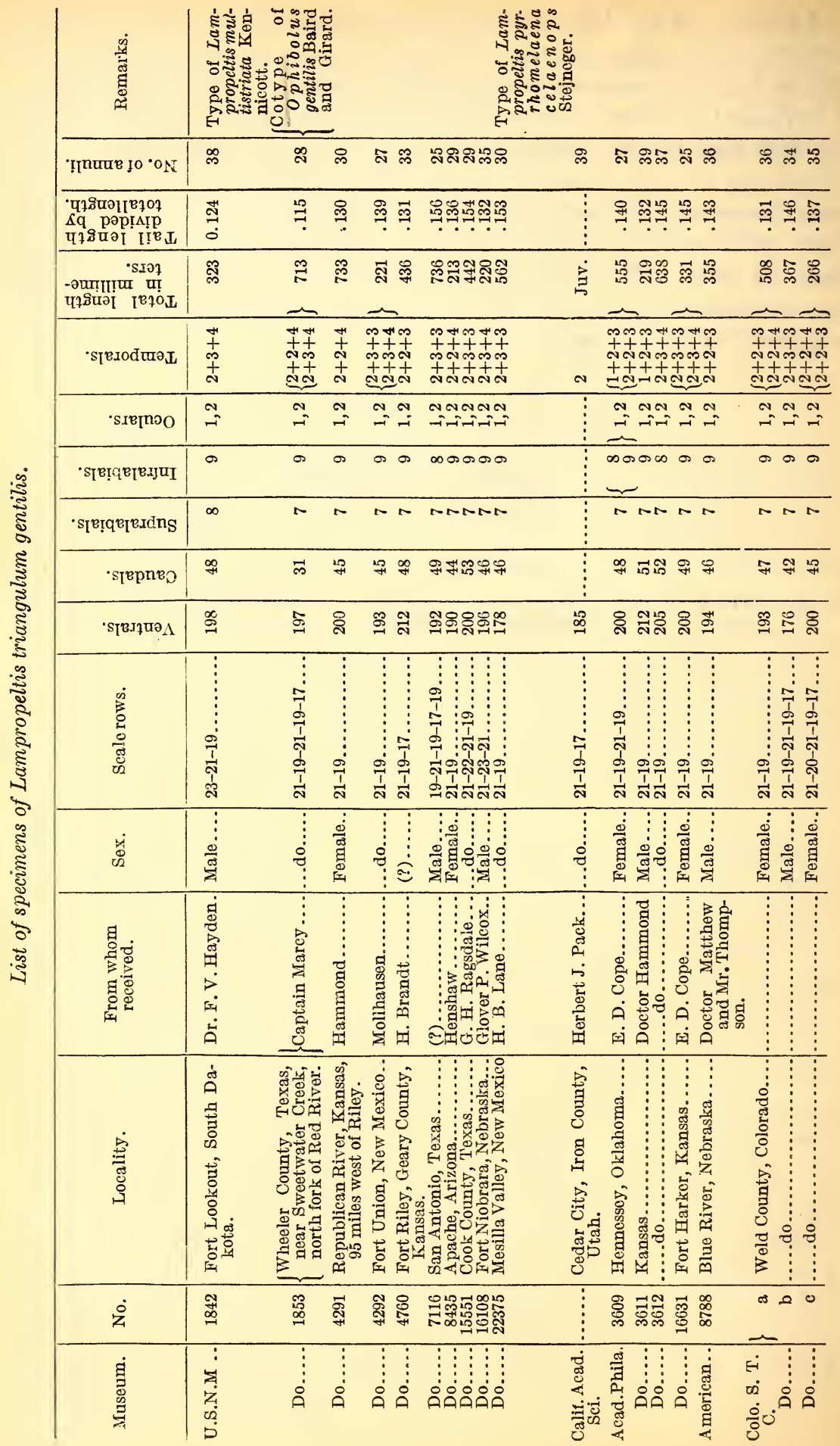




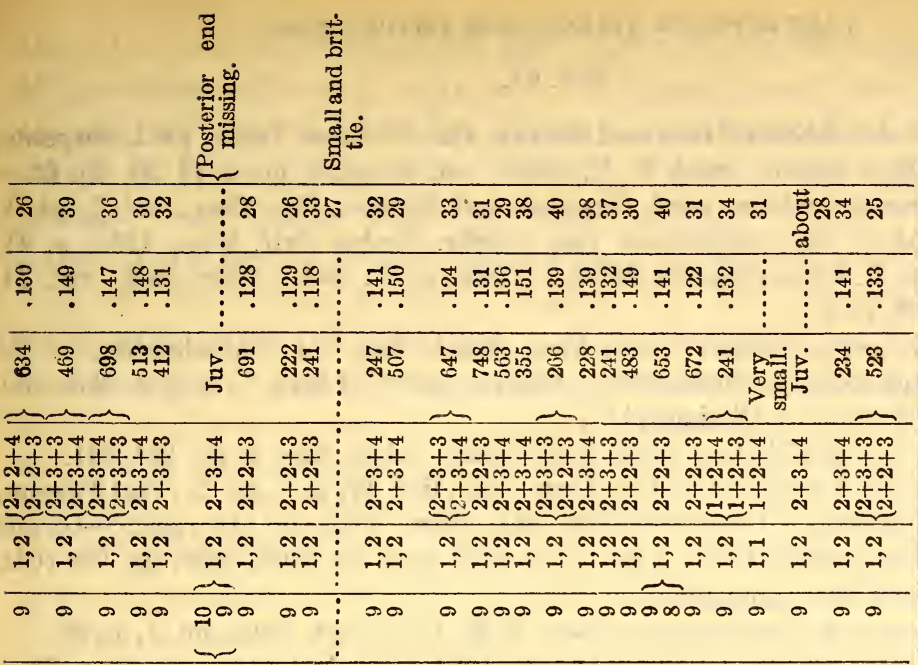

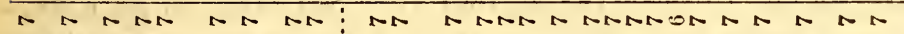

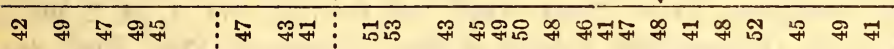

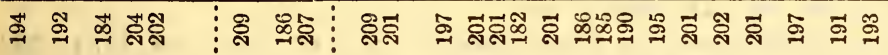

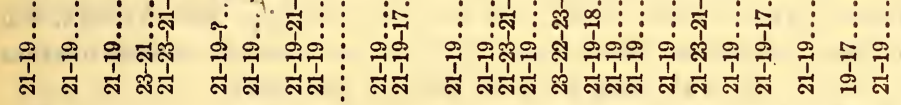

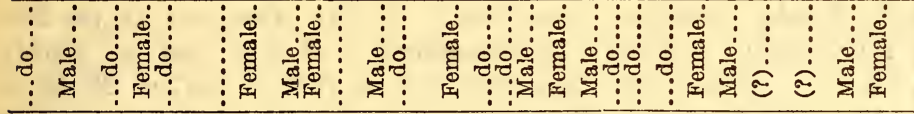

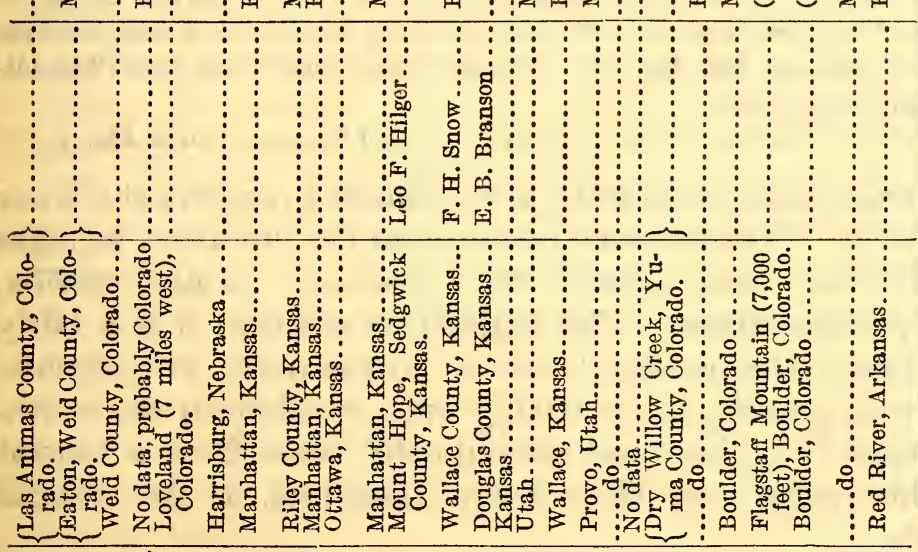

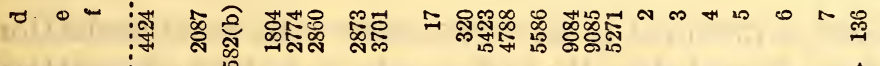

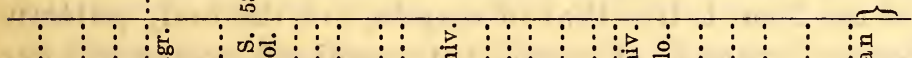

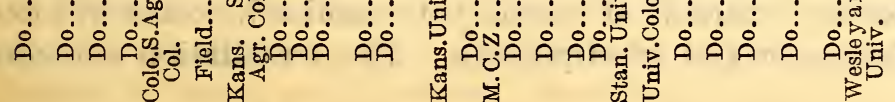
186550-21-Bull. 114-12 


\section{LAMPROPELTIS TRIANGULUM AMAURA (Cope).}

Fig. 67.

1853. Ophibolus doliatus Baird and Girard, Cat. N. Amer. Rept., pt. 1, Serpents, p. 89.-Barrd, Pacif. R. R. Surv., vol. 10, pt. 3, no. 1, pl. 30, fig. 63.Coronella doliata (part) Dumeril and Bibron, Erp. Gen., vol. 7, pt. 1, 1854, p. 621.-GüNTHER, Cat. Colubr. Snakes Brit. Mus., 1858, p. 41, var. B.-Lampropeltis doliatus Garman, S., Bull. Essex Inst., vol. 24, 1892 , p. 9.

1860. Lampropeltis amaura Cope, Proc. Acad. Nat. Sci. Philadelphia, p. 258 (type locality, "unknown"-Original entry of type U. S. Nat. Mus., no. 5282 reads "? Mississippi").

1863. Corone,ia gentilis JAN, Arch. Zool. Anat., vol. 2, fasc. 2, pp. 237, 241.

1866. Coronella doliata gentilis $\mathrm{JAN}_{\mathrm{N}}$, Icon. Gen., livr. 17, pl. 1, fig. 2, (Fort Towson, Oklahoma).-Bocourt, Miss. Sci. Mex., 1886, p. 610 (part).-Osceola doliata gentilis Cope, Rep. U. S. Nat. Mus. for 1898, 1900, fig. 218 (Calcasieu Pass, Louisiana).

1875. Ophibolus doliatus amaurus Cope, Bull. U. S. Nat. Mus., no. 1, p. 36.

1882. Ophibolus doliatus doliatus YARrow, Bull. U. S. Nat. Mus., no. 24, p. 89.STRECKER, Baylor Univ. Bull., vol. 18, no. 4, 1915, p. 38.-Osceola doliata doliata Strecker, Trans. Texas Acad. Sci. for 1901, vol. 4, pt. 2, no. 5, 1902, p. 3.-Lampropeltis doliatus doliatus Strecker, Proc. Biol. Soc. Washington, vol. 21, 1908, p. 75.

1888. Ophibolus doliatus coccineus Cope, Proc. U. S. Nat. Mus., vol. 11, p. 382; vol. 14, 1891, pp. 608, 609; Amer. Nat., vol. 27, 1893, p. 1067, pl. 28, fig. 10; Rep. U. S. Nat. Mus. for 1898, 1900, pl. 36, fig. 10.-STone, Proc. Acad. Nat. Sci. Philadelphia, 1903, p. 542 (Limestone fap, Oklahoma).Strecker, Baylor Univ. Bull., vol. 18, no. 4, 1915, p. 38.-VioscA, 6th Bien. Rep. Louisiana State Mus., 1918, p. 72.-Osceola doliata coccinea Cope, Rep. U. S. Nat. Mus. for 1898, 1900, p. 896 (part).

1888. Ophibolus doliatus parallelus Cope, Proc. U. S. Nat. Mus., vol. 11, pp. 383, 385 (type locality, unknown; type specimen, U. S. Nat. Mus., no. 10544); vol. 14, 1891, pp. 608, 609; Amer. Nat. vol. 27, 1893, p. 1067 pl. 27, fig. 8; Rep. U. S. Nat. Mus. for 1898, 1900, pl. 35, fig. 8.-Osceola doliata parallela Cope, same, p. 893, fig. 217.-Wright, Proc. Acad. Nat. Sci. Philadelphia, 1915, p. 140.

1917. Lampropeltis triangulum amaura STEJNEGER and BARBer, Check List, p. 90.

As here defined, amaura occupies a very limited range in the lower Mississippi Valley. Nearly every reference in the literature includes with it individuals here referred to elapsoides, syspila, gentilis, nelsoni, and perhaps others. The indications are that it is a fairly well-defined form, intergrading, however, on the north with syspila, on the west with gentilis, and probably with annulata on the southwest. The type is typical, and undoubtedly came from a central portion of this range, very likely from Mississippi, as the original entry suggests.

Parallelus Cope is included in the synonomy with some hesitation. The pattern of the head is like that of syspila, but the body pattern, which is unlike any example of syspila yet examined, occurs in some specimens of amaura and of virginiana. The scutellation excludes 
the latter, so that there is the least difficulty in referring it to amaura. Where it came from is unknown. Originally only one specimen bore the United States National Museum number 10544. This was entered as from Gainesville, Florida, James Bell, collector. Later another was found with the same number-10544. The original name in the record book is erased and "? Ophibolus doliatus" written over it. This was probably meant for the specimen which later became the type of parallelus. This "? Ophibolus doliatus" has a line through it and above is written "? Osceola elapsoidea;" this was doubtless the specimen that originally bore the number 10544 . This, too, has a line through it, and above it is written "Ophibolus doliatus parallelus." Then when it was noticed that two different specimens bore the number 10544, one was given a new number, 20137, and the type of parallelus was left with the old number. Specimen number 20137 is a perfect example of elapsoides, and is without doubt the one received from James Bell. This leaves parallelus with no locality and no way of finding it out.

Description.-This form has the following scutellation: Ventral plates, 180 to 205 ; caudals, 39 to 51 (males, 41 to 51, average about 45 ; females, 39 to 47 , average about 44 ); supralabials, 7 , infralabials, 9 , occasionally 8 or $10 ; 1$ preocular, 2 postoculars; temporals, $2+2+3$ or $2+3+4$, sometimes $1+2+3$; posterior chin shields shorter than anterior, and frequently separated by one or two small scales; loreal distinctly longer than deep; scale rows usually $21-19$, occasionaly as low as 19-21-19-17, and as high as 21-23-21-19.

This is a small snake, but not as small as elapsoides. It is rather slender; the snout is a little more pointed and projecting than that of gentilis; the tail varies from 0.118 to 0.156 of the total length (males, 0.133 (0.118) to 0.156 , average 0.143 ; females, 0.125 to 0.143 , average 0.136). The largest specimen examined measured $629 \mathrm{~mm}$. , and came from Jefferson County, Texas.

The pattern is typically in rings of black, yellow, and red. There are 18 to 26 yellow rings on body and tail bordered with black and separated by red. The yellow rings widen on the lower rows of scales, and traverse the belly, but are sometimes more or less interrupted here with black blotches. The red areas may be continuous across the belly or interrupted by the ventral junctions of the black borders of adjacent pairs of rings (fig. 67). The head is usually black and the snout red, but the red, in a few cases extends back onto the parietals.

This form may be distinguished from elapsoides by the greater number of ventral plates (nearly 200), a maximum of 21 instead of 19 rows of scales, the usually greater extent of black on the head, the fact that the snout is usually more or less mottled with black instead of being a uniform red; from syspila it may be distinguished 
by the fact that (1) the pattern is in rings, or, when in blotches of red, there is no ventro-lateral series of dark spots alternating with the dorsal blotches, (2) the head is black with a red snout, instead of red with a posterior black band and various dark-edged light markings between the eyes, and (3) the number of transverse yellow bands is not commonly above 23; from gentilis it is best known (1) by the smaller number of yellow cross bands, usually not more than 25 , (2) by the fact that the black rings show but slight tendency to encroach dorsally upon the red, and (3) the black of the belly in

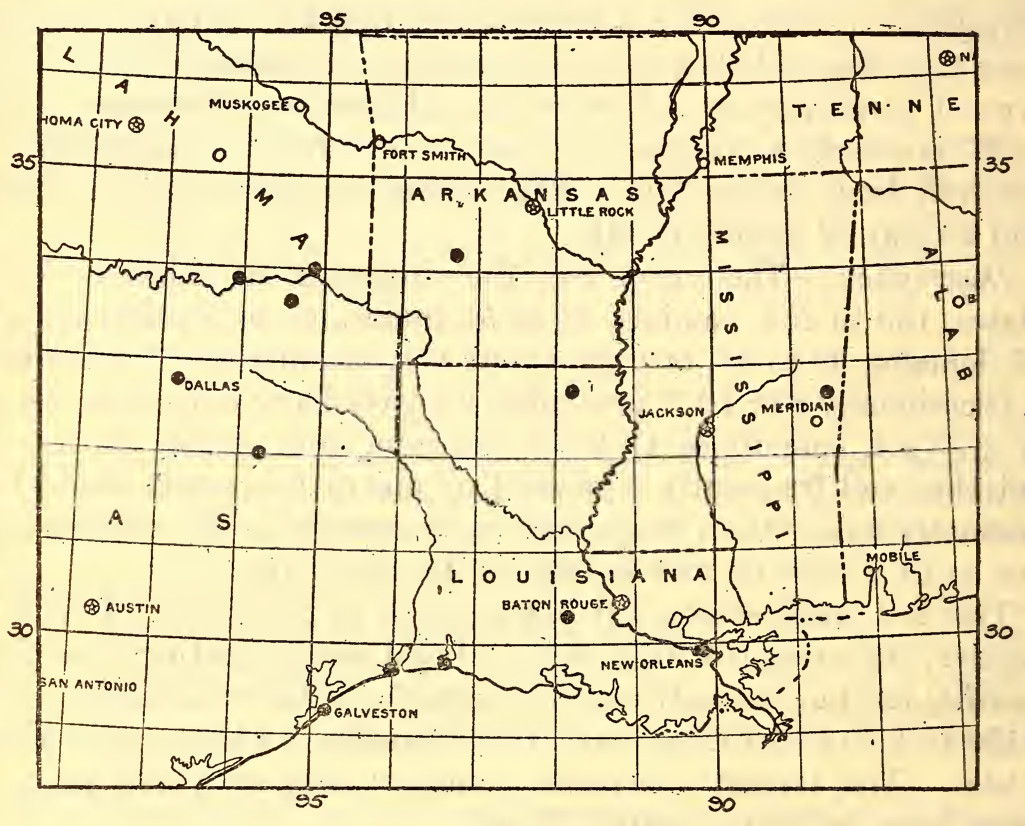

FIg. 51.-MAP SHOWING LOCALITX RECORDS FOR LAMPROPELTIS TRLANGULUM AMAURA.

gentilis is usually concentrated between the black rings opposite the dorsal red areas, instead of being divided with red, as in amaura.

Habitat and habits.- Of the natural history of this form nothing is recorded.

Range.-As here defined, amaura occupies the southern portion of the Mississippi Valley, from eastern Mississippi to southern Arkansas, and west to about the 97 th meridian.

There are no apparently reliable locality records aside from those included in the accompanying list of specimens.

Variation and affinities. - With this form we must confine ourselves to the discussion of individual variation, since the demonstration of geographic variation is rendered unsatisfactory by the insufficiency 
and poor distribution of the material, and, except for pattern characters, by the small extent of the range. In the matter of scale rows it should be noted that the common formula is 21-19. In this, and the small percentage of specimens with 17 rows at the end, amaura is like gentilis, and probably like annulata (but the undue proportion of females among the specimens of this form lessens the value of figures based upon characters that vary with sex). The infrequent occurrence of a lower formula, as 19-21-19-17, foreshadows a situation that is common in syspila and still more common in triangulum. The distribution of scale formulae between the sexes in amaura is as follows:

\begin{tabular}{|c|c|c|}
\hline Formula. & Male. & Female. \\
\cline { 1 - 2 } $21-23-21-19$ & 0 & 3 \\
$21-19$ & 6 & 7 \\
$19-21-19$ & 3 & 1 \\
$19-21-19-17$ & 3 & 1 \\
$19-17$ & 1 & 0 \\
\hline
\end{tabular}

Thus the formula $21-19$ is about as common to one sex as to the other, and may be considered the normal. In accordance with the general rule, the higher formulae are mostly possessed by females, and the lower by males.

The number of ventrals in the majority of cases lies between 188 and 199, therefore averaging a little less than annulata in northeastern Mexico. With the exception of local variation, this number of ventrals is hardly different from that of syspila and triangulum. Variation in infralabials and temporals is the same in kind and apparently about the same in frequency as in these same two forms.

The pattern is rather variable, and to properly interpret this variation many more specimens must be secured. We may say that amaura is characterized by a black head, reddish snout somewhat mottled with darker, and about 22 pairs of black annuli bordering yellow, and separated by red. The latter color may encircle the body or be restricted to wide saddles bordered below with black. When the latter is the case we may have the ventral borders of the saddles near together on the belly, or, at the northern edge of the range, they may be indistinct and only just reach the ventrals. This is a close approach to syspila. When, added to this, there are developed alternating spots near the ends of the ventrals, and the whitish bands have increased to more than 25, and the black of the head has receded or become broken up, then we have syspila. The change to gentilis is not as well shown for lack of specimens, but westward, where the paired black rings increase to more than 25, 
and the black spreads more or less over the red, in particular above the dorsal line, we have gentitis.

On the basis of this single form and its variations, it would not be safe to assert that evolution had proceeded in one direction and not in another, for proof that it did not occur in any one of several ways would be difficult to produce. We will therefore leave to the summary of the group our hypothesis of its actual relations to its nearest relatives, and the reasons therefore, and, with the briefest summary, leave the subject at this point.

It can hardly be doubted that the closest affinities of amaura are with syspila on the north and with gentilis on the west, and with these forms intergradation certainly occurs. With annulata its relationship is very close, but whether direct or through gentitis is uncertain. It is the closest relative of elapsoides, but between the two there is apparently a slight but distinct structural gap, strongly suggesting differentiation of the latter by isolation, followed by a rejoining of the two ranges. 


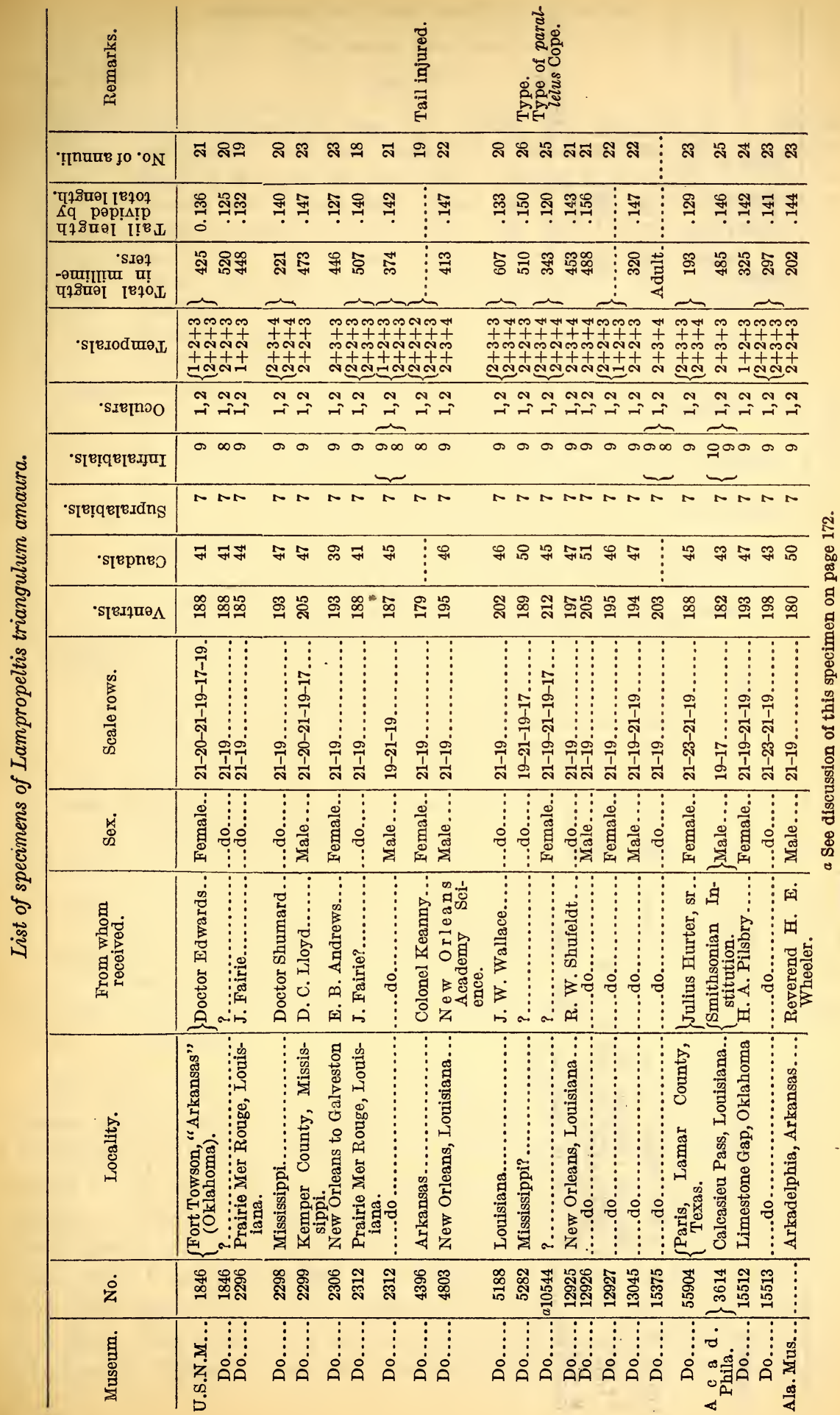




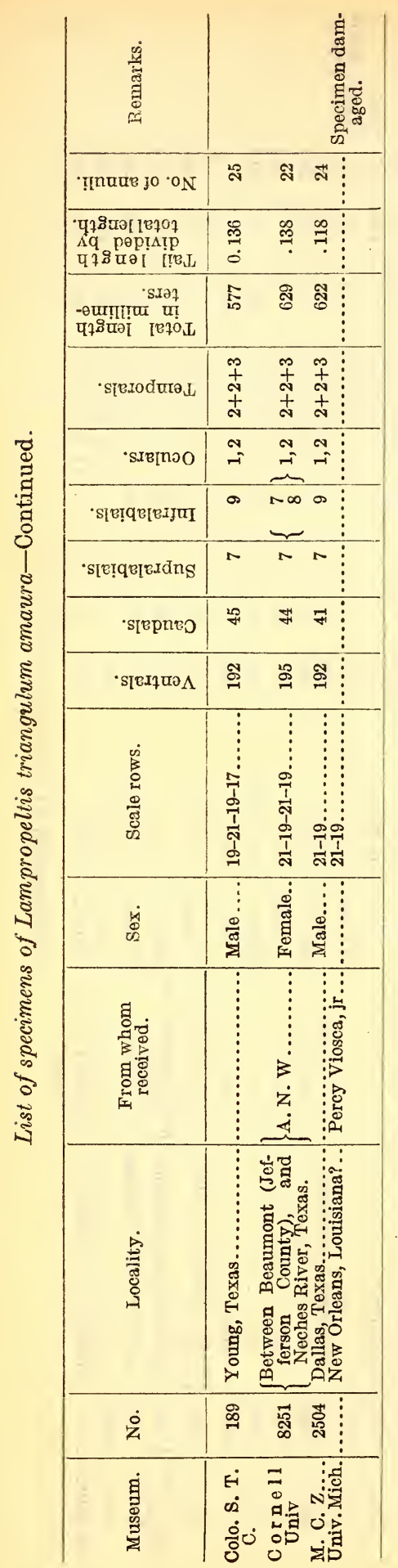




\section{LAMPROPELTIS TRIANGULUM SYSPIAA (Cope).}

RED SNAKE; RED MILK Snake

Figs. 52, 68:

1861. Coronella doliata JAN, Icon. Gen. Ophid., livr. 14, pl. 4, fig. A (Illinois meridional); Arch. Zool. Anat., vol. 2, fasc. 2, 1863, p. 237.-BocourT, Miss. Sci. Mex., pt. 3, vol. 2, 1886, p. 609, vol. 3, pl. 39, fig. 2.-Ophibolus doliatus Siith, Geol. Surv. Ohio, vol. 4, 1882, p. 691.-Blatchley, Journ., Cincinnati Soc. Nat. Hist., 1891, p. 32.-Hurter, Trans. Acad. Sci. St. Louis, vol. 6, no. 2, 1893, p. 255.-Lampropeltis doliata McLanN, Notes Coll. Rept., 1899, p. 3.-Lampropeltis doliatus Hurter and Strecker, Trans.' Acad. Sci. St. Louis, vol. 18, no. 2, 1909, p. 26.HurTER, Trans. Acad. Sci. St. Louis, vol. 20, no. 5, 1911, p. 183.Ruthyen, Proc. Iowa Acad. Sci., vol. 19, 1912, p. 207.

1882. Ophibolus doliatus doliatus (part) YarRow, Bull. U. S. Nat. Mus., no. 24, p. 89.-Hay, 36th Annual Rep. State Board Agric. Indiana for 1886, vol. 28, 1887, p. 210; Journ. Cincinnati Soc. Nat. Hist., vol. 10, no. 2, 1887, p. 64 (New Harmony, Ind.); 17th Annual Rep. Indiana Dept. Geol. Nat. Res., 1892, p. 515.-Cope, Proc. Acad. Nat. Sci. Philadelphia, 1893, p. 385 ; Rep. U. S. Nat. Mus. for 1898,1900 , pls. 34,35 , figs. 5 to 7.-Branson, Kansas Univ. Sci. Bull., vol. 2, no. 13, 1904, p. 400.-Osccola doliata doliata Morse, Proc. Ohio State Acad. Sci., vol. 4, pt. 3, spec. pap. no. 9, p. 130.-Lampropeltis doliatus doliatus StrRecker, Proc. Biol. Soc. Washington, vol. 21, 1908, p. 89 (Hot Springs, Arkansas).

1888. Ophibolus doliatus syspilus Cope, Proc. U. S. Nat. Mus., vol. 11, p. 384 (type locality, Richland County, Illinois; type specimen, U. S. Nat. Mus., no. 13380; Robert Ridgway, collector); vol. 14, 1891, pp. 608, 609.Hay, 17th Annual Rep. Dept. Geol. Nat. Res. Indiana, 1892, p. 517.Cope, Amer. Nat., vol. 27, 1893, p. 1067, pl. 27, fig. 7.-Osceola doliata syspila Cope, Rep. U. S. Nat. Mus. for 1898, 1900, p. 891, fig. 216.

1892. Ophibolus triangulus doliatus Garman, H., Bull. Illinois State Lab. Nat. - Hist. vol. 3, art. 13, p. 295.

1898. Coronella triangulum, var. collaris Boettger, Kat. Rept.-Samml. Frankfurt, pt. 2, p. 72.

1903. Lampropeltis doliatus coccineus Stone, Proc. Acad. Nat. Sci. Philadelphia, p. 542 (Petit Jean Mountain, Arkansas; South McAlester, Oklahoma).

1919. Lampropcltis triangulum syspila Ruthven, Occ. Pap., Mus. Zool., Univ. Mich., no. 66, p. 3.

1919. Lampropeltis triangulum amaura Sснмпт, Copeia, no. 73, p. 72 (Sapulpa, Oklahoma).

This form has usually been known as dotiatus Linnaeus, but this name, as Stejneger has pointed out $(1918,99)$, can not be definitely identified with any known form of Lompropettis. The name syspitus Cope is the next one to be considered. This is a composite, as a glance at the list of specimens accompanying Cope's original description shows, but the type is definitely indicated, and as this belongs to the present form its name is available. An error in the locality of the type occurred in the original entry and was copied by Cope in his list. The entry in the record book of the National Museum is Richland, Illinois; this was undoubtedly intended for Richland 
County, Illinois, as Mr. Ridgway has collected extensively here but not at Richland, which is in Sagamon County. Richland County is in much better agreement with the specimen; its pattern is not typical for syspila, as here defined, but is closely approached by some specimens from southeastern Illinois and southern Indiana. Sagamon County is close to the range of triangutum, and an individual like the type of syspila is not to be expected there.

Description.-The scutellation, as exhibited by nearly a hundred specimens, is as follows: Ventrals, 180 to 215 ; caudals, 40 to 54 (males, 43 to 54, average 48 ; females, 40 to 50 , average 47 ); supralabials, 7 ; infralabials, 9 , rarely 8 or $10 ; 1$ preocular, very rarely 2 ; 2 postoculars, rarely 1 ; temporals commonly $2+2+3$, or $2+3+4$, occasionally $1+2+3$; posterior chin shields usually shorter than the anterior, sometimes about as long, in contact with each other or separated by a small scale; loreal distinctly longer than high; maximum number of scale rows commonly 21 , of ten 23 , very rarely 19 , beginning with 21 or 19 and ending with 19 or 17 .

In size and proportion this form is nearest like triangulum. The head is scarcely distinct from the body, is tapering, and blunt; the body is fairly stout, and cylindrical, except that the belly meets the sides at something like a right angle; the tail is typically short and tapers quickly to a horny tip. Of the total length, the tail varies from 0.114 to 0.157 (males, $0.130(0.116)$ to 0.156 , average 0.137 ; females, 0.114 to $0.146(0.157)$, average 0.131$)$. The largest specimen examined was from St. Clair County, Illinois, and measured $1060 \mathrm{~mm}$.

The pattern (fig. 68), although apparently in rings when viewed from above, has definitely changed to the blotched or saddled type. The whitish cross bands, varying from 23 to 36 (one specimen, 43) in number, are $1 \frac{1}{2}$ to 3 scales wide above and from one to several scales wider on the lower rows. They are usually strongly mottled on the sides with darker, and are narrowly bordered with black. The black borders of adjacent pairs meet usually on the first or second row of scales to inclose the dorsal saddles of the predominating color-red, or brownish, or gray. These dorsal saddles vary much in width but are usually decidedly broader than the groups of white and black bands that separate them. The belly is generally strongly checked with black and white. On the sides, usually overlapping ventral and dorsal scales, is a series of small black blotches, often inclosing some of the ground color, and alternating with the dorsal saddles. These alternating spots are nearly always present (rarely fused into a single midventral series), except in transitional individuals from the western and southern limits of the range, where intergradation occurs with the ringed forms, gentilis and amaura.

The head typically shows a narrow black band across the posterior extremities of the parietals, followed by a whitish half collar on the 
neck (fig. 52). Anterior to the black band the head is reddish or brownish to the snout, or the latter may be grayish. The markings on the top of the head vary much with locality; in southern Missouri and Arkansas there is much black, lightened by streaks or vague spots of the ground color; in eastern Kansas the black may be restricted to the tips of the parietals while the rest of the head is without markings, or the black of gentilis may be more prominent; eastward the markings typical of triangulum appear in varying combinations and perfection. Light, black-bordered superciliary spots are generally present (fig. 52) and often there is a black line from the eye to the angle of the mouth.

Syspila is bounded on three sides by closely allied forms, from which it is not separated by well-defined physical barriers. Consequently difficulties in identification must be expected. From gentilis it is best distinguished by the restriction of black on the head to the posterior portions of the parietal plates, and the narrower black cross bands on the body which do not tend to overspread the red areas

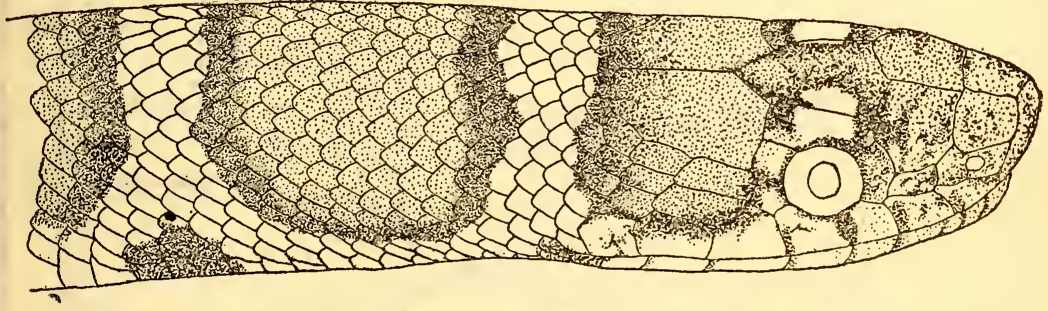

Fig. 52,-LaAmpropeltis triangulum Syspila (U.S.N.M. No. 61680, Jefrerson County, Missouri). ABOUT $1 \frac{1}{2} \times$ NAT. SIZE. SHOWING TYPICAL COLOR PATTERN OF ANTERIOR END OF BODY.

dorsally; from amaura it may best be known by the greater number of transverse whitish bands, usually 25 or more, the presence of ventro-lateral alternating spots, and the breaking up or practical absence of black on the frontal and anterior portion of the parietal plates; from triangulum it may be distinguished by the smaller number of dorsal saddles-35 or less-the presence of only one series of spots in alternation with the dorsal saddles, the yellow half collar behind the head, the incompleteness of the head pattern of triangulum, and the generally red color of the dorsal saddles as contrasted with the usually brown or gray in triangulum (See also under Variation in triangulum, p. 200).

The dentition, as indicated by a few specimens, is as follows: Maxillaries, 11 to 13, the last 2 a little larger; mandibulars 11 to 14 , the anterior the largest; palatines, 10,11, or 12 ; pterygoids, 17 to 20 .

Range.-As here defined, syspila is found from the ninety-seventh meridian north to northwestern Iowa, south to southeastern Oklahoma, and east to western and southern Illinois, southern Indiana, and extreme southwestern Ohio. It also may be expected in western 
Kentucky, western Tennessee, and northern Mississippi, and it should be looked for in southern Minnesota.

Specimens have been examined from the following localities in addition to those represented by specimens in the United States National Museum: Now Harmony and Vigo County, Indiana; Charleston, Grand Chain (Pulaski County), St. Clair County, and Horseshoe Lake at Olive Branch (Alexander County), Illinois; Ames, Boone, Fort Des Moines, Grinnell, and vicinity of Sioux City, Iowa; Galena, Missouri; Petit Jean Mountain and Fort Smith, Arkansas;

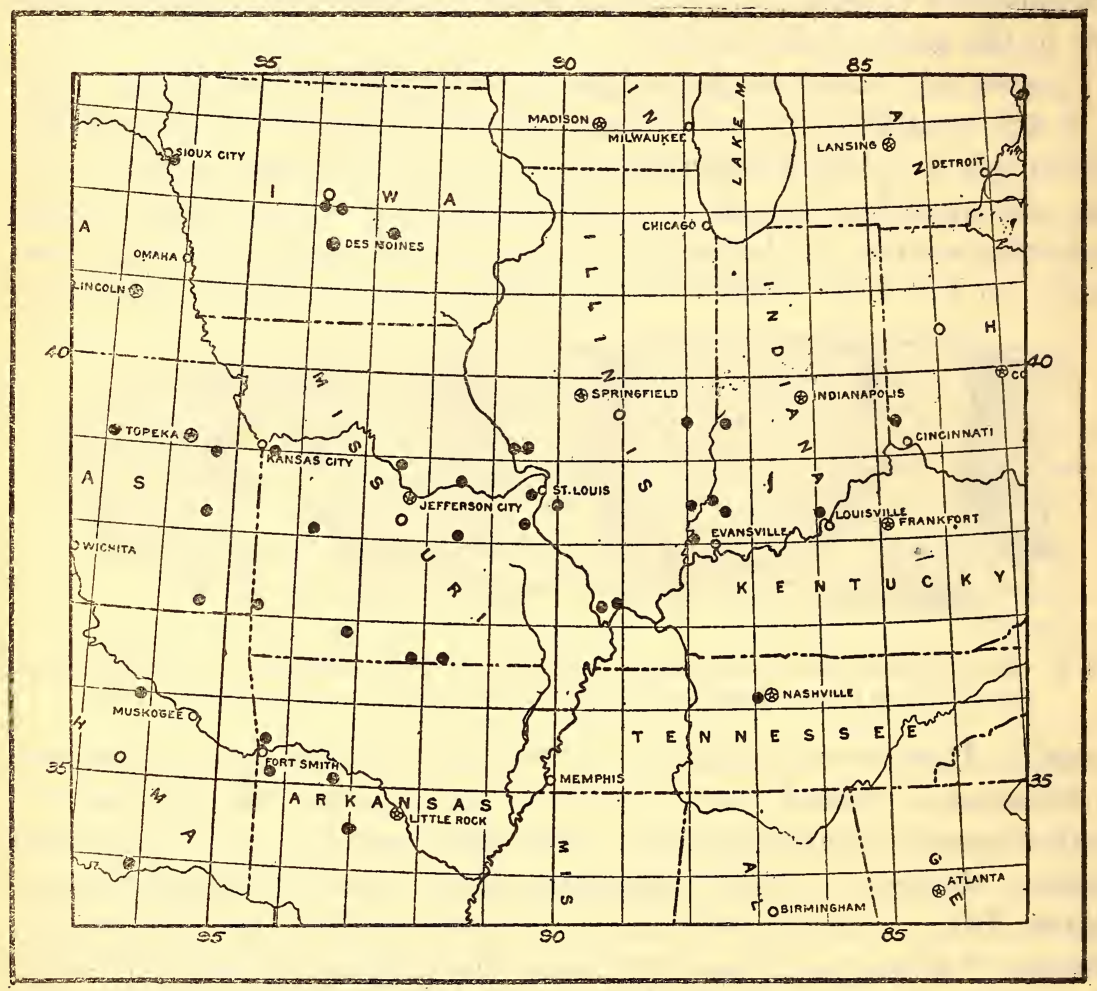

FIG. 53.-MAP SHOWING LOCALITY RECORDS FOR LAMPROPELTIS TRIANGULUM SYSPILA.

South McAlester and Sapulpa, Oklahoma; Manhattan, Douglas County, Anderson County, and Labette County, Kansas; and near Belleview (Davidson County), Tennessee.

Habitat and habits.-According to Hurter (1911, 184) this snake makes its home around spring houses so as to be near its food-rats and mice. He mentions finding one hiding under the loose bark of a heavy rotten log. "I placed it in my collecting bucket with a lizard, Eumeces fasciaius. On looking into the bucket a little later I found only a small end of the lizard sticking out of the snake's mouth, and the wriggling tail, which had been broken off in the struggle, at the 
bottom of the bucket." According to the same authority this snake "is a cannibal, swallowing its own kind and other small serpents and lizards."

Branson (1904, 401-402) says that "these snakes are very gentle. They nerer bite unless very much aggravated. When they do bite they do not strike like other snakes, but take the offending object in their mouths and shut down on it. Their teeth are so small that they can do little injury."

Mr. Mackelden of St. Louis writes that "nearly all the milk snakes I have caught were found under rocks, boards, or logs, etc., in the early part of the day. I have found them in the open field and also in the densest woods. The stomach contents of those I examined revealed earthworms, June beetles, spiders, and smaller insects. I recall having caught one that was in the act of swallowing a young blue racer."

This form is so closely related to triangulum and so similar in size and structure that its habits must be much the same as those of the latter.

Variation and affinities.-Examination of the table showing geographic variation in number of ventral plates, brings out plainly the fact that the lowest numbers occur in the southern portion of the range.

Table of ventral plates in syspila.

\begin{tabular}{|c|c|c|c|}
\hline Lorality. & $\begin{array}{l}\text { Number of } \\
\text { specimens. }\end{array}$ & Extremes. & $A$ vernges. \\
\hline Arkansas and Oklahoma. & 8 & $18.5-193$ & 188 \\
\hline Southern Missouri...... & 5 & $180-198$ & 100 \\
\hline East central Missouri..... & 21 & $190-213$ & 199.8 \\
\hline Southeastern Illinois and & & & \\
\hline southern Indiana ........... & 12 & $194-205$ & 201.1 \\
\hline Iowa $\ldots \ldots \ldots \ldots \ldots \ldots \ldots$ & 6 & $203-213$ & 208.7 \\
\hline Eastern Kansas ...... & 5 & $202-213$ & 208 \\
\hline
\end{tabular}

Table of scale formulae in syspila.

\begin{tabular}{|c|c|c|}
\hline Formula. & Male. & Forasie. \\
\cline { 1 - 2 } & & \\
$21-23-21-19$ & 3 & 4 \\
$21-19$ & 7 & 21 \\
$19-21-19$ & 2 & 2 \\
$21-19-17$ & 34 & 13 \\
$19-21-19-17$ & 1 & 0 \\
$19-17$ & 1 & 40 \\
Total..... & 47 & \\
\hline
\end{tabular}


Arkansas and Oklahoma with an average of 188, and southern Missouri with 190 show a condition closely like amaura, the average for which throughout its range is 193 . In east central Missouri, and in southern Indiana and the adjacent portion of Illinois the averages are 200 and 201 respectively. This is closely like the averages for triangutum in Indiana and Ohio, and in Michigan, which are respectively 201.6 and 202. The figures for syspita in Iowa and eastern Kansas are 208 in each case. These are high like triangulum in northern Illinois and Wisconsin (202), and gentitis in Kansas (202). The point to be noted is that on the three sides of its range where syspita meets a closely allied form it shows in the number of its ventral plates a definite approach to these respective forms.

Since the dorsal scale rows vary somewhat with sex, and the specimens available are very limited in number, geographic variation in this character cannot be conclusively shown. The totals for the whole range, however, are of interest for comparison with allied forms. The table shows that the general expectation of a greater proportion of high formulae in females holds here. While in amaura about half of each sex has the formula 21-19, in syspita only about one-seventh of the males have this number; and, whereas, in the former only a tenth of the females and half of the males have 17 rows at the end, in this form about one-third of the females and three-fourths of the males have this number at the end. This indicates a distinct difference between amaura and syspita and a decided approach to triangulum.

Differences in other matters of scalation between this form and its near relatives are too slight to demonstrate change with locality.

In its color pattern, as in the number of its ventral plates, syspita proves its close relationship to its three nearest neighbors. The line of separation on the south is arbitrary at best. Here it is the change from a ringed pattern to a saddled pattern that marks the change from amaura to syspila, while on the north and east it is the change from a saddled to a blotched pattern that indicates the change from syspila to triangulum. Whatever may be our conception of the origin of these forms, we must agree that syspila gives every evidence of being an intermediate or connecting link between amaura and triangulum. On the south, near the range of the former, it is of smaller size, tends to partake of the ringed pattern of amaura, has more black on the head, and only scant indications of the complicated head pattern of triangulum. In Missouri the body is larger, the saddles of red well-defined, long, and broad, with usually a ventrolateral series of smaller spots alternating with them, the black is restricted to a black band across the posterior portion of the parietal plates, forming an anterior border to the first whitish cross band, 
while on the rest of the head various portions of the elaborate pattern of triangulum appear, commonly a dark-edged light spot over each eye, and more or less of a light band from behind or over the eye to the side of the neck, bordered below by a dark band from the eye to the angle of the mouth. As the range of triangulum is approached the head markings characteristic of that form attain greater perfection, and some specimens show a tendency to a dorso-lateral fusion of the dark borders of the first whitish cross band, to inclose an oval or Y-shaped spot of white or gray within the ground color of the head on its posterior portion. This and the shortening and narrowing of the dorsal saddles are the slowest of the characteristics of triangulum to appear, and when they have been attained, we say that we have triangulum.

Thus, syspila is central both geographically and structurally to the three forms, triangulum, amaura, and gentilis, and with each of these forms intergradation takes place in the region of the common boundary of the respective ranges. 


\begin{tabular}{|c|c|}
\hline 墑 & 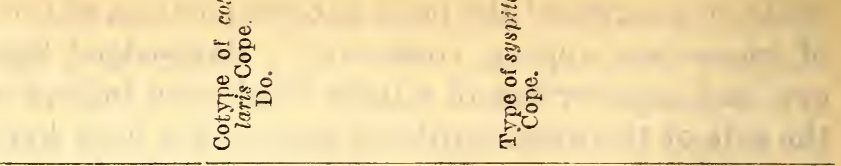 \\
\hline 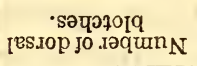 & 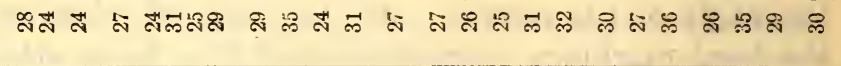 \\
\hline 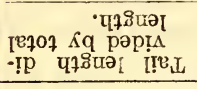 & 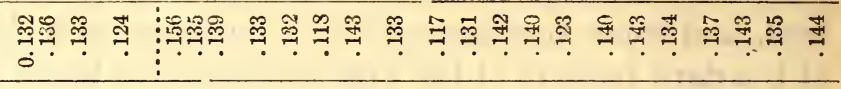 \\
\hline 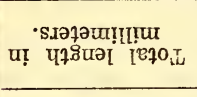 & 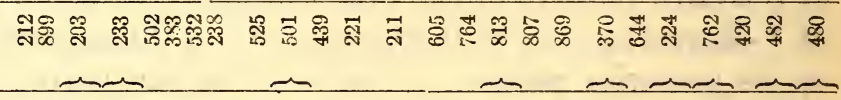 \\
\hline -S[e, & 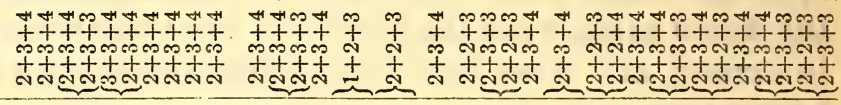 \\
\hline 'suęnoo & NN \\
\hline 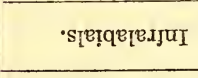 & 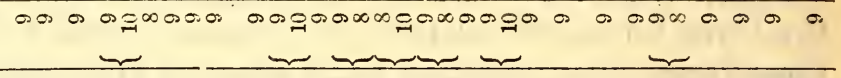 \\
\hline 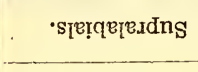 & 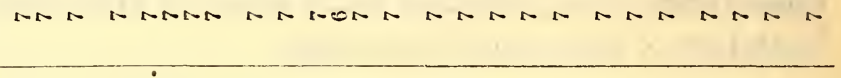 \\
\hline ·sİpnED & 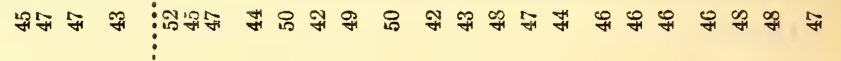 \\
\hline -S[G.JqUә $\Lambda$ & 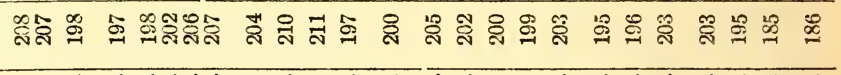 \\
\hline 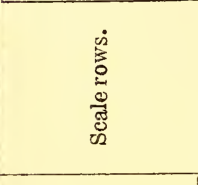 & 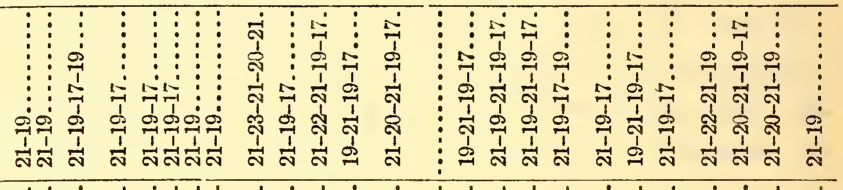 \\
\hline 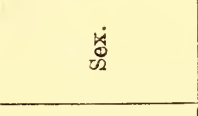 & 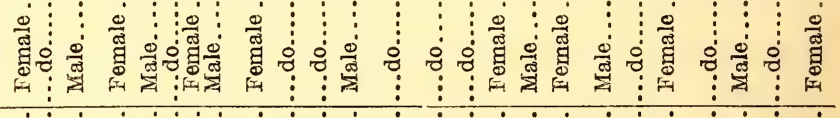 \\
\hline 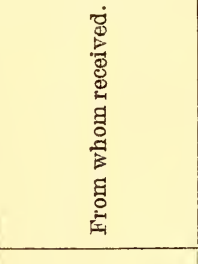 & 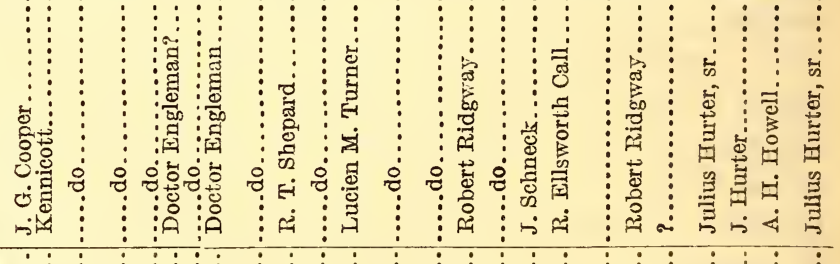 \\
\hline 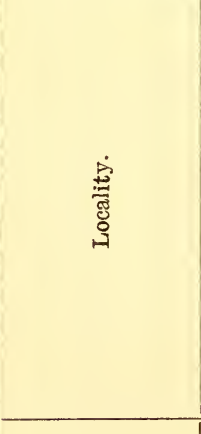 & 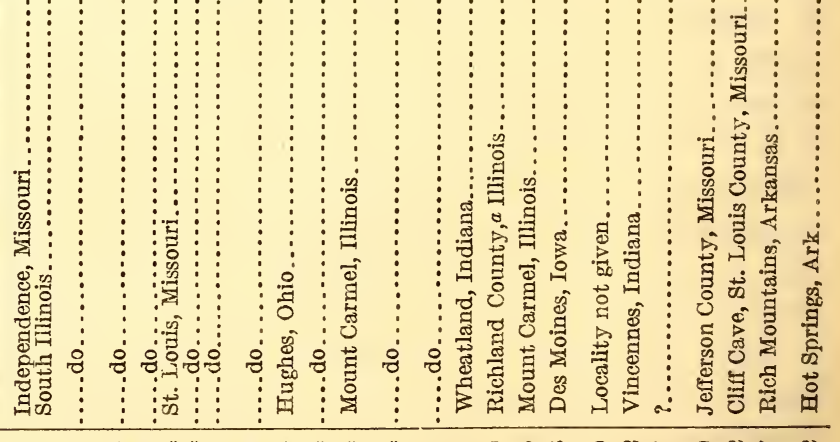 \\
\hline$\dot{\circ}$ & 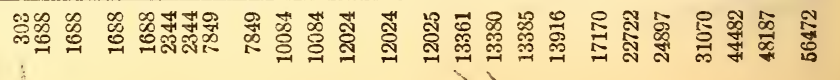 \\
\hline
\end{tabular}




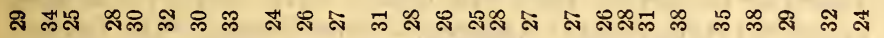

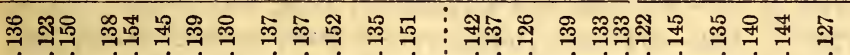

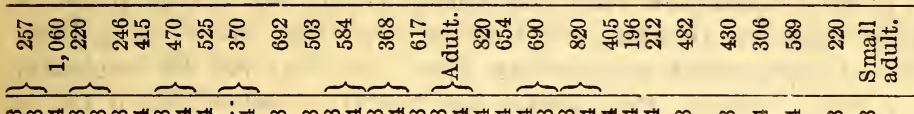

pop Tom

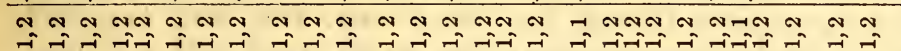
os as as as os os

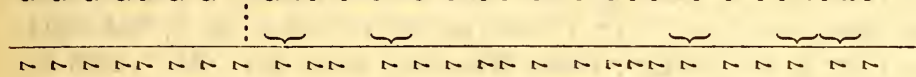

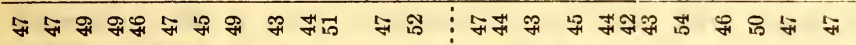

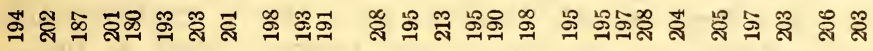

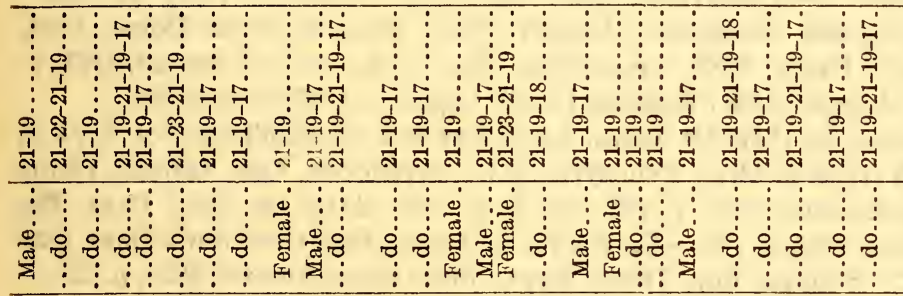

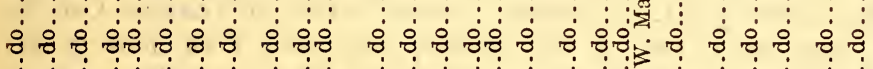




\section{LAMPROPELTIS TRIANGULUM TRIANGULUM (Lacêpède).}

MILK SNAKE; SPOTTED ADDER; CHECKERED ADDER; HOUSE MOCCASIN; HOUSE SNAKE.

Figs. 54, 69.

1789. Coluber triangulum LACÉPÈDE, Hist. Nat. Quadr. Ovip. Serp., vol. 2, tabl. meth., pp. 86, 331 (type locality, America).-Bonn aterre, Tabl. Encycl. Meth., 1790, p. 18.-Sonnini and Latreille, Hist. Nat. Rept., vol. 4, part 2, 1799, p. 132.-DAudin, Rept., vol. 6, 1800, p. 322.-BoIE, Isis, 1827, p. 537.-LACÉPÈDE, Hist. Nat. Quadr. Ovip., vol. 1, 1836, p. 307.Ablabes triangulum Dumeril and Bibron, Erp. Gen., vol. 7, pt. 1, 1854, p. 315.-Lampropeltis triangula Cope, Proc. Acad. Nat. Sci. Philadelphia, 1860, p. 256.-Verricl, Proc. Boston Soc. Nat. Hist., vol. 9, 1863, p. 197.Аввотт, Geol. New Jersey, Append. E, 1868, p. 802.-Allen, Proc. Boston Soc. Nat. Hist., vol. 12, 1868, p. 180; vol. 13, 1870, p. 262.Ophibolus triangulum Goode, Proc. Amer. Ass. Adv. Sci., Aug. 1873, p. 182.-Ophibolus triangulus SmitH, Sup. to Sci. News, 1879, p. 6; Geol. Surv. Ohio, vol. 4, 1882, pp. 636, 639, 689.-Garman, S., Mem. Mus. Comp. Zool., vol. 8, no. 3, pt. 1, 1883, pp. 65, 155, pl. 5, fig. 1; Nat. Hist. notes, 1887, p. 2.-Higley, Trans. Wisconsin Acad. Sci., vol. 7, 1883-87, pp. 166, 174.-Garman, H., Bull. Essex Inst., vol. 26, 1894, p. 35.Rhoades, Proc. Acad. Nat. Sci. Philadelphia, 1895, p. 392.-Coronella. triangulum Boulenger, Cat. Snakes Brit. Mus., vol. 2, 1894, p. 200.Boetrger, Kat. Rept.-Samml. Frankfurt, pt. 2, 1898, p. 72 (Milwaukee Wisconsin).-STernfeld, Sitz. Ges. Nat. Freunde, 1913, p. 105.Lampropeltis triangulum Аввотт, Nat. Rambles about Home, 1894, p. 300.-Dunn, Bull. Amer. Mus. Nat. Hist., vol. 37, art. 23, 1917, p. 630.-Lampropeltis triangulus DunN, Copeia, no. 25, 1915, p. 63.

1827. Coluber eximius Harlan, Journ. Acad. Nat. Sci. Philadelphia, vol. 5, pt. 2, p. 360 (type locality, Pennsylvania).-HIтchcock, Cat. Animals Plants Massachusetts, 1833, p. 552, ed. 2, p. 534.-Harlan, Med. Phys. Researches, 1835, p. 123.-Kintland, 2d Annual Rep. Geol. Surv. Ohio, 1838 p. 167.-Storer, Rep. Fishes, Rept., Birds Massachusetts, 1839, p. 227.Ногввоок, N. Amer. Herp., ed. 2, vol. 3, 1842, p. 69, pl. 15.-DEKAY, New York Fauna, 1842, pt. 3, p. 38, plates, Rept. Amph., pl. 12, fig. 25.Linsley, Amer. Journ. Sci., 1843, p. 43.-Hovgh, Cat. Rept. Fishes St. Lawrence County, N. Y., 1852, p. 23.-GüNtHer, Cat. Colbur. Snakes Brit. Mus., 1858, p. 91.-Ophibolus eximius Barrd and GIrard, Cat. N. Amer. Rept., pt. 1, 1853, p. 87.-BaIRD, Serp. New York, 1854, p. 21; Pacif. R. R. Surv., vol. 10, pt. 3, no. 1, 1859, pl. 30, fig. 61.-Mrles, Rep. Geol. Surv. Michigan, 1861, p. 233.-Fogg, Proc. Portland Soc. Nat. Hist., vol. 1, 1862, p. 86.-Ophibolus eximia Hoy, Geol. Surv., Wisconsin, vol. 1, 1883, p. 424.-Coronella eximia JAN, Arch: Zool. Anat., vol. 2, fasc. 2, 1863, pp. 237, 242; Icon. Gen., livr. 17, 1866, pl. 1, figs. 3, 3A, $3 \mathrm{~B}, 3 \mathrm{C}$.

1842. Pseudoelaps $Y$ Berthold, Abh. d. k. Ges. d. Wiss. Göttingen, vol. 1, p. 23, pl. 1, figs. 11, 12 (type locality, North America).

1853. Ophibolus clericus BAIRD and GIRARD, Cat. N. Amer. Rept., pt. 1, p. 88 (type locality, Clarke County, Virginia; type, U. S. Nat. Mus., no. 2380; C. B. Kennerly, collector).-BAIRD, Pacif. R. R. Surv., vol. 10, pt. 3, no. 1, 1859 , pl. 30 , fig. 62 .

1856. Ablabes triangulum var. clericus Halloweld, Proc. Acad. Nat. Sci. Philadelphia, p. 246. 
1860. Lampropeltis doliata (part) Cope, Proc. Acad. Nat. Sci. Philadelphia, p. 257 (Del., Washington, D. C.).-Аввотт, Geol. of New Jersey, Append. E, 1868, p. 802.-Ophibolus doliatus Nelson, Rep. State Geol. New Jersey, vol. 2, 1890, p. 647.-Osceola doliata Atkinson, Ann. Carnegie Mus., vol. 1, 1901, p. 150.-Lampropeltis doliatus Stone, Amer. Nat., vol. 40, no. 471, 1906, p. 167.-Evermann and Clark, Proc. Indiana Acad. Sci. for 1914, 1915, p. 345.-Fowler, Copeia, no. 22, 1915, p. 40.

1875. Ophibolus doliatus triangulus Cope, Bull. U. S. Nat. Mus., no. 1, p. 37.YARRow, Bull. U. S. Nat. Mus., no. 24, 1882, p. 90.-DAvis and Rice, N. Amer. Rept. and Batr., 1883, p. 34; Batr. Rept. Illinois, 1883, p. 29.Butler, Journ. Cincinnati Soc. Nat. Hist., vol. 10, 1887, p. 148.-HAY, 36th Annual Rep. State Board Agric. Indiana for 1886, vol. 28, 1887, p. 210; Journ. Cincinnati Soc. Nat. Hist., vol. 10, no. 2, 1887, p. 64.-Cope, Proc. U. S. Nat. Mus., vol. 11, 1888, p. 383.-Nelson, Rep. State Geol. New Jersey, vol. 2, 1890, p. 647.-Blatchley, Journ. Cincinnati Soc. Nat. Hist., 1891, p. 32.-Cope, Proc. U. S. Nat. Mus., vol. 14, 1891, p. 609.-HAY, 17th Annual Rep. Indiana Dept. Geol. Nat. Res., 1892, p. 517.-Cope, Amer. Nat., vol. 27, 1893, p. 1068, pl. 24, fig. 1.-Ditmans, Proc. Linn. Soc. New York, 1896, p. 13.-Cope, Rep. U. S. Nat. Mus. for 1898, 1900, pl. 32, fig. 1.-Brown, Proc. Acad. Nat. Sci. Philadelphia, 1901, p. 72.-Branson, Kansas Univ. Sci. Bull., vol. 2, no. 3, 1904, p. 399.-Wallace, 56th Annual Rep. New York State Mus. for 1902, 1904, p. r140.-Brimley, Amer. Nat., vol. 37, 1903, p. 264.-Notestein, 7th Rep. Michigan Acad. Sci., 1905, p. 118.-Brimlex, Journ. Elisha Mitchell Sci. Soc., 1907, pp. 146, 148.-Drtmars, Reptile Book, 1907, pp. 341, 342, pl. 103, figs. 1, 3, pl. 105 (upper fig.); Reptiles of the World, 1910, p. 271.-Thompson, 13th Rep. Michigan Acad. Sci., 1911, p. 107.-Somes, Proc. Iowa Acad. Sci., 1912, p. 150.-BrmLeY, Journ. Elisha Mitchell Sci. Soc., vol. 30, no. 4, 1915, p. 202.-Lampropeltis doliatus triangulus Ditmars, Proc. Linn. Soc. New York, 1896, p. 13.-Mearns, Bull. Amer. Mus. Nat. Hist., vol. 10, art. 16, 1898, p. 326.-HAy, Proc. Biol. Soc. Washington, vol. 15, 1902, p. 138.-Cuark, 7th Rep. Michigan Acad. Sci., 1905, p. 110.-Ditmars, Amer. Mus. Journ., vol. 5, no. 3, July, 1905, p. 98, figs. 4. 5.-Surface, Bull. Div. Zool. Pennsylvania, vol. 4, 1906, p. 174.-Fowler, Annual Rep. New Jersey State Mus. for 1906, 1907, p. 180.-Hahn, Proc. U. S. Nat. Mus., vol 35, 1908, p. 566.-Ruthven, Michigan Geol. Biol. Surv., publ. 4, biol. ser. 2, 1911, pp. 261, 267; 13th Rep. Michigan Acad. Sci., 1911, p. 115; Michigan Geol. and Biol. Surv., publ. 10, ser. 3,1912 , p. 110.-Thompson and Thompson, 14th Rep. Michigan Acad. Sci., 1912, p. 158.-SHufELDT, Guide to Nature, vol. 5, no. 9, 1913, p. 270, fig. 4.-DunN, Copeia, no. 16, 1915, p. 1.-ENGELHARDT, et al., Copeia, no. 17, 1915, p. 4.-Fowler, Proc. Delaware County Inst. Sci., vol. 7, no. 2, 1915, p. 43.-Thompson, Occ. Pap. Mus. Zool. Univ., Michigan, no. 18, 1915, p. 5.-Euxıs, 19th Annual Rep. Michigan Acad. Sci., 1917, p. 49.-Lampropeltis doliata triangula McLain, Notes Coll. Rept., 1899, p. 3.-Osceola doliata triangula Cope, Rep. U. S. Nat. Mus. for 1898, 1900, p. 885, fig. 210.-Atkinson, Ann. Carnegie Mus., vol. 1, 1901, p. 150.-EcKeL, Amer. Nat., vol. 35, no. 40, 1901, p. 152.-Morse, Ohio Nat., vol. 1, 1901, p. 127.-REED, [Snakes Vic. Ithaca, New York, ] 1901.-Eckel, Bull, New York State Mus., no. 51, 1902, p. 374.Henshaw, S., Occ. Pap. Boston Soc. Nat. Hist., vol. 7; 1904, p. 8.Morse, Proc. Ohio State Acad. Sci., vol. 4, pt. 3, spec. pap. no. 9, p. 130.-Drowne, Mon. Roger Williams Park Mus., no. 15, 1905, p. 11.McAtee, Proc. Biol. Soc. Washington, vol. 20, 1907, p. 10. 
1888. Ophibolus doliatus collaris Cope, Proc. U. S. Nat. Mus., vol. 11, p. 383 (type locality, Elmira, Illinois; cotype, U. S. Nat. Mus., no. 2433, E. R. Boardman, collector); same, vol. 14, 1891, p. 609; Amer. Nat., vol. 27, 1893, p. 1068, pl. 25, fig. 3; Rep. U. S. Nat. Mus. for 1898, 1900, pl. 33, fig. 3.Osceola doliata collaris Cope, Rep. U. S. Nat. Mus. for 1898, 1900, p. 887, fig. 211.-Lampropeltis doliatus collaris Hay, Proc. Biol. Soc. Washington, vol. 15, 1902, p. 138.

1888. Ophibolus doliatus clericus Cope, Proc. U. S. Nat. Mus., vol. 11, p. 383; vol. 14, 1891, p. 609; Amer. Nat., vol. 27, 1893, p. 1068, pl. 24, fig. 2; Rep. U. S. Nat. Mus. for 1898, 1900, pl. 32, fig. 2.-Brown, Proc. Acad. Nat. Sci. Philadelphia, 1901, p. 72.-Dirmars, Reptile Book, 1907, pp. 341, 346, pl. 103, figs. 2, 4, pl. 105 (middle fig.).-Osceola doliata clerica Cope, Rep. U. S. Nat. Mus. for 1898, 1900, p. 888, fig. 212.-Eckel, Amer. Nat., vol. 35, no. 40, 1901, p. 152.-Lampropeltis doliatus clericus Fowler, Annual Rep. New Jersey State Mus. for 1906, 1907, p. 181, text figs., pl. 46.

1892. Ophibolus triangulus triangulus Garman, H., Bull. Illinois State Lab. Nat. Hist., vol. 2, art. 13, p. 295.-Lampropeltis triangulum triangulum Stejneger and Barbour, Check List, 1917, p. 89.-Noble, Copeia, no. 88, 1920, p. 98.

1893. Ophibolus doliatus temporalis Cope, Amer. Nat., vol. 27, p. 1068, pl. 25, fig. 4 (type locality, Delaware; type specimen, Acad. Nat. Sci. Philadelphia, no. 3597; Mr. Drexler, collector); Rep. U. S. Nat. Mus. for 1898, 1900, pl. 33, fig. 4.-Osceola doliata temporalis Cope, Rep. U. S. Nat. Mus. for 1898,1900 , p. 889 , fig. 213 . $=$

1900. Osceola doliata triangulum Cope, Rep. U. S. Nat. Mus. for 1898, pl. 18, fig. 4.

1902. Lampropeltis doliatus doliatus HAY, Proc. Biol. Soc. Washington, vol. 15, 1902 , p. 138.

Description. - This is the best known form of the genus, and the one of which the most specimens have been available for study. The following summary of the scutellation is based upon the examination of about 400 specimens: Ventrals, 180 to 213; caudals, 29 to 54 (males average about 47 and females about 44); supralabials 7 , rarely 8 ; infralabials 9 , occasionally 8 , less often 10 , very rarely 11 ; 1 , very rarely 2 , preoculars; 2 , rarely 1 , postoculars; temporals commonly $2+3+4$, often some lower combination, as $2+3+3,2+2+3$, $1+2+3$; posterior chin shields usually shorter than anterior, in contact with each other or separated by 1 or 2 small scales; loreal distinctly longer than high, rarely absent; scale rows on middle of body usually 21 , occasionally 23 , rarely only 19 (the formula is most commonly $21-19-17$ or 19-21-19-17, often 21-19, sometimes 21-23-21-19, rarely 19-17).

This snake is of moderate size. An adult is commonly $2 \frac{1}{2}$ to 3 feet long. The largest specimen examined was $1,085 \mathrm{~mm}$. in length, and was taken at Cold Spring, New York. Proportions: Head but slightly distinct from the neck, tapering from the temples forward, and truncate at the end; body, rather slender, tapering slightly toward the neck and toward the tail, cylindrical above or rery slightly compressed; belly flat, and meeting the sides at right angles; tail 
0.100 to 0.155 of the total length (males average about 0.135 and females about 0.130 ).

Pattern: From head to tip of tail, 28 to 62 dorsal blotches or saddles of brown, gray, or red (young and some adults), extending down on the sides as far as to the fifth to second rows of scales. These blotches are narrowly edged with black, and set on a ground color of whitish, yellowish or grayish, minutely mottled with darker. On the sides, alternating with the dorsal blotches, one or two series of roundish spots, the upper row brown edged with black, the lower mostly black; belly checked with black and white, sometimes suffused with red; on back of head (fig. 54) usually a Y-shaped or oval spot of white; from the side of the neck forward over the eye, a white band, meeting its fellow across the frontal plate; a black band from the eye to the angle of the mouth.

Typical individuals from the northern portion of the range may be described as follows: Body above with 45 to 60 squarish brown

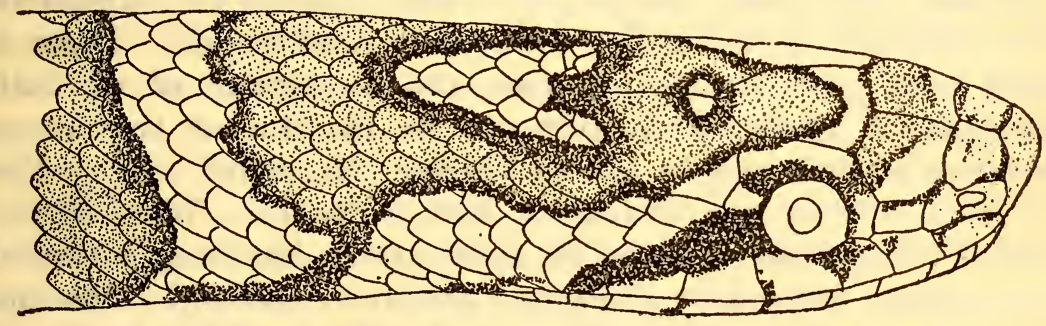

Fig. 54:- lampropeltis triangulum triangulum (Acad. Phila., no. 3621, from Belmont, Philadelphia, Pennsylvania). About $1 \frac{1}{2} \times$ Nat. Size. Showing typical Pattern of anterior end of BODY.

blotches, narrowly edged with black, that extend down on the sides to the fifth row of scales; on each side just below the dorsal blotches is a series of roundish spots, also edged with black, that alternate with the dorsal blotches; below these lateral spots and alternating with them is a second series; these are mostly black, but often inclose a little brown, and lie partly on the lower rows of scales and partly on the ends of the ventrals; between these series of spots or blotches is a ground color of grayish, minutely mottled with black, the mottling appearing most strongly on the sides; the belly is white (sometimes tinged with red), variegated with small quadrate blotches of black. Prominent on the posterior portion of the head (fig. 54) is a $Y$-shaped mark of the ground color, edged with black, and separated from the white of the neck by a brown band on each side that joins the first dorsal blotch with the brown of the head. The ground color of the side of the neck is carried forward above the eye to meet a transverse band of the same color across the frontal plate. This cross band is bounded in front by a brown bar, narrowly edged with black, which crosses the posterior portions of the pre- 
frontal plates and overlaps the anterior edge of the frontal. Anterior to this the snout is light, mottled with dark, except for a narrow bar of black across the prefrontal-internasal suture. There are usually two oval light spots near the parietal suture; a black band extends diagonally from the eye to the angle of the mouth. The labials and chin shields are whitish, except for more or less black near the sutures.

The dentition, as indicated by a dozen specimens from all parts of the range, is as follows: Maxillaries, more of ten 12, less of ten 13, larger in front, decreasing behind, except that the last two are somewhat longer and stouter than any of the preceding; mandibulars, 11 to 15 , most often 13 , distinctly larger anteriorly, decreasing rapidly behind, the third, fourth, and fifth largest, a slightly greater space between the fourth and fifth or between the fifth and sixth; palatines, 9,10 , or 11 , decreasing slightly in size posteriorly; pterygoids, 17 to 23 , becoming smaller posteriorly.

Although sufficiently distinct as a rule, there is no characteristic which will always distinguish triangulum from syspila. These two forms have been contrasted under the description of the latter. Specimens of doubtful identity will be found near the common boundary of their ranges, and in Virginia, Maryland, eastern Pennsylvania, New Jersey, Delaware, and perhaps in West Virginia. Typical triangulum occurs in all these states, but many individuals show marked degeneracy in pattern and in scutellation. Specimens will be found with as few as 28 dorsal saddles, which extend to the second or first row of scales, and with head markings typical of syspila, but such individuals average to have a less number of ventrals and caudals, and a lower scale formula than similar examples of syspila. Specimens from these localities identifiable in the key as syspila must, for the present at least, be referred on geographic grounds to triangulum.

Habitat and habits.-From Wisconsin and 1llinois, east to New England, this is a common and well-known snake, but in the southeastern States, except in the mountains, it appears to be rare. It is of very general occurrence in all upland situations, woods and fields, and is not uncommon in the vicinity of dwellings and stables. It does not appear to haunt the shores of streams or lakes, but may be expected in most other situations. Its wide choice of habitat is related to the widespread occurrence of its principal food-mice. For the vicinity of Saginaw Bay, Michigan, Ruthven (1911, 267) says that "they were mostly found in the decaying logs on the fossil beaches and pine ridges, where they fed, in part at least, on the Michigan mouse (Peromyscus maniculatus bairdii) and the blue-tailed skink (Eumeces quinquelineatus), as remains of these animals were found in the stomachs examined." A specimen taken in a hay field 
in Cheboygan County, Michigan, disgorged an adult meadow vole (Microtus pennsylvanicus); another had eaten an adult short-tailed shrew (Blarina brevicaudata).

Its presence in the vicinity of dwellings may be largely explained by its fondness for mice. Better than a cat, it can follow a mouse to its nest and eat the whole brood of young. Ditmars (1907, 344) mentions finding one that had been killed in a barn, in Sullivan County, New York, that had in its stomach five very young rats. Surface (1906, 178-179) finds that in Pennsylvania three-fourths of the food of this snake consists of small mammals, chiefly mice, and that the destructive meadow mouse (Microtus pennsylvanicus) constitutes about half its food. This fact alone should be sufficient to assure its protection at the hands of farmers and others; and, when one considers that it is a perfectly harmless, non-aggressive, unfearing creature, he may well wonder why it is so persistently persecuted. Its lack of fear is one cause of its great decrease in numbers. As a farmer will say, "You have to kick it out of the way." Of course it is considered poisonous by the majority of people, and is killed for that reason, or just because it is a snake. Many snakes are, indeed, of slight, if any, economic value; some, as the rattlesnakes that destroy pests, have the disadvantage of being poisonous, but the spotted adder, or milk snake, has perhaps the distinction of combining the greatest number of valuable traits with the minimum of undesirable or neutral qualities. It is true that he must be charged with the eating of young birds when the nests are located in accessible places, but Surface (1906, 178-179) has shown that birds constitute but a small proportion of its diet, and doubtless some of the birds it is found to have eaten were taken dead. Snakes and lizards constitute a regular, although small, proportion of its diet. It is known to eat the Butler garter snake (Thamnophis butleri), the smooth green snake (Liopeltis vernalis), the water snake (Natrix sipedon), the ring-necked snake (Diadophis punctatus, McAtee, 1907, 10); De Kay's snake, the queen snake or striped water snake, the red-bellied snake, robin's eggs, jumping mice, the white-footed mouse, and slugs are charged to it by Surface (1906, 178-179); and young individuals have been observed, in captivity, to eat small dead minnows, and pieces of the same.

"In captivity [Ditmars, 1907, 344] this snake is indifferent in feeding and seldom lives long. It prefers mice, which are quickly constricted to death in the reptile's strong coils. Young specimens can seldom be induced to take food of any character. Although rather a quiet reptile, the milk snake will sometimes resent handling in a curious and rather treacherous manner. Without a pretense of striking it will swing the head about suddenly and grasp the hand, when it deliberately chews in such a manner that the fine, recurved 
teeth lacerate the flesh sufficiently to bring the blood, although the minute punctures are but very superficial wounds and heal at once, like a scratch from a fine point."

It is likely that this snake does much of its foraging at night, as then it would have the best chance to find mice and the small snakes and lizards that hide under boards, logs, and bark. Its occasional presence in dwellings may be explained, as Surface has indicated $(1906,177)$, by the attraction of a warm atmosphere when the air outside is cold, or its prowling along crevices, in to cracks and holes may lead it into buildings. Without doubt it is of ten brought into cellars and sheds under the bark or in the cracks of firewood.

This snake is oviparous, depositing from 8 to 13 oval eggs (Ditmars, $1907,344-345)$ with a leathery shell, and presenting the same soft and white appearance as the surface of a toadstool. Ditmars records batches of 8,11 , and 9, laid on July 10, 12, and 28, and hatching on September 5, 6 to 8, and October 1 to 3, respectively. Mr. E. B. Williamson took a batch of 13 eggs in Wells County, Indiana, in August, 1917, 7 of which hatched September 15 to 17. O. P. Hay $(1892,518)$ reports finding eggs of this snake in Indiana, in a pile of manure, more or less glued together. Young snakes are about $6 \frac{3}{4}$ to $8 \frac{1}{4}$ inches in length. They molt very soon after hatching.

Nothing definite seems to be known about its hibernation. It probably burrows in the ground, as it is of ten turned out by the plow in the spring. It appears to be rather late entering winter quarters and early emerging, although probably less so than the garter snake. Hay $(1892,518)$ reports taking it in Indiana on March 30, and of having seen a dead one in the road still earlier.

Range.-From Minneapolis south through northern Illinois, Indiana (except the southwestern section), eastern Tennessee, Georgia, and Florida, and north through all the eastern States to the forty-sixth parallel.

On the west from Tennessee to Minnesota it meets and intergrades with its only close relative, syspila. In the southeastern States, except in the mountains, it appears to be a rare snake. The most northern record is for a specimen taken in 1917 at Cecil Bay, Emmett County, Michigan, by Dr. J. H. Ehlers; in New England it has not been reported north of Vassalboro, Maine; it is common in Cheboygan and Emmett Counties, Michigan, but is not reported for the Upper Peninsula; it should however be looked for on the south shore of the northern peninsula of Michigan, as it has been taken at Newport, Door County, Wisconsin. In Florida it has been taken as far south as Candler, in Marion County.

The most northern localities for Canada are Spence's Lake, Bracebridge, Ontario, and Aylmer, near Quebec. 
Specimens have been examined from the following localities, in addition to those represented by specimens in the United States National Museum: Portland, and Middletown, in Connecticut; Delaware; Candler (Marion County), and Gotha (Orange County), in Florida; Athens, Beverly Hills, Danville (Vermillion County), Glen Ellyn and Hinsdale (Du Page County), Joliet (Will County), Kendall,

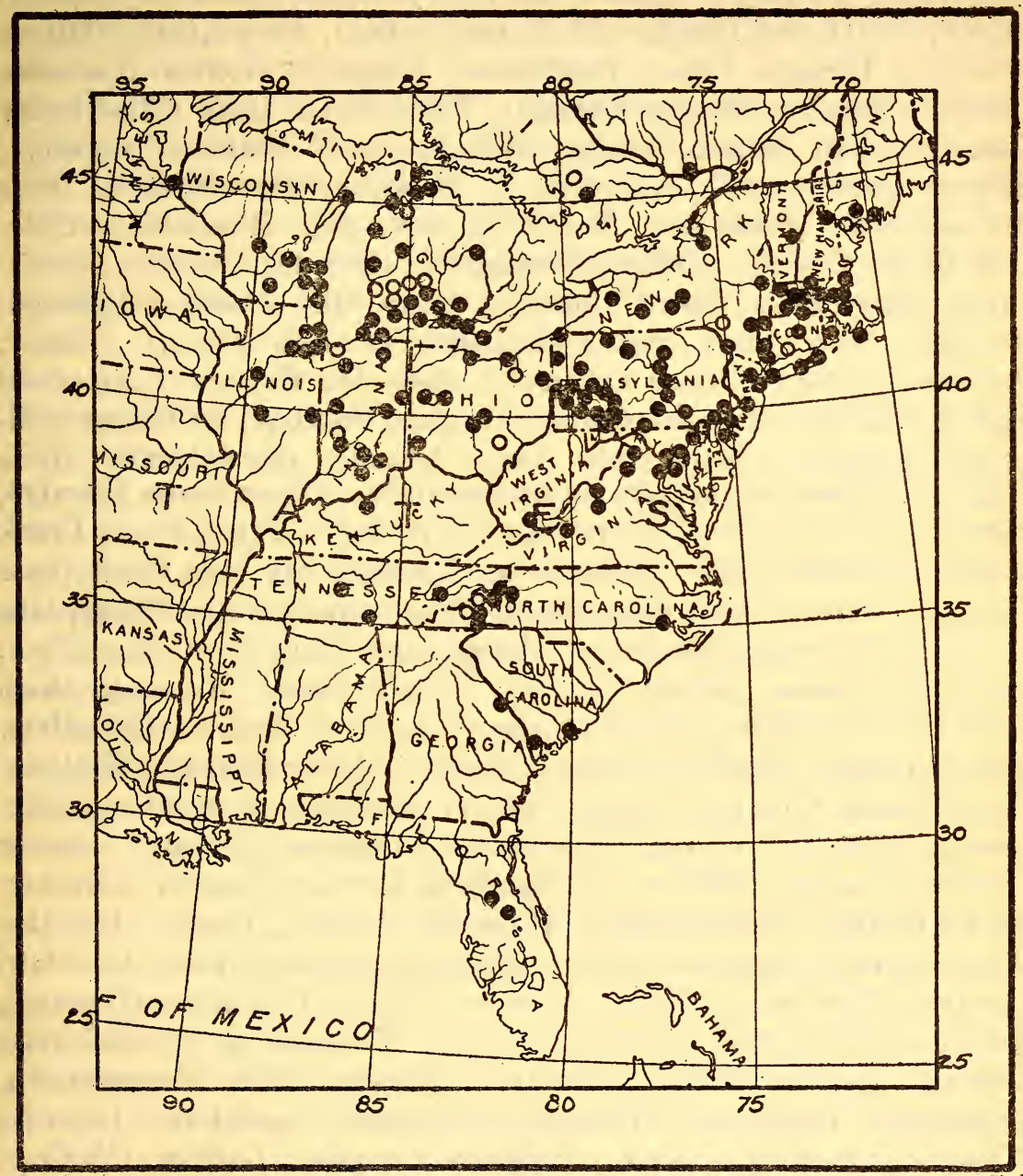

FIG. 55.-MAP SHOWING LOCALITY RECORDS FOR LAMPROPELTIS TRIANGULUM TRIANGULUM.

Kenilworth (Cook County), in Illinois; Bloomington (Munroe County), Blufiton (Wells County), La Fayette, Lebanon (Boone County), Mitchell (Lawrence County), North Vernon (Jennings County), Sims (Grant County), Vigo County, and Winona Lake, in Indiana; Lewiston, and Vassalboro, Maine; Brookline, Cambridge, Deerfield, Feltonville, Hudson, Iancaster, Lynn, Magnolia, Malden, 
Medford, Naushon Island, near Northampton, Waltham, Ware, Warwick, Wenham, and Williamstown, in Massachusetts; Ann Arbor, Bay View (Emmett County), Berrien County, Brighton (Livingston County), Cass County, Cecil Bay (Emmett County), Charity Islands (Lake Huron), Douglas Lake (Cheboygan County), East Lake (Manistee County), East Lansing (Ingram County), Jackson County, Kalamazoo, Le Roy (Osceola County), Northport (Leelanau County), Olivet, Orion and Pontiac (Oakland County), Port Austin (Huron County), Portage Lake (Washtenaw County), Rollins (Lenawee County), Shelby (Oceana County), Third Sister Lake (Washtenaw County), Van Buren County, Walnut Lake (Oakland County), Wayne County, and Ypsilanti, in Michigan; Fort Snelling (near Minneapolis), Minnesota; North Conway, New Hampshire; Caldwell (Essex County), Delair, Haddonfield (Camden County), Morristown, Short Hills (Essex County), Snow Hill (Camden County), Trenton, Woodstown (Salem County), in New Jersey; Albany, Ashoken Survey (Ulster County), west side Cayuga Lake, Cold Spring (Putnam County), Cornell Heights, Cousook, Fallsburg (Sullivan County), Forest Hills (Long Island), Hornellsville, Hyde Park (Dutchess County), Irvington-on-Hudson (Westchester County), New Lots (Long Island) Perry City (Wyoming County), Purdy Creek (Steuben County), Rye (Westchester County), Six Mile Creek (near Ithaca), Staten Island (Grosmere), Taughannock Falls (Thompkins County), Wascabne Mountain (Westchester County) in New York; Brevard, Pineola (Avery County), Pisgah Forest Reserve, Roan Mountain (6,000 feet, Mitchell County), in North Carolina; Columbus, East Rockport, Franklin County, Hughes (Butler County), Kettlersville (Shelby County), Logan County, Sandusky, Youngstown (Mahoning County), in Ohio; Bakerstown (Allegheny County), Beaver (Beaver County), Belmont (Philadelphia County), Carlisle (Cumberland County), Chambersburg (Franklin County), Cherry Run (Indiana County), Concord (Delaware County), Conneaut Lake (Crawford County), Cumberland Valley, Diamond Valley (Huntington County), Fairmont Park and Germantown and Holmesburg (Philadelphia County), Indiana (Indiana County), Jackson Valley, Jennerstown, Johnstown, LaGrange (Philadelphia County), Lewisburg, Linsville (Crawford County), Lopez (Sullivan County), Ludlow (McKean County), Mill Creek (Montgomery County), Mount Washington (Allegheny County), Northumberland, Overbrook (Philadelphia County), Pike County, Pittsburgh, Presque Isle, Raymonds (Potter County), Sewickley (Allegheny County), Summit, Tarentum (Allegheny County), Two Lick Creek (Indiana County), Venango County, Walnut Hill (Montgomery County), Wama (Delaware County), Water Street (Huntington County), Waynesburg (Green County), Westchester (Delaware County), Williamsport (Lycoming County), Wilmerding (Allegheny County, in Pennsylvania; Hampton County, South Carolina; Franklin 
County), Knoxville, and Nashville, Tennessee; Bethel, Vermont; Loudoun County, and Staunton (Augusta County), Virginia; Cheat River, West Virginia; Beaver Lake (Dodge County), Cedarburg, Cedar Lake (Washington County), Madison, Mauston, Milwaukee, Newport (Door County), and Waukesha, in Wisconsin; Aylmer (Quebec), Hull (Ottawa), near Ottawa, Point Pelee (Ontario), Spence's Lake (Bracebridge, Ontario), and near Toronto, in Canada.

Published records, that appear to be reliable, for other localities, are as follows: Huntington, Connecticut, (Linsley, 1843, 43); Norway, Maine, (Verrill, 1863, 197); Springfield, Massachusetts, (Allen, 1868, 180); near Waveland, Montgomery County, (Butler, 1887, 148), and Greencastle (McLain, 1899, 3), Indiana; London, Ohio (Morse, 1901, 127), Hamilton County, Akron, and Nelsonville, Ohio (Morse, 1904, 130); Alma, Michigan (Ruthven, 1912, 113); Antrim, Montcalm, Kent, Ottawa, and Barry Counties, Michigan, (Clark 1905, 110); Rockland (Wallace, 1904, r140), Rossie, St. Lawrence County, New York (Hough, 1852, 23), and Cold Spring Harbor, Yaphank, Orient, Greenport, and Southold, on Long Island, New York (Engelhardt, 1915, 4); Stony Run, Cecil County, Maryland (Fowler, 1915, 40); St. Clair township (Allegheny County), Pennsylvania (Atkinson, 1901, 150); Shower Hill, New Jersey (Fowler, 1907, 181); Sunburst, Haywood County (Brimley, 1915, 202), and Chestnut Knob Mountain, North Carolina (Dunn, 1917, 630).

Variation.-In spite of the apparent constancy and distinctness of triangulum in the northern tier of States, the form as a whole is one of the most variable. The diagram showing geographic differences in number of ventrals (fig. 56) brings out some notable variations with locality. The dependability of the figures varies somewhat with the number of specimens upon which they are based. It is evident, however, that in the northern and western portion of its range the ventrals average higher, more than 200, and the extremes are higher than for the central and northeastern parts. The few specimens from the southeastern States, except in the mountains, show the high numbers of the northwest. From New England to Virginia and in the Alleghenies the averages and the extremes are low, and distinctly lower in New Jersey and Delaware, and near the District of Columbia.

This variation in ventrals should be compared with the table of scale formulae. It will be noted that in the states close to the range of syspila the scale rows average about the same as for that form, that is, a formula lower than 21-19 is very common in males and a little less so in females. In New York and Pennsylvania the only change is a slightly lower average, but in New England, the most distant region, only one male is recorded with a formula of $21-19$, more than half the females have a lower formula than this, and the smallest proportion of specimens reaches 23 rows. This compares closely with the southern Alleghenies. The formulae for New Jersey and the 
District of Columbia average still lower than in New England and the Alleghenies, and it is here that the lowest point of all, 19-17, is attained.

Of other features of the scutellation the temporals are perhaps the most variable. The normal number for the group and for the genus is $2+3+4$, but in this group in particular a reduced number is very

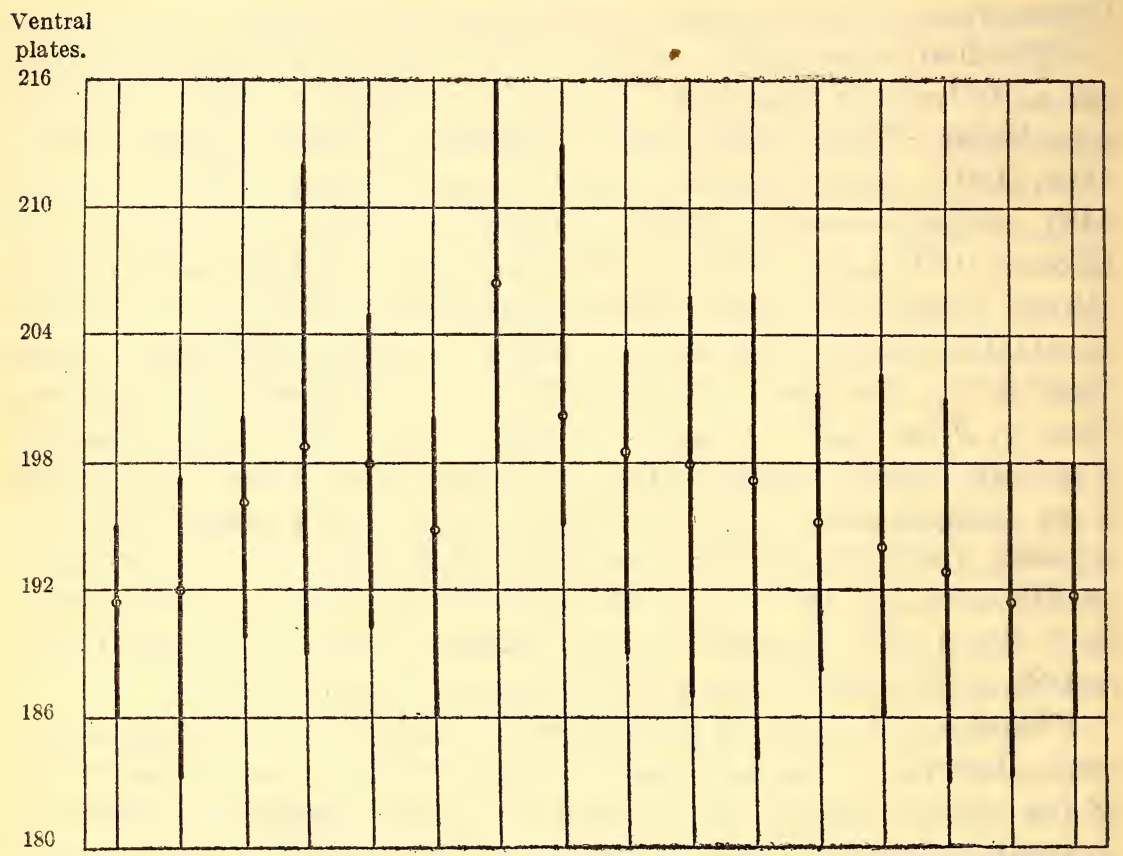

In- North- Wis- Mich- Can- New South- East- N.J. D. C. Ohio. West- Alle- N.C. Ten- Fla. diana. ern con- igan. ada. Eng. ern ern Del. $23 \quad 7$ ern ghen- S.C. nes- 3

19 Ill. $\sin . \quad 61 \quad 6 \quad$ land. N.Y. Pa. $14 \quad$ Pa. $\begin{array}{rrrr}\text { ies. } & 3 & \text { see. }\end{array}$

LOCALITIES, AND NUMBERS OF SPECIMENS.

FIG. 56.-DIAGRAM SHOWING GEOGRAPHiC VARIATION IN NUMBER OF VENTRAL PLATES IN LAMPROPELTIS TRIANGULUM TRIANGULUM.

frequent-the last row is oftenest reduced by one, the second row less often so reduced, and the first row is the most constant. The specimens from the District of Columbia show the greatest reduction in temporals. The accompanying table gives at a glance the averages to two places of "decimals, of the temporals in the first and third rows for Missouri, Massachusetts, and the District of Columbia.

\begin{tabular}{|c|c|c|}
\hline & $\begin{array}{l}\text { Temporals } \\
\text { of the } \\
\text { first row. }\end{array}$ & $\begin{array}{l}\text { Temporals } \\
\text { of the } \\
\text { third row. }\end{array}$ \\
\hline 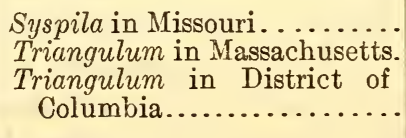 & $\begin{array}{l}1.88 \\
1.94 \\
1.63\end{array}$ & $\begin{array}{l}3.65 \\
3.83\end{array}$ \\
\hline
\end{tabular}




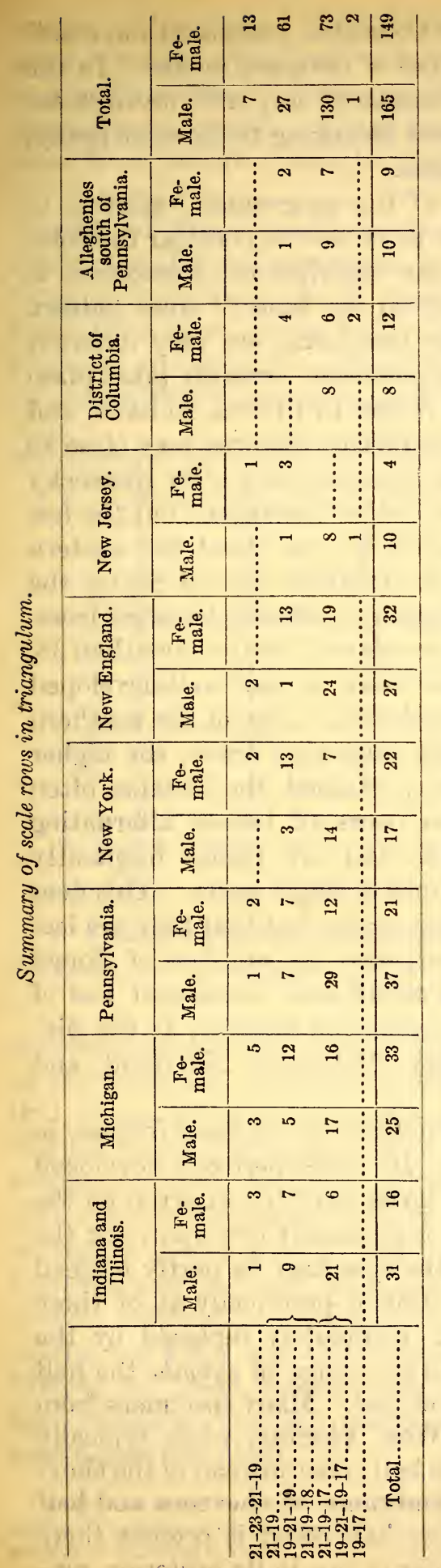


This indicates that the District of Columbia specimens have suffered an actual reduction in the number of temporal scutes. In the extent of this reduction they can be compared only with microphotis, elapsoides, and virginiana, reduced forms belonging to the same group, but only distantly related to triangulum.

Bearing in mind the peculiarities of the geographic variation in ventrals, scale rows, and temporals we have now to consider the color pattern. As will be evident from the descriptions, triangulum is separated from syspila almost entirely on the basis of color pattern differences. Typical specimens of the two forms are very different appearing animals, and, although intergradation certainly takes place along the common boundary of their ranges in Illinois, Indiana, and Ohio, each form seems to retain its distinctive features very close to the border of its range. Just how true this statement is for Kentucky and Tennessee can not be told now for lack of specimens, but the few we do possess indicate that syspila extends over about the western third of these States. Throughout the northern tier of States the typical pattern, as given in the description, is seldom departed from. The dorsal blotches average about 47 , are almost always more than 35 , and are usually accompanied by two more or less well-developed series of lateral alternating spots on each side. But in the southern Alleghenies the dorsal blotches average somewhat fewer, the higher numbers of the north are rarely, if ever, attained, the blotches often extend lower down the sides, the two rows of lateral alternating blotches also often extend down lower, and are rather frequently fused, either partially or completely, into a single series. This does not mean that typical examples do not occur, but that they are less frequent than in the north. This reduction in number of dorsal blotches, accompanied by increase in width and consequent loss of the upper series of alternating spots, reaches its extreme, as the diagram shows (fig. 57), in New Jersey, Delaware, Maryland, and northern Virginia.

The complicated and characteristic pattern of the head follows, in a general way, the pattern of the body. It is most perfectly developed in the northern parts of the range. Even here the cherron on the back of the head may appear only as a transversely oval spot, and the white line between, over, and behind the eyes may be partly bridged by extension of the brown pattern. But in practically all of these northern specimens the half collar is completely replaced by the chevron or its representative. Close to the range of syspila the half collar is often partly or completely developed. Many specimens from western Pennsylvania and northern West Virginia, while typically triangulum in other respects, possess the half collar instead of the chevron. South in the Alleghenies all conditions of chevrons and half collars may be found. Often when the half collar is present there will be two notches in its anterior border or one in its posterior, rep- 
resenting the arms of the chevron. The District of Columbia specimens often have the half collar complete and the other head markings much reduced. Some specimens cannot be distinguished from examples of syspila. Those from New Jersey, and Delaware and some from eastern Pennsylvania and parts of Maryland are reduced in the same way.

Some of these specimens have received varietal names. Thus Baird and Girard described an individual from Clarke County, Virginia, as clericus, and the name has been frequently used for specimens from New Jersey and other states, and the name has been supposed to apply to a close relative of triangulum that replaced it on the south. It can be stated, however, that the material at hand

Dorsal

blotches.

61

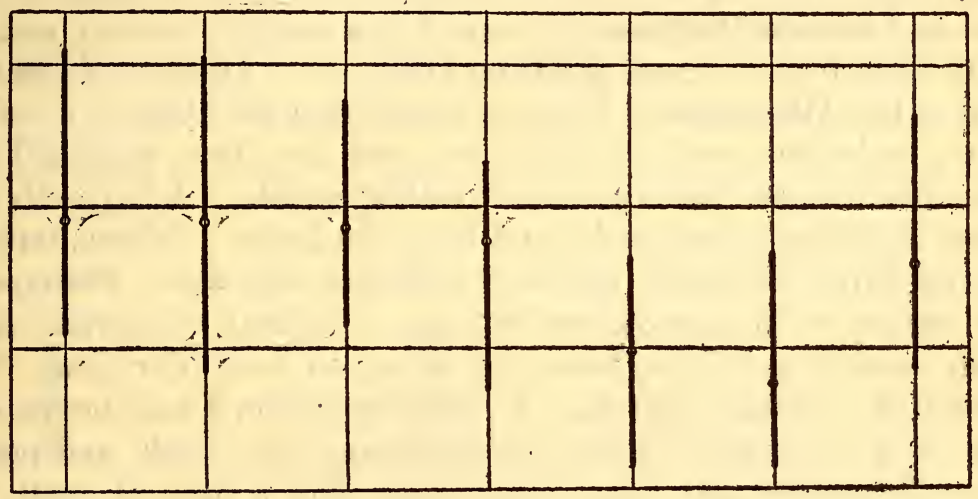

25

$\begin{array}{ccccccc}\text { Wis- } & \text { Michi- } & \text { New } & \text { New } & \text { New } & \text { District } & \text { Southern } \\ \text { consin. } & \text { gan. } & \text { England. } & \text { York. } & \text { Jersey. } & \text { of Columbia. Alleghenies. } \\ 16 & 61 & 63 & 45 & 14 & 22 & 14\end{array}$

LOCALITIES, AND NUMBERS OF SPECIMENS.

Fig. 57.-DIAGRAM SHOWING GEOGRAPHIC VARIATION IN NUMBER OF DORSAL BLOTCHES IN LAMPROPELTIS TRIANGULUM TRIANGULUM.

indicates that the supposably distinguishing features of clericus have no constancy and no geographic basis. However, it is not improbable that when sufficient specimens are available for study, a local race will be found having its center in New Jersey and Delaware, and perhaps southern Virginia. Stone $(1906,167)$ and others have noted that typical triangulum appears to be replaced in the coastal plain regions of these States by individuals with fewer and broader dorsal blotches and reduced head markings, but as already stated the present material is insufficient for identifying a separate race. The collaris $^{4}$ of Cope was based upon selected individuals from Elmira, Illinois, St. Louis, Missouri, and Washington, District of Columbia, that exhibited the half collar, regardless of whatever other characters they possessed.

- Although no type was specifically designated, Cope twice figured United States National Museum specimen No. 2433 from Elmira, Illinois, in connection with descriptions of collaris, and this may therefore properly be considered the type. As this specimen is a triangulum, the name collaris becomes a synonym. 
Similarly an aberrant individual from Delaware (Acad. Nat. Sci. Philadelphia, no. 3597) became the type of temporalis Cope. There may be others like this in Delaware (Stone, 1906, 167) but so far this appears to be the only example of temporalis. The head pattern is obsolete; the dorsal blotches are wide, few, and somewhat fused with each other; and the scale formula is 19-17.

Affinities.-Under variation it was shown that triangulum attains its most perfect development in the northern States, that in the Alleghenies and on the Atlantic coast it has suffered more or less reduction in scutellation and pattern, and that the greatest reduction occurs from southern New York to Virginia. The meaning of this extreme condition is not at all clear, and, in attempting an explanation, it must be remembered that from the whole peninsula of Delaware and eastern Maryland we have but a single specimen, and that all of those from Virginia are from close to the District of Columbia or from the Alleghenies. Some of those from the District have been known under the name of "dotiatus," and have been supposed to be the same thing as what we are here calling syspila. Admittedly some young individuals can not be told from the latter. Others, however, are typically triangulum, and still more are mixtures. Perhaps this is a region of intergradation between a typical triangulum and a coastal variety extending from New Jersey.to North Carolina. There seems to be nothing constant. In this connection it may be remarked that more than half of these specimens are very small, and perhaps some of the aberrant ones would have died a natural death very soon if they had not been found and preserved. It is a fact that somie of the most aberrant individuals, described and not described, are juveniles. Of the former multistrata Kennicott is an example. If these Washington specimens were fairly constant in pattern and scalation and possessed a definite geographic range, they could be recognized with a name, but such does not appear to be the case. The resemblance to syspila must be regarded as secondary because the scutellation is definitely reduced, and the pattern as well bears every evidence of being capable of derivation by reduction from typical triangulum. Whatever may be the reason it seems evident that in the parts of its range where triangulum is farthest removed from syspita it has a reduced scutellation or pattern or both; for example, New England east of the Berkshires, New Jersey and Virginia east of the Alleghenies.

The fact that the pattern of triangulum seems to be developed in perfection only north of the southern limit of glaciers argues against the assumption of this pattern as primitive. As brought out in the discussion of syspila, triangulum must be considered as at one end of the chain, amaura-syspila-triangulum. If we are to favor erolution or differentiation accompanying migration, we can not do otherwise than regard triangulum as the latest of this chain. 


\begin{tabular}{|c|c|c|c|c|c|c|c|c|c|}
\hline 产 & 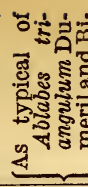 & & & 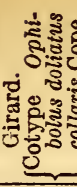 & & & 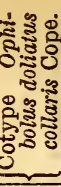 & $\begin{array}{l}775 \\
0.5 \\
\text { घ. }\end{array}$ & \\
\hline 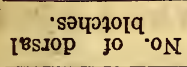 & $\Re$ & F & 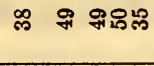 & 迥 & ฟ & F & ศ & ని న్ల న్ & ణ \\
\hline 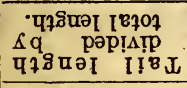 & $\stackrel{艹}{3}$ & $\stackrel{\dddot{n}}{?}$ & 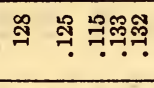 & 节 & $\stackrel{9}{?}$ & $\stackrel{\Re}{\because}$ & $\stackrel{\Re}{\longrightarrow}$ & & \begin{tabular}{c:c}
$\dddot{9}$ \\
\hdashline
\end{tabular} \\
\hline 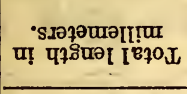 & జేีః & 怘 & 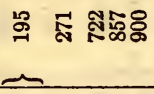 & 동 & & & 옹 & & ๑̊ สิ สิล \\
\hline 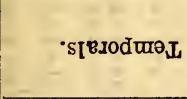 & $\begin{array}{l}4 \\
+ \\
+ \\
+\end{array}$ & $\begin{array}{l}\not \\
+ \\
+ \\
+ \\
\text { a }\end{array}$ & 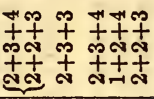 & $\begin{array}{l}\stackrel{+}{+} \\
+ \\
+ \\
+\end{array}$ & & 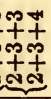 & 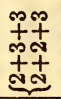 & 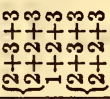 & 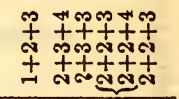 \\
\hline 'srepnoo & $\stackrel{-}{=}$ & $\stackrel{\sim}{\mp}$ & ๙ & $\stackrel{\sim}{\sim}$ & $\stackrel{\sim}{\sim}$ & $\stackrel{-}{-}$ & $\cong$ & ન્ & $\approx$ \\
\hline 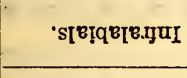 & $\underbrace{\circ 0}$ & $\infty$ & $\underbrace{\infty} \underbrace{\infty \infty 000000}$ & $\underbrace{\infty \infty}$ & $\infty \infty$ & 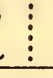 & $\infty$ & $\underbrace{0000000}$ & $\underbrace{\infty 00}$ \\
\hline 's[r!̣qriejdns & $n$ & $\sim$ & 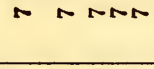 & $n$ & $r$ & r & - & $N N$ & NAN N \\
\hline 's[вpnв & F & \& & 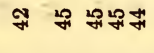 & f & q & F & 아 & & 州柇方 \\
\hline •sโB]นข $\Lambda$ & క్ & శึ & 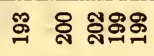 & 을 & జึ & Ф્త & ฮี & 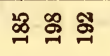 & 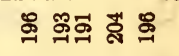 \\
\hline 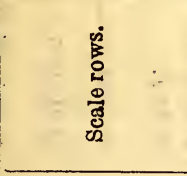 & $\begin{array}{c}\vdots \\
\bar{a} \\
\frac{1}{\pi} \\
\text { a }\end{array}$ & $\begin{array}{c}\vdots \\
\vdots \\
\vdots \\
\frac{1}{1} \\
\frac{1}{\pi} \\
\end{array}$ & 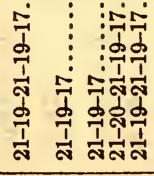 & 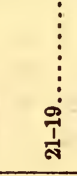 & 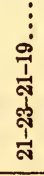 & $\begin{array}{c}\vdots \\
\vdots \\
\vdots \\
\frac{1}{\pi} \\
\end{array}$ & $\begin{array}{l}\frac{5}{1} \\
\frac{1}{3} \\
\frac{1}{3} \\
\frac{1}{3}\end{array}$ & 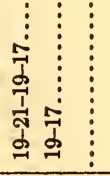 & 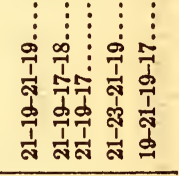 \\
\hline $\begin{array}{l}\text { मूं } \\
\text { ณू }\end{array}$ & 丞 & 范 & 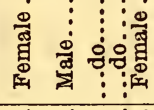 & ఏ & $\begin{array}{c}\vdots \\
\vdots \\
\vdots \\
\end{array}$ & ל: & $\vdots$ & $\begin{array}{c}\vdots \\
\vdots \\
\vdots \\
\vdots \\
\vdots \\
\vdots\end{array}$ & $\begin{array}{ccc}\vdots & \vdots \\
\vdots & \vdots \\
\vdots & \vdots \\
\vdots & \vdots \\
\vdots\end{array}$ \\
\hline 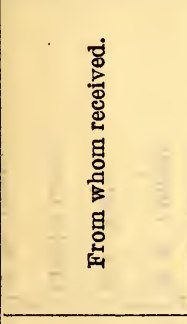 & 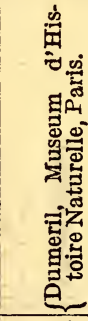 & 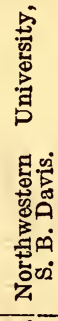 & 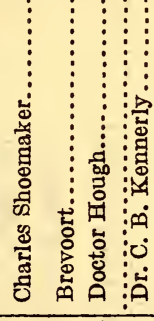 & 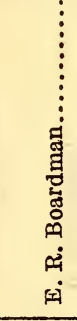 & 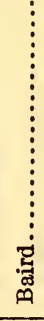 & 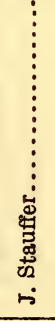 & $\begin{array}{c}\vdots \\
\vdots \\
\vdots \\
\vdots\end{array}$ & 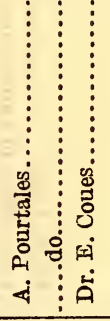 & 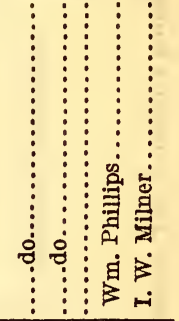 \\
\hline 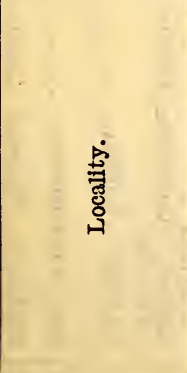 & 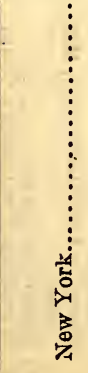 & 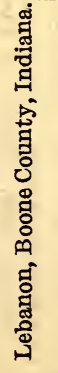 & 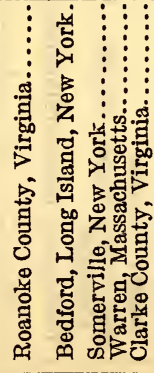 & 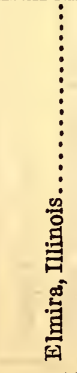 & 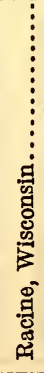 & 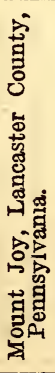 & 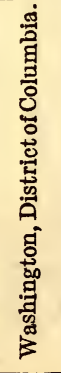 & 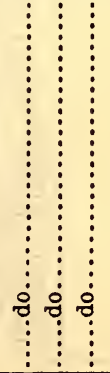 & 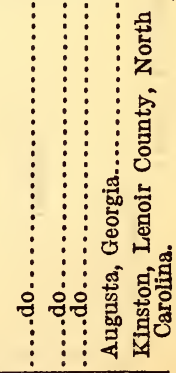 \\
\hline
\end{tabular}

宗 186550-21-Bull. 114 14 
204 BULLETIN 114, UNITED STATES NATIONAL MUSEUM.

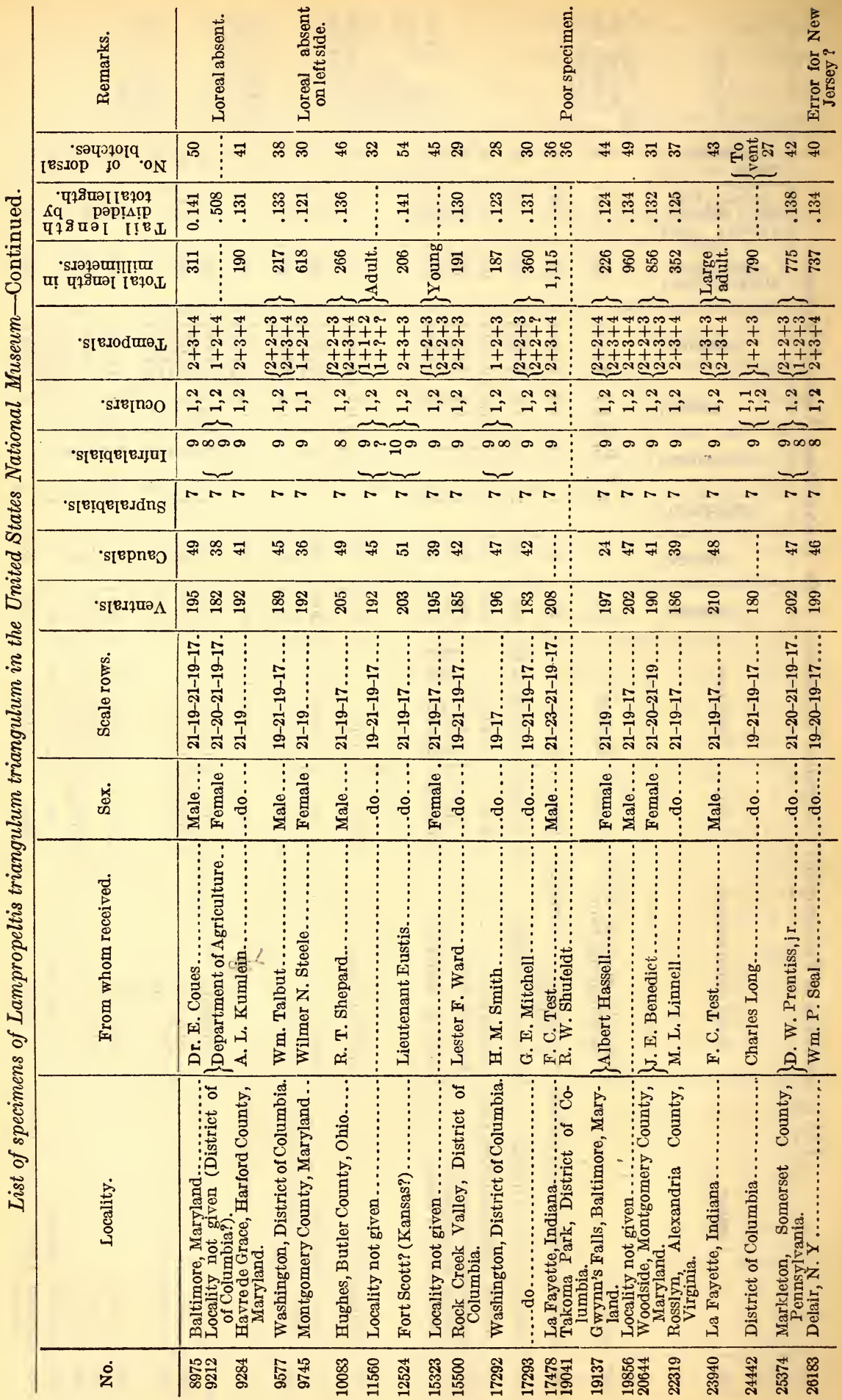




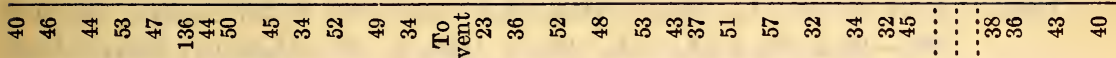

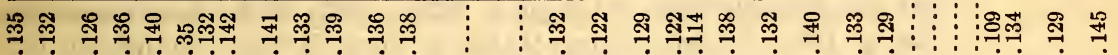

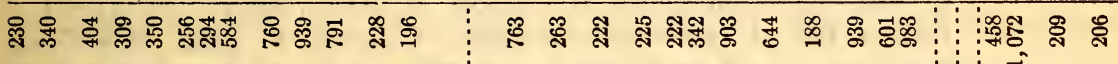

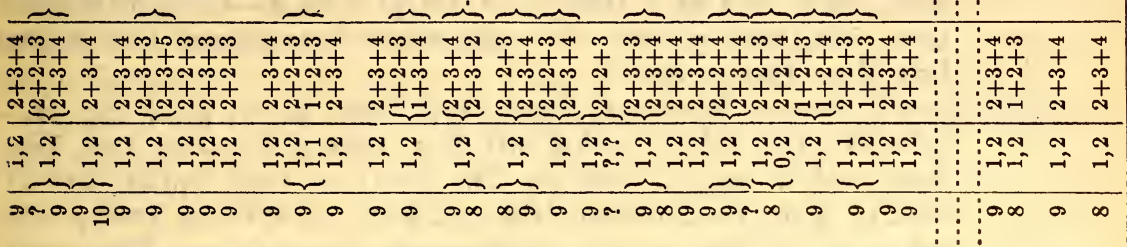

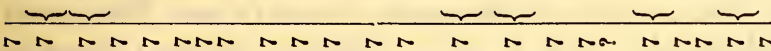

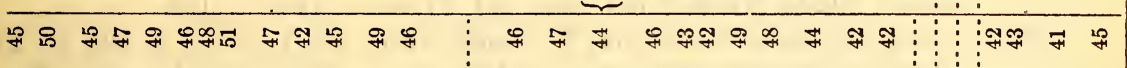

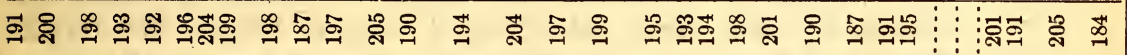

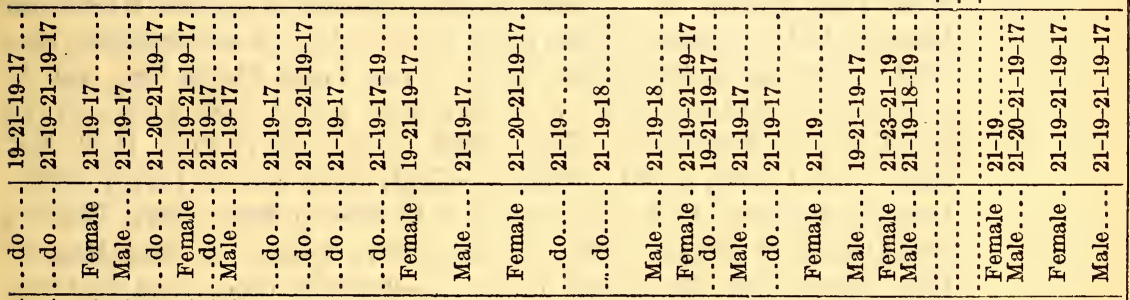


LAMPROPELTIS ELAPSOIDES ELAPSOIDES (Holbrook).

SCARLET KING SNAKE, RED KING SNAKE, THUNDER SNAKE, "CORAL SNAKE."

Figs. 58, 73.

1789. Coluber doliatus LacéPÈDe, Hist. Nat. Serp., vol. 2, tabl. meth., pp. 104, 294.-Daudin, Hist. Nat., vol. 7, 1800, p. 74.-Harlan, Journ. Acad. Nat. Sci. Philadelphia, vol. 5, pt. 2, 1827, p. 362; Med. Phys. Researches 1835, p. 125.-? Natrix doliatus Merrem, Versuch Syst. Amphibien, 1820 p. 129.-Coronella doliata Holвrooк, N. Amer. Herp., ed. 2, vol. 3, 1842 , p. 105, pl. 24.-Ophibolus doliatus Garman, S., Mem. Mus. Comp, Zool., vol. 8, no. 3, pt. 1, 1883, pp. 64, 154, pl. 5, fig. 2.-Coronella doliatus, Boie, Isis, 1827, p. 539.-Coronella doliata Boulenger, Cat. Snakes Brit. Mus., 1894, p. 205.

1837. Coronella coccinea Schleger, Essai Phys. Scrp., p. 57, pl. 2, fig. 11.GüNTHer, Cat. Colubr. Snakes Brit. Mus., 1858, p. 42.-JAN, Arch. Zool. Anat., vol. 2, fasc. 2, 1863, pp. 237, 239; Icon. Gen. Ophid., livr 17, 1866, pl. 1, fig. 1.-Bocourt, Miss. Sci. Mex., pt. 3, vol. 2, 1886, p. 608, vol. 3, pl. 39, figs. $1 a$ to 1e-LLampropeltis coccinea Cope, Proc. Acad. Nat. Sci. Philadelphia, 1860, p. 257.-Ophibolus coccineus Brimley, Journ. Elisha Mitchell Sci. Soc., vol. 21, no. 4, 1905, p. 152.

1838. Coluber elapsoides HoLвrooк, N. Amer. Herp., ed. 1, vol. 2, p. 123, pl. 28 (type locality, South Carolina and Georgia).-Calamaria elapsoidea HoLBRоor, N. Amer. Herp., ed. 2, vol. 3, 1842, p. 119, pl. 28.-DeKAY, New York Fauna, pt. 3, 1842, p. 49.-Osceola elapsoidea BAIRD and Girard, Cat. N. Amer. Rept., pt. 1, 1853, p. 133.-Iichtenstein, Mus. Zool. Berolinenses, 1856, p. 24.-Cope, Proc. Amer. Philos. Soc., vol. 17, 1878, p. 65.-YARrow, Bull. U. S. Nat. Mus., no. 24, 1882, p. 89.-DAvis and Rice, N. Amer. Batr. Rept., 1883, p. 33.-Cope, Proc. U. S. Nat. Mus., vol. 11, 1888, p. 381; Proc. U. S. Nat. Mus., vol. 14, 1891, p. 606.Loennberg, Proc. U. S. Nat. Mus., vol. 17, 1894, p. 325.-Cory, Hunting and Fishing in Florida, 1896, p. 130.-Cope, Rep. U. S. Nat. Mus. for 1898, 1900, p. 900, fig. 221, pl. 18, fig. 3.-Wright, Proc. Acad. Nat. Sci. Philadelphì, 1915, pp. 139, 140, 148.-Ophibolus elapsoideus GarmaN, H., Bull. Illinois State Lab. Nat. Hist., vol. 3, art. 13, 1892, p. 229 (Anna, Ill.).-Lampropeltis elapsoides SteJneger and BARBour, Check List, 1917, p. 88.-Srejneger, Proc. Biol. Soc. Washington, vol. 31, 1918, p. 99.

1883. Ophibolus doliatus elapsoideus Garman, S., Mem. Mus. Comp. Zool., vol. 8, no. 3 , pt. 1 , pp. $65,155$.

1901. Ophibolus doliatus coccineus Brown, Proc. Acad. Nat. Sci. Philadelphia, p. 74.-Brimley, Journ. Elisha Mitchell Sci. Soc., vol. 21, no. 4, 1905, p. 145; 1907, pp. 145, 148.-Ditmars, Reptile Book, 1907, pp. 341, 350, pl. 105 (lower figure).-Brimuey, Journ. Elisha Mitchell Sci. Soc., vol. 30, no. 4, 1915, p. 202.-Lampropeltis doliatus coccineus Wright, Proc. Acad. Nat. Sci. Philadelphia, 1915, pp. 142 and following, also p. 165, fig. 5 .

1915. Osceola doliata doliata Wright, Proc. Acad. Nat. Sci. Philadelphia, p. 139.

The name Coluber doliatus of Linnaeus must, as Stejneger has pointed out $(1918,99)$, be rejected as unidentifiable; it is unlikely that it was intended for any form that we now know as Lampropeltis. The next name to be considered, therefore, is the Coronella coccinea of Schlegel. He, without doubt, had the present species before him 
but he referred it to the form described as Coluber coccineus by Latreille (Sonini and Latreille, 1799, 138), in the belief that the latter had had the same thing that he (Schlegel) had but erroneously thought it to be the Coluber coccinea of Blumenbach $(1788,11)$. As a matter of fact, there can be no doubt that Latreille had only Blumenbach's coccinea, and this, as is well known, is the Cemphora coccinea that we know to-day, and which is a very different snake from our $L$. elapsoides, but one that presents an unusually strong superficial resemblance to it. Therefore, since Schlegel refers his coccinea to Latreille's, and since the latter was plainly a very different thing, the name coccinea Schlegel is a synonym of Cemophora coccinea (Biumenbach).

Description.-This form is the smallest of the genus and the most removed structurally from the ancestral type. The scutellation, based upon 83 specimens, is as follows: Ventral plates, 152 to 193, average about 175 ; caudals, 32 to 48 (males, 38 to 48 , average 42 ; females 32 to 42 , average 37.5 ); supralabials, 7 ; infralabials, 8 , sometimes 9 , rarely 7 ; 1 preocular; 2 , very rarely 1 or 3 , postoculars; temporals, $1+2+3$, occasionally an additional scute in one of the rows; posterior chin shields usually in contact, shorter than or about as long as the anterior; loreal decidedly longer than high, or entirely replaced by a downward extension of the prefrontal; scale rows usually $17-19-17$, sometimes $19-17$, or $17-19-17-15$ or $17-15$, very rarely reaching 21 , always having at least as few as 19 rows on the neck and never ending with more than 17 .

Head but slightly distinct from the neck; body slender, somewhat compressed, varying but little in diameter, sides meeting belly in a well-defined angle; tail slender, tapering, 0.118 to 0.169 of the total length (males, 0.129 to 0.169 , average 0.149 ; females, 0.118 to 0.147 , average 0.135 ). The largest specimen examined measured $599 \mathrm{~mm}$. and came from the Okefinokee Swamp in southern Georgia.

The pattern is made up of 15 to 25 pairs of black rings encircling the body from head to tip of tail. These border narrower rings of yellow (Brown, 1901, 74, says "white in the young, yellow in aduits") and are separated by broader ones of red. The black rings are a little wider on the dorsal line and sometimes meet here across the red; they become narrower on the first row of scales and usually extend across the belly, but if interrupted here, they extend at least onto the ends of the ventrals. The yellow rings are about $1 \frac{1}{2}$ to 2 scales wide on the middorsal line and 2 to 4 on the first row of scales; they are complete on the belly or partially interrupted by a black spot; on the sides they are often more or less mottled with darker. The red bands average to be about as wide as the groups of black and yellow rings that separate them; they are complete on the belly, although"sometimes slightly mottled or spotted there with black. 
The occiput is crossed by a black band (fig. 58) that may extend forward between the eyes. The snout is reddish and immaculate. Behind the occipital black band is a yellow collar, and behind this is another black band which is generally interrupted on the throat. The chin is a mingled red and yellow passing into yellow on the throat.

The actual colors of an adult specimen from Florida are as follows (color names from Ridgway, 1912): Morocco red above, changing to a dragon's blood red below; encircled by narrow bands of a baryta yellow on the sides, slightly deeper chrome above and paler below, which are bordered with black, the latter becoming blackish brown below. On the occiput a sooty black band; snout a claret brown; labials, morocco red mingled with a little yellow, anterior and posterior edges black; chin and throat, mingled Morocco red and pale martin's yellow. First yellow ring conspicuously mottled with red, succeeding ones slightly so down to the second or third row of scales

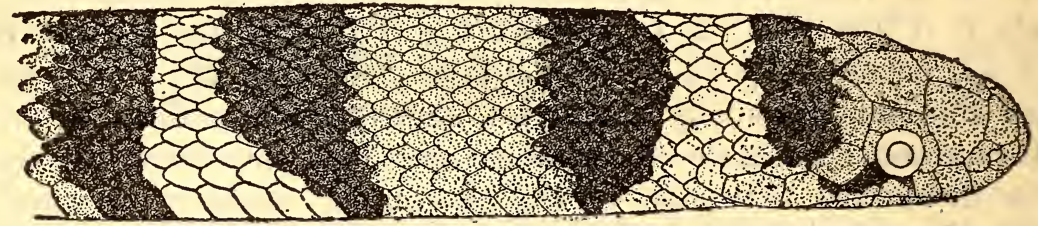

Fig. 58.-Lampropeltis elapsoides elapsoides (U.S.N.M. No. 55903, St. John County, Florida). ABOUT $22 \frac{2}{3} \times$ NAT. SIZE. SHOWING TYPICAL PATTERN OF ANTERIOR END OF BODY.

(the red in minute flecks on the yellow). Iris, Morocco red; pupil black; tongue Morocco red, or browner.

The dentition, as based upon examination of eight specimens, is as follows: Maxillaries, 13, 12, or 14, subequal, the last two slightly larger; mandibulars, 12 to 14 , the third, fourth, and fifth the largest, decreasing decidedly behind, the greatest space between the fourth and fifth; palatines, 11, 10, or 12, subequal; pterygoids, 17 to 23 (except that a specimen from Raleigh, North Carolina, has 26 and 27 ), smaller than the palatines, and decreasing posteriorly.

The copulatory organ may be described as follows: Bilobed (but not forked); sulcus single, and extending over the side of the larger lobe. A small space at the distal end of the organ may be practically free of calyces, or exhibit only ridges of the latter extending across it. Calyces not numerous; fringes few, extending distinctly, although only a little, below the end of the organ before changing to spines. The latter numerous, closely set together, increasing gradually in size to about the middle of the organ, then getting smaller again, but not abruptly so. Thus the spines extend more than half way to the base, sometimes nearly all of the way. Unless the organ was fully everted when the specimen was fresh, but little more will be made out than that it has a few calyces at the extreme distal end, 
bearing short fringes, followed by slender, closely set spines, extending distinctly more than half way to the base of the organ.

Habitat and habits. - The best account of its habits is given by Ditmars (1907, 352):

The Scarlet King Snake is a burrowing species, thus demonstrating in habits, as well as in form, its degenerate character as compared with the other snakes of the genus Ophibolus. Specimens may be most commonly found under the loose bark of fallen and decaying trees. Here they prey upon the smaller species of snakes, lizards, or upon very young mice that are yet in the nest. It is probable that this little snake issues at night from its lair and searches in crevices in the bark for various lizards that crawl into such places to sleep. This theory appears logical 'after an examination of a series of preserved specimens, in which the stomachs of several contained the remains of swifts (Sceloporus) and "blue-tail" lizards (Eumeces).

In captivity this snake evinces a very gentle disposition, seldom offering to bite. However, it invariably burrows into the soil of its cage or hides under loose objects, such as pieces of bark or flat stones. Thus it constitutes a very indifferent object for observation and study. While displaying a very indifferent appetite as a captive, it may be occasionally induced to take very young mice. Although diminutive in make-up, the reptile constricts its prey in exactly the same fashion as its larger and more powerful allies.

Wright says (from observations in the Okefinokee Swamp, 1915, 167):

In food habits this species is more or less of a constrictor. It feeds on ground lizards, skinks, swifts, and other snakes and insects. In the stomach of No. 6242 we found an angle worm and the remains of two killifishes, suggesting more of an aquatic nature than usually ascribed, but after every rain Billy's Island is covered with little water pools containing fish which as evaporation goes on become stranded. Such would be easy of capture. Our specimens yielded no clue to the oviparity or breeding of this species.

Suggesting its probable climbing ability, Wright records the capture of a specimen "on one of the frames of an old building, the snake being $3 \frac{1}{2}$ to 4 feet above the ground."

Range.-This form is known to occur from New Orleans east to Mobile, thence north as far as central Kentucky, Knoxville, Tennessee, and Raleigh, North Carolina, and south throughout Florida.

Besides the localities represented by the list of specimens examined, this species is recorded by Loennburg (1894, 325) from Toronto, Orange County, and Key West, Florida, and by Brimley $(1905,146)$ from Tarpon Springs, Florida, and $(1920,108)$ from Rutherfordton, North Carolina.

Variation and affinities.-It takes no great familiarity with the snakes of the triangulum group to become aware that in elapsoides we have a form that occupies a distinctly isolated position, structurally, from all the others. Specimens from the most diverse localities-New Orleans, Kentucky, Florida, North Carolina-preserve the distinctive characters of the species with the greatest fidelity. It apparently does not intergrade with any other member of the group (except perhaps with its own derivative, virginiana, in 
the north). In the vicinity of New Orleans its range appears to overlap that of its close relative amaura, yet each form preserves its identity. ${ }^{5}$

With the exception of Florida and the vicinity of Raleigh, North Carolina, specimens of elapsoides are not numerous in collections. This must be attributed to lack of collecting in other parts of its range. Thus, although questions of geographic variation can not

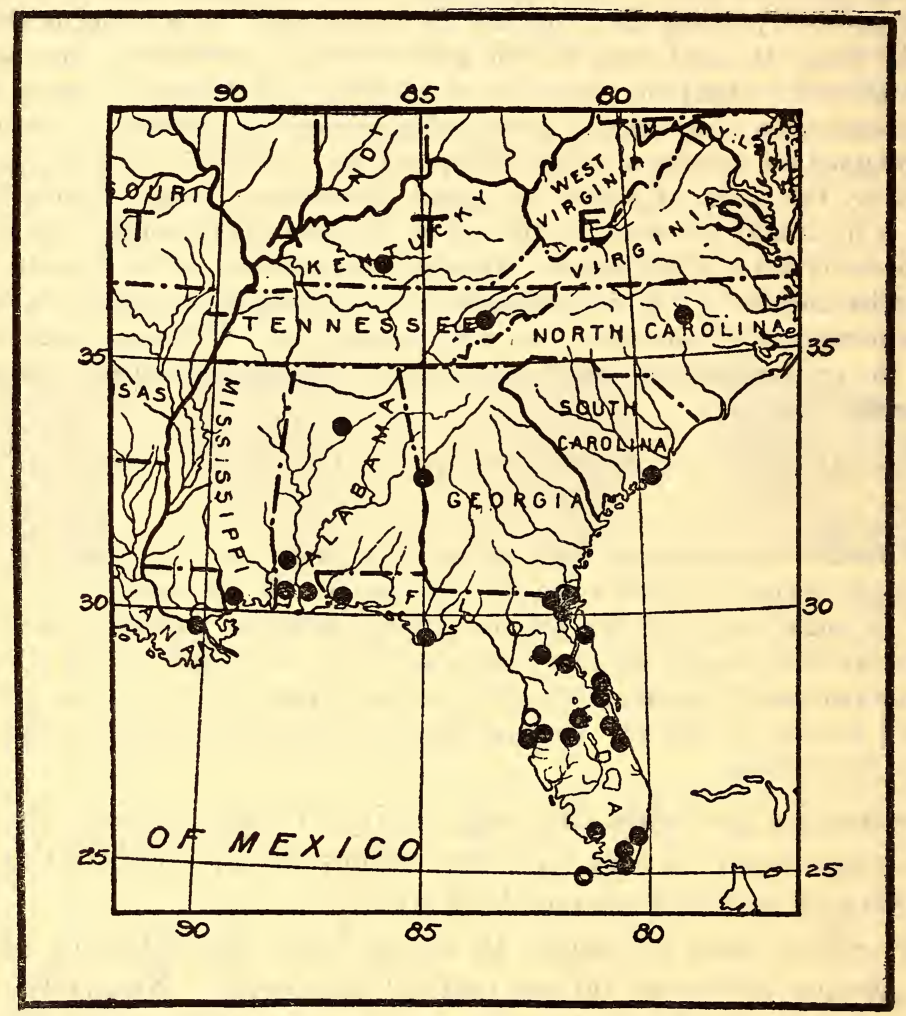

FIG. 59.-MAP SHOWLNG LOCALITY RECORDS FOR LAMPROPELTIS ELAPSOIDES ELAPSOIDES.

be treated as they should, something may be learned from a comparison of selected localities.

5 We may at this point, perhaps, best record a most puzzling specimen (Cat. no. 56196, U.S.N.M.) belonging originais to the Hurter collection and labeled "Florida, 1902." In size it resembles an adult triangulum; ventrals, 200, temporals, $2+3+4$, and scale rows 19-21-19-17 also suggest triangulum (the only other nearly related Lampropeltis in this region). Perhaps the only structural feature indicating elapsoides is the reduced number of lower labials, eight, on each side. The pattern is most simllar to that of virginiana, but the intervais on the belly opposite the dorsal yellow bands are filled with black. There are 18 red areas on the body and tail; the head is mostly red except for a black band across the first dorss 1 scales and the posterior ends of the parietals. This specimen quite evidently fits no recognized form in the genus nor can it be regarded as the first specimen of a form hitherto unknown, for its characters are apparently not such as could belong to any form theoreticalıy possible in Florids. It is not, however, inconceivable that a young adult of triangulum might mate with a large adult of elapsoides. Such a coincidence could easily explain the make-up of this unusual specimen, and to regard it as such a hybrid is per. haps the best disposal that can be made of it at present. 
Reference to the accompanying table of geographic variation shows that the averages for ventral plates are highest in the region from New Orleans to Florida and near Raleigh, lower at the Okefinokee Swamp, and lowest in southern Florida. The maxima and minima are correlated with the averages - the lowest number occurs at Lemon City and the highest at Mobile. Precisely the same situation holds with regard to the infralabials, and this is closely paralleled by the presence or absence of the loreal. The scale rows, too, show the same relation to locality. While the formula is commonly $17-19-17$, it is very noticeable that $19-17$ or 19-20-19-17 appears in the extreme western portion of the range, and in the extreme north, while in peninsular Florida nothing higher than 17-19-17 has been noted (except one individual, said to be from Marion County, which has the unusual formula 18-21-19-17); at Lemon City 17 rows throughout have been noted in 3 specimens, $17-15$ in 2 , and $15-17-15$ in 1 .

Table showing geographic variation in elapsoides.

\begin{tabular}{|c|c|c|c|c|c|c|c|}
\hline \multirow{2}{*}{ Localits. } & \multirow{2}{*}{$\begin{array}{l}\text { Num- } \\
\text { ber of } \\
\text { speci- } \\
\text { mens. }\end{array}$} & \multicolumn{2}{|c|}{ Ventral plates. } & \multicolumn{2}{|c|}{ Loreal. } & \multicolumn{2}{|c|}{ Infralabials. } \\
\hline & & Extremes. & $\begin{array}{c}\text { Aver- } \\
\text { age. }\end{array}$ & $\begin{array}{l}\text { Pres- } \\
\text { ent. }\end{array}$ & $\begin{array}{c}\text { Al)- } \\
\text { sent. }\end{array}$ & Extremes. & $\begin{array}{c}\text { Aver- } \\
\text { age. }\end{array}$ \\
\hline 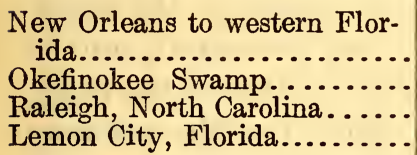 & $\begin{array}{r}8 \\
6 \\
10 \\
11\end{array}$ & $\begin{array}{l}168-193 \\
170-185 \\
173-186 \\
152-180\end{array}$ & $\begin{array}{l}180 \\
176 \\
181 \\
172\end{array}$ & $\begin{array}{l}5 \\
5 \\
8 \\
5\end{array}$ & $\begin{array}{l}3 \\
1 \\
2 \\
6\end{array}$ & $\begin{array}{l}8-9 \\
8-9 \\
8-9 \\
7-9\end{array}$ & $\begin{array}{l}8.63 \\
8.15 \\
8.38 \\
7.95\end{array}$ \\
\hline
\end{tabular}

It seems quite evident that the tendency to reduction in size and scutellation has been able to proceed faster in the most isolated portion of the range, that is, Florida. We can not doubt that the form as it occurs here is a direct derivative of the same as it occurs in Georgia and Alabama, for the reason that Florida is geologically too recent to be a region of preservation of animal types. For this reason and because the only difference between the Florida elapsoides and the same from the region north of Florida is that the former attains lower structural limits and averages than the latter, we must conclude that evolution in this form is here proceeding in the direction of reduction or degeneration. When therefore we see elapsoides in Alabama presenting such an approach and close resemblance to a nearly related form, overlapping in individual instances every difference between the two, we can not but conclude that the same processes by which clapsoides is becoming changed in Florida have operated to evolve elapsoides from amaura. A study of all the material available shows that the structural differences between them are only such as would result from intensification of degenerative 
tendencies expressed as individual variations in amaura and other forms of the triangulum group. Following is a summary of the most evident differences:

Decrease in bodily size has resulted in (1) a reduction in number of ventral plates-a change that is paralleled by several other forms in the group and genus, the only difference being that here the decrease is more pronounced; (2) a slight decrease in number of caudal scutes, resulting in a slightly greater proportionate tail length; (3) a decrease in number of dorsal scale rows to a point that averages even lower than the lowest individual variation in other members of the group and genus. Accompanying decrease in bodily size the head has become smaller and slightly different in shape; (4) the lower labials are reduced by one in the majority of individuals; (5) the temporals are reduced by one in each row; (6) the loreal has become narrow and elongate, and in many individuals it has been replaced entirely by a downward extension of the prefrontal plate; (7) the supraoculars have become small; (8) the rostral has become more pointed and slightly extended beyond the lower jaw. The pattern has suffered less marked change; (9) the paired black annuli have been reduced by about two in correlation with the change in number of ventrals and caudals; (10) the ringed pattern has become well fixed and there is less widening of the yellow annuli on the sides; (11) the black pigment has receded entirely from the snout, and in most cases has become restricted to the posterior portion of the head.

That two forms, directly related, can be so distinct at the common boundary of their ranges calls for an explanation. First, it must be recognized that elapsoides is more profoundly modified than any other member of the group. This undoubtedly means that it is older than the others, or that it has been isolated for a considerable time, or both. If we assume a northeastward migration from northern Mexico antedating that by which triangulum, syspila, and the others may be supposed to have reached the United States, we have an explanation for elapsoides. If, after this form or its forerunner reached the southeast, an embayment from the Gulf of Mexico extended up the lower Mississippi Valley (and it is probable that such actually occurred during the Quaternary), it might have divided the ancestral stock into an east and a west division. The section in the southeast might then very conceivably have undergone a modification, due to its isolation, into what we now know as elapsoides, while the main stock, still connected with its Mexican relatives, was but slightly changed. When the gulf waters receded the ranges of the isolated sections would have been joined again. It then appeared that differentiation had been so great that intergradation seldom if ever occurred, while it was not sufficiently great to allow either form to encroach much upon the range of the other. 


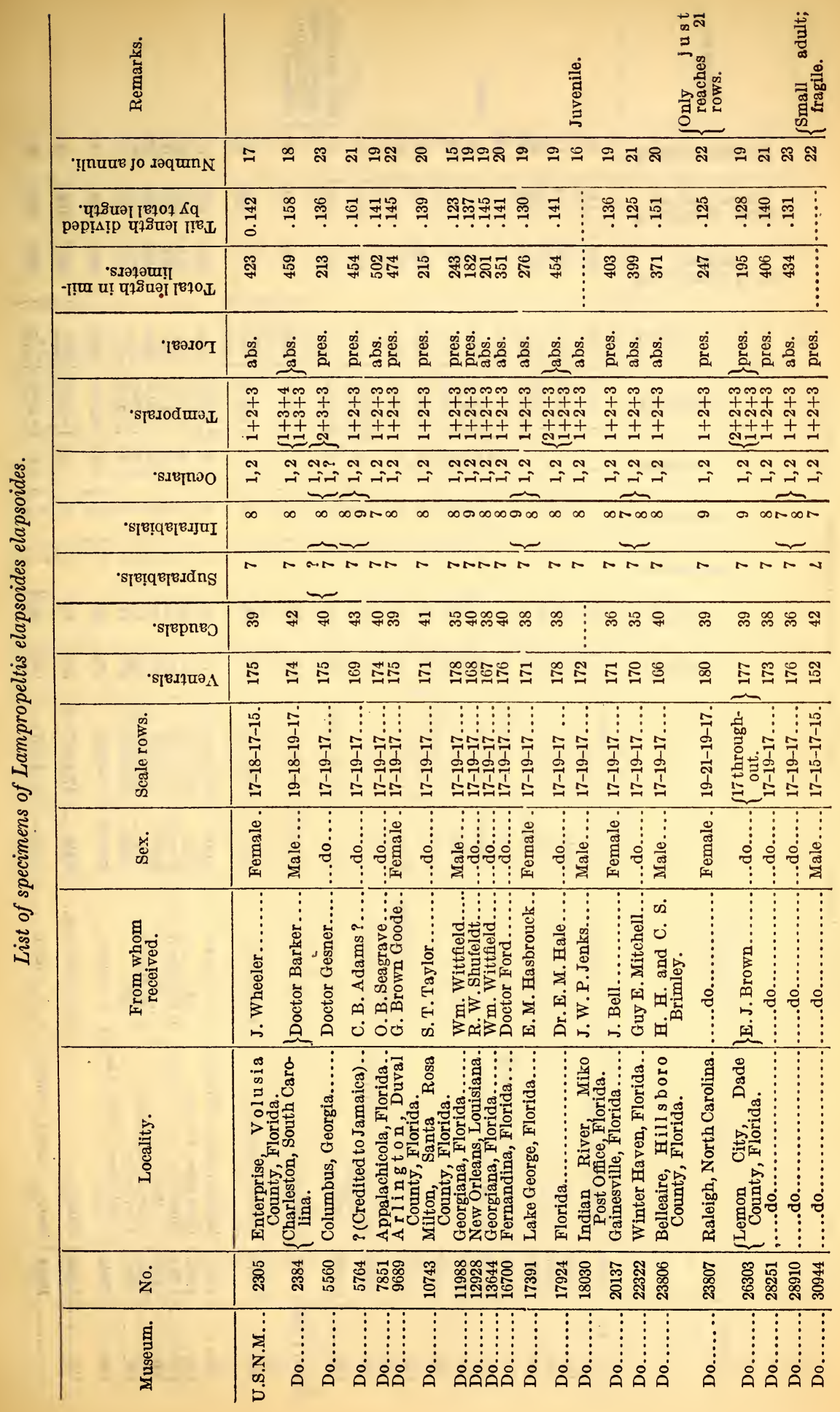




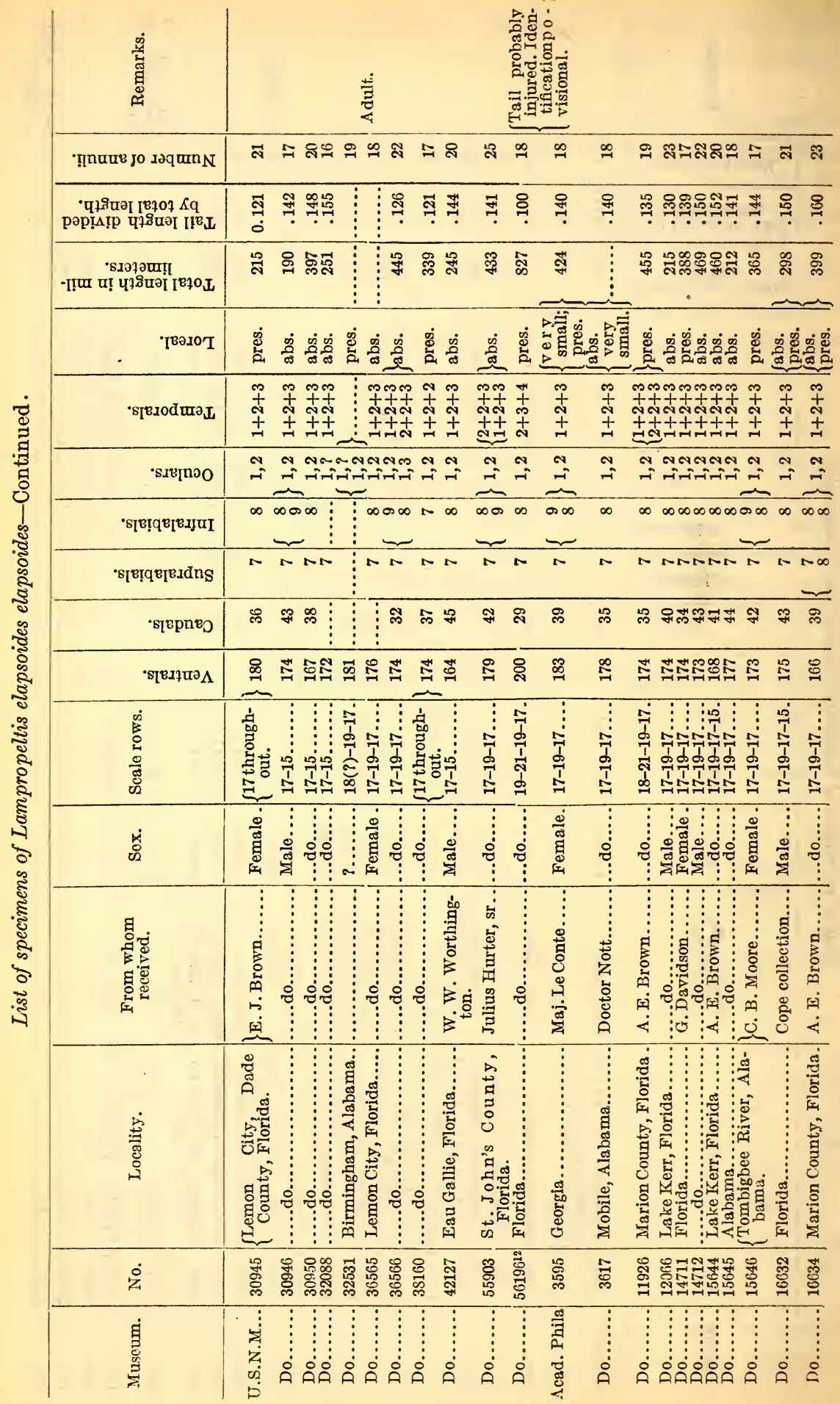


च

ส ণิ নี

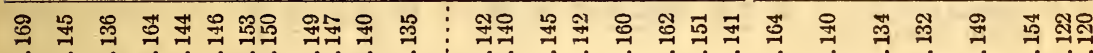

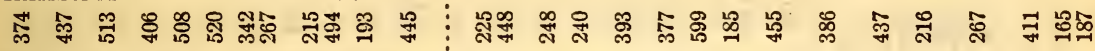

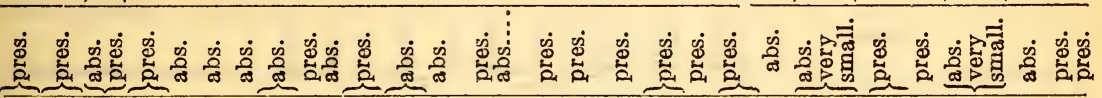
mmm m m m m m m m ††

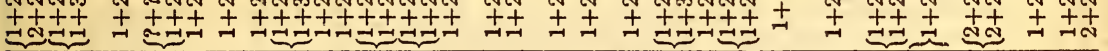
ง

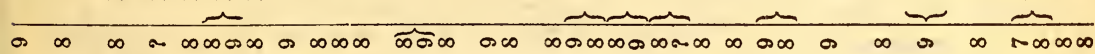

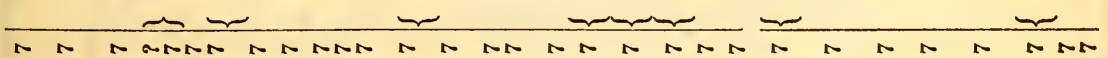

ॠ

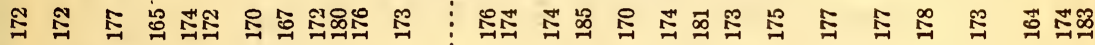

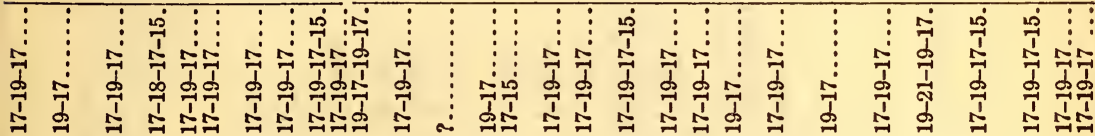

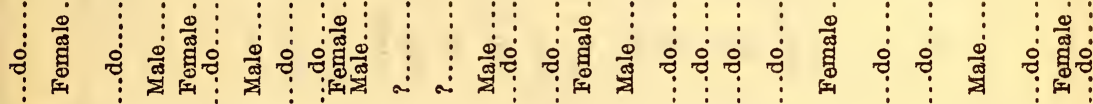

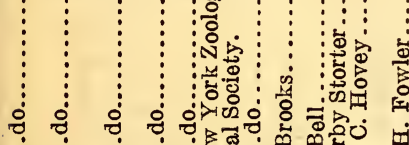
深

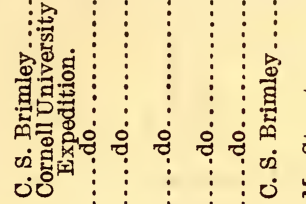

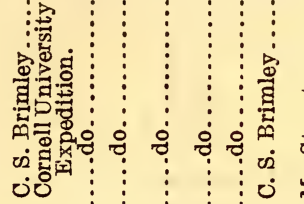

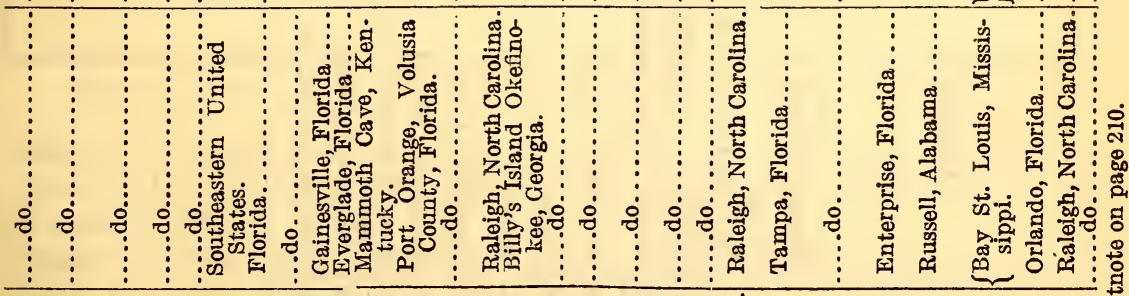

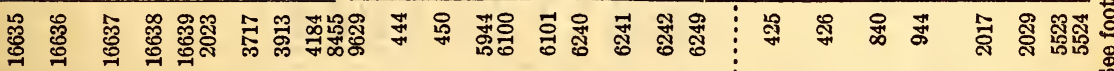

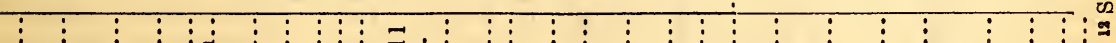

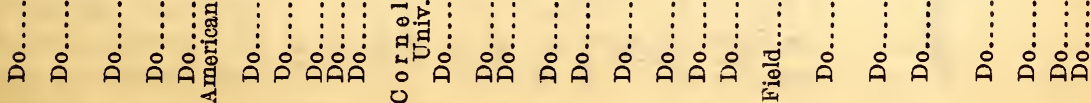




\begin{tabular}{|c|c|}
\hline 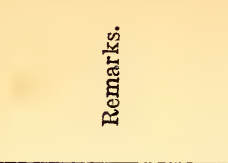 & 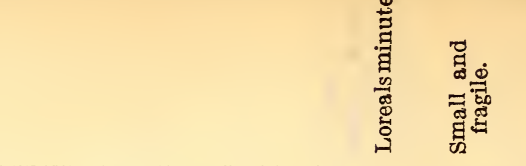 \\
\hline 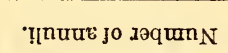 & ส สฐ สีสิก \\
\hline 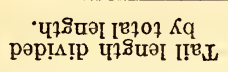 & 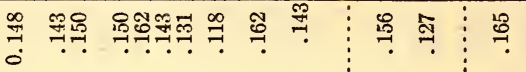 \\
\hline 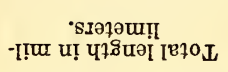 & 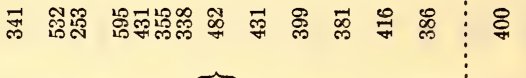 \\
\hline Irejort & 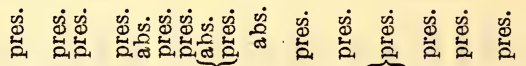 \\
\hline •ร̨вIodurəL & 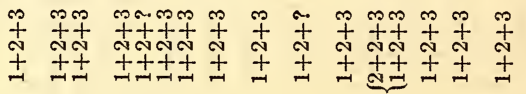 \\
\hline -sage & 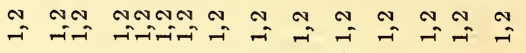 \\
\hline 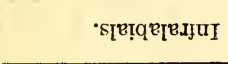 & 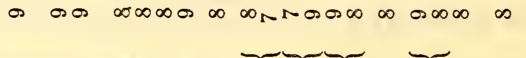 \\
\hline 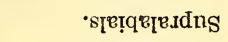 & ha hathenth \\
\hline 's[rpn & 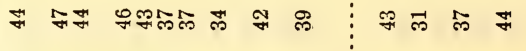 \\
\hline 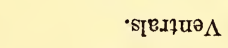 & 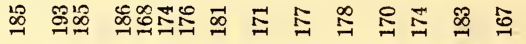 \\
\hline 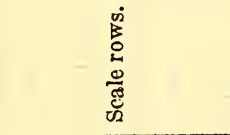 & 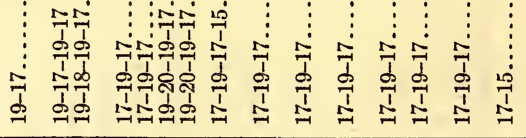 \\
\hline $\begin{array}{l}\dot{0} \\
\dot{0} \\
\dot{\delta}\end{array}$ & 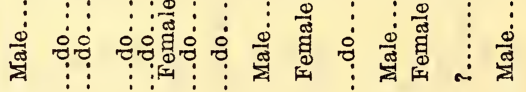 \\
\hline 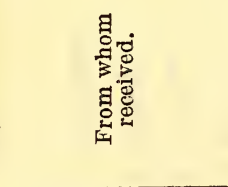 & 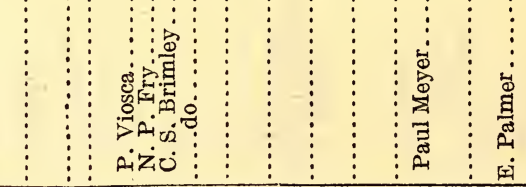 \\
\hline 密 & 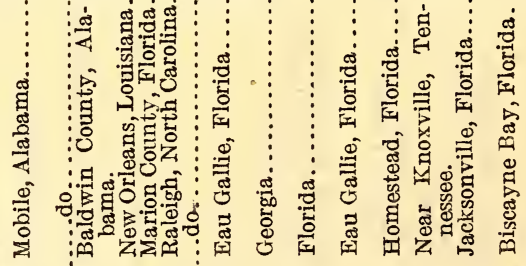 \\
\hline$\dot{z}$ & 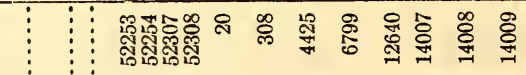 \\
\hline 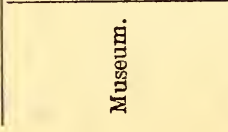 & 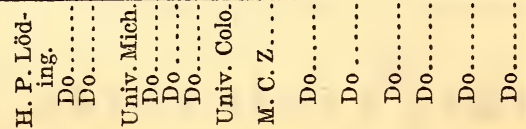 \\
\hline
\end{tabular}




\section{LAMPROPELTIS ELAPSOIDES VIRGINIANA Blanchard.}

1920. Lampropeltis elapsoides virginiana Blanchard, Occ. Pap., Mus. Zool., Univ. Michigan, no. 81 , p. 2 (type locality, Raleigh, North Carolina; type specimen, U.S.N.M. no. 21163; collected June 16, 1893).-BRIMLEY, C. S., Copeia, no. 89, 1920, pp. 106-109.

Since no new specimens of this form have been examined since the publication of the original description, the latter, with the remarks following it, is here quoted in full:

Diagnosis.-Similar in scutellation and proportions to L. elapsoides elapsoides (Holbrook), but the red areas instead of completely encircling the body are restricted to black-bordered dorsal saddles which extend upon the ends of the ventral plates.

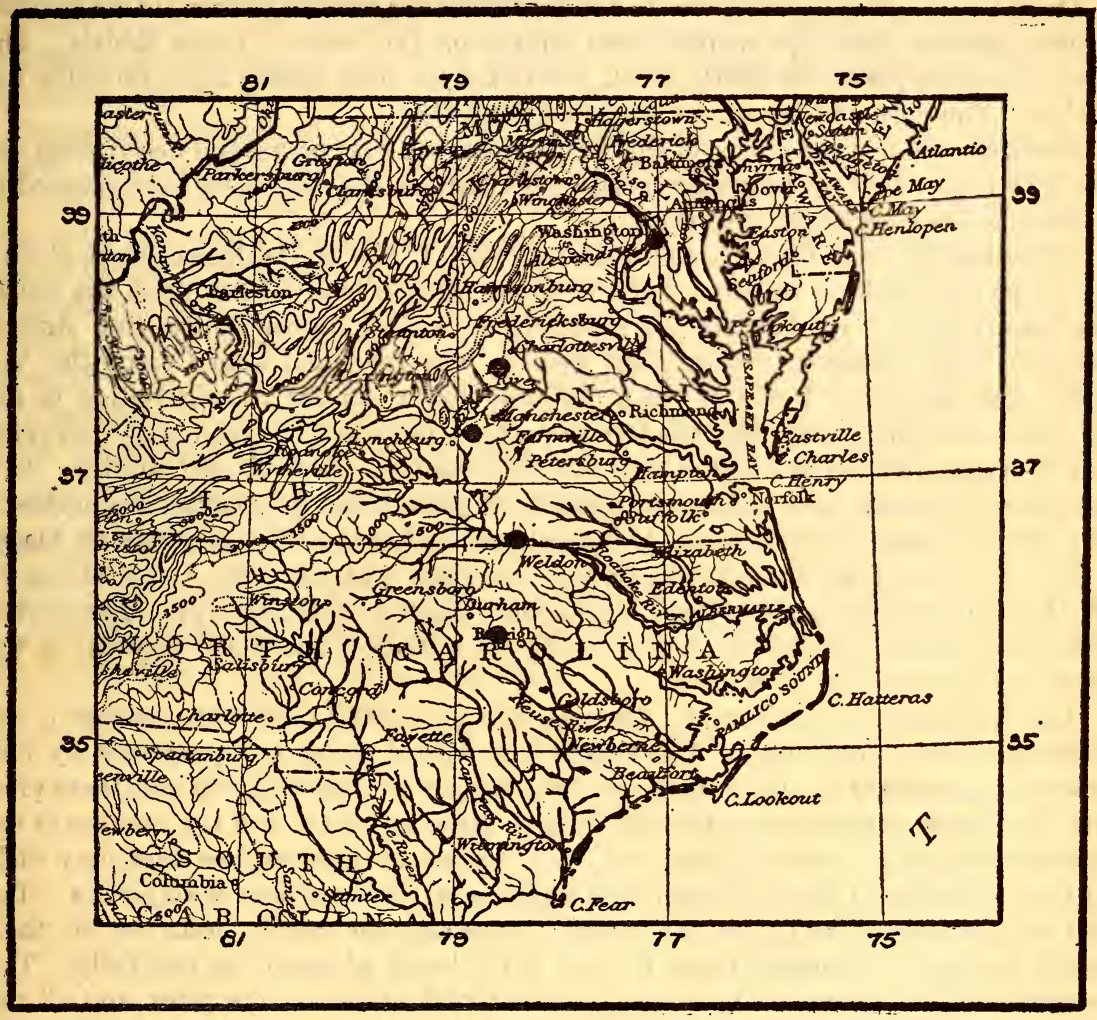

Fig. 60.-MAP SHOWING LOCALITY RECORDS FO̊R LAMPROPELTIS ELAPSOIDES VIRGINIANA.

Range.-Northern North Carolina and Virginia, east of the Allegheny Mountains. Type specimen.-United States National Museum No. 21163; Raleigh, North Carolina, June 16, 1893.

Description of type specimen.-Ventral plates 183; anal single and entire; caudals 44 pairs; dorsal scale rows 19 on middle of body, 17 anteriorly and posteriorly (formula 19-17-19-17); upper labials 7; lower labials 7 on the right side and 8 on the left; 1 preocular, 2 postoculars; 1 temporal of the first row, and 2 of the second; no loreal plates, the prefrontal in contact with the second upper labial on each side; nasal divided; anterior chin shields in contact with each other, the posterior nearly as large, in contact with each other anteriorly, diverging somewhat posteriorly; rostral protruding, as in L. elapsoides; other head shields normal for the genus. 
Total length $473 \mathrm{~mm}$; tail length $73 \mathrm{~mm}$; tail therefore about 13 per cent of total length. Sex, male.

The dentition is as follows: Maxillary teeth 13 on each side; mandibular teeth 14 on the left side, 15 on the right; palatine teeth 10 on the left side; pterygoid teeth 22 on the left, and 19 on the right.

Pattern of body composed of 18 dorsal saddles of red, bordered with black, separated by whitish areas, and extending upon the ends of the ventral plates; 4 additional saddles of red on the tail. The dorsal saddles are from 5 to 8 scales in length above, narrowing to 2 to 4 scales on the first row. The black borders are $1 \frac{1}{2}$ to 2 scales wide on the middorsal line, and $\frac{1}{2}$ to 1 scale on the first row. The whitish cross bands are about $1 \frac{1}{2}$ scales wide above, widening suddenly on the lower rows to 4 or 5 scales on the first row. On the belly, opposite each dorsal whitish cross band is a large squarish blotch of black.

On the head a black band $2 \mathrm{~mm}$. in width crosses the posterior portions of the parietal plates, leaving their tips whitish, and ending on the seventh upper labials. The frontal and temporals are mostly black, the rest of the head mostly light, probably red in life. The chin and throat are immaculate whitish.

Remarks.-So few specimens of this form are known that no general description can be drawn up. It is by no means certain even that all the specimens here referred to virginiana are conspecific with the type.

The other specimen from Raleigh (cat. no. 56197, U.S.N.M.) is almost identical with the type in structural features, but the red saddles extend farther upon the belly. Anteriorly their black borders are separated by only a narrow midventral strip of whitish, while posteriorly they meet below. The specimen from Cuscowilla, Virginia (cat. no. 26181, U.S.N.M.) is a juvenile closely similar in scutellation to the two preceding and nearly like the last in pattern, but there is a tendency to develop black pigment on the fore part of the belly between the ends of the red saddles. This tendency becomes more and more pronounced posteriorly, developing also opposite the whitish dorsal cross bands, so that the latter half of the belly is nearly all black.

The specimen from Appomattox County, Virginia (Cat. no. 4466, U.S.N.M.) lacks the head but otherwise shows itself to be almost identical with the type. The ventral borders of the red saddles are, however, less well defined, and black pigment on the belly is less regularly distributed.

The specimen from Alberene, Virginia (Cat. no. 25321, U.S.N.M.) shows a few differences from the others. The twenty-first row of scales is represented by four scales on one side of the body, the lower labials are 9 on each side, the loreals are present, the upper anterior temporals are present, although small, and the number of red saddles reaches 25 . Furthermore, the black borders of these saddles show very little of that widening in the middorsal region that is so characteristic of elapsoides. The red saddles extend well upon the ventral plates and are sharply delimited by their black borders. Otherwise there is very little black pigment on the belly. The whitish crossbands are rather strongly mottled with darker on the sides, and all the dorsal scales in the red areas are less strongly but very distinctly mottled with dark. In scutellation this specimen is perhaps nearer to $L$. triangulum triangulum, but it can certainly never be regarded as identical with that form, and, all things considered, it seems much better to identify it provisionally as virginiana.

The specimen from the District of Columbia (Museum of Zoology, University of Michigan, no. 52203) is much more puzzling. The scutellation is closely like elapsoides, but the whole snake is larger and stouter, measuring $581 \mathrm{~mm}$., even with the tip of the tail missing. Furthermore the red saddles number 27 and overlap the ends of the ventral plates only a little. The black borders of the saddles show scant if any tendency to widen in the middorsal region, and the head shows faint but recognizable vestiges of the common parietal and supraocular spots of triangulum and some speci- 
mens of $L$. triangulum syspila (Cope). There are no lateral spots alternating with the dorsal saddles, but anteriorly on the belly there is, as in the type, a single large black blotch opposite each of the dorsal whitish bands. Posteriorly, however, these blotches become irregular and the black pigment is much increased in amount. Whatever this specimen is, it is not a triangulum. It may represent a derivative of triangulum as yet unrecognized, but in view of the great variability exhibited by specimens from this middle Atlantic region and the lack of representatives from large areas of Virginia, Delaware, and Maryland it is not possible at present to define the characters of this unknown form or even to be certain that such a form exists. The present plan of identifying this aberrant specimen as virginiana is admittedly an expedient for delaying the settlement of the difficulty until more specimens shall be available for study. The dentition of this individual, except for the pterygoid teeth is as follows: maxillaries, 13; mandibulars, 13; palatines, 11.

The specimen in the Academy of Natural Sciences of Philadelphia (no. 3601) is of uncertain origin. It may be from Delaware. It is closely similar to the Cuscowilla specimen, and is with little duubt a virginiana.

The form virginiana, as defined by the type and represented by all the others listed except the two doubtful ones (those from Alberene and the District of Columbia), is without doubt a derivative of elapsoides by an alteration of the pattern closely similar to that which took place when the subspecies of triangulum changed from the ringed to the saddled type of pattern. Whether this change toward the triangulum type went so far that individuals of virginiana were able to hybridize with the degenerating section of triangulum of the mid-Atlantic States seems improbable. It is more likely, as indicated above, that there exists in this region a degenerate derivative of triangulum. This question can be settled only when specimens shall be available from the Delaware-Maryland peninsula, and from eastern Virginia.

Mr. C. S. Brimley has recently published notes on numerous examples of red king snakes from the vicinity of Raleigh, North Carolina (1920, 106-109), which confirm our expectation that this is the boundary region between the ranges of elapsoides and virginiana and that the two forms here intergrade.

186550-21-Bull. $114-15$ 


\begin{tabular}{|c|c|c|c|c|}
\hline 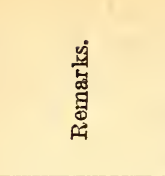 & 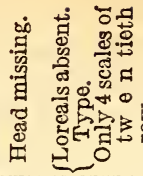 & & 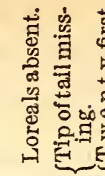 & $\begin{array}{l}0 \\
0 \\
0\end{array}$ \\
\hline 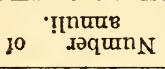 & ก ล ล & జ & $\overrightarrow{\mathrm{N}}$ ลे & $\mathscr{N}$ \\
\hline 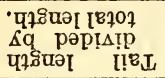 & $\begin{array}{l}\vdots \\
\vdots \\
\vdots\end{array}$ & $\stackrel{\mathbb{T}}{\longrightarrow}$ & $\stackrel{\circ}{\dddot{\dddot{m}}}$ & $\stackrel{\dddot{m}}{\dddot{m}}$ \\
\hline 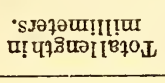 & 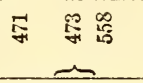 & ๓్ & 床 & $: \ddot{\circ}$ \\
\hline 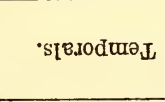 & 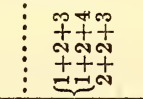 & $\begin{array}{l}\underset{+}{+} \\
\stackrel{+}{+} \\
-1\end{array}$ & 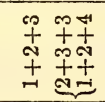 & 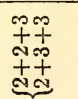 \\
\hline 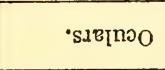 & $\vdots \overbrace{}^{N} \underset{-1}{N}$ & $\cong$ & $\stackrel{-\approx}{=}$ & $\stackrel{N}{-1}$ \\
\hline 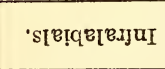 & & & $\underbrace{\infty \sim \infty \infty}$ & 0 \\
\hline 's[ध!q & $\vdots \begin{array}{l}1 \\
\vdots\end{array}$ & $\sim$ & 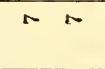 & N \\
\hline 's[epneD & 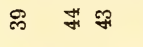 & $\stackrel{\infty}{\infty}$ & F & 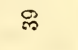 \\
\hline$\cdot \operatorname{s[Ex\} u\partial \Lambda }$ & 怘 喿呑 & 志 & $\stackrel{\infty}{\circledR}$ & $\stackrel{\infty}{\infty}$ \\
\hline 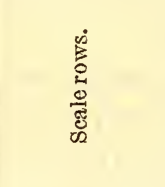 & 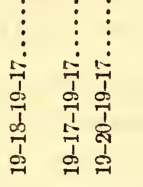 & 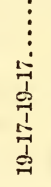 & 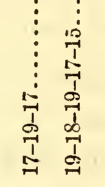 & $\begin{array}{c}\vdots \\
\vdots \\
2 \\
-1 \\
0 \\
\frac{1}{1} \\
\frac{1}{1} \\
0 \\
0\end{array}$ \\
\hline $\begin{array}{l}\text { मे } \\
\text { की } \\
\text { की }\end{array}$ & 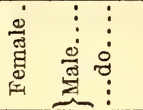 & $\begin{array}{c}\vdots \\
\vdots \\
\vdots \\
\vdots \\
\vdots\end{array}$ & مِّ & 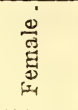 \\
\hline 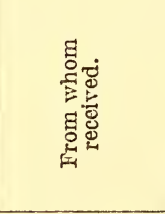 & 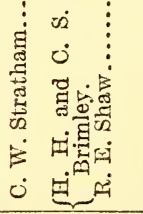 & 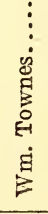 & 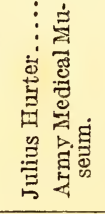 & \\
\hline 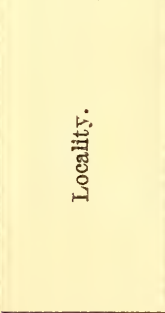 & 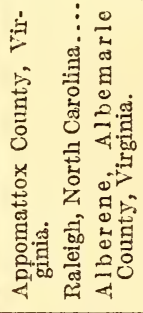 & 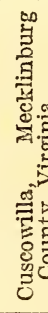 & 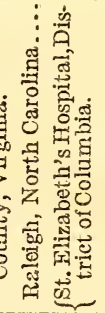 & 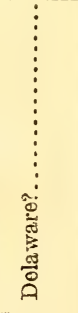 \\
\hline$\dot{8}$ & 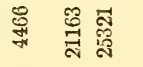 & 预 & 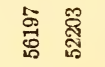 & 灾 \\
\hline 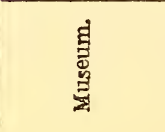 & 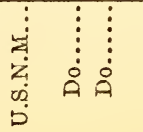 & $\begin{array}{c}\vdots \\
\vdots \\
\vdots\end{array}$ & 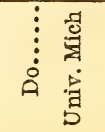 & 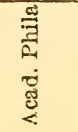 \\
\hline
\end{tabular}




\section{LAMPROPELTIS RUTHVENI Blanchard.}

Fig. 74.

1920. Lampropeitis ruthveni Blanchard, Occ. Pap., Univ. Mich., no. 81, p. 8 , pl. 1, fig. 2 (type locality, Patzcuaro, Michoacan, Mexico; type specimen, U. S. Nat. Mús., no. 46558; collected by E. W. Nelson, Aug. 2, 1892).

Since the type specimen is the only one known, the original description is quoted in full:

Diagnosis.-A ringed form similar in coloration to $L$. polyzona Cope, L. triangulum nelsoni Blanchard, and L. multicincta (Yarrow). From L. polyzona it differs in the complete absence of black tips on the red and whitish scales, in the completely black head, and in the low number of ventral plates, 189. From nelsoni it differs principally in the higher number of annuli, 30, and the much narrower red rings, 2 to 3 scales in width. From L. multicincia it is distinguished by the low numbers of ventrals and annuli, by the fact that the black rings show scant, if any, tendency to overspread the red areas dorsally, and by the mottling of the yellow rings with darker, particularly on the sides.

Range-Patzcuaro, Michoacan, Mexico.

Type Specimen.-United States National Museum No. 46558 (skin and head only); Patzcuaro, Michoacan, Mexico; collected by E. W. Nelson, August 2, 1892.

Description of type specimen.-Ventrals, 189; anal single and entire; caudal scutes 50 plus, divided (tip of tail missing); dorsal scale rows, 21 anteriorly, 23 on middle of of body, and 19 posteriorly (formula therefore 21-23-21-19); upper labials 8 on left side, 7 on right; lower labials $9 ; 1$ preocular, 2 postoculars; temporals somewhat irregular, about $2+3+4$, the upper left anterior temporals much reduced; loreal longer than high; nasals injured on each side; anterior chin shields in ${ }^{\circ}$ contact with each other and with the first. four lower labials; posterior chin shields shorter than the anterior and separated from each other by 2 or 3 small scales; other head shields normal for the genus.

Total length (tip of tail missing), ahout $745 \mathrm{~mm}$., tail length $112 \mathrm{~mm}$.

The dentition is as follows: Maxillary teeth, 14 on the left side, 15 on the right, the last two distinctly enlarged; mandibular teeth, 14 on the left side 13 on the right, decreasing slightly in size; palatine teeth, 13 on the left, 11 on the right; pterygoid teeth, 21 on the right side.

The color pattern is composed of 24 whitish rings on the body and 6 on the tail. These rings are about $1 \frac{1}{2}$ scales wide on the middorsal line and 2 scales wide on the first row of scales; on the sides and on the belly, posteriorly, they are mottled with darker. Bordering the whitish rings are black annuli about 2 scales $n$ ide dorsally and 1 scale wide on the belly. The black rings are separated by red rings, 2 to 3 scales in width. The actual colors can not be determined from so old a specimen, but there are indications that the whitish rings may have been suffused with pink.

The head is black nearly to the tips of the parietal shields, except for flecks of whitish on the lower portions of some of the upper labials. The chin is whitish except for some black on the first 5 or 6 of the lower labials. The first black ring begins about 2 scales behind the parietals and is continuous across the throat.

Remarks. -The status and significance of this form, represented as it is by only a single specimen, must remain in doubt for the present. It appears, however, to be more closely allied to $L$. multicincta than to any other form in the genus. 


\section{LAMPROPELTIS MULTICINCTA (Yarrow).}

CORAL KING SNAKE; RING SNAKE; RED MILK SNAKE; HARLEQUIN SNAKE.

Fig. 75.

1876. Bellophis zonatus Lockington, Proc. California Acad. Sci., vol. 7, May 1, p. 52 (type locality, northern California ${ }^{6}$ ).-Coronella zonata Bouleng ER, Cat. Snakes Brit. Mus., vol. 2, 1894, p. 202.-Lampropeltis zonata VAN Denburgh, Occ. Papers California Acad. Sci., vol. 5, 1897, p. 167, fig. p. 168.-McLain, Coll. Rept. W. Coast U. S., 1899, p. 11.-MeEK, Field Columb. Mus. Pub., 104, vol. 7, no. 1, 1906, p. 15.-Ophibolus zonatus Ditmars, Reptile Book, p. 357, pl. 103, figs. 7, 10, pl. 107 (middle fig.).

1882. Ophibolus getulus multicinctus YarRow, Proc. U. S. Nat. Mus., vol. 5, p. 440 (type locality, Fresno, California; type specimen, U. S. Nat. Mus., no. 11753; G. Eisen, collector); Bull. U. S. Nat. Mus., no. 24, 1882, p. 94.

1886. Coronella multifasciata Bocourt, Miss. Sci. Mex., pt. 3, p. 616, pl. 40, figs. 2, 2a-2c (type locality, California; type specimen in Paris Museum; M. de Cessac, collector).

1900. Ophibolus getulus boylii Cope (part), Rep. U. S. Nat. Mus. for 1898, p. 921. 1902. Lampropeltis pyrrhomelaena multicincta Stejneger, Proc. U. S. Nat. Mus., vol. 25, p. 153.-Grinnell and Grinnell, Throop Inst. Bull., no. 35, 1907, p. 39, fig. 16.-Grinnell, Univ. California Publ. Zool., vol. 5, no. 1, 1908, p. 165.-Atsatt, Univ. California Publ. Zool., vol. 12, no. 3, p. 41.-Grinneli and Camp, Univ. California Publ. Zool., vol. 17, no. 10, 1917, p. 184.-STEJNeger and BARBour, Check List, 1917, p. 89.Lampropeltis pyromelana multicincta Hall and Grinnell, Proc. California Acad. Sci., ser. 4, vol. 9, no. 2, 1919, p. 60.

As Stejneger has already shown $(1902,153)$ the Coluber (Zacholus) zonatus of Blainville $(1835,293)$ is of too uncertain identity for its name to be used for the present form. Therefore, although no specific rule applies in this case, it is in the interest of stability to ignore the name as revived by Lockington.

Description.-Forty-nine specimens of this form have been examined. Their scutellation is as follows: Ventrals, 202 to 222 ; caudals, 45 to 61 (males, 45 to 61 , average, 55 ; females, 46 to 56 , average 52 ); supralabials, 7 , very rarely 8 ; infralabials, 9 , rarely 10 or 8 ; preoculars, 1, very rarely 2 ; postoculars, 2 ; temporals, $2+3+4$, infrequently 1 less in any row; posterior chin shields as long as anterior, or but little shorter, in contact or separated by one or two small scales; loreal longer than high, rarely absent; scale rows on middle of body usually 23 , sometimes only 21 , rarely 25 .

In proportions this form differs somewhat from the varieties of triangulum in having the head a little more distinct from the neck, but less so than in pyrrhomelaena, in having a proportionately somewhat longer and blunter snout, and in having a longer tail. The latter

- Dr. John Van Denburgh, of the California Academy of Sciences writes: "1Rcgarding the types of Lockington's Belloplis zonatus I can state that they were two in number and were labeled Santa Barbara, but probably were collected in the mountains near there, and that they were in the Academy's collection until destroyed by the great flre in April, 1806." 
divided by the total length varies from 0.131 to 0.161 , averaging about 0.146 for each sex. The largest specimen examined came from Callahan, California, and measured $973 \mathrm{~mm}$.

The pattern is formed of about 45 whitish rings separated by black ones which are more or less completely split with red. The white rings, 23 to 57 in number, are from 1 to 3 scales in width, not widened on the sides nor mottled there with darker, and are complete on the belly. The black rings are from two to several times as wide as the white, and are usually more or less completely split with red, which is wider on the lower rows of scales. The first black ring is usually but not always, complete on the throat. The head is black, only occasionally lightened in the frontal, prefrontal, and loreal region.

The dentition is indicated by a few specimens to be as follows: Maxillary teeth, 11 to 13 , commonly 12 , second to fifth longest, rest smaller, except the last two, which are blade-like and distinctly enlarged; mandibular teeth, 12 to 14 , usually 12 , second to fifth longest, becoming much smaller posteriorly; palatines, 9 to 11 , commonly 9 , becoming smaller posteriorly; pterygoids, 15 to 18 , small, diminishing in size posteriorly.

This form may be distinguished from gentilis, as it occurs west of the Rocky Mountains, by the greater number of ventral plates, more than 200, and by the fact that the white rings do not widen on the sides; the snout of gentilis may be red at the tip, but in multicincta it is only black. From pyrrhomelaena it may be known by the black instead of whitish snout, by the number of caudal plates, not more than 61 in multicincta nor less than that number in pyrrhomelaena, by the lower numbers of ventral plates and white annuli, and by the infrequency of 10 infralabials. Occasional specimens in which the red is reduced to practical disappearance may resemble boylii, but may be immediately distinguished by the totally black snout, and the fact that the white rings are not particularly wider below than above. From annulata it may be known by the greater number of white rings, nearly always more than 30 .

Habitat and habits.-According to Van Denburgh (1897, 169) "this brilliant snake seems to prefer the moister, cooler portions of the state [of California], such as are occupied by coniferous forests." According to Grinnell and Camp $(1917,186)$ it "inhabits forest floors and chaparral-covered hillsides." For Los Angeles County Grinnell and Grinnell $(1907,40)$ say it is of "very general distribution in the large canyons all through our mountains. In most of its range it appears to be the commonest snake; at least it is the one most often to attract attention. The coral king snake is a relatively small snake, of slow movements, and perfectly harmless. Yet when roughly handled it bites to the best of its strength. The senior 
author has allowed himself to be bitten on two different occasions by king snakes, and although the needle-sharp teeth sank deeply enough into his hand to draw blood, the resulting wounds healed promptly with no unpleasant complications whatever." "Very

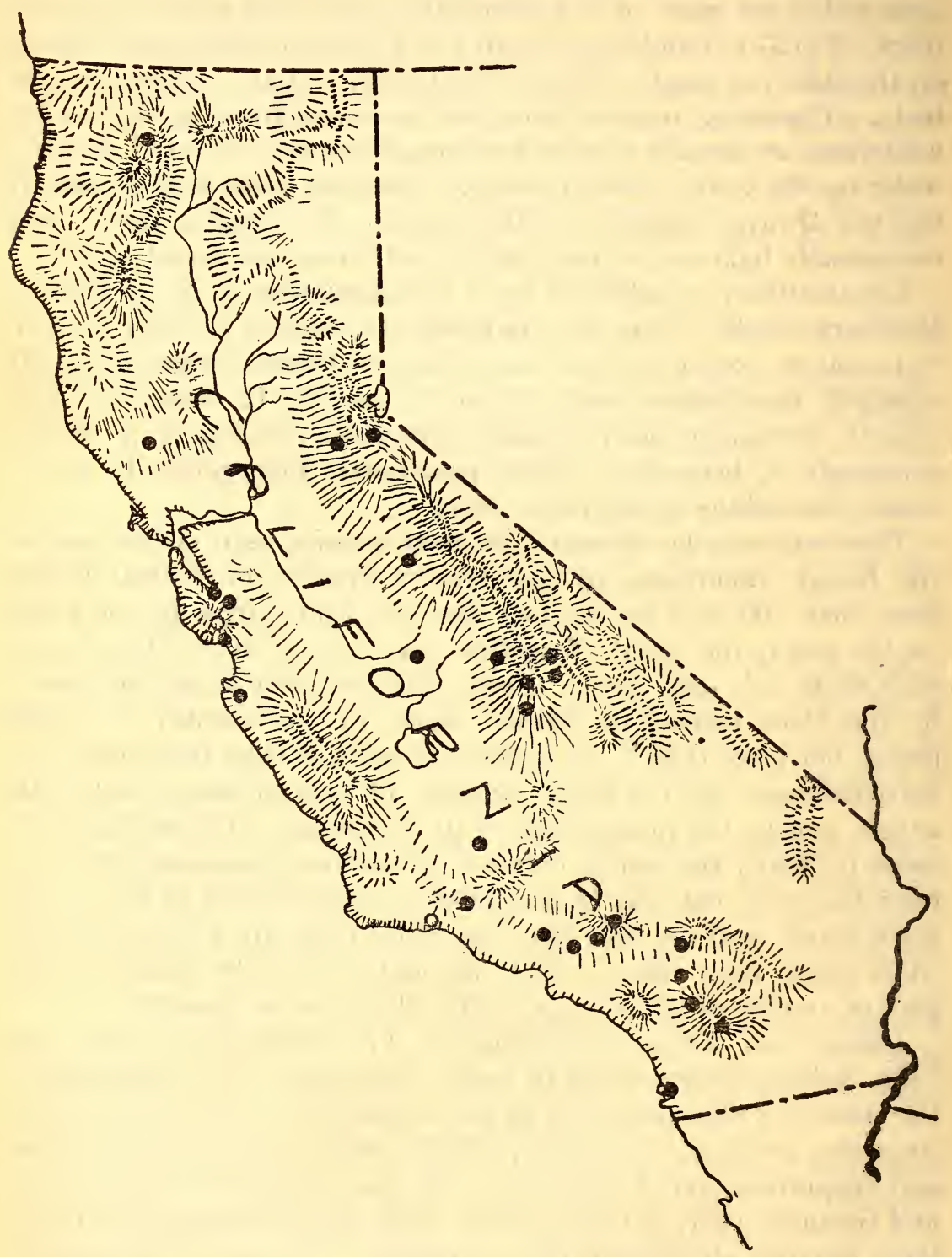

Fig. 61.--MAP SHOWING LOCALITY RECORDS FOR LAMPROPELTIS MULTINCINCTA.

little is known of the habits of this snake (Van Denburgh, 1893, 169). Old hunters say that it destroys many rattlers and other snakes. One of my specimens had eaten two blue-bellied Lizards (Sceloporus occidentalis). It is popularly supposed to be very poisonous." 
A specimen kept in captivity by the writer ate an adult Thamnophis butleri, coiling about it in true constrictor style.

Range.-Occurs throughout the State of California except in the deserts. A fine large specimen from Callahan, Siskiyou County (California Academy of Sciences, no. 36062), constitutes the most northern record; San Diego is the most southern locality. A specimen in the collection of the Field Museum of Chicago (no. 1426) from Mount Whitney in Inyo County proves its occurrence east of the Sierra Nevada. It is found at greater elevations than any other form of the genus (Hot Springs, Long Canyon, Mount Whitney, 8,000 feet; Strawberry Valley, San Jacinto Mountains, 6,000 feet; Lyth Crick, San Bernardino Mountains, 6,000 feet; Santa Ana River, San Bernardino Mountains, 5,600 feet; San Jacinto Mountains, 5,400 feet; King River Canyon, Fresno County, 5,000 feet; Yosemite Valley, 5,000 and 4,000 feet; San Bernardino Mountains, 4,000 feet).

In addition to the localities included in the list of specimens examined, Van Denburgh $(1893,169)$ records Santa Barbara; Soquel, Santa Cruz, and Glenwood, in Santa Cruz County; Hodgdon's, Tuolumne County; Heaven's Gate, near Little Kern Lake, Tulare County. Grinnell $(1908,165)$ records a specimen from Cedar Cabin, at about 5,500 feet in the San Bernardino Mountains.

Variation.-The different scale formulae, as shown by the table, are numerous. Little can be said about their geographic variation, except to note indications of higher averages in the Sierra Nevada and lower averages in western California. But between the sexes a decided difference is observable. Reference to the table of scale formulae will show that the highest formulae are not reached by the males, and that, in this sex, there are usually only 17 rows at the posterior end of the body, while in females there are 19; the few of the latter that do have 17 at the end fail to reach 23 at the middle of the body. Therefore from the scale formulae alone one may make a close guess as to the sex.

The numbers of ventrals and annuli are likewise unsatisfactory from a geographic standpoint, but the indications are in much the same sense as the scale rows. While but little difference is noticeable between eastern California and Los Angeles County, there is suggestion of decrease in both in the northwest. And in this connection it may be remarked that the most heavily pigmented individuals come from the Sierra Nevada, and the least from western and northwestern California. One specimen from Santa Clara County has but 23 white rings, and the pairs of black ones are separated by wide intervals of red. In fact individuals from this region seem generally to have the red in complete rings, and there is sometimes a development of red in the prefrontal region. 
Scale formulae of multicincta.

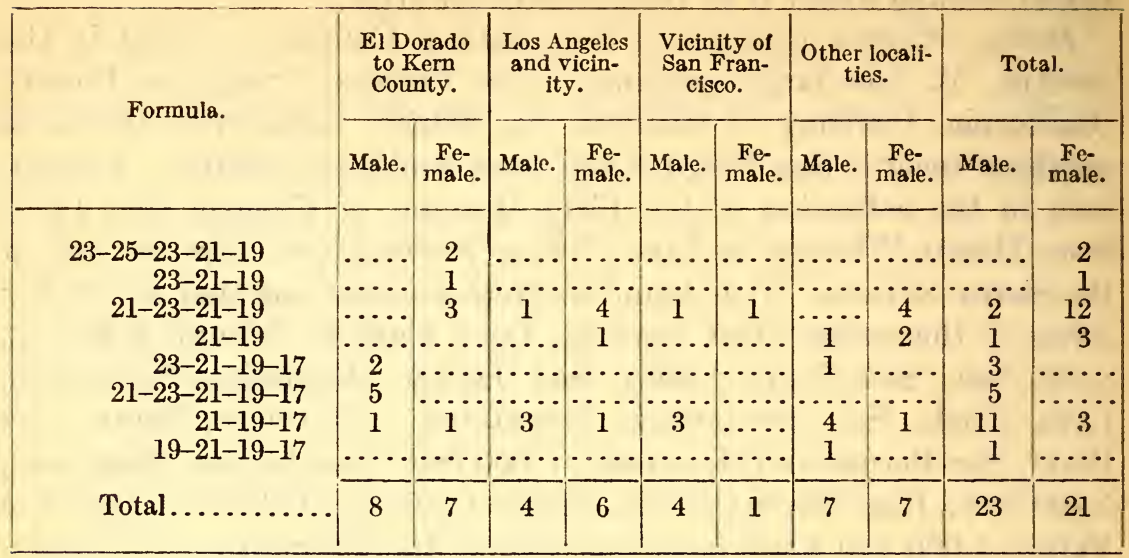

Ventrals and annuli of multicincta.

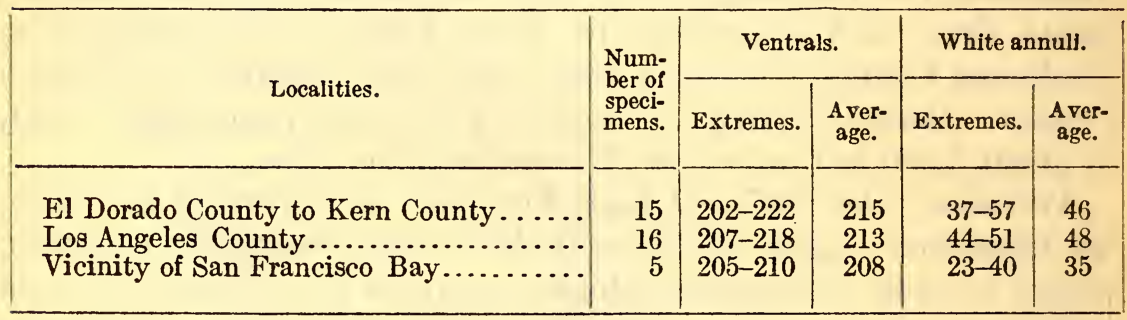

Affinities.-The affinities of this form are much in doubt. It was originally described as a subspecies of getulus. More recently Stejneger $(1902,153)$ rated it as a subspecies of pyrrhomelaena. This is undoubtedly much nearer to its true relation. In favor of this it may be noted that (1) the two forms present a striking superficial resemblance to each other; (2) they occupy adjacent regions; (3) a considerable proportion of the specimens of each possess the scale formula 23-21-19-17, a formula very rare in other forms of the genus. It is generally accepted that two forms to be rated as subspecies must intergrade in the region of the common boundary of their ranges. Multicincta is certainly not now known to intergrade with pyrrhomelaena, and the differences between them are so great as to render it unlikely that they do intergrade. Pyrrhomelaena is much further removed in structural characters from the mean of the group than multicincta, so that we could hardly derive the latter from it; to derive the former from multicincta we must assume the west coast as the center of origin of this group, but, even assuming this, we have far too much specialization in pyrrhomelaena for the short geographical distance that it is removed from its ancestor, and furthermore we have great differentiation in structural features with but 
little in pattern-a reverse of the normal situation. It is difficult for the writer to conceive these forms as directly related.

Besides pyrrhomelaena we have to consider gentilis. The range of the latter broadly overlaps that of the former. We do not know how far west it extends, as it is a secretive species, and very little careful collecting has been done in Utah and Nevada. In the western portion of its range gentilis certainly takes on a striking resemblance to multicincta. It must be noted, however, that it appears to undergo a decided reduction in number of ventrals. It is perhaps not impossible that on reaching California it could become modified into multicincta, but it seems unlikely.

This would leave multicincta quite isolated, were it not for the single specimen found by E. W. Nelson at Patzcuaro, Michoacan, Mexico, and named by the writer, ruthveni. This specimen appears to be very closely allied to multicincta, yet distinct from it. The discovery of confirmatory specimens would be gratifying. 


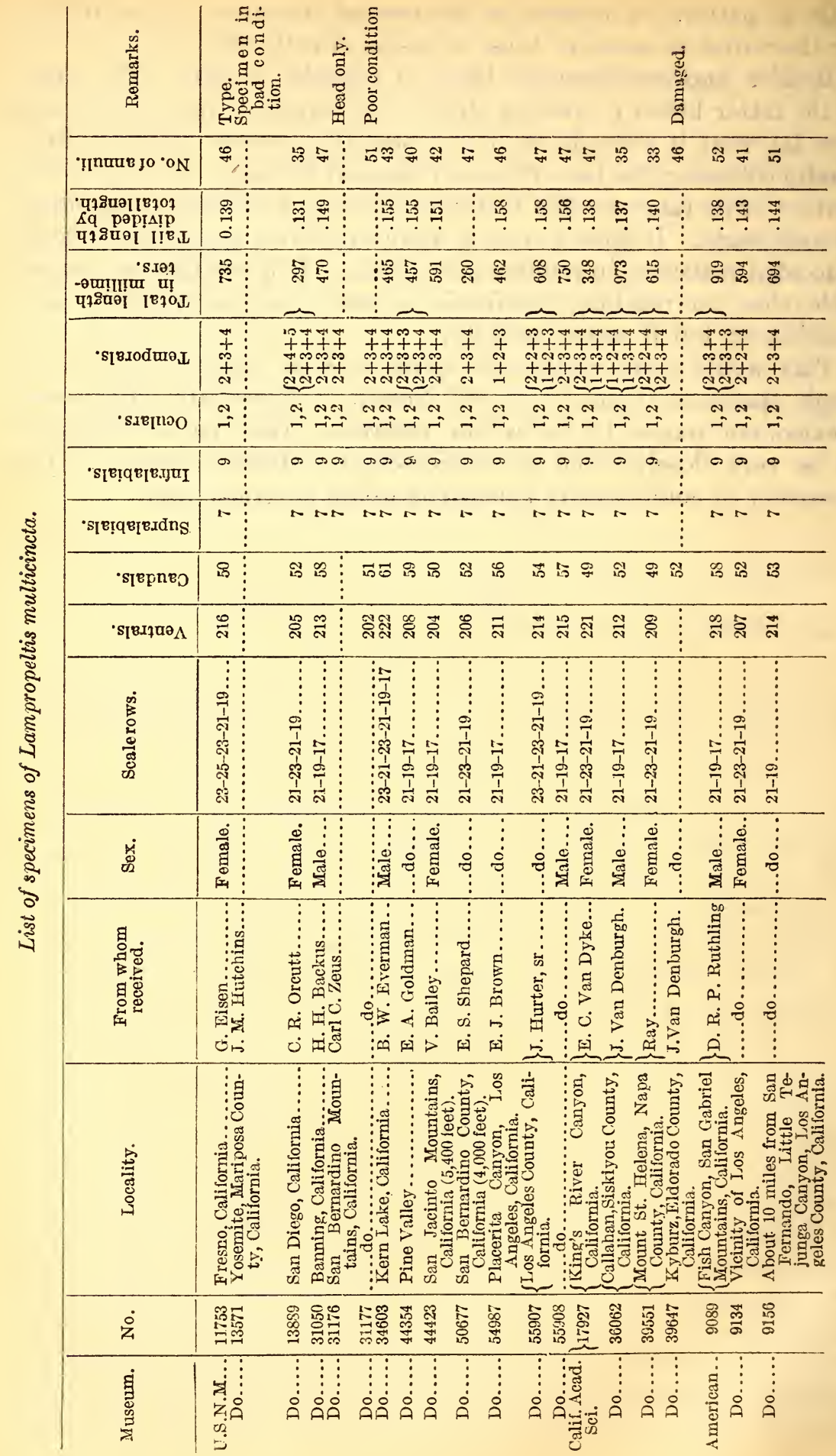




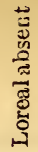

\&

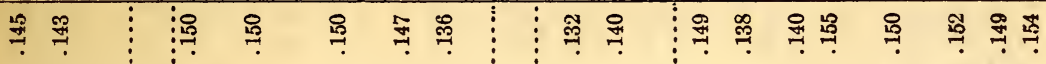
透

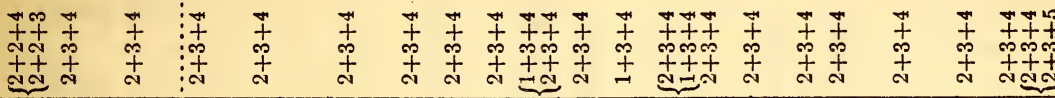
ขู

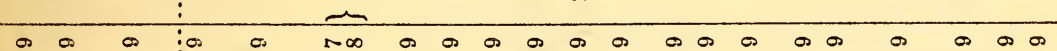

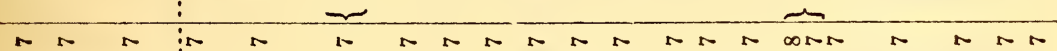

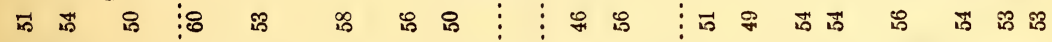
券范 击

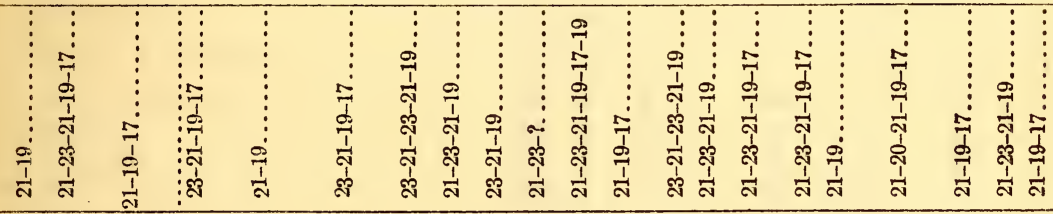

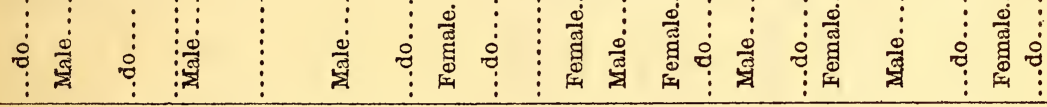

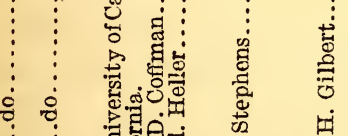

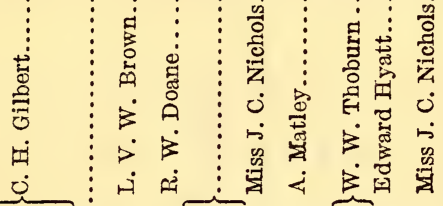
:

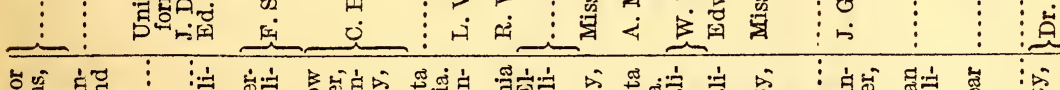

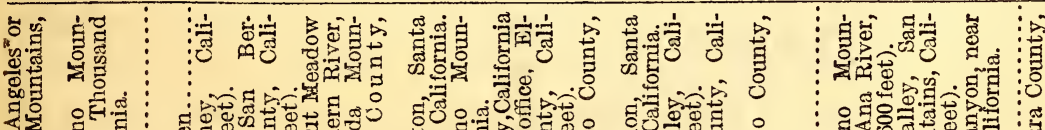

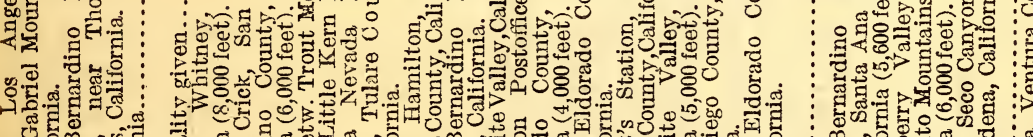

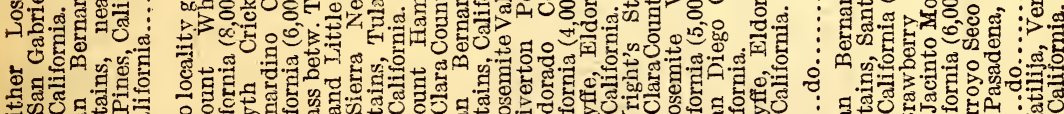

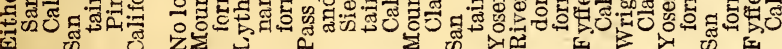
四

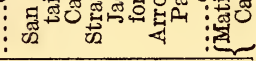

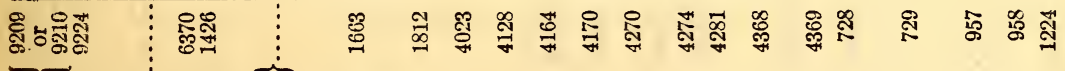

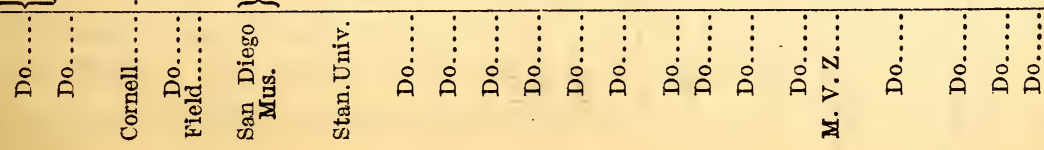




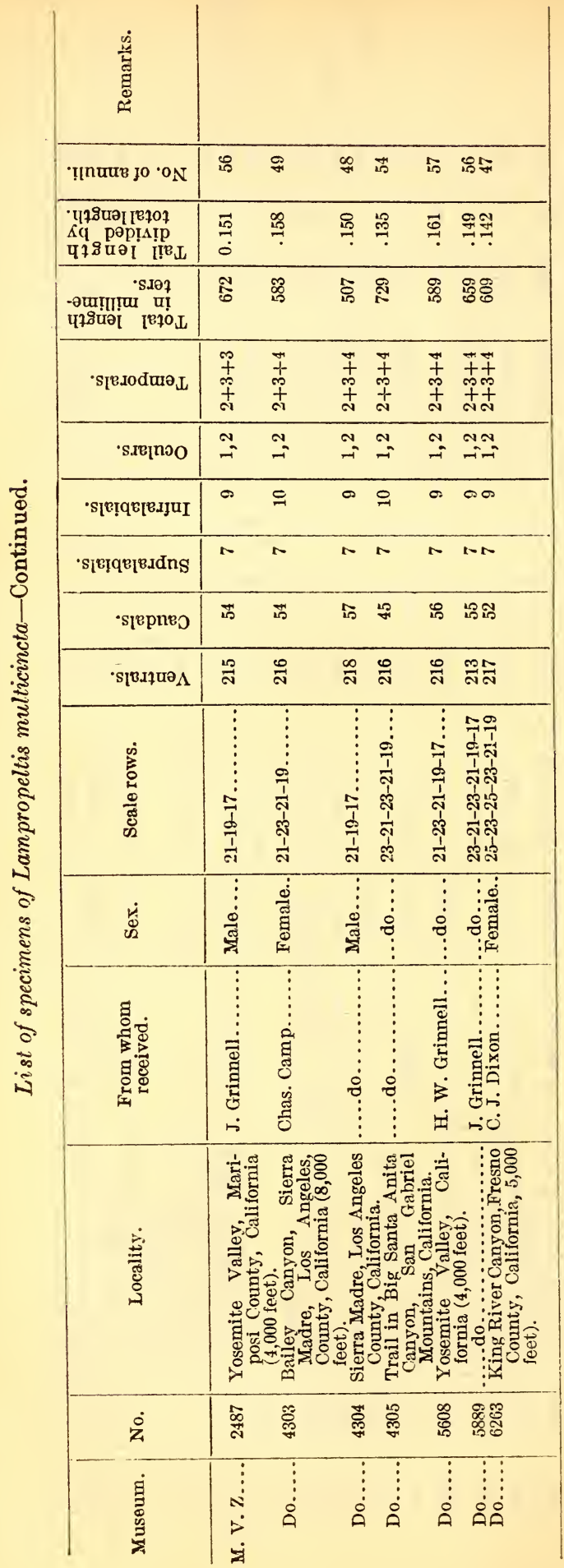


LAMPROPELTIS PYRRHOMELAENA (Cope).

ARIZONA RINGED SNAKE.

Figs. 5, 71.

1866. Ophibolus pyromelanus Cope, Proc. Acad. Nat. Sci. Philadelphia, p. 305 (type locality, Fort Whipple, Arizona).

1875. Ophibolus pyrrhomelas Yarrow, Geog. Geol. Explor. Surv. W. 100th Mer., vol. 5, chap. 4, p. 537, pl. 19.-Cope, Bull. U. S. Nat. Mus., no. 1, 1875, p. 37.-Yarrow, same, no. 24, 1882, p. 91.-Cope, Proc. U. S. Nat. Mus., vol. 14, 1891, p. 610; Rep. U. S. Nat. Mus. for 1898, 1900, p. 907, fig. 224.-Lampropeltis pyrrhomelas Van Denburgh, Proc. California Acad. Sci., ser. 2, vol. 6,1896, p. 347.

1875. Ophibolus pyromelas Coues, Geog. Geol. Explor. Surv. W. 100th Mer., vol. 5 , chap. 5 , p. 619.

1883. Ophibolus getulus pyromelanus Garman, S., Mem. Mus. Comp., Zool., vol. 8 , no. 3 , pt. 1 , pp. $67,157$.

1901. Ophibolus zonatus Brown, Proc. Acad. Nat. Sci. Philadelphia, p. 79.Ditmars, Reptile Book, 1907, pl. 103, fig. 6, pl. 107 (upper fig.).-Tucker, Dang. Pois. Snakes U. S., 1912, p. 1, pl. 1, fig. F.

1902. Lampropeltis pyrrhomelaena Stejneger, Proc. U. S. Nat. Mus., vol. 25, p. 152.-Van Denburgh and Slevin, Proc. California Acad. Sci., ser. 4 , vol. 3,1913, p. 415 .

1917. Lampropeltis pyrrhomelaena pyrhomelaena Stejneger and Barbour, Check List, p. 88.

Description.-The scutellation, based upon 32 specimens, is as follows: Ventrals, 216 to 235 ; caudals, 61 to 79 ; supralabials, 7, occasionally 8 ; infralabials, 10 , sometimes 9 , rarely 11 or 12 ; a single preocular; 2 , rarely 3 , postoculars; temporals, $2+3+4$, occasionally an extra scute in any row; posterior chin shields usually shorter and narrower than the anterior, and generally separated from each other by 1 or 2 small scales; loreal distinctly longer than high; scale rows 23 or 25 on middle of body, formulae varying from $23-25-23-21-19$ to 21-23-21-19-17.

Body long, slender, varying but little in diameter; sides meeting belly in a fairly well defined angle; head distinct from neck, widest at the temples; snout rather long, tapering, and almost truncate; eye proportionately larger than in other forms of the genus; tail long and slender, from 0.153 to 0.182 of the total length (males, 0.162 to 0.182 ; average, 0.172 ; females, 0.153 to 0.176 , average, 0.167 ). The longest specimen examined came from the Huachuca Mountains in southern Arizona and measured $1067 \mathrm{~mm}$.

The pattern (fig. 71) is of 35 to 71 whitish annuli on body and tail, separated by black which is more or less completely split with red. Some specimens are ringed throughout with white, red, and black, in others the red is continuous across the dorsal line only at the anterior end of the body and near the anal region. The red widens at the expense of the black on the lower rows of scales and usually crosses the belly. The black becomes much narrower on the sides, and traverses the belly or sometimes fails to reach it. 'The whitish annuli 
are from $\frac{1}{2}$ to $2 \frac{1}{2}$, usually 1 to 2 , scales in width, not wider on the sides, and usually more or less obstructed on the belly with black.

The head is black from about the anterior portion of the frontal to the posterior part of the parietals and laterally to the eyes or middle upper labials. The whole snout is whitish, and there is sometimes a light spot above each eye; the chin and gular region is white and quite or nearly immaculate. A white band crosses the tips of

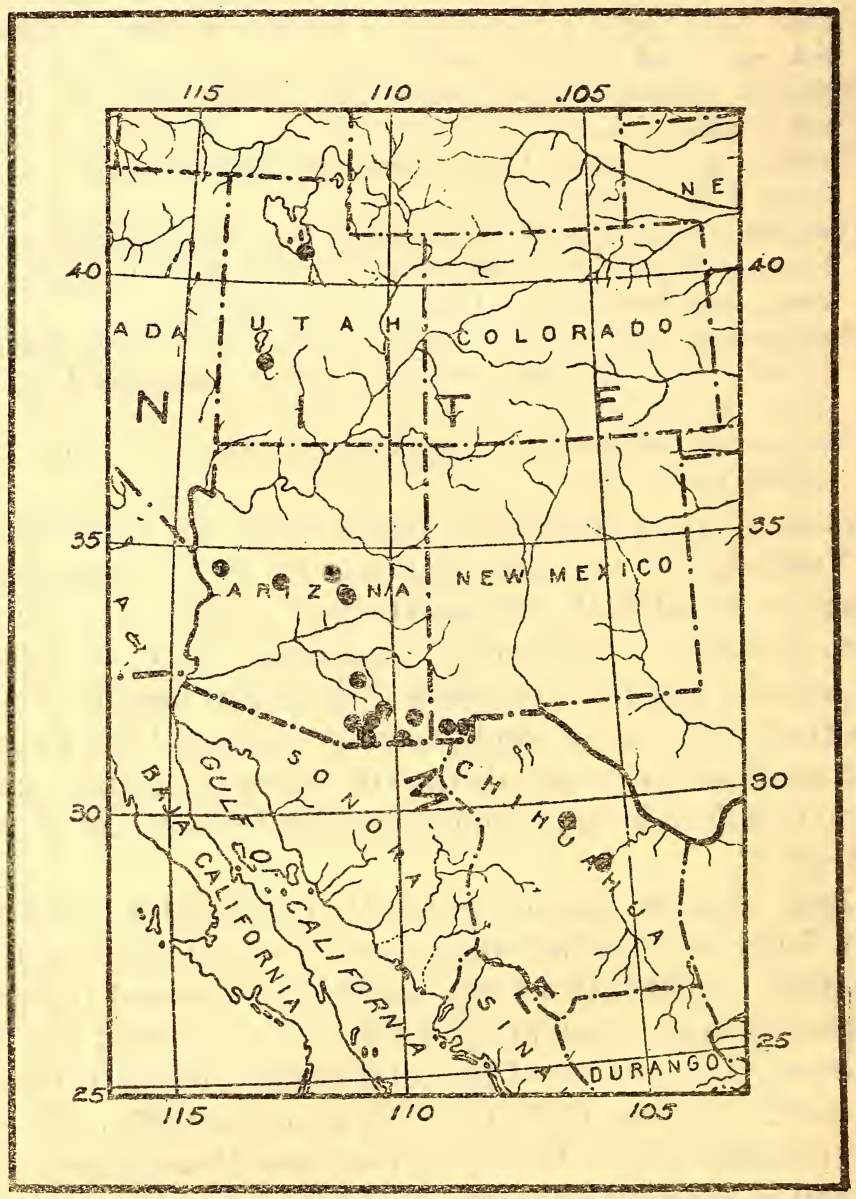

Fig. 62.-MAP SIIOWING LOCALITY RECORDS FOR LAMPROPELTIS PYRRHOMELAENA.

the parietals, widening anteriorly on the sides; behind this is a black band, which narrows on the sides and is rarely, if ever, complete on the throat.

The dentition is as follows: Maxillary teeth, 13 to 20, commonly 14 to 16 , somewhat longer anteriorly, the last two a little stouter and more flattened laterally; mandibular teeth, 14 to 18 , second to sixth largest, becoming much smaller posteriorly; palatine teeth, 11, less 
often 12 or 13 , rarely 14 , becoming slightly smaller posteriorly; pterygoids, 16 to 22 , smaller than the palatines, likewise diminishing in size posteriorly.

The penial characters are approximately as follows: Organ small and slender in comparison with size of animal; calyces few, with fringes few and short; latter succeeded by slender spines, which increase in size only slightly; about halfway from the base the latter decrease rapidly in size and disappear entirely, or remain over most of basal portion of organ as minute spines more or less imbedded.

This form may be distinguished from gentilis, multicincta, and annulata by the prominently whitish snout, the greater number of ventrals and caudals, the more numerous annuli, the head distinct from the neck, and the frequent occurrence of 10 infralabials. All but the first two of these points will serve to distinguish it from nelsoni.

Habitat and habits.-From a few brief notes accompanying specimens and from the localities it seems that this snake prefers the canyons and mountains, and is not found at all in the deserts. Van Denburgh and Slevin $(1913,415)$ record three specimens from pine woods in Bear Canyon in the Catalina Mountains, in Ramsey Canyon, Huachuca Mountains, and Oak Creek Canyon in Coconimo County, Arizona. One from the Hualapai Mountains was also taken in a pine forest.

Range.-Pyrrinomelaena is known to occur from the Great Salt Lake south through Utah, Arizona, and western New Mexico to Sonora and Chihuahua. Careful collecting may be expected to extend its range in all directions. The vertical range of this form is comparable, so far as we now know, only with that of mulicincta. The following altitudes are recorded with specimens: 7,000 feet-Bear Canyon on Mount Lemon in the Catalina Mountains, Arizona, and Beaver Canyon, Beaver County, Utah; 6,300 and 5,800 feetHualapai Mountains; 5,410 feet-Carr's Ranch, Sierra Ancha, Gila County, Arizona.

No records have been noted for localities not included in the list of specimens examined.

Variation and affinities.-The present material indicates that this form is remarkably constant throughout its range, but a fuller series of specimens may be expected to reveal geographic difierences that can not now be detected. 
'The distribution of the scale formulae between the sexes is of interest. It is as follows:

\begin{tabular}{|c|c|c|c|}
\hline Formula. & Male. & Female. & Toial. \\
\cline { 1 - 3 } $23-25-23-21-19$ & 2 & 3 & \\
$23-21-19$ & 7 & 3 & 10 \\
$21-23-21-19$ & 4 & 3 & 7 \\
$23-21-19-17$ & 5 & 1 & 6 \\
$21-23-21-19-17$ & 2 & 0 & 2 \\
\hline Totals.......... & 20 & 10 & 30 \\
\hline
\end{tabular}

Only 1 female out of 10 ends with 17 rows. A striking feature in which this form resembles muliicincta and in which both apparently differ from all other forms in the genus is the possession by many of the same individuals of a maximum of 23 rows and a minimum of 17. Three changes from the middle to the posterior end of the body is common when the maximum is 25 rows, but is elsewhere very rare when the maximum is 23 , and is quite unknown when the maximum is 21 or 19 . In this feature there is certainly support to the proposition that pyrrhomelaena and multicincta are more closely related to each other than to any other form of the genus. In other respects, however, the gap between the two seems to be rather wide. Pyrrhomelaena is in every way a more specialized form. Its scale rows average higher-the maximum in no individual yet examined being lower than 23; there are more ventrals; the tail is the longest in the genus; the lower labials are commonly 10, the upper labials are oftener 8 than in any other form in the genus; the head compares in shape and in distinctness from the neck only with alterna; the dentition is the highest for the genus.

All these features proclaim this form an old and specialized derivative of some more normal representative of the genus. While we do not say that it can not have been derived from multicincta, it is nevertheless difficult to conceive of such great structural differentiation where the geographical separation is so little and where the habitat preferences of the two seem to be so similar. It is not impossible that the relationships of multicincta and gentilis may yet prove to be so close as to exclude the former from the possibility of direct relationship with pyrrhomelaena. More material from the Great Basin region is the first essential. We would therefore prefer at present to regard pyrrhomelaena as a relatively ancient and isolated type, because of (1) its high specialization, (2) its great constancy throughout its wide range, and (3) the lack of any form with which it may safely be considered as closely related. 
REVISION OF THE KING SNAKEG.

\begin{tabular}{|c|c|c|c|c|c|}
\hline 这 & 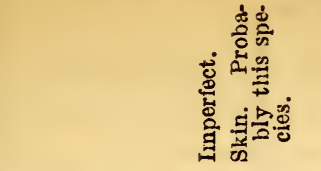 & & 吾 & & \\
\hline 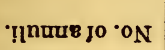 & 太年年故 $\vdots \vdots \vdots$ & పే & $: 8$ & 궁 & F F 육 \\
\hline 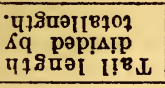 & 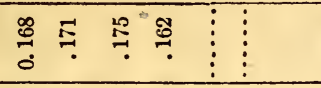 & 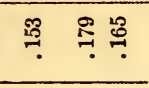 & 를 & $\stackrel{0}{\because} \stackrel{0}{\bullet}$ & $\stackrel{\infty}{\rightarrow} \stackrel{0}{?}$ \\
\hline 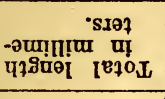 & 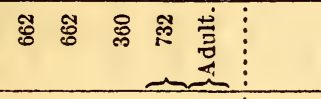 & 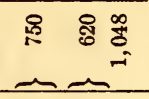 & : & 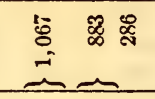 & ๙ \\
\hline 's[в.oduəa & 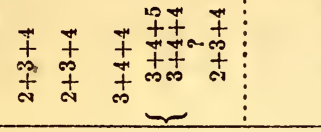 & 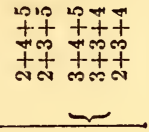 & $\begin{array}{l}\vec{t} \\
m \\
+ \\
+\end{array}$ & 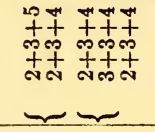 & 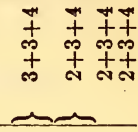 \\
\hline -sIBIño & 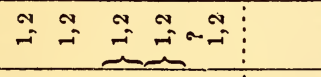 & $\approx N \cong$ & $\stackrel{9}{=}$ & $\stackrel{\sim}{\approx} \cong$ & ๓⿴囗十 \\
\hline 's]в!̣ & I o ogomas! & $\underbrace{\infty 9} 0$ & & $\stackrel{\Omega}{=}=$ & 궈요 옹요 \\
\hline 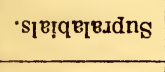 & $+N+\underbrace{-a r}$ & 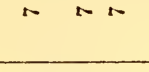 & s & $\underbrace{\infty+N}$ & $\infty \sim \infty \infty$ \\
\hline •sโยpne⿻ & 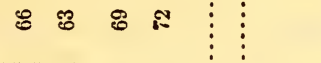 & 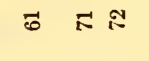 & ส & : $心 \mathbb{E}$ & แี \\
\hline$\cdot$ s[หr] $^{\prime}$ & สี สู สู่ สี & สี๋ สึ สู & ส్้ ส్టి & ลิ ลี สิ & 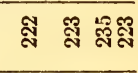 \\
\hline 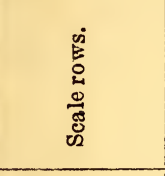 & 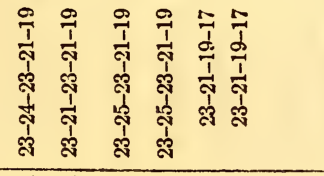 & 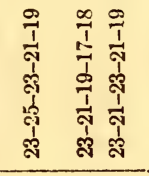 & 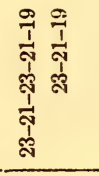 & 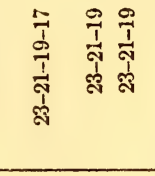 & 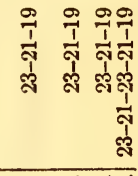 \\
\hline 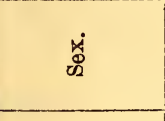 & 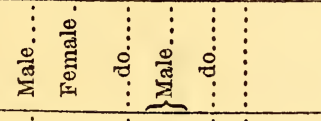 & 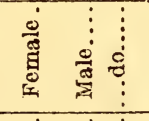 & 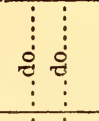 & \begin{tabular}{rrr}
$\vdots$ & $\vdots$ & $\vdots$ \\
$\vdots$ & $\vdots$ & $\vdots$ \\
\hdashline & 0 & 0 \\
$\vdots$ & $\vdots$ & $\vdots$ \\
\end{tabular} & 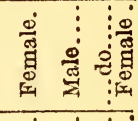 \\
\hline 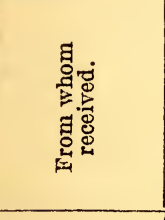 & 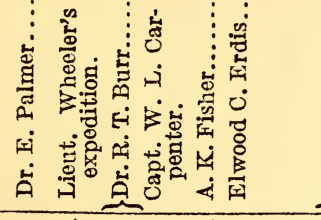 & 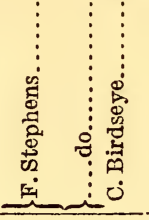 & $\begin{array}{c}\vdots \\
\vdots \\
\vdots \\
\vdots \\
\vdots \\
\vdots \\
\vdots \\
\vdots \\
\vdots \\
\end{array}$ & $\begin{array}{cc}\vdots & \vdots \\
\vdots & \vdots \\
\vdots & \vdots \\
\vdots & \vdots \\
\vdots & \vdots \\
\vdots & \vdots\end{array}$ & 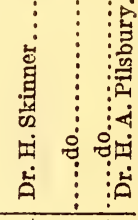 \\
\hline 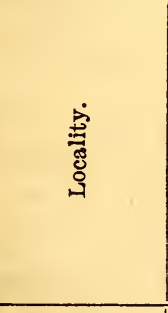 & 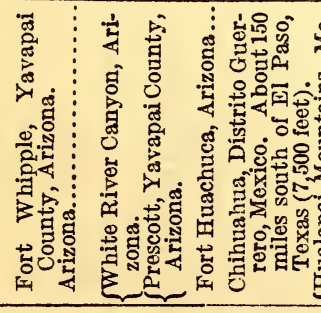 & 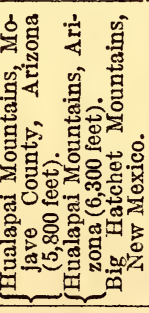 & 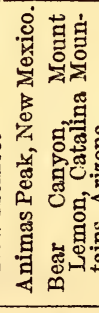 & 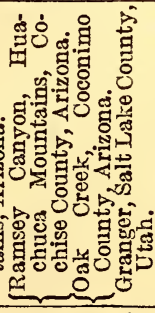 & 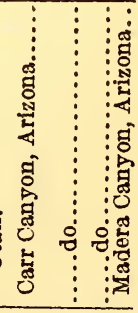 \\
\hline 安 & 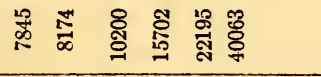 & 覀蒂 & 总落 & 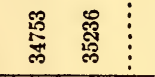 & 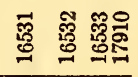 \\
\hline 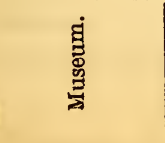 & 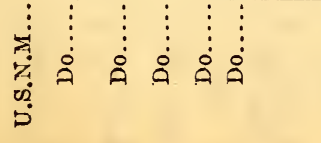 & $\begin{array}{c}\vdots \\
\vdots \\
\vdots \\
\AA\end{array}$ & 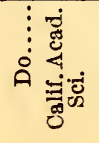 & $\begin{array}{ccc}\vdots & \vdots & \vdots \\
\vdots & \vdots & \vdots \\
\AA & \AA & \AA\end{array}$ & 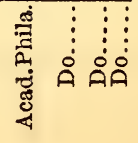 \\
\hline
\end{tabular}




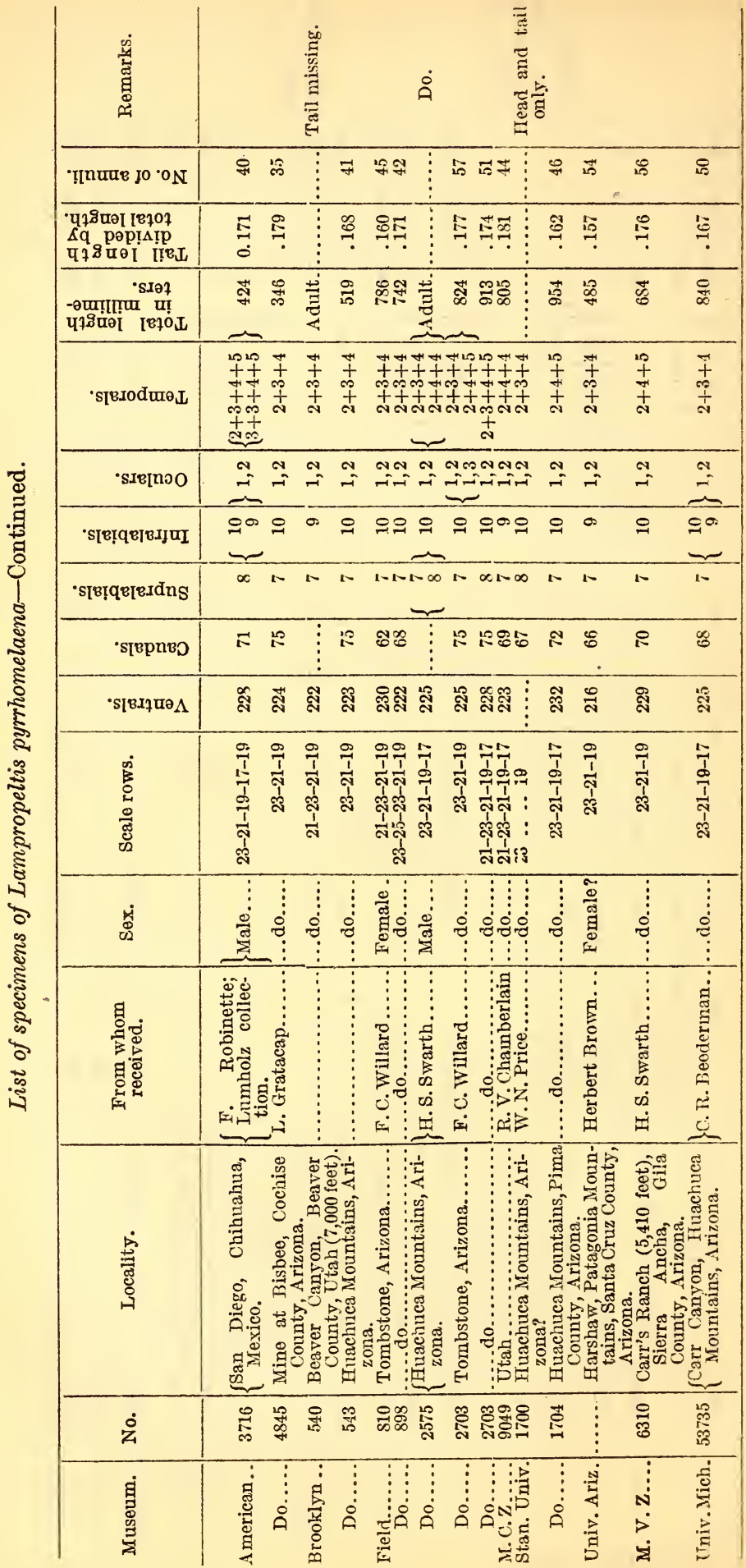


SUMMARY.

Included in this group, on the basis of intergradation along the common boundaries of their ranges, are, nelsoni, annulata, gentilis, amaura, syspila, and triangulum; by reason of close similarity with the first two, polyzona and micropholis; elapsoides and virginiana on account of close resemblance to amaura; because of apparently closer relationship to this than to any other group in the genus, ruthveni, multicincta, and pyrrhomelaena.

As already shown, micropholis can be derived only from polyzona. The most evident reasons for this are (1) it is closely allied to this form and to this one only; (2) it is decidedly isolated geographically from all other forms of the genus; (3) it is inadmissable as a primitive type on account of specialization in important structural and color pattern characters, particularly $(a)$ in reduction of anterior temporals to one, $(b)$ in the frequency of entire caudal plates, and (c) in the white rings of the pattern being much widened and suffused with red. Polyzona must be regarded as closely allied to annulata and particularly, perhaps, to nelsoni, but its exact relationship is uncertain, due to insufficient material.

- The evolution of elapsoides from amaura has already been explained under the discussion of the former, and we need not do more here than repeat our belief that it represents an earlier and less extensive migration than that which gave rise to the subspecies of triangulum; that it underwent differentiation and specialization through an isolation which may have been affected by a not very extensive embayment of the Gulf of Mexico up the lower Mississippi Valley. Its close ally, virginiana, was differentiated from elapsoides by a joining of the adjacent black rings on the belly across the red spaces, and their lateral migration, thus restricting the red to wide dorsal saddles. This, as will be shown below, is almost exactly the same method as that by which syspila was derived from amaura.

If now we consider the subspecies of triangulum, we find that the structural differences, separating any two adjacent forms are only average and so quite insufficient to distinguish them, and even extreme forms are but moderately distinct in structure. The differences are thus too slight to be a main reliance in determining the center of origin of the series. This structural similarity is, however, of much value in assuring us of the close genetic relationships existing between all these forms, and, if we are able by other means to determine direction of relationship, structural tendencies will then be of value in either strengthening or weakening those conclusions.

Aside from the geographic demands which must be met, our main reliance must be upon color pattern. This, as well as the scutellation, demonstrates the close relationship of the whole series and in par- 
ticular of any two adjacent forms, but, as the differences registered in the pattern are more evident and more distinctive than any others, these have been made the main basis of distinction between different forms. However, near the boundaries between any two ranges

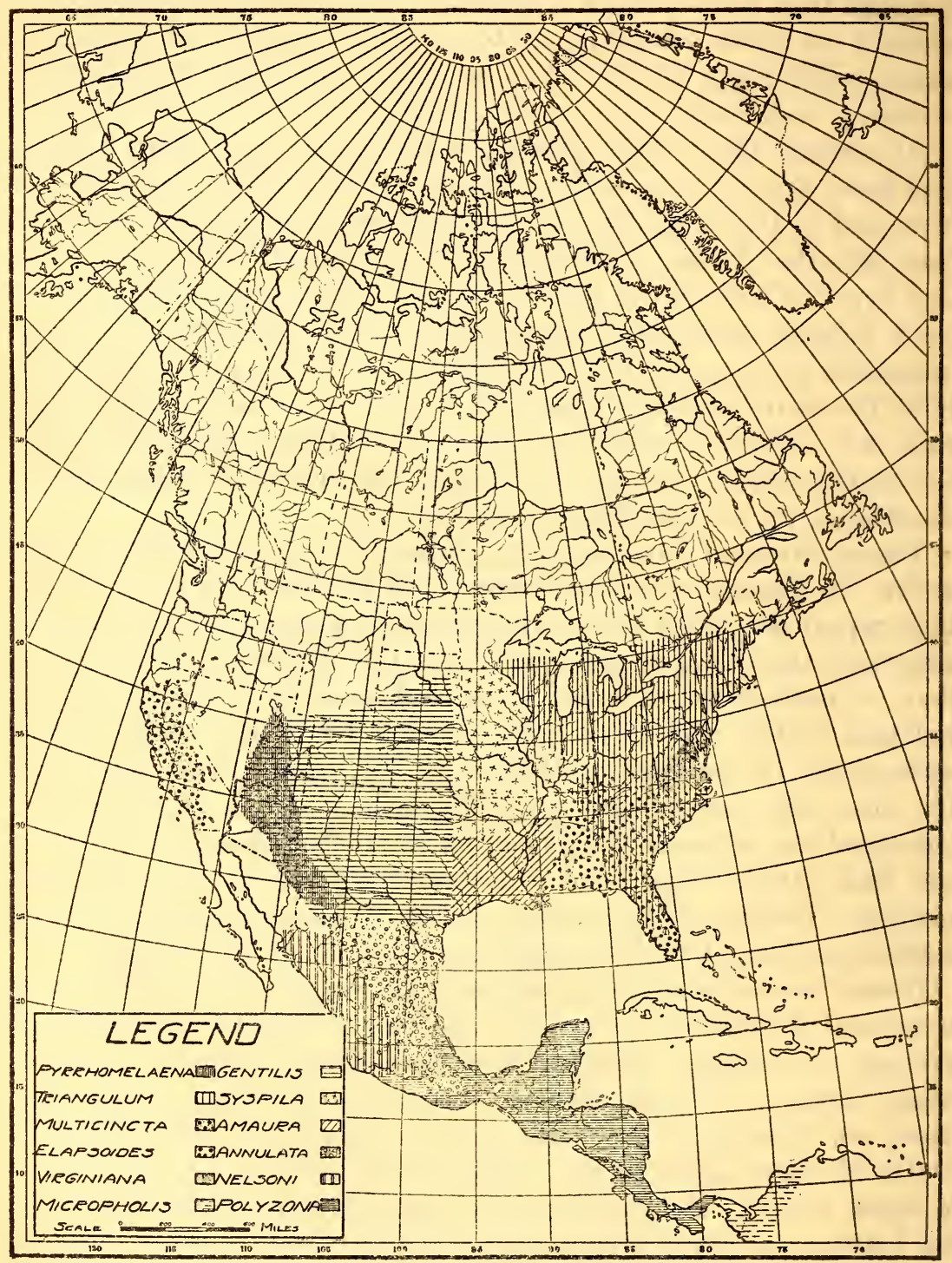

FIG. 63.-MAP SHOWING DISTRIBUTION OF THE VARIOUS FORMS OF THE TRIANGULUM GROUP.

even these distinctions break down and we find individuals which can not be definitely assigned to either form. This completes the proof furnished by the structural features of the close relationship existing between all these forms. 
The races of triangulum form a continuous chain from southern Mexico to southeastern Canada. Some form in the series must be closer to the ancestral type than all the others. Let us consider the northern end of this chain.

If we start with typical triangulum, as it occurs in western New York, and examine a series of representative specimens from localities between here and Central Florida, we will notice a very gradual change in pattern in Pennsylvania, West Virginia, and southward; the half collar behind the neck very frequently replaces the chevron mark; the latter, when present, is more imperfectly shaped than in the north, and the other characteristic head markings are often very badly formed. Throughout this wide extent of latitude we will find no distinctive change in triangulum and no closely allied form-nothing closer than elapsoides, getulus, and rhombomaculata. If we now examine a representative series of specimens from northern Indiana and Illinois southward into Louisiana, we will find a very different situation. In southern Illinois and southern Indiana triangulum intergrades perfectly with syspila. The latter is spotted like triangulum but the spots are typically longer, wider and fewer; normally they are red, but occasional examples have them brown or gray as in triangulum. The head pattern of the latter (fig. 54) rarely appears in full in syspila (fig. 52) but portions of it are usually present, as, for instance, the anterior black border of the half collar behind the neck is sometimes indented, indicating the position of the arms of the chevron mark of triangulum; the half collar may be more or less interrupted by the approximations of its black borders on one or both sides of the median line; light superciliary spots with black borders are often present over the eyes, and these are sometimes joined, as in triangulum; the light postocular band is often represented by lateral indentations of the anterior black border of the half collar and sometimes it is present in entirety. As we go south and west from southern Illinois the frequency and perfection of these markings decreases. To one who has examined considerable numbers of these specimens the geographic change is most striking. Typical triangulum (figs. 54 and 69) occurs about as far south as Vigo County, Indiana; at this point there is a relatively rapid change through intergrades to syspila (figs. 52 and 68); then south into Arkansas we find a gradual, progressive change which leads directly into amaura (fig. 67), in the southern part of the state. That syspila. is the only close relative of triangulum, and that the former passes by perfect intergradation into amaura, can not be denied. One of these forms must then be ancestral to the others.

It has been said that the color pattern of triangulum must be rcgarded as primitive, because its distinctive features are repeated in other forms in widely separated groups, as, for instance, the calli- 
gaster group of the present genus, the genus Elaphe, in particular, and numerous other genera. This, however, is an assumption that must be proved. Simplicity and specialization in color pattern can not be decided on a priori grounds. It is not safe to say that because a certain type of pattern is primitive or specialized in one or several genera that it is so in any given case. Close examination may bring out reasons why the rule does not hold in a particular instance. Thus we have a spotted pattern in Drymobius margaritiferus and in the three forms of the getulus group, floridana, holbrooki, and splendida. In Drymobius there is good reason for considering this pattern specialized, namely, as belonging to an end form. As these are all closely allied and all different, they are probably not all specialized, or, if so, some are less specialized than others. In the case of floridana geographic probabilities alone are enough to place its pattern as recent, and as derived from something else, even if we failed to note that it still bears the vestiges of an earlier pattern; and careful study of geographic probabilities and structural and pattern differences have shown that the pattern of holbrooki is a derivative of that of splendida, and that the pattern of the latter is the only one from which all the others in the group may be derived. Thus we would have been in error had we said in the first place that because the pattern of splendida looked similar to that of Drymobius that it was specialized and not a suitable starting point for the derivation of other patterns. A type of pattern therefore that is specialized in one form may prove, for reasons quite evident upon examination and comparison, to be primitive in another.

In the case of triangulum there are numerous real difficulties in the way of considering this form as primitive. It should be noticed that (1) the pattern is best and most perfectly developed only in a region that can not have been a center of preservation of reptilian life, the glaciated portion of the northeast; (2) in the southeast, from West Virginia and Maryland to Florida, it is erratic and not typical; (3) it is much less stable and widespread than the ringed type of pattern, and in the central Atlantic States it is undergoing degeneration in company with structural reduction; (4) no other form of the triangulum group presents any approach to this pattern except syspita, the nearest relative of triangulum; (5) if triangulum be considered the stem form of the group the explanation of elapsoides becomes exceedingly difficult. It is well known that the pattern and color of some snakes change during development from young to adult, and the young stages in some cases are supposed to indicate ancestral conditions. This is the case with the racer, Coluber constrictor, which changes from a spotted to a plain black or bluish snake during growth from young to adult. In the young of conjuncta the body pattern can not be told from that of boytii, but that of the 
adult is quite distinct. Conjuncta is in all probability a derivative of boylii. A similar situation probably holds with respect to hol. brooki, and probably also with several other forms of this genusThe probability is therefore strong that the fact that the young of triangulum have red instead of brown blotches indicates that the ancestor of triangulum was a red instead of brown spotted snake. (6) If we have any regard for the evidence derived from the getulus and calligaster groups that marked reduction in structural features is evidence of specialization, we can not ignore the fact that triangulum is the most reduced form in this whole series. This reduction is expressed particularly in the great frequency of the scale formulae 21-19-17 and 19-21-19-17 and the large number of specimens that possess a temporal formula lower than $2+3+4$, i. e., $2+3+3,2+2+3$, $1+2+3$.

If we accept these reasons for not regarding triangulum as ancestral we are led next to syspita. But this form does not possess the pattern that was alleged to be primitive in triangulum. In scale rows and temporals it shows the same degenerative tendencies that are more strongly expressed in triangulum. In fact, there appear to be no good reasons for considering syspila as primitive. This leads us directly to amaura. This form is restricted to the lower Mississippi Valley - a region geologically new and therefore totally unsuited to be a center of origin of a group of animals. Gentilis could scarcely be regarded as an ancestral type as its color pattern is very evidently a derived one, it is a reduced form in number of ventrals, and it inhabits a region entirely unsuited for preservation of old types. The only other possibilities are the Mexican forms nelsoni and annulata, and for present purposes it is immaterial which of these may be the oldest. Nelsoni is less likely to be primitive because it inhabits chiefly the coastal area, and it presents a derived appearance in the extreme width of the red interspaces. There are for annulata, however, several positive reasons for regarding it as the ancestral type of the triangulum series. (1) In structural features it presents the closest approach to the primitive types of the other large groups: The loreal is oblong with no peculiarity in shape; the scales rows are 23 or 21 (no specimens drop to 17 at the end); the temporals are $2+3+4$; the labials are 7 and 9 ; the chin shields are normal; the proportions of head, body, and tail are average; the ventral plates average but slightly less than for splendida, (2) It occupies a geographically favorable region, the Mexican plateau. (3) It is in a region inhabited by the ancestors of the getulus and calligaster groups. (4) It is in a region shown to have been the center of dispersal for another widespread and recent group of North American snakes, the garter snakes. (5) The color pattern of all the forms of triangulum may be most simply derived from that 
of annulata. (6) Still more important is the fact that annulata lies at the point of convergence of three separate genetic series of the triangulum group: The triangulum-syspila-amaura-annulata series, the virginianaelapsoides-amaura-annulata series, and the gentilis-annulata series. This situation fulfills therefore the most convincing of the criteria formulated by Adams $(1902,122)$ for determination of centers of dispersal, namely, "continuity and convergence of lines of dispersal."

If we accept annulata as the stem form of the triangulum series we may describe the derivation of the color patterns as follows: From the plateau region of southern Mexico north to extreme southern Texas we have a form, annulata (fig. 66), ringed with black and white or yellow, the black more or less split with red dorsally but continuous between the white rings on the belly, except at the extreme anterior end of the body, where the red may cross the belly. The white rings are nearly uniform in width on the dorsal scales and only slightly, if any, widened on the ventrals; they are not encroached upon by the black, but may be more or less mottled with black, particularly on the sides. Figure 66 shows this pattern as exhibited by a typical specimen from Puebla, Mexico. Passing to amaura (fig. 67), we see that the white rings have become distinctly widened on the lower rows of scales, that the black on the belly has become separated on the midventral line, and that the red has increased in extent at the expense of the black. The black has here ceased to encircle the body, and has become restricted to a border for wide dorsal saddles of red. Figure 68 is a typical example of syspila from Arkansas. This pattern is derived from the last by a lateral contraction of the dorsal red saddles, a narrowing of the black borders, the development of a ventro-lateral series of black spots in alternation with the dorsal blotches, a checking of the belly with small quadrate spots of black, and an increase in the mottling of the white dorsal scales (no mottling was shown on the white scales of figure 67 because the specimen was much faded). The alternating spots and perhaps some of the small quadrate spots may be the result of a pinching off, as suggested by figures 67 and 68 . Figure 69 shows the pattern of a typical triangulum from northern Michigan. Whether the upper series of alternating spots is the result of an upward migration of the first series (fig. 69) is uncertain, but it appears much more likely that it is due to a pinching off of segments of the dorsal blotches in the course of their contraction. This is the end of the series in this direction.

To derive gentilis we must return to annulata. The course of evolution has here been different. Instead of a lateral shrinking of the black and red, there has been a longitudinal shrinking. The beginning was the same as for the other series. The white rings widened on the lower rows of scales and on the ventrals, thus greatly increasing the width of the white rings in proportion to the black on the belly. 



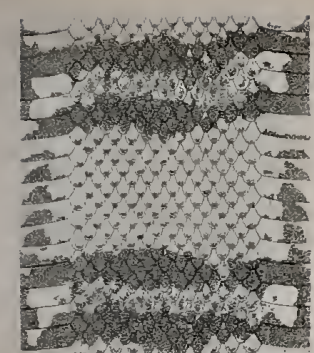

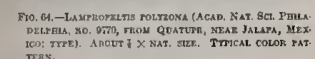

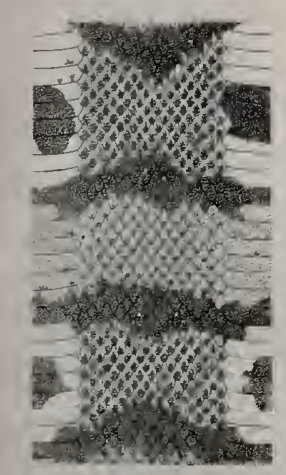

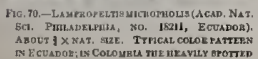

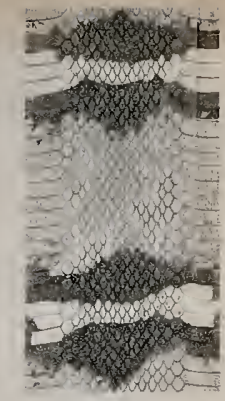

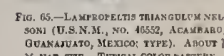

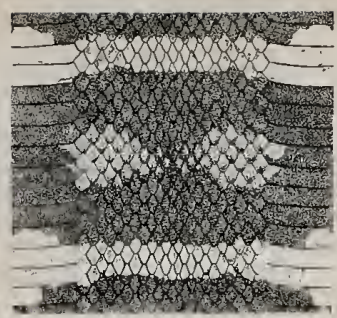

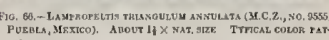
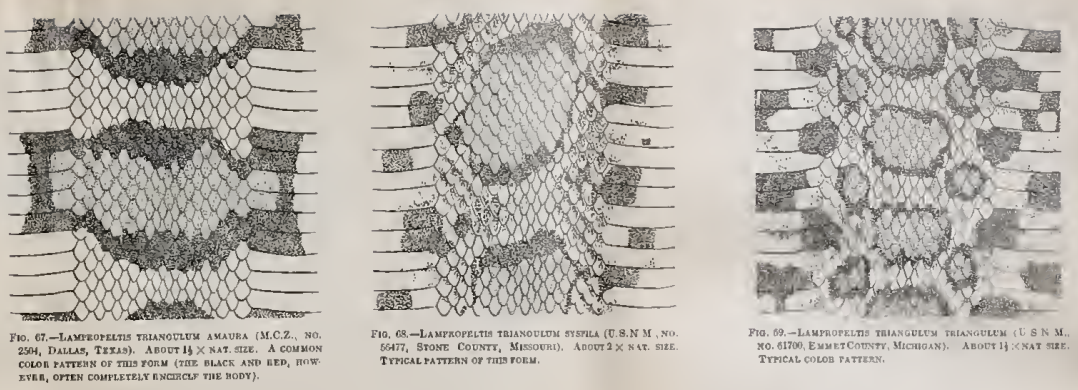

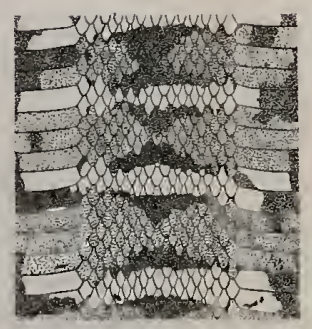

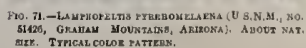

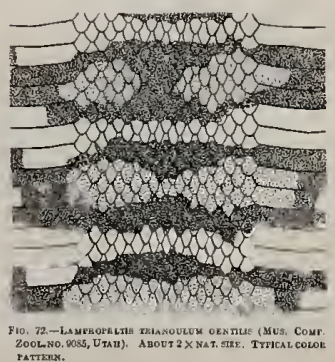

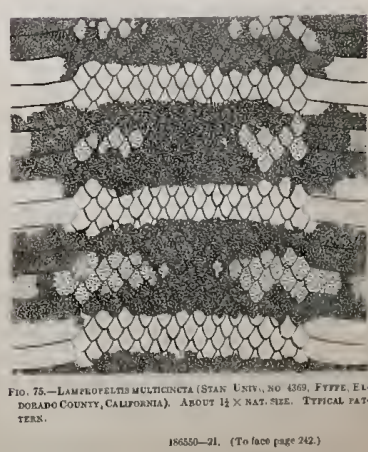



Here the black failed to split on the midline, or, if it did split, it failed to recede. The red failed to increase in area at the expense of the black, so that in this form the black is usually wider on the middorsal line than on the lower rows of scales and often excludes the red entirely from here, as shown in figure 72 (a specimen from Provo, Utah). Mottling of the white rings is variable in gentitis, but usually present to some degree at least.

Examination of the available material indicates that the split in these two courses of evolution is not a clearly defined one, but that the tendency to develop the pattern shown in figure 68 is gradually intensified to the east. A fairly well-marked division is, however, noticeable in the region of the ninety-seventh meridian. Here there is a distinction in head pattern as well as in body pattern. 'To the east the head is mostly red, and alternating spots are developed on the lower rows of scales; to the west these are not developed and the head is mostly black. The situation would be met if the ancestral form spread from northeastern Mexico at the same time northeast, north, and northwest.

The relationships of pyrrhomelaena and multicincta to each other and to the other forms of the genus are still in doubt. There is little if anything in the penial characters to ally them closely with the getulus group. It is true that the calyces are but few and slightly fringed, but the spines are much more numerous and more slender, and extend more than half way to the base of the organ, as is characteristic of the triangulum series. Multicincta was described by Yarrow as a subspecies of geiulus and more recently has been regarded by Stejneger and others as a subspecies of pyrrhomelaena.

Cope confused it with both of these forms. It can hardly be a close ally of boylii, since their ranges overlap and their structural differences are too great, particularly in respect to scale rows, penial characters, and color pattern. Its relation to gentilis may be closer than has been supposed. Typical patterns of gentilis and multicincta (figs. 72 and 75) show that the white rings in gentilis are but little widened in the most western specimens, perhaps an approach to multicincta in which they are practically uniform in diameter; and it is noticeable that in the latter form, as in gentilis, the black on the belly is mostly concentrated opposite the dorsal red areas. The color pattern of multicincta could without violence be regarded as an intensification of that of gentilis; that is, the black has still further encroached on the red and has completely excluded the latter color from the snout. The scutellation would be considered as a wide, but perhaps not impossible, step. Thorough collecting in Nevada, eastern California, and Arizona should be of much assistance in deciding this matter. Scale rows and ventrals average at least as high as may be expected for annulata in the plateau portion of its range, and higher 
than for any of the subspocies of triangulum, except nelsoni, of the west coast of Mexico. In proportions, dentition, and scalation it is so close to the average for the genus that it is difficult to conceive of it as much specialized or as a derivative of pyrrhomelaena. In fact, for regarding it as a subspecies of the latter there is no evidence. We do not know whether their ranges meet, but the specimens on hand show no approach of one form to the other in pattern or scalation. It is even possible that multicincta may be only distantly related to pyrrinomelaena. Its color pattern is similar, to be sure, and their ranges are practically adjacent, but if pyrrhomelaena did not exist we would probably not be unwilling to regard multicincta as the west coast representative of the subspecies of triangulum. The discovery of the Patzcuaro specimen, indicating, as it does, the occurrence in southern Mexico of a close relative of multicincta, puts a new face on the situation. Nothing definite can be said, however, until more specimens of the new form, ruthveni, shall have been found.

Pyrrhomelaena gives much evidence of specialization in (1) its high number of labials, (2) its atypical pattern, (3) long tail, (4) high dentition, and (5) wide head. If we examine its color pattern (fig. 71) we notice that while there is the same marked tendency for the black to overspread the red dorsally, the former narrows decidedly on the sides and often fails to reach the ventrals-a decided difference from gentilis and multicincta; and the black of the belly, contrary to the situation in the latter two forms, is concentrated chiefly opposite the dorsal white rings, and it is the red that most regularly crosses the belly. It is difficult to say how important this distinction may be. The prominent specializations in structural features indicate old age in the form and show that there may have been time for the pattern to develop these peculiarities starting from the annulata condition. The suspicion can not be avoided, however, that the present similarity in the patterns of multicincta and pyrrhomelaena are due to convergent evolution.

It is noticeable that multicincta is less removed structurally from the average of the genus than pyrrhomelaena, as it is less removed in style of color pattern from gentilis and annulata.

On the whole it would seem best to place these two forms with the triangulum group on the basis of similarity in general style of color pattern-that is, rings of red, yellow, and black-and to regard pyrrhomelaena tentatively as an isolated form, at least as old as elapsoides, and multicincta as the isolated representative on the Pacific coast of the rest of the triangulum group.

The preceding discussion may be summarized as follows:

1. Micropholis must be regarded as a specialized derivative of polyzona; the relationship of the latter to nelsoni and annulata is close but not clear. 
2. Elapsoides is a derivative of amaura, or of the form that represented it in the Texas region before the appearance of syspila and triangulum. In the northeastern portion of its range it has given rise to the color pattern variety, virginiana.

3. The subspecies of triangulum may all be traced to a center of dispersal in the plateau region of Mexico.

4. The relationships of pyrrhomelaena and multicincta are doubtful, but there seems to be the least difficulty in regarding pyrrhomelaena

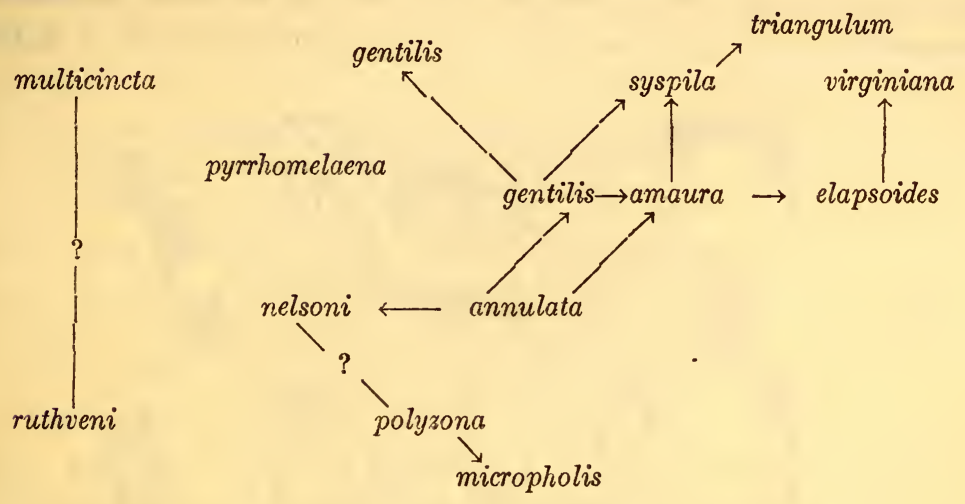

Fig. 76.-A Diagramatic Presentation of the Relationships of the Forms of the Triangulum GROUP.

as a specialized and isolated form, much older than the subspecies of triangulum, and multicincta as the west coast representative of the rest of the triangulum group.

ISOLATED FORMS.

\section{LANPROPELTIS MEXICANA (Garman).}

Fig. 77.

1883. Ophibolus triangulus, var. mexicanus Garman, S., Mem. Mus. Comp. Zool., vol. 7 , no. 3, p. 66 (type locality, Mexico, near San Luis Potosi; cotypes, probably numbers 4652 and 4653 of the collection of the Museum of Comparative Zoology at Cambridge, Massachusetts).

1902. Coronella mexicana GüNther, Biol. Cent.-Amer., p. 110.

No type was designated in the original description of mexicaria, and no specimens were listed. The description shows, however, that there were at least two specimens, and it fits remarkably well for two from that locality in the collection of the Museum of Comparative Zoology. The scales of both are in 23 rows; the ventral plates are exactly 193 and 199, as in the original description; the head is "much swollen at the temples;" and the pattern and coloration answer well. According to the description, the caudals are 56-58 pairs, and the dorsal blotches are 38-40; these specimens seem to have 55 pairs each of caudals, and about 39 blotches each. These differences when compared with the coincidences are too 
slight to render it improbable that these are the specimens from which the original description of mexicana was prepared, and their numbers have therefore been given above as the cotypes of this form.

Description.-Since the original description is somewhat incomplete, the following is offered in its stead: Ventrals, 193 and 199; caudals, 55, in two rows (both specimens females); supralabials, 7 ; infralabials 10 , fifth largest, 5 under the last 3 upper labials; preocular single except that it is divided in number 4652 on the left side; postoculars, 2 ; temporals, 2 in the first row, 3 in the second, and 4 or 5 in the

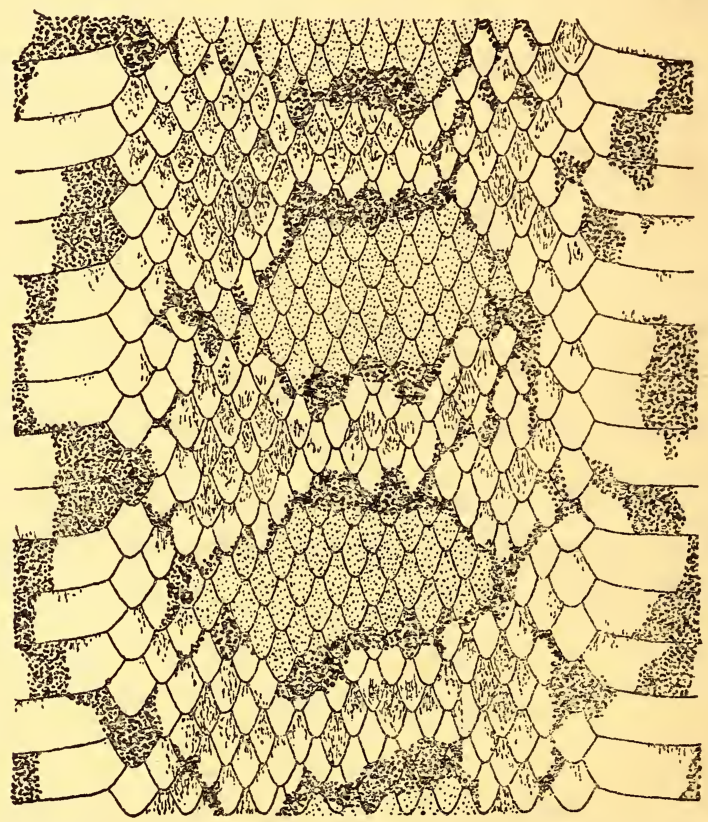

Fig. 77.-LAMPROPELTIS MEXICANA (M.C.Z., SCALE PATTERN FROM NO. 4653, COLOR PATTERN FROM NO. 652, San Luis Potosi, Mexico). ABout $1 \frac{1}{4} \times$ Nat. Size. Showng Color Patteri.

third; posterior chin shields shorter than the anterior, and separated from each other by 2 small scales; loreal about twice as long as high; anal plate entire; scales smooth, with 2 apical pits; dorsal scale rows, 23-21-19.

Body moderately slender, tapering slightly toward the tail; belly flat, meeting the sides in a rather distinct angle; head flat, distinct from the neck, swollen at the temples, tapering anteriorly, snout truncate; tail, 0.16 to 0.17 of the total length; eye large, its diameter nearly twice the height of the third upper labials. One of the specimens measures 803 millimeters, the other 452 .

The pattern of the body (fig. 77) recalls that of triangulum. There are about 39 transversely oblong red blotches on head and tail 
bordered with black, and separated by narrower grayish mottled spaces. The red blotches are about 2 to $3 \frac{1}{2}$ scales long, and they maintain this length through a width of about 8 scales across the back, then narrowing, they extend down on the sides to about the second or third row of scales. These downward extensions are sometimes nearly or quite isolated from the dorsal blotches. The black borders are $\frac{1}{2}$ to 1 scale in width dorsally, becoming narrower on the sides. The spaces between the blotches are whitish, and strongly but minutely mottled with dark, except close to the black borders. The belly is heavily blotched with black; the tendency is for narrow transverse bands to cross the belly and end on the first row of scales in alternation with the dorsal blotches, but these are often broken in the middle and obscured by large black patches between them and opposite to the dorsal blotches. On the head of the small specimen are two red V-shaped marks black-bordered, opening forward, the larger chiefly on the parietals, the smaller chiefly on the frontal. Behind the eye is a large black blotch. Rest of head, chin, and throat whitish, minutely mottled with darker.

The dentition is as follows: Maxillary teeth, 13, the last two enlarged, not grooved nor separated from the rest by an interspace; mandibular teeth, 14 in one specimen (number 4652) and 16 and 17 in the other, the third, fourth, and fifth large, the last small; palatines, 13 in each instance; pterygoids, 22 (only one set counted).

Remarks.-If, as is entirely probable, the two specimens described above are the originals, then they are the only specimens of the form known. That they belong to the genus Lampropeltis as at present defined, must be conceded. They can not, however, be closely related to any other form in the genus; the head pattern is unique, and, although the body pattern bears a superficial resemblance to triangulum and to the members of the calligaster group, it yet bears a distinct stamp of originality; the 10 lower labials, long tail, swollen temples, and high number of palatine teeth are all features that mark it as specialized. It is doubtless more closely allied to the triangulum group than to either of the other two.

\section{LAMPROPELTIS ALTERNA (Brown).}

Fig. 78.

1902. Ophibolus alternus Brown, Proc. Acad. Nat. Sci. Philadelphia for 1901 (Feb. 6, 1902), p. 612, pl. 34 (type locality, Davis Mountains, Jeff Davis County, Texas; type specimen, number 14977, Acad. Nat. Sci., Philadelphia, E. Meyenberg, collector); same, 1903, p. 550.-Ditmars, Reptile Book, 1907, p. 356.-STrecker, Baylor Bull., vol. 18, no. 4, 1915 , p. 39.-Lampropeltis alterna Stejneger and BArbour, Check List, 1917, p. 87.

This name rests upon a single specimen, received alive at the Zoological Gardens in Philadelphia, and said to have been found in 
the Davis Mountains, Texas. It answers so closely in structural features to the genus Lampropeltis that, in spite of its unique type of pattern, and lesser structural peculiarities, it must be included here until further specimens make possible a determination of its true status.

Description.-Since the original description is very accurate it is quoted in entirety:

Maxillary teeth 13; mandibular 14-15. Body moderately slender; head distinct, muzzle contracted; eye rather large. Rostral low and broad, barely visible from

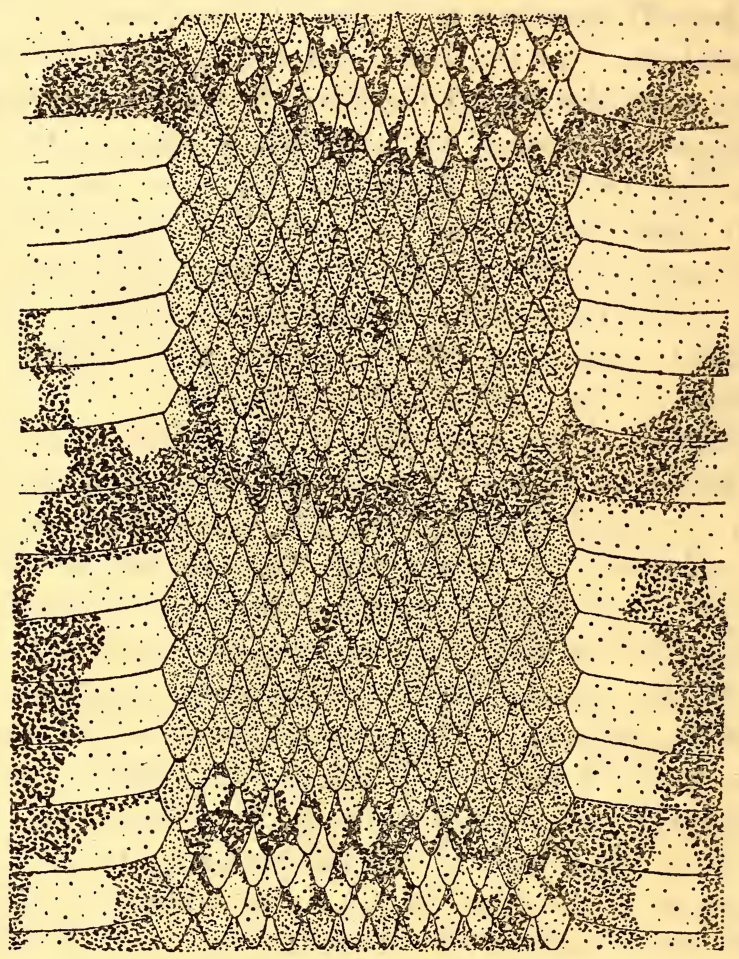

Fig. 78.-Lampropeltis alterna (A Cad. Nat. Sci., Philadelphia, no. 14977, type, Davis Mounta in s, TEXAS). $2 \times$ NAT. Size. ShOWING STYLE OF COLOR PATTERN.

above; internasals about half the length of prefrontals; frontal a little longer than the suture between parietals, longer than the snout; parietals large, wide in front, narrow behind; nasals 2 , the nostril between them; loreal small, longer than high; preocular 1; postoculars, 2 on one side, 3 on the other; temporals, $2+3$ on one side, $3+4$ on the other; upper labials 7 , third and fourth in orbit; lower labials 11 . Posterior chin shields a little shorter than the anterior, not separated by scales. Scales smooth, with two inconspicuous pits, in 25 rows. Ventrals 217; anal entire; subcaudals 60 pairs. Total length $710 \mathrm{~mm}$. (tail 115).

The ground color is slate gray, crossed on the back, at intervals of 3 to 5 scales, by bands of black which are alternately wider and narrower, the wide ones covering from 2 to 3 scales on the middle of the back, and more or less divided transversely on their centers with scarlet. The narrow bands are about 1 scale wide and wholly black, occasionally broken through by the ground color. On the neck the bands are narrower 
and less defined, while the red is more pronounced on the posterior part of the body. There are 19 red and black bands on the body, and an equal number of the intermediate black ones. On the tail there are 5 bands, which form quite distinct rings, on the last two of which the red is absent. The head, including the labials, is dark gray with small dark mottlings, not well defined, and a narrow black streak from the postoculars to the angle of the mouth. Ventral surface grayish white, heavily blotched with black, into which the black portion of the cross bands runs.

By way of correction and addition to the above it may be noted that the temporals are $3+4+5$ on each side; the left lower labials are 11, the right, 10; the third postocular is on the left side and is a derivative of the fourth supralabial; the last two maxillary teeth are slightly enlarged, and the palatines are 12 on each side; the dorsal scale formula is 25-23-25-23-21-19-20, and the changes in the number of rows take place in the manner usual for this genus; the tail is about 0.17 of the total length.

Remarks.-It will be evident from the above description that this specimen is about as far removed in its structural features from the normal forms of the genus as is pyrrhomelaena. Like the latter it has a long tail, wide head, high numbers of ventrals, caudals, scale rows, temporals, infralabials, and a long, narrow loreal. Its style of coloration is, however, quite different from anything else in the genus, but knowing how easily one pattern may be changed into another radically different in appearance, we can not assign great importance to that fact alone. The writer would agree with Brown $(1901,613)$ in placing it nearer to pyrrhomelaena in structural features than to any other form of the genus, but it does not appear to lie at all near to leonis, as that author suggested. It would seem best to await the finding of more specimens before making any definite statement as to its status.

\section{CONCLUSION.}

The preceding descriptions and discussions have brought out the fact that the genus Lampropeltis is naturally divided into three main groups, of closely related forms (exclusive of two forms of doubtful relationships, mexicana and alterna). Two (the GETULUS and CALIIGASTIR groups) are more closely allied to each other than either to the third, and the latter (the TRIANGULUM group) is composed of at least three minor groups, representing different degrees and kinds of differentiation, and different periods of dispersal. On account of these facts and because the most primitive forms of the groups are apparently very far from being directly related, each group has been treated very nearly independently in searching for its center of dispersal, for it is conceivable that the groups as now known may have started from different centers without affecting the propriety of uniting them all in a single genus. This treatment has resulted in showing that in all probability each of these groups origi- 
nated in some portion of the region between Texas and Nicaragua. This, together with the fact that the only forms of doubtful relationships are located in this region, indicates that the center of dispersal of the entire genus is in the Southwest.

Let us now consider how the genus as a whole answers to the criteria for determination of centers of dispersal, as formulated by Adams $(1902,122)$. There are 10 of these criteria, as follows:

1. Location of greatest differentiation of a type.

2. Location of dominance or great abundance of individuals.

3. Location of synthetic or closely related forms (Allen).

4. Location of maximum size of individuals (Ridgway-Allen).

5. Location of greatest productiveness and its relative stability, in crops (Hyde).

6. Continuity and convergence of lines of dispersal.

7. Location of least dependence upon a restricted habitat.

8. Continuity and directness of individual variations or modifications radiating from the center of origin along the highways of dispersal.

9. Direction indicated by biogeographical affinities.

10. Direction indicated by the annual migration routes, in birds (Palmen).

Some of these criteria are of only limited value, and the fifth, ninth, and tenth can not be used at all in the present instance. The others will be discussed in order.

1. Location of greatest differentiation of a type.-In the Southwest we have polyzona, nelsoni, annulata, leonis, calligaster, splendida, pyrrhomelaena, ruthveni, and alterna. The only region at all comparable with this in diversity of type is the Southeast. Here we have four forms, all specialized, and two of them (elapsoides and rhombomaculata) obvious derivatives of western types; but there is no representative of pyrrhomelaena in the Southeast, nor of mexicana, nor of alterna. The greatest differentiation is therefore unquestionably in the Southwest.

2. Location of dominance or great abundance of individuals.-This criterion is of only minor value; exceptions may be readily called to mind. It is valueless in this case, however, since, in the present unsatisfactory state of our knowledge, there is as much to be said on one side as on the other.

3. Location of synthetic or closely related forms. - It has been noted frequently that those forms of this genus to which the groups trace their origin are more closely allied in structure with each other than with any of the other forms in the genus. For example, the southwestern types, calligaster and leonis may, much more readily than the specialized rhombomaculata of the Southeast, be associated with the GETULUS group, and it is with the western representatives of 
the latter rather than with the eastern that the closest relationship lies. Of the TRIANGULUM group the outlying types, micropholis, elapsoides, virginiana, and triangulum, are much more differentiated from the other groups than its southwestern representatives, polyzona and annulata. This criterion is therefore admirably fulfilled by the Southwest, and by this region only, and its value as a criterion may be regarded as second only to the sixth.

4. Location of maximum size of individuals.-Apparently no greater size is obtained by any forms than that reached by the southwestern representatives of all the groups, with the exception of the purely peninsular and derived forms, floridana and brooksi; and it will be remembered that the forms which are most reduced in size and scutellation occupy regions most distant from the southwest, namely conjuncta of the Cape region of Lower California, and elapsoides, and rhombomaculata of the southeastern States. Of nelsoni and annulata we have too few specimens to know what the normal or the maximum size may be but polyzona of southern Mexico may properly be compared with triangulum of the northeastern States. Of 300 specimens of the latter the largest measured $1,085 \mathrm{~mm}$., and of 61 of the former the largest measured 1,610 and the next largest 1,580 $\mathrm{mm}$., a decided difference in favor of the Southwest. The forms of the GETULUS group are of approximately equal size; of the two well-known forms of the CALLIGASTER group, the western representative is decidedly the larger. This criterion therefore points definitely to the Southwest.

6. Continuity and convergence of lines of dispersal.-Both the GETULUS and CALLIGASTER groups are represented in the Southwest, and the isolated types, mexicana, alterna, and pyrrhomelaena, are not represented outside of the Southwest. But it is the TRIANGULUM group that illustrates this most admirably. In this we see the convergence toward Mexico of the polyzonamicrophotis line from the south, the annulata-gentilis line from the north, the annulata-elapsoides line from the east, and the annulata-triangulum line from the northeast.

All genetic lines in the genus, therefore, either converge to the Southwest, or are represented in the Southwest as well as elsewhere, or are not represented outside of the Southwest, and no genetic lines converge to any region other than the Southwest. Thus this most dependable of all criteria is satisfied only by the Southwest.

7. Location of least dependence upon a restricted habitat.-Too littlo is known of the habitat relations of these snakes to discuss this criterion profitably, but it may be noted that the only burrowing forms (elapsoides, virginiana, and rhombomaculata) are located in the Southeast. 
8. Continuity and directness of individual variations or modifications radiating from the center of origin along the highways of dispersal.Lengthy demonstration of this criterion is not necessary here, since the descriptions and summaries demonstrate conclusively its direct applicability to the Southwest.

It will be evident that although these criteria are not of equal value, all point to the Southwest, and that the most dependable of these, the third, sixth, and eighth, are especially definite in this respect. The argument for the Southwest is not expected to rest upon any single piece or line of evidence, but it is believed that the weight of positive and the lack of negative evidence, as brought out in the summaries of the separate groups and in the discussion of the preceding criteria, amount to a demonstration that the center of dispersal of the genus Lampropeltis is in the southwestern portion of the North American continent.

Before concluding, a few remarks on the relation between the environment and the distribution of species and subspecies, as exhibited by the genus Lampropeltis, may not be out of place. It is noticeable that each form inhabits a region of rather definite environmental conditions, and that, within any such region, a group of directly related forms has but a single representative. Thus, restricted to the southeastern States, we have three forms, each representing a different line of descent. Each of these forms is replaced west of the Alabama-Mississippi region by a closely allied form, and the different environmental conditions of southern Florida are reflected in these forms as follows: One. apparently does not extend south of the northern portion of the State, one is replaced by a closely allied form derived from it, and the third expresses an extreme reduction that may yet lead to subspecific differentiation. The prairie region is characterized by two forms (calligaster and syspita), the lower Mississippi Valley by one (amaura), and another (holbrooki) ranges over both of these areas, but does not extend to any adjacent region. Two characterize the northeastern deciduous forest province; one of these (niger) is confined to the southern section, west of the Alleghenies, the other (triangulum) inhabits the whole province, but has developed most successfully in the north. At the western limit of forests in Texas, both holbrooki and amaura are replaced by their close relatives, splendida and gentilis, respectively. In Mexico the major environments are represented by polyzona in the lowlands of the east and south, nelsoni on the west coast, and annulata in the plateau region. Whatever may be the cause of speciation, or the breaking up into subspecies, it is a fact that when a form has migrated into a region of decidedly different environment it has become altered, and the alteration has remained constant in its main features 
throughout that environment. Thus it has come about that the direct relative of any form is found in an adjacent environment. The peculiar exception offered by californiae (p. 94), where speciation by mutation is indicated, affords opportunity for a most interesting investigation. But in general, the oft emphasized rule holds for this genus; namely, the occurrence of two different forms of the same genus in the same locality is prima facie evidence that they belong to different lines of descent, and, conversely, directly related forms are not found in the same locality.

The preceding might be detailed more fully, and more complete information on the little known forms would doubtless result in added illustrations of the fact that the environment seems to exert a circumscribing influence on the species, that is, the range of the species is determined by the environment, and, that when the latter changes, the species is altered or dies out.

The obvious differences in the relative ages of certain forms and groups of forms in the genus Lampropeltis, as shown by specialization, structural isolation and diversification, geographic position, etc., leads naturally to speculation as to the time relations of their spread from the Southwest. Since triangulum is typically developed only north of the southern limit of glaciers, we may assign it to a postPleistocene migration. The range of syspila and the northern portion of the range of gentilis were doubtless likewise largely uninhabitable during the glacial epoch, and this together with the perfect intergradation between these forms indicates that they belong to the same "wave" of dispersal. The high specialization of elapsoides and its distinctness from its nearest relative argues for isolation, and greater age than that of triangulum and syspila. These demands are satisfied by assuming it to have reached the Southeast at some favorable time during or before the ice age, and to have been isolated by an embayment of the lower Mississippi Valley during the Pleistocene (see map in Willis and Salisbury, 1910, 277). The high degree of specialization and structural isolation of pyrrhomelaena suggests that it is as old as any form in the genus. As it certainly has no relatives outside of the Southwest, it may be regarded as indigenous to this region, and its structural isolation is doubtless due to an early differentiation from the primitive stock. In the CALLIGASTER group the apparently sharp separation and the specialization of its eastern representative, make natural an assignment to a period similar to that when elapsoides reached the Southeast. Consequent separation during a greater or less portion of the Glacial Epoch induced divergent differentiation. The GETULUS group may be considered nearly or quite as recent as the varieties of triangulum, with, perhaps, greater age indicated for the western representatives 
to allow them to reach Cape San Lucas and Santa Catalina Island. The Central American forms are less easy to account for. Nelsoni assumed its specific identity before the Tres Marias Islands were separated from the mainland. This is likely to have been prePleistocene. Polyzona shows too great variability to be easily regarded as an ancient type, but it is old enough to have produced the well-marked micropholis in Colombia and Ecuador, and is therefore without doubt older than the northern varieties of triangulum.

The preceding paragraph may be summarized as follows: The genus Lampropeltis underwent a differentiation in the southwestern portion of the North American continent in the late Tertiary, producing a type that favored the mountains and uplands, the ancestor of the TRIATGULUM group, and another type that favored the lowlands, ancestor of the GETULUS and CALIIGASTER groups. The latter early differentiated into the progenitors of the two last groups, and of these it was the CALLIGASTER section that first spread northeast and east. This must have occurred previous to the Pleistocene, and at about the same time that the migration took place which brought the progenitor of elapsoides to the southeast. During the Pleistocene, the latter and the ancestral type of rhombomaculata suffered an isolation from their direct relatives west of the present position of the Mississippi River and were thus free to undergo considerable differentiation. Following the Pleistocene, elapsoides extended its range south into Florida, there undergoing still further specialization during the Recent Epoch, and west to Louisiana, here meeting the form amaura, the post-Pleistocene representative of its ancestral stock. If rhombomaculata extended its range into southern Florida, it is yet to be found there. Calligaster, after the retreat of the glaciers, was able to extend its range throughout the prairie region northeastward, and north to the limit of its endurance of cold. The western section of the GETULUS group may have begun its evolution during or perhaps preceding the Pleistocene, but it was only following that period that the spread east and northeast occurred. And it was following the Ice Age, also, that the latest forms of the TRIANGULUM group reached their present ranges (amaura, syspila, triangulum, and at least the northern section of gentilis).

This historical outline corresponds with the present distribution and structural relations of the king snakes, and with probable Pleistocene geography. The genus as a whole seems to be relatively recent, but the question of its origin is beyond the limits of the present study. In this connection, however, we may say that there are apparently no nearly related genera in South America, in the West Indies, nor in Asia, and that it is entirely likely that its nearest relatives are to be found in the genus Coronella of Europe and northern Africa. 


\section{BIBLIOGRAPHY.}

(Including only references cited in the text.)

1902. Adams, C. C. Southeastern United States as a center of geographical distribution of flora and fauna. Biol. Bull., vol. 3, pp. 115-131.

1868. Allen, J. A. Catalogue of the reptiles and batrachians found in the vicinity of Springfield, Massachusetts. Proc. Boston Soc. Nat. Hist., vol. 12, pp. 171-204.

1901. Atkinson, D. A. The reptiles of Allegheny County, Pennsylvania. Ann. Carnegie Mus., vol. 1, pp. 145-157.

1854. BaIrd, Spencer F. On the serpents of New York. Albany, New York.

1859. - Reptiles of the boundary. United States and Mexican Bound. Surv., pp. 1-35, pls. $1-41$.

1853. BAIRD, S. F., and Girard, C. Catalogue of North American reptiles in the Museum of the Smithsonian Institution, pt. 1, Serpents, pp. 1-172+16.

1835. Buarnville, H. D. de. Description de quelques espèces de reptiles de la Californie. Nouv. Ann. Mus. d'Hist. Nat., vol. 4, pp. 233-296, pls. 24-27.

1899. Blatchley, W. S. Notes on the batrachians and reptiles of Vigo County, Indiana. 24th Ann. Rep.' Dept. Geol. Nat. Res. Indiana, pp. 537-552.

1788. Blumenbach. Voigt's Mag. Neu. Phys. Naturg., vol. 5, pt. 1, p. 11, pl. 1.

1886. Bocourt, M. Miss. Sci. Mex. l'Amer. Centr., pt. 3, vol. 2.

1880. Boulenger, G. A. Reptiles et batraciens recueillis par M. Emile de Ville dans les Andes de l'Equateur. Bull. Soc. Zool. France, vol. 5, pp. 41-48.

1894. - Catalogue of the snakes in the British Museum, vol. 2.

1904. Branson, Edwin B. Snakes of Kansas. Kansas Univ. Sci. Bull., vol. 2, no. 13 (whole series, vol. 12 , no. 13), pp. 353-430.

1903. Brimley, C. S. Notes on the reproduction of certain reptiles. Amer. Nat., vol. 37 , no. 436 , pp. $261-266$.

1905. Notes on the scutellation of the red king snake, Ophibolus doliatus coccineus Schlegel. Journ. Elisha Mitchell Sci. Soc., vol. 21, no. 4,pp. 145-148.

1915. - List of reptiles and amphibians of North Carolina. Journ. Elisha Mitchell Sci. Soc., vol. 30, no. 4, pp. 195-206.

1920. - Notes on Lampropeltis elapsoides virginiana Blanchard. Copeia, no. 89 , pp. 106-109.

1901. Brown, A. E. A review of the genera and species of American snakes north of Mexico. Proc. Acad. Nat. Sci. Philadelphia, pp. 10-110.

1901. - A new species of Ophibolus from western Texas. Proc. Acad. Nat. Sci. Philadelphia, vol. 53, December, pp. 612-613, pl. 34.

1887. Butler, Amos W. Some notes on Indiana amphibians and reptiles. Journ. Cincinnati Soc. Nat. Hist., vol. 10, pp. 147-148.

1731. CAtesby, M. The natural history of Carolina, Florida, and the Bahama Islands. London.

1905. Clark, H. L. A preliminary list of the amphibia and reptilia of Michigan. 7th Rep. Michigan Acad. Sci., pp. 109-110.

1860. Cope, E. D. Catajlogue of the Colubridae in the Museum of the Academy of, Natural Sciences of Philadel phia, with notes and descriptions of new species. pt. 2. Proc. Acad. Nat. Sci. Philadel phia, pp. 241-266.

1862. - Contributions to the ophiology of Lower California, Mexico, and Central America. Proc. Acad. Nat. Sci. Philadelphia for 1861, pp. 292-306.

1891. - A critical review of the characters and variations of the snakes of North America. Proc. U. S. Nat. Mus., vol. 14, pp. 589-694.

1894. - The classification of snakes. Amer. Nat., vol. 28, pp. 831-844.

1900. - The crocodilians, lizards, and snakes of North America. Rep. U. S. Nat. Mus. for 1898, pp. 153-1270. 
1875. Coues, E. Synopsis of the reptiles and batrachians of Arizona. Rep. Geog. Geol. Explor. Surv. w. 100th Mer., vol. 5, chap. 5., pp. 618-619.

1878. - and YARROW, H. C. Notes on the herpetology of Dakota and Montana. Bull. U. S. Geol. Geog. Surv. Terr., vol. 4, art. 11, pp. 259-291.

1883. Davis, N. S., Jr., and Rice, Frank L. North American batrachia and reptilia, found east of the Mississippi River. Illinois State Lab. Nat. Hist., Bull. 5, pp. 1-64.

1842. De KAy, James E. Reptiles and amphibia. Nat. Hist. New York, pt. 3, pp. 1-415.

1910. Despax, R. Liste des ophidiens et description des expèces nouvelles. Mus. National Hist., Nat. Bull., no. 7, pp. 368-376.

1896. Ditmars, Raymond I. The snakes found within 50 miles of New York City. Proc. Linn. Soc. New York for year ending Mar. 24, 1896, pp. 1-27.

1907. The reptile book. New York.

1876. Dugés, D. A. El ofibolus doliatus. La Naturaleza, vol. 3, pp. 222-226. fig.

1917. Dunv, E. R. Reptile and amphibian collections from North Carolina mountains: Bull. Amer. Mus. Nat. Hist., vol. 37, art. 23, pp. 593-634.

1902. Eckel, Edwin C., and Paulmier, Frederick C. Catalogue of New York reptiles and batrachians. New York State Mus. Bull. 51, pp. 355-414.

1913. Eluis, Max M., and Henderson, J. The amphibia and reptilia of Colorado. Univ. Colo. Stud., vol. 10, no. 2, pp. 35-129, pl. 1-8.

1915. Engelhardt, G. P., et al. Long Island snakes. Copeia, no. 17, pp. 1-4.

1886. Ferrari-Perez, F. Catalogue of animals collected by the geographical and exploring commission of the Republic of Mexico. Proc. U. S. Nat. Mus., vol. 9, pp. 125-199.

1907. Fowler, H. W. The amphibians and reptiles of New Jersey. Ann. R.ep. New Jersey State Mus. for 1906, pp. 29-250.

1913. - Amphibians and reptiles from Ecuador, Venezuela, and Yucatan. Proc. Acad. Nat. Sci. Philadelphia, vol. 65, pp. 153-170.

1915. - Some amphibians and reptiles of Cecil County, Md. Copeia, no, 22, pp. 37-38.

1905. Gadow, Hans. The distribution of Mexican amphibians and reptiles. Proc. Zool. Soc. London, vol. 2, pp. 191-244.

1911. - Isotely and coral snakes. Zool. Jahr., Abt. Syst., Geog., Biol., vol. 31, pp. 1-24, pl. 1, figs. 6, 7.

1892. Garman, H. A synopsis of the reptiles and amphibians of Illinois. Bull. Illinois State Lab. Nat. Hist., vol. 3, art. 13, pp. 215-389.

1894. - A preliminary list of the vertebrate animals of Kentucky. Bull. Essex Inst., vol. 26, pp. 1-64.

1883. Garman, S. The reptiles and batrachians of North America. Mem. Mus. Comp. Zool., vol. 8, no. 3, pt. 1, pp. 1-185, pls. 1-9.

1892. - On Texan reptiles. Bull. Essex Inst., vol., 24, pp. 1-12.

1908. Grinnell, Joseph. The biota of the San Bernardino Mountains. Univ. Calif. Publ. Zool., vol. 5, no. 1, pp. 1-170, pls. 1-24.

1917. Grinnelt, J., and CAMP, C. L. A distributional list of the amphibians and reptiles of California. Univ. Calif. Publ. Zool., vol. 17, no. 10, pp. 127-208.

1907. Grinneli, J., and Grinneld, H. W. Reptiles of Loa Angeles County, Calif. Throop Inst. Bull. no. 35, pp. 1-64.

1856. Hallowell, EDWARD. Notice of a collection of reptiles from Kansas and Nebraska. Proc. Acad. Nat. Sci. Philadelphia, pp: 244-246.

1859. - Report upon the reptiles collected on the survey. Pacif. R. R. Surv., vol. 10, no. 1, pp. 1-27, pls. 1-10. 
1827. Harlan, Richard. Genera of North American reptilia, and a synopsis of the species. Journ. Acad. Nat. Sci. Philadelphia, vol. 5, pt. 2, pp. 317-372.

1892. HAY, O. P. The batrachians and reptiles of the state of Indiana. 17th Ann. Rept. Dept. Geol. Nat. Res. Indiana, pp. 409-602, pl. 1-3.

1902. HaY, W. P. The color of the fully adult Ophibolus rhombomaculatus Holbrook. Proc. Biol. Soc. Washington, vol. 15, p. 90.

1842. HоLвRоок, J. E. North American herpetology, ed. 2, vols. 2, 3, 4.

1852. Hough, Frankun B. Catalogue of reptiles and fishes from St. Lawrence County, procured for the State Cabinet of Natural History. 5th Ann. Rep. State Cab. Nat. Hist., Albany, New York, pp. 23-28.

1881. Humphreys, JoHn T. The King Snake Sups on a Full Grown Water Moccasin. Amer. Nat., vol. 15, pp. 561-562.

1911. Hurter, Julius, Sr. Herpetology of Missouri. Trans. Acad. Sci. St. Louis, vol. 20 , no. 5 , pp. $59-274$, pls. $18-24$.

1909. Hurter, J., and Strecker, JoHn K. The amphibians and reptiles of Arkansas, Trans. Acad. Sci. St. Louis, vol. 18, no. 2, pp. 11-27.

1859. Kennicott, Robert. Notes on Coluber calligaster of Say, and a description of new species of serpents in the collection of the Northwestern University of Evanston, Illinois. Proc. Acad. Nat. Sci. Philadelphia, pp. 98-100.

1843. Linsley, James H. A catalogue of the reptiles of Connecticut, arranged according to their natural families. Amer. Journ. Sci. Arts., vol. 46, pp. 37-51.

1894. Loennberg, Einar. Notes on the reptiles and batrachians collected in Florida in 1892 and 1893. Proc. U. S. Nat. Mus., vol. 17, pp. 317-339.

1907. McAtes, W. L. A list of the mammals, reptiles, and batrachians of Munroe County, Indiana. Proc. Biol. Soc. Washington, vol. 20, p. 10.

1899. McLain, Robert B. Notes on a collection of reptiles made by Mr. C. J. Pierson at Fort Smith, Arkansas, with remarks on other eastern reptiles. Contr. to N. Amer. Herp., pp. 1-5, Wheeling, West Virginia.

1899. - Contributions to neotropical herpetology. pp. 1-5, pl. 1.

1902. Mruler, Gerrit S., Jr. A fully adult specimen of Ophibolus rhombomaculatus. Proc. Biol. Soc. Washington, vol. 15, p. 36.

1901. Morse, M. Ohio reptiles in the Ohio State University Zoological Museum. Ohio Nat., vol. 1, pp. 126-128.

1904. - Batrachians and reptiles of Ohio. Proc. Ohio State Acad. Sci., vol. 4 pt. 3, spec. pap. no. 9, pp. 95-144.

1897. Peracca, M. G. Viaggio del Dr. Enrico Festa nell' Ecuador e regioni vicine. Bull. Mus. Zool. Anat. Comp. Univ. Torino, vol. 12, no. 300, pp. 1-20.

1904. — Viaggio del Dr. Enrico Festa nell' Ecuador e regioni vicine. Bull. Mus. Zool. Anat. Comp. Torino, vol. 19, no. 465, pp. 1-41.

1914. _ Reptiles et batraciens de Colombie. Voy. Expl. Sci. en Colombie, pp. 96-111.

1912. RIDGWAY, RoBert. Color standards and color nomenclature. Washington, D. C.

1908 Ruthven, A. G. Variations and genetic relationships of the garter snakes. Bull. U. S. Nat. Mus., no. 61.

1911. - Amphibians and reptiles, in a biological survey of the sand dune region on the south shore of Saginaw Bay, Michigan. Michigan Geol. Biol. Surv., publ. 4, biol. ser. 2, pp. 257-272.

1912. - Thompson, C., and Thompson, H. The herpetology of Michigan. Michigan Geol. Biol. Surv., publ. 10, biol. ser. 3, pp. -1801 .

1861. Salvin, Osbert. On a collection of reptiles from Guatemala. Proc. Zool. Soc. London, pp. 227-229.

1837. Schlegel, H. Essai sur la physionomie des serpens. Sep. vol., pls. 1-21. Amsterdam. 
1919. Schmidt, KarL P. Rediscovery of Amphiardis inornatus (Garman), with notes on other specimens from Oklahoma. Copeia, no. 73, pp. 71-73:

1802. Shaw, George. General Zoology, vol. 3, pt. 2, Amphibia, pp. 313-615.

1882. Sмrтн, W. H. Report on the reptiles and amphibians of Ohio. Geol. Surv. Ohio, vol. 4, pp. 633-734.

1799. Sonnini, C. S., and Latreille, P. A. Histoire naturelle des reptiles, vo?. 4, pt. 2, Serpens.

1893. Stejneger, Leonard. Annotated list of the reptiles and batrachians collected by the Death Valley Expedition in 1891, with descriptions of new species. N. A. Fauna, no. 7, pt. 2, pp. 159-228.

1902. - The reptiles of the Huachuca Mountains, Arizona. Proc. U. S. Nat. Mus., vol. 25, pp. 149-158.

1918. Nomenclatorial notes on milk snakes. Proc. Biol. Soc. Washington, vol. 31, p. 99.

1906. Stone, Whitmer. Notes on reptiles and batrachians of Pennsylvania, New Jersey, and Delaware. Amer. Nat., vol. 40, March, pp. 159-170.

1909. Strecker, J. K. Contributions to Texan herpetology. Baylor Univ. Bull., vol. 12 , no. 1, pp. 1-9.

1915. Reptiles and amphibians of Texas. Baylor Univ. Bull. 18, no. 4, pp. 1-82.

1880. Sumichrast, F. Notes sur une collection de reptiles et de batraciens de la partie occidentale de l'Isthme de Tehauntepec. Bull. Soc. Zool. France, vol. 15, pp. 162-190.

1906. Surface, H. A. The serpents of Pennsylvania. Monthly Bull. Div. Zool., vol. 4, nos. 4 and 5, pp. 114-208.

1887. Townsend, Charles H. Field notes on the mammals, birds, and reptiles of Northern California. Proc. U. S. Nat. Mus., vol. 10, pp. 159-241.

1897. Van Denburgh, John. The reptiles of the Pacific coast and Great Basin. Occ. Pap. California Acad. Sci., vol. 5, pp. 169-172.

1912. - Notes on a collection of reptiles from Southern California and Arizona. Proc. California Acad. Sci., vol. 3, pp. 147-154.

1913. Van Denburge, J., and Sievin, Joseph R. A list of the amphibians and reptiles of Arizona, with notes on the species in the collection of the Academy. Proc. California Acad. Sci., ser. 4, vol. 3, pp. 391-454, pls. 17-28.

1863. Verrill, A. E. Catalogue of the reptiles and batrachians found in the vicinity of Norway, Oxford County, Maine. Proc. Boston Soc. Nat. Hist., vol. 9, pp. 195-199.

1904. Wallace, W. S. Snakes of Rockland County, New York. 56th Ann. Rep. New York State Mus. for 1902, pp. r 135-r 145.

1903. Werner, F. Ueber reptilien und Batrachier aus Guatemala und China. Abh. d. II Kl. \& K. Ak. d. Wiss., vol.22, pt. 2, pp. 341-384.

1910. Wrluis, Bailey, and Salisbury, Rollin D. Outlines of geologic history with especial reference to North America. Univ. Chicago Press.

1915. Wright, Albert H., and Bishop, S. C. Snakes. Sec. 2 in A biological reconnaissance of the Okefinokee Swamp in Georgia. Proc. Acad. Nat. Sci. Philadelphia, pp. 139-192, pl. 3, figs. 1-7.

1878. Yarrow, H. C. A two-headed snake. Amer. Nat., vol. 12, p. 470.

1882. - Check list of North American reptilia and batrachia. Bull. U. S. Nat. Mus., no. 24, pp. 1-249. 


\section{INDEX.}

[The black-faced numbers indicate specific headings.]

Page.

Page.

Adder, spottcd, checkered.............. 188, 193 aiterna............ 5,6,7,17,234, 247, $249,250,251$

alternus............................... 247 amaura.................. 162, 169, 172, 179, 181, $184,185,202,210,211,212,237$ et seq., 252,254 amaurus........................... 172 annulata.............................. 142, $146,155,156,157,159,169,172,175$, $176,223,223,237$ et seq., $250,251,252$ annulatus.............................. 159, 165 anomala............................. 6,139 arcifera................................. 140

Arizona ringed snake..................... 231

baiteata............................... 75

Bastard horn snake..................... 49

Bellophis............................ 4 zonatus............................. 4

Black and white king snake.............. 75

Black moccasin......................... 49

boylei................................. 75

Boyle's king snake..................... $\quad 75$

boylii........... 12,66, 68,69,73,75, 89 et seq., 103, 104 et seq., 163, 222, 223, 240, 241, 250 et seq. brooksi.............. 4, 57, 58, 66, 105, 113, 115, 251 Brown king snake...................... 128 californiae........... 6, 58,94, 103, 105, 115, 163, 253 californica ............................. 94 calligaster................. $5,7,10,15,115,128$, $132,133,134,138,139,250,252,254$

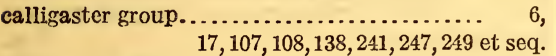
Caudals, variation of, in genus ............ 15,24 celaenops............................... 165 Cemophora coccinea .................... 207

Centers of dispersal, criteria for ............ 250

Chain suake.............................. 49

Checkered adder...................... 188

clerica................................ 190

clericus........................... 188, 190, 201

coccinea ............................... 172,200

coccinea, Coronella ...................... 4

coccineus............... 140,155, 172,179,206, 207

collaris............................ 179,201

Color pattern (see also description of each form). 16,24

Coluber constrictor...................... 240

Colubridae.

conjuncta. $5,12,15,66,73,76,77,89,95,103$, $114,115,159,163,240$ et seq., 251

conjunctus 89,159

constrictor, Coluber...................... 240

Coral king snake...................... 222, 223

Corallilo.

139,142

Coral snake............................ 206

Coronella............................. 5,254

coccinea.

ucker....

Dental characters, value of............... 16

Dentition (see also description of each form)... $\quad 7,25$ doliata.................... 139, 165, 179, 189, 206 doliatus............ 172,173, 179, 189, 120, 202, 206 Drymobius margaritiferus............... 240 eiseni................................. 94 Elaphe:

guttata............................ 10

laeta......................... 10,116,117, 122

obsoleta........................... 10 elapsoidea......................... 173, 206 elapsoides. ..... 5, $6,8,10,11,12,15,16,163,172,173$, $176,200,205,219,237,250,251,253,254$

elapsoideus............................ 206

evansii.............................. 116, 117

Evans king snake..................... 115

Evolution in scutellation................. 11

eximia.............................. 188

eximius........................... 116, 188

foridana.............. 5, 11.15, $51,55,57,58, \mathbf{6 2}$, $66,105,113,114,115,240,251$

formosa........................ 139, 140,149

Formulae of scale rows. ................ 10-12 gentilis . $7,159,161,162,163,155,172,174,175,176,181$ $184,185,223,227,233,234,237$ et seq., $251,252,253$ getula........................... 33, 49,75,94 getulus............. 12, $33,36,38,43,44,45,46,49$, $62,64,80,104$ et seq., 226,243 getulus group............6, $11,13,16,17,26,119$ $241,243,249$ et seq

map of........................... 104

relationships of ................... 115, 132

summary of. . ..................... 104-115

getulus, Herpetodryas.................... 4

Groups of king snakes.................... $\quad 17$

Guinea snake........................... 33

guttata, Elaphe ........................ 10

Harlequin snake........................ 222

Herpetodryas getulus.................... holbrooki.......... 7, 12, 28, 29, 30, 33,43, 44, 46, 51, $57,80,104$ et seq., $\overrightarrow{163}, 240,241,252$

Horse racer............................. 49

House moccasin........................ 188

House snake............................. 188

Key to forms of Lampropeltis.............. 18

King snake.................... 26, 33, 36, 49, 66

Labials, variation of, in genus ........... 13-15, 24

laeta, Elaphe.......................... 116, 117

Lampropeltis........................... 4

leonis......................... 138, 249, 250

Loreal, variation of, in genus .............. 15

figure of $. . . \ldots \ldots \ldots \ldots \ldots \ldots \ldots \ldots \ldots \ldots \ldots \ldots, 5$

Maps. See under description of each form.

margaritiferus, Drymobius. 


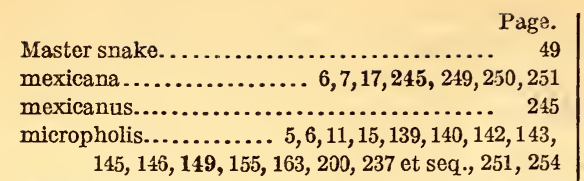
Milk snake.......................... 75, 188, 193

Moccasin, House...................... 188

Molecatcher............................ 128

multicincta............... 7, 11, 165, 168, 221,222, $226,227,233,234,237,243,244,215,249$ et seq.
multicinctus............................. 222

multifasciata.............................. 222

multistrata............................ 165,202

multistratus........................... 155, 165

multistriata.............................. 165

Mutation............................... 99,100

Natrix doliatus........................ 206

nelsoni................... 142, 143, 145, 146,155,

$152,163,172,221,233,237$ et seq., 250, 251, 252

niger......... 12, 38, 39, 43, 51, 58, 104 et seq., 252 nitida................... 92, 95, 100, 103, 105, 115 obsoleta, Elaphe......................... 10

occipitalis............................. 159

oligozona............................... 140,155

Ophibolus............................ 4,5

Osceola.................................. 4

parallelus............................. 172, 173

Penial characters (see also description of each

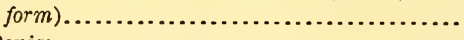

Penis:

in calligaster group.

17

in getulus group................ 17, 108-109

in Lampropeltis...................... 7

in triangulum group................... 17

Pituophis sayi........................... 34 polyzona.............11,139, 149,151,152, 155, 156,

$161,162,163,221,237$ et seq., $250,251,252,254$

polyzonus......................... 139, 140,149

Pseudoelaps Y......................... 188

pseudogetulus............................. $\quad 75$

pyromelanus........................... $\quad 231$

pyromelas............................. 231

pyrrhomelaena.......... 5, 6,7,11, 15, 163, 166, 223, $226,231,237,243,244,245,249,250,251,253$

pyrrhomelas............................ 231

Rattlesnake pilot........................... 49

Red king snake.......................... 206

Red milk snake..................... 179, 222

Red snake............................ 179

Ring snake............................ 222

rhombomaculata..................... 5,8 ,

$12,15,117,119,120,124,128$,

$138,139,163,250,251,254$
rhombomaculatus..................... 116, 128
Page.

ruthveni................. 221, $227,237,245,250$
sayi...........................26,33,34,43

sayi, Pituophis........................... 34

Say:s king snake ........................ $\quad 33$

Scale rows:

formulae of...................... 10-12,25

variation of, in genus................ 9

Scarlet kingsnake..................... 206

Scotophis............................. 116

Sex, to distinguish ....................... 6

Speckled king snake....................... 33

Sphenophis............................. 4

splendida ................ 7, 26, 35, 38, 39, 44, 66 $67,68,69,73,83,104$ et seq., $240,250,252$

spendidus.............................. 26

Spotted adder........................... 188

Spotted king snake....................... 33

Summary:

calligaster group..................... 138

characteristics of genus................ 24,25

general summary..................... 249

getulus group ....................... 104

triangulum group.................... 237

syspila............................... 168, $169,172,173,175,176,179,184,192,194,197$, $198,200,201,202,212,237$ et seq., 252,253

syspilus.............................. 179

sysputus............................. 165

Tail length, proportionate................. 24

temporalis.......................... 190, 202

Temporals, variation of, in genus.......... 15,24

Thamnophis............................ 8,9,10

Thunder and lightning snake............... 49

Thunder snake.......................... 49, 206

tigrina................................ 116

triangula............................... 188,189

triangulum............................. 6,7 ,

$11,15,163,168,175,181,183,184,185,188$.

210, 212, 219, 237 et seq., 251, 252, 253, 254

triangulum group ...................... 1, 6 ,

$13,16,17,108,139,247,249-254$

map of ........................... 238

summary of........................... 237

triangulus......................... 188, 189, 190

Ventrals, variation of in genus............ 15, 24

virginiana...... 5, 8, 10,15, 172, 200, 209, 217, 237, 251

Wamper............................. 49

Wampum snake....................... 49

Yellow-bellied king snake................. $\quad 115$

Y, Pseudoelaps....................... 188

yumensis........................... 7,28 ,

$29,30,66,76,77,80$ et seq., $99,103,104$ et seq.

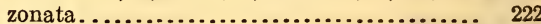

zonatus............................ 139,222,231

zonatus, Bellophis.. 






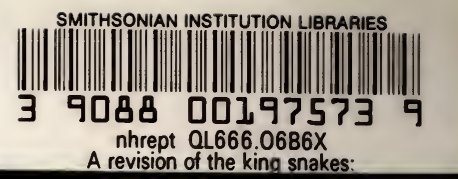

